\title{
Task 3.17 - Hot-Gas Cleanup
}

\author{
Final Report \\ January 1 - June 30, 1997
}

\author{
By \\ Ronald C. Timpe \\ Michael D. Mann
}

Work Performed Under Contract No.: DE-FC21-93MC30097

\author{
For \\ U.S. Department of Energy \\ Office of Fossil Energy \\ Federal Energy Technology Center \\ P.O. Box 880 \\ Morgantown, West Virginia 26507-0880
}

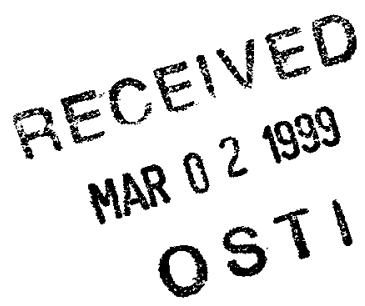

By

Energy \& Environmental Research Center

University of North Dakota

P. O. Box 9018

Grand Forks, North Dakota 58202-9018 


\section{Disclaimer}

This report was prepared as an account of work sponsored by an agency of the United States Government. Neither the United States Government nor any agency thereof, nor any of their employees, makes any warranty, express or implied, or assumes any legal liability or responsibility for the accuracy, completeness, or usefulness of any information, apparatus, product, or process disclosed, or represents that its use would not infringe privately owed rights. Reference herein to any specific commercial product, process, or service by trade name, trademark, manufacturer, or otherwise does not necessarily constitute or imply its endorsement, recommendation, or favoring by the United States Government or any agency thereof. The views and opinions of authors expressed herein do not necessarily state or reflect those of the United States Government or any agency thereof. 


\section{DISCLAIMER}

Portions of this document may be illegible in electronic image products. Images are produced from the best available original document. 


\section{TABLE OF CONTENTS}

LIST OF FIGURES $\ldots \ldots \ldots \ldots \ldots \ldots \ldots \ldots \ldots \ldots \ldots \ldots \ldots$

LIST OF TABLES $\ldots \ldots \ldots \ldots \ldots \ldots \ldots \ldots \ldots \ldots \ldots \ldots \ldots \ldots$

1.0 INTRODUCTION $\ldots \ldots \ldots \ldots \ldots \ldots \ldots \ldots \ldots \ldots \ldots \ldots \ldots \ldots$

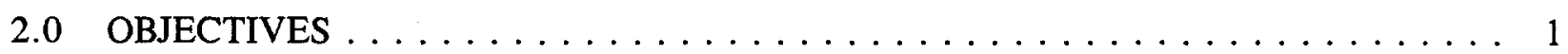

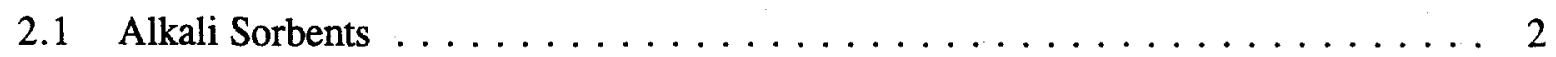

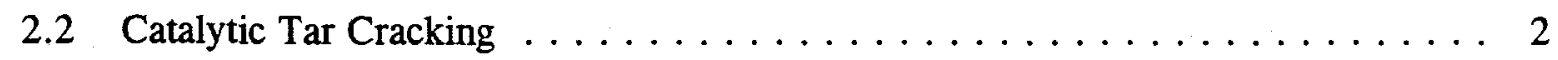

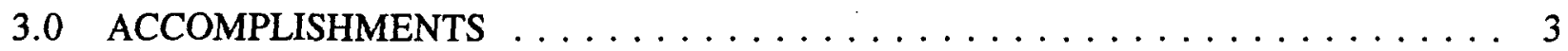

3.1 Capture of Alkali During PFBC Using In-Bed Sorbents . . . . . . . . . 3

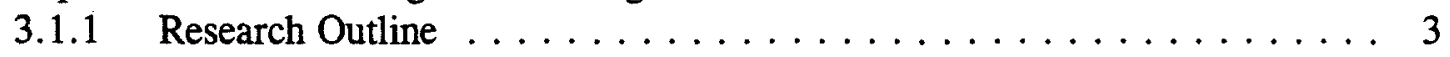

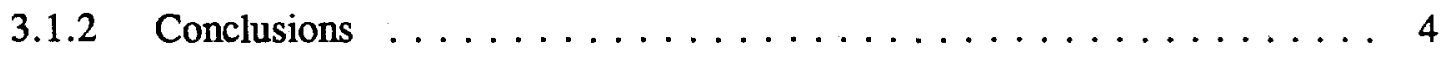

3.1 .3 Recommendations $\ldots \ldots \ldots \ldots \ldots \ldots \ldots \ldots$

3.2 Catalytic Tar Cracking $\ldots \ldots \ldots \ldots \ldots \ldots \ldots \ldots \ldots \ldots \ldots \ldots$

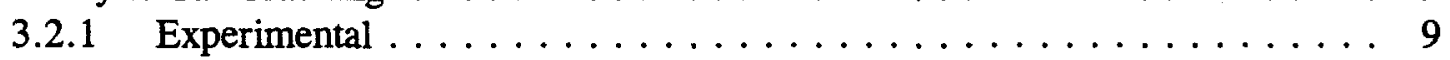

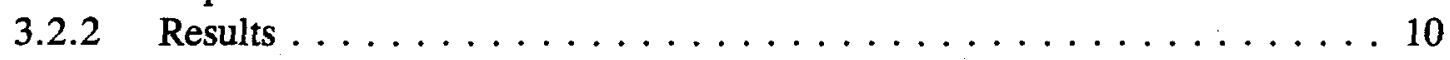

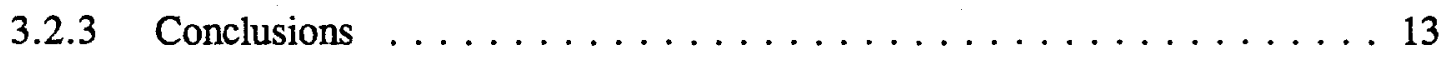

3.2 .4 Recommendations $\ldots \ldots \ldots \ldots \ldots \ldots \ldots \ldots \ldots \ldots$

CAPTURE OF ALKALI DURING PRESSURIZED FLUIDIZED-BED COMBUSTION

USING IN-BED SORBENTS . . . . . . . . . . . . . . Appendix A 


\section{LIST OF FIGURES}

1 Quantities of tar and gas products from catalytic cracking of tar produced during gasification of Illinois bituminous coal by different amounts of $1 \% \mathrm{Pt}$ on zeolite $\ldots \ldots 12$

2 Weight percent decrease in tar and weight percent increase in gas collected following

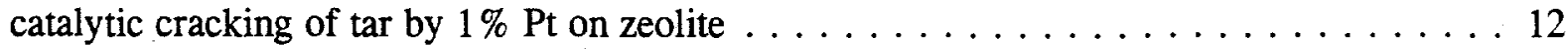

3 Gasification tar converted to product gas stream after contact with $1 \% \mathrm{Pt}$ on zeolite at

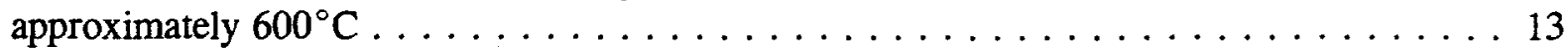

4 Hydrogen content of product gas as a function of contact time with catalyst . . . . . . 14

\section{LIST OF TABLES}

1 Proximate Analysis of IBC-101 Bituminous Coal $\ldots \ldots \ldots \ldots \ldots \ldots$

2 Comparison of Catalyst on Tar Cracking and Subsequent Catalyst Recovery . . . . . . 13 


\section{SUBTASK 3.17 - HOT-GAS CLEANUP}

\subsection{INTRODUCTION}

Emerging power systems, including pressurized fluidized-bed combustion (PFBC) and integrated gasification combined cycle (IGCC), being demonstrated under the U.S. Department of Energy (DOE) Clean Coal Technology Program and other technologies at earlier stages in their development will, over time, present opportunities for achieving generating efficiencies of $50 \%$ or higher, with stringent control of $\mathrm{SO}_{2}, \mathrm{NO}_{x}$, and particulate emissions. At their present stage of development and demonstration, these coal-fired technologies offer superior environmental performance for repowering, cogeneration, and greenfield projects at costs comparable to pulverized fuel firing with full stack gas cleaning, but at a considerably higher technical and financial risk. The development of hot-gas cleaning technologies that are less expensive and capable of operating at higher temperatures and pressures will greatly reduce the risks associated with PFBC and IGCC.

Catalytic tar cracking is another issue that advanced power systems are facing at this time. Tars and oils produced during combustion or gasification of coal result in a contaminated gas stream that fouls equipment and makes direct utilization of the stream impractical. Tar production in the gasification of coal is deleterious to the operation of downstream equipment, including fuel cells, gas turbines, hot-gas filters, and pressure-swing adsorption systems, all of which are candidate technologies for use as or in small power generation systems. Cracking of these tars into smaller hydrocarbons is a very important technical issue to be addressed. The oils tend to coat surfaces and enter pores and voids in hot-gas filters and pressure-swing sorbents, causing reduction in efficiencies during hot-gas cleanup. In addition to the problems caused by the oils, the tars, with their high dew points, condense on the surfaces of power generation equipment. Turbine blades can become coated with this condensate, resulting in deviation from acceptable aerodynamics and in metal corrosion. Deposits of tars on fuel cell components result in loss of cell efficiency. Tar coatings on gas separation equipment such as membranes, molecular sieves, and filters reduce gas cleanup efficiency. These are some of the operational complications that need to be addressed by this subtask on hot-gas cleanup.

\subsection{OBJECTIVES}

The programmatic goal in advanced power systems is to develop advanced methods for gas stream cleanup in combustion and gasification systems, using in situ and back-end technologies. The characteristics of the fuel, its ash, and sorbents are evaluated to determine their impact on overall performance, including the reduction of gas stream contaminants. Objectives for the work performed under this subtask included the following:

- Identify effective means for hot-gas cleanup and testing in-bed sorbents for accomplishing 99\% alkali capture as well as effective capture of sulfur and chlorine during PFBC.

- Develop catalysts and effective operating ranges for removing tar from gasification process streams. 
The two activities outlined below correspond to the above-stated objectives for Subtask 3.17.

\subsection{Alkali Sorbents}

PFBC has been identified as a promising technology for the future. The objective of this task was the development of sorbents for in-bed alkali, sulfur, and chlorine capture to reduce or eliminate problems on back-end equipment. Several of the aluminosilicate minerals have the potential to capture alkalies, especially sodium and potassium, under conditions typical of fluid-bed operation $\left(1400^{\circ}\right.$ to $\left.1850^{\circ} \mathrm{F}\right)$. The alkalies are absorbed on the surface and diffuse into the bulk of the alkali getter. In addition, the nonbridging oxygen atoms released when alkalies modify the aluminosilicate mineral structure are potential sites for sulfur capture. The use of a getter to capture alkali in the bed reduces the need for downstream alkali capture devices. Sulfur capture on the getter also reduces the amount of dolomite needed to meet sulfur emission standards. Chlorine can also be captured by certain types of sorbent. These systems are not without potential problems, however. Modification of the aluminosilicate matrix will lower melting points and could cause sintering and agglomeration problems. This and other potential complications were addressed.

During FY95, a limited number of alkali sorbent tests were performed. A capture of vapor-phase alkali of $93 \%$ was accomplished using kaolin. The final sodium level of $270 \mathrm{ppb}$ is still higher than the $24 \mathrm{ppb}$ recommended by turbine manufactures. The kaolin was also found to significantly reduce agglomeration. This and other promising sorbents were tested in the pressurized fluid-bed reactor.

The fundamental question to be answered by this task is whether in-bed alkali sorbents are technically feasible for capturing alkali in PFBC systems. The impacts of in-bed sorbents on reducing convective pass fouling and blinding of ceramic filter elements were also investigated. Any related operating problems and improvements in sulfur capture were noted.

\subsection{Catalytic Tar Cracking}

Previous and current work has involved selecting and screening catalysts that are available and relatively inexpensive. Synthetic montmorillonite, a pillared laboratory-prepared clay impregnated with nickel, was initially tested in combination with the feed in the reactor bed and as a separate bed. In-bed catalysis proved to be less effective in cracking tars than tar contact with catalyst in a separate bed. A separate bed of either zeolite or dolomite was more effective in cracking tar than the Ni-impregnated synthetic montmorillonite. Although the dolomite cracked the tar, decrepitation of the hot solid resulted in loss of catalyst through gas steam entrainment. In this study, the effect of selected operating conditions for the chosen catalyst was addressed. The effect of catalyst-tar contact time at approximately $900 \mathrm{~K}$ and 100 psig on catalytic tar cracking by zeolite impregnated with $<1 \% \mathrm{Pt}$ was determined. The results from the study provide an uncomplicated means of tar removal from gas streams with reduction in the size of the hydrocarbon content of the usable gas stream.

The work was carried out on the integrated bench-scale gasifier (IBG) and involved evaluating the effect of the catalyst on the cracking of tars. The tars that escaped the fluidized bed of the reactor were cracked in catalyst beds of depths designed to produce contact times of $0,1,2$, and 3 seconds. The effect of contact time (bed depth) was determined. 


\subsection{ACCOMPLISHMENTS}

\subsection{Capture of Alkali During PFBC Using In-Bed Sorbents}

The work for this task was performed by Michael Mann as his doctoral research for a Ph.D. in energy engineering. The outline of his work is presented here along with the conclusions from his work. Details are included in his dissertation which is presented as Appendix A to this project report.

\subsubsection{Research Outline}

PFBC has been identified as a promising technology for the future; however, there are a number of obstacles for maximizing its potential. These include removal of 1 ) fine particulates to eliminate erosion and deposition on turbine blades, 2) alkalies which can lead to corrosion of turbine blades and blinding of ceramic filters, 3) sulfur at very high sorbent utilization efficiencies, 4) halogens that can lead to corrosion, and 5) toxic metals that were specified in the $1990 \mathrm{Clean}$ Air Act Amendments. The primary focus of this research was the removal of alkali from PFBC flue gases to a level specified by turbine manufactures. The target level was less than 24 parts per billion by weight (ppbw). Several of the aluminosilicate minerals have the potential to capture alkalies, especially sodium and potassium, under conditions typical of fluid-bed operation $\left(1400^{\circ}\right.$ to $\left.1850^{\circ} \mathrm{F}\right)$. The alkalies are absorbed on the surface and diffuse into the bulk of the alkali getter. In addition, the nonbridging oxygen atoms released when alkalies modify the aluminosilicate mineral structure are potential sites for sulfur capture. The use of a getter to capture alkali in the bed reduces the need for downstream alkali capture devices. Other goals were to investigate the potential for simultaneously removing $\mathrm{SO}_{2}$ and $\mathrm{Cl}$ from the PFBC gas stream.

Several side benefits were anticipated, and the goal was to demonstrate these. A reduction in the amount of fine particulate was expected when alkali was removed from the bed, since condensation of volatile alkalies is one of the primary mechanisms for the formation of these difficult-to-remove particulates. Improved performance of ceramic filters was expected, since alkalies can lead to bridging, pore plugging, and other problems in ceramic filters. Deposition on the walls of the PFBC and on heat-transfer surfaces can reduce the performance of the PFBC and may be controllable by capture of the alkalies with in-bed sorbents. The propensity of certain fuels to sinter and/or agglomerate in the fluid bed was also expected to be reduced or eliminated with the introduction of alkali getters.

The work reported here focused primarily on one class of sorbents, sodalites. The goal will be to determine whether sodalites can be used as an in-bed sorbent to simultaneously remove alkali and sulfur. Some of the key reactions that were studied are listed below:

$$
\begin{aligned}
& \mathrm{NaCl}+3\left(\mathrm{NaAlSiO}_{4}\right) \Rightarrow \mathrm{Na}_{4} \mathrm{Al}_{3} \mathrm{Si}_{3} \mathrm{O}_{12} \mathrm{Cl} \\
& \text { (nepheline) (sodalite) } \\
& \mathrm{Na}_{4} \mathrm{Al}_{3} \mathrm{Si}_{3} \mathrm{O}_{12} \mathrm{Cl}+6 \mathrm{SiO}_{2} \Rightarrow \mathrm{NaCl}+3\left(\mathrm{NaAlSi}_{3} \mathrm{O}_{8}\right) \\
& \text { (sodalite) (albite) }
\end{aligned}
$$




$$
\begin{aligned}
& 2\left(\mathrm{Na}_{4} \mathrm{Al}_{3} \mathrm{Si}_{3} \mathrm{O}_{12} \mathrm{Cl}\right)+\mathrm{Na}_{2} \mathrm{SO}_{4} \Rightarrow 2(\mathrm{NaCl})+\mathrm{Na}_{8} \mathrm{Al}_{6} \mathrm{Si}_{6} \mathrm{O}_{24}\left(\mathrm{SO}_{4}\right) \\
& \text { (sodalite) (nosean) } \\
& \mathrm{Na}_{8} \mathrm{Al}_{6} \mathrm{Si}_{6} \mathrm{O}_{24}\left(\mathrm{SO}_{4}\right)+12\left(\mathrm{SiO}_{2}\right) \Rightarrow \mathrm{Na}_{2} \mathrm{SO}_{4}+6\left(\mathrm{NaAlSi}_{3} \mathrm{O}_{8}\right) \\
& \text { (nosean) (albite) } \\
& 2\left(\mathrm{Na}_{4} \mathrm{Al}_{3} \mathrm{Si}_{3} \mathrm{O}_{12} \mathrm{Cl}\right)+\mathrm{SO}_{2}+\mathrm{O}_{2} \Rightarrow \mathrm{Na}_{8} \mathrm{Al}_{6} \mathrm{Si}_{6} \mathrm{O}_{24}\left(\mathrm{SO}_{4}\right)+\mathrm{Cl}_{2} \\
& \text { (sodalite) (nosean) }
\end{aligned}
$$

Reactions 1 and 3 are the primary mechanisms for the removal of sodium from the gas stream. In these reactions, nepheline and albite are removing sodium chloride from the gas stream to form sodalite. The fate of the sodalite is dependent upon the other constituents that make up the sorbent/ash bed and the gas stream. For systems high in silica, the potential exists for the silica to react with the sodalite or nosean by Reactions 2 and 4 to release the alkali. Sulfates, on the other hand, will replace the chlorine. In Reaction 3, sodium sulfate reacts to release sodium chloride with no net change in the amount of alkali captured. Provided there is sufficient nepheline, the released sodium chloride could react according to Reaction 1, with the overall result being a capture of both sulfur and chlorine. Reaction 5 shows the exchange of $\mathrm{SO}_{2}$ for $\mathrm{Cl}_{2}$. For most fuels, the expected concentration of $\mathrm{SO}_{2}$ relative to chlorine is high. Therefore, Reaction 5 will likely proceed. The extent of Reactions 2 and 4 will probably depend upon the chemistry of the ash and bed material.

A pressurized thermogravimetric analyzer (PTGA) was used to study the mechanism of alkali capture outlined in Reactions 1 through 5. Further testing was performed on a 3-in.-diameter pressurized fluid-bed reactor. In addition to studying the gettering capability of the sorbent, the impact of the getter on operational performance was evaluated. This evaluation included examining potential agglomeration of bed particles, deposition on heat-transfer surfaces, and the bridging of ceramic candle filters.

\subsubsection{Conclusions}

The work performed as a part of the dissertation consisted of three main efforts: the literature survey, thermogravimetric testing, and bench-scale testing. Conclusions from each of these three efforts are presented below. Following the conclusions, recommendations are presented based on the findings of this work.

\subsubsection{Conclusions from Literature Review}

- Electricity-generating demands are expected to grow at a rate ranging from $1 \%$ to $2 \%$ per year in the United States, creating a need for over $200 \mathrm{GW}$ of new generating capacity. PFBC is projected to capture up to $25 \%$ of the new market for advanced coal technologies, with much of its market penetration in the area of repowering. Therefore, PFBC is expected to be a major source of new power in the 21 st century.

- A number of issues must be resolved for PFBC to capture its projected share of the market. These issues include reducing capital costs and improving reliability and environmental performance. Technical issues related to hot-gas particulate removal, alkali 
and chlorine control, trace emissions, and the use of advanced cycles must also be resolved for PFBC to reach its full potential.

- The reactions of organically associated mineral matter are of importance in the operating regime of the PFBC. The alkalies, chlorine, and sulfur will vaporize and condense heterogeneously on the surfaces of other ash particles, condense homogeneously to form very fine aerosols, or remain in the vapor phase. These constituents can cause agglomeration and ash deposition, bridging and blinding of hot-gas filters, and corrosion and deposition of turbine blades and, therefore, must be controlled to allow proper operation of the PFBC.

- Measured gas-phase alkali concentrations of 500 to $4000 \mathrm{ppm}$, depending upon coal type, are high relative to turbine blade specifications of $24 \mathrm{ppb}$. Therefore, turbine manufacturer specifications for vapor-phase alkali are exceeded even though less than $1 \%$ of the total sodium in the fuel is present as vapor. Gas-phase alkali will be higher for those fuels higher in chlorine. The sodium sulfate concentration in the gas phase remains relatively constant because of condensation.

- When sorbents are used in the bubbling fluid bed for adsorption of components from the gas phase, the outlet concentration of the controlled gas will vary inversely to the amount of the sorbent utilized. Therefore, very high sorbent feed rates will be required for high removals of alkali from the gas phase. The capture efficiency will vary directly with sorbent particle size for a kinetically limited system and with the square of particle size for diffusion controlled, assuming there is no elutriation of fines from the bed.

- Aluminosilicates have the most potential for adsorbing alkali under PFBC conditions. Bauxite, kaolinite, and emathlite have been demonstrated to effectively remove alkali vapors when used in packed, moving, and fixed beds.

- Reactions leading to the formation of sodalites have the potential for combined alkali and chlorine removal.

- Alkali metals can be measured either on-line, producing instantaneous alkali values, or off-line, using batch sampling techniques. The accuracy of on-line methods is still not reliable enough for use in PFBC. Therefore, batch sampling procedures are recommended even though they provide only average values of alkali metal over a given period of time.

\subsubsection{Conclusions from TGA Screening Tests}

- The PTGA at the EERC could not be equipped to feed a continuous and controlled amount of sodium vapor without extensive modifications. Therefore, testing was performed at atmospheric pressure.

- The atmospheric TGA made a good tool for screening sorbents and determining reaction mechanisms. The TGA allows the impact of gas type, temperature, and alkali concentration to be evaluated and rate data extracted. Samples large enough for analysis 
by scanning electron microscopy can be generated in the TGA, with these analyses used to help understand the reaction mechanisms.

- Nosean, a sulfur-bearing zeolite, was the favored reaction product when sorbents were used for combined alkali, chlorine, and sulfur under the conditions tested. Sodalite, the chlorine-bearing counterpart, would be favored at higher chlorine-to-sulfur ratios and/or higher oxygen partial pressures. Albite reacts with $\mathrm{NaCl}$ vapor in an $\mathrm{SO}_{2}$-bearing gas to capture sodium. The primary mechanism is condensation of $\mathrm{Na}_{2} \mathrm{SO}_{4}$ on the surface of the albite followed by chemical reaction. The rate of sodium adsorption decreases with decreasing $\mathrm{SO}_{2}$ concentration in the gas phase because of reductions in the amount of condensed sulfate.

- Albite, quartz, and kaolinite captured sodium by chemical reaction and were kinetically limited. Sodalite and bauxite use physical adsorption as the primary capture method and are diffusion-controlled. After being physically adsorbed, some reaction occurs to permanently bind the alkali.

- The sorbents identified from the TGA screening tests as having commercial potential include albite, kaolinite, and bauxite.

\subsubsection{Conclusions from Bench-Scale Testing}

\subsection{General Observations from the Use of Alkali Sorbents}

- The pressurized fluid-bed reactor at the EERC provides a good tool for determining the effectiveness of sorbents in controlling ash chemistry in the PFBC. The impacts of sorbents on bed agglomeration, ash deposition, ash distribution and chemistry, filter blinding and bridging, vapor-phase alkali, and sulfur and nitrogen oxide emissions can be determined.

- The use of bauxite and kaolinite as in-bed sorbents resulted in a decrease in $\mathrm{NO}_{\mathrm{x}}$ over the base case without sorbent addition. This may be due to a catalytic effect of the sorbent on the $\mathrm{NO}_{\mathrm{x}}$ formation and destruction reactions, similar to those reported for dolomite.

\subsection{Impacts of Sorbents on Ash Distribution}

- Tests with the Beulah coal, which is typical of fuels with high organically bound sodium, tended to show bed agglomeration, deposition on heat-transfer surfaces, and loosely bonded deposits that hung up in the reactor piping. Reduction of the vapor-phase sodium content using bauxite as an in-bed getter eliminated these problems.

- All sorbents increased the mass loading of ash to both the cyclone and the filter vessel. The fine sorbents ( -30 mesh) caused a disproportionate increase in cyclone ash while the coarse sorbents $(-1 / 8$ inch) caused a disproportionate increase in filter vessel ash.

- The fine sorbents displayed a higher tendency to form loosely bonded deposits that hung up in the reactor. 


\subsection{Impacts of Sorbents on Vapor-Phase Alkali Concentration}

- The vapor-phase alkali concentration is directly related to the quantity of organically bound alkali in the fuel. The vapor-phase sodium concentrations measured from the Beulah, Belle Ayr, and spiked Belle Ayr were approximately proportional to the initial sodium concentration in the starting fuel.

- Kaolinite and bauxite were effective and albite was not effective at reducing the vaporphase alkali concentration. Kaolinite and bauxite captured similar amounts of sodium at comparable add rates, indicating that both were equally effective at alkali capture.

- At a 10:1 sorbent-to-sodium add rate, kaolinite and bauxite reduced the vapor-phase sodium concentration to between 500 and $700 \mathrm{ppm}$. At a 30:1 add rate, the resulting sodium concentration was $270 \mathrm{ppm}$. Therefore, it is unlikely that the turbine specifications of 25 to $125 \mathrm{ppm}$ total alkali can be reached using in-bed sorbents.

- In-bed sorbents have an increased capture efficiency for higher initial alkali concentrations. For example, $90 \%$ reduction in sodium from $3600 \mathrm{ppm}$ was realized for tests with the Beulah lignite, but only $67 \%$ reduction from $1700 \mathrm{ppm}$ using the Belle Ayr coal at the same sorbent add rate.

- The fine sorbents were more effective at reducing vapor-phase sodium concentrations than the coarser sorbents, indicating that the increases in surface area more than offset the shorter bed residence time experienced by the finer sorbents.

\subsection{Impacts of Sorbents on Ash Deposition}

- For fuels high in organically bound sodium (Beulah lignite for example), sodium calcium sulfates form dense, tenacious deposits. When alkali sorbents are utilized to capture sodium, the amount of deposition is reduced, and the form changes to loosely bonded, lightly sintered deposits that could easily be removed by sootblowing.

- The use of albite as a sorbent resulted in no change in deposition characteristics. When kaolinite was used, some reduction in deposition was noted; however, considerable amounts of fines deposited in the reactor piping. Bauxite effectively eliminated deposition at add rates of 10:1 bauxite-to-sodium and greatly reduced the deposition at lower add rates. This indicates that certain sorbents themselves have a propensity for deposition regardless of the vapor-phase sodium concentration, since the kaolinite and bauxite were equally effective at reducing the vapor-phase sodium concentration.

- Bed agglomeration was apparent when the Beulah lignite was used. Bauxite effectively controlled agglomeration while albite did not. No evaluation for kaolinite was available from this work. 


\subsection{Impacts of Sorbents on Filter Performance}

- The vapor-phase sodium concentration directly impacts bridging of the ceramic filter used for hot-gas particulate removal. Severe filter blinding was noted when the Beulah lignite, with a vapor-phase sodium concentration of $3600 \mathrm{ppm}$, was used. When using the asreceived and sodium-spiked Belle Ayr (900 and 1700 ppm vapor-phase sodium), no blinding occurred. Analyses indicate the blinding is caused by condensation and freezing of $\mathrm{Na}_{2} \mathrm{SO}_{4}$ on the surface of the filter, forming a relatively impervious layer that cannot be removed by backpulsing.

- For the Beulah lignite with a baseline vapor-phase alkali concentration of $3600 \mathrm{ppm}$, the addition of bauxite at a 10:1 sorbent-to-sodium ratio effectively controlled pressure drop in the filter vessel. An add rate of 3:1 was not effective at controlling pressure drop, while a 5:1 add rate of bauxite was only marginally effective.

- For the sodium-spiked Belle Ayr subbituminous with a baseline vapor-phase alkali concentration of $1700 \mathrm{ppm}$, the pressure drop in the filter vessel never exceeded $10 \mathrm{in}$. $\mathrm{H}_{2} \mathrm{O}$ for the entire duration of the tests using both the kaolinite and bauxite as sorbents at the 10:1 add rate. The pressure drop without the use of sorbents approached 15 in. $\mathrm{H}_{2} \mathrm{O}$, indicating that the sorbents were effectively reducing filter pressure drop.

- The size of the sorbent utilized had no apparent effect on filter pressure drop at similar add rates. Bridging was noted after the test with Beulah coal with bauxite at a 10:1 add rate and only a moderate reduction in vapor-phase sodium concentration. Sodium calcium sulfate was the major component of the bridging material. High sorbent add rates may be effective at eliminating bridges by facilitating high vapor-phase sodium removal, thereby reducing the amount available for homogeneous and heterogeneous condensation to form sticky sulfates.

- During the test program, one of the ceramic filters experienced degradation in the form of spalling from the exterior of the filter. While the filter itself did not fail during the test program, it is speculated that over time this spalling would result in a filter failure. The sodium and sulfur appear to be attacking the protective yttrium coating on certain ceramic filters. Yttrium sulfate appears to be the reaction product. The more mobile phases such as sodium, sulfur, and calcium were found impregnated deep within the surface of the candle.

The overall conclusion from this work is that in-bed alkali sorbents can effectively reduce the vapor-phase alkali concentration. This reduction is of a magnitude great enough to control ash deposition and agglomeration and filter blinding but not to a level low enough to meet current turbine manufacturer recommendations for vapor-phase alkali. Bauxite was the best sorbent tested based on its ability to control all of the above-mentioned problems. Kaolinite is less effective because of its tendency to form sintered deposits from its fine fraction. Finally, although sodalite and nosean can be formed and result in combined sodium and chlorine or sulfur capture, they do not form at a rate high enough to make them effective getters under PFBC conditions. 


\subsubsection{Recommendations}

Bauxite and kaolinite are both effective in reducing the vapor-phase sodium concentration. The increased loading to the cyclone and filter vessel indicate that they have a limited residence time in the bed. These tests also indicated that the high surface area of finer sorbents enhanced alkali removal. Therefore, alkali capture could be improved by changing the form of the sorbent to keep the high surface area, but increasing its size and physical strength to give the sorbent a longer in-bed residence time. This could be accomplished by pelletizing a fine sorbent to a size approaching the mean size of the bed material. It is recommended that pelletization techniques be examined to determine if they can be utilized for kaolinite and bauxite. If not, other aluminosilicate materials should be researched to find a selection that has a propensity to adsorb alkalies and can form good, strong pellets. Even if these alternative sorbents may not be as effective as bauxite and kaolinite in their raw form, they could prove to be more effective overall if pelletizing can substantially increase their residence time in the bed.

If bauxite is chosen as a sorbent, consideration should be given to capturing the cyclone and filter ash and recycling the material back to the PFBC. This should improve the overall efficiency of both the bauxite and the dolomite. Pelletizing the material prior to reintroducing it to the combustor would help stabilize the recycled ash and increase its residence time. The presence of the dolomite in the ash may improve the pelletizing characteristics. This process has been demonstrated for the recycle of fly ash from the circulating FBC of petroleum coke and increased the utilization of the limestone from approximately $35 \%$ to over $70 \%$.

For future testing on the PFBR for screening alkali sorbents, consideration should be given to sampling from the outlet of the filter vessel in addition to the top of the reactor. This would provide an indication of how much, if any, alkali is captured by the entrained ash and the ash that builds up on the filters. Results of other work have shown that $\mathrm{SO}_{2}$ is captured on the filters as the flue gas passes through the filter cake. These measurements would be a better indication of the final vaporphase concentration that the turbine blades would see. Tests at various filter vessel temperatures could provide information to determine how much cooling of flue gas is required to lower the alkali content from the nominal 500 to $700 \mathrm{ppb}$ measured during this work to the 25 to $125 \mathrm{ppb}$ recommended by turbine manufacturers.

Testing should continue to find effective in-bed sorbents for PFBC. If the PFBC is to realize high coal-to-electricity conversion efficiencies, inexpensive methods of capturing alkali are required. In-bed sorbents offer the capability to accomplish this goal.

\subsection{Catalytic Tar Cracking}

\subsubsection{Experimental}

Steam gasification tests were carried out on a high-volatile Illinois bituminous coal (IBC-101) at $1380^{\circ} \mathrm{F}(1023 \mathrm{~K})$ and $100 \mathrm{psig}$ in an integrated bench-scale gasifier (IBG) fitted with a catalyst module at the outlet. The catalyst module was attached to the outlet of the reactor to take advantage of the excess reactor heat to keep the catalyst at elevated temperature and to crack the tars before they condensed. 


\subsubsection{Integrated Bench-Scale Gasifier}

The IBG is a small batch process gasifier, with a charge capacity of nominally $70 \mathrm{~g}$ of coal. This unit provides data on the effects of bed fluidization, conversion of feedstock, reaction rate response to temperature, pressure, catalyst and feed gas composition and flow rate, and gaseous products, while providing sufficient quantities of conversion products for subsequent analysis. The top of the reactor was fitted with a catalyst module through which the hot exhaust gas passed before entering the series of two condensers. Although the catalyst module had no heaters of its own, it received heat from the reactor and tended to remain predictably within $122^{\circ}-212^{\circ} \mathrm{F}(323-373 \mathrm{~K})$ of the reactor. A typical catalyst charge to the module was approximately $90-300 \mathrm{~g}$. Gas flowed uninterrupted through the system. Gas exiting the second condenser was collected in gas bags at 12-minute intervals. The gas was analyzed by a refinery gas analyzer. The effect on the tar was determined by measuring the levels of methane and other hydrocarbons in the gas stream and the weight of the tar recovered from the system. In this study, EMcat Elite S-3699 was tested for its tar-cracking effect.

\subsubsection{Gasification Tests}

Four tests were carried out on identical quantities of coal under the same conditions of time, temperature, pressure, fluidization gas $\left(\mathrm{N}_{2}\right)$ velocity, and steam injection with approximately 0,90 , 180 , and $270 \mathrm{~g}$ (module full) of Engelhard EMcat Elite S-3699. This zeolite catalyst was impregnated by the manufacturer with $<1 \%$ Pt. One test at $1380^{\circ} \mathrm{F}(1023 \mathrm{~K})$ and 100 psig was carried out with dolomite as the catalyst and one test at the same conditions with commercial $\mathrm{CoO}-\mathrm{MoO}-$ on-alumina catalyst.

Gasification conditions were $1380^{\circ} \mathrm{F}(1023 \mathrm{~K})$ and $100 \mathrm{psig}$ in a fluidized bed with fluidization gas $\left(\mathrm{N}_{2}\right)$ flow at (nominally) $20 \mathrm{scfh}$ (550 liters per hour). The gas stream was passed through a catalyst bed that was contained in a module immediately downstream from the reactor and spontaneously heated by convection and conduction from the reactor. The temperature during gasification was $1110-1170^{\circ} \mathrm{F}(875-905 \mathrm{~K})$. Each 60 -minute test was carried out on $75 \mathrm{~g}$ of feed, with gas samples drawn each 12 minutes. Fluidization of the -60 -mesh coal was achieved with nitrogen carrier gas flow of approximately $9.4 \mathrm{~L} / \mathrm{min}$, and steam was injected at approximately $11 \mathrm{~g}$ per minute. Gas-catalyst contact times were $0,1,2$, and 3 seconds except in the single tests with dolomite and CoO-MoO-on-alumina, in which the contact time was 2 seconds. Solids and tar recoveries were obtained, and gas was collected and analyzed.

\subsubsection{Results}

Production of heavy tar always accompanies steam gasification of coal. This tar is detrimental to the process for several reasons, including environmental, operational, and product economics. Aerosols that escape into the atmosphere degrade air quality as well as surfaces on which they condense. Condensed droplets result in equipment fouling. This is particularly undesirable in processes such as cogeneration that utilize turbines. In addition, tar formation seriously affects the energy per pound of coal available as gaseous fuel. Conversion of this tar to additional gas and at the same time removing the fouling problems would favorably impact the economics of the process. Catalytic tar cracking is one solution to the problem. The search for an inexpensive, efficient catalyst is a necessary part of this solution. 
Engelhard EMcat Elite S-3699 was tested for tar cracking of coal tar produced during steam gasification of Illinois No. 6 Bituminous Coal (IBC-101). The proximate analysis of the feed coal is given in Table 1.

\section{TABLE 1}

Proximate Analysis of IBC-101 Bituminous Coal

\begin{tabular}{lc}
\hline Sample: & IBC-101 \\
Treatment: & Raw \\
\hline Moisture, wt\%, ar* & 7.64 \\
Volatiles, wt\%, mf** & 43.10 \\
Fixed C, wt\%, mf & 49.27 \\
Ash, wt\%, mf & 7.62 \\
\hline$*$ As received. & \\
$* *$ Moisture-free. &
\end{tabular}

The effect of this catalyst in cracking heavy tar produced during steam gasification of IBC101 is demonstrated by the total gas production and coincident total heavy tar yield as a percent of feed with increasing Pt-zeolite-tar contact time, shown in Figure 1.

The changes in tar and gas yields in weight percent with contact time are shown in Figure 2. A contact time of 3 seconds cracked nearly $80 \%$ of the tar. Tar conversion increased linearly as contact time increased over the conditions of this test series as shown in Figure 3 . With the current catalyst module full and the gas flow rates set as above, tar-catalyst contact time was 3 seconds. At those conditions, $80 \%$ of the tar was cracked. Hydrogasification occurred using only the hydrogen produced by the gasification reaction.

Tests carried out with $<1 \%$ Pt on Zeolite, $\mathrm{CoO}-\mathrm{MoO}$ on alumina, and natural dolomite as catalysts with a contact time of 2 seconds were carried out. The CoO-MoO cracked the tar as effectively with 2 -second contact time as the Pt-zeolite did in 3 seconds. The conversion of tar by each of the three catalysts at similar conditions are shown in Table 2 . The dolomite was as effective as the Pt-Zeolite but, as mentioned above, the loss of catalyst through decrepitation and gas entrainment was objectionable as shown in Table 2.

Hydrogen gas in the product gas stream decreases as a function of contact time with the catalyst as shown in Figure 4. As hydrocarbon production increases, hydrogen in the gas stream decreases. 


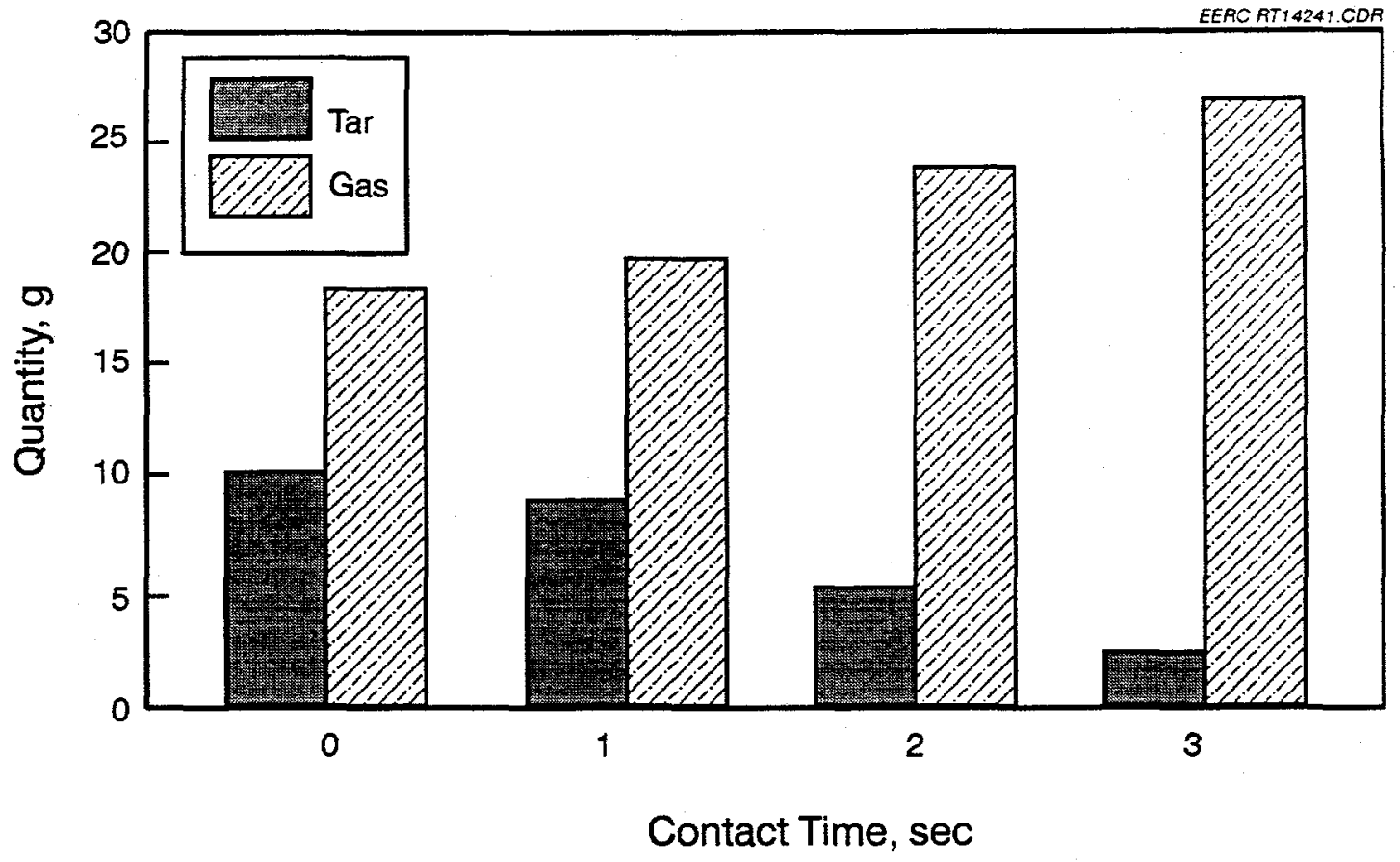

Figure 1. Quantities of tar and gas products from catalytic cracking of tar produced during gasification of Illinois bituminous coal by different amounts of $1 \% \mathrm{Pt}$ on zeolite.

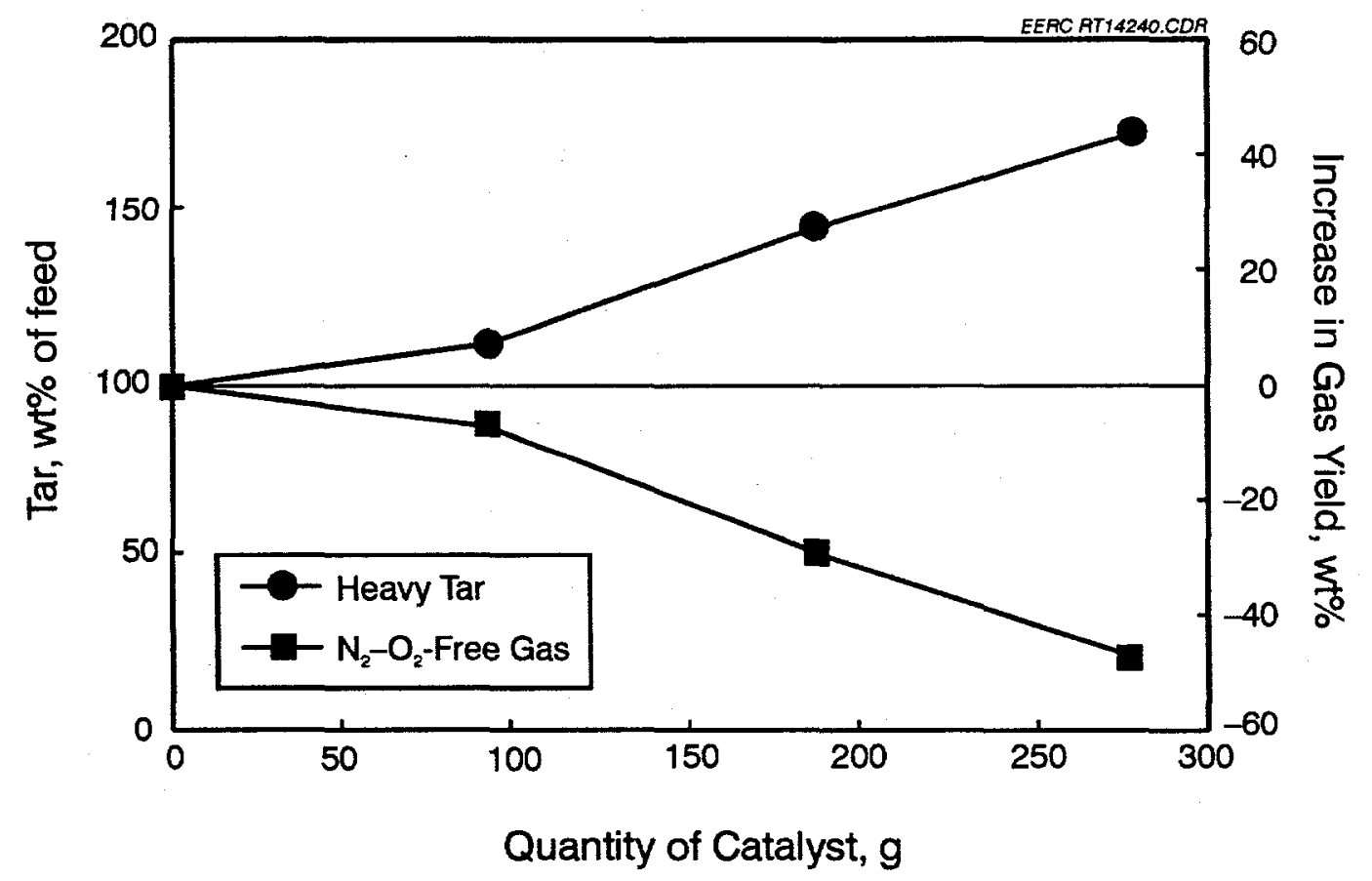

Figure 2. Weight percent decrease in tar and weight percent increase in gas collected following catalytic cracking of tar by $1 \% \mathrm{Pt}$ on zeolite. 


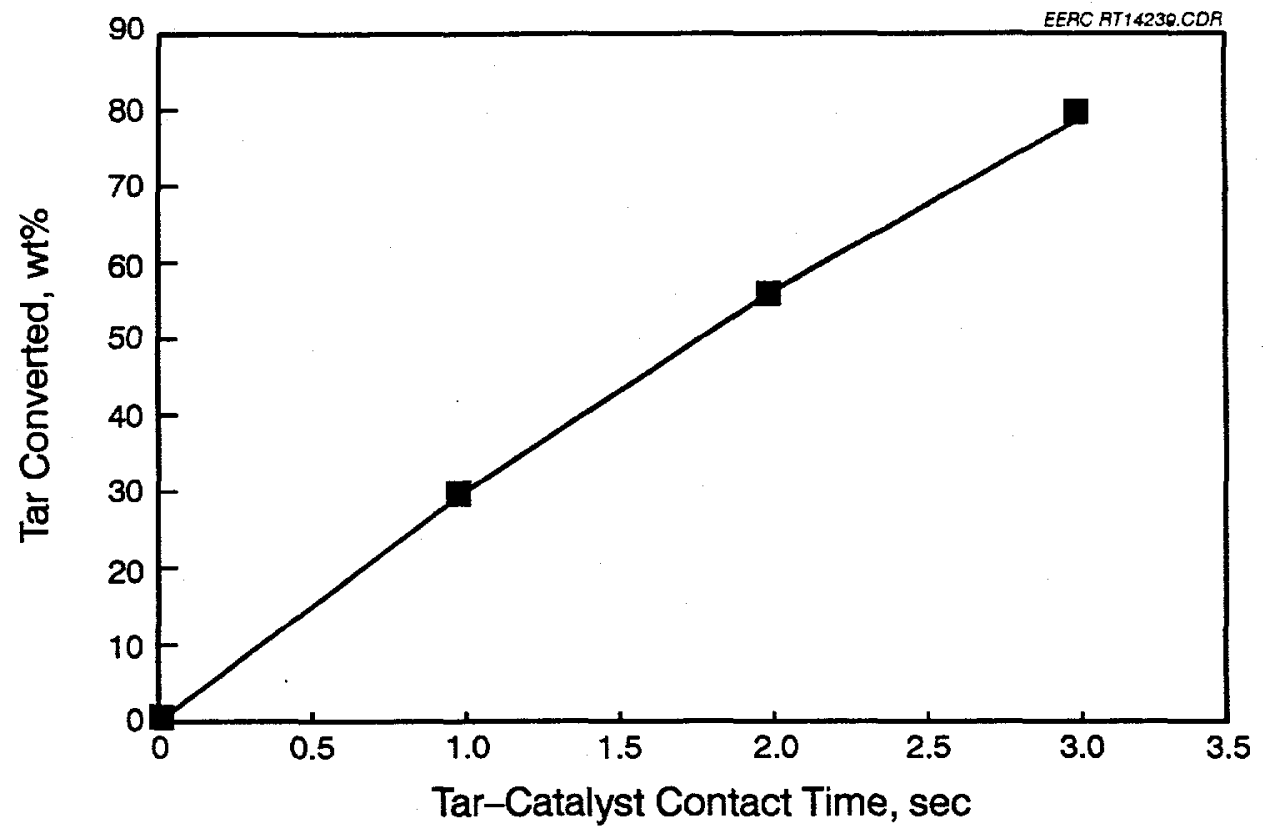

Figure 3. Gasification tar converted to product gas stream after contact with $1 \% \mathrm{Pt}$ on zeolite at approximately $600^{\circ} \mathrm{C}$.

TABLE 2

Comparison of Catalyst on Tar Cracking and Subsequent Catalyst Recovery

\begin{tabular}{lcc} 
Catalyst & $\begin{array}{c}\text { Conversion of } \\
\text { Tar, \% }\end{array}$ & $\begin{array}{c}\text { Recovery of } \\
\text { Catalyst, \% }\end{array}$ \\
\hline$<1 \%$ Pt on Zeolite & 55 & 96 \\
CoO-MoO on Alumina & 82 & 92 \\
Dolomite & 58 & 75 \\
\hline
\end{tabular}

\subsubsection{Conclusions}

- In initial tests where catalyst temperature was in excess of $1110^{\circ} \mathrm{F}(875 \mathrm{~K})$, dolomite decrepitated and became entrained in the gas stream, resulting in loss of catalyst and contamination of tar, introducing error into tar measurements.

- Emcat Elite S-3699, which is $<1 \%$ Pt on zeolite, withstood the high temperature and cracked coal tar. 


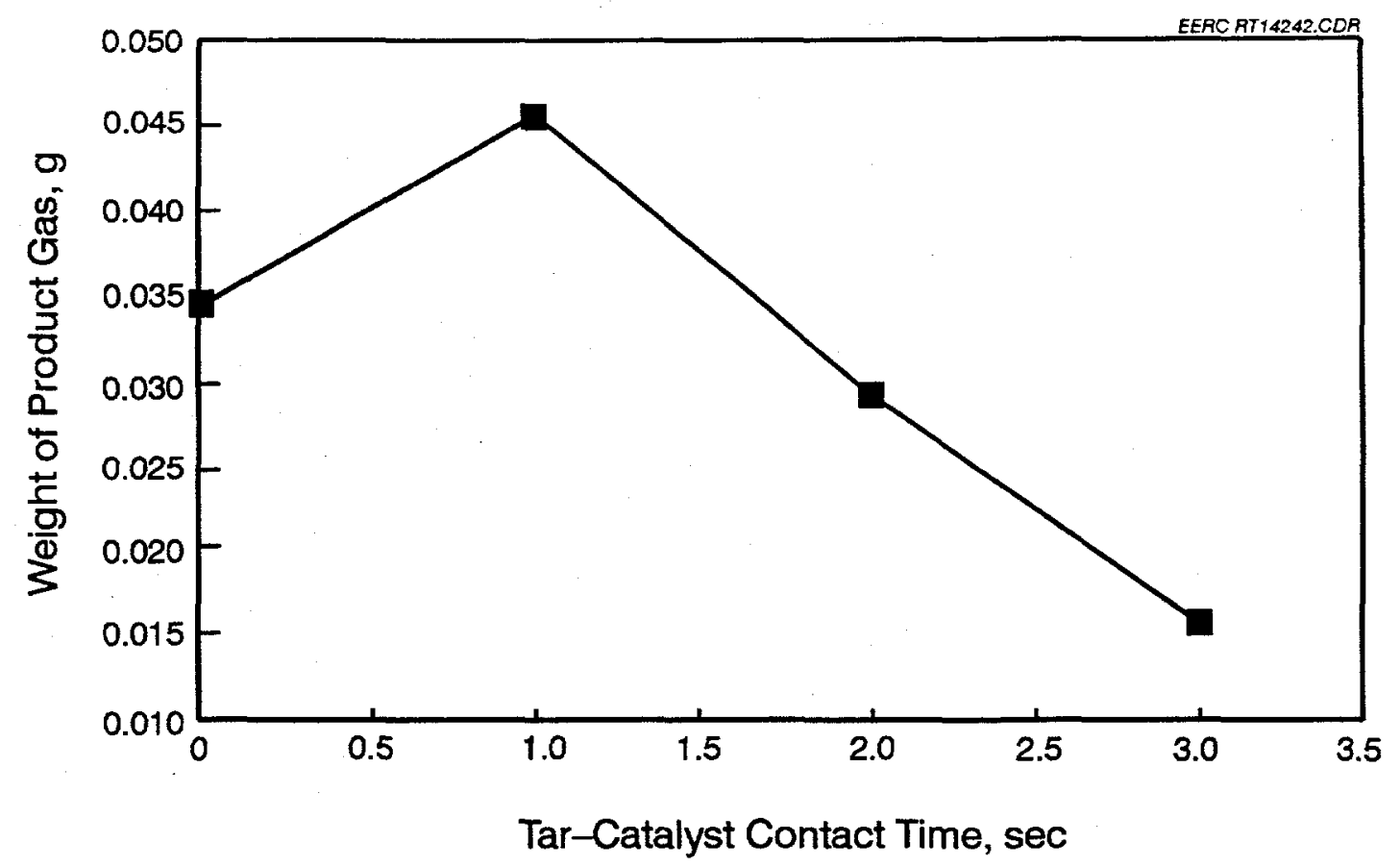

Figure 4. Hydrogen content of product gas as a function of contact time with catalyst.

- Tar cracking increased linearly with tar-catalyst contact time for 0-3 seconds. Three seconds was the upper contact time limit since the module was full of catalyst and the fluidization gas which served as a carrier gas for the product gas was flowing as slowly as possible for maintaining fluidization.

- Tar-catalyst (EMcat Elite S-3699) contact time of 3 seconds cracked $80 \%$ of the tar entrained in the hot-gas stream. Since the curve produced by plotting tar cracked versus contact time up to 3 seconds is linear, it is expected that additional contact time would produce additional cracking.

- CoO-MoO on alumina was more effective in cracking the IBC-101 tar at the conditions of this study than either $<1 \% \mathrm{Pt}$ on zeolite or natural dolomite.

\subsubsection{Recommendations}

- Construct a larger catalyst module to increase contact time.

- Determine the effective life of the catalyst.

- Perform a similar suite of tests with dolomite in which the catalyst module is held at lower temperatures.

- Perform a similar suite of tests on other commercial catalysts. 


\title{
APPENDIX A
}

\section{CAPTURE OF ALKALI DURING PRESSURIZED FLUIDIZED-BED COMBUSTION USING IN-BED SORBENTS}

\author{
Ph.D. Dissertation by Michael D. Mann
}


CAPTURE OF ALKALI DURING PRESSURIZED FLUIDIZED-BED

COMBUSTION USING IN-BED SORBENTS

by

\author{
Michael D. Mann \\ Masters of Science, University of North Dakota, 1981
}

\author{
A Dissertation \\ Submitted to the Graduate Faculty \\ of the \\ University of North Dakota \\ in partial fulfillment of the requirements
}

for the degree of

Doctor of Philosophy

Grand Forks, North Dakota

May

1997 


\section{Copyright by}

Michael D. Mann

1996 
This dissertation, submitted by Michael D. Mann in partial fulfillment of the requirements for the Degree of Doctor of Philosophy from the University of North Dakota, has been read by the Faculty Advisory Committee under whom the work has been done and is hereby approved.

(Chairperson)

This dissertation meets the standards for appearance, conforms to the style and format requirements of the Graduate School of the University of North Dakota, and is hereby approved.

Dean of the Graduate School 


\section{PERMISSION}

Title Capture of Alkali During Pressurized Fluidized-Bed Combustion Using In-bed Sorbents

Department School of Engineering and Mines

Degree Doctor of Philosophy

In presenting this dissertation in partial fulfillment of the requirements for a graduate degree from the University of North Dakota, I agree that the library of this University shall make it freely available for inspection. I further agree that permission for extensive copying for scholarly purposes may be granted by the professor who supervised by dissertation work or, in his absence, by the chairperson of the department or the dean of the Graduate School. It is understood that any copying or publication or other use of this dissertation or part thereof for financial gain shall not be allowed without my written permission. It is also understood that due recognition shall be given to me and to the University of North Dakota in any scholarly use which may be made of any material in my dissertation.

Signature

Date 


\section{TABLE OF CONTENTS}

LIST OF FIGURES $\ldots \ldots \ldots \ldots \ldots \ldots \ldots \ldots \ldots \ldots \ldots \ldots \ldots \ldots \ldots \ldots \ldots$

LIST OF TABLES $\ldots \ldots \ldots \ldots \ldots \ldots \ldots \ldots \ldots \ldots \ldots \ldots \ldots \ldots \ldots \ldots \ldots \ldots \ldots$

ACKNOWLEDGMENTS $\ldots \ldots \ldots \ldots \ldots \ldots \ldots \ldots \ldots \ldots \ldots \ldots \ldots \ldots \ldots \ldots \ldots$

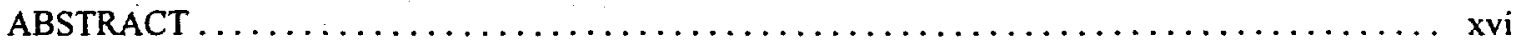

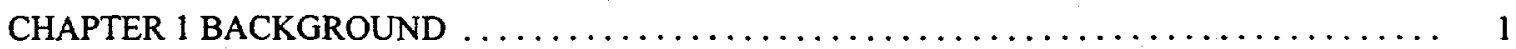

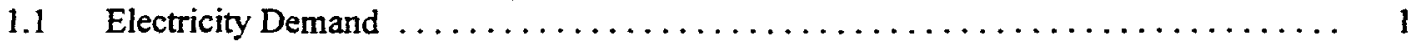

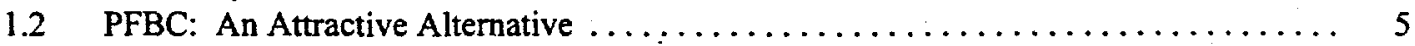

1.3 Projected PFBC Market $\ldots \ldots \ldots \ldots \ldots \ldots \ldots \ldots \ldots \ldots \ldots \ldots \ldots \ldots \ldots \ldots \ldots \ldots$

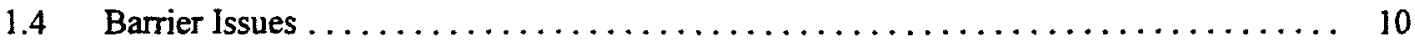

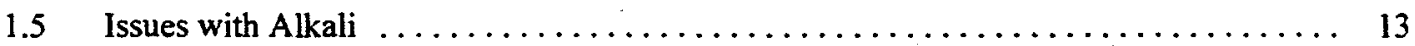

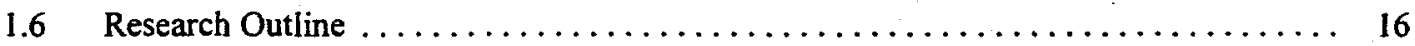

CHAPTER 2 LITERATURE REVIEW $\ldots \ldots \ldots \ldots \ldots \ldots \ldots \ldots \ldots \ldots \ldots \ldots$

2.1 Transformation of Mineral Matter in Coal $\ldots \ldots \ldots \ldots \ldots \ldots \ldots \ldots \ldots \ldots \ldots \ldots \ldots$

2.1.1 The Nature of the Inorganic Constituents $\ldots \ldots \ldots \ldots \ldots \ldots \ldots \ldots \ldots \ldots$

2.1.2 Ash Formation and Partitioning During Combustion and Gasification . . . . . . 22

2.2 Modeling of Gas-Phase Alkali Composition . . . . . . . . . . . . . . . . . 28

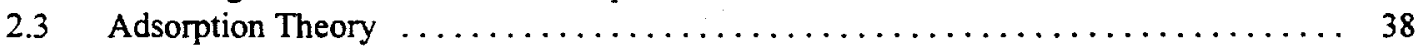

2.3.1 Mass Transfer in Batch Operations . . . . . . . . . . . . . . . . 40

2.3.2 Mass Transfer in Continuous Operations $\ldots \ldots \ldots \ldots \ldots \ldots \ldots \ldots \ldots \ldots \ldots$

2.3.3 Kinetic Models for the Conversion of Solids $\ldots \ldots \ldots \ldots \ldots \ldots \ldots$

2.3.3.1 Uniform-Reaction Model for Porous Solids of Unchanging Size . . . . . . . 46

2.3.3.2 Shrinking-Core Model for Solids of Unchanging Size $\ldots \ldots \ldots \ldots \ldots \ldots$

2.3.3.3 Intermediate Models for Particles of Unchanging Size . . . . . . . . . . 50

2.3 .4 Applying the Models to a Dynamic System $\ldots \ldots \ldots \ldots \ldots \ldots \ldots \ldots \ldots \ldots \ldots$

2.3.4.1 Conversion of Both $\mathrm{Gas}$ and Solids $\ldots \ldots \ldots \ldots \ldots \ldots \ldots \ldots \ldots \ldots \ldots$

2.3.4.2 Performance Calculations for the Large-Particle Bed . . . . . . . . . . 54

2.3.4.3 Performance Calculations for the Fine-Particle Bed $\ldots \ldots \ldots \ldots \ldots \ldots$

2.3 .5 Model Implications $\ldots \ldots \ldots \ldots \ldots \ldots \ldots \ldots \ldots \ldots \ldots \ldots \ldots \ldots \ldots$

2.4 Mechanisms of Capture using Aluminosilicates $\ldots \ldots \ldots \ldots \ldots \ldots \ldots \ldots \ldots \ldots \ldots$

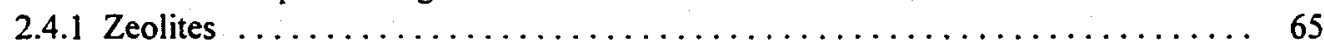

2.4 .2 Layered Silicates $\ldots \ldots \ldots \ldots \ldots \ldots \ldots \ldots \ldots \ldots \ldots \ldots \ldots \ldots \ldots \ldots \ldots$

$2.5 \quad$ Alkali Sorbents Tested $\ldots \ldots \ldots \ldots \ldots \ldots \ldots \ldots \ldots \ldots \ldots \ldots \ldots \ldots \ldots \ldots \ldots \ldots$

2.5.1 Alkali Removal Performance $\ldots \ldots \ldots \ldots \ldots \ldots \ldots \ldots \ldots \ldots$

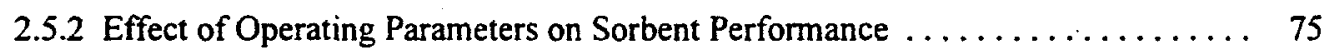

2.6 Measurement Techniques $\ldots \ldots \ldots \ldots \ldots \ldots \ldots \ldots \ldots \ldots \ldots \ldots \ldots \ldots \ldots \ldots$

Continued... 
TABLE OF CONTENTS (continued)

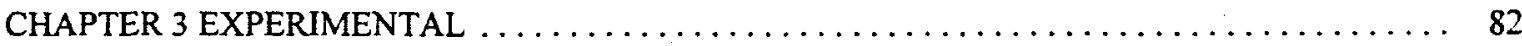

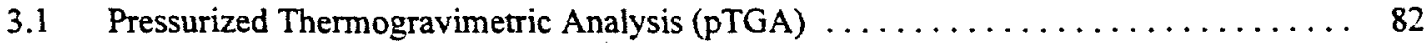

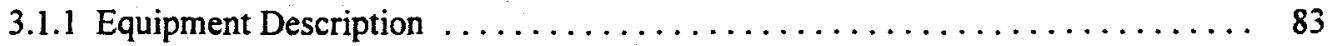

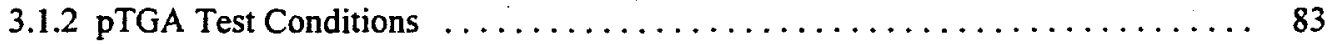

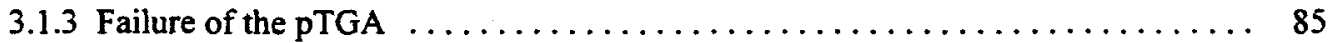

3.2 Atmospheric Thermogravimetric Analysis (TGA) $\ldots \ldots \ldots \ldots \ldots \ldots \ldots \ldots \ldots \ldots$

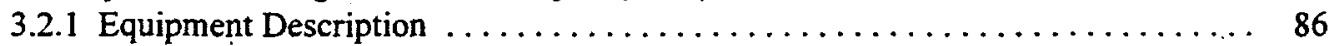

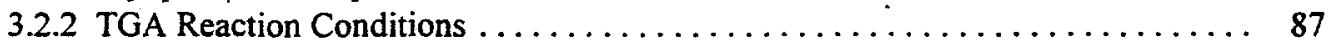

3.2.3 Test Matrix for TGA Determinations $\ldots \ldots \ldots \ldots \ldots \ldots \ldots \ldots \ldots \ldots \ldots . \ldots \ldots$

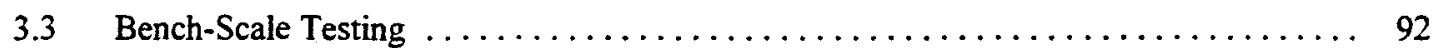

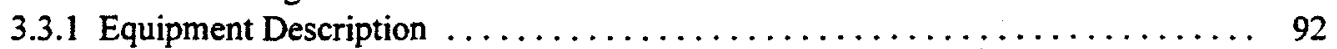

3.3.1.2 Description of Hot-Gas Filter Vessel . . . . . . . . . . . . . . . . . . 96

3.3.1.3 EERC Alkali-Sampling Probe Equipment Description .............. 97

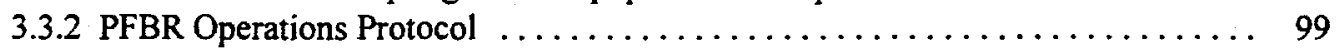

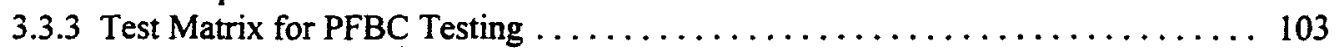

CHAPTER 4 RESULTS OF TGA SCREENING TESTS $\ldots \ldots \ldots \ldots \ldots \ldots \ldots \ldots \ldots \ldots \ldots \ldots$

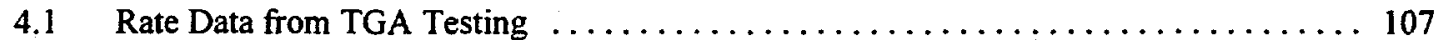

4.2 Sodalite Reactions .............................................. 108

4.3 Adsorption Rates and Mechanisms ............................. 117

4.4 Selection of Sorbents . . . . . . . . . . . . . . . . . . . . . . . . . . . 123

CHAPTER 5 BENCH-SCALE TESTING OF ALKALI SORBENTS $\ldots \ldots \ldots \ldots \ldots \ldots \ldots \ldots \ldots$

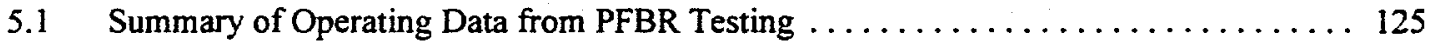

5.2 Distribution and Chemistry of the Ash Generated from Capture Tests ............ 134

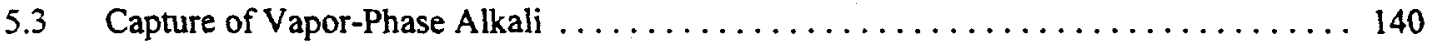

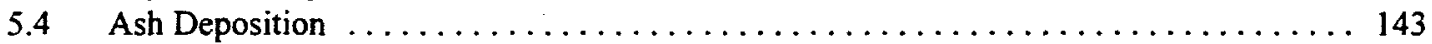

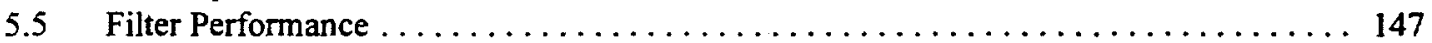

CHAPTER 6 CONCLUSIONS AND RECOMMENDATIONS $\ldots \ldots \ldots \ldots \ldots \ldots \ldots \ldots \ldots \ldots \ldots 162$

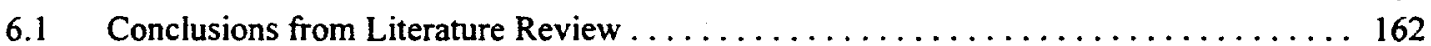

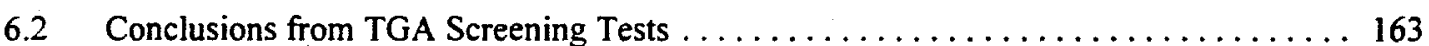

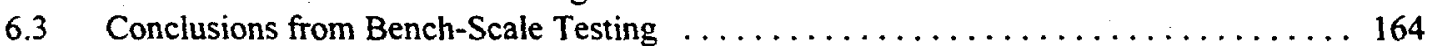

6.3.1 General Observations from the Use of Alkali Sorbents $\ldots \ldots \ldots \ldots \ldots \ldots \ldots$

6.3.2 Impacts of Sorbents on Ash Distribution ...................... 164

6.3.3 Impacts of Sorbents on Vapor-Phase Alkali Concentration ............ 165

6.3.4 Impacts of Sorbents on Ash Deposition ...................... 166

6.3.5 Impacts of Sorbents on Filter Performance ................... 166

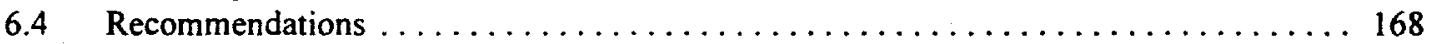

Appendix A $\ldots \ldots \ldots \ldots \ldots \ldots \ldots \ldots \ldots \ldots \ldots \ldots \ldots \ldots$ GLOSSARY OF TERMS AND ACRONYMS

Appendix B $\ldots \ldots \ldots \ldots \ldots \ldots \ldots \ldots \ldots \ldots \ldots$ SUMMARY OF RUN DATA FROM THE PFBR

Appendix $C \ldots \ldots \ldots \ldots \ldots \ldots \ldots$ THERMOGRAMS FROM SORBENT-SCREENING TESTS

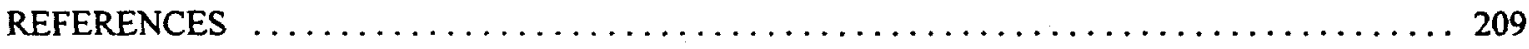




\section{LIST OF FIGURES}

$\begin{array}{ll}\text { Figure } & \text { Page }\end{array}$

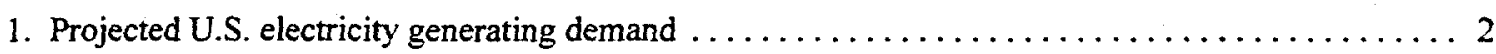

2. U.S. power plants over 40 years old that are candidates for repowering $\ldots \ldots \ldots \ldots \ldots \ldots 2$

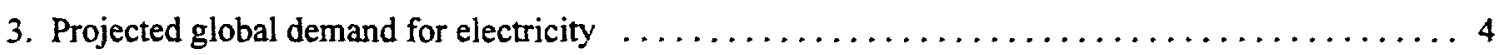

4. Schematic of a pressurized fluidized-bed combustion plant $\ldots \ldots \ldots \ldots \ldots \ldots \ldots \ldots \ldots$.

5. Advanced coal technology market penetration $\ldots \ldots \ldots \ldots \ldots \ldots \ldots \ldots \ldots \ldots \ldots \ldots$. 9

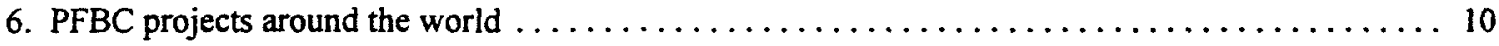

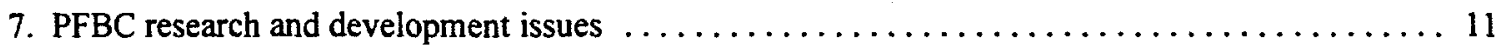

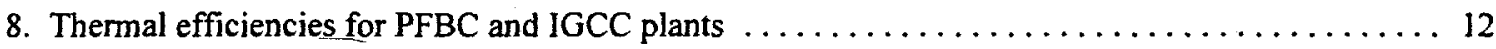

9. Mechanisms of mineral matter release under $\mathrm{FBC}$ conditions $\ldots \ldots \ldots \ldots \ldots \ldots \ldots \ldots \ldots \ldots$

10. Distribution of $\mathrm{Na}, \mathrm{K}$, and $\mathrm{Cl}$ in three phases under $\mathrm{PFBC}$ conditions $\ldots \ldots \ldots \ldots \ldots \ldots \ldots$

11. Variation of the partial pressure of the gaseous alkali species with temperature $\ldots \ldots \ldots \ldots . \ldots 32$

12. Variation of the vapor-phase $\mathrm{Na}$ and $\mathrm{K}$ concentrations in the flue gas with temperature for three

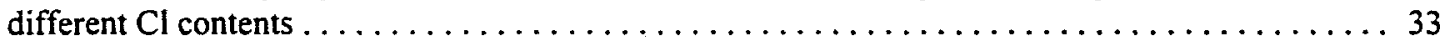

13. Variation of the partial pressure of the gaseous alkali species with $(\mathrm{Na}+\mathrm{K}) / \mathrm{Cl}$ ratio $\ldots \ldots \ldots . .34$

14. Variations of the partial pressure of gaseous alkali species with $(\mathrm{K}+\mathrm{NA}) / \mathrm{S}$ ratio $\ldots \ldots \ldots \ldots 35$

15. $\mathrm{Na}$ and $\mathrm{K}$ concentration in the vapor phase in the flue gas at 1 to 25 bar pressure range under

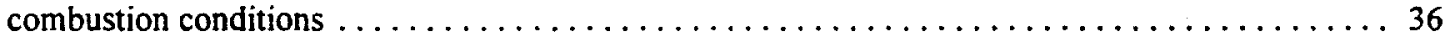

16. Composition of condensed mineral phases formed under oxidizing conditions when burning an

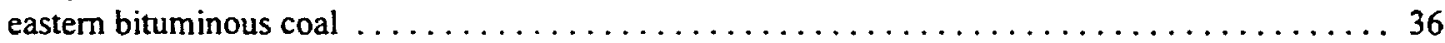

17. Partial pressures of important gaseous species formed during the combustion of an eastern bituminous coal 


\section{LIST OF FIGURES (continued)}

18. Adsorption of vapor by a batch of solids. The calculated lines are for theoretical adsorption of

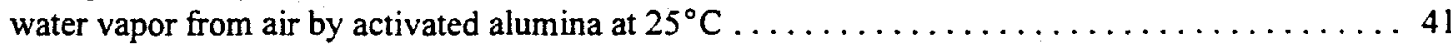

19. Examples of equilibrium isotherms between water vapor on the solid and in air, $Q(\mathrm{~kg}$ adsorbed $/ \mathrm{kg}$ solid) for 1) silica gel, 2) molecular sieve, and 3) activated alumina $\ldots \ldots \ldots \ldots \ldots \ldots$

20. Continuous mass transfer operations between solids and gas in a single fluidized bed, for gas in.

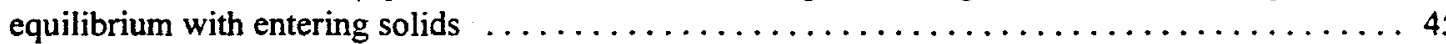

21. Uniform-reaction model. Here the reaction proceeds throughout the particle $\ldots \ldots \ldots$

22. Shrinking-core model. Here the reaction proceeds at a narrow front that advances into the particle 47

23. Variables for a fluidized-bed reactor treating particles of uniform size using the shrinking-core

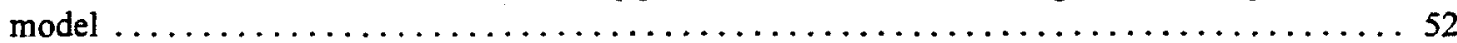

24. Relationship between alkali content and the percent utilization of the sorbent particle .......58

25. Relationship between alkali content and the percent utilization of the sorbent particle plotted on

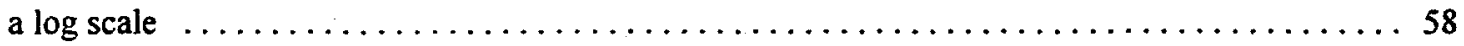

26. Tetrad arrangement of silicic acids and silicates with chain tap and leaf-type structures ......662

27. Effect of oxygen-to-silicon ratio on silicate structure $\ldots \ldots \ldots \ldots \ldots \ldots$

28. Schematic representations of the atomic arrangement in soda-silica glass $\ldots \ldots \ldots 4$

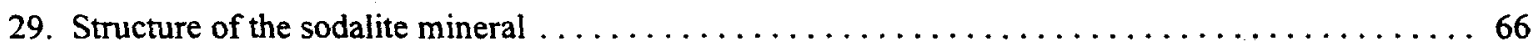

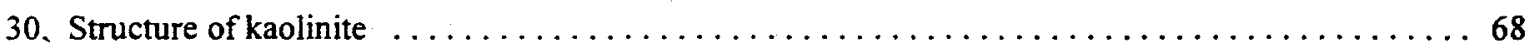

31. Temporal profile of $\mathrm{NaCl}$ adsorption on sorbents at $800^{\circ} \mathrm{C} \ldots \ldots \ldots \ldots \ldots$

32. Apparent rate constants for bauxite and kaolinite $\ldots \ldots \ldots \ldots \ldots \ldots \ldots$

33. Effect of gas composition and conditions on the adsorption efficiency of sillimanite/silica in a

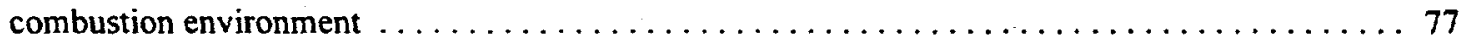

34. Configuration of the pTGA during attempted alkali generation/capture studies $\ldots \ldots \ldots 5$

35. Schematic of the Dupont 951 Thermogravimetric Analyzer $\ldots \ldots \ldots \ldots$

36. Thermogram from a stepwise TGA using albite as the sorbent with $\mathrm{NaCl}$ in combustion gas . . . . 89

37. Schematic representation of the PFBR and hot-gas filter vessel test system $\ldots \ldots \ldots 2$

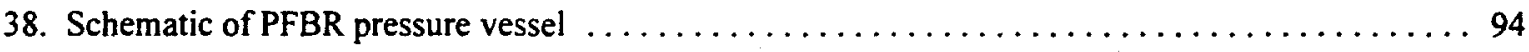

Continued... 


\section{LIST OF FIGURES (continued)}

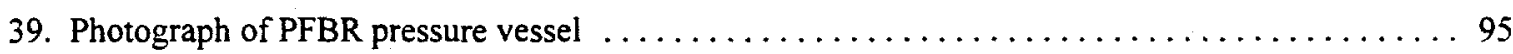

40. Photograph of the inside of the bench-scale hot-gas filter vessel on the PFBR $\ldots \ldots \ldots \ldots \ldots 96$

41. Schematic of EERC extractive alkali-sampling probe $\ldots \ldots \ldots \ldots \ldots \ldots \ldots \ldots \ldots \ldots$

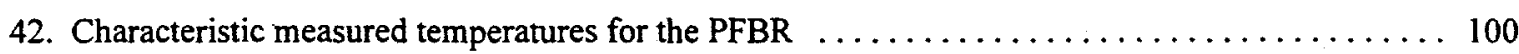

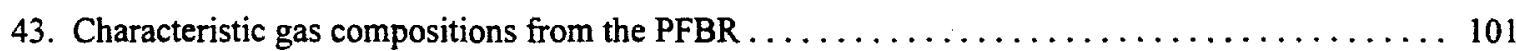

44. Pressure-temperature equilibrium of $\mathrm{CaCO}_{3}$ and $\mathrm{CaO} \ldots \ldots \ldots \ldots \ldots \ldots \ldots \ldots \ldots \ldots \ldots \ldots \ldots \ldots \ldots$

45. Characteristic temperature profile from the hot-gas filter vessel $\ldots \ldots \ldots \ldots \ldots \ldots \ldots \ldots$

46. Characteristic pressure profile from the hot-gas filter vessel $\ldots \ldots \ldots \ldots \ldots \ldots \ldots \ldots \ldots$

47. Thermogram of albite exposed to $\mathrm{NaCl}$ with a combustion carrier gas $\ldots \ldots \ldots \ldots \ldots \ldots \ldots 108$

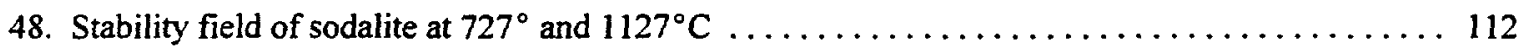

49. SEM photograph of albite and quartz sample from $\mathrm{TGA}$ using $\mathrm{NaCl}$ and combustion gas $\ldots \ldots 113$

50. SEM photograph of albite and quartz sample from TGA using $\mathrm{NaCl}$ and combustion gas $\ldots \ldots 114$

51. SEM point analysis of albite and silica exposed to $\mathrm{NaCl}$ in combustion gas in TGA $\ldots \ldots \ldots 115$

52. Equilibrium between nosean and sodalite at constant oxygen fugacity $\ldots \ldots \ldots \ldots \ldots \ldots$

53. Graphical presentation of TGA data utilized for extracting kinetic information $\ldots \ldots \ldots \ldots \ldots 118$

54. Morphology of bauxite after 6 -hr exposure to combustion gas and $\mathrm{NaCl}$ in the $\mathrm{TGA} \ldots \ldots \ldots 122$

55. $\mathrm{NO}_{\mathrm{x}}$ emissions as a function of temperature for PFBR tests $\ldots \ldots \ldots \ldots \ldots \ldots \ldots \ldots \ldots \ldots$

56. Material balance for PFBR testing expressed as percent of ash removed based on total solid

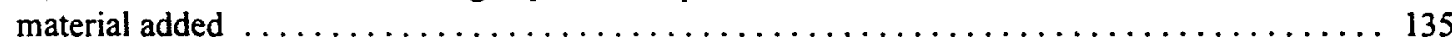

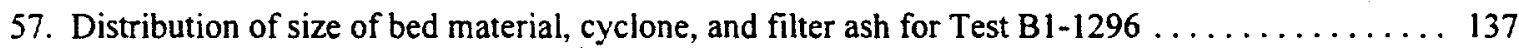

58. Mass flow of cyclone and filter vessel ash from PFBR tests $\ldots \ldots \ldots \ldots \ldots \ldots \ldots \ldots \ldots$

59. Schematic of the top of the PFBR showing the location of the ash deposition probe $\ldots \ldots \ldots 143$

60. Photographs of ash deposition probe from the PFBR after alkali capture tests $\ldots \ldots \ldots \ldots \ldots .144$

61. Filter pressure drop for PFBR tests using Beulah lignite $\ldots \ldots \ldots \ldots \ldots \ldots \ldots \ldots \ldots \ldots$

Continued... 


\section{LIST OF FIGURES (continued)}

62. Filter vessel pressure drop for the Belle Ayr tests on the PFBR $\ldots \ldots \ldots \ldots \ldots \ldots \ldots \ldots \ldots$

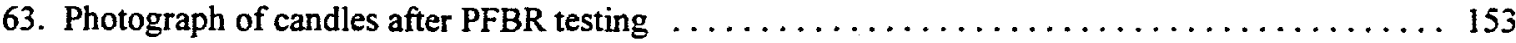

64. SEM photograph and elemental map of candle deposit from Test $1296 \ldots \ldots \ldots \ldots \ldots \ldots \ldots 154$

65. Close-up SEM photograph and elemental map of filter deposit from Test B1-1296 ........ 154

66. SEM photograph of an unexposed section of the filter that failed during the PFBR tests $\ldots \ldots \ldots 156$

67. SEM photographs of a section of filter with ash layer taken after Test BEL-1896 $\ldots \ldots \ldots \ldots 157$

68. SEM photograph of a piece of filter removed after Test B1-1996 ............... 158

69. Elemental map of a piece of filter with deposit from Test B1-1996 .............. 159

70. Photograph of an ash bridge formed in the filter vessel during Test B1-2096 $\ldots \ldots \ldots \ldots \ldots 159$

71. Thermogram from Test 1 , albite with $\mathrm{NaCl}$ and nitrogen as the initial gas $\ldots \ldots \ldots \ldots \ldots 200$

72. Thermogram from $\mathrm{Test} 2$, albite without $\mathrm{NaCl}$ and nitrogen as the initial gas $\ldots \ldots \ldots \ldots \ldots 200$

73. Thermogram from Test 3 , albite with $\mathrm{NaCl}$ and combustion gas as the initial gas $\ldots \ldots \ldots \ldots 201$

74. Thermogram from Test 4, albite without $\mathrm{NaCl}$ and combustion gas as the initial gas $\ldots \ldots \ldots 201$

75. Thermogram from Test 5 , albite and quartz with $\mathrm{NaCl}$ and combustion gas as the initial gas $\ldots .202$

76. Thermogram from Test 6 , albite and quartz with $\mathrm{NaCl}$ and nitrogen as the initial gas $\ldots \ldots \ldots 202$

77. Thermogram from Test 7 , sodalite with $\mathrm{NaCl}$ and combustion gas as the initial gas $\ldots \ldots \ldots 203$

78. Thermogram from Test 8 , sodalite without $\mathrm{NaCl}$ and combustion gas as the initial gas $\ldots \ldots 203$

79. Thermogram from Test 9 , sodalite with $\mathrm{NaCl}$ and nitrogen as the initial gas $\ldots \ldots \ldots \ldots 204$

80. Thermogram from Test 10 , nepheline with $\mathrm{NaCl}$ and combustion gas as the initial gas $\ldots \ldots 204$

81. Thermogram from Test $11, \mathrm{AlO}(\mathrm{OH})_{3}$ with $\mathrm{NaCl}$ and combustion gas as the initial gas ..... 205

82. Thermogram from Test 12 , kaolinite with $\mathrm{NaCl}$ and combustion gas as the initial gas $\ldots \ldots 205$

83. Thermogram from Test 13 , activated bauxite with $\mathrm{NaCl}$ and nitrogen as the initial gas $\ldots \ldots 206$

84. Thermogram from Test 14 , activated bauxite with $\mathrm{NaCl}$ and combustion gas as the initial gas $\ldots 206$

85. Thermogram from Test 15 , zeolite with $\mathrm{NaCl}$ and nitrogen as the initial gas $\ldots \ldots \ldots \ldots . \ldots 207$

Continued... 


\section{LIST OF FIGURES (continued)}

86. Thermogram from Test 16 , sodalite without $\mathrm{NaCl}$ and nitrogen as the initial gas $\ldots \ldots \ldots 207$

87. Thermogram from Test 17, albite with $\mathrm{NaCl}$ and combustion gas as the initial gas ........ 208 


\section{LIST OF TABLES}

Table

Page

1 Operating Characteristics of Westinghouse Gas Turbines

2 Permissible Impurities in Coal Gas

3 Ranges in Concentrations of Inorganic Elements and Percents Extracted by 1 Molar Ammonium

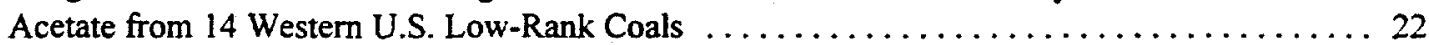

4 Ranges of Inorganic Elements Extracted by $1 \mathrm{Molar} \mathrm{HCl}$ and Remaining in the Residues from

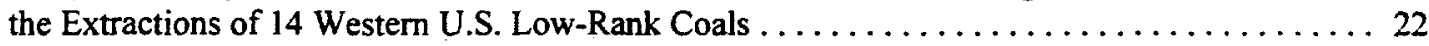

5 Chemical Species Considered in the Equilibrium Calculations $\ldots \ldots \ldots \ldots \ldots \ldots \ldots \ldots, 30$

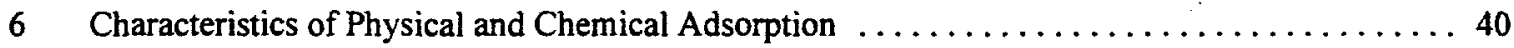

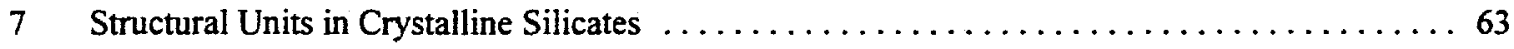

8 Reaction Mechanisms of Vaporous Alkalies with Aluminosilicates to Form Alkali Alumina

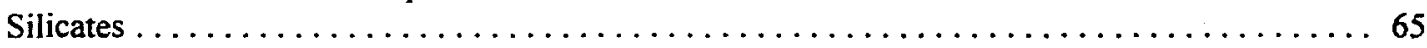

9 Summary of Alkali Chloride Adsorbent Screening Tests $\ldots \ldots \ldots \ldots \ldots \ldots \ldots \ldots \ldots \ldots$

10 Vapor-Phase Sodium Concentrations at the Various Temperatures Tested Using TGA ..... 88

11 Test Matrix for Evaluation of Sodalite Reactions Performed on the TGA $\ldots \ldots \ldots \ldots \ldots$. 1

12 Test Matrix for Screening of Conventional Sorbents in the TGA $\ldots \ldots \ldots \ldots \ldots \ldots \ldots \ldots 1$

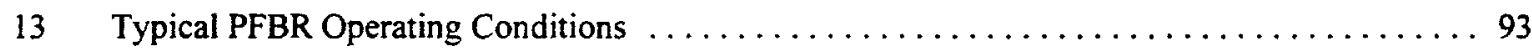

14 High-Temperature High-Pressure (HTHP) Filter Vessel Operating Capabilities $\ldots \ldots \ldots \ldots 97$

15 Test Matrix for Bench-Scale Testing Utilizing the PFBC $\ldots \ldots \ldots \ldots \ldots \ldots \ldots \ldots$

16 Properties of Fuels Used for Bench-Scale Testing on the PFBR $\ldots \ldots \ldots \ldots \ldots \ldots \ldots \ldots$

17 Rates of Adsorption Calculated from TGA Experiments $\ldots \ldots \ldots \ldots \ldots \ldots \ldots \ldots \ldots$

18 Point Analysis of SEM of Albite and Quartz Particles from SEM Using $\mathrm{NaCl}$ and Combustion

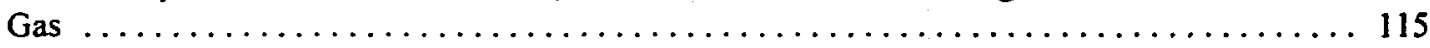

Continued... 


\section{LIST OF TABLES (continued)}

19 Rate Data Collected During TGA Experiments

20 Point Analyses of Bauxite after 6-hr of Exposure to Combustion $\mathrm{Gas}$ and $\mathrm{NaCl}$ in the TGA ... 123

Test Matrix for PFBR Testing 126

Analysis of Additives Used During PFBR Testing

Analysis of the Fuels Used for PFBR Testing Including Added Sodium, Sulfur, and Sorbents . 128

Elemental Analysis of Cyclone and Filter Vessel Ash from PFBR Testing on Sulfur-Free

Basis

Comparison of the Ash Chemistry of the Cyclone and Filter Vessel Ash to the Parent Fuel

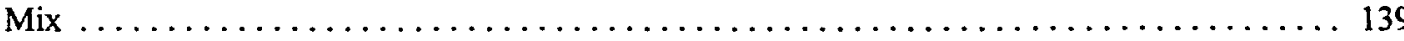

Analysis of Selected Points from an Unexposed Filter and the Filter after Test 1896 and

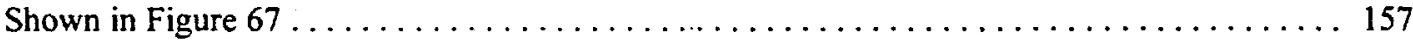

37 Analysis of the Bridge and Other Ash Material from Test B1-2096 $\ldots \ldots \ldots \ldots \ldots \ldots \ldots$

38 Elemental Analysis of Candle Deposits from Various PFBR Tests $\ldots \ldots \ldots \ldots \ldots \ldots \ldots 16$ 


\section{LIST OF TABLES (continued)}

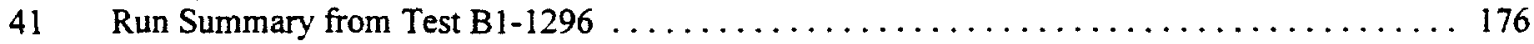

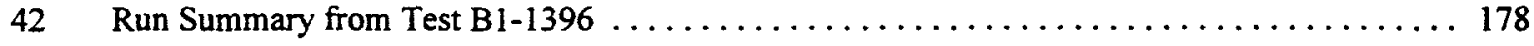

$43 \quad$ Run Summary from Test BEL-1496 $\ldots \ldots \ldots \ldots \ldots \ldots \ldots \ldots \ldots \ldots \ldots \ldots \ldots \ldots$

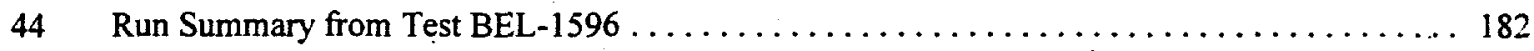

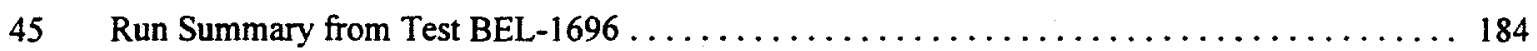

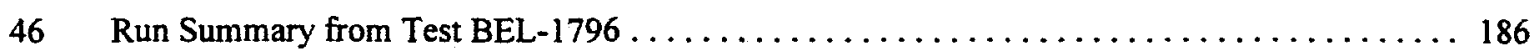

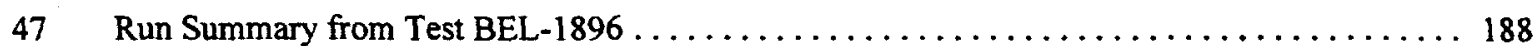

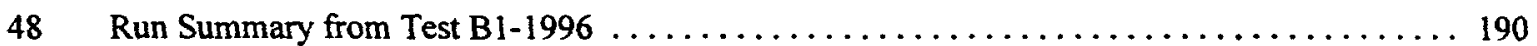

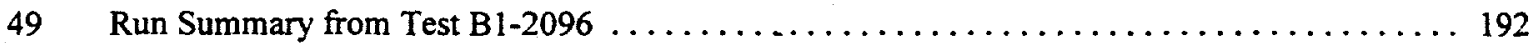

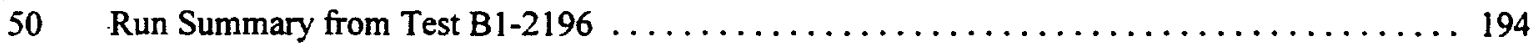

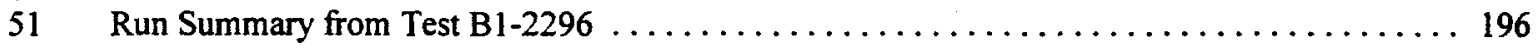

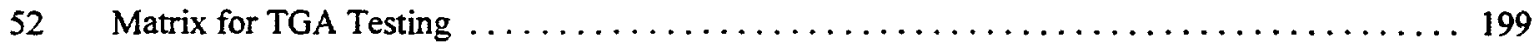




\section{ACKNOWLEDGMENTS}

I would like to acknowledge and offer a sincere thank you to the Link Energy Foundation and the U.S. Department of Energy for their financial support of this work. I would further like to thank Steve Benson and Gerry Groenewold for establishing the framework that allowed me to focus on my research and complete this dissertation. The efforts of Ron Kulas in performing the TGA experiments, Glen Frericks for operating the PFBR, Ann Henderson for assisting in data reduction, and Ray Pikarski for preparing the figures are greatly appreciated. I would also like to thank my committee members, especially my advisor, Dr. Douglas Ludlow, for their time and effort to make this a finished product. Most importantly, I would like to thank my wife Terrie, my daughter Jessica, and my son Justin for all of the time they gave up with me so that I reach my goal of becoming Dr. Mann. 


\begin{abstract}
Pressurized fluidized-bed combustion (PFBC) has been identified as a promising technology for the future; however, there are a number of obstacles that must be overcome to maximize the potential of PFBC. These include removal of 1) fine particulates to eliminate erosion and deposition on turbine blades, 2) alkalies that can lead to corrosion of turbine blades and blinding of ceramic filters, 3) sulfur at very high sorbent utilization efficiencies, 4) halogens that can lead to corrosion, and 5) toxic metals that were specified in the 1990 Clean Air Act Amendments. The primary focus of this research was the removal of alkali from PFBC flue gases to a level specified by turbine manufacturers. The target level was less than 24 ppbw. Several of the aluminosilicate minerals have the potential to capture alkalies, especially sodium and potassium, under conditions typical of fluid-bed operation $\left(760^{\circ}\right.$ to $1010^{\circ} \mathrm{C}\left[1400^{\circ}\right.$ to $\left.\left.1850^{\circ} \mathrm{F}\right]\right)$. The alkalies are adsorbed onto the surface and diffuse into the bulk of the alkali sorbent. In addition, the nonbridging oxygen atoms released when alkalies modify the aluminosilicate mineral structure are potential sites for sulfur capture. The use of a sorbent to capture alkali in the bed reduces the need for downstream alkali capture devices. Other goals of this work were to investigate the potential for simultaneously removing $\mathrm{SO}_{2}$ and $\mathrm{Cl}$ from the $\mathrm{PFBC}$ gas stream.

Several side benefits were anticipated, and the goal was to demonstrate these during this work. A reduction in the amount of fine particulate was expected when alkali is removed in the bed, since condensation of volatile alkalies is one of the primary mechanisms for the formation of these difficult-toremove particulates. Improved performance of ceramic filters was expected, since alkalies can lead to bridging, pore plugging, and other problems in ceramic filters. Deposition on the walls of the PFBC and on heat-transfer surface can reduce the performance of the PFBC and may be controllable by capture of the
\end{abstract}


alkalies with in-bed sorbents. The propensity of certain fuels to sinter and/or agglomerate in the fluid bed was also expected to be reduced or eliminated with the introduction of alkali sorbents.

The initial work focused primarily on one class of sorbents, sodalites, with the goal of determining whether sodalites can be used as an in-bed sorbent to simultaneously remove alkali and sulfur. Thermal gravimetric analysis was used to study the mechanism of alkali capture using sodalite. Further testing was performed on a 3-in.-diameter pressurized fluid-bed reactor. Early results indicated that simultaneous removal of alkali and sulfur and/or chlorine was not practical under the conditions for commercial PFBC operations. Therefore, the focus of the later part of this work was on sorbents that have been shown to capture alkali in other systems. The effectiveness of bauxite and kaolinite to reduce vapor-phase alkali concentrations was determined. In addition to studying the capture capability of the sorbent, the impact of the sorbent on operational performance was evaluated. This evaluation included examining potential agglomeration of bed particles, deposition on heat-transfer surfaces, and the bridging and blinding of ceramic candle filters.

The overall conclusion from this work is that in-bed alkali sorbents can effectively reduce the vapor-phase alkali concentrations. This reduction is of a magnitude great enough to control ash deposition and agglomeration and filter blinding, but not to a level low enough to meet current turbine manufacturer recommendations for vapor-phase alkali. Bauxite was the best sorbent tested based on its ability to control all of the above-mentioned problems. Kaolinite is less effective because of its tendency to form sintered deposits from its fine fraction. Finally, although sodalite and nosean can be formed and result in combined sodium and chlorine or sulfur capture, they do not form at a rate high enough to make them effective sorbents under PFBC conditions.

The effectiveness of in-bed alkali sorbents could be improved by pelletizing the material prior to feeding it into the PFBC. The production of a porous pellet from fine material would capture both the advantage of high sorbent surface area (small particle size) and long residence time in the bed (large particle size). Recycle of the fly ash back to the combustor should also improve the overall effectiveness of the sorbents for capturing alkalies and, if coupled with pelletization, should decrease deposition 
problems associated with the fine ash. Testing should continue to find effective in-bed alkali sorbents for PFBC. If the PFBC is to realize cost-effective, high coal-to-electricity conversion efficiencies, inexpensive methods of capturing alkali are required. In-bed sorbents offer the capability to accomplish this goal. 


\section{CHAPTER 1}

\section{BACKGROUND}

As the demand for electricity grows, pressurized fluidized-bed combustion (PFBC) is poised to capture a significant share of the market, especially for repowering older coal-fired units. This is due in part to the PFBC's inherent ability to achieve high efficiencies and low emissions. A number of obstacles hinder maximizing the potential for PFBC. These include the removal of fine particulates to eliminate erosion and deposition on turbine blades, alkalies which can lead to corrosion of turbine blades and blinding of ceramic filters, sulfur at very high sorbent utilization efficiencies, halogens that can lead to corrosion, and toxic metals that were specified in the 1990 Clean Air Act Amendments. The primary focus of this research is on the removal of alkalies from the gas stream of the PFBC. Current methods for alkali removal are either capital-intensive or result in a loss in overall system efficiency. The goal of this research was to identify sorbents that could be used to capture alkalies without impacting the overall capital costs or system efficiency.

\subsection{Electricity Demand}

Electricity demand is projected to grow as the U.S. economy grows. Estimates of new capacity requirements over the next 15 years differ widely, with predictions varying from $0.9 \%$ to $2.0 \%$ per year (IEA [International Energy Agency], 1992, 1994; Makovich and Smalley, 1993; Alliance to Save Energy, 1992). Estimated trends from various groups are shown in Figure 1. There appears to be significant markets for retrofit and repowering options, as well as new capacity construction as indicated in Figure 2 (Bdar, 1996; Longwell et al., 1995; Makovich and Smalley, 1993).

Changes in the regulatory structure and practice in the electric utility industry since 1979 have contributed to a trend toward more widely distributed, smaller-scale power generation facilities that have 


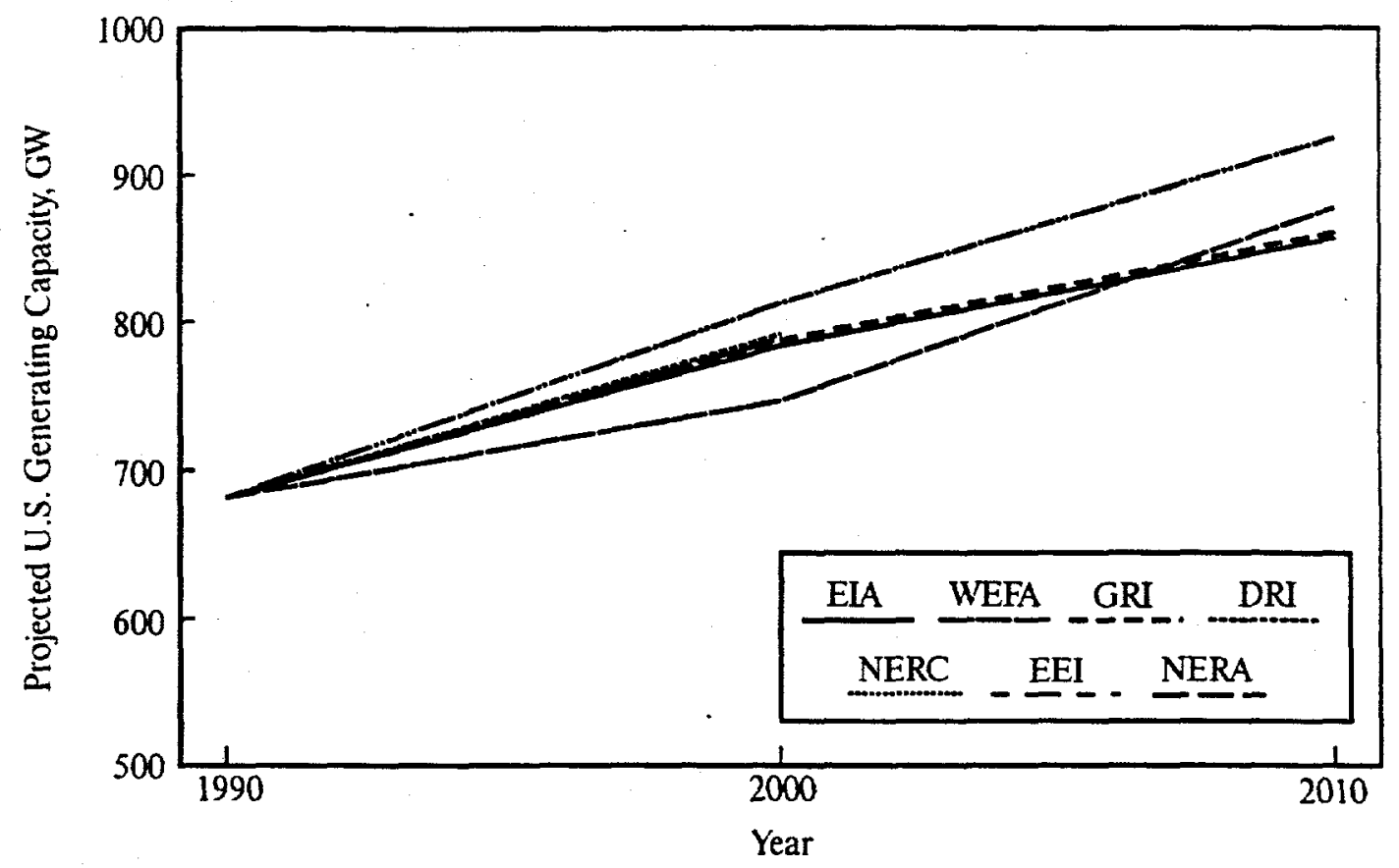

Figure 1. Projected U.S. electricity generating demand (Energy Information Agency [EIA], Wharton Economic Forecasting Association [WEFA], Gas Research Institute [GRI], Data Research Institute [DRI], North American Electric Reliability Association [NERC], Edison Electric Institute [EEI], and National Economic Research Association [NERA])

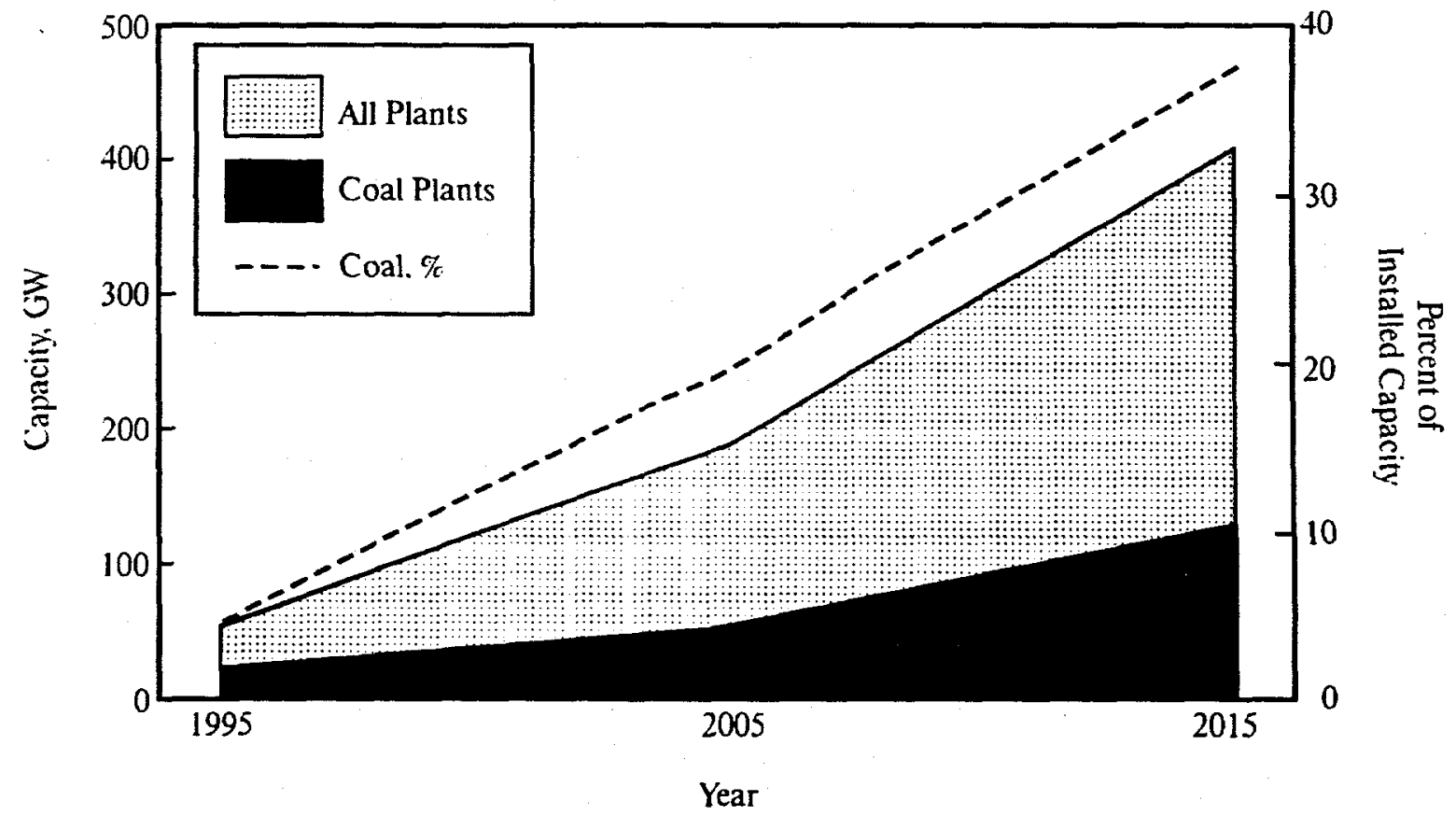

Figure 2. U.S. power plants over 40 years old that are candidates for repowering (Bdar, 1996) 
relatively low risk and capital costs. In addition, increased competition is reducing the willingness of the utility industry to develop and deploy advanced power generation technologies that are perceived as having higher risk.

In the near term, natural gas-fired systems will likely be the primary source of new capacity additions, driven by demands for peak and intermediate power, low gas prices, and low capital costs. However, coal is expected to remain the largest single energy source for power generation (IEA, 1993; EIA, 1994; Longwell et al., 1995), and resource limitations for domestic natural gas are expected to result in price increases (EIA, 1994; GRI, 1994). Combining this with a substantial need for new baseload generating capacity between 2006 and 2040 (Makovich and Smalley, 1993), a resurgence of coal-based power generation is expected.

Environmental concerns will probably have the most significant influence on future coal use in the United States, and requirements to reduce the environmental and health risks of waste streams from coal technologies are expected to be more stringent (Rubin, 1989; NRC [National Research Council], 1992). Control of $\mathrm{SO}_{2}, \mathrm{NO}_{x}$, and fine particulate air pollutant, solid wastes, and air toxics will continue to determine the acceptability of coal-based systems with state and local regulators placing the most restrictive demands on power plant emissions. Among these, concern over global warming could present the greatest long-term threat to coal use because of the $\mathrm{CO}_{2}$ emissions from coal combustion.

Expansion of coal-based power generation is anticipated in the developing nations, notably China, and major intemational markets exist for coal utilization technologies (EIA, 1993, 1996). The projected global demand is depicted in Figure 3. In the near term, capital investment requirements are expected to be a controlling consideration in most foreign markets. Foreign requirements to minimize conventional pollutant and greenhouse gas emissions will lag those imposed in the United States, but their introduction is expected to have a large impact on international sales of coal-based technologies (Coal and Synfuels Technology, 1993; U.S. DOE [Department of Energy], 1993; Longwall et al., 1995). 


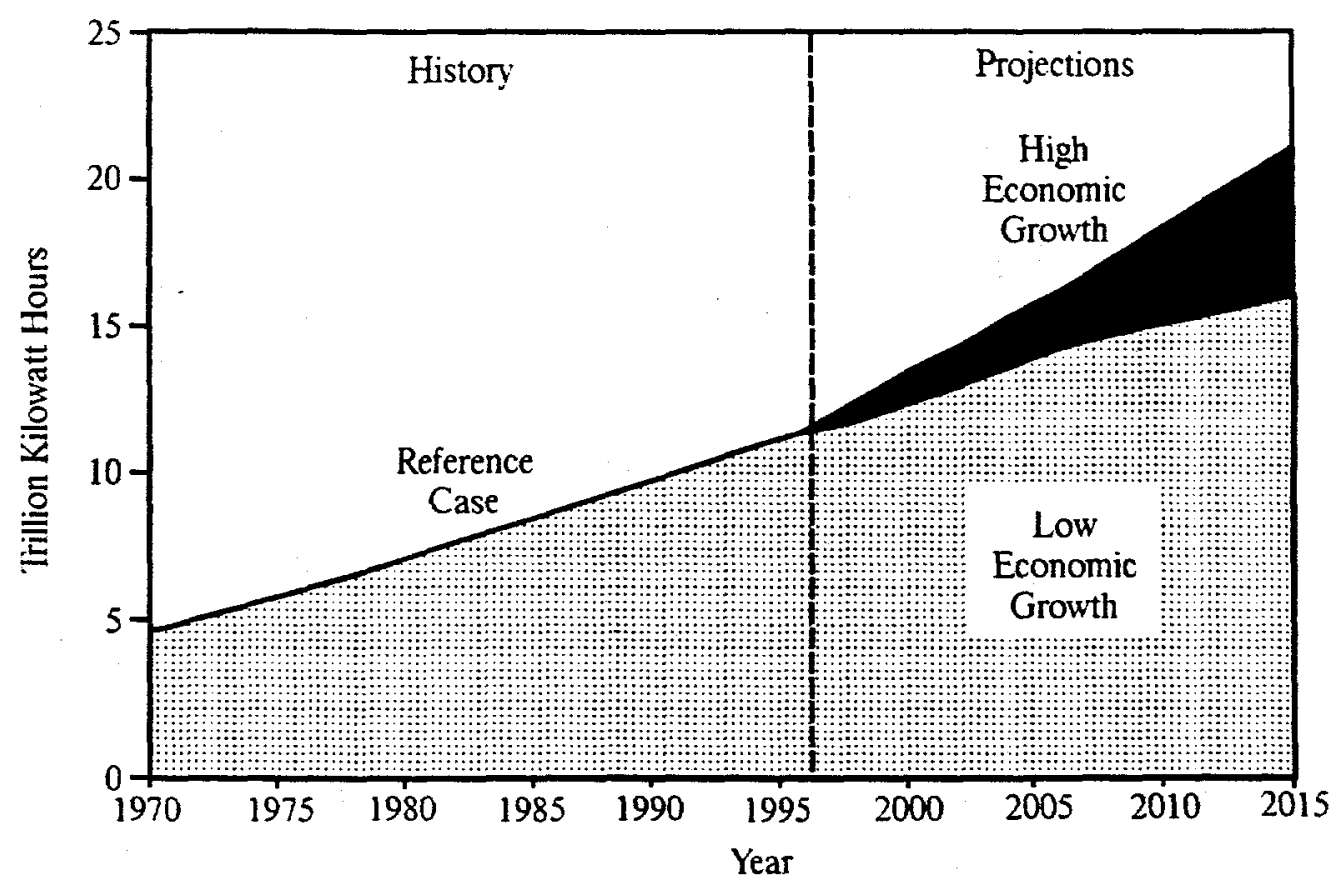

World Electricity Consumption

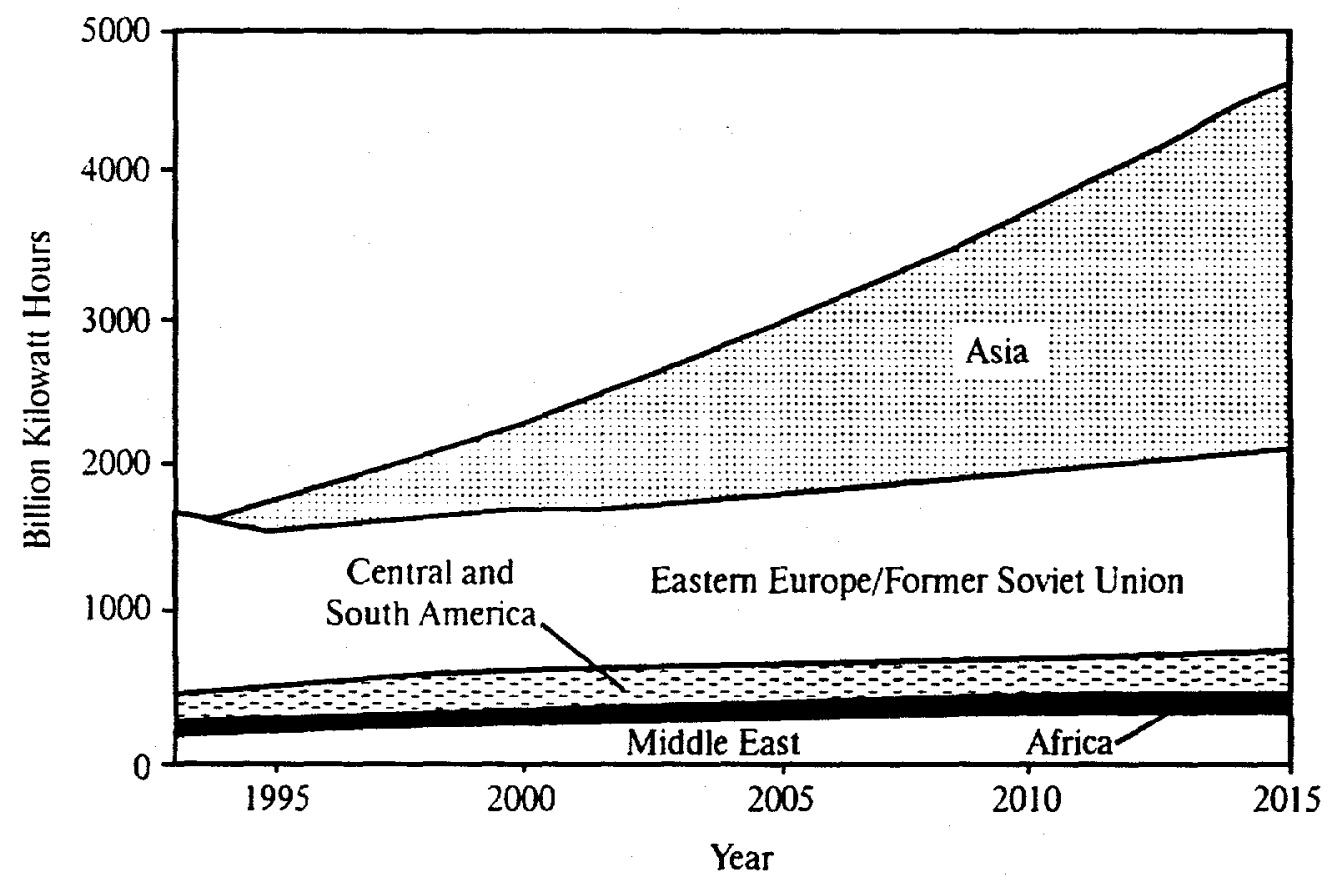

Non-OECO Electricity Consumption

Figure 3. Projected global demand for electricity (EIA, 1993, 1996) 


\subsection{PFBC: An Attractive Alternative}

Fluidized-bed combustion (FBC) is the combustion of fuel in a bed of particles made up of fuel ash, limestone, and fuel suspended by an upward flow of air. The bed of suspended particles behaves similarly to a fluid. The minimum air velocity required to fluidize the coal is defined by the balance between the aerodynamic drag force on the particles and the gravitational force. The degree of fluidization in an FBC system is typically controlled by the air/gas velocity for a specific particle-size distribution. At velocities below the terminal velocity, the material is retained within a given height, and the fluid bed is said to be bubbling. A circulating fluid bed is operated at velocities above the terminal velocity, where particles are carried out of the reactor, captured in a high-efficiency cyclone, and returned to the reactor.

Uniform bed conditions are important in the performance of a fluid-bed combustion system as controlled gas-to-solid reactions are necessary. Indications of good fluidization quality are even temperature distribution across the bed and, essentially, a constant overall pressure drop with consistent low-amplitude pulsations in pressure. Large pressure fluctuations and/or low pressure drops, compared with the total bed weight, indicate poor fluidization.

In a fluidized bed, combustion takes place at low temperatures of $760^{\circ}-980^{\circ} \mathrm{C}\left(1400^{\circ}-1800^{\circ} \mathrm{F}\right)$ compared to $1370^{\circ}-1900^{\circ} \mathrm{C}\left(2500^{\circ}-3450^{\circ} \mathrm{F}\right)$ in conventional coal combustion systems (Singer, 1981). The lower temperature of the fluid bed substantially reduces the potential emissions of $\mathrm{SO}_{2}$ and $\mathrm{NO}_{\mathbf{x}}$ compared to a conventional system. The bed serves as an excellent media for heat and mass transfer and has a high thermal capacity. This results in good carbon burnout, even at the relatively low operating temperatures. The action of the bed also generates very high heat-transfer coefficients, typically three to five times those experienced in convective tubes of a conventional boiler.

Advantages offered by fluid-bed combustion technology compared to that in conventional coal combustion are due to the intense turbulence in the bed and to the comparatively long solid residence times in the bed without a long, linear-flow path requirement. The advantages are as follows: 
- At FBC operating temperatures, $\mathrm{SO}_{2}$ produced by the combustion of coal-bound sulfur can be adsorbed by alkaline components within the fuel (ash) or by added sorbents in the well-mixed combustion zone, thereby eliminating the need for additional $\mathrm{SO}_{2}$ control equipment.

- At the lower combustion temperature in the $\mathrm{FBC}, \mathrm{NO}_{\mathrm{x}}$ is substantially lower than in conventional combustion systems. Very few of the trace metals are mobilized at these temperatures, minimizing concerns over air toxics.

- Because of mixing and intimate contact of hot solids, the FBC can fire fuels of low and varying quality. The long residence time allows nearly complete burnout of the solid carbon and allows virtually complete destruction of the volatile organic compounds.

- Because of the solids contact and radiation from the suspension of hot particles, the heat-transfer rates to in-bed tubes in FBCs are approximately three to five times that in the convective section of a conventional combustion system, thereby reducing overall combustor size.

- Because of the FBC's capability to accept larger and less uniform fuel particle sizes, the fuel preparation costs are lower than those for pulverized-coal-fired systems.

- Waste products from the FBC process are dry solids and have been shown to be relatively harmless compared with wastes from conventional wet scrubbing processes.

- Tube fouling is reduced because of the lower combustion temperature.

- The smaller size facilitates modular units with package construction.

FBC systems can be operated at atmospheric or elevated pressure, hence the designations of atmospheric (AFBC) and pressurized (PFBC) fluidized-bed combustion. PFBC typically operates at pressures ranging from 10 to 16 atmospheres. Operation in this manner allows the pressurized gas stream from a PFBC unit to be cleaned and fed to a gas turbine. The exhaust gas from the turbine is then passed through a heat recovery boiler to produce steam. The steam from the PFBC unit and that from the heat recovery boiler are then fed to a steam turbine. This combined-cycle mode of operation significantly increases PFBC system efficiency over AFBC systems. If the PFBC exhaust gas can be cleaned sufficiently without reducing its temperature, additional cycle efficiency can be achieved. Figure 4 depicts a first-generation (nontopped) PFBC system. 


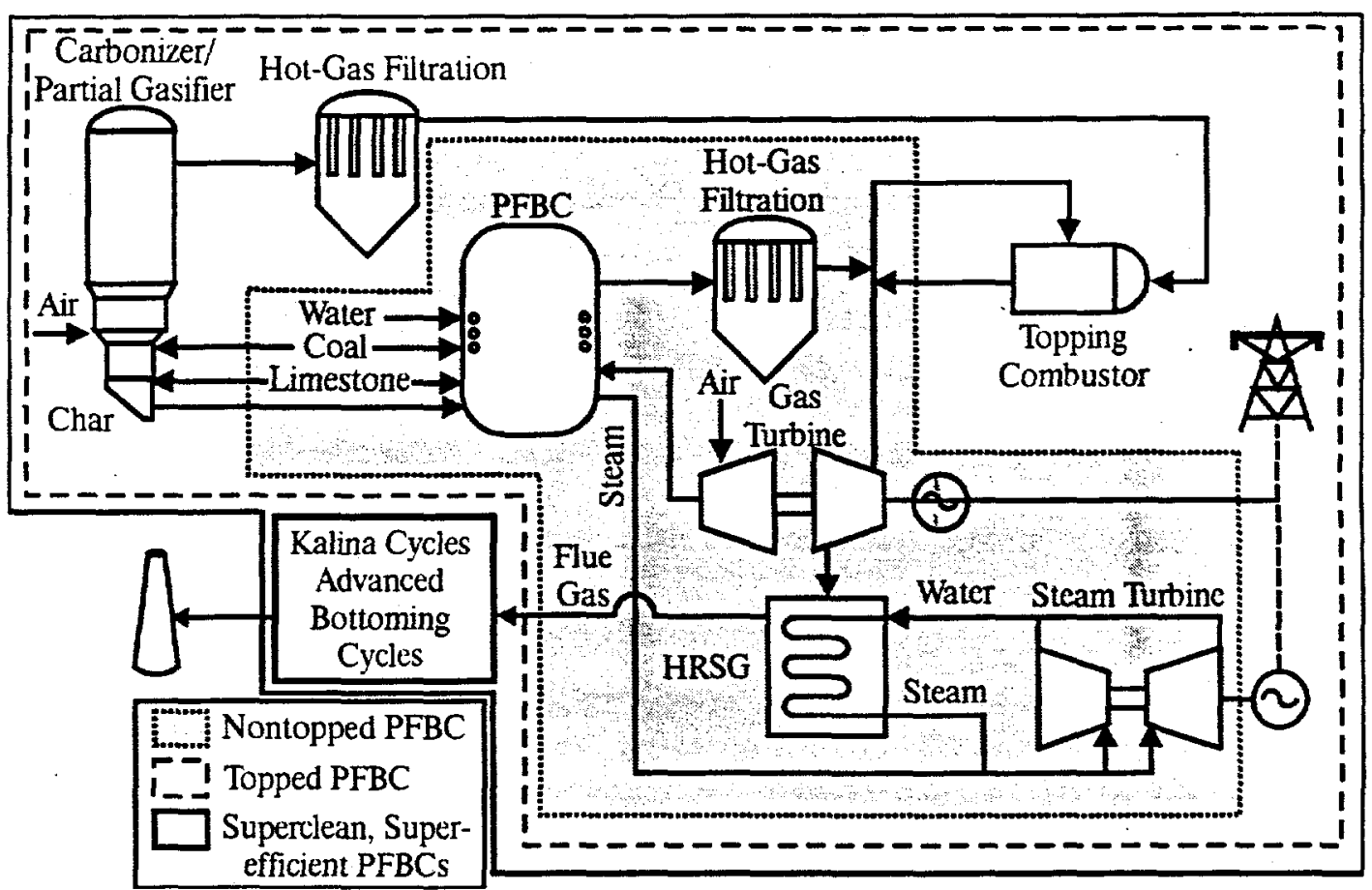

Figure 4. Schematic of a PFBC plant (Bdar, 1996)

When operating under pressure, the PFBC offers significant advantages over atmospheric units, including:

- Power output similar to an AFBC but with a unit that has a smaller "footprint" because of the higher pressure and increased efficiency of the PFBC.

- Steam flows for PFBC units that are compatible with steam turbines at existing power plants making the technology especially attractive for repowering existing units at existing sites, avoiding the need and difficulty of developing new sites.

- Reduced equipment size and higher efficiencies which help offset the higher equipment costs related to the pressurized operation.

- Efficiencies of $39 \%$ to $42 \%$ (HHV [higher heating value]) with first-generation PFBC compared with 34\% efficiency for AFBC.

- Emissions of $\mathrm{CO}_{2}$ are $20 \%$ lower than AFBC for first-generation PFBC due to the higher overall efficiency. Advanced PFBCs can reduce $\mathrm{CO}_{2}$ by over $30 \%$ as compared to AFBCs. 
Hybrid PFBC systems (topped PFBC in Figure 4) offer substantial improvements in efficiency by afterbuming with coal gas or natural gas to raise gas temperatures and efficiencies up to the limits imposed by the gas turbine (Dellefield and Reed, 1992). This decoupling of the gas turbine temperature allows flexibility for reducing PFBC temperatures when operating on high-alkali fuels to reduce the risk of alkali vapor carryover to the turbine and agglomeration of the bed.

In a hybrid PFBC system, sulfur control in the fluidized-bed gasifier supplying the gas for afterburning is proved by adding limestone or dolomite to capture $\mathrm{H}_{2} \mathrm{~S}$ as calcium sulfide ( $\mathrm{CaS}$ ). Achieving high levels of sulfur capture (e.g., $90 \%$ ) in the gasifier requires operation at temperatures above $1650^{\circ} \mathrm{F}$ to calcine $\mathrm{CaCO}_{3}$ to $\mathrm{CaO}$ (Pitrolo and Bechtel, 1988). The reaction of calcined limestone or dolomite is rapid, and $\mathrm{H}_{2} \mathrm{~S}$ removals approach equilibrium (Abbasian and Rehmal, 1990). However, high gasification temperatures intensify concern over alkali release and bed agglomeration when high alkali fuels are used. Efficiencies from $45 \%$ to $48 \%$ are expected from second-generation (hybrid) PFBC.

\subsection{Projected PFBC Market}

AFBC technology has achieved commercial acceptance, while PFBC technology is currently undergoing commercial demonstration. The 1995 U.S. Fluid Bed Directory lists over 600 AFBC operating units with an average steam capacity of $235,000 \mathrm{lb} / \mathrm{hr}$ ( $72 \mathrm{MWe}$ equivalent) (Stephens' Utility and Cogeneration Services, 1995). PFBC, meanwhile, is projected to see a strong demand over the next 50 years. Figure 5 shows a projection of the coal-fired technology market through 2050 (Guha and McCall, 1990). The U.S. utility market for all coal technologies, the penetration of first-generation PFBC systems, and the penetration of advanced PFBC systems are shown. The market penetrations shown in Figure 5 are similar to those developed by DOE (Dellefield and Reed, 1992). The projection recognizes that after an initial spurt of first-generation PFBC installations, the trend starting in the 2005 time frame will be toward utilities installing more efficient advanced PFBC systems. DOE's assessment of PFBC's ability to capture a significant share of the future coal generated electricity market warrants additional research to develop more efficient and environmentally superior PFBC systems, as well as to conduct 


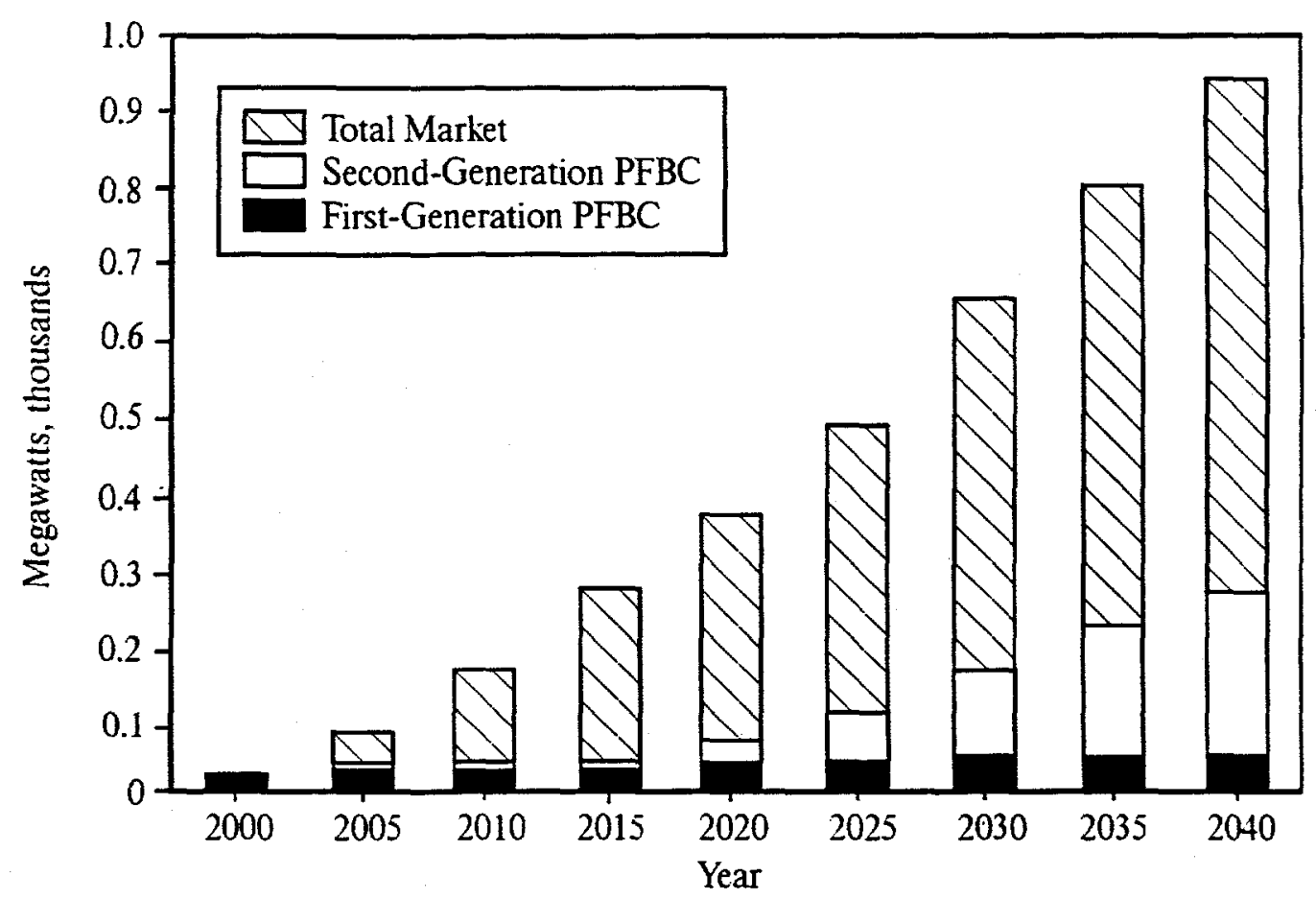

Figure 5. Advanced coal technology market penetration (Guha and McCall, 1990)

large-scale commercial demonstrations of PFBC systems in the Clean Coal Technology Programs (Dellefield and Reed, 1992; Bdar, 1996).

Evidence of PFBC's ability to penetrate the power generation market is given in Figure 6 . Thirteen PFBC units greater than $50 \mathrm{MWe}$ have either been built or are planned. Japan has made the biggest commitment to PFBC, with four commercial units in various stages of construction and/or operation and two additional units planned (Takahashi et al., 1995). PFBC will most likely be used for the retrofit/repowering projects at the unit size of 300 to $400 \mathrm{MW}$. Bubbling beds will dominate the PFBC systems in the beginning, with advanced designs competing by the year 2005 . While further improvements in environmental and thermal performance will be required to maintain PFBC technology as a competitive option to gasification-based power systems in the 2000s, PFBC appears to be a strong contender for capturing a significant share of the power industry over the next 50 years. 


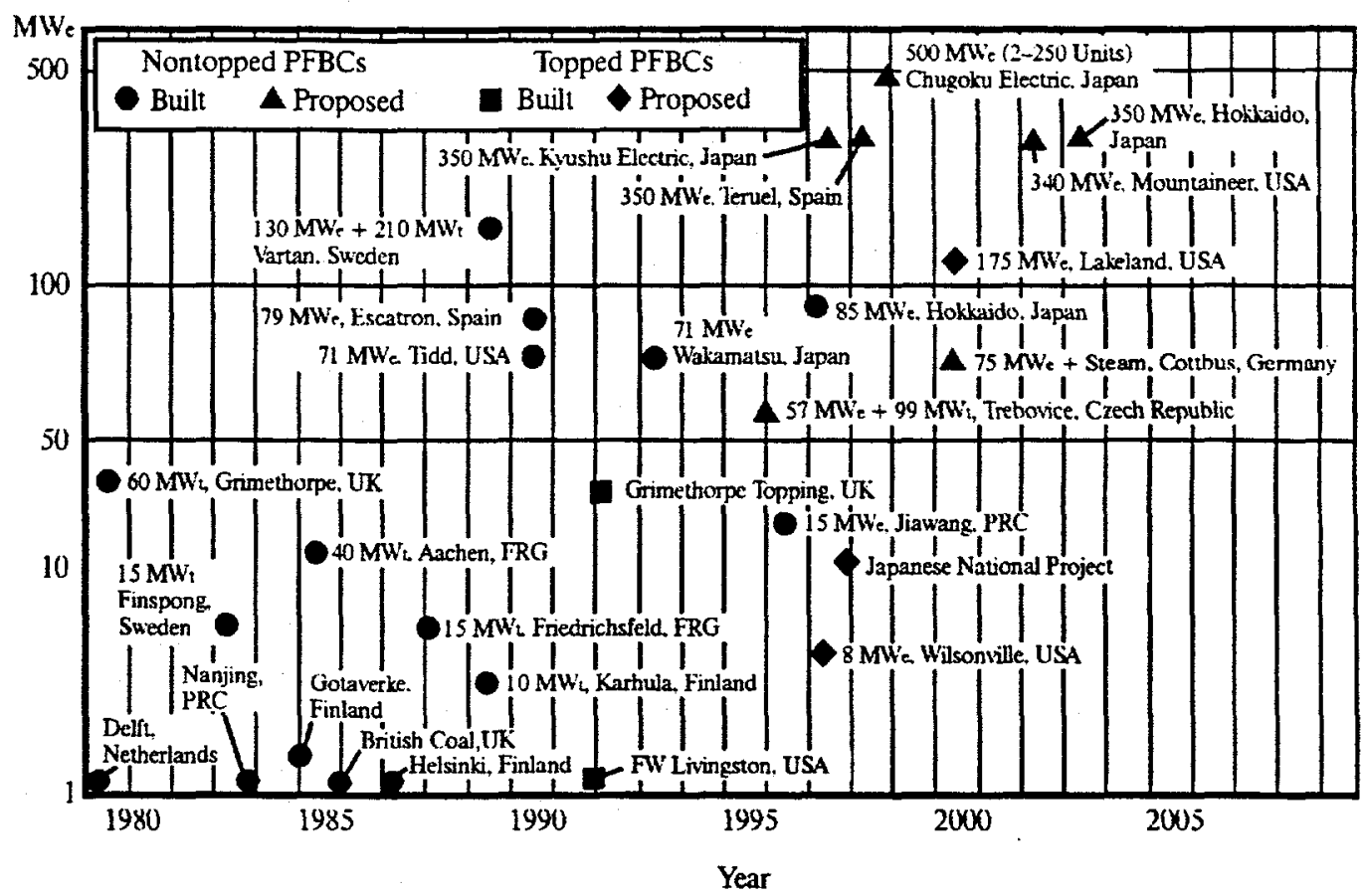

Figure 6. PFBC projects around the world (Bdar, 1996)

\subsection{Barrier Issues}

There are several areas where PFBC systems need to improve their competitiveness in order to succeed in the year 2000 and beyond. Market-based issues that must be resolved to achieve the penetration projected in Figure 5 include (Dellefield and Reed, 1992; Longwell et al., 1995):

- Capital costs must be lowered.

- Reliability of the components and major subsystems must be demonstrated to the degree necessary to satisfy the owner's operating staffs.

- Environmental performance must be made to exceed any standards that could be placed upon the utility industry during the next several decades.

- The bottom line cost of electricity (COE) must not only be better than current solid fuel technology, but must also be comparable to future electricity options, including nuclear power, coal gasification, and renewable energy sources. 
In addition to these market-based issues, a number of technical barriers must also be overcome if PFBC is to achieve a reasonable market status. The major issues identified by DOE requiring additional development work are shown in Figure 7 (Bdar, 1996). The commercialization of topping combustors are needed to take advantage of present state-of-the-art gas turbines. Work needs to continue to push the gas turbine inlet temperature as high as possible to match developments in the turbine industry. Development must also occur to produce higher efficiency, higher inlet temperature gas turbines to help the competitive position of PFBC units. Figure 8 shows the potential that gas turbines with higher inlet temperatures offer PFBC systems (Jansson, 1991). This figure compares the efficiency of PFBC and integrated gasification combined cycle (IGCC) systems employing gas turbines with increasing inlet temperatures, showing that the possible gains are dramatic. It is interesting to note that the hybrid PFBC will have higher efficiencies than the IGCC until the gas turbines reach the capability to have ISO (International Organization for Standardization) inlet temperatures in the $1250^{\circ} \mathrm{C}\left(2280^{\circ} \mathrm{F}\right)$ range. This compares to a U.S. gas turbine inlet temperature of $1340^{\circ} \mathrm{C}\left(2450^{\circ} \mathrm{F}\right)$. Advanced steam cycles and the use of a Kalina bottoming cycle should push the efficiency of the hybrid PFBC to over $50 \%$ based on the higher heating value.

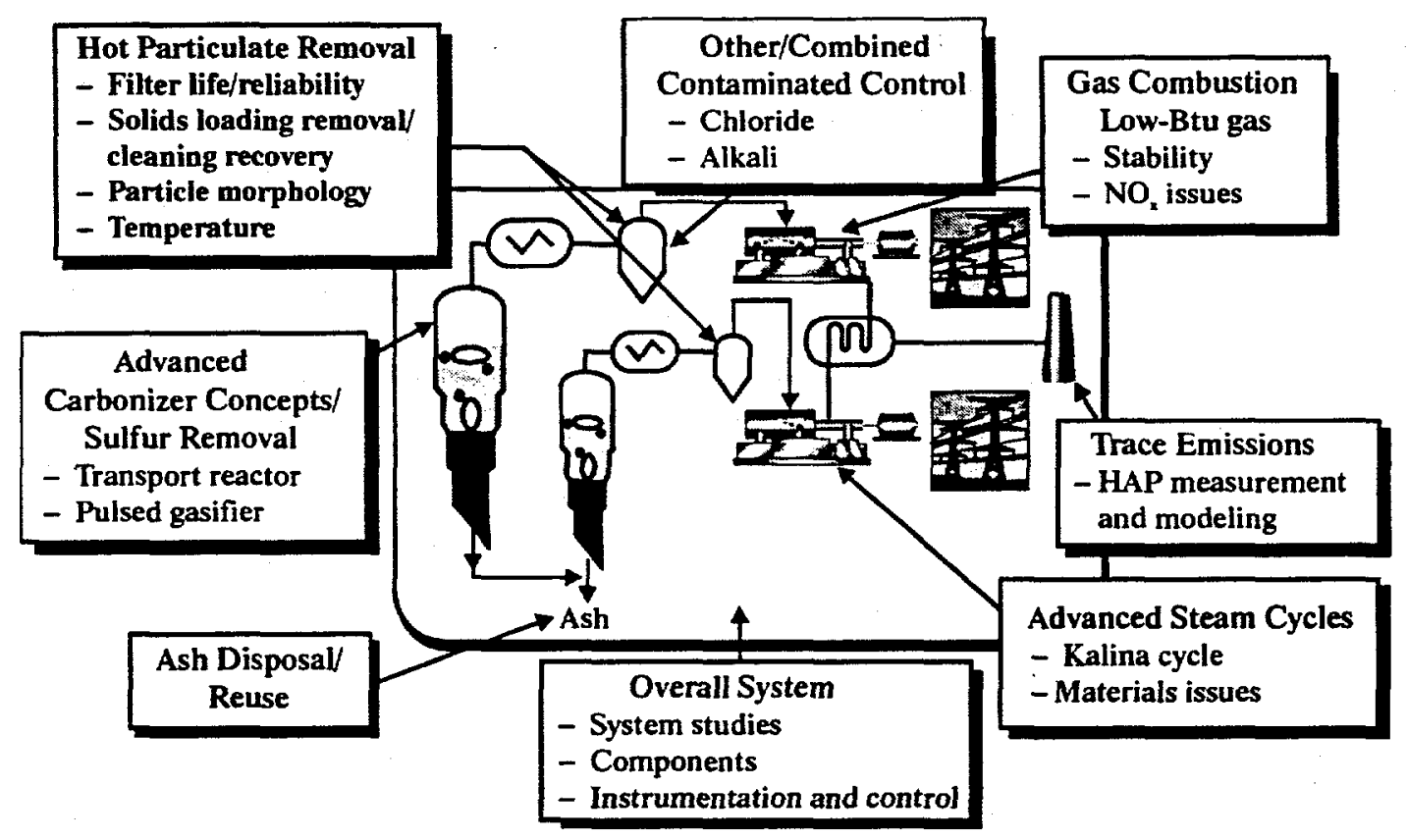

Figure 7. PFBC research and development issues (Bdar, 1996) 


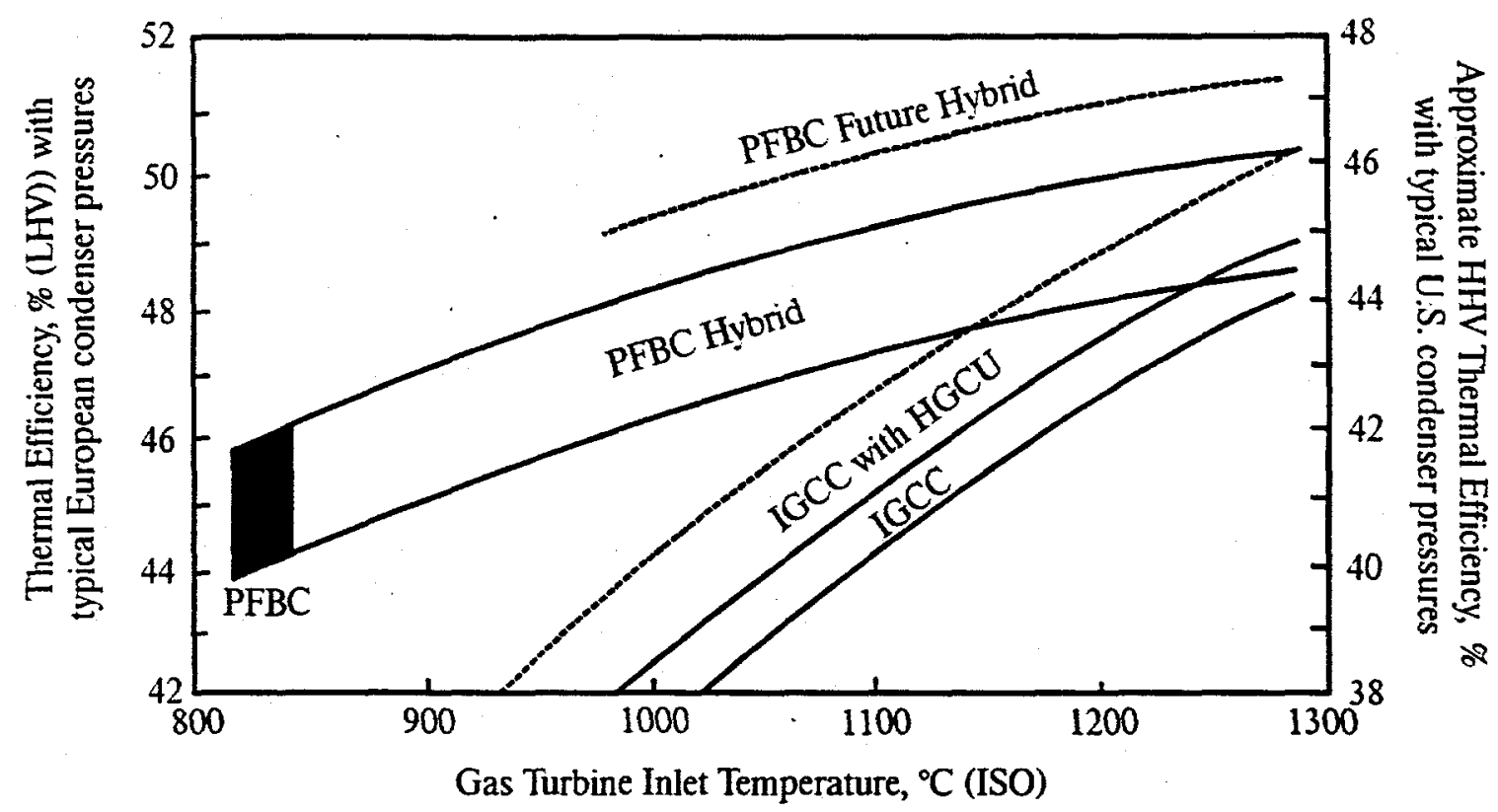

Figure 8. Thermal efficiencies for PFBC and IGCC plants (Jansson et al., 1992)

While overall system efficiency should be improved, the environmental performance of the PFBC must also improve. PFBCs must prove that they are long-term viable alternatives to other low-emission coal systems such as IGCCs. Key areas of environmental performance include increasing the sulfur capture to above $95 \%$, controlling $\mathrm{NO}_{\mathrm{x}}$ to meet stringent local and state regulations (as low as 25 parts per million by weight [ppmw]), and ensuring hazardous air pollutants (HAPs) are controlled. This must be accomplished while minimizing solid wastes. For second-generation PFBCs, conversion of the CaS produced during the pyrolysis/gasification step to $\mathrm{CaSO}_{4}$ is also a major environmental concern.

Boiler vendors and turbine vendors must design the system that allows essentially off-the-shelf turbines or advanced designs to be used. Hot-gas particulate filtration is the key component to making this a reality. Hot-gas filtration is needed to meet the stringent particulate requirements placed upon PFBC systems by gas turbine manufacturers to prevent erosion of turbine blades. Another issue that the hot-gas cleanup system must deal with is removal of alkalies. Current technology allows for cooling the gas to condense the alkalies which are then removed as particulates. Possible penalties in the overall efficiency 
can be $1 \%$ to $3 \%$ (Longwell et al., 1995). The ability of hot-gas cleanup systems to reduce contaminants to levels acceptable for high-temperature advanced turbines has not yet been demonstrated.

\subsection{Issues with Alkali}

In PFBC combined-cycle systems, the alkalies, particularly those whose boiling point is less than the turbine blade temperature, act vigorously on the blade material. This alkali-induced corrosion can greatly reduce the life of the turbine. For example, an increase in sodium content of 2 to 4 ppmw reduces the service life of a turbine by half (Pintsch and Gudenau, 1991a). Therefore, special demands are made on the purity of the coal-derived gas if it is to be used in a combined-cycle process. Specifications for the purity of the gas entering the turbine are set to provide an economic life of at least 50,000 operating hours. The specifications for three turbines manufactured by Westinghouse and the operating characteristics are shown in Table 1. General Electric specifies a limit value of a maximum of $24 \mathrm{ppbw}$ (parts per billion by weight) for alkalies (Radhakrishman et al., 1986). Foreign manufacturers and authors have proposed higher limits. Cramer (1986) mentions a study on alkalies with a limit of 500 ppbw, while the Federal Ministry for Research and Technology in Germany recommends alkali levels below $0.125 \mathrm{mg} / \mathrm{m}^{3}$

Table 1

Operating Characteristics of Westinghouse Gas Turbines

\begin{tabular}{lccc}
\hline Model & W501B12 & W501D5 & $501 \mathrm{~F}$ \\
Power Rating, MW & 50 & 100 & 150 \\
Inlet Gas Temp., ${ }^{\circ} \mathrm{F}$ & 2065 & 2070 & 2300 \\
$\begin{array}{l}\text { Pressure Ratio } \\
\text { Thermal Eff. }\end{array}$ & 14.2 & 14.2 & 14.2 \\
$\quad$ Single Cycle & 32 & 33 & 36 \\
$\begin{array}{l}\text { Thermal Eff. } \\
\text { Combined Cycle }\end{array}$ & 46 & 48 & $50-52$ \\
$\begin{array}{l}\text { Operating Life, hr } \\
\text { Particulate Spec. }\end{array}$ & 100,000 & 100,000 & 40,000 \\
Alkali Spec. & $10 \mathrm{ppm} @ 5 \mu \mathrm{m}$ & $10 \mathrm{ppm} @ 5 \mu \mathrm{m}$ & $10 \mathrm{ppm} @ 5 \mu \mathrm{m}$ \\
Mass Flow, lb/sec & 1 ppm fuel & $20 \mathrm{ppb} @$ blade & $20 \mathrm{ppb} @$ blade \\
Exhaust Temp., ${ }^{\circ} \mathrm{F}$ & Not available & 813 & 935 \\
\hline
\end{tabular}


(approximately $113 \mathrm{ppbw}$ ) (Pintsch and Gudenau, 1991). The recommended purity of clean gas for turbine applications in the Federal Republic of Germany (FRG) is given in Table 2.

Table 2

Permissible Impurities in Coal Gas (clean gas) (Pintsch and Gudenau, 1991)

\begin{tabular}{|c|c|c|}
\hline Toxic Matter & Limit & Permissible concentration in clean gas $\left(\mathrm{H}_{\mathrm{u}}=11,000 \mathrm{~kJ} / \mathrm{kg}\right)$ \\
\hline Sulfur & Emission & Depending on limit value \\
\hline $\begin{array}{l}\text { Nitrogen } \\
\text { (chemically bound) }\end{array}$ & Emission & Depending on limit value and thermic $\mathrm{NO}_{\mathrm{x}}$ \\
\hline Chlorine & $\begin{array}{l}\text { Emission } \\
\text { Corrosion }\end{array}$ & $\begin{array}{l}400 \mathrm{mg} / \mathrm{m}^{3}\left(\mathrm{STP}^{1}\right)\left(=30 \mathrm{mg} / \mathrm{m}^{3} \text { in exhaust gas }\right) \\
\text { Unknown, present limit } 0.5 \mathrm{mg} / \mathrm{m}^{3} \text { (STP) }\end{array}$ \\
\hline Fluorine & $\begin{array}{l}\text { Emission } \\
\text { Corrosion }\end{array}$ & $\begin{array}{l}70 \mathrm{mg} / \mathrm{m}^{3}(\mathrm{STP})\left(=5 \mathrm{mg} / \mathrm{m}^{3} \text { in exhaust gas }\right) \\
\text { Unknown }\end{array}$ \\
\hline Sodium and Potassium & Corrosion & $0.125 \mathrm{mg} / \mathrm{m}^{3}(\mathrm{STP})$ \\
\hline Lead & Corrosion & $0.25 \mathrm{mg} / \mathrm{m}^{3}(\mathrm{STP})$ \\
\hline Zinc & Corrosion & $0.5 \mathrm{mg} / \mathrm{m}^{3}(\mathrm{STP})$ \\
\hline Calcium & Deposits & $2.5 \mathrm{mg} / \mathrm{m}^{3}(\mathrm{STP})$ \\
\hline Particle Total & Emission & $275 \mathrm{mg} / \mathrm{m}^{3}(\mathrm{STP})\left(=20 \mathrm{mg} / \mathrm{m}^{3}\right.$ in exhaust gas $)$ \\
\hline Particle $<2 \mu \mathrm{m}$ & Deposits & $140 \mathrm{mg} / \mathrm{m}^{3}(\mathrm{STP})$ \\
\hline Particles 2 to $5 \mu \mathrm{m}$ & Erosion & $5.5 \mathrm{mg} / \mathrm{m}^{3}(\mathrm{STP})$ \\
\hline Particles 5 to $10 \mu \mathrm{m}$ & Erosion & $0.4 \mathrm{mg} / \mathrm{m}^{3}(\mathrm{STP})$ \\
\hline Particles $>10 \mu \mathrm{m}$ & Erosion & Impermissible \\
\hline
\end{tabular}

' Standard temperature and pressure.

The alkali vapor concentration resulting from the PFBC of a variety of fuels has been measured over a wide range of PFBC operating conditions. The measured values have been reported on the order of 60 to over 4000 ppbw sodium and 7 to 800 ppbw potassium (Lee and Carls, 1988; Lee et al., 1987, 1989, 1991, 1993; Lee and Swift, 1991; Laatikaninen et al., 1993; Mann et al., 1995; Mojtahedi and Backman, 1989). High-temperature operation and the use of high-alkali fuels will result in vapor-phase alkali concentrations well above even the least conservative recommended levels for turbine safety. Therefore, 
alkali capture must be developed to advance the efficiency of the PFBC. Thus far, the jury is still out on the verdict of a solution. Westinghouse is investigating filtering the hot gas through a bed of emathlite, a clay that will remove virtually all of the alkali by adsorption (Cuenca and Anthony, 1995). This option requires the addition of a packed, moving, or granular bed into the overall system, resulting in an increased capital cost. Foster Wheeler has currently chosen the path of cooling the gas below the dew point of the alkalies, $760^{\circ} \mathrm{C}$ to $815^{\circ} \mathrm{C}\left(1400^{\circ}\right.$ to $\left.1500^{\circ} \mathrm{F}\right)$, and removing them with the particulates in the hot-gas cleanup step (Abdulally, 1996). This option is effective at removing the alkalies and eliminates the capital expense of adding an alkali-contacting vessel; however, a loss in overall efficiency results from this approach. The impact of the lower efficiency on the COE is less than that experienced by adding an alkali sorbent-contacting vessel. ABB Carbon, on the other hand, appears to be deferring the decision on alkali removal. While observing the response of its rugged turbines to hot high-pressure flue gas that has been cleaned of particulates only by passage through two stages of cyclones at two demonstration and one commercial plant, $\mathrm{ABB}$ Carbon is monitoring the alkali concentrations in the flue gas but making no attempt to reduce it (Jansson, 1991). Only after sufficient hours of operation are logged will ABB Carbon be able to gauge the effectiveness of this approach.

A number of researchers and developers have been working with various alkali sorbents to remove alkali from the hot-gas stream. Since contacting the alkali with the sorbent is critical, various packed-bed and granular bed filters have been used. Westinghouse (Bachovicn et al., 1986), Argonne National Laboratory (Lee and Swift, 1991), and the Coal Research Establishment (Scandrett and Clift, 1984) have all looked at alkali sorbents in a packed bed, while work done at Combustion Power Company (Goldback and Haas, 1991; Wilson, 1985) and New York University (NYU) (Radhakrishnan et al., 1986; Zakkay et al., 1989) utilized a granular bed filter design (moving bed). The University of Arizona considered using the sorbent in situ with the combustion process (Punjak et al., 1989; Uberoi et al., 1990). Data generated from these facilities have identified a number of good alkali sorbents, including bauxite, diatomaceous earth, emathlite, and kaolinite. Alkali capture exceeding $99 \%$ has been achieved in pilot-scale combustion testing at NYU, with the average capture at $90 \%$ to $96 \%$. The main barrier to implementing any of these 
systems is the optimization of the filter system packing to facilitate scaleup in a cost-effective manner. Other systems investigated include a tailing dry plate washer by Air Pollution Control Technology (Calvert et al., 1981), a traveling bed ceramic filter by Rockwell International (Giliberti, 1982), and a magnetically stabilized cross-flow filter bed by Exxon R\&D (Research and Development) Company (Golan et al., 1982).

\subsection{Research Outline}

PFBC has been identified as a promising technology for the future; however, there are a number of obstacles for maximizing the potential of PFBC. These include removal of 1) fine particulates to eliminate erosion and deposition on turbine blades, 2) alkalies which can lead to corrosion of turbine blades and blinding of ceramic filters, 3) sulfur at very high sorbent utilization efficiencies, 4) halogens that can lead to corrosion, and 5) toxic metals that were specified in the 1990 Clean Air Act Amendments. The primary focus of this research was the removal of alkali from PFBC flue gases to a level specified by turbine manufactures. The target level was less than $24 \mathrm{ppbw}$. Several of the aluminosilicate minerals have the potential to capture alkalies, especially sodium and potassium, under conditions typical of fluid-bed operation $\left(1400^{\circ}\right.$ to $\left.1850^{\circ} \mathrm{F}\right)$. The alkalies are absorbed on the surface and diffuse into the bulk of the alkali sorbent. In addition, the nonbridging oxygen atoms released when alkalies modify the aluminosilicate mineral structure are potential sites for sulfur capture. The use of a sorbent to capture alkali in the bed reduces the need for downstream alkali capture devices. Other goals of this work were to investigate the potential for simultaneously removing $\mathrm{SO}_{2}$ and $\mathrm{Cl}$ from the $\mathrm{PFBC}$ gas stream.

Several side benefits were anticipated, and the goal was to demonstrate these benefits during this work. A reduction in the amount of fine particulate was expected when alkali is removed in the bed, since condensation of volatile alkalies is one of the primary mechanisms for the formation of these difficult-toremove particulates. Improved performance of ceramic filters was expected, since alkalies can lead to bridging, pore plugging, and other problems in ceramic filters. Deposition on the walls of the PFBC and on heat-transfer surface can reduce the performance of the PFBC and may be controllable by capture of the alkalies with in-bed sorbents. The propensity of certain fuels to sinter and/or agglomerate in the fluid bed was also expected to be reduced or eliminated with the introduction of alkali sorbents. 
The work reported here was initjally focused primarily on one class of sorbents, sodalites. The goal was to determine whether sodalites could be used as an in-bed sorbent to simultaneously remove alkali, sulfur, and chlorine. Some of the key reactions that were studied are listed below:

$$
\begin{aligned}
& \mathrm{NaCl}+3 \mathrm{NaAlSiO}_{4}=\mathrm{Na}_{4} \mathrm{Al}_{3} \mathrm{Si}_{3} \mathrm{O}_{12} \mathrm{Cl} \\
& \text { (nepheline) (sodalite) } \\
& \mathrm{NaCl}+3 \mathrm{NaAlSi}_{3} \mathrm{O}_{8}-\mathrm{Na}_{4} \mathrm{Al}_{3} \mathrm{Si}_{3} \mathrm{O}_{12} \mathrm{Cl}+6 \mathrm{SiO}_{2} \\
& \text { (albite) (sodalite) } \\
& 2 \mathrm{NaCl}+\mathrm{Na}_{8} \mathrm{Al}_{6} \mathrm{Si}_{6} \mathrm{O}_{24}\left(\mathrm{SO}_{4}\right)-2 \mathrm{Na}_{4} \mathrm{Al}_{3} \mathrm{Si}_{3} \mathrm{O}_{12} \mathrm{Cl}+\mathrm{Na}_{2} \mathrm{SO}_{4} \\
& \text { (nosean) (sodalite) } \\
& \mathrm{Na}_{8} \mathrm{Al}_{6} \mathrm{Si}_{6} \mathrm{O}_{24}\left(\mathrm{SO}_{4}\right)+12 \mathrm{SiO}_{2}-\mathrm{Na}_{2} \mathrm{SO}_{4}+6 \mathrm{NaAlSi}_{3} \mathrm{O}_{8} \\
& \text { (nosean) (albite) } \\
& 2 \mathrm{Na}_{4} \mathrm{Al}_{3} \mathrm{Si}_{3} \mathrm{O}_{12} \mathrm{Cl}+\mathrm{SO}_{2}+\mathrm{O}_{2}-\mathrm{Na}_{8} \mathrm{Al}_{6} \mathrm{Si}_{6} \mathrm{O}_{24}\left(\mathrm{SO}_{4}\right)+\mathrm{Cl}_{2} \\
& \text { (sodalite) (nosean) }
\end{aligned}
$$

Reactions 1 through 3 are the primary mechanisms for the removal of sodium from the gas stream. In these reactions, nepheline, albite, and nosean are removing sodium chloride from the gas stream to form sodalite. The fate of the sodalite is dependent upon the other constituents that make up the sorbent/ash bed and the gas stream. For systems high in silica, the potential exists for the silica to react with the sodalite or nosean by Reactions 2 and 4 to release the alkali. Sulfates, on the other hand, will replace the chlorine. In Reaction 3, sodium sulfate reacts to release sodium chloride with no net change in the amount of alkali captured. Provided there is sufficient nepheline, the released sodium chloride could react according to Reaction 1, with the overall result being a capture of both sulfur and chlorine. Reaction 5 shows the exchange of $\mathrm{SO}_{2}$ for $\mathrm{Cl}_{2}$. For most fuels, the expected concentration of $\mathrm{SO}_{2}$ relative to chlorine is high. Therefore, Reaction 5 will likely proceed to the right. The direction and extent of Reactions 2 and 4 will probably depend upon the chemistry of the ash and bed material.

Thermal gravimetric analysis was used to study the mechanism of alkali capture outlined in Reactions 1 through 5. Further testing was performed on a 3 in.-diameter pressurized fluid-bed reactor. 
Early results indicated that simultaneous removal of alkali and sulfur and/or chlorine was not practical under conditions for commercial PFBC operations. Therefore, the focus of the later part of this work was on sorbents that have been shown to capture alkali in other systems. The effectiveness of kaolinite and bauxite to reduce the vapor-phase alkali concentrations was determined while the impact of the sorbent on operational performance was evaluated. This evaluation included examining potential agglomeration of bed particles, deposition on heat-transfer surfaces, and the bridging and blinding of ceramic candle filters. 


\section{CHAPTER 2}

\section{LITERATURE REVIEW}

The goal of this research was to investigate methods to reduce the level of alkalies in the exit gas from the PFBC to meet the current and proposed design standards for high-efficiency gas turbines. Understanding all aspects of the process was necessary, beginning with the evolution of the alkali from the coal and its formation of gaseous species, capture by the alkali sorbent and, finally, determining the quality of the gas that enters the turbine. Therefore, a basic understanding of these processes was extracted from the literature and is presented in this chapter. The chapter first discusses the transformation of the mineral matter in coal to gaseous, liquid, and solid species. Since direct measurement of the alkali components of the flue gas is difficult and many times inaccurate, thermochemical modeling is often used to predict the fate of the alkali in the flue gases and to predict the impact of changes in operating conditions and fuel properties on the gas quality. Results from several modelers are reported here, along with measurements taken to determine the validity of the models. Sorption theory is reviewed, with an emphasis on sorbent behavior in a fluidized bed and on the interactions of alkalies with aluminum silicates. Other researchers' success with various alkali sorbents is presented to provide a baseline with which to compare results from my work. Their experimental techniques are also presented, especially as they relate to my choice of experimental techniques. The various measurement techniques utilized are reviewed, since the accurate measurement of the alkalies leaving the PFBC is an essential component in demonstrating the success of my work. Some conclusions from the literature review are presented in this chapter. The material presented in this chapter will be referenced heavily in the remainder of this dissertation as it is used to justify choices made for the experimental approach and interpretation of the results generated from my work. 


\subsection{Transformation of Mineral Matter in Coal}

The purpose of this subsection is to provide the background necessary to understand which coals are potentially high emitters of alkali and how that alkali is released during the combustion process. This knowledge was used in designing the original fundamental experiments to ensure that useful real-world information could be extracted. This understanding will also be important as one tries to apply the experience gained during this work to other fuels and applications.

\subsubsection{The Nature of the Inorganic Constituents}

Coal is a primarily organic sedimentary rock that contains small amounts of inorganic constituents. Although comprising only a small fraction of the total weight of the coal, the inorganic constituents affect every facet of coal preparation and usage. The inorganics have three principal origins: they existed in the original plant material whose remains make up the organic fraction of the coal; they were carried into the coal-forming environment by water or wind as detrital mineral matter; or they were deposited from solution through ion-exchange or precipitation (authigenic formation). Whatever the origin, the inorganic constituents of coals exhibit two modes of occurrence: as discrete mineral particles or, most importantly with low-rank coals, as cations associated with organic acids or other organic complexation sites.

The ash particulate and alkali concentrations in the hot gases leaving a PFBC depend on the mode of occurrence of inorganic elements in the coal and their high-temperature reaction chemistry. The size and morphology of the minerals found within coal vary greatly, but depend on the type and origin of the mineral inclusion. The clay minerals often occur as layers within the coal seam, but can also occur as finely dispersed inclusions. In pulverized coal, the clay particles vary from masses as large as the largest coal particles to individual particles less than 10 nanometers in diameter (Stach et al., 1982). Quartz particles most often occur as partially rounded grains of probable detrital origin, but can also exist as massive cryptocrystalline bodies that formed authigenically (Miller and Given, 1979). Pyrite can also exist in such forms, but in addition may occur as raspberrylike agglomerations of smaller particles, termed framboids. The carbonate and sulfate minerals most often occur as precipitates that fill cracks or fissures in the coal (Stach et al., 1982). The size range of the mineral matter in pulverized coal varies from the largest size that will pass the pulverizer to particles 2 nanometers in diameter that contain only a few hundred atoms 
(Hurley, 1990). A typical mass median diameter for the mineral matter in a pulverized western U.S. lowrank coal is approximately 20 microns. In a PFBC, since the coal is typically crushed to only $-1 / 8$ in., larger mineral grains typically are seen. .

In addition to association as discrete mineral matter, the inorganic constituents can exist as cations associated with organic acids or other organic complexation sites. Miller and Given (1979) list eight oxygen or nitrogen functional groups that are known to exist in peats and lignites that could participate in complexing metal ions. This is the major mode of occurrence of the alkalis in most western U.S. coals.

One method of determining whether the elements are organically associated or present in discrete mineral particles is to extract the elements from the coal using different aqueous reagents. Using techniques modified from those used by Miller and Given (1979), Benson and Holm (1985), and Hurley and others (1986), 14 western U.S. coals, lithotypes, and size-fractionated coal samples were extracted in an effort to delineate the associations of the inorganic elements in the coals. Table 3 lists the ranges of concentrations of the major inorganic elements in the 14 coals studied and the percentages of each element removed by the one molar $\mathrm{NH}_{4} \mathrm{OAc}$ extractions. Table 4 lists the ranges in the percentages of the elements extracted from the $\mathrm{NH}_{4} \mathrm{OAc}$-extracted residues by one molar $\mathrm{HCl}$ and the percentages of the elements remaining. The data for Tables 3 and 4 were taken from a series of DOE quarterly technical progress reports (Benson and Hurley, 1983; Benson et al., 1984ab; Karner et al., 1984).

The elements removed from the coals by the $\mathrm{NH}_{4} \mathrm{OAc}$ extractions exist in the coals predominantly as cations associated as the salts of organic acids, although small amounts may be present as soluble minerals such as gypsum. Morgan (1980), however, showed that greater than $90 \%$ of the elements that could be extracted with one molar $\mathrm{NH}_{4} \mathrm{OAc}$ from the western U.S. lignites that he studied were ion-exchanged from organic associations. In general, the majority of sodium and calcium in the coals was organically associated. In addition, large fractions of potassium and magnesium may be organically associated, although these percentages are much more variable. Potassium is most often not highly exchangeable and, therefore, assigned to clay minerals. As will be discussed later, the organically bound cations are of the most importance in PFBC since they are the most likely to volatilize during combustion and cause problems elsewhere in the combustion system. 
Table 3

Ranges in Concentrations of Inorganic Elements and Percents Extracted by 1 Molar Ammonium Acetate from 14 Western U.S. Low-Rank Coals

\begin{tabular}{lcc}
\hline Element & Initial, ppm & Removed by $\mathrm{NH}_{4} \mathrm{OAc}, \%$ \\
\hline $\mathrm{Na}$ & $960-6200$ & $76-100$ \\
$\mathrm{Mg}$ & $980-20,540$ & $17-100$ \\
$\mathrm{Al}$ & $2180-11,480$ & $0-23$ \\
$\mathrm{Si}$ & $2050-33,060$ & $0-12$ \\
$\mathrm{~K}$ & $390-1530$ & $2-89$ \\
$\mathrm{Ca}$ & $7500-22,790$ & $39-85$ \\
$\mathrm{Ti}$ & $104-1180$ & $0-5$ \\
$\mathrm{Fe}$ & $1450-11,090$ & 0 \\
\hline
\end{tabular}

Table 4

Ranges of Inorganic Elements Extracted by $1 \mathrm{Molar} \mathrm{HCl}$ and Remaining in the Residues from the Extractions of 14 Western U.S. Low-Rank Coals

\begin{tabular}{lcc}
\hline Element & Removed by $\mathrm{HCl}, \%$ & Remaining, \% \\
\hline $\mathrm{Na}$ & $0-2$ & $0-24$ \\
$\mathrm{Mg}$ & $0-17$ & $0-82$ \\
$\mathrm{Al}$ & $29-81$ & $19-58$ \\
$\mathrm{Si}$ & $2-17$ & $72-97$ \\
$\mathrm{~K}$ & $0-30$ & $11-97$ \\
$\mathrm{Ca}$ & $11-29$ & $1-49$ \\
$\mathrm{Ti}$ & $2-57$ & $43-98$ \\
$\mathrm{Fe}$ & $14-73$ & $27-79$ \\
\hline
\end{tabular}

The sources of the elements extracted by one molar $\mathrm{HCl}$ are less clear than the sources of the elements extracted by one molar $\mathrm{NH}_{4} \mathrm{OAc}$. Like the $\mathrm{NH}_{4} \mathrm{OAc}$ extractions, the $\mathrm{HCl}$ extractions also remove elements associated with the organic fraction of the coal, principally those associated with coordination complexes. However, they also remove some elements present in mineral forms such as carbonates, sulfates, and oxides. Therefore, the amounts of elements extracted by one molar $\mathrm{HCl}$ indicate the maximum amount of the element that is organically complexed in the coal. Additional information about the concentrations of acid-soluble mineral matter is needed in order to calculate from the acid extraction data the actual concentrations of organically associated elements present in the coal.

\subsubsection{Ash Formation and Partitioning During Combustion and Gasification}

During combustion or gasification, the inorganic constituents of coal can undergo a variety of physical and chemical transformations. The transformations depend on the original mode of occurrence of 
the constituent, the time-temperature history of the constituent during combustion or gasification, and the degree of the interaction with other constituents. The transformations are usually so extensive that the mineralogy and size distribution of the ash produced from the utilization of coal are quite different from the inorganic particles in the coal. Of critical importance to this work are the transformations that influence the partitioning of the ash among solid, liquid, and vapor phases.

Tracing the reactions that lead to the formation of the different species in the ash is a difficult process. There are, however, two main reaction paths: that encountered by the inorganics present in the coal as discrete particles of mineral matter and that followed by the organically associated inorganic species.

Several types of changes can occur in the discrete mineral matter present in coal during combustion. The main changes include:

- Vaporization and condensation.

- Fragmentation of inorganic grains.

- Convective transport of ash during rapid organic reaction (release of ash particles from burning char).

- Structural disintegration of char during the combustion process.

- Shedding of ash during receding of the surface of char particles.

- Coalescence of ash particles.

- Cenosphere formation.

All of these mechanisms will be discussed briefly here for completeness; however, it should be recognized that many of these will not occur at the relatively low temperatures of the PFBC.

The initial reactions of the discrete mineral matter can begin at relatively low temperatures compared to those ultimately reached within the coal flame. Unfortunately, knowing at exactly what temperatures certain reactions or physical processes occur is complicated by the rapid heating rate experienced by the coal as it enters the combustor. The high heating rates and comparatively slow reaction rates cause initiation and completion temperatures to be different from those determined at slow heating rates, such as those obtained with laboratory analytical equipment. In addition, the high heating rates may cause some 
reactions to occur concurrently, whereas at low heating rates they may occur sequentially. Therefore, the temperatures at which various reactions occur as determined by laboratory equipment operating at relatively low heating rates should be used only as a guide when attempting to delineate the reactions undergone by the mineral matter in coal during combustion.

Using thermogravimetric analysis (TGA) and differential thermal analysis (DTA), O'Gorman and Walker (1973) studied the thermally induced decomposition and oxidation reactions in commonly occurring coal minerals as a function of temperature. When heating a mixture of pure minerals in air, $O^{\prime}$ Gorman and Walker showed that loss of adsorbed and interlayer water from clays occurs between $50^{\circ}$ and $150^{\circ} \mathrm{C}\left(125^{\circ}\right.$ and $\left.300^{\circ} \mathrm{F}\right)$. Gypsum $\left(\mathrm{CaSO}_{4} \cdot 2 \mathrm{H}_{2} \mathrm{O}\right)$ also dehydrates in this temperature range, converting to bassanite $\left(\mathrm{CaSO}_{4} \cdot 1 / 2 \mathrm{H}_{2} \mathrm{O}\right)$ and finally to anhydrite $\left(\mathrm{CaSO}_{4}\right)$ at $175^{\circ} \mathrm{C}\left(350^{\circ} \mathrm{F}\right)$. From $325^{\circ}$ to $620^{\circ} \mathrm{C}\left(617^{\circ}\right.$ to $\left.1150^{\circ} \mathrm{F}\right)$, loss of hydroxyl water from clays occurs as well as oxidation of pyrite $\left(\mathrm{FeS}_{2}\right)$. Between $700^{\circ}$ and $830^{\circ} \mathrm{C}\left(1300^{\circ}\right.$ and $\left.1525^{\circ} \mathrm{F}\right)$, the decomposition of calcite $\left(\mathrm{CaCO}_{3}\right)$ takes place, with no other weight losses occurring up to $1090^{\circ} \mathrm{C}\left(2000^{\circ} \mathrm{F}\right)$. In a simulated flue gas atmosphere, the weight loss curve was similar, except that the decomposition of calcite occurred about $150^{\circ} \mathrm{C}\left(270^{\circ} \mathrm{F}\right)$ higher than in air due to the presence of $\mathrm{CO}_{2}$, along with a possible decomposition of anhydrite to calcium oxide above $800^{\circ} \mathrm{C}$ $\left(1475^{\circ} \mathrm{F}\right)$. No significant solid-phase interactions between the minerals were noted below $1090^{\circ} \mathrm{C}$ $\left(2000^{\circ} \mathrm{F}\right)$ (O’Gorman and Walker, 1973).

Manzoori (1990) focused his work primarily on the interactions of sodium and chlorine during fluidbed combustion. As a result of his work, he concluded that the inherent moisture in the coal evaporates as the coal is heated. The evaporation is complete when the particle temperature reaches $200^{\circ} \mathrm{C}\left(390^{\circ} \mathrm{F}\right)$. Sodium chloride and other salts dissolved in the inherent water crystallize within the coal particles. The crystals are likely to be finely distributed in the coal matrix. At temperatures between $400^{\circ}$ and $900^{\circ} \mathrm{C}$ $\left(705^{\circ}\right.$ and $1650^{\circ} \mathrm{F}$ ), the coal devolatilizes, releasing the organic volatiles. During pyrolysis, the functional groups containing the inorganics decompose resulting in the formation, inside the coal particles, of reactive inorganic species. Some of these species are volatile (i.e., those from $\mathrm{Na}, \mathrm{S}$, and $\mathrm{Cl}$ ) and may be released into the gas phase. Those species remaining in the coal are finely distributed in the coal matrix. Sodium carbonate, calcium oxide, magnesium oxide, alkali sulfates, iron oxide, and alumina phases may be formed. 
Sodium chloride melts at about $815^{\circ} \mathrm{C}\left(1500^{\circ} \mathrm{F}\right)$ and has a significant vapor pressure at temperatures found in an FBC. At these temperatures, however, it reacts with other compounds inside and/or at the char's surface, resulting in a disproportionate release of sodium and chloride. Direct vaporization of sodium chloride increases with increasing temperatures. The volatilized alkali species can react with sulfur, silica, and clay to form sulfates, silicates, and aluminum silicates (Erickson et al., 1991). Above the temperatures typical in the $\mathrm{FBC}\left(900^{\circ} \mathrm{C}\left[1650^{\circ} \mathrm{F}\right]\right)$, significant reactions can occur between the acidic and basic oxides with the resultant formation of low melting eutectics. Sodium chloride and the species formed from the alkali elements, however, can form solid solutions with melting temperatures often below those found in FBC systems.

In pc (pulverized coal)-fired systems, fragmentation of some minerals has been shown to occur. Raask (1984) reports that under rapid heating conditions, pyrite fractures and fragments upon partial oxidation to $\mathrm{FeS}$ and before the $\mathrm{FeS}$ melts at $1075^{\circ} \mathrm{C}\left(1970^{\circ} \mathrm{F}\right)$. Raask (1984) also reports that significant portions of the carbonate minerals calcite, siderite $\left(\mathrm{FeCO}_{3}\right)$, and ankerite $\left(\mathrm{CaFeCO}_{3}\right)$ also fragment upon decomposition to form fume particles. Unlike the carbonate minerals, the silicate minerals do not undergo fragmentation during combustion or gasification. Instead, silicate and aluminosilicate particles tend to fuse into glassy spheres. In drop-tube furnace tests, aluminosilicate particles were found to spheroidize between $1300^{\circ}$ and $1450^{\circ} \mathrm{C}\left(2375^{\circ}\right.$ and $\left.2650^{\circ} \mathrm{F}\right)$, while larger quartz particles required temperatures above $1450^{\circ} \mathrm{C}$ $\left(2650^{\circ} \mathrm{F}\right)$ (Raask, 1985). Fragmentation and melting will not typically occur at the temperatures seen in a PFBC (Erickson et al., 1992).

Of more importance to the temperatures experienced in the PFBC, and essential to this project, are the reactions of the organically associated mineral matter. The initial step in the release of alkali and alkaline earth metals from carboxylate groups in low-rank coal during combustion is decomposition of the carboxylate to form the metal carbonate. In DTA and TGA studies of sodium and potassium benzoates, Stewart and others (1982) described the formation of sodium and potassium carbonates in the temperature range of $400^{\circ}$ to $600^{\circ} \mathrm{C}\left(750^{\circ}\right.$ to $\left.1110^{\circ} \mathrm{F}\right)$. The formation of the carbonates was independent of the atmosphere used. 
At higher temperatures, decomposition of the carbonates occurs. The exact mode of decomposition is not always clear and may vary with the metal in question. The general route of the decomposition of alkali metal carbonates is believed to be decomposition of the alkali metal carbonate to the metal oxide, followed by reduction of the oxide to metal vapor by carbon monoxide or char. The metal vapor then diffuses through the porous char to the surface of the char where it can react with ash particles or escape to the gas surrounding the burning char particle. In quadrupole mass spectrometry studies of the gas species present in a pulverized low-rank coal-air flame, Greene and O'Donnell (1987) demonstrated the appearance and disappearance of sodium atoms in the gas phase within 5 milliseconds of the time the coal entered the flame. After 5 milliseconds, sodium hydroxide appeared to be the dominant sodium species. However, the concentrations of all of the sodium species present in the flame after the disappearance of the atomic sodium were not enough to account for the disappearance of the atomic sodium from the gas phase, indicating condensation reactions had occurred. Neville and others (1981) have found that up to $60 \%$ of the sodium in a Montana lignite can escape the char during combustion in an entrained-flow reactor. Quann and Sarofim (1986) found that up to $20 \%$ of the magnesium, a small percentage of the calcium, and less than $1 \%$ of the aluminum found in the western U.S. low-rank coals that they studied were vaporized from the char during combustion in an entrained-flow reactor. Knudsen cell mass spectroscopy work on lowtemperature ashed sample of Illinois No. 6 and Wyodak coals was conducted by SRI (Southern Research Institute) International (SRI International, 1989). In the work with the Wyodak subbituminous coal, $\mathrm{NaCl}$ and $\mathrm{KCl}$ vapor species were observed above the coal ash, but these species were not detected above the Illinois No. 6 coal ash. The chlorine levels in the Wyodak were approximately three times higher than in the Illinois No. 6 sample.

As the metal vapors leave the burning char particle, they diffuse through the boundary layer of gas surrounding the char. The boundary layer is a region surrounding the oxidizing char within which gas concentrations and temperatures make the transition from conditions at the surface of the burning char to the conditions in the main combustor or gasifier atmosphere. In diffusing outward, the metal vapors encounter decreasing gas temperature and increasing compositions of gases, such as oxygen, that promote the condensation of the alkali. 
In his work, Manzoori (1990) focused on the physicochemical transformations experienced by the inorganic mineral matter during AFBC. He analyzed the residual char and/or ash residues at various stages during combustion and attributed any loss of a specific component to vaporization. In his work with a highsodium (12.4\% $\mathrm{Na}_{2} \mathrm{O}$ in the ash) Australian coal from the Lochiel trial pit, Manzoori found that the extent of vaporization of the sodium species including the sodium chloride was small. Most of the species formed from the organically bound sodium remain in the char and are likely to participate in ash formation on the char's surface. Chlorine was released at a disproportionately higher level than the sodium, suggesting that sodium chloride reacts with other compounds inside the char and/or on the char's surface. Sodium species formed as a result of these reactions can also participate in the ash formation mechanism. The presence of organic sulfur and sodium in low-rank coals resulted in a formation of a molten ash matrix on the char's surface. The ash matrix retains some of the solid species formed during the transformations of the organically bound elements such as $\mathrm{Ca}, \mathrm{Mg}$, and $\mathrm{Al}$ as well as some of the mineral inclusions in the coal including submicron silica particles which are intimately distributed in the coal matrix. Although the molten phase is likely to include sodium species formed from $\mathrm{NaCl}$ transformations, it contains only minute quantities of $\mathrm{Cl}$. Figure 9 reviews the mechanisms of mineral matter release under $\mathrm{FBC}$ conditions.

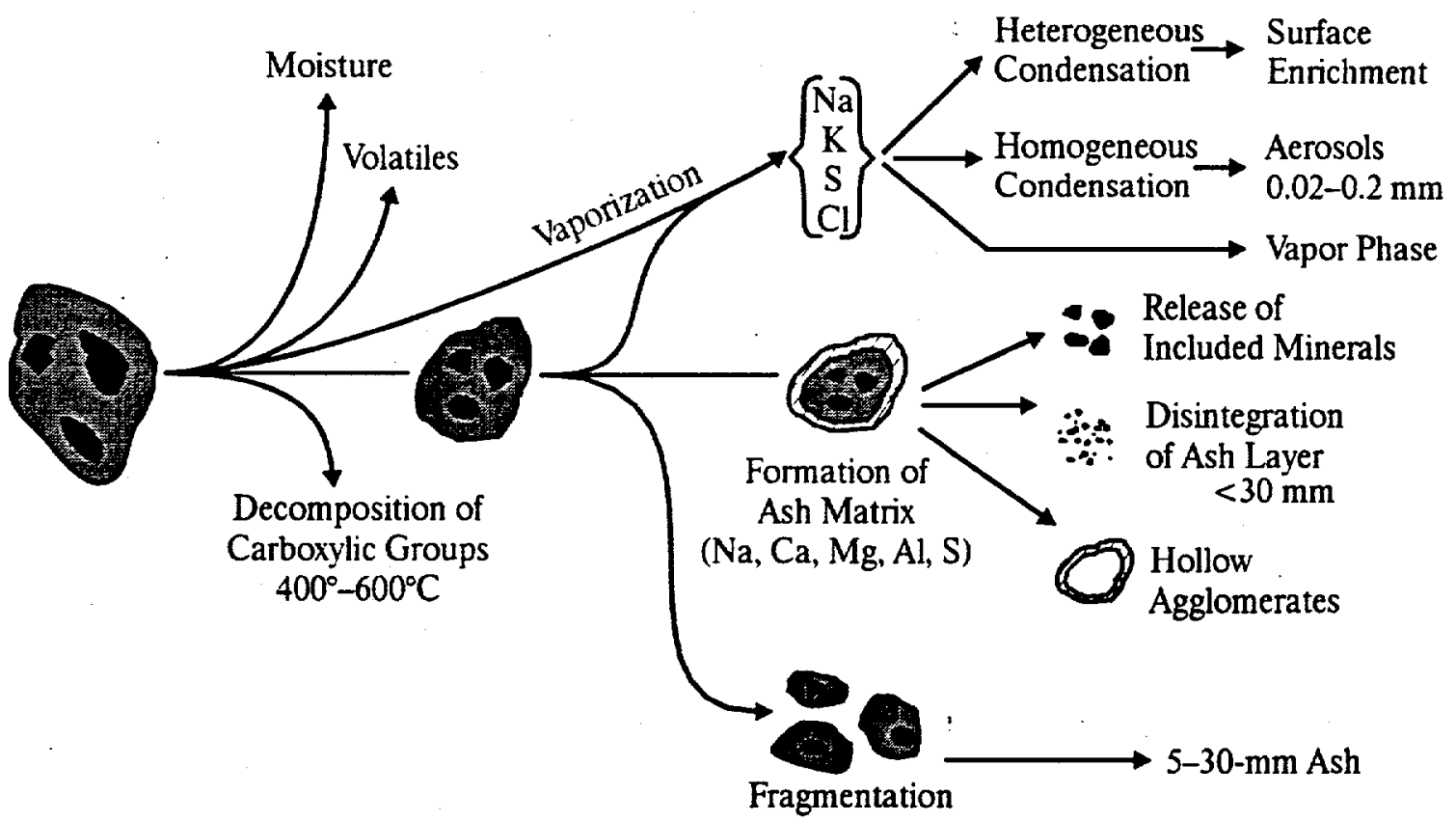

Figure 9. Mechanisms of mineral matter release under FBC conditions 
Cooling of the combustion gas has been utilized as one method for limiting the alkali content in the flue gas entering the turbine. The temperature and gas compositions necessary for the metals to condense depend on the metal and gas species, with alkali metals requiring cooler temperatures and greater reactant gas partial pressures than the alkaline earth metals. Consequently, the alkaline earth metals are predominantly in a condensed form in both combustion and gasification systems. The alkali metals, however, are present in much higher concentrations in the vapor phase. The most common vapor forms of the alkali metals are sulfate, hydroxide, and chloride. The saturation partial pressures of the potassium salts are slightly higher than those of the sodium salts, although they are generally similar.

In combustion systems, where $\mathrm{SO}_{2}$ is available, condensed sulfates and silicates are the thermodynamically favored forms of sodium and potassium, so most, but not all, of the alkalies are present in those forms. The vapor pressure of the sulfate forms is high enough that a portion of the alkali sulfates can exist in vapor form. Therefore, some alkali exists as vapor, with sulfates and hydroxides as the dominant forms. Although the saturation vapor pressures of the alkali hydroxides are higher than those of the sulfates, the sulfates are more thermodynamically stable and so usually make up the larger fraction of the vapor-phase alkali. Only a small proportion of the other more volatile trace elements leave the PFBC in the vapor phase. Emissions range from $0.5 \%$ to $1.2 \%$ for $\mathrm{Cu}, 7.5 \%$ to $16 \%$ for $\mathrm{Hg}, 1 \%$ to $3 \%$ for $\mathrm{Pb}, 5 \%$ for Cd, and 4\% for As (Mojtahedi et al., 1990).

\subsection{Modeling of Gas-Phase Alkali Composition}

While the previous discussion focused on the mechanisms by which sodium, potassium, and chlorine are initially released in a coal conversion process, equally important are the chemical interactions that occur in the gas phase. These interactions subsequently alter the chemical compositions and the resultant phase equilibria of the alkali and halogen compounds. The gas composition is important in determining the exact methods by which the alkali and halogen compounds can be removed from the gas stream or in evaluating their effect on material corrosion. Recent studies to evaluate these aspects have assumed two formats: thermodynamic studies where thermochemical equilibrium models have been used to predict the composition and nature of the chemical species present in various reactant systems (Scandrett, 1983; Scandrett and Clift, 1984; Spacil and Luthra, 1982; Mulik et al., 1983; and Pintsch and Gudenau, 1991) and experimental studies where measurements are performed to determine the same parameters (Bachovchin et 
al., 1986; Bachovchin and Alvin, 1987; Lee and Johnson, 1980; Lee and Myles, 1987; Lee and Swift, 1991; Scandrett and Clift, 1984; Radhakrishnan et al., 1986; Pintsch and Gudenau, 1991b; Zakkay et al., 1989; Punjak et al.,1989; Uberoi et al., 1990). This subsection will review the thermochemical equilibrium studies, while the next section will present experimental results. Understanding the processes affecting the composition, phase equilibria, and unit operations for the removal of the alkali and halogen compounds formed in the PFBC is an important step toward developing methods to clean the product gas to a level that can meet current turbine manufacturer standards.

A number of different thermochemical equilibrium models have been used to calculate the distribution of alkali species both with and without alkali sorbents. Most of these models are based on calculating the equilibrium composition by minimizing the Gibbs free energy of the system. Similar results have been obtained by various researchers using these types of models. When using results from these calculations, it is important to remember that all calculations based on thermochemical data are subject to limitations. First, they are dependent upon the accuracy of the data on which they are based. Second, thermochemical data can be difficult to obtain for all of the relevant species at high temperatures. Third, these calculations estimate the conditions at thermodynamic equilibrium only and do not take kinetic limitations into account. However, thermodynamic equilibrium represents a composition toward which chemical reactions proceed. This type of calculation can be used to distinguish between reactions that can and cannot proceed under given conditions of temperature, pressure, and composition. The rates of approach to this thermodynamic equilibrium (chemical kinetics), however, must normally be investigated experimentally.

Mojtahedi and Backman (1989) utilized a computer program (SOLGASMIX) developed by Erickson (1975) to predict the gas-phase composition of alkali species as a function of temperature, pressure, and the relative content of sodium, potassium, chlorine, and sulfur. The 64 chemical species listed in Table 5 were included in model predictions. Equilibrium compositions were calculated assuming that gas mixtures are ideal and that all solid condensed phases are immiscible. This is a reasonable assumption for the relatively low temperatures and pressures under which the PFBC operated. For the liquid phase, a nonideal subregular model was used for alkali carbonates and sulfates. 
Table 5

Chemical Species Considered in the Equilibrium Calculations (Mojtahedi and Backman, 1989)

\begin{tabular}{ll}
\hline Gas Phase: & $\mathrm{CO}_{2}, \mathrm{H}_{2} \mathrm{O}, \mathrm{O}_{2}, \mathrm{OH}, \mathrm{N}_{2}, \mathrm{H}_{2}, \mathrm{CH}, \mathrm{HCO}, \mathrm{H}, \mathrm{O}, \mathrm{N}, \mathrm{HCN}, \mathrm{C}, \mathrm{NH}_{3}, \mathrm{HCl}, \mathrm{Cl}, \mathrm{Cl}_{2}$, \\
& $\mathrm{SO}_{3}, \mathrm{SO}_{2}, \mathrm{~S}, \mathrm{~S}_{2}, \mathrm{H}_{2}, \mathrm{~S}, \mathrm{COS}, \mathrm{HS}, \mathrm{CS}, \mathrm{CS}_{2}, \mathrm{~S}_{2} \mathrm{O}, \mathrm{H}_{2} \mathrm{SO}_{4}, \mathrm{Na}, \mathrm{Na}_{2}, \mathrm{NaCl}_{2} \mathrm{Na}_{2} \mathrm{Cl}_{2}$, \\
Liquid Phase: & $\mathrm{Na}_{2} \mathrm{CO}_{3}, \mathrm{Na}_{2} \mathrm{SO}_{4}, \mathrm{Na}_{2} \mathrm{~S}, \mathrm{NaCl}, \mathrm{NaOH}, \mathrm{K}_{2} \mathrm{CO}_{3}, \mathrm{~K}_{2} \mathrm{SO}_{4}, \mathrm{~K}, \mathrm{~S}, \mathrm{KCl}, \mathrm{KOH}$ \\
Solid Phases: & $\mathrm{Na}_{2} \mathrm{CO}_{3}, \mathrm{Na}_{2} \mathrm{SO}_{4}, \mathrm{Na}_{2} \mathrm{~S}, \mathrm{NaCl}, \mathrm{NaOH}, \mathrm{K}_{2} \mathrm{CO}_{3}, \mathrm{~K}_{2} \mathrm{SO}_{4}, \mathrm{~K}, \mathrm{~S}, \mathrm{KCl}, \mathrm{KOH}$ \\
Feedstock Composition, & wt\% on a dry basis \\
Carbon & 55 \\
Hydrogen & 5.5 \\
Oxygen & 32.6 \\
Nitrogen & 1.7 \\
Sodium & $0.005-0.16$ \\
Potassium & $0.014-0.448$ \\
Chlorine & $0.005-0.8$ \\
Sulfur & $0.01-0.26$ \\
(40 wt\% $\mathrm{H}_{2} \mathrm{O}$ in the as-received fuel)
\end{tabular}

Figure 10 shows the predicted phase distribution of sodium, potassium, and chlorine for the case with a pressure of 10 bar; a stoichiometric air ratio of 1.2 ; and potassium, sodium, and chlorine concentrations of 400,100 , and $400 \mathrm{ppmw}$, respectively. The liquid phase consists almost entirely of the sulfates of sodium and potassium. Solid sodium sulfate seems to form below $740^{\circ} \mathrm{C}\left(1364^{\circ} \mathrm{F}\right)$, but solid potassium sulfate could be present even at $900^{\circ} \mathrm{C}\left(1650^{\circ} \mathrm{F}\right)$. The total alkali content in the vapor phase was predicted to be $0.06 \mathrm{ppmv}$ (parts per million by volume) $(0.01 \mathrm{Na}$ and $0.05 \mathrm{~K})$ at $800^{\circ} \mathrm{C}\left(1472^{\circ} \mathrm{F}\right)$ under these PFBC conditions. These values represent about $0.1 \%$ of the sodium and $0.16 \%$ of the potassium in the system. The corresponding values at $900^{\circ} \mathrm{C}\left(1650^{\circ} \mathrm{F}\right)$ are $0.83 \mathrm{ppmv}$ for the total volatilized alkali $(\mathrm{Na}=0.14 ; \mathrm{K}=0.69)$, an increase of 10 -fold. This represents about $1.2 \%$ of the total sodium and $2.5 \%$ of the potassium entering the system. 

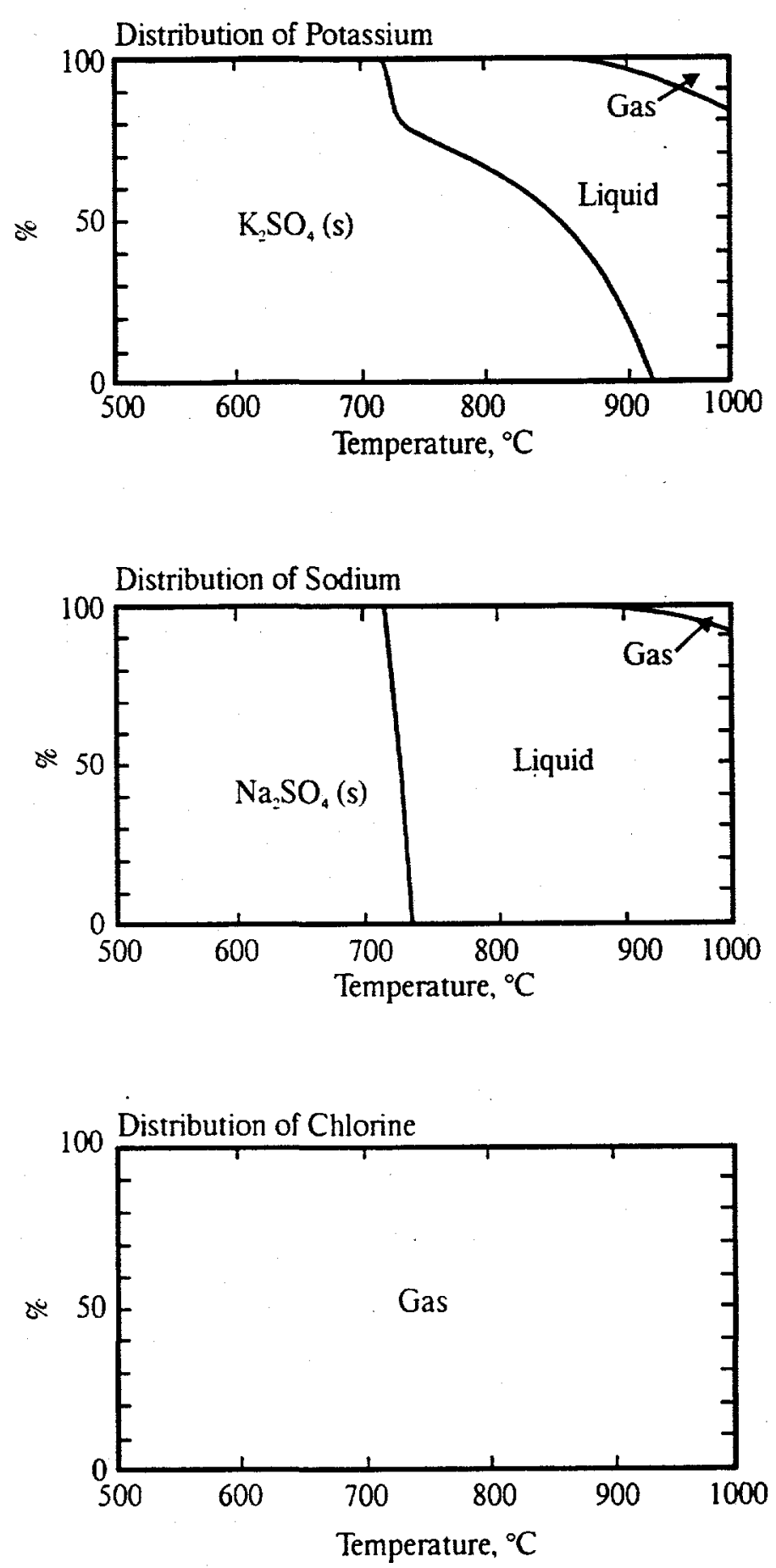

Figure 10. Distribution of $\mathrm{Na}, \mathrm{K}$, and $\mathrm{Cl}$ in three phases under PFBC conditions (Mojtahedi and Backman, 1989) 
The predicted gas-phase composition is presented in Figure 11. This figure shows a dominance of $\mathrm{HCl}$ in the gas phase. Of the alkalies, the chlorides exist in significantly higher quantities than do the corresponding sulfates and hydroxides. The alkali chlorides are 1 to 3 orders of magnitude higher in the PFBC operating range. The effect of the chlorine content of the fuel on the distribution of the two metals is interesting to note. Because the $\mathrm{HCl}(\mathrm{g})$ concentration is much higher than that of the alkali chlorides, its formation would be expected to have a negligible effect upon the latter's concentration in the gas.

However, Figure 12 shows that the volatilization of both sodium and potassium can be strongly dependent on the chlorine content of the in-going fuel. The higher the $\mathrm{Cl}$ content is, the higher the vapor-phase alkali chlorides in the flue gas. At $900^{\circ} \mathrm{C}\left(1650^{\circ} \mathrm{F}\right)$, the alkali content in the vapor phase more than doubles with a corresponding doubling of the chlorine content in the fuel.

The dependency of alkali vapor concentrations on the fuel's chlorine concentration is reinforced in Figure 13. Here, the chlorine content of the feedstock was varied between 50 and $800 \mathrm{mg} / \mathrm{kg}$ which represents the two extremes in the chlorine studied. Both vapor-phase chlorides of sodium and potassium

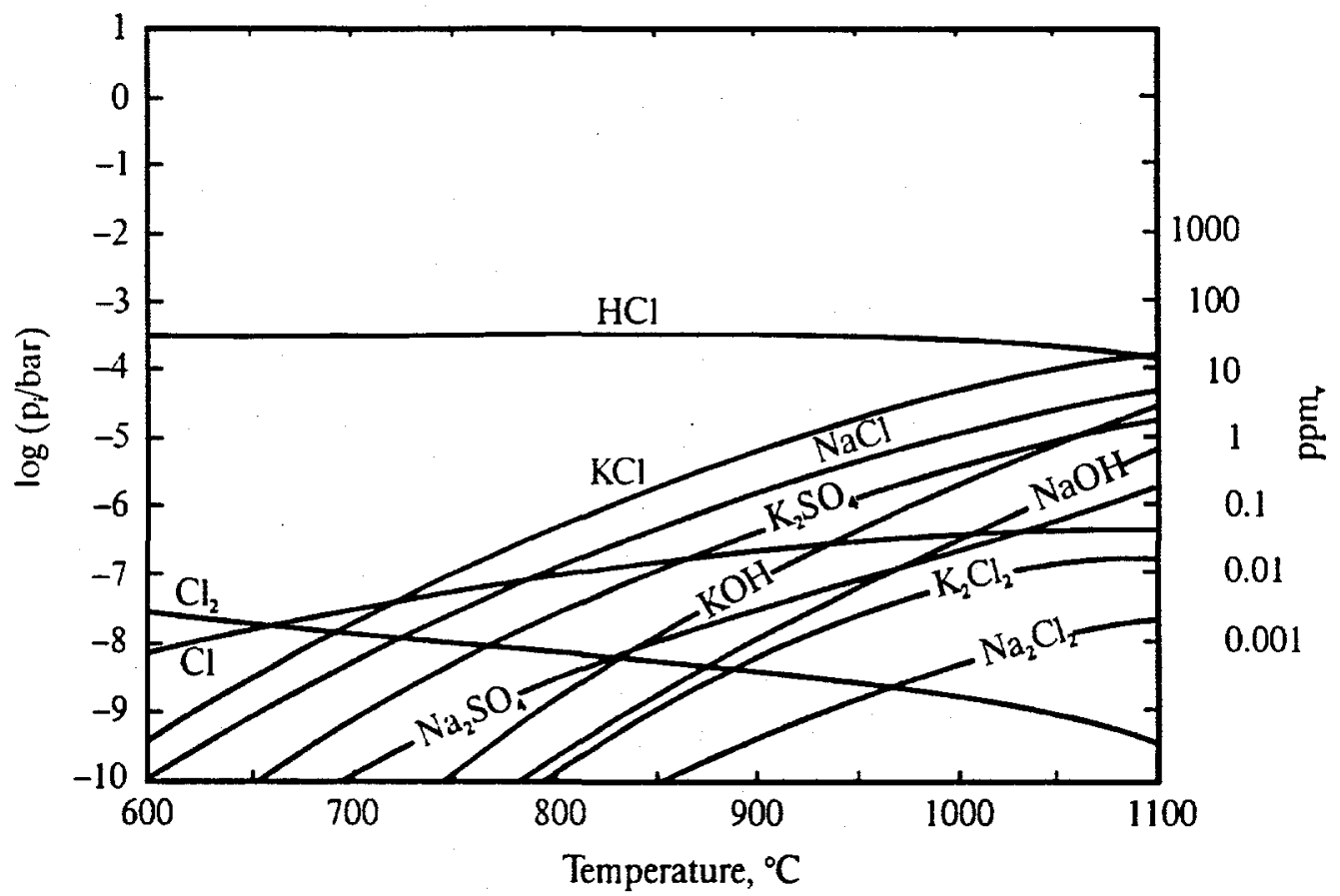

Figure 11. Variation of the partial pressure of the gaseous alkali species with temperature (Mojtahedi and Backman, 1989) 


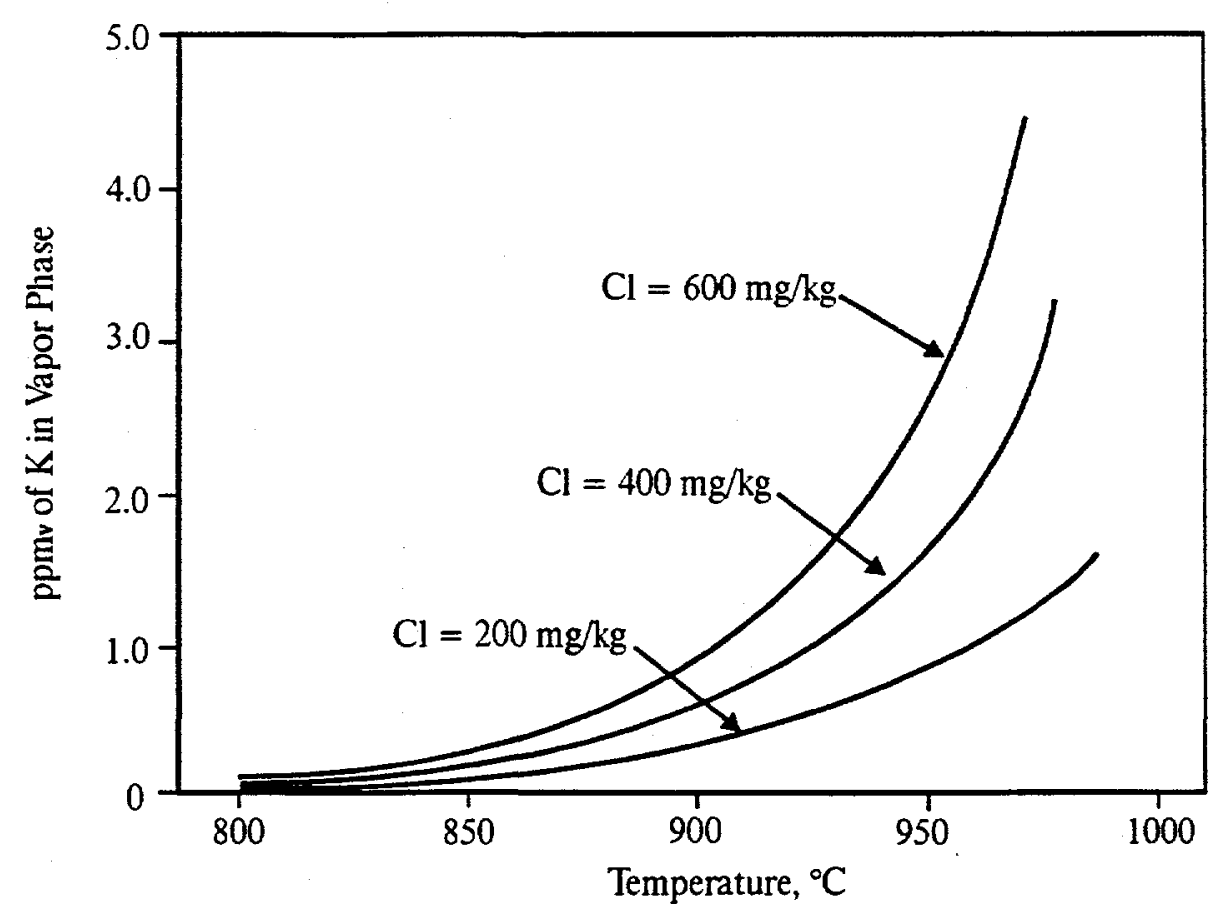

Potassium in Vapor Phase

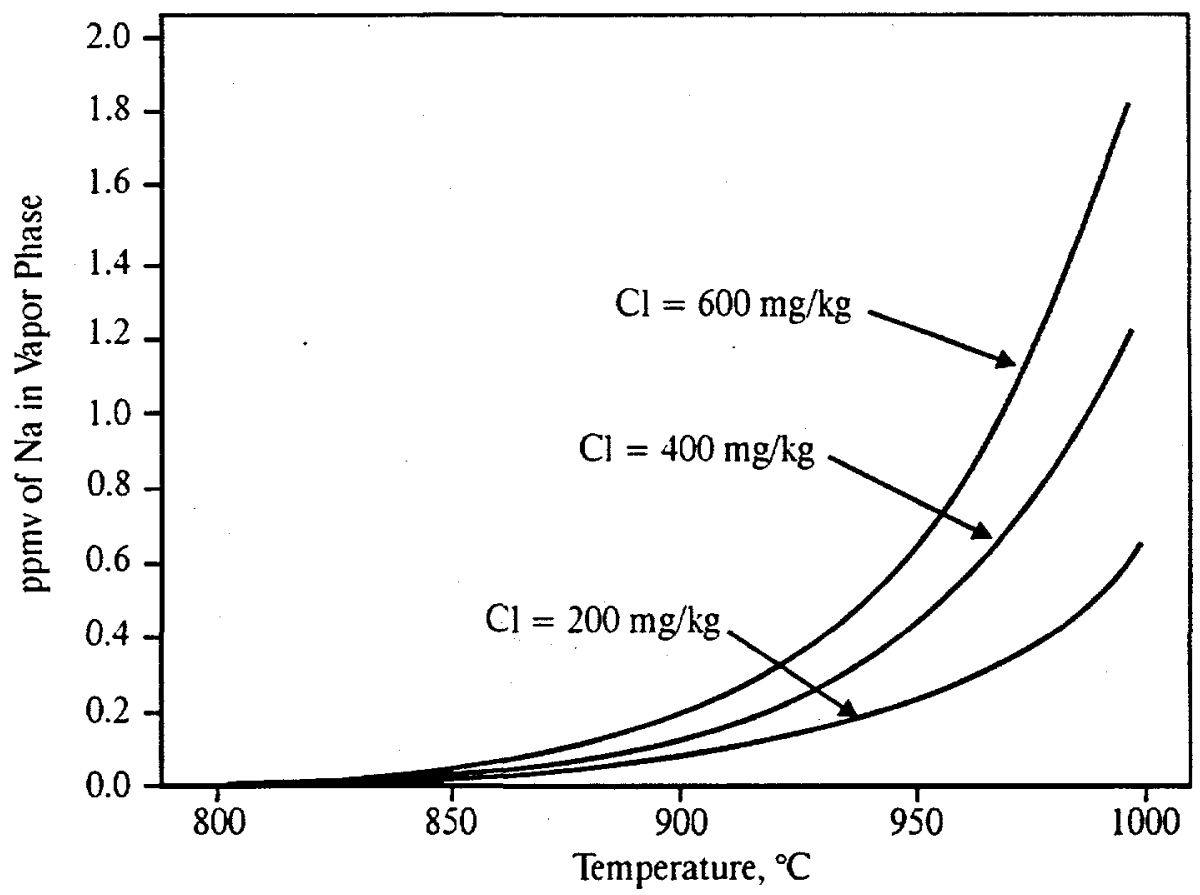

Sodium in Vapor Phase

Figure 12. Variation of the vapor-phase $\mathrm{Na}$ and $\mathrm{K}$ concentrations in the flue gas with temperature for three different $\mathrm{Cl}$ contents (Mojtahedi and Backman, 1989) 


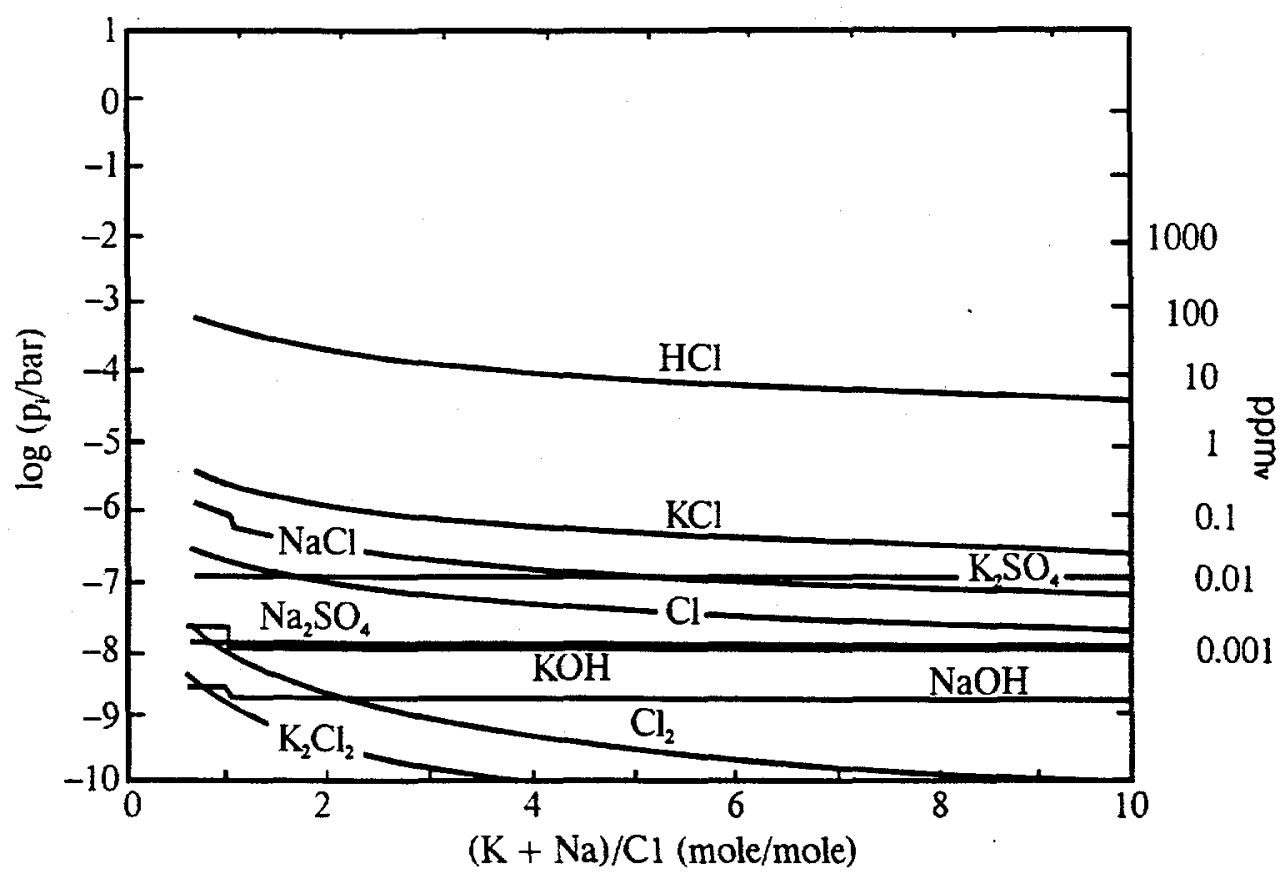

Figure 13. Variation of the partial pressure of the gaseous alkali species with $(\mathrm{Na}+\mathrm{K}) / \mathrm{Cl}$ ratio (Mojtahedi and Backman, 1989)

show a decrease of almost an order of magnitude in their concentration when the chlorine content is reduced by about $90 \%$. The total alkali $(\mathrm{Na}+\mathrm{K})$ content in the vapor phase decreases from 0.5 to $0.04 \mathrm{ppmv}$. This indicates the importance of the chlorine concentration of the fuel used in a PFBC. The flue gas composition with respect to the volatilized alkali compound (principally chlorides), the necessity to remove these compounds, and the removal mechanisms selected would depend to some extent on the type of fuel combusted, i.e., the initial chlorine and alkali content.

One of the attributes of the PFBC is the ability to remove sulfur in the bed using sulfur sorbents. The effect of sulfur removal on vapor-phase alkali concentrations is demonstrated in Figure 14. The sulfur content of the fuel was varied between 100 and $2600 \mathrm{mg} / \mathrm{kg}$, while the alkali content, chlorine content, and $\mathrm{Na} / \mathrm{K}$ ratio were maintained. The operating conditions, temperature of $850^{\circ} \mathrm{C}\left(1560^{\circ} \mathrm{F}\right)$, and pressure of 10 bar were also kept constant. The concentration of chlorides shows a steady increase with decreasing sulfur content. This is due to the fact that the percentage of condensed alkali sulfates decreases when the alkali/sulfur ratio increases, releasing more alkali to form alkali chlorides in the gas phase. The presence of condensed alkali sulfates causes the concentrations of vapor-phase alkali sulfates to be constant in the whole 


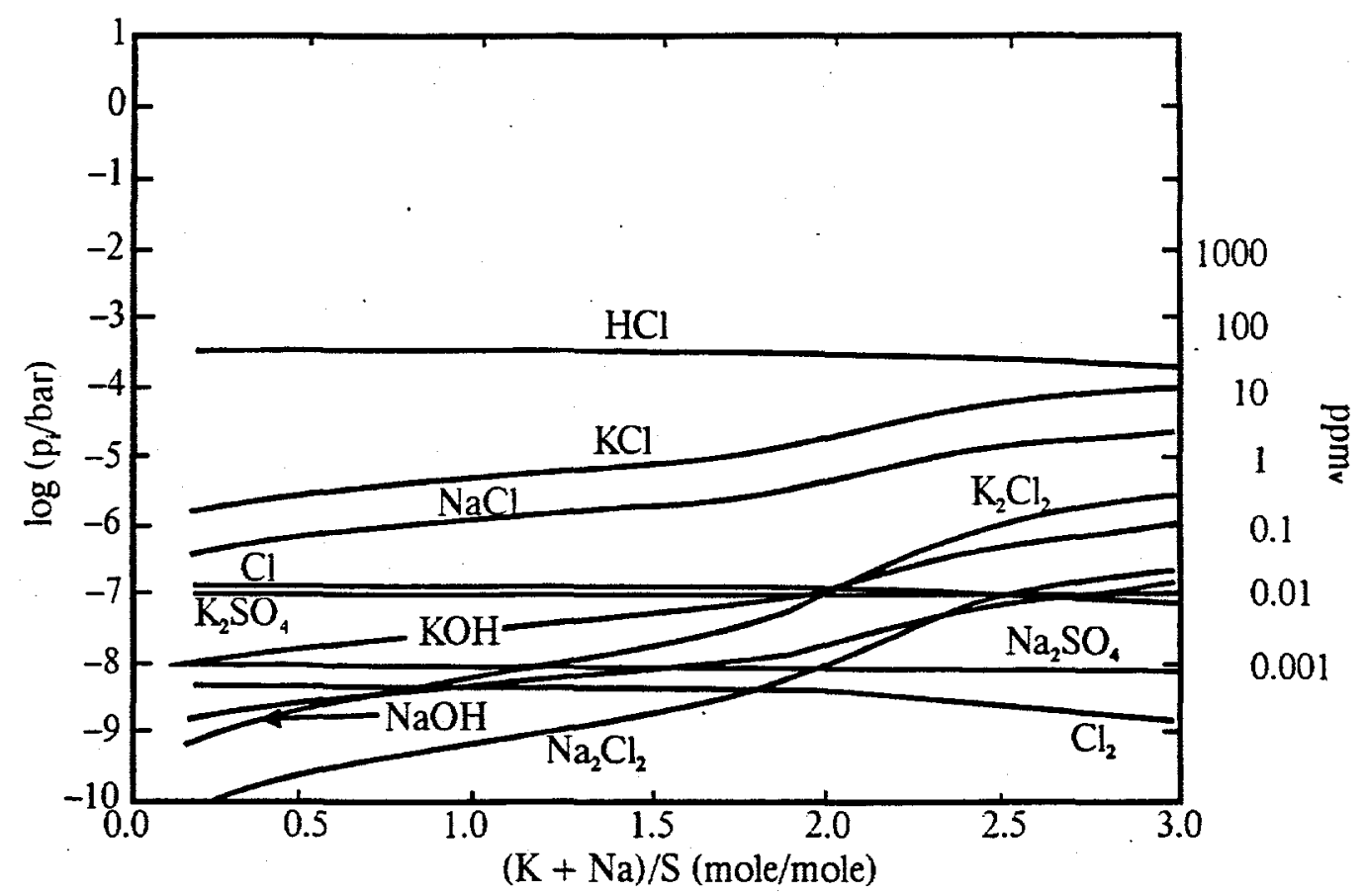

Figure 14. Variations of the partial pressure of gaseous alkali species with $(K+N A) / S$ ratio (Mojtahedi and Backman, 1989)

alkali/sulfur range considered. Use of low-sulfur fuel or an efficient sulfur removal sorbent seems to result in increased vapor-phase alkali content in the flue gas. The curves corresponding to the volatilized sulfates show no change in concentration with changing $(\mathrm{Na}+\mathrm{K}) / \mathrm{S}$ ratios.

Calculations were also performed by Mojtahedi and Backman (1989) at operating conditions corresponding to AFBC ( 1 bar). As with the pressurized case, the higher chlorine content of the fuel enhances alkali metal volatilization in the form of alkali chlorides. The effect of increasing the operating pressure of the system on the concentration of alkali metals released in the gas phase at equilibrium is shown in Figure 15. At $850^{\circ} \mathrm{C}\left(1560^{\circ} \mathrm{F}\right)$, the equilibrium concentration of sodium in the gas-phases increases from almost 0.04 to about $0.67 \mathrm{ppmv}$ when the pressure is reduced from 10 to 1 bar. Similar calculations with potassium show an increase of more than 10 -fold $(0.19$ to $2.76 \mathrm{ppmv})$ in the concentration of volatilized potassium released into the flue gas.

Sinha and others (1987) have also performed equilibrium calculations to estimate the most likely compounds and phases formed during PFBC. They used a high-sulfur eastern U.S. bituminous coal as the basis of their calculations. Figure 16 presents a summary of the calculated molar concentrations for the 


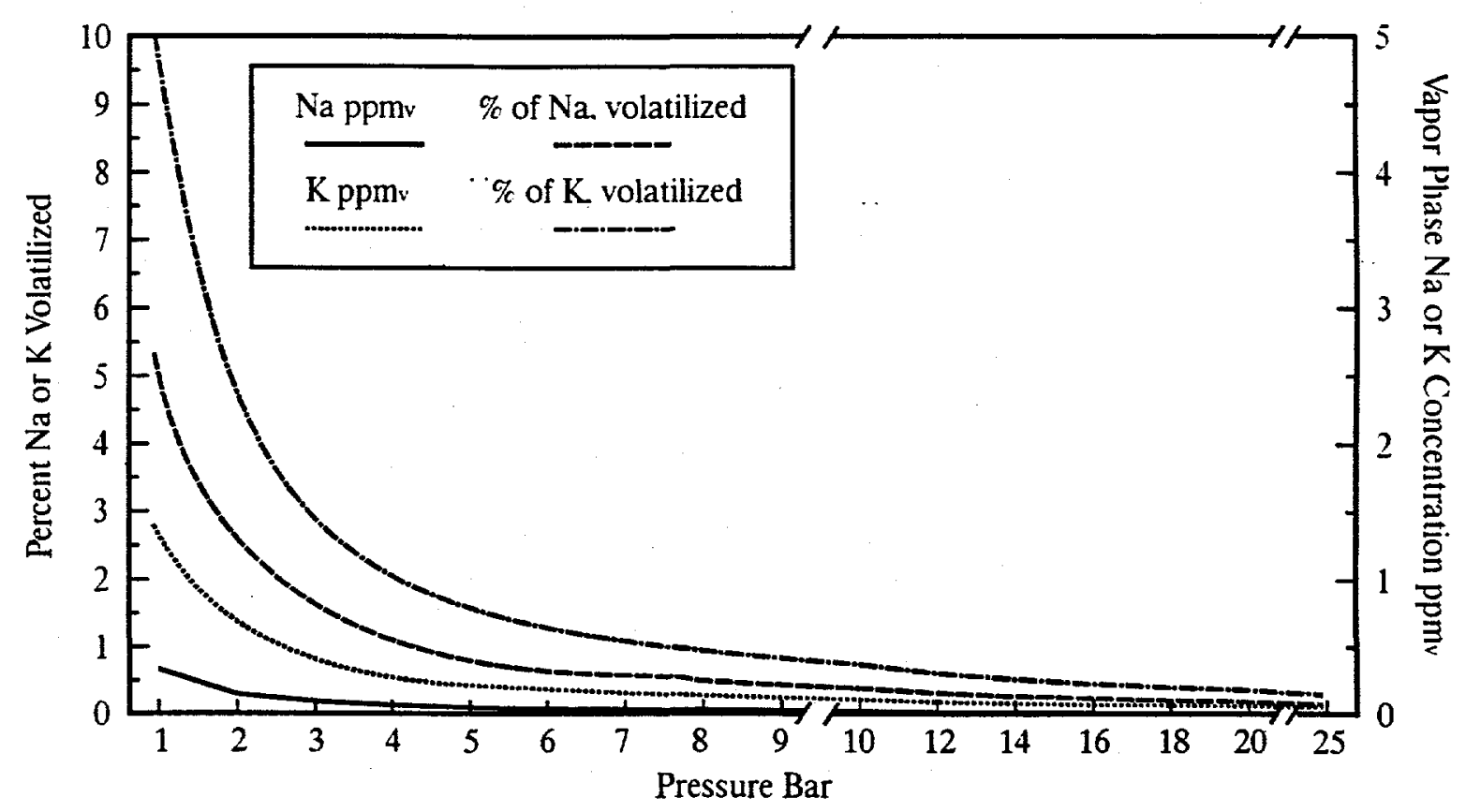

Figure 15. $\mathrm{Na}$ and $\mathrm{K}$ concentration in the vapor phase in the flue gas at 1 to 25 bar pressure range under combustion conditions (Mojtahedi and Backman, 1989)

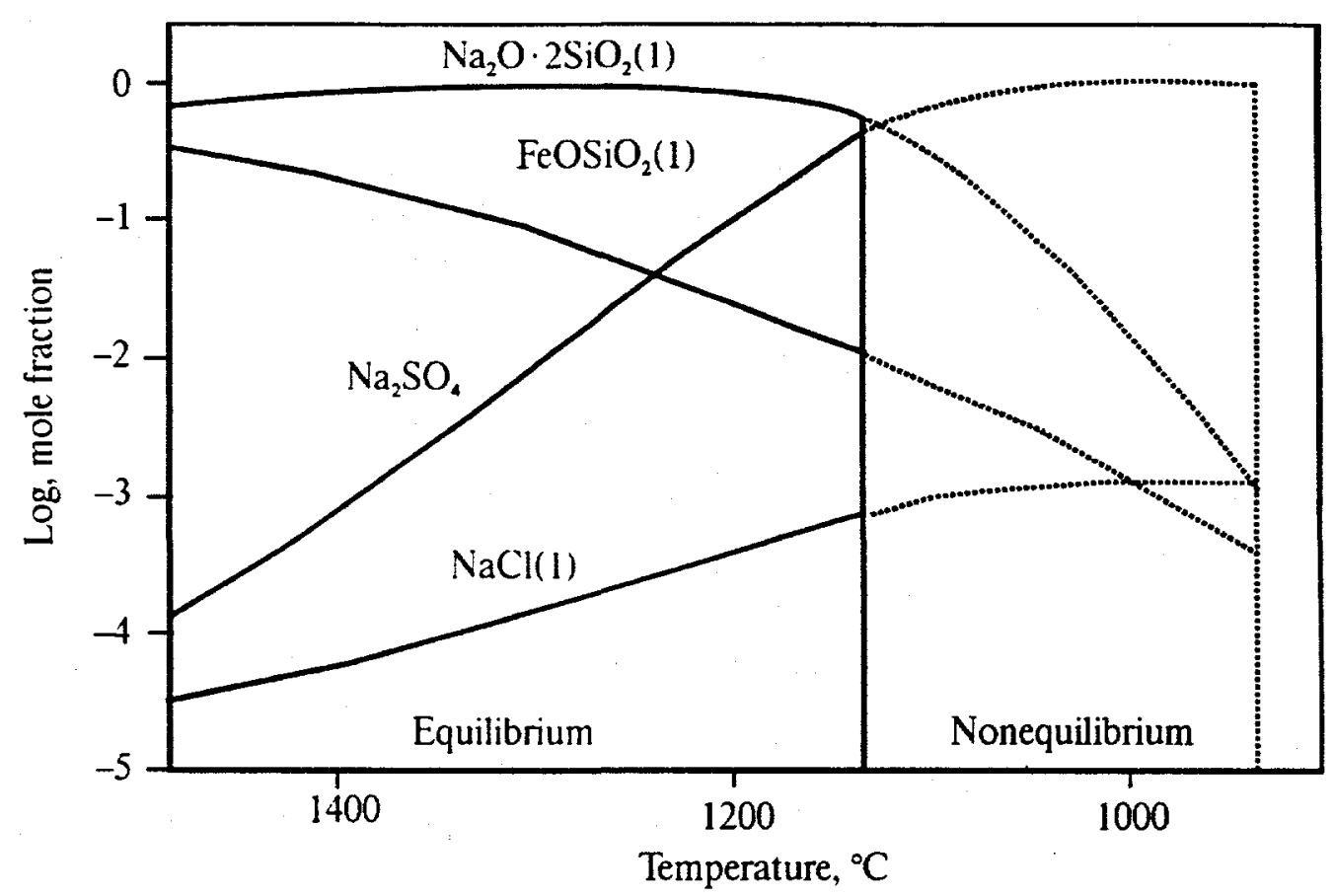

Figure 16. Composition of condensed mineral phases formed under oxidizing conditions when burning an eastern bituminous coal (Sinha et al., 1987) 
relatively large number of sodium- and nonsodium-based liquid species formed in a combustion environment. At high gas temperatures outside of the PFBC range (above $1327^{\circ} \mathrm{C}\left[2420^{\circ} \mathrm{F}\right]$ ), the equilibrium concentration of the condensed liquid species formed are dominated by the presence of $\mathrm{Na}_{2} \cdot 2 \mathrm{SiO}_{2}$ and $\mathrm{FeO} \cdot \mathrm{SiO}_{2}$ compounds. At PFBC temperatures below $977^{\circ} \mathrm{C}\left(1790^{\circ} \mathrm{F}\right)$, the condensed phases were predicted to consist mainly of $\mathrm{Na}_{2} \mathrm{SO}_{4}$. This is in agreement with the work reported by Mojtahedi and Backman (1989). However, the studies by Mulik and others (1983) and Scandrett and Clift (1984) suggest that the vapor-phase alkali chlorides may react to form alkali aluminosilicates. Some of the glassy phase aluminosilicate compounds that were predicted to exist at equilibrium conditions can only be formed by very slow reactions that rely on the intimate contact between the $\mathrm{Na}_{2} \mathrm{SO}_{4}$ liquid and an ash-based aluminosilicate phase, and these reactions are unlikely to proceed to completion in a practical system. Therefore, the liquid phase compositions which were calculated by Sinha and others (1987) at temperatures lower than $1117^{\circ} \mathrm{C}\left(2040^{\circ} \mathrm{F}\right)$ represent higher nonequilibrium concentrations of these compounds (shown as dotted lines in Figure 16).

Even though the reactions with the aluminosilicates are slow and do not proceed to equilibrium, aluminosilicate phases have been observed in PFBC fly ashes and bed material (Mann, 1994) and should be included in modeling efforts. When Sinha included the aluminosilicate phases in his modeling efforts, the $\mathrm{Na}_{2} \mathrm{SO}_{4}$ liquid phases practically disappeared at temperatures below $1117^{\circ} \mathrm{C}$. In reality, it is anticipated that the $\mathrm{Na}_{2} \mathrm{SO}_{4}$ will be the major phase, but aluminosilicates will also be present. However, within this temperature range, the sodium silicates are not expected to be formed as indicated by the results of Sinha's modeling. Vapor pressures of the chlorine compounds calculated under equilibrium and nonequilibrium conditions are reported in Figure 17 and show $\mathrm{NaCl}$ and $\mathrm{HCl}$ are the major carries of the chlorine in the system. They also show a predominance of the alkali chlorides versus the sulfates and hydroxides. These results are again similar to those of Mojtahedi and Backman (1989) and others who have performed thermochemical equilibrium calculations under PFBC or gasification conditions (Scandrett, 1983; Scandrett and Clift, 1984; Spacil and Luthra, 1982; Mulik et al., 1983; Pintsch and Gudenau, 1991b).

The thermochemical equilibria calculations of the alkali compounds show that when coals are burned in a PFBC, condensed alkali sulfates are formed in the flue gas. The alkali sulfates will most likely 


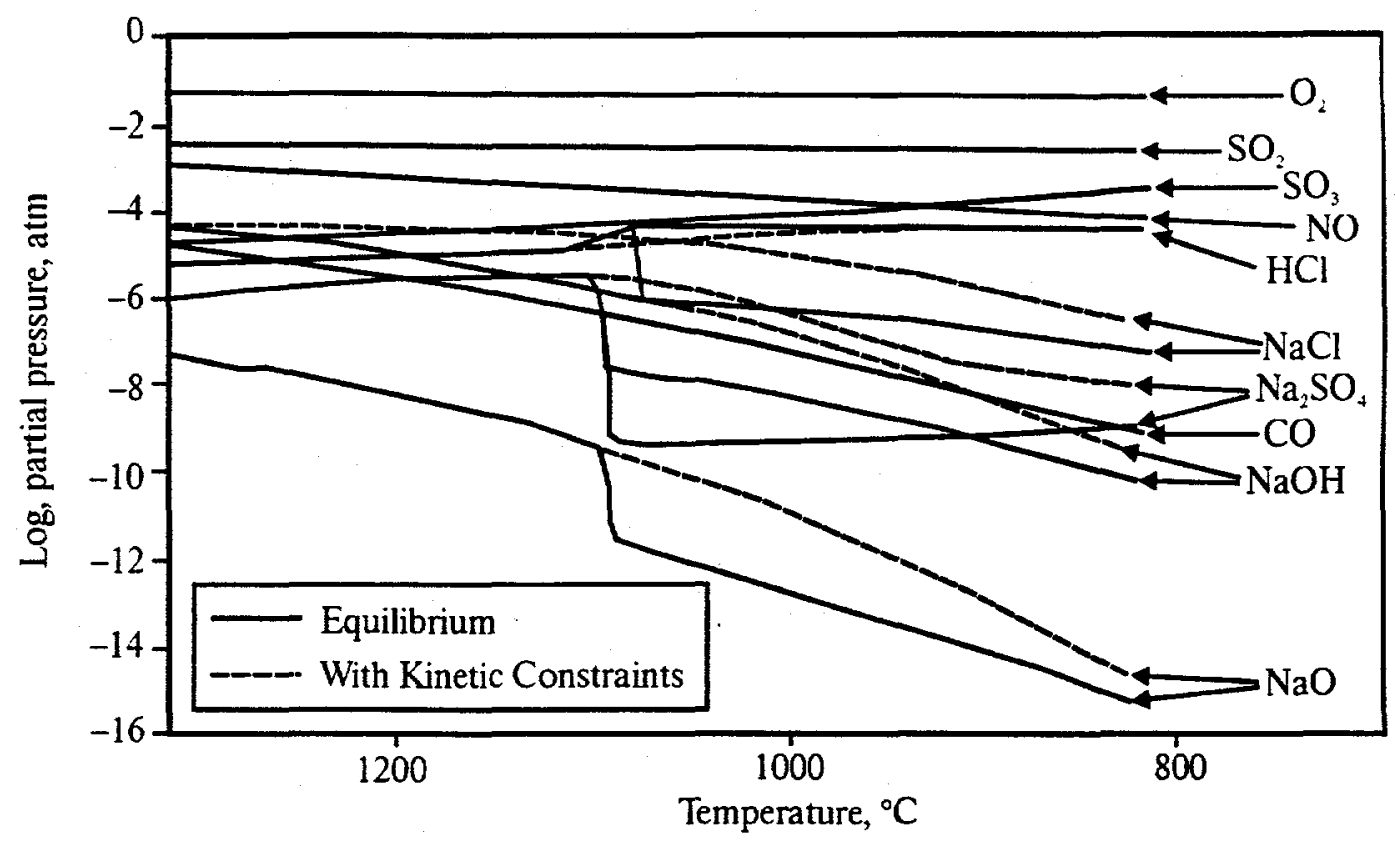

Figure 17. Partial pressures of important gaseous species formed during the combustion of an eastern bituminous coal (Singh et al., 1989)

deposit on the fly ash particles and be removed from the gas phase by filtration in a dust suppression system. Some may condense to form fine particulate that would be more difficult to collect in conventional filter devices. Alkali sulfate deposition in the fly ash would be expected to improve the cohesivity and retention properties of the PFBC fly ash and lower the sintering temperatures. The calculations also show that a substantial residual fraction of the alkalies will remain in the gas phase, primarily as alkali chlorides for higher-chlorine coals. In theory, the condensation and removal of alkali sulfates by particulate filtration alone can remove all of the alkali contaminant released when a coal is burned with negligible or zero chlorine content. However, virtually all coals have enough chlorine where particulate filters alone will not be able to remove the higher residual concentrations of the volatile alkali chlorides present in the PFBC environment, and combined alkali and chlorine removal may prove to be an essential element in effectively controlling alkalies.

\subsection{Adsorption Theory}

Removal of a vapor from a gas can be accomplished either physically by absorption in a liquid or adsorption on a solid surface or by chemical reaction. Physical adsorption, or "van der Waals" adsorption, 
a readily reversible phenomenon, is the result of intermolecular forces of attraction between molecules of the solid and the substance adsorbed. When, for example, the intermolecular attractive forces between a solid and a gas are greater than those existing between molecules of the gas itself, the gas will condense upon the surface of the solid even though its pressure may be lower than the vapor pressure corresponding to the prevailing temperature. Such a condensation will be accompanied by an evolution of heat, in an amount usually somewhat larger than the latent heat of vaporization and of the order of the heat of sublimination of the gas. The adsorbed substance does not penetrate within the crystal lattice of the solid and does not dissolve in it but remains entirely upon the surface. If, however, the solid is highly porous, containing many fine capillaries, the adsorbed substance will penetrate these interstices if it wets the solid. At equilibrium, the partial pressure of the adsorbed substance equals that of the contacting gas phase, and by lowering the pressure of the gas phase or by raising the temperature, the adsorbed gas is readily removed or desorbed in unchanged form.

Chemisorption, or activated adsorption, is the result of chemical interaction between the solid and the adsorbed substance. The strength of the chemical bond may vary considerably, and identifiable chemical compounds in the usual sense may not actually form, but the adhesive force is generally much greater than that found in physical adsorption. The heat liberated during chemisorption is usually large, of the order of the heat of chemical reaction. The process is frequently irreversible, and on desorption the original substance will often be found to have undergone a chemical change. The same substance which, under conditions of low temperature, will undergo substantially only physical adsorption upon a solid will sometimes exhibit chemisorption at higher temperatures, and both phenomena may occur at the same time.

Some of the attributes of sorbents whose primary removal mechanisms are either physical or chemical adsorption are listed in Table 6. For most parameters, the sorbent characteristics are very different depending upon its adsorption mechanism. It is critical to understand these differences to ensure selection of a sorbent with the characteristics required for use as an in-bed capturing agent. The characteristics of a good sorbent for this application include the following:

- High-temperature compatibility

- Rapid rate of adsorption 
- High loading capacity

- Transformation of alkali into a less corrosive form

- Irreversible adsorption

- Physical stability

- Solid at system temperature

- No toxicological effects

- Low cost

Table 6

Characteristics of Physical and Chemical Adsorption

\begin{tabular}{lll}
\hline Parameter & Physical Adsorption & Chemical Adsorption \\
\hline Adsorbent & All solids & Some solids \\
Adsorbate & All gases below critical temperature & Some chemically reactive gases \\
Temperature Range & Low Temperature & High Temperature \\
Heat of Adsorption & Low & High (order of heat of reaction) \\
Rate, Activation & Very rapid, Low E & Nonactivated, low E; Activated, high E \\
Coverage & Multilayer possible & Monolayer \\
Reversibility & Highly reversible & Often irreversible \\
\hline
\end{tabular}

This subsection will discuss the mechanism of adsorption theory to identify the importance of gas-solid adsorption. Subsection 2.4 will discuss aluminosilicate adsorbents to show specific attributes required for adsorption of alkali gases.

\subsubsection{Mass Transfer in Batch Operations}

The adsorption process in fluid beds is rather complex. The approach taken here is first to describe mass transfer in general for fluid-bed operations using a general rate equation for adsorption. This analogy will present some limitations on the maximum effectiveness of the FBC for removing specific vapor components from the flue gas. Following will be a discussion of the various rate-limiting steps and how each of these impacts the conversion efficiencies and residence time requirements for the adsorption process. The impact of operating parameters will also be discussed. The general theory discussed is taken from Kunii and Levenspiel, 1991. 
Figure 18 defines the system where a batch of solids is fluidized with an inert carrier gas containing dilute A of mass concentration $C_{A i}\left(\mathrm{~kg} / \mathrm{m}^{3}\right)$, which is adsorbed isothermally by the solids. Let $Q$ be the weight fraction of adsorbed vapor (adsorbate) on the solids, and let $C_{A}{ }^{*}$ be the vapor concentration of $\mathrm{A}$ in equilibrium with solids having a vapor fraction $Q$. Figure 19 shows the equilibrium relationships found by experiment for various adsorbent systems with $Q_{o}$ and $Q_{i}$ representing the weight fraction of volatiles, initially in the solids and in equilibrium with the entering gas, respectively. The $y$-axis is the amount of solute adsorbed by the solids divided by the maximum that could be adsorbed. The time required to reach zero (full adsorbance) indicates long solids residence times are required for efficient use of adsorbents in a fluid bed.

For this preliminary analysis, it is assumed that the difference in concentration of diffusing vapor between the center and surface of adsorbent particles is negligibly small except for an extremely fast change in vapor composition with the time in the bed. Also, for normal fluidizing conditions such as particle diameter, $d_{\mathrm{p}}<1 \mathrm{~mm}$ and bed depth, $L_{\mathrm{m}}>0.2$ to $0.3 \mathrm{~m}$, the exiting gas can be taken to be in equilibrium with the solids in the bed, or:

$$
C_{A e}=C_{A}^{*}
$$
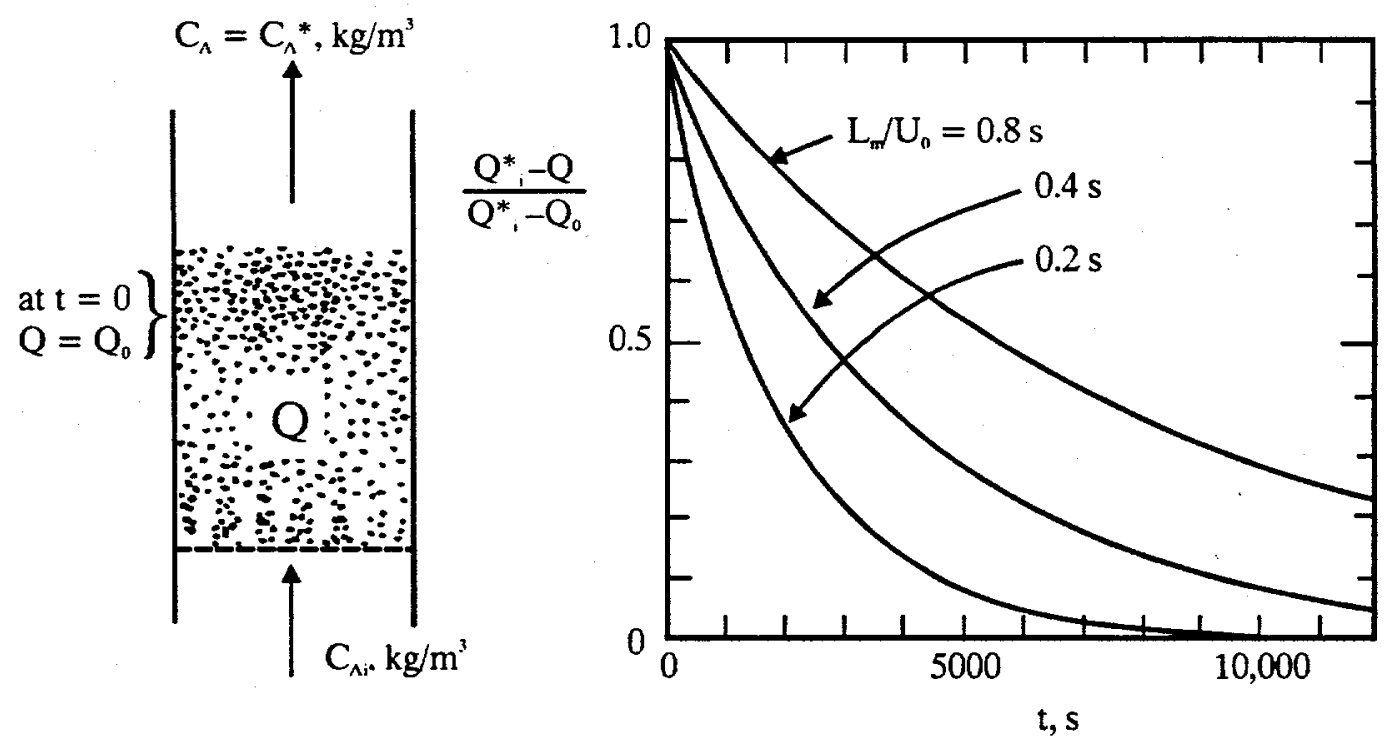

Figure 18. Adsorption of vapor by a batch of solids. The calculated lines are for theoretical adsorption of water vapor from air by activated alumina at $25^{\circ} \mathrm{C}$ 


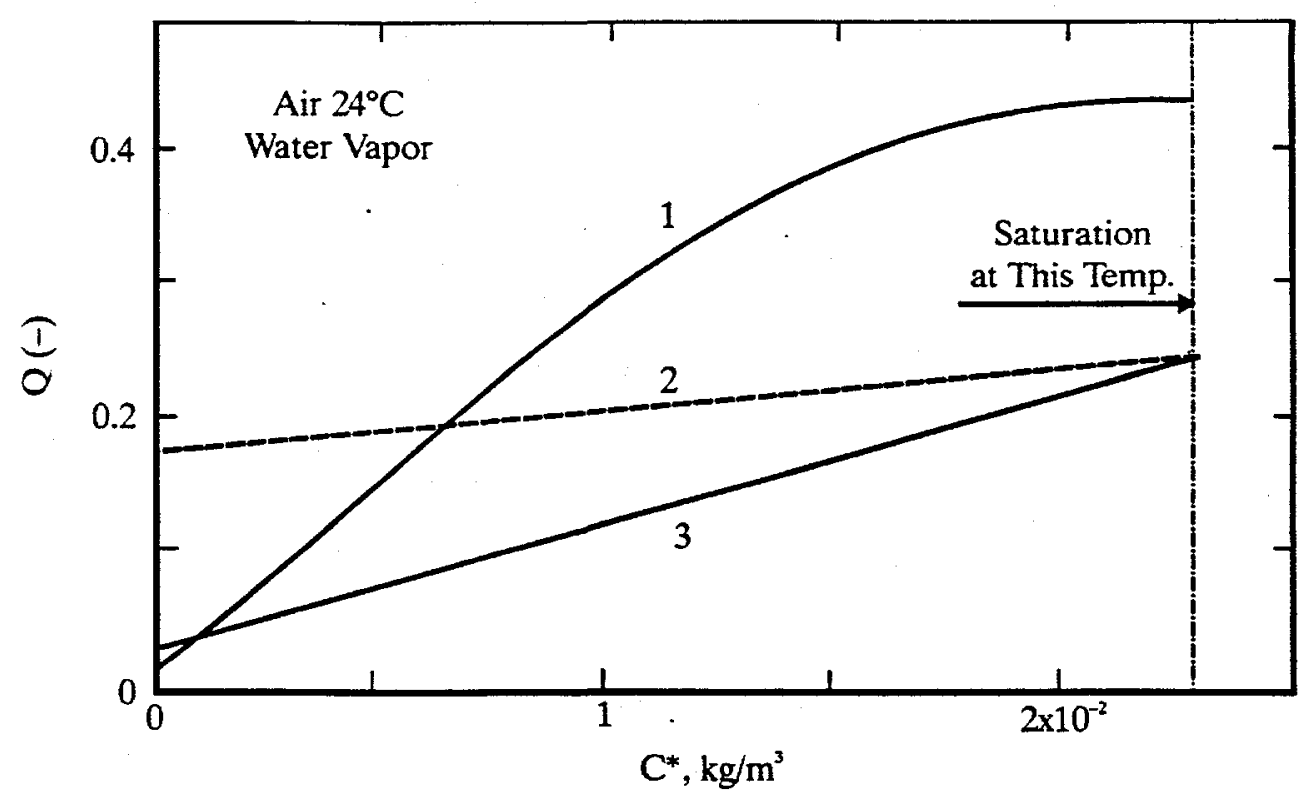

Figure 19. Examples of equilibrium isotherms between water vapor on the solid and in air, Q (kg adsorbed $/ \mathrm{kg}$ solid) for 1) silica gel, 2) molecular sieve, and 3) activated alumina

A material balance about the whole bed gives:

$$
\left(\begin{array}{c}
\text { vapor lost } \\
\text { by gas }
\end{array}\right)=\left(\begin{array}{c}
\text { vapor adsorbed } \\
\text { by solids }
\end{array}\right)
$$

From Eq. 6 this expression becomes:

$$
A_{i} u_{o}\left(C_{A_{t}}-C_{A}^{*}\right) d t=A_{l} L_{m}\left(1-\varepsilon_{m}\right) \rho_{s} d Q, \quad[k g]
$$

where $A$, is the bed cross-sectional area, $u_{o}$ is the superficial gas velocity, $\rho_{s}$ is the solids density, and $\epsilon_{m}$ is the void fraction in the bed. Separating and integrating for an initial vapor content on the solids $Q_{0}$ gives:

$$
\int_{Q_{0}}^{Q} \frac{d Q}{C_{A}-C_{A}^{*}}=\frac{u_{o} t}{\rho_{s} L_{m}\left(1-\varepsilon_{m}\right)}
$$


Given the relationship between $\mathrm{C}_{\mathrm{A}}{ }^{\circ}$ and $Q$ for the system on hand, we can then find how $Q$ changes with time. For example, for the adsorption of water vapor from air by activated alumina, as shown in Figure 19, we have approximately:

$$
C_{A}^{*}=b_{1}+b_{2} Q
$$

where $b_{1}$ and $b_{2}$ are arbitrary constants. Substituting Eq. 9 in Eq. 8 and solving gives:

$$
\frac{Q_{i}^{*}-Q}{Q_{i}^{*}-Q_{0}}=\exp \left[-\frac{b_{2} u_{0} t}{\rho_{s}\left(1-\varepsilon_{m}\right) L_{m}}\right]
$$

where $Q_{1}^{*}$ is the vapor fraction of the solid that would be in equilibrium with the incoming gas, or

$$
C_{A i}=b_{1}+b_{2} Q_{i}^{*}
$$

With $b_{2}=0.1 \mathrm{~kg} / \mathrm{m}^{3}$ and $\rho_{\mathrm{s}}=2000 \mathrm{~kg} / \mathrm{m}^{3}$, and $\mathrm{Em}=0.5$ for alumina, Eq. 10 can be written as:

$$
\frac{Q_{i}^{*}-Q}{Q_{i}^{*}-Q_{0}}=\exp \left[-\exp \frac{1 \times 10^{-4} t}{L_{m} / u_{o}}\right]
$$

Eq. 12 shows that the moisture fraction in the solids rises exponentially with time with rate proportional to gas velocity and inversely proportional to bed height. This result is presented in Figure 18 and shows that the approach to equilibrium for the solids is rather slow under normal fluidizing conditions.

For desorption of volatile matter from porous adsorbed solids, a similar analysis gives:

$$
-\int_{Q=Q_{0}}^{Q} \frac{d Q}{C_{A}^{*}-C_{A t}}=\frac{u_{o} t}{\rho_{s}\left(1-\varepsilon_{m}\right) L_{m}}
$$

With the linear equilibrium relationship of Eq. 11 , this integrates to:

$$
\frac{Q-Q_{1}^{*}}{Q_{0}-Q_{i}^{*}}=\exp \left[-\frac{b_{2} u_{o} t}{\rho_{s}\left(1-\varepsilon_{m}\right) L_{m}}\right]
$$

Again, $Q_{0}$ and $Q_{i}^{*}$ are the weight fractions of volatiles initially in the solid and in equilibrium with the entering gas, respectively. 


\subsubsection{Mass Transfer in Continuous Operations}

A similar analogy can be done for a continuous operation. This section considers only reversible mass transfer. Irreversible transfer or adsorption followed by reaction with solid will be discussed in the next subsection. A rigorous treatment of continuous operations is quite complicated; however, a great simplification can be made with the fairly good assumption, suggested from batch operations, that the bed solids are in equilibrium with the leaving gas. Thus for beds that are not too shallow, $L_{\mathrm{m}} / d_{\mathrm{p}}>100$ to 200 , assume an equilibrium operation, and take a mass balance. Referring to Figure 20 , a mass balance for the transferring vapor gives:

$$
A_{1} u_{o}\left(C_{A i}-C_{A}^{*}\right)=F_{0}\left(Q-Q_{i}\right) \quad[\mathrm{kg} \text { moisture } / \mathrm{s}]
$$

where each gas-solid system has its own particular equilibrium relationship, such as given by Eq. 11 . In general, Eqs. 11 and 15 can then be solved simultaneously and directly without integration.

Again, using the adsorption of water vapor on activated alumina for example, the relationship of bed solids and exit gas becomes:

$$
C_{A}^{*}=b_{1}+b_{2} Q
$$

For gas in equilibrium with entering solids:

$$
C_{A_{1}}^{*}=b_{1}+b_{2} Q_{1}
$$

and for solids in equilibrium with entering gas:

$$
C_{A t}=b_{1}+b_{2} Q_{1}^{*}
$$

Rearranging Eq. 15 allows the following efficiency measures to be defined:

$$
\eta_{g}^{\prime}=\left(\begin{array}{c}
\begin{array}{c}
\text { amount of solute } \\
\text { actually given up by gas }
\end{array} \\
\begin{array}{c}
\text { maximum that could } \\
\text { be given up }
\end{array}
\end{array}\right)=\frac{C_{A i}-C_{A e}}{C_{A i}-C_{A i}^{*}}=\frac{1}{1+\phi^{\prime}}
$$


and:

$$
\eta_{s}^{\prime}=\left(\begin{array}{c}
\text { amount of solute } \\
\text { adsorbed by solids } \\
\begin{array}{c}
\text { maximum that could } \\
\text { be adsorbed }
\end{array}
\end{array}\right)=\frac{Q-Q_{i}}{Q_{i}^{*}-Q_{i}}=\frac{\phi^{\prime}}{1+\phi^{\prime}}=1-\eta_{g}^{\prime}
$$

where:

$$
\phi^{\prime}=\frac{A_{t} u_{o} b_{2}}{F_{0}}
$$

These equations show that a $99 \%$ efficiency in removing solute from the gas is possible only at the expense of a $1 \%$ efficiency in the use of solids as an adsorbent. This requires using large amounts of solids and illustrates the general finding that single-stage contacting is accompanied by low efficiencies. This may be a concern for finding an economical in-bed sorbent capable of meeting the stringent turbine manufacturer guidelines.

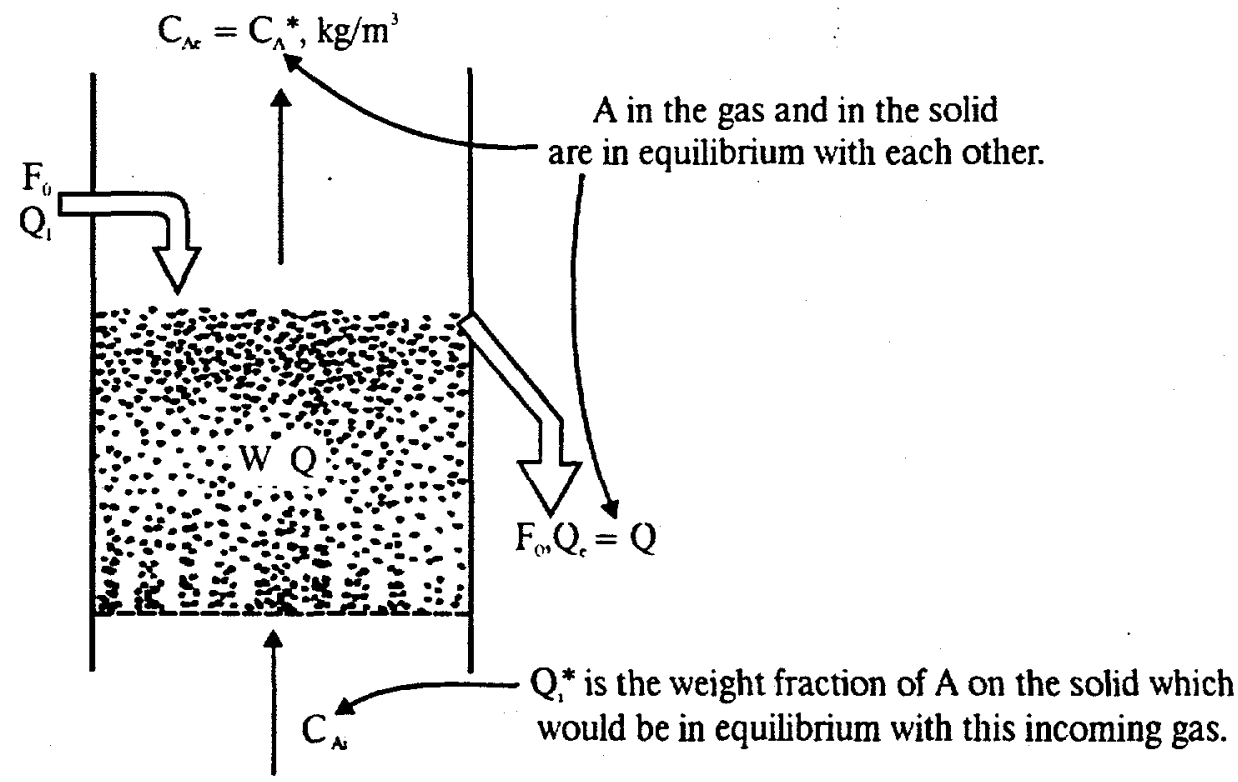

Figure 20. Continuous mass transfer operations between solids and gas in a single fluidized bed, for gas in equilibrium with entering solids 


\subsubsection{Kinetic Models for the Conversion of Solids}

The conversion of solids can follow one of two extremes of behavior. At one extreme, the diffusion of gaseous reactant into a particle is rapid enough compared to chemical reaction so that solid reactant $B$ is consumed more or less uniformly throughout the particle. This is the uniform-reaction model (Figure 21). At the other extreme, diffusion into the reactant particle is so slow that the reaction zone is restricted to a thin front that advances from the outer surface into the particle. This model is called the unreacted-or shrinking-core model (Figure 22). Real situations lie between these extremes; however, because these extremes are easy to treat, they are used to represent the real situation. The first and most important consideration to applying these models is to select the model that most closely represents reality, and only then should the detailed mechanism and the rate constants be evaluated.

\subsubsection{Uniform-Reaction Model for Porous Solids of Unchanging Size}

As shown in Figure 21, gaseous reactant A is present evenly, or close to evenly, throughout the particle and reacts with solid reactant B everywhere. Although further analysis in terms of a detailed

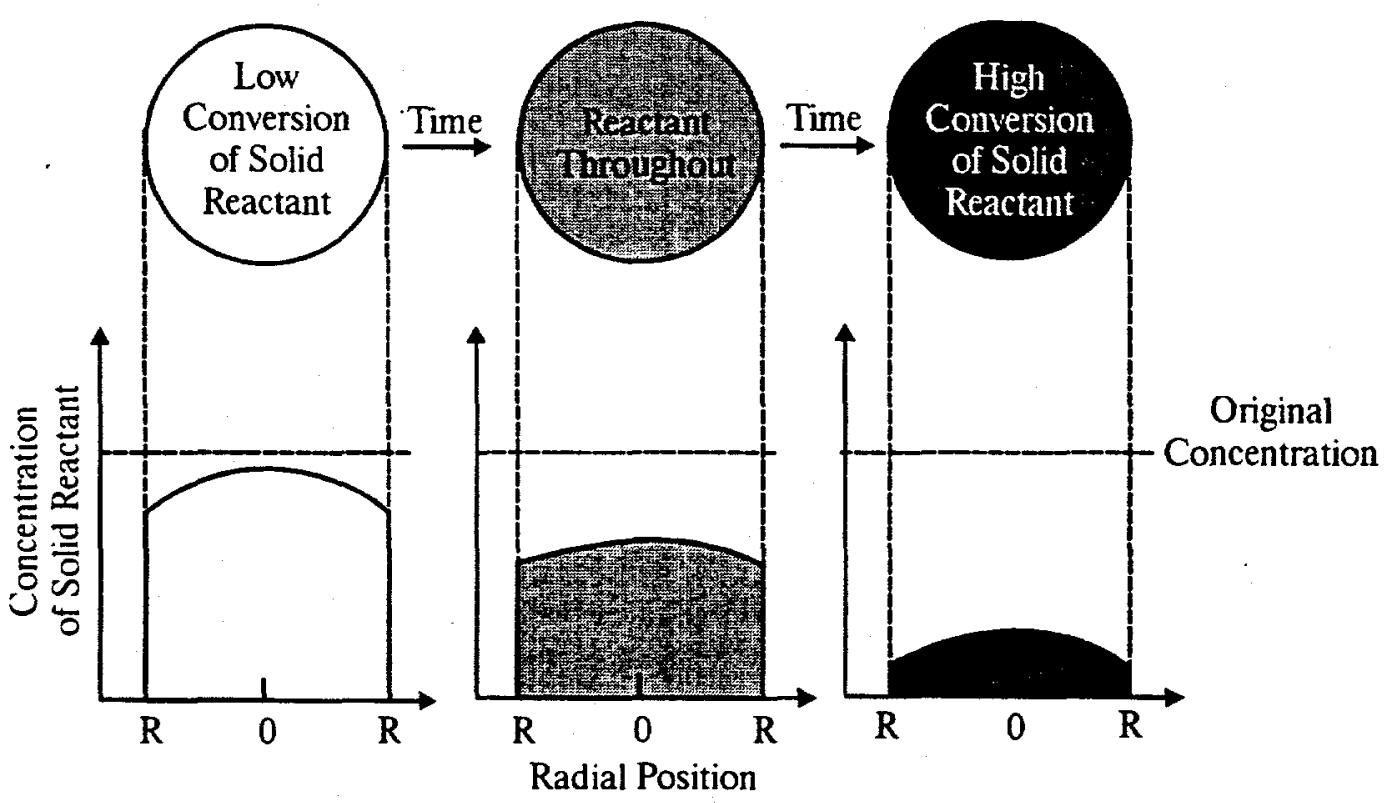

Figure 21. Uniform-reaction model. Here the reaction proceeds throughout the particle 


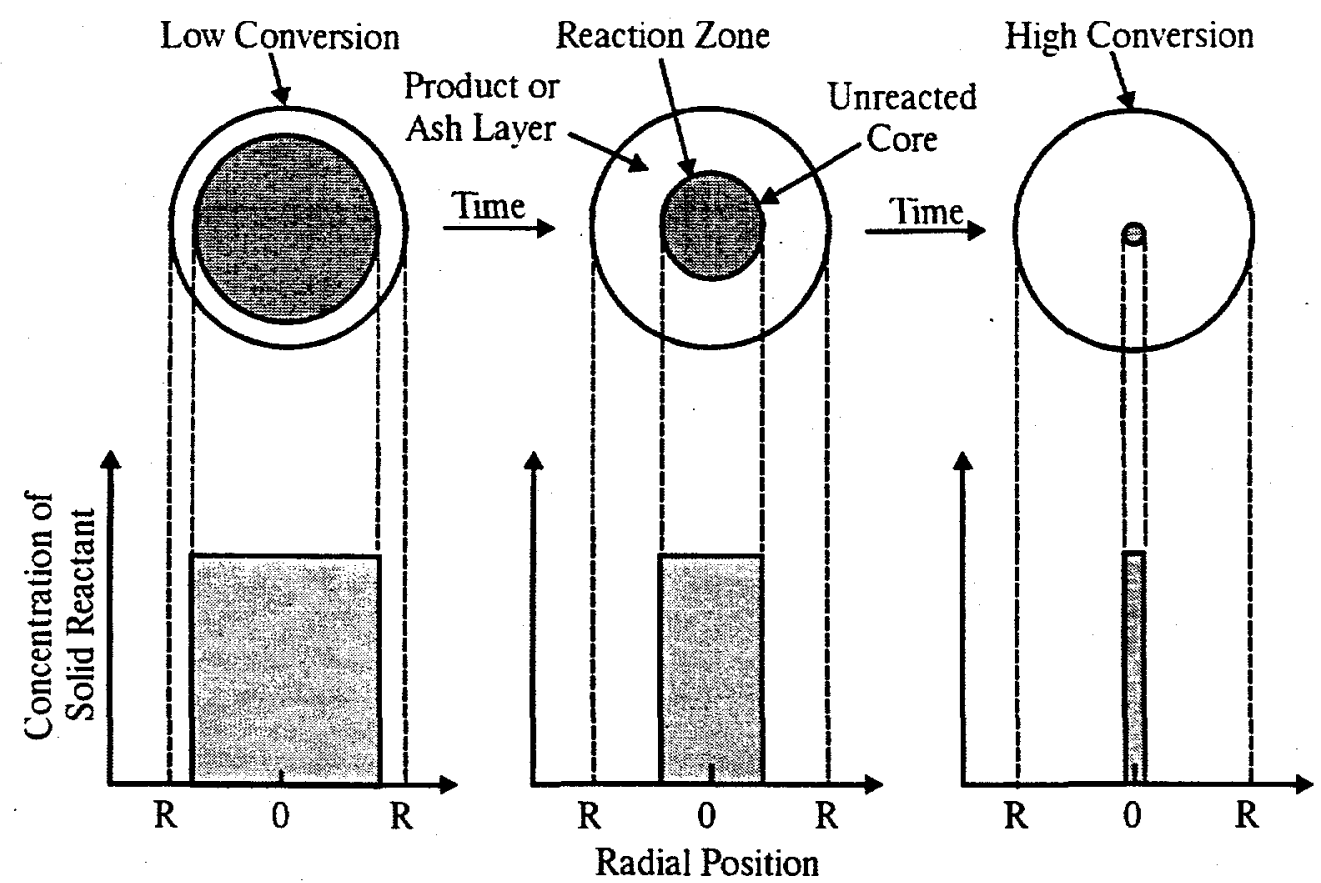

Figure 22. Shrinking-core model. Here the reaction proceeds at a narrow front that advances into the particle

mechanism may lead to a more complicated reaction rate expression, it can be assumed that

$$
\left(\begin{array}{c}
\text { rate of consumption } \\
\text { of } B
\end{array}\right) \propto\left(\begin{array}{c}
\text { concentration of } A \\
\text { bathing the particle }
\end{array}\right)\left(\begin{array}{c}
\text { amount of reactant } \\
B \text { left unreacted }
\end{array}\right)
$$

as a first approximation. In terms of the fraction of $B$ converted, $X_{8}$, and for a uniform concentration of gaseous reactant, $C_{\mathrm{A}}$, the rate expression becomes

$$
\frac{d X_{B}}{d t}=k_{r} C_{A}\left(1-X_{B}\right)
$$

Since $C_{\mathrm{A}}$ is a constant, integration gives the progress of conversion with time, or

$$
1-X_{B}=\exp \left(-k_{r} C_{A} t\right)
$$

where $k_{\mathrm{T}}\left(\mathrm{m}^{3} \mathrm{gas} / \mathrm{mol} \mathrm{A} \cdot \mathrm{s}\right)$ is the rate coefficient based on unit volume of solid. 


\subsubsection{Shrinking-Core Model for Solids of Unchanging Size}

Figure 22 shows that the reaction front advances from the outer surface into the particle leaving behind a layer of completely converted and inert material. At the same time, the core of unreacted solid shrinks and finally disappears. For a reacting particle at some intermediate stage of conversion, the following steps can occur in series:

Step 1. Gaseous A diffuses through the film surrounding the particle to its surface.

Step 2. Gaseous A penetrates and diffuses through the blanket of product solid to reach the reaction front.

Step 3. Gaseous A reacts with reactant B in the narrow reaction zone.

Step 4. Gaseous reaction products diffuse through the product layer from the reaction zone to the surface of the particle.

Step. 5 Gaseous reaction products diffuse into the main gas stream.

A reaction need not involve all these steps. For example, if no gaseous product forms, only the first three steps occur.

The kinetic expressions and integrated conversion equations are given when one of the above resistance controls. The detailed derivations of these expressions are given elsewhere (Levenspiel, 1972) and are based on the assumptions that reaction is irreversible, that particles are spherical, and that the thickness of reaction zone is small compared with the dimensions of the particle. This last assumption allows us to use the shrinking-core model. This model may reasonably represent large particles while the uniform-reaction model better represents small particles in the same environment.

Finally, the distinguishing feature of the conversion equations that follow is that they are expressed in terms of a characteristic time $\tau$, the time required to completely convert an unreacted particle into product. This differs from what usually is encountered in other areas of kinetics. This analogy was used since $\tau$ is a critical design parameter that can be used to evaluate the effectiveness of the sorbent.

Chemical Reaction Controls. Here the rate of conversion of solid is proportional to the area of reaction front. Thus for an unreacted core of radius $r_{\mathrm{c}}$ in a particle of radius $R$, the rate of reaction of $A$ can be reasonably be represented by: 


$$
-\frac{1}{4 \pi r_{c}^{2}} \frac{d N_{A}}{d t}=-\frac{1}{4 \pi r_{c}^{2} b} \frac{d N_{B}}{d t}=k_{c} C_{A}
$$

where $k_{\mathrm{c}}\left(\mathrm{m}^{3} \mathrm{gas} / \mathrm{m}^{2}\right.$ solid $\left.\cdot \mathrm{s}\right)$ is a rate constant for the chemical reaction, but is proportional to the volume fraction of $B$ in the solid.

The progress of reaction in a single particle, in terms of the core size or conversion, is:

$$
\frac{t}{\tau}=1-\frac{r_{c}}{R}=1-\left(1-X_{B}\right)^{1 / 3}
$$

where the relation between conversion and radius of shrinking core is:

$$
\left(\frac{r_{c}}{R}\right)^{3}=1-X_{B}
$$

In Eq. 25 the time for complete conversion is:

$$
\tau=\frac{\rho_{B} R}{b k_{c} C_{A}}=\frac{\rho_{B} d_{p}}{2 b k_{c} C_{A}}
$$

where $\tau$ is independent of the volume fraction of $B$ in the solid and $\rho_{B}\left(\mathrm{~mol} / \mathrm{m}^{3}\right)$ is the molar density of $B$ in the solid (Kimura et al., 1982).

Diffusion Through Gas Film Controls. This mechanism can only control in the early stages of conversion when no product layer is present. As soon as a product layer forms, its resistance dominates; consequently, for engineering applications, the resistance to diffusion through the gas film surrounding the particle can safely be ignored whenever a product layer remains on the particle.

Diffusion Through the Product Layer Controls. The direct application of Fick's law for diffusion of reactant $A$ through the product layer gives the progress of reaction with time as:

$$
\frac{t}{\tau}=1-3\left(\frac{r_{c}}{R}\right)^{2}+2\left(\frac{r_{c}}{R}\right)^{3}
$$

where $\tau$ is the time for complete conversion of a fresh particle and is given by: 


$$
\tau=\frac{\rho_{B} R^{2}}{6 b D_{s} C_{A}}=\frac{\rho_{B} d_{p}^{2}}{24 b D_{s} C_{A}}
$$

where $D_{\mathrm{s}}$ is the effective diffusivity of gaseous reactant through the product blanket and $\rho_{\mathrm{B}}$ is the molar density of $B$ in the unreacted solid.

Combination of Resistances. When the resistances of the chemical reaction and diffusion steps are comparable, we can approximately represent the overall progress of the reactions by Eqs. 24 and 27 , where the reaction rate constant $k_{\mathrm{c}}$ is replaced by $\bar{K}$, defined by:

$$
\frac{1}{\bar{k}} \cong \frac{1}{k_{c}}+\frac{d_{p}}{12 D_{s}}, \quad\left[\mathrm{~m}^{2} \text { solid } \cdot \mathrm{s} / \mathrm{m}^{3} \mathrm{gas}\right]
$$

For completely porous spherical particles, we can define a Thiele-type modulus:

$$
M_{T}=R \sqrt{\frac{K_{r}}{D_{s}}} \quad \text { with } \quad K_{r}=\frac{\left(3 \text { to } \frac{1}{3}\right) k_{c}}{R}=\frac{K_{r} \times \rho_{B}}{b} \quad\left[\mathrm{~m}^{3} \mathrm{gas} / \mathrm{m}^{3} \text { solid } \mathrm{s}\right]
$$

to represent the relative rates of diffusion of $A$ into the particle and the reaction of $A$ in the particle. Then, as shown by Kimura, 1981):

When $M_{\mathrm{T}} \leq 1$, gaseous reactant $A$ can easily penetrate the particle and is close to evenly distributed therein, thus the uniform-conversion model of Eq. 23 applies.

When $M_{\mathrm{T}}>20$, the progression of reaction of the particle follows the shrinking-core model with diffusion through the product layer controlling, as given by Eq. 29 .

\subsubsection{Intermediate Models for Particles of Unchanging Size}

Numerous models have been developed to account for particle behavior between the extremes of the uniform-conversion and the shrinking-core models. These intermediate models fall into two classes: those for porous particles and those for particles that start as nonporous but then become porous on reaction. For porous particles, the porous-pellet model of Ishida and Wen (1968) and the grain model of Sohn and Szekely (1972) are applicable. The conversion-versus-time curves for these models are closely 
similar to the curves for the shrinking-core model-high rate of conversion at the beginning, slowing progressively as conversion rises. For particles that start as nonporous, we have the crackling-core model of Park and Levenspeil (1975). By action of reactant gas, the pellet transforms progressively from the outside in, by crackling and fissuring, to form an easily penetrated (no diffusional resistance) porous structure consisting of grain material that then reacts away to the final product according to the shrinkingcore model. Of special interest is that this model can account for the sometimes observed S-shaped conversion-versus-time curves-thus, slow conversion at the start, then fast, and finally slow.

Finally, in any particular reacting system, the controlling resistance not only may shift from diffusion to reaction, but it may even change from the shrinking-core model to the uniform-reaction model as particle size and temperature of operations are changed.

\subsubsection{Applying the Models to a Dynamic System}

In a real fluid bed, there is a constant feed rate of both solids and gas. Figure 23 represents a simple system where the particles are of uniform size and there is no carryover of material from the fluid bed.

The conversion $X_{\mathrm{B}}$ of an individual particle of solid depends on its length of stay in the bed. For the appropriate controlling resistance, this conversion is given by Eq. 23,25 , or 29 . However, the individual particles have different residence times in the bed. For this reason, the conversion level varies from particle to particle, and on accounting for this, the mean conversion of the exit stream of solids $\bar{X}_{B}$ is:

$$
\left(\begin{array}{c}
\text { fraction of } B \\
\text { unconverted in } \\
\text { the leaving solids }
\end{array}\right)=\sum_{\text {particles }}\left(\begin{array}{c}
\text { fraction of } B \\
\text { onconverted in } \\
\text { particles staying } \\
\text { in the reactor } \\
\text { for time between } \\
t \text { and } t+d t
\end{array}\right)\left(\begin{array}{c}
\text { fraction of exit } \\
\text { stream that stays } \\
\text { this length of time } \\
\text { in the reactor }
\end{array}\right)
$$

In symbols:

$$
1-\bar{X}_{B}=\int_{t=0}^{\infty}\left(1-X_{B}\right)_{\text {particle }} E(t) d t
$$


where the exit age distribution for the solids in a single fluidized bed is:

$$
E(t)=\frac{1}{\bar{t}} e^{-t / \bar{t}}
$$

and where the mean residence time of these solids is:

$$
\bar{t}=\frac{W}{F_{1}}
$$

This allows us to give the conversion expressions for a fluidized bed for the various controlling resistances. For the uniform-reaction model and first-order reaction with respect to the reactant gas, substitution of Eqs. 23 and 33 in Eq. 32 gives:

$$
1-\bar{X}_{B}=\int_{t=0}^{\infty} \exp \left(-k_{r} C_{A} t\right) \frac{e^{-t / \bar{t}}}{\bar{t}} d t=\frac{1}{1+k_{r} C_{A} \bar{t}}
$$

For shrinking-core reaction-controlling kinetics, substitution of Eqs. 25 and 33 in Eq. 32 gives

$$
1-\bar{X}_{B}=\int_{0}^{\tau}\left(1-\frac{t}{\tau}\right)^{3} \frac{e^{-s / \bar{t}}}{\bar{t}} d t
$$

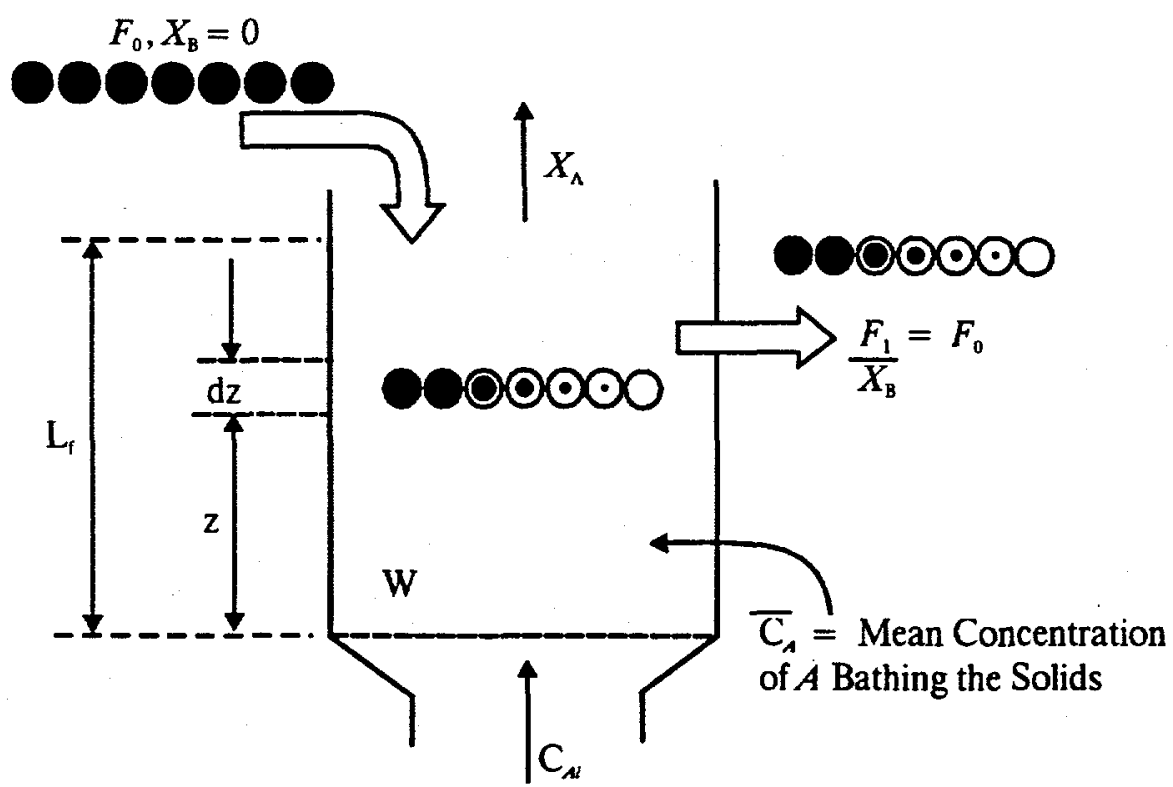

Figure 23. Variables for a fluidized-bed reactor treating particles of uniform size using the shrinking-core model 
The range of integration is from 0 to $\tau$ rather than from 0 to $\infty$, because a particle that stays in the bed longer than time $\tau$ does not contribute to $1-\bar{X}_{\mathrm{B}}$. Integrating this expression gives:

$$
1-\bar{X}_{B}=1-3\left(\frac{\bar{t}}{\tau}\right)+6\left(\frac{\bar{t}}{\tau}\right)^{2}-6\left(\frac{\bar{t}}{\tau}\right)^{3}\left(1-\bar{e}^{\tau / \tau}\right)
$$

or, in equivalent expanded form, useful for $\bar{t} / \tau>1$ :

$$
1-\bar{X}_{B}=\frac{1}{4}\left(\frac{\tau}{\bar{t}}\right)-\frac{1}{20}\left(\frac{\tau}{\bar{t}}\right)^{2}+\frac{1}{120}\left(\frac{\tau}{\bar{t}}\right)^{3}-\cdots
$$

or for $\bar{t} / \tau>5$

$$
1-\bar{X}_{B} \cong \frac{1}{4} \frac{\tau}{\bar{t}}
$$

In all these expressions, $\tau$ is given by Eq. 27 .

For shrinking-core diffusion in product-layer-controlling kinetics, replacing Eq. 29 in Eq. 32 and integrating gives an expression that, on expansion, reduces to:

$$
1-X_{B}=\frac{1}{5}\left(\frac{\tau}{\bar{t}}\right)-\frac{19}{420}\left(\frac{\tau}{\bar{t}}\right)^{2}+\frac{41}{4620}\left(\frac{\tau}{\bar{t}}\right)^{3}-0.00149\left(\frac{\tau}{\bar{t}}\right)^{4}+\cdots
$$

Again, for high conversions, or where $\bar{t} / \tau>5$ :

$$
1-\bar{X}_{B} \cong \frac{1}{5}\left(\frac{\tau}{\bar{t}}\right)
$$

In these expressions $\tau$ is given by Eq. 29 .

\subsubsection{Conversion of Both Gas and Solids}

Until now, it has been assumed that the reacting solids are bathed by gas of the same mean composition, no matter what changes are made in the operating conditions. Often this approximation is reasonable, such as when reaction is slow and the concentration of gaseous reactant does not change much in passing through the bed. In this case, the conversion equations given so far can reasonably be expected to apply. This assumption also applies when solids are transformed into product without the action of gaseous reactant, such as in the calcination of limestone. 
In the general case, however, the mean gas-phase driving force in the bed is a variable that changes with operating conditions. For example, if the feed rate of solid is lowered, then the concentration of gaseous reactant in the bed rises. Thus the conversion of solid and the concentration of gaseous reactant leaving and within the bed are interdependent, and a proper analysis of the bed behavior requires accounting for both these changes. This can be dealt with by a three-step calculation that is applicable to solids of constant size and of changing size:

Step 1: Conversion of gas. Write expressions for the conversion of gaseous reactant $A$ in terms of a mean first-order reaction rate constant $\overline{K_{T}}$, and for the mean concentration of $A$ encountered by the bed solids.

Step 2: Conversion of solids. Write an expression for the conversion of $B$ in the particles that are bathed by gas of mean composition $\overline{C_{\mathrm{A}}}$. This would be one of the models developed for particles of constant size or of changing size.

Step 3: Overall material balance. Then relate the conversion of gaseous reactant $A$ with that of solid reactant $B$.

As examples of the calculation procedure, the equations for the reactions of small and large sorbent particles in a bed of large particles is given. This analogy is chosen since it represents the expected conditions in a PFBC.

2.3.4.2 Performance Calculations for the Large-Particle Bed

Figure 23 illustrates the situation when large sorbent particles are used. The three-step procedure is outlined below.

Step 1. Assume a first-order reaction for the disappearance of $A$ :

$$
-\frac{1}{V_{\text {solid }}} \frac{d N_{A}}{d t}=\bar{K}_{r} C_{A}
$$

where $\overline{K_{\zeta}}$ is the mean value of the rate constant for the reaction of $A$ with all the solids in the bed, some fresh, others highly converted. This constant depends, in general, on the extent of conversion of the solids in the bed. Kunii and Levenspiel (1991) have developed the equations that can be used for the large 
particle conversion expressions. The conversion of gaseous reactant $A$ leaving the reactor utilizing these expressions becomes:

$$
X_{A}=1-\exp \left[-\bar{K}_{r} \frac{L_{m f}\left(1-\varepsilon_{m f}\right) u_{m f}(1-\delta)}{u_{o}^{2}}\right] .
$$

where $u_{m f}$ is the minimum fluidization velocity and $\delta$ is the fraction of bubbles in the bed.

In addition, the mean concentration of $A$ which bathes the solids must be calculated. Since the gas passes in a combination of bypass and plug flow through the bed in this flow regime, we can write, with Eq. 43:

$$
\begin{aligned}
\bar{C}_{A} & =\frac{1}{L_{f}} \int_{0}^{L_{f}} C_{A}(z) d z=\frac{1}{L_{f}} \int_{0}^{L_{f}} C_{A i} \exp \left[-\bar{K}_{r} \frac{L_{m f}\left(1-\varepsilon_{m f}\right) u_{m f}(1-\delta)}{u_{o}^{2}}\right] d z \\
& =\frac{C_{A} X_{A} u_{o}^{2}}{\bar{K}_{r} L_{m f}\left(1-\varepsilon_{m f}\right) u_{m f}(1-\delta)}=\frac{C_{A r} X_{A}}{\bar{K}_{r} \pi} \frac{u_{o}}{u_{m f}(1-\delta)}
\end{aligned}
$$

Step 2. For the shrinking-core model with diffusion through the ash layer controlling (for example) and one size of particle, we write:

$$
\bar{X}_{B}=1-\frac{1}{5} \frac{\tau}{t}+\frac{19}{420}\left(\frac{\tau}{t}\right)^{2}-\cdots
$$

where, in the $\overline{C_{\mathrm{A}}}$ environment:

$$
\tau=\frac{\rho_{B} d_{p}^{2}}{24 b D_{s} \bar{C}_{A}}
$$

Step 3. Here:

$$
\left(\begin{array}{c}
\text { disappearance } \\
\text { of } \mathrm{B} \text { from solids } \\
(\mathrm{mol} / \mathrm{s})
\end{array}\right)=\mathrm{b}\left(\begin{array}{c}
\text { disappearance } \\
\text { of } \mathrm{A} \text { from gas } \\
(\mathrm{mol} / \mathrm{s})
\end{array}\right)
$$

With $M_{\mathrm{B}}$ as the molecular weight of $B$ and $F_{\mathrm{o}}(\mathrm{kg} / \mathrm{s})$ as the feed rate of $B$ to the reactor, Eq. 47 becomes: 


$$
\left(\frac{F_{0}}{M_{B}}\right) \bar{X}_{B}=b\left(A_{t} u_{0} C_{A} X_{A}\right)
$$

\subsubsection{Performance Calculations for the Fine-Particle Bed}

When a small sorbent particle is used, the kinetic limiting model for gas and the uniform-reaction model for solids are likely to apply. Hence, the three-step procedure is as follows.

Step 1. Using the mean value of the first-order reaction rate constant $\bar{K}$ (as done previously) we have:

$$
X_{A}=1-\exp \left[-K_{f} \frac{\delta L_{f}}{U-o}\right]
$$

where:

$$
K_{f}=\left[\gamma_{b} \bar{K}_{r}+\frac{1}{\frac{1}{K_{b c}}+\frac{1}{\gamma_{c} \bar{K}_{r}+\frac{1}{\frac{1}{K_{c e}}+\frac{1}{\gamma_{e} \bar{K}_{r}}}}}\right]
$$

In addition, the mean concentration of $A$ bathing the solids can be expressed by the simple plug flow expression (Kunii and Levenspiel, 1991):

$$
\bar{C}_{A}=\frac{C_{A} X_{A} u_{o}}{\bar{K}_{r} L_{m f}\left(1-\varepsilon_{m f}\right)}=\frac{C_{A r} X_{A}}{K_{r} \tau}
$$

This type of expression results because gaseous reactant reacts away by a first-order reaction.

Step 2. Applying the uniform-reaction model, we have for the conversion of solids:

$$
\bar{X}_{B}=1-\frac{1}{1+k_{r} \bar{C}_{A} W / F_{0}}
$$

For the shrinking-core models, $\overline{X_{8}}$ is given by Eqs. $37-41$. Eqs. 38 and 40 can reasonably be approximated by Eq. 35 whenever $\overline{X_{8}}>0.80$.

Step 3. Here Eq. 48 applies. 


\subsubsection{Model Implications}

The models developed in this section provide the design equations for an adsorption system in a fluid bed. It also provides the relationships necessary to qualitatively assess the impacts of changing sorbent size and type as well as operating conditions on the sorbent efficiency. This last section will perform such an assessment for the three models: the uniform reactant model, the kinetically controlled shrinking-core model, and the diffusion-controlled shrinking-core model.

The uniform reactant model is represented by Eq. 35 as:

$$
1-\bar{X}_{B}=\int_{t=0}^{\infty} \exp \left(-k_{r} C_{A} t\right) \frac{e^{-t / \bar{t}}}{\bar{t}} d t=\frac{1}{1+k_{r} C_{A} \bar{t}}
$$

Since we are interested in reducing the concentration of the alkali vapor to a low level rather than maximizing conversion of the sorbent, this equation is rewritten as:

$$
C_{A}=\left(\frac{1}{\left(1-\bar{X}_{B}\right)}-1\right)\left(\frac{1}{k_{r}}\right)
$$

From this relationship, it is easily seen that the outlet vapor concentration is proportional to $\left[1 /\left(1-X_{B}\right)-1\right]$. This relationship is shown generally in Figures 24 and 25 . It becomes obvious that to obtain a reasonably low concentration of the vapor-phase alkali, a relatively large excess of sorbent will be required. It is also seen from Eq. 53 that the alkali vapor concentration will be inversely proportional to the rate constant. Therefore, the capture efficiency of the sorbent will be temperature-dependent, with that dependency a function of whether the reaction is endothermic or exothermic.

In examining the shrinking-core model where the kinetic reaction rate is limiting, the conversion of the adsorbent is given by Eq. 39 as:

$$
1-\bar{X}_{B} \cong \frac{1}{4} \frac{\tau}{\bar{t}}
$$

where $\tau$ was defined in Eq. 27 as: 


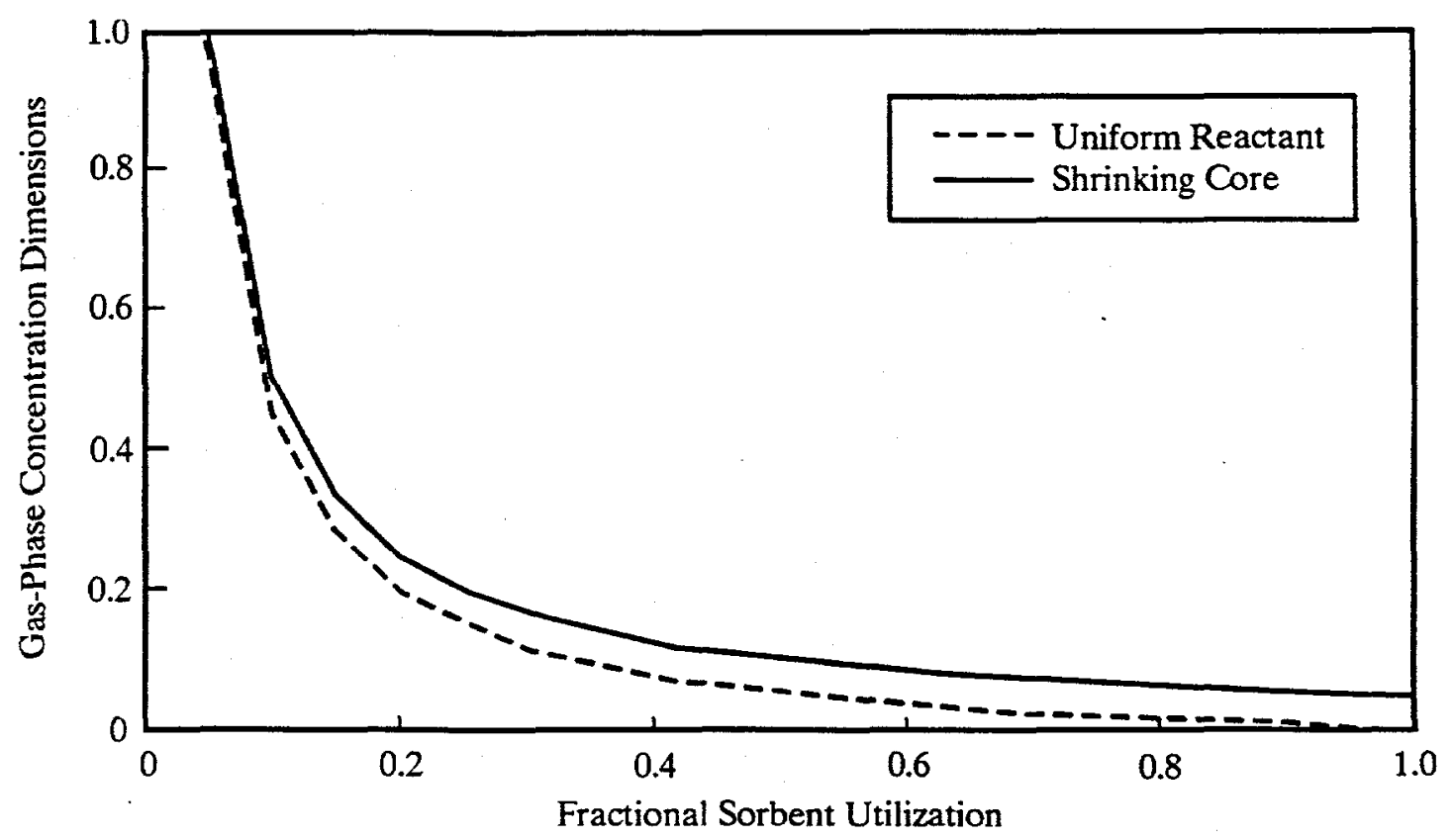

Figure 24. Relationship between alkali content and the percent utilization of the sorbent particle

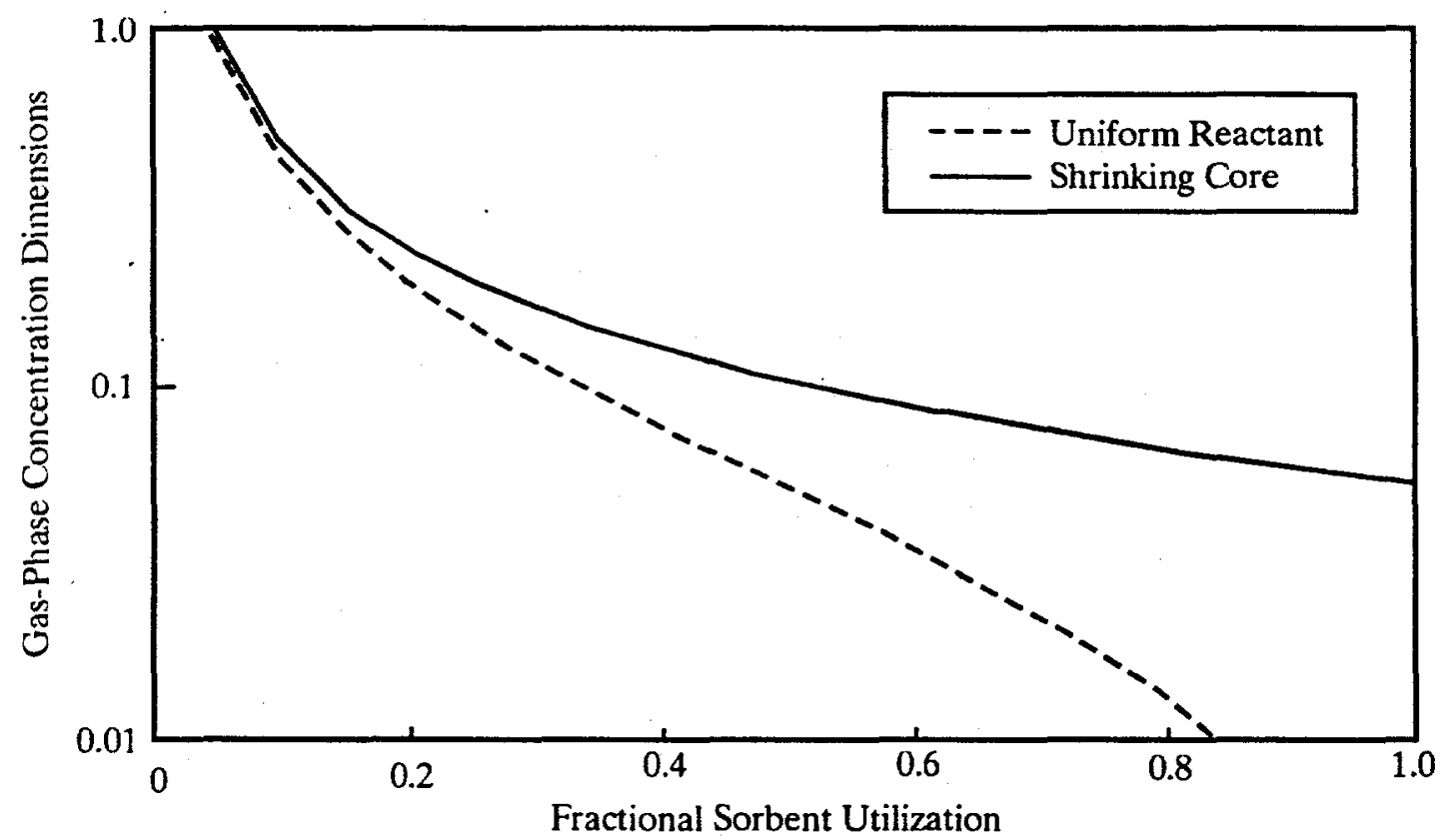

Figure 25. Relationship between alkali content and the percent utilization of the sorbent particle plotted on a log scale 


$$
\tau=\frac{\rho_{B} R}{b k_{c} C_{A}}=\frac{\rho_{B} d_{p}}{2 b k_{c} C_{A}}
$$

Inserting Eq. 27 into Eq. 29, the expression becomes:

$$
1-\bar{X}_{B}=\frac{d_{p}}{4 k_{c} C_{A} t}
$$

This can be rewritten as a function of the outlet adsorbate concentration as:

$$
C_{A}=\frac{d_{p}}{4 k_{c} t(1-\bar{X})}
$$

The following conclusions can be made from this relationship. For a shrinking-core model where kinetics are the rate-limiting step, the outlet alkali vapor concentration will be directly proportional to the particle size of the adsorbent and inversely proportional to the rate constant. This provides a clear indication of the importance of sorbent particle size and the need to find an optimal size to maximize alkali capture (small particle) while being large enough not to be blown from the bed after only a short residence time. The form of the rate constant will dictate the impact of temperature on the conversion efficiency of the adsorbent and the relative outlet alkali concentration.

The shrinking-core model also shows that the outlet vapor phase concentration is inversely proportional to the conversion of the adsorbent $\left(1-X_{B}\right)$. This relationship is shown graphically in Figures 24 and 25. As is the case with the uniform reactant model, it is not practical to achieve low outlet vapor concentrations while simultaneously achieving high adsorbent conversions. A comparison of the shapes of the curves for the uniform reactant and shrinking core also shows a more rapid decrease in adsorbent efficiency with decreasing outlet vapor concentration. Therefore, when the shrinking-core model is applicable, which is most likely the applicable model for the alkali vapor system being considered as a part of this research, even lower conversion efficiencies of the adsorbent can be expected to achieve a target outlet alkali vapor concentration.

When the shrinking-core model is diffusion-limited, the relationships shown in Eqs. 41 and 29 govern the behavior: 


$$
\begin{gathered}
1-\bar{X}_{B} \cong \frac{1}{5}\left(\frac{\tau}{\bar{t}}\right) \\
\tau=\frac{\rho_{B} R^{2}}{6 b D_{s} C_{A}}=\frac{\rho_{B} d_{p}^{2}}{24 b D_{s} C_{A}}
\end{gathered}
$$

These can be combined to represent the conversion of the adsorbent as a function of the adsorbate concentration as follows:

$$
1-\bar{X}_{B}=\frac{d_{p}^{2}}{5 D_{s} C_{A}}
$$

This relationship shows that the outlet alkali vapor concentration when limited by diffusion is given by:

$$
C_{A}=\frac{d_{p}^{2}}{5 D_{s}\left(1-\bar{X}_{B}\right)}
$$

The diffusion coefficient generally takes the form of:

$$
D_{s}=\frac{a T^{b}}{p}
$$

where $\mathrm{a}$ and $\mathrm{b}$ are constants depending upon properties of the adsorbent. From this it is seen that the outlet alkali concentration is proportional to adsorbent particle size, temperature, pressure, and adsorbent conversion by the following relationship:

$$
C_{A}=\frac{d_{p}^{2} p}{5 a T^{b}\left(1-\bar{X}_{B}\right)}
$$

A look at this relationship shows that the particle size of the sorbent now becomes very important for minimizing the outlet alkali concentration. Extremely poor conversions of the sorbent would be expected for larger particle sizes. The equation given in Eq. 57 shows an inverse relationship between outlet alkali concentration and diffusivity as expected. Therefore, any changes that effectively increase the diffusivity 
will have the desired effect of reducing the outlet alkali vapor concentration. From Eqs. 58 and 59, it can be seen that increasing the system temperature and decreasing the system pressure would increase the overall efficiency of alkali capture. It should be noted that increasing the temperature and decreasing the pressure will also result in more alkali vapor being generated from the combustion of the coal. Therefore, even though the collection efficiency of the sorbent will improve, it is probably the outlet concentration of the alkali vapors will increase with this change in operating variables.

\subsection{Mechanisms of Capture using Aluminosilicates}

Silicon dioxide $\left(\mathrm{SiO}_{2}\right)$ is the building block of an important group of minerals for use in alkali capture. It has a molecular structure which, in the aggregate condition, is a solid body with a high melting point. Each oxygen atom combines with two silicon atoms in the crystallized or even amorphous condition (glass) of silicon dioxide. Thus each silicon atom is combined via four such oxygen bonds with four neighbors since no $\mathrm{Si}=\mathrm{O}$ double bonds are formed. This allows the $\mathrm{Si}$ and $\mathrm{O}$ atoms to form a threedimensional atomic crystal, in which each $\mathrm{Si}$ atom is tetrahedrally surrounded by four $\mathrm{O}$ atoms.

Warren and Pincus (1940) pictured the atomic bonding in a glass as largely ionic and calculated the bonding energy from the equation:

$$
E=\left(-z_{1} z_{2} e^{2}\right) / R_{12}
$$

where $E$ is the bonding energy between an ion pair, $z_{i}$ and $z_{2}$ are the valences of the respective ions, $e$ is the charge on the electron, and $R_{12}$ is the separation between ions. The Si-O bond is extremely stable because of the high charge and small ionic radius of the silicon atom $\left(\mathrm{Si}=4+, \mathrm{O}=2-, R_{12}=1.62 \mathrm{~A}\right)$. By contrast, the $\mathrm{Na}-\mathrm{O}$ bond is relatively weak $\left(\mathrm{Na}=1+, \mathrm{O}=2-, R_{l 2}=2.35 A\right)$.

In the silicate system, silicon has the coordination constant of four. In quartz, tridymite, crystobalite and other modifications of $\mathrm{SiO}_{2}$, a tetrad bond results which fills up the entire crystal, which is held together in all directions without interruption of the solid $\mathrm{Si}-\mathrm{O}$ bonds. The $\mathrm{SiO}_{4}{ }^{4}$ ion with its tetrad structure has a large tendency for forming greater bonds of differing structures (Figure 26). This structure will differ depending upon the silicate structural units, which differ as a function of the oxygen-to-silicon ratio. Figure 27 shows this effect, with the structural units of some of the common silicate systems summarized in 

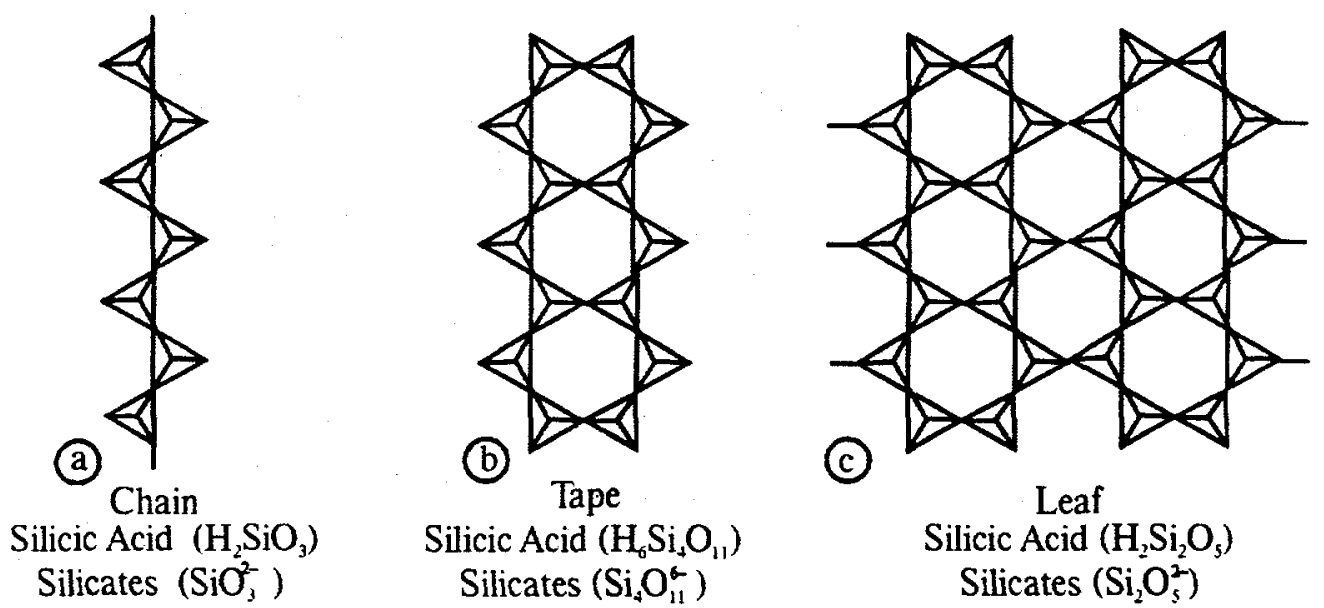

Figure 26. Tetrad arrangement of silicic acids and silicates with chain-, tape- and leaf-type structures (Pintsch and Gudenau, 1991)

Table 7. The tendency for the silicates to form greater bonds of differing structure appears to be the reason for the preferred binding of alkalies.

Orthosilicates have largely the composition $\mathrm{Me}_{2}^{+2} \mathrm{SiO}_{4}$. The $\mathrm{Si}$ atoms are contained in the tetrad "hollow spaces" and the metal cations in the octahedric hollow spaces (Figure 28). The dimension and charge of the ions is important for the crystalline structure; ions of similar dimensions can be replaced in the crystal. Therefore, the orthosilicates have a composition which fluctuates within certain limits; i.e., they have a nonstoichiometric composition. This is apparently an important mechanism for alkali sorption. Chain silicates contain chain-type lattice anions to which bonded $\mathrm{SiO}_{4}$ groups or bands made of several such $\mathrm{SiO}_{4}$ chains are attached. The composition of these compounds becomes more complicated because aluminum and silicon atoms can be interchanged in the SiQ tetrads due to their similar dimension. Therefore, they are called aluminosilicates. Although aluminum has the coordination number four in this case, it has only three outer electrons. Thus one part of the tetrad $\mathrm{Sl}^{1+}$ ion is replaced by $\mathrm{Al}^{3+}$ ions. The total negative charge of the anion is raised by one unit because of the replacement of one silicon atom by 


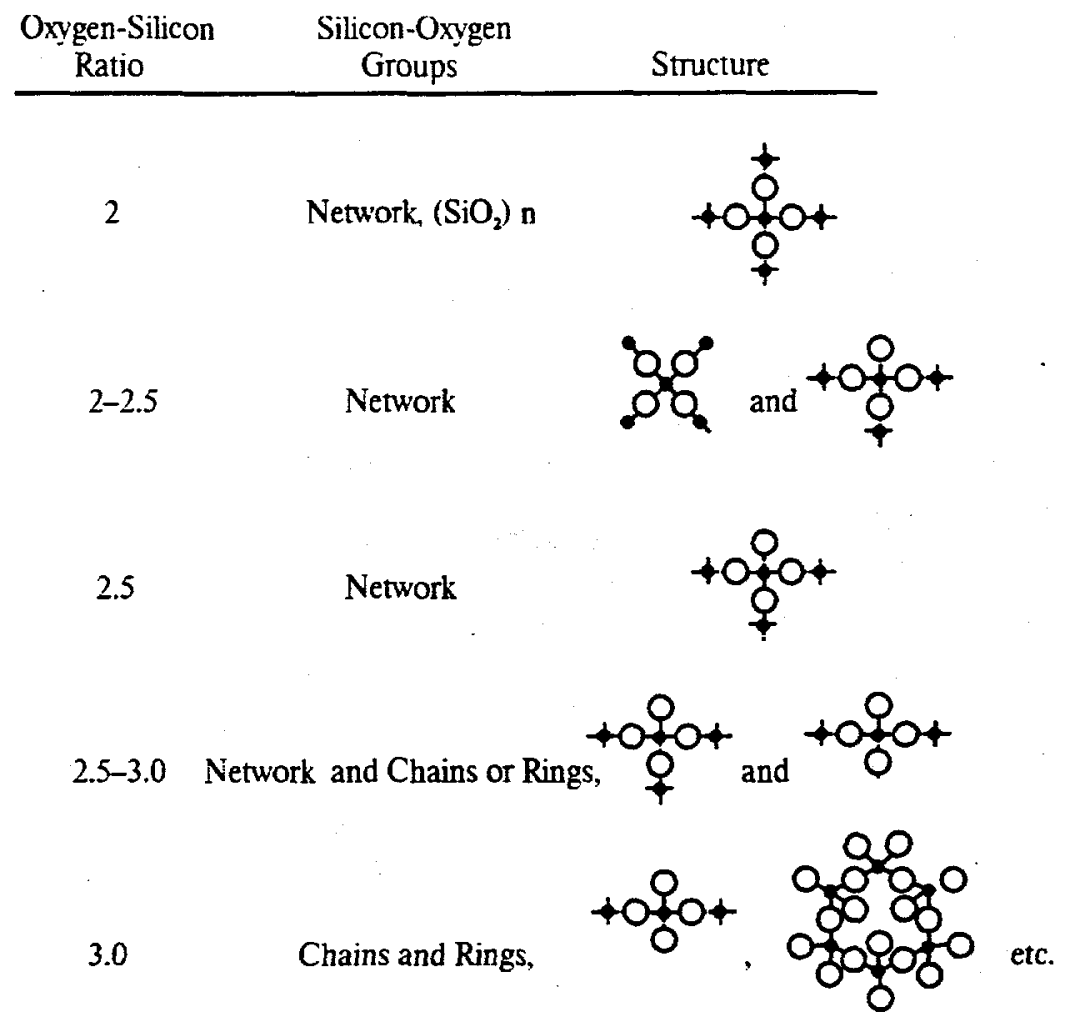

3.0-3.5 Chains, Rings, and Pyrosilicate lons

3.5 Pyrosilicate Ions

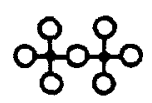

3.5-4.0 Pyrosilicates and Orthosilicate Ions<smiles>C1OOO1</smiles>

$4.0 \quad$ Orthosilicate lons

Figure 27. Effect of oxygen-to-silicon ratio on silicate structure (Kingery et al., 1976)

Table 7

Structural Units in Crystalline Silicates

\begin{tabular}{lccc}
\hline Oxygen-Silicon Ratio & Silicon-Oxygen Groups & Structural Units & Examples \\
\hline 2 & $\mathrm{SiO}_{2}$ & 3-Dimensional network & Quartz \\
3 & $\mathrm{SiO}_{3}$ & Chain-rings & Pyroxenes \\
3.5 & $\mathrm{Si}_{2} \mathrm{O}_{7}$ & Tetrahedra sharing one oxygen & Pyrosilicates \\
4 & $\mathrm{SiO}_{4}$ & Isolated tetrahedra & Orthosilicates \\
\hline
\end{tabular}




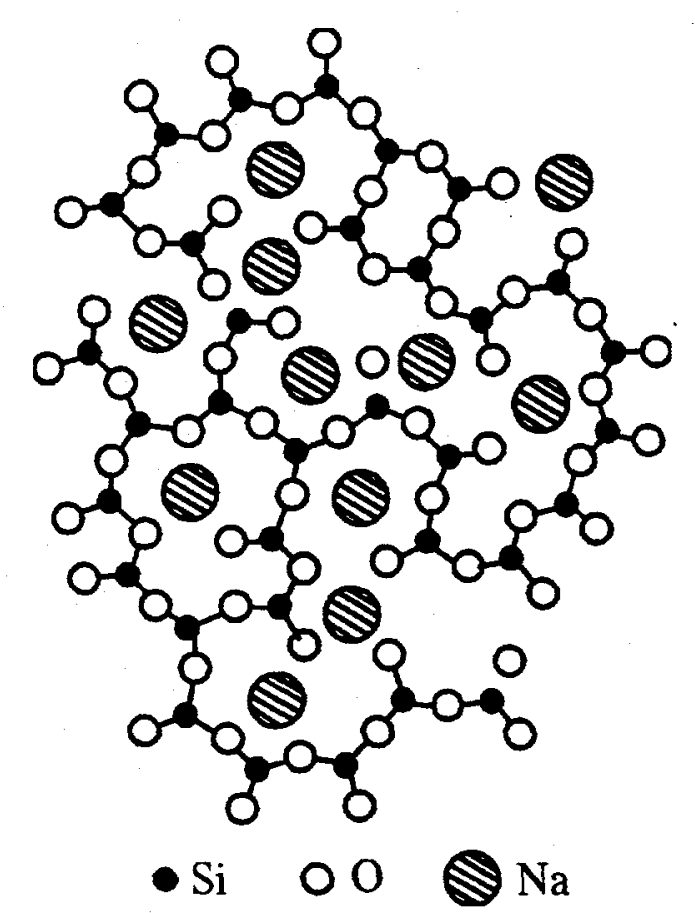

Figure 28. Schematic representations of the atomic arrangement in soda-silica glass (Kingery et al., 1976)

one aluminum atom. Thus more cations like $\mathrm{K}, \mathrm{Na}^{+}$, or $\mathrm{Ca}^{2+}$ are necessary to build up one electrically neutral lattice; i.e., the charge is compensated by the binding of cations. The lattice structure, however, remains intact. For example, nepheline $\left(\mathrm{Na}\left[\mathrm{AlSiO}_{4}\right]\right)$ exhibits the same (hexagonal) tetrad structure as tridymite; carnegieite $\left(\mathrm{Na}\left[\mathrm{AlSiO}_{4}\right]\right)$ exhibits the same (cubic) lattice as crystobalite.

Sodium and other alkalies.are incapable of building a continuous network. These "network modifiers" break up the network by adding oxygen to produce nonbridging oxygen. For example, when a network modifier is added to the silicate system, the Si-O bond is broken, and the added oxygen will join with one of the silicon atoms, producing a gap in the chain. The cation associated with the added oxygen will balance the charge produced by the breaking of the tetrahedra structure and the addition of another oxygen atom. Sodium, calcium, and magnesium oxides are good examples of network modifiers. If the silicates are present in the glass form, this breakup of the network will reduce the viscosity and, if enough is added, will result in crystallization of the glass.

The ability of the alkalies to modify the network of the aluminosilicates makes the aluminosilicates good candidates for alkali capture. The general reaction mechanism for alkali capture by the 
aluminosilicates is given in Table 8. The characteristics of two of the more promising silicate groups for alkali capture are discussed in more detail in the next two subsections.

Table 8

Reaction Mechanisms of Vaporous Alkalies with Aluminosilicates to Form Alkali Alumina Silicates

\begin{tabular}{l}
$\begin{array}{l}\text { Alumina Silicate } \\
\text { Additive }\end{array}$ \\
$\left.\begin{array}{l}\text { Reactive Alkalies } \\
\mathrm{KOH} / \mathrm{K}_{2} \mathrm{O} \\
\mathrm{NaOH} / \mathrm{Na}_{2} \mathrm{O} \\
\mathrm{KCL} \\
\mathrm{NaCl} \\
\mathrm{K}_{2} \mathrm{CO}_{3} \\
\mathrm{Na}_{2} \mathrm{CO}_{3} \\
\mathrm{~K}_{2} \mathrm{SO}_{4} \\
\mathrm{Na}_{2} \mathrm{SO}_{4}\end{array}\right\}+\left\{\begin{array}{l}\mathrm{KAlSi}_{3} \mathrm{O}_{8} \\
\mathrm{NaAlS}_{3} \mathrm{O}_{8} \\
\mathrm{KAlSi}_{2} \mathrm{O}_{6} \\
\mathrm{NaAlSi}_{2} \mathrm{O}_{6} \\
\left.\mathrm{NaAlSi}_{2} \mathrm{O}_{3} \cdot \mathrm{ySiO}_{3}\right\} \\
\text { plus calcium } \\
\text { and mixed alumina } \\
\text { silicates } \\
\text { (gas/vapor } \\
\text { and liquids) }\end{array}\right.$ \\
\hline
\end{tabular}

\subsubsection{Zeolites}

The zeolite minerals constitute a large and important group within the network silicates. Like all network silicates, the zeolites have a primary frame made up of $\mathrm{SiO}_{4}$ and $\mathrm{AlO}_{4}$ tetrahedra that link together by comer sharing to form a connected, three-dimensional network. Like the feldspars and feldspathoids, the negative charge on the zeolite frame is balanced by cations that occupy the intraframe cavities.

The structural differences between the zeolites and the other network silicates are the dimensions of the intraframe cavities and the connecting channels between them. In the feldspar structure, the cavities are relatively small, and the cations occupying them are so strongly bonded to the primary frame that their substitution by other cations having different valences requires a change in the $\mathrm{Al} / \mathrm{Si}$ ratio. The cavities are not connected and are occupied only by monovalent and divalent cations. The feldspathoid frame is more expanded than the felspar structure, and some connectivity exists between the intraframe cavities. Some of the cavities are occupied by cations, and the other cavities are large enough to accommodate molecular 
water. In comparison with the feldspathoid frame, the primary frame of the zeolites is even more expanded, containing larger cavities that are connected by broad channels.

Upon heating, molecular water is readily driven out of the zeolite structure. The anhydrous material can then absorb other kinds of molecules, providing they are not larger than the channels through which they must pass. This special aspect of the structure makes zeolites useful as molecular sieves.

The sodalite group's structure consists of loops of six tetrahedra linked by loops of four tetrahedra to form complex polyhedral cages (see Figure 29). The sodalite minerals have a tetrahedral cation to oxygen ratio of $1: 2$, and within the tetrahedra, $\mathrm{AP}^{\mathrm{P}}$ may never be in excess of $\mathrm{Si}^{4+}$. Depending on the ratio of $\mathrm{AP}^{3+}$ to $\mathrm{Si}^{4+}$ in tetrahedra sites, various amounts of $\mathrm{Na}, \mathrm{Ca}, \mathrm{K}$, and $\mathrm{Ba}$ may occupy the intraframe cavities. The coupled substitution of $\mathrm{Ca}^{2+}+\mathrm{Al}^{3+}=\mathrm{Na}^{1+}+\mathrm{Si}^{4+}$ characteristic of other network silicates such as plagioclase feldspars does not apply to zeolites. Unlike the feldspars, zeolites, including sodalite, have so much intraframe volume that cations need not be exchanged on a one-to-one basis. For example, natrolite can be derived from sodalite by substituting $2 \mathrm{Na}^{1+}$ for $\mathrm{Ca}^{2+}$. In addition, this structure allows for the interchange of the major anion groups, such as $\mathrm{SO}_{4}^{2-}$ for $2 \mathrm{Cl}^{1-}$ between sodalite and nosean. These properties are of interest for this study.
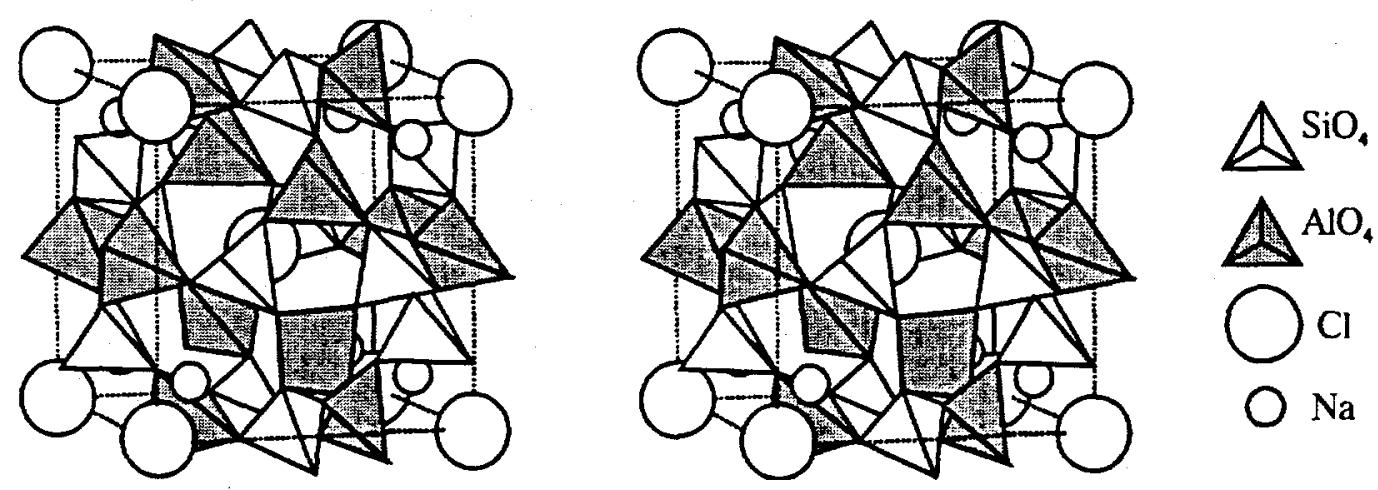

Figure 29. Structure of the sodalite mineral 


\subsubsection{Lavered Silicates}

The most important mineral groups within the layered silicates are micas and clays, with the most common clay minerals being kaolinite, illite, and montmorillonite. The clays are of interest for their potential to adsorb alkalies. The tetrahedral frame of all layered silicates is a two-dimensional network in which three of the four apical oxygens of every tetrahedron are shared with other tetrahedra (Type $C$ in Figure 26). The resulting tetrahedral layer usually has a sharing coefficient of 1.75 compared to 2.00 for most network silicates, creating strong Si-O bonds with each layer.

The term "clay" has two meanings. The first usage refers to minerals that possess a claylike crystal structure, and the term is used without consideration of grain size. The second usage refers to any mineral with diameters less than 2 microns. Feldspars and quartz, for example, can be considered as clay-sized particles in many sedimentary rocks, but they are not true clays in the structural sense. Any reference to clays in this dissertation refers to those minerals that possess the claylike structure.

The basic structure of the common layer silicates (clays) consists of tetrahedral layers alternating with parallel layers of octahedrally coordinated cations. Two types of alternation occur: one referred to by the symbol TO to denote single tetrahedral, $T$, and octahedral layers, $O$, joined together by sharing oxygens, and the other referred to as TOT to denote a structural unit that consists of a single octahedral layer sandwiched between two tetrahedral layers. Kaolinite is of the first category (TO), and is the primary clay used for alkali capture.

The structure of kaolinite (Figure 30) shows that each apical oxygen of each tetrahedron is shared with the apical oxygen of three octahedra in an adjoining layer. The TO units of kaolinite are joined by relatively weak hydrogen bonds. Upon heating to $500^{\circ} \mathrm{C}\left(930^{\circ} \mathrm{F}\right)$, kaolinite will lose $2 \mathrm{H}_{2} \mathrm{O}$ to transform from $\mathrm{Al}_{2} \mathrm{Si}_{2} \mathrm{O}_{5}(\mathrm{OH})_{4}$ to metakaolinite $\left(\mathrm{Al}_{2} \mathrm{O}_{3} \cdot \mathrm{SiO}_{2}\right)$. This opens up the crystal structure and makes it more readily accessible to mobile cations. This structure provides the good sorbing properties to kaolinite and other similar minerals. 

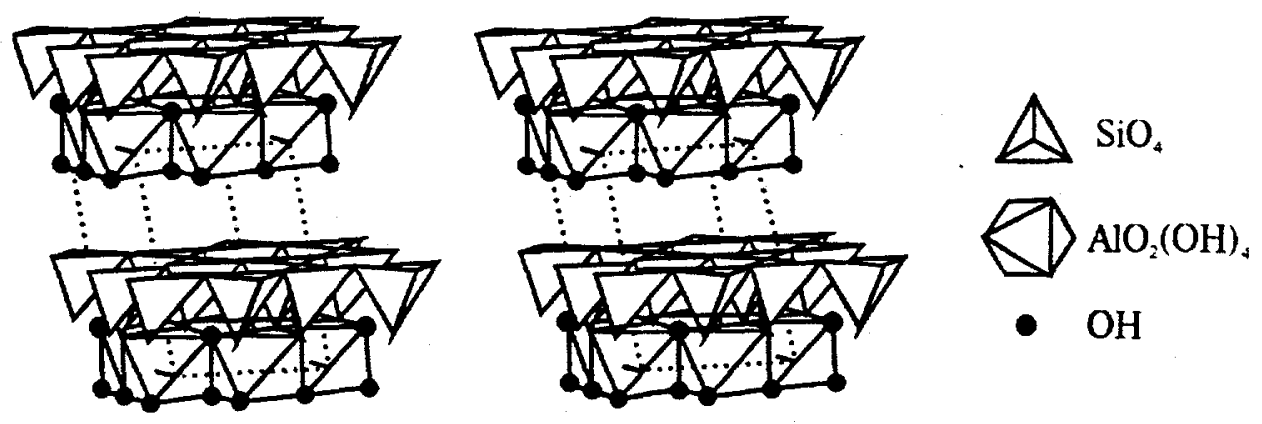

Figure 30. Structure of kaolinite

\subsection{Alkali Sorbents Tested}

Many different potential alkali sorbents have been tested by various institutions (Bachovchin et al., 1986; Bachovchin and Alvin, 1987; Lee and Johnson, 1980; Lee and Myles, 1989; Lee and Swift, 1991; Scandrett and Clift, 1984; Radhakrishnan et al., 1986; Pintsch and Gudenau, 1991b; Zakkay et al., 1989; Punjak et al., 1989; Uberoi et al., 1990). Following these sorbents listed below the attributes of several of the more effective sorbents are discussed, including how their performance is affected by operating conditions and fuel properties:

- Diatomaceous earth (Celatom-MP-91)

- Activated bauxite

- Silica gel

- Burgess No. 10 pigment (kaolin clay)

- Limestone, alumina powder, and dolomite

- Bentonite and franconite (natural minerals based on montmorillonite)

- Feldspar and kyanite (not very effective)

- Talcum $\left(\mathrm{Mg}_{6}[\mathrm{OH}]_{4} \mathrm{Si}_{8} \mathrm{O}_{20}\right)$ (effective to some extent) 
- Calcium silicates

- Kaolinite $\left(\mathrm{Al}_{2} \mathrm{O}_{3} \cdot 2 \mathrm{SiO}_{2} \cdot 2 \mathrm{H}_{2} \mathrm{O}\right)$

- Montmorillonite (n[Ca, $\mathrm{Mg}] \mathrm{O} \mathrm{Al}_{2} \mathrm{O}_{2} \cdot 4 \mathrm{SiO}_{2} \cdot \mathrm{nH}_{2} \mathrm{O}$ )

- Halloysite $\left(\mathrm{Al}_{2} \mathrm{O}_{3} \cdot 2 \mathrm{SiO}_{2} \cdot \mathrm{nH}_{2} \mathrm{O}\right) \mathrm{n}=2$ to 4

- Allophane $\left(\mathrm{Al}_{2} \mathrm{O}_{3} \cdot \mathrm{nSiO}_{2} \cdot \mathrm{nH}_{2} \mathrm{O}\right)$

- Sericite $\left([\mathrm{Na}, \mathrm{K}]_{2} \mathrm{O} \cdot 3 \mathrm{Al}_{2} \mathrm{O}_{3} \cdot \mathrm{nH}_{2} \mathrm{O}\right)$

- Beidellite $\left(\mathrm{Al}_{2} \mathrm{O}_{3} \cdot 3 \mathrm{SiO}_{2} \cdot \mathrm{nH}_{2} \mathrm{O}\right)$

- Pyrophyllite $\left(\mathrm{Fe}_{2} \mathrm{O}_{3} \cdot 3 \mathrm{SiO}_{2} \cdot \mathrm{nH}_{2} \mathrm{O}\right)$

- Illite $\left(\mathrm{K}_{1-15} \mathrm{Al}_{4}\left[\mathrm{Si}_{7-65} \mathrm{Al}_{1-1.5} \mathrm{O}_{20}\right][\mathrm{OH}]_{4}\right)$

- Illite-montmorillonite $\left(\left[\mathrm{Na}, \mathrm{Ca}_{b_{33}}\left[\mathrm{Al}, \mathrm{Mg}_{2} \mathrm{Si}_{4} \mathrm{O}_{10}[\mathrm{OH}]_{2} \cdot \mathrm{nH}_{2} \mathrm{O}\right)\right.\right.$

- Mullite $\left(3 \mathrm{Al}_{2} \mathrm{O}_{3} \cdot 2 \mathrm{SiO}_{2}\right)$

- Sillimanite $\left(\mathrm{Al}_{2} \mathrm{O}_{3} \cdot \mathrm{SiO}_{2}\right)$

- Alundum

- Attapulgus clay

- Novacite

- Emathlite

- Vansil $\left(\mathrm{CaSiO}_{3}\right)$

- Zeolite

- $\mathrm{CaO}$ impregnated in bauxite or kaolinite for $\mathrm{SO}_{2}$ and alkali control

\subsubsection{Alkali Removal Performance}

The three most successful sorbents tested are bauxite, kaolinite, and emathlite. Alkali is captured by bauxite primarily by physical adsorption. Some chemical fixation by the clay impurities also occurs. Bauxite has been tested as an alkali sorbent at temperatures ranging from $730^{\circ}$ to $1010^{\circ} \mathrm{C}\left(1350^{\circ}\right.$ to $1850^{\circ} \mathrm{F}$ ). The apparent activation energy for the bauxite is low, indicating that temperature has only a small impact on its ability to adsorb alkali. Since an adsorption process is exothermic, the amount of alkali adsorbed decreases with increasing temperature. In contrast, kaolinite and emathlite remove alkali by chemical reaction of the sodium and potassium with these silicate-based minerals. Kaolinite has a high 
activation energy, indicating it is sensitive to temperature, with alkali removal increasing with increasing temperature. Emathlite had a small activation energy, indicating its relative insensitivity to temperature.

The maximum temperature limitations will differ for these three sorbents. The emathlite reacts with the sodium to form albite, a sodium aluminosilicate compound. Albite has a melting temperature of $1000^{\circ} \mathrm{C}\left(1832^{\circ} \mathrm{F}\right)$. At temperatures above $1000^{\circ} \mathrm{C}\left(1832^{\circ} \mathrm{F}\right)$, a glass will form which could potentially cause sticking and agglomerating problems within the bed (Bachovchin et al., 1986). Kaolinite, on the other hand, will form nephelite and/or carnegieite, depending upon the temperature of the bed. The relative melting point of nephelite, which is the favored species at higher temperatures, is $1560^{\circ} \mathrm{C}\left(2840^{\circ} \mathrm{F}\right)$ (Uberoi et al., 1990). If a granular bed of nephelite proves an effective alkali sorbent, it would have the distinct advantage of operating at combustor exit temperatures, eliminating the costly steps of cooling, cleaning, and reheating the flue gas. Bauxite will not melt until $1982^{\circ} \mathrm{C}\left(3600^{\circ} \mathrm{F}\right)$; however, its adsorption capacity will decrease as the temperature increases.

Uberoi and others (1990) studied the kinetics and mechanisms of alkali removal from flue gases using a microgravimetric analyzer (modified TGA). The intent of their work was to identify solid sorbents for either in situ or downstream removal of alkali from high-temperature combustion systems. Typical weight gain profiles generated in the microbalance system for the three sorbents tested, bauxite, kaolinite, and emathlite, are shown in Figure 31. The results for all sorbents indicate a decrease in sorption rate as loading increases. On continued exposure to the alkali vapors, the sorbents reach their maximum capacity for alkali removal, and the rate of sorption drops to zero. At $800^{\circ} \mathrm{C}\left(1472^{\circ} \mathrm{F}\right)$, bauxite was observed to have the highest initial rate, while kaolinite had the largest increase in mass. Each sorbent was also tested for desorption by reducing the alkali vapor concentration to zero after the sorbent was saturated. Kaolinite and emathlite did not undergo any loss in weight, but bauxite lost approximately $10 \%$ of the original weight gain. Scanning Auger microprobe indicated that chlorine was not retained by kaolinite or emathlite. Bauxite did capture some chlorine; however, this chlorine was readily lost during desorption. Since the chlorine is desorbed from the bauxite, the weight loss during desorption could correspond to the release of physiosorbed $\mathrm{NaCl}$. 


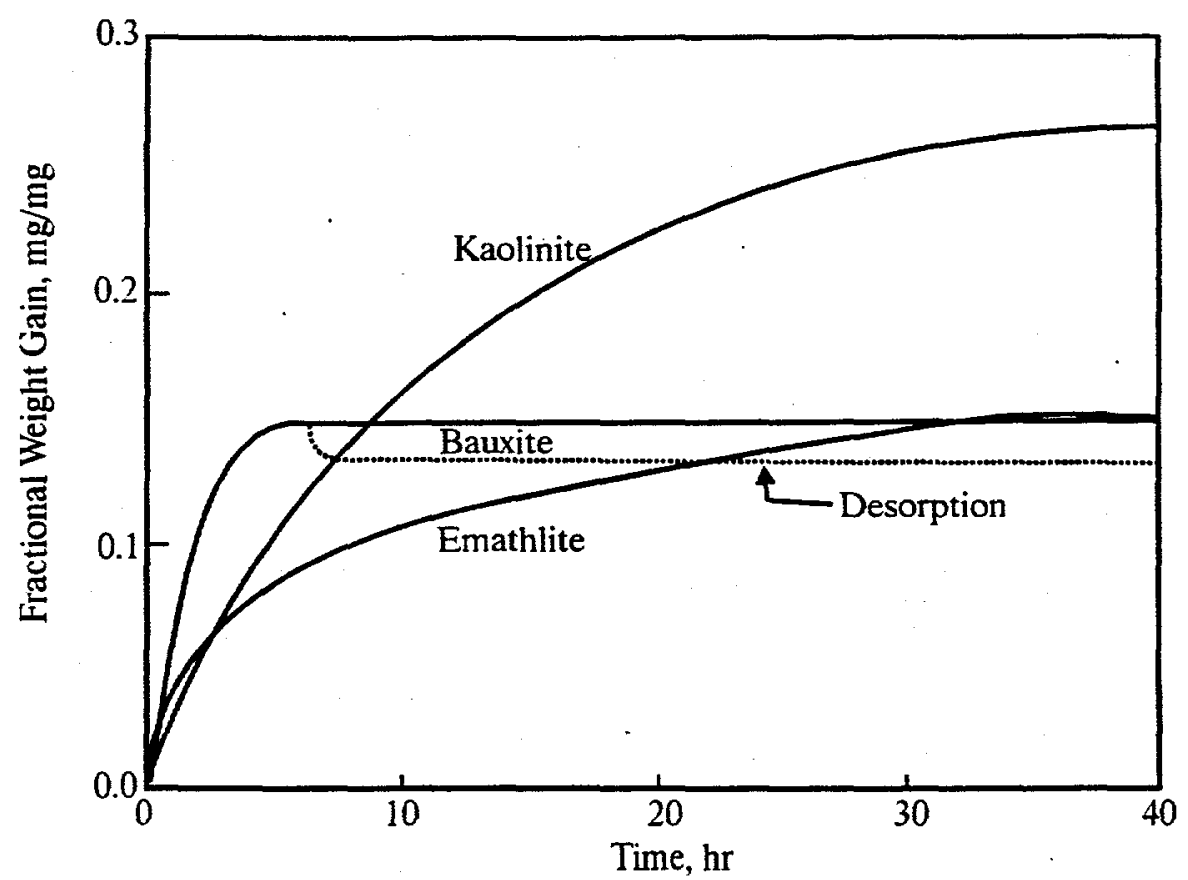

Figure 31. Temporal profile of $\mathrm{NaCl}$ adsorption on sorbents at $800^{\circ} \mathrm{C}$ (Uberoi et al., 1990)

The effect of temperature on the rate constants of bauxite and kaolinite was also measured by Uberoi and others (1990) and is shown in Figure 32. The activation energy for kaolinite is higher than that for bauxite, indicating that alkali removal by kaolinite is more sensitive to temperature. This is consistent with the observation that sorption on kaolinite occurs by chemical reaction alone, while sorption on bauxite occurs by both physiosorption and chemical reaction.

Pilot-scale tests have been performed by Argonne National Laboratory (ANL) on its pilot-scale PFBC using bauxite as an alkali sorbent (Lee and Johnson, 1980; Lee and Myles, 1987; Lee and Swift, 1991). Tests were performed at $850^{\circ} \mathrm{C}$ and $875^{\circ} \mathrm{C}\left(1560^{\circ}\right.$ and $\left.1610^{\circ} \mathrm{F}\right)$ using a Beulah, North Dakota, lignite. Flue gas concentrations of 1.4 to $1.5 \mathrm{ppmw}$ sodium and $0.1 \mathrm{ppmw}$ potassium were measured at the inlet to the filter device. Using a packed bed of bauxite with a particle size ranging from 2 to $2.4 \mathrm{~mm}$, greater than $99 \%$ removal of the alkali was effected. The outlet alkali measurements were less than 10 ppbw. Adsorption data were collected that can be used for preliminary design scaleup. 


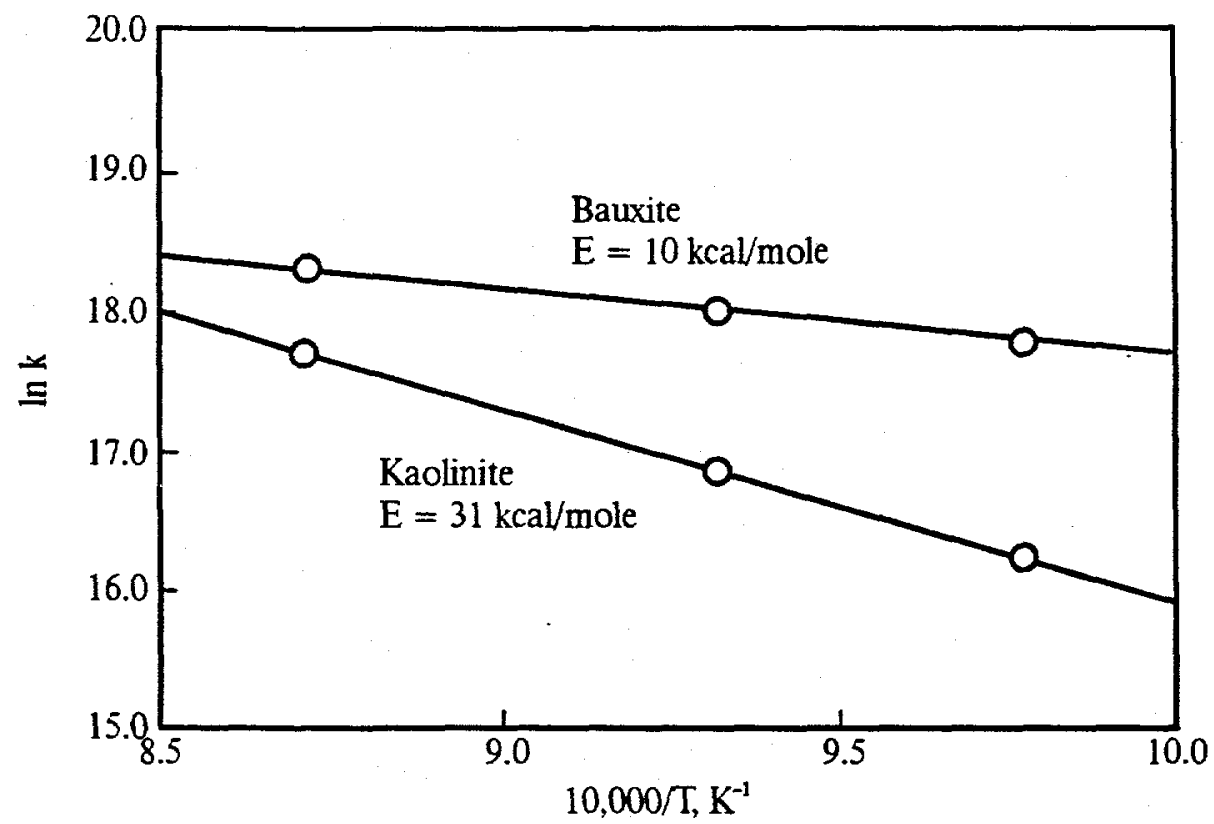

Figure 32. Apparent rate constants for bauxite and kaolinite (Uberoi et al., 1990)

The Combustion Power Company (CPC) granular bed filter (GBF) was tested at NYU using Beulah lignite with $8.0 \%$ ash and $0.62 \%$ sodium (as $\mathrm{Na}_{2} \mathrm{O}$ ) in the coal as the fuel (Radhakrishnan et al., 1986; Zakkay et al., 1989). The PFBC pilot plant was operated at temperatures ranging from $810^{\circ}$ to $870^{\circ} \mathrm{C}$ $\left(1490^{\circ}\right.$ to $\left.1600^{\circ} \mathrm{F}\right)$ and 6.9 to 9.2 atmospheres. Both 2-millimeter $(\mathrm{mm})$ and 3-mm mullite particles were tested. The average alkali content in the flue gas entering the GBF was measured to be $1.25 \%$ of the sodium and $1.12 \%$ of the potassium in the coal. The measured alkali capture efficiency for all of the tests was between $90 \%$ and $96 \%$, with a possible error of $5 \%$. The outlet alkali concentration ranged from 3 to $20 \mathrm{ppbw}$, which is below the 24-ppmw recommended turbine tolerance limit. In that work, no attempt was made to determine the mechanism of capture, i.e., whether the alkali reduction was due to condensation on the filter media, capture of fine alkali sulfate dust and aerosol particles, physical adsorption, or chemical absorption and reaction. Therefore, although it was proven that the concept will simultaneously capture particulate and alkali in practice, no scaleup data were obtained.

A more practical study was performed by Westinghouse, focusing on emathlite as the sorbent material (Bachovchin et al., 1986). Results from their testing indicated that the concept of using a fixed bed 
of emathlite pellets is a practical technique for alkali removal from hot flue gases. Process development tests included a 102-hour test where gas containing 10-ppmv $\mathrm{NaCl}$ was reduced to less than $0.2 \mathrm{ppmv}$ (detection limits). In other studies, alkali removal of greater than $99 \%$ was demonstrated, with a reduction of sodium to below the 24-ppbw turbine tolerance level. A commercialized process has been identified for manufacture of the emathlite pellets. In their testing, the kinetics were found to be insensitive to temperature over the range of $775^{\circ}$ to $900^{\circ} \mathrm{C}\left(1426^{\circ}\right.$ to $\left.1651^{\circ} \mathrm{F}\right)$. The adsorption rate was proportional to the alkali gas-phase concentration, with no capacity limitations due to adsorption limitation at low gasphase alkali concentrations. The Westinghouse research was based on a packed-bed design, and it was concluded that it would be necessary to install a particulate cleanup device ahead of the sorbent bed. The Westinghouse researchers had envisioned a long time between replacement of the bed material (one-half to one year) and had concerns about bed pluggage due to the fly ash. The use of a GBF would prevent this from happening. An important finding from the Westinghouse work was that no attrition of the emathlite pellets was noted during any of the testing. Six-mm pellets were recommended for the packed-bed.

All of these studies have been performed using combustion gases. In a combustion atmosphere, most of the alkali material is vaporized during combustion and will be present as a sulfate. At the typical filter temperatures $\left(788^{\circ}\right.$ to $900^{\circ} \mathrm{C}\left[1450^{\circ}\right.$ to $\left.\left.1650^{\circ} \mathrm{F}\right]\right)$, a majority of the sulfates will have condensed on the surface of other ash particles or as fine particles and aerosols (Scandrett and Clift, 1984; Spacil and Luthra, 1982; Mojtahedi and Backman, 1989). The removal of the alkali in this form is difficult because of the need to capture the fine sulfate particles and either remove them as sulfates or provide the contact necessary to react the sulfates with the sorbent material. The good performance results by ANL, NYU, and Westinghouse indicated this is possible.

Less testing has been done for gasification systems. Thermodynamic calculations for a reducing atmosphere indicate that the alkali will be present as hydroxide vapors or chloride vapors for high-chlorine coals. In these cases, the alkali capture can be achieved by direct reaction of the vapor with the capture material to form a nonvolatile product. This type of capture is much more effective than the removal of the sulfates from the combustion gases (Scandrett and Clift, 1984; Spacil and Luthra, 1982; Mojtahedi and Backman, 1989) and is the preferred method of alkali removal for the current study. Some of the sorbents 
tested in screening tests by McLaughlin (1990) are listed in Table 9. Typical nonsorbents identified in these tests are high silica, alumina, or aluminosilicate materials that were characterized by a tightly layered crystalline structure and which did not react to any significant extent with water vapor in the $400^{\circ}$ to $1000^{\circ} \mathrm{C}\left(750^{\circ}\right.$ to $\left.1832^{\circ} \mathrm{F}\right)$ temperature range. The effective sorbents had more open layered crystal structure, with a higher concentration of interlayer cations or other reaction sites that were rapidly rehydoxylated by reaction with water vapor. These hydroxylated groups subsequently acted as reactive sites for the adsorption of the vapor-phase alkalies. This is consistent with the previous discussions on the mechanisms of alkali removal using aluminosilicate minerals.

Table 9

Summary of Alkali Chloride Adsorbent Screening Tests (McLaughlin, 1990)

\begin{tabular}{ll}
\hline Unreactive Adsorbent, nonsorbent & Reactive Adsorbent, sorbent \\
\hline Alpha $\mathrm{Al}_{2} \mathrm{O}_{3}$ & Activated bauxite \\
Gamma $\mathrm{Al}_{2} \mathrm{O}_{3}$ & Attapulgus clay \\
Activated Alumina & Barytes \\
Andalusite & Burgess no. 10 pigment \\
Celestite & Calcium montmorillonite \\
Iron Oxide & Celetom \\
Kyanite & Diatomaceous earth \\
Olivine & Ebony novacite \\
Silicalite & Emathlite \\
Silicon Carbide & Kaolin \\
Sillimanite & Pumice \\
Talc & Pyrophillite \\
Zeolite $4 \mathrm{~A}$ & Vansil \\
Zeolite $\mathrm{ZSM}-5$ & \\
\hline
\end{tabular}

Significant work has also been performed to identify sorbents to capture other metals from flue or waste gases. At relatively low temperatures, mercury, cadmium, lead, and zinc have been removed from gas streams. At temperatures similar to PFBC, cadmium, lead, zinc, nickel, vanadium, and arsenic have been removed using sorbents. Some sorbents have also shown an affinity to chlorine. Finding a sorbent that is selective to trace metals and chlorine in addition to alkali will greatly enhance the effectiveness of that sorbent. 
For the individual coal-bound trace metal species, Mojtahedi and others (1990) estimate that the vapor-phase emissions range from 0.5 to $1.2 \%$ for $\mathrm{Cu}, 7.5$ to $16.0 \%$ for $\mathrm{Hg}, 1$ to $3 \%$ for $\mathrm{Pb}, 5 \%$ for $\mathrm{Cd}$, and up to $4 \%$ for As, with the balance tied up in either the bottom or fly ash. These results showed that the trace metal emissions from a PFBC unit can be controlled effectively with a barrier filter. The authors suggest that despite the initially high volatilization of the trace metals into the gas phase, the low levels of vapor emissions may be attributed to adsorption onto the high surface area and highly irregular, crystalline fly ash particles. Unless stringent standards are adopted, the need to control these trace metals is unlikely.

Work from previous researchers has demonstrated that alkali sorbents can be effective in removing alkali from both combustion and gasification gas streams. Both packed beds and GBFs have been utilized. Drawbacks include the need for a particulate removal device both before and after a packed bed and the expense of the added pressure vessels to contain the packed or granular bed. The granular bed may be costeffective if both particulate and alkali control can be achieved. However, because of the disadvantages associated with packed and granular beds, in situ removal of alkali may be preferred. A sorbent, used in the same manner as a sorbent is used to remove sulfur, would not add any significant cost to the system, would be easy to maintain, and could be used in both oxidizing and reducing atmospheres.

\subsubsection{Effect of Operating Parameters on Sorbent Performance}

Lee and Johnson (1980) investigated the impact of sorbent bed temperature, exposure time, superficial gas velocity, and gas hourly space velocity (GHSV) on alkali capture in a packed bed. The results show an increase in $\mathrm{NaCl}$ capture with increasing temperature for the diatomaceous earth and the opposite effect for the activated bauxite tested. This is expected since capture by diatomaceous earth is by chemical reaction, with the rate increasing with temperature according to the Arrhenius equation, while capture with bauxite is primarily through physical adsorption. Since physical adsorption is exothermic, the amount adsorbed should decrease with increasing temperature according to Le Chatelier's principle. In both cases, the amount of capture increases nonlinearly with time, indicating that under the experimental conditions, the rates of $\mathrm{NaCl}$ capture are not controlled by the mass transfer of $\mathrm{NaCl}$ vapor from the bulk of the flue gas to the extemal surfaces of the sorbent. 
To further investigate the rate-controlling mechanism, tests were conducted at various superficial gas velocities while holding the GHSV constant. For mass-transfer-controlled reactions, an increase in superficial gas velocity increases the mass-transfer coefficient, thereby increasing the extent of reaction. Within the limits of experimental and analytical errors, the rate of $\mathrm{NaCl}$ capture was found to remain constant over the velocity range tests. This indicates that the rate of $\mathrm{NaCl}$ capture is not mass-transfercontrolled, but controlled by either the diffusion of $\mathrm{NaCl}$ vapor through the internal pores, the adsorption of $\mathrm{NaCl}$ on the active sites of the sorbent, or the chemical kinetics.

Work performed by Lippert and others (1991) investigated the use of sorbents for removing alkalies in GBFs. Most of their work was performed using nitrogen as the carrier gas for the alkali chloride. However, when several tests were performed adding water vapor to the gas stream, a marked improvement in sorbent performance was noted. The weight gains experienced during their TGA-based experiments were 3 to 5 times higher when water vapor was added versus those tests with no water added. McLaughlin (1990) also showed a significant improvement in sorbent effectiveness when the carrier gas stream contained $5 \%$ water vapor in his work with calcium montmorillonite.

The effect of chlorine on the performance of alkali sorbents has been reported by Singh and others (1986) under both PFBC and gasification conditions. Under both sets of operating conditions, the presence of $\mathrm{HCl}$ in the flue gas is expected to decrease the sorbent efficiency, although gasification operating conditions seem to be more significantly affected. Increasing pressure and decreasing temperature also seem to improve the sorbent efficiency. Potential sorbent reactions for alkali chloride compounds all form $\mathrm{HCl}$ in the product gas; therefore, if there is a high $\mathrm{HCl}$ concentration in the product gas, the "capture" reaction is limited because of the thermochemical equilibrium. Methods for the removal of $\mathrm{HCl}$ were studied (Krishnan et al., 1986), but they used a $\mathrm{Na}_{2} \mathrm{CO}_{3}$-based mineral at lower operating temperatures $\left(535^{\circ}\right.$ to $\left.650^{\circ} \mathrm{C}\right)$

In their theoretical evaluation, Singh and others (1986) effectively estimated the impact of gas composition and operating conditions on the adsorption efficiency of sillimanite/silica. Figure 33 summarizes their results, expressed as reduced parameters relative to a baseline value. The critical influence of temperature and $\mathrm{HCl}$ concentration on alkali chloride adsorption is evident in this figure. A zero 
dependence on the $\mathrm{SO}_{2}$ concentration is shown because the formation of the condensed $\mathrm{NaSO}_{4}$ phase has no effect on the capture reaction (Singh et al., 1987) or in the sulfation of the vapor-phase alkali chloride species in the temperature range of $800^{\circ}$ to $1117^{\circ} \mathrm{C}\left(1472^{\circ}\right.$ to $\left.2040^{\circ} \mathrm{F}\right)$. Clearly more work is necessary to identify the optimum process conditions and the alkali adsorbents that can be used in a PFBC cycle.

\subsection{Measurement Techniques}

Alkali metal components contained in coal are released during combustion into the exhaust gas as particulate material, vapor, and aerosol. In a PFBC, the hot offgas is expanded through a gas turbine. The amount of alkali material in the gas, as well as the condensation and/or accumulation of material on the turbine blades, may cause hot corrosion of these materials. The measurement of the levels of alkali in the exhaust gases is, therefore, of particular interest. Alkalies that are condensed on particulates or held within the particulate are collected on the ceramic barrier filter, while vapor-phase alkali and suspended aerosols can pass through these barrier filters and attack the turbine blades. It is, therefore, important to be able to differentiate between the form of alkali when determining its effect on PFBC turbine performance.

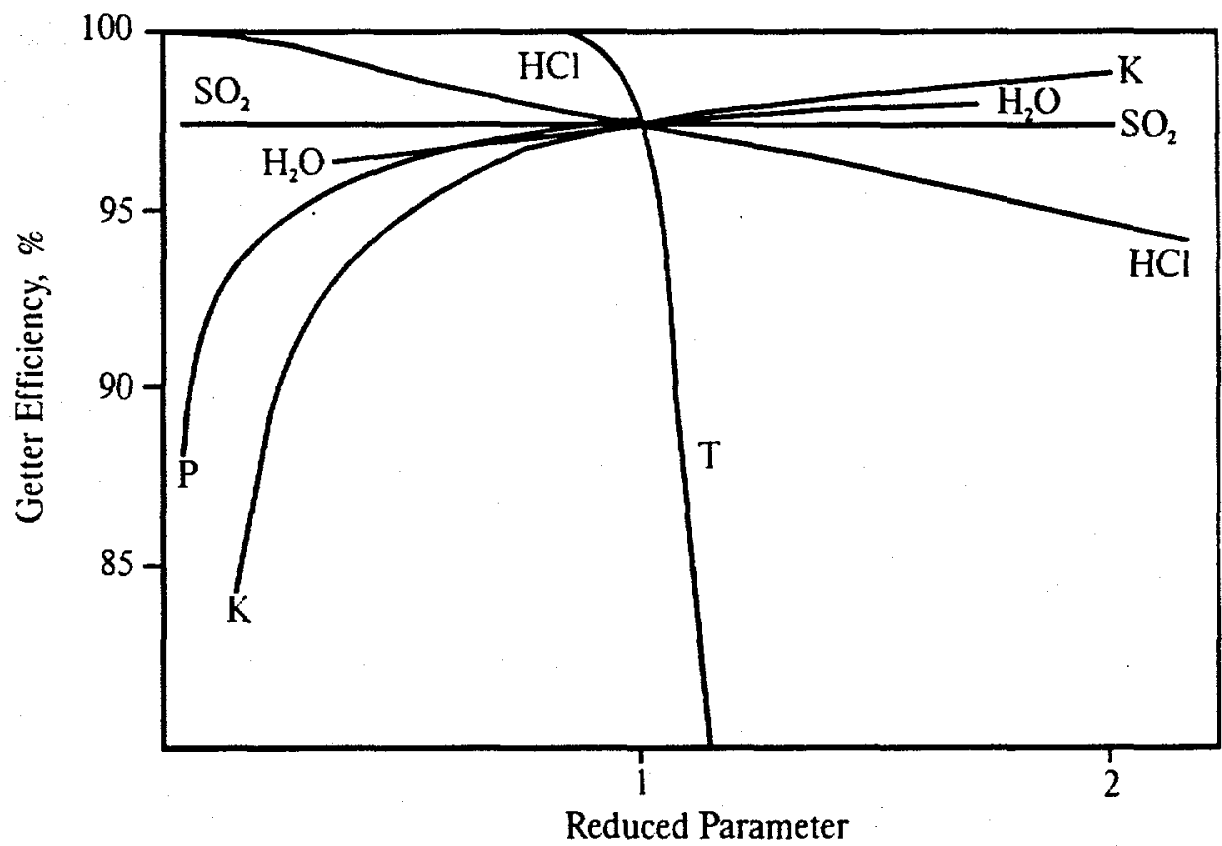

Figure 33. Effect of gas composition and conditions on the adsorption efficiency of sillimanite/silica in a combustion environment (Singh et al., 1986) 
Design of an alkali-sampling probe is no trivial task. For accurate alkali measurement, the following design and operational criteria must be met:

- The sample gas must be cleaned of all particulate matter before it enters the sampling system.

- All surfaces of the sampling system in contact with the sample gas must be inert towards alkali; that is, they must neither react or emit alkalies.

- In order to avoid premature condensation of alkalies or salts from alkali, the gas must be kept at combustion temperatures until it has entered the sampling system.

- No alkali metal-or only negligible amounts-must be allowed to pass through the sampling train.

- The sampling system should be completely detachable in order to allow total recovery of alkali compounds on completion of sampling.

- The sampling system should be calibrated with a known amount of alkali salt under conditions similar to those during operation.

- Potential errors due to the sampling procedure should be considered, such as the accuracy of the techniques for measuring the alkalies in the extracted solution and measurement of the sampled gas.

Several techniques have been developed to measure the alkali levels in flue gases. These techniques include in situ techniques such as laser-induced fluorescence spectroscopy (LIFS); laser-induced photo and fluorescence (LIPF); laser-induced breakdown spectroscopy (LIBS); hot-extraction techniques, such as the Ames alkali monitor, the Federal Energy Technology Center (FETC) fiber-optic alkali monitor (FOAM) analyzer, and the Western Research Institute (WRI) condensing/electric conductance probe; and batch-type, condensation cold traps such as the alkali and particulate sampling train (APST) technique. One additional technique is the use of a fixed bed of alkali sorbent material in which a known amount of flue gas is passed through the bed for a given time, after which the bed material is regenerated and analyzed for its alkali content.

The Energy \& Environmental Research Center (EERC) has performed some testing using a LIFS system to look at the concentration of sodium atoms in a small-scale burner (Benson et al., 1989). These tests looked at sodium in solution, solid-phase sodium compounds, sodium impregnated on carbon, and three different Beulah lignite coal samples: a demineralized Beulah lignite, a demineralized Beulah lignite with sodium acetate impregnated back into the sample, and a raw Beulah lignite. The form of the sodium in 
solution was found to have no effect on the concentrations measured. The solid-phase sodium salts (benzoate, sulfate, and carbonate) gave signals similar to the solutions, while the sodium montmorillonite and chloride gave signals much less than those observed for solutions. The coal and char samples gave signals higher than the solutions, and there was a linear response of the coal samples with Na concentration in the sample. The thermodynamic code SOLGASMIX was used to predict how much $\mathrm{Na}$ would be in the atomic state. The code did agree with the general observations that $\mathrm{NaCl}$ and sodium montmorillonite liberated less $\mathrm{Na}$ atoms when combusted; however, the predictions were $30 \%$ to $70 \%$ in error, since the mole fraction values put into the program are that much in error. This system is no longer in operation.

Los Alamos National Laboratory has performed some laboratory testing with a photofragment fluorescence technique that is capable of identifying different anions of the same alkali (Oldenberg, 1989). This technique is based on the UV laser-induced photo dissociation of alkali-containing compounds. Sodium and potassium compounds can be distinguished by their characteristic emission wavelength (589 $\mathrm{nm}$ for $\mathrm{Na}+, 766 \mathrm{~nm}$ for $\mathrm{K}+$ ). Variation of the threshold energy wavelength should allow good discrimination between alkali compounds with different anion groups. Research indicates that the instrument is sensitive down to $0.03 \mathrm{ppb} \mathrm{NaCl}$ and $0.4 \mathrm{ppb} \mathrm{KCl}, 0.1 \mathrm{ppb} \mathrm{NaOH}$ and $7 \mathrm{ppb} \mathrm{KOH}$, and $0.01 \mathrm{ppb} \mathrm{Na} 2 \mathrm{SO}_{4}$ and $0.3 \mathrm{ppb} \mathrm{K}_{2} \mathrm{SO}_{4}$. This research concluded that, in predominantly binary mixtures of the chloride anion with the hydroxide or sulfate anion, the photofragment fluorescence technique will be able to distinguish the concentration of each compound. However, in mixtures containing comparable amounts of the hydroxide and sulfate anions, the spectra are similar enough to make concentration measurements difficult: Research with the photo dissociation fluorescence technique is being continued at PSI Technologies Company in testing on its laminar flow drop-tube furnace (Helbe et al., 1990). Results have been obtained which indicate that chlorine is the species-limiting compound in the formation of $\mathrm{NaCl}$. SOLGASMIX was used to validate the dependence of $\mathrm{NaCl}$ formation on the chlorine levels in the coal. Additional kinetic modeling was performed to determine that the $\mathrm{NaCl}$ equilibrium is approached in approximately $5 \mathrm{~ms}$. There is little report of the use of this instrument in practical applications.

Argonne National Laboratory utilized several different approaches for measuring the amount of alkali in the process gas stream from the PFBC. One technique utilized a filter to remove particulate matter prior to passing the gas through a stainless steel cold trap followed by water bubblers. The intent was to 
remove any particulate matter and aerosols from the gas stream using the filter and allow only the vaporphase material to pass into the cold trap. The alkali that did not condense in the cold trap was scrubbed out in the water bath. Argonne National Laboratory investigated several different filtering materials. The ideal filter is one that is effective in removing fine particulate matter, but is inert toward alkali vapor. A ceramic ultrafiber made by $3 \mathrm{M}$, Nextel, was used in early tests. While effective in removing particulate matter, this material was shown to have some reactivity to alkali vapor (Lee and Myles, 1987).

As a part of its work for FETC, ANL investigated the reliability of various alkali measurement techniques. One technique investigated was the analytical alkali sorber bed (AASB). Clean gas (after candle filter) is passed through a packed bed of sorbent material such as activated bauxite or diatomaceous earth which captures the alkali vapor. After the designated sample time, the sorbent is removed and digested first in gently boiling water and then in acid. Atomic absorption spectrometry (AA) is used to quantify the amount of sodium and potassium in the solutions. The AASBs were placed directly in the pressure vessel to eliminate problems with condensation in the sample lines. Results were compared to those from the Ames on-line analyzer. The APST batch-type condensation train gave alkali levels between 0.6 to $1.0 \mathrm{ppm} \mathrm{Na}$, while the sorbent bed technique gave values between 1.3 to $1.5 \mathrm{ppm} \mathrm{Na}$. The discrepancies in the numbers have been attributed to the adsorption of the alkali on the heated sample lines, while the sorbent bed is right in the flow gas, so there is no sample line to change the concentrations. The sorbent bed numbers could be inflated because of some contamination by particulate.

One important result from the work at ANL was the discovery that the stainless steel (both 304 and 316) used for the sample lines capture both $\mathrm{NaCl}$ and $\mathrm{KCl}$ vapors and that the sodium and potassium captured by the steel showed reversible release to an alkali-vapor-free gas. This interaction with the stainless steel lines can lead to lower than expected readings as the actual alkali concentration increases from a baseline value or, conversely, higher than expected when the alkali concentrations decrease from the baseline value. Lee and Myles (1989) also observed condensation and vaporization of alkali vapors, primarily as $\mathrm{Na}_{2} \mathrm{SO}_{4}$ and $\mathrm{K}_{2} \mathrm{SO}_{4}$ in the sample lines. When the gas-sampling line was cooler than the PFBC gas stream, condensation in the sample line occurred, resulting in low alkali readings. Higher than expected readings were noticed when the sampling line was hotter than the PFBC flue gas. To minimize these 
problems, Lee and Myles recommend using as short of a sample line as practical, using an inert (nonstainless steel) sample line, and maintaining the sample line at the system temperature.

A novel concept for an on-line alkali monitoring probe based on monitoring the vapor-phase alkali by condensing them on a sensing element held in a temperature gradient is being developed at WRI (Sethi, 1995). Portions of the element, which are at temperatures below the dew point, develop a condensate layer either as a solid deposit or as a liquid film. Areas of the probe where a solid layer of alkali compounds is present can then be detected by remote-sensing techniques based on differences in the electrical conductance between the liquid and the solid salt. Laboratory verification tests indicate that the concept can be made to work in furnace tests, and remote sensing of deposited salts is possible (Sethi, 1995).

A review of the literature used to design the carbonizer for the Foster Wheeler second-generation PFBC system (Boteler, 1973) indicates that the dry tar had ash levels ranging from 0.1 to $3.2 \mathrm{wt} \%$ ash (avg. $1.0 \mathrm{wt} \%$ ). While some of the ash could be the result of fine fly ash carrying over out of the carbonizer, some of the ash is probably due to the volatilization of alkali metal compounds which would not be collectible by hot-gas cleanup device such as ceramic candle filters, etc. The presence of organic vapors in the gas stream will also make the sampling and identification of alkali compounds more difficult for carbonization (advanced PFBC) and gasification conditions. The organic vapors are known to absorb ultraviolet (UV) radiation which will preclude the use of any LIFS technique because they fluoresce in the UV wavelengths. Condensation cold trap sampling trains would also condense the organic tars, making the analyses for alkali compounds much more difficult. A fixed bed of sorbent material could potentially work as an alkali measurement device provided the bed is maintained at the same temperature as the gas-tar stream to prevent the condensation of tars on the sorbent material.

In summary, alkali metals can be measured either on-line producing instantaneous alkali values or off-line where a batch-sampling technique typically requiring several hours is used. Unfortunately, the accuracy of on-line methods is still not reliable enough for use in a PFBC (Lee and Swift, 1991; Fantom, 1993). Therefore, batch-sampling procedures are recommended even though they only provide average values of alkali metal over a given period of time. 


\section{CHAPTER 3}

\section{EXPERIMENTAL}

The experimental work undertaken as a part of this research was conducted in both static laboratory and dynamic bench-scale settings. The intent of the laboratory testing was to screen candidate sorbents, collect rate data, and verify the reaction schemes proposed in Section 1.5. Initially, all of the laboratory screening was planned for the PTGA. However, because of limitations of the pTGA equipment, the bulk of the laboratory screening work was done at atmospheric pressures using the more conventional TGA. The purpose of the work on the bench-scale was to simulate real-world conditions and to determine the impacts of utilizing alkali sorbents on the overall performance of the entire system. The pressurized fluid-bed reactor (PFBR) was the main tool used for this portion of the work. Thermochemical equilibrium modeling was also utilized during all aspects of this research to verify and/or help explain phenomena seen during the laboratory and bench-scale experiments. SOLGASMIX and FACT were the two thermochemical equilibrium codes utilized.

The purpose of this chapter is to describe the equipment, explain the test protocols, and define the test matrices. Additionally, the information sought from each test sequence is presented to allow the reader to better understand the reasoning behind the choices made for this testing. Knowing this logic should make it easier to follow the data interpretation presented in Section 4 and understand the basis of the conclusions formulated as a result of this work.

\subsection{Pressurized Thermogravimetric Analysis}

The original experimental plan included the use of the pTGA for testing the use of candidate sorbents for capturing alkalies. It was hoped that this instrument could be utilized to measure rate constants from temperature versus weight gain curves, reaction orders from temperature versus weight gain at varying inlet $\mathrm{NaCl}$ concentrations, maximum uptake for each sorbent, reversibility of adsorption; determine whether 
physical or chemical adsorption was the predominant mechanism; and identify the rate-limiting step. However, because of limitations of the equipment available at the EERC and the availability of resources to modify this equipment, these goals were not obtained using the pTGA. Some of the goals were obtained at atmospheric pressure using a regular TGA, as will be discussed in the Section 3.2. The experiments attempted in the pTGA will be described in the following section along with the failure of this equipment, to produce usable data.

\subsubsection{Equipment Description}

A pressurized TGA with the capability to characterize coal, char, sorbent, and catalyst materials is available at the EERC. The Spectrum Research and Engineering Corporation 900/600 "TG-Mini-Reactor" is reported to have a heatup rate of up to $100^{\circ} \mathrm{C} / \mathrm{min}$ to $>900^{\circ} \mathrm{C}\left(180^{\circ} \mathrm{F} / \mathrm{min}\right.$ to $\left.>1650^{\circ} \mathrm{F}\right)$ and can be operated at pressures from vacuum to $600 \mathrm{psig}$. The balance is capable of handling samples of up to $100 \mathrm{mg}$. Gas inlet and outlet ports enable the use of flowing inert and reactant gases while maintaining the preset pressure. The gas outlet from the sample chamber is readily interfaced to other instrumentation, i.e., FT-IR (Fourier transform infrared), GC-MS (gas chromatography-mass spectrometry), or impinger trains, for real-time gas analysis or gas effluent extraction. Control of the instrument and data collection is accomplished using manufacturer software on an IBM (or compatible) PC (personal computer). The raw data can be downloaded into ASCI files for import into commercial spreadsheets for data reduction and reporting.

\subsection{2 pTGA Test Conditions}

To meet the goals laid out in the introduction to this section, sodium needed to be introduced into the pTGA as a vapor at a controlled but variable concentration. Several different options were explored based partially on reports of previous researchers and partially on the experience of the operators of the pTGA at the EERC. The first avenue explored was to produce the sodium vapor in a separate "generator" and use a carrier gas to introduce the vapor into the pTGA. The desired concentrations ranged from 1 to $200 \mathrm{ppm}$. A review of the vapor pressures of various sodium salts indicated that sodium chloride has the highest vapor pressure and would, therefore, deliver these concentrations at the lowest temperature. However, because of the relatively high vapor pressure, high temperatures are required in the alkali 
generator. At these temperatures, it is necessary to close-couple the generator and the pTGA and to heat all connecting lines between the two vessels to ensure that the sodium will not condense prior to reaching the pTGA. A pressure vessel capable of meeting these temperature/pressure conditions would be needed for the generator, as well as a heating source to heat this vessel to the required temperature. Because of the design of the inlet to the pTGA it was questioned whether the pTGA and alkali generator could be physically coupled because of the heating required to prevent condensation. In addition, even if possible, these system modifications far exceeded the resources available to this project. It should also be noted that sodium amide was considered as a source of alkali since it could potentially produce the desired sodium concentration at a lower system temperature; however, due to safety concerns (explosiveness), this option was not pursued.

A second option considered was to mix a water solution of sodium chloride and pump this solution into the pTGA. This would allow control of the sodium concentration by either varying the add rate of the solution to the pTGA or varying the concentration of the sodium in the solution. Previous researchers utilizing this technique noticed an accumulation of sodium chloride on the injection nozzle, implying that the water was evaporating leaving solid sodium chloride behind, eventually plugging the nozzle. Therefore, there was no guarantee that the sodium in the solution was making its way into the reactor; therefore, the vapor-phase concentration could not be controlled. A secondary concern was the injection of water vapor into the pTGA. The working components of the pTGA are exposed to the atmosphere within the pTGA and, therefore, are highly susceptible to corrosion. In the presence of water vapor, both $\mathrm{HCl}$ and $\mathrm{H}_{2} \mathrm{SO}_{4}$ would be present in relatively high concentrations, making corrosion a serious concern for the type of experiments being proposed.

The third idea for introducing the sodium to the pTGA was to put solid $\mathrm{NaCl}$ directly into the pTGA and let it vaporize in the pTGA. It would be necessary to place the $\mathrm{NaCl}$ in a location where the gas being introduced into the pTGA could pass across the $\mathrm{NaCl}$ and act as a carrier to move the alkali vapors across the sorbent. This method was chosen for testing on the pTGA. Figure 34 shows the pTGA schematically, with the $\mathrm{NaCl}$ located in a specially designed pan. This pan was made of a porous mesh to allow gases to 


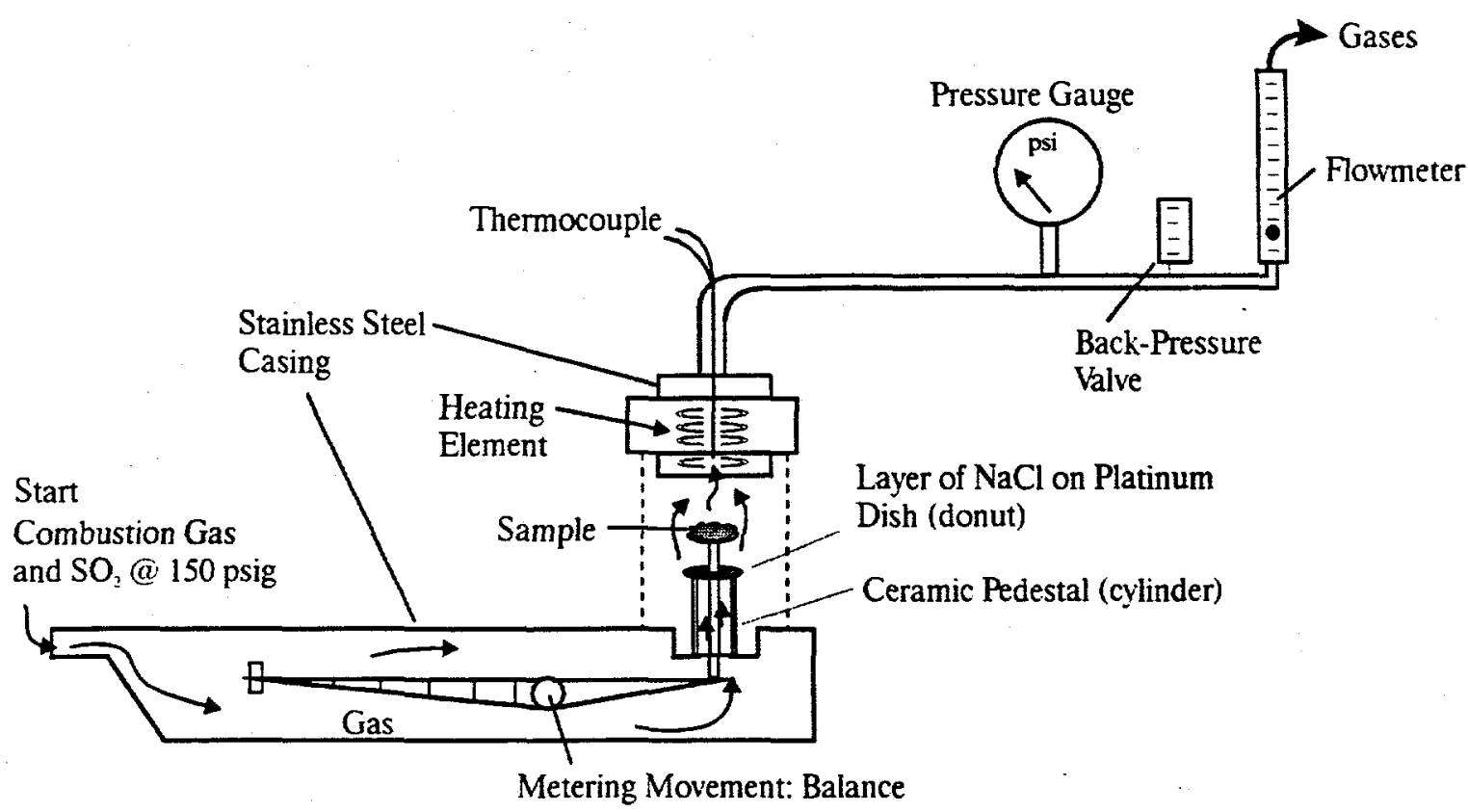

Figure 34. Configuration of the pTGA during attempted alkali generation/capture studies

pass through and located where the gas stream entering the pTGA should pass across it. The experimental trials performed under this configuration are described in the following subsection.

\subsubsection{Failure of the pTGA}

Testing on the pTGA was performed at 150 psig. The test protocol involved heating at a rate of $20^{\circ} \mathrm{C} / \mathrm{min}\left(36^{\circ} \mathrm{F} / \mathrm{min}\right)$ to the set point of $700^{\circ} \mathrm{C}\left(1292^{\circ} \mathrm{F}\right)$. The reactor was held at $700^{\circ} \mathrm{C}$ for $30 \mathrm{~min}$ and then ramped up to $775^{\circ} \mathrm{C}\left(1427^{\circ} \mathrm{F}\right)$ and held for another $30 \mathrm{~min}$. Initially, baseline tests were performed with nepheline, albite, and sodalite in $\mathrm{N}_{2}$ to establish a baseline without $\mathrm{NaCl}$ addition. These tests showed no weight change, indicating no decomposition was occurring. A test was then performed with nepheline in combustion gas. Again, no weight gain was noticed, indicating that $\mathrm{SQ}_{2}$ was not being absorbed by the nepheline. The next test was performed using albite and $\mathrm{NaCl}$. No weight change was recorded. Because a gain in weight was expected, the next test utilized kaolin as the sorbent. Work by previous researchers (Uberoi et al., 1990) indicated that kaolinite should adsorb $\mathrm{NaCl}$ at these pressures and temperatures. The kaolinite showed a weight loss as the sample was being brought up to temperature. This is expected as it 
releases water at approximately $550^{\circ} \mathrm{C}\left(950^{\circ} \mathrm{F}\right)$. No weight gain was noted for the kaolinite and $\mathrm{NaCl}$ at temperatures of $700^{\circ} \mathrm{C}\left(1292^{\circ} \mathrm{F}\right)$ and $775^{\circ} \mathrm{C}\left(1427^{\circ} \mathrm{F}\right)$.

The next step in evaluating the effectiveness of the pTGA as a screening tool for alkali sorbents was to perform a TGA at atmospheric pressure using the Dupont analyzer described in Section 3.2.1. The thermogram generated from albite plus $\mathrm{NaCl}$ showed a significant weight gain at $800^{\circ} \mathrm{C}\left(1472^{\circ} \mathrm{F}\right)$. The same test was repeated in the pTGA, with the pTGA operated at atmospheric pressure. No weight gain was observed. Although not conclusively determined, it was speculated that the flow of gas in the pTGA was such that the $\mathrm{NaCl}$ was not being transferred to the sorbent. As one final test, albite was mixed directly with $\mathrm{NaCl}$ at a ratio of $10: 1$ and put in the balance pan. No weight gain was noted when the sample was heated to $800^{\circ} \mathrm{C}\left(1472^{\circ} \mathrm{F}\right)$. At this point, it was decided that the pTGA could not be used for the sorbent-screening studies.

\subsection{Atmospheric Thermogravimetric Analysis}

Once it was determined that the EERC's pTGA was not suitable for investigating alkali sorbents, the emphasis was changed to the atmospheric TGA. This TGA was used 1) to investigate the original series of reactions proposed in Section 1.5 for capture of alkali using sodalites, 2) to gather rate data for candidate sorbents, and 3) to assist in the selection of sorbents for testing in the bench-scale reactor.

\subsubsection{Equipment Description}

The TGA equipment used in the research was a Dupont 951 TGA interfaced with a 1090 thermal analyzer control unit and data processor. The TGA consists of an electronic balance and a furmace capable of operating at temperatures up to $1200^{\circ} \mathrm{C}\left(2192^{\circ} \mathrm{F}\right)$. The instrument has a 100 -mg sample capacity and a maximum heatup rate of $100^{\circ} \mathrm{C} / \mathrm{min}$. Typical sample sizes range from 10 to $40 \mathrm{mg}$ of material.

Figure 35 is a diagram of the TGA as utilized for this work. Gas flows through the balance across the platinum sample pan, which is suspended by a horizontal quartz beam at the center of the furnace. The sample temperatures are determined by a chromel-alumel thermocouple located about $1 \mathrm{~mm}$ above the center of the sample pan. Weight, time, and temperature are computer-logged for later analysis. 


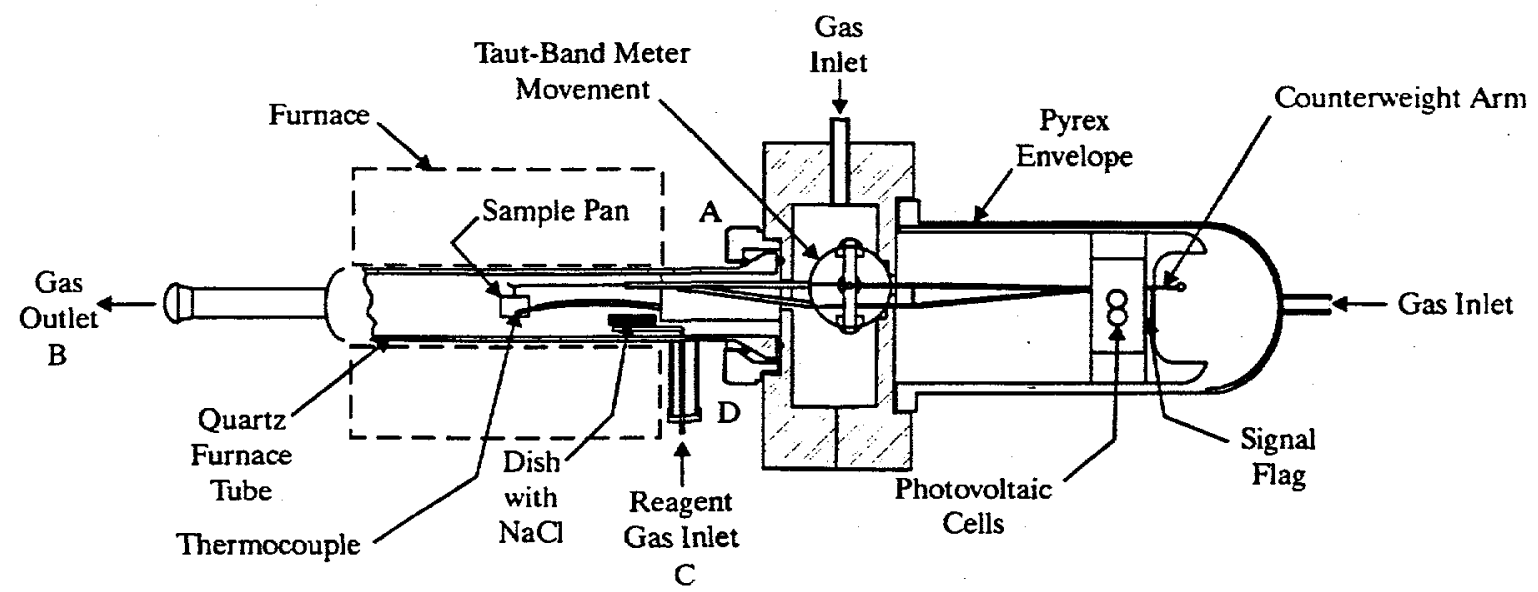

Figure 35. Schematic of the Dupont 951 TGA

For the experimental work performed, two different gas compositions were utilized. Some tests were performed using nitrogen. The intent of this selection was to expose the sorbents only to the sodium, chloride, and an inert gas. For other tests, a synthetic gas mixture of $\mathrm{SO}_{2}, \mathrm{CO}_{2}, \mathrm{O}_{2}$, and $\mathrm{N}_{2}$ was used to simulate the gas stream that the sorbent might see in a real combustion situation. It was thought that this gas composition would provide an evaluation of the sorbent's performance in a "true" environment. It was also felt that having $\mathrm{SO}_{2}$ present in the system was critical, since the reaction scheme being proposed for simultaneous sodium and chlorine capture has reactions where $\mathrm{SO}_{2}$ and $\mathrm{Cl}_{2}$ compete. The concentrations of gases in the synthetic combustion mix are $2015 \mathrm{ppm} \mathrm{SO}, 14.29 \% \mathrm{CO}_{2}, 4.95 \% \mathrm{O}_{2}$, and the balance $\mathrm{N}_{2}$.

\subsubsection{TGA Reaction Conditions}

As discussed in the previous section, a method to add sodium to the sample gas that passes across the sorbent material was required for these experiments. For the same reasons as discussed for the pTGA, the approach taken for introducing vapor-phase sodium into the TGA was to place $\mathrm{NaCl}$ crystals in a pan upstream (to the gas inlet side as shown in Figure 35) of the sample pan that holds the sorbent. The intent of this configuration was to allow the sodium to vaporize in the heated chamber of the TGA and then have 
the carrier gas sweep this sodium across the sorbent material. $\mathrm{NaCl}$ was chosen because it is the sodium salt that has the highest vapor pressure and, therefore, the highest sodium concentration over the range of interest. The temperatures utilized for the experiments and the corresponding sodium vapor-phase concentration are presented in Table 10. The concentrations presented in the table were determined from thermochemical equilibrium calculations and were not measured. The temperature required to reach these concentrations at $10.2 \mathrm{~atm}$ is also given. It can be seen from Table 10 that this range of sodium concentrations encompass the range expected for PFBC over the normal range of operation.

Table 10 Vapor-Phase Sodium Concentrations at the Various Temperatures Tested Using TGA

\begin{tabular}{lcc}
\hline TGA Temperature, ${ }^{\circ} \mathrm{C}$ & $\mathrm{NaCl}$ Concentration, ppm & Equivalent Temperature at $10.2 \mathrm{~atm},{ }^{\circ} \mathrm{C}^{\prime}$ \\
\hline 700 & 29 & 791 \\
733 & 68 & 824 \\
766 & 158 & 857 \\
800 & 336 & 887 \\
\hline
\end{tabular}

${ }^{1}$ Temperature that would result in the same concentration at $10.2 \mathrm{~atm}$.

The sorbents tested in the TGA were all fine powders. In PFBC, the bed is granular in nature and would consist of a broad range of particles with a $1 / 8$-in. topsize. The use of powders was preferred for the initial screening, however, since powders minimize sample variability and permit control of particle size (all samples were screened through a 30 -mesh screen).

The general procedure for the TGA tests involved staged heating to quantify the adsorption rate at several different temperatures and $\mathrm{NaCl}$ concentrations during a single test sequence. The TGA was loaded with approximately $50 \mathrm{mg}$ of the sorbent to be tested in the balance. If $\mathrm{NaCl}$ was to be used during the test, approximately $200 \mathrm{mg}$ was placed in the pan at the inlet of the reactor, as shown in Figure 35 . The TGA was heated up to $700^{\circ} \mathrm{C}$ and held at that temperature for $1 / 2 \mathrm{hr}$. The temperature in the TGA was then raised to $733^{\circ} \mathrm{C}$ and held for another $30 \mathrm{~min}$. This was repeated for $766^{\circ}$ and $800^{\circ} \mathrm{C}$. After the 30 -min exposure at $800^{\circ} \mathrm{C}$, the reactant gas was changed and the TGA held at $800^{\circ} \mathrm{C}$ for another $30 \mathrm{~min}$. For example, if the 
main run was performed using a combustion gas mixture, the reactant gas was changed to inert (nitrogen) for the last $30 \mathrm{~min}$. The intent was to provide an indication of the impact of carrier gas for the sample being tested.

This procedure generated thermograms similar to Figure 36 . The time and weight gain at each condition are marked. A rate of adsorption was calculated as a fractional weight gain per unit time. This calculation yielded the amount of gas adsorbed (weight gained by sample) per weight of sorbent per unit time. The units chosen were $\mathrm{mg}$ gas adsorbed per gram sorbent per hour $(\mathrm{mg} / \mathrm{g} / \mathrm{hr})$. The measured values ranged from 0 to 75 .

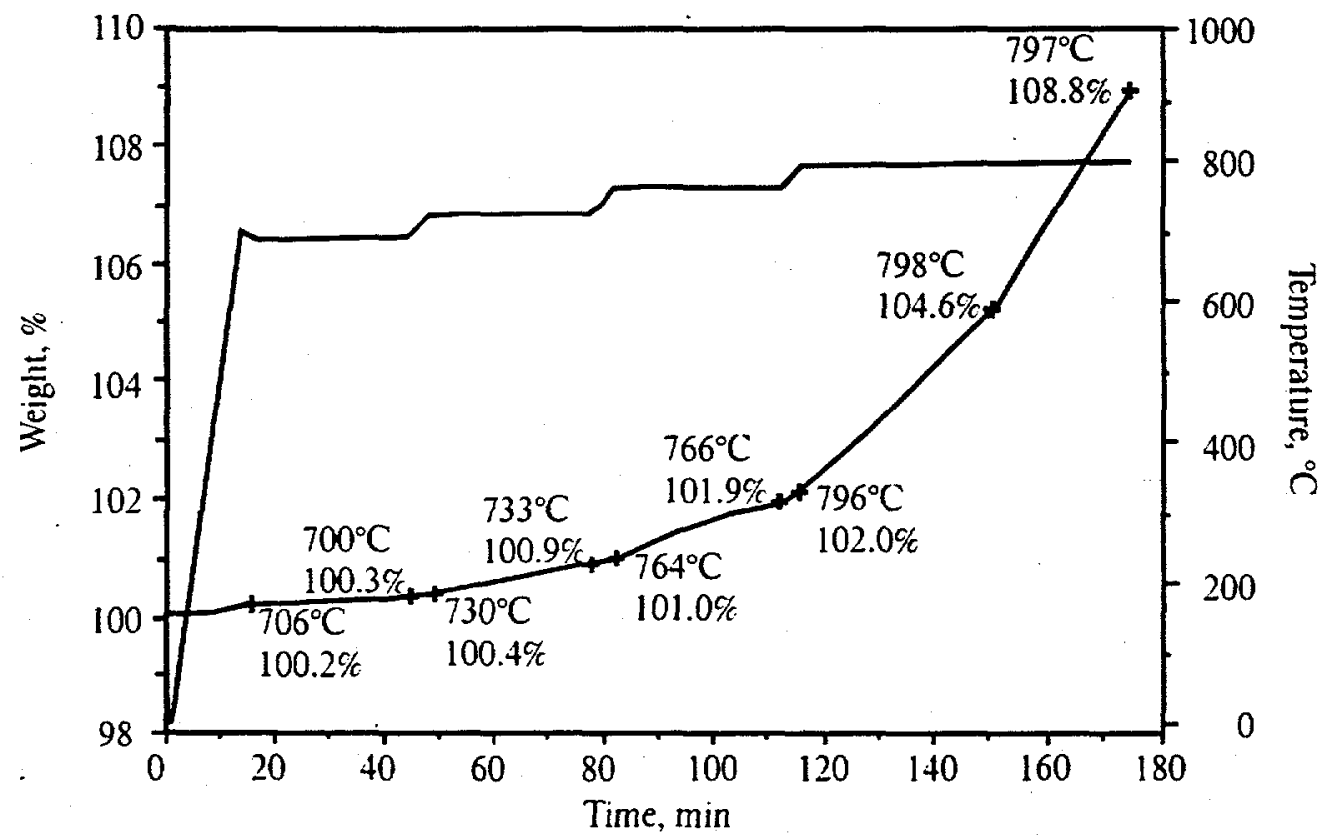

Figure 36. Thermogram from a stepwise TGA using albite as the sorbent with $\mathrm{NaCl}$ in combustion gas

\subsubsection{Test Matrix for TGA Determinations}

One objective of the TGA tests was to develop a better understanding of the rates and direction of the reactions proposed for simultaneously capturing alkali, sulfur, and chlorine. The reactions as presented in Section 1.6 are:

$$
\begin{aligned}
& \mathrm{NaCl}+3 \mathrm{NaAlSiO}_{4}-\mathrm{Na}_{4} \mathrm{Al}_{3} \mathrm{Si}_{3} \mathrm{O}_{12} \mathrm{Cl} \\
& \text { (nepheline) (sodalite) }
\end{aligned}
$$




$$
\begin{array}{cc}
\mathrm{Na}_{4} \mathrm{Al}_{3} \mathrm{Si}_{3} \mathrm{O}_{12} \mathrm{Cl}+6 \mathrm{SiO}_{2}-\mathrm{NaCl}+3 \mathrm{NaAlSi}_{3} \mathrm{O}_{8} \\
\text { (sodalite) } & \text { (albite) } \\
\mathrm{Na}_{4} \mathrm{Al}_{3} \mathrm{Si}_{3} \mathrm{O}_{12} \mathrm{Cl}+\mathrm{Na}_{2} \mathrm{SO}_{4}-2 \mathrm{NaCl}+\mathrm{Na}_{8} \mathrm{Al}_{6} \mathrm{Si}_{6} \mathrm{O}_{24}\left(\mathrm{SO}_{4}\right) \\
\text { (sodalite) } \\
\mathrm{Na}_{8} \mathrm{Al}_{6} \mathrm{Si}_{6} \mathrm{O}_{24}\left(\mathrm{SO}_{4}\right)+12 \mathrm{SiO}_{2}-\mathrm{Na}_{2} \mathrm{SO}_{4}+6 \mathrm{NaAlSi}_{3} \mathrm{O}_{8} \\
\text { (nosean) } \\
2 \mathrm{Na}_{4} \mathrm{Al}_{3} \mathrm{Si}_{3} \mathrm{O}_{12} \mathrm{Cl}+\mathrm{SO}_{2}+\mathrm{O}_{2}-\mathrm{Na}_{8} \mathrm{Al}_{6} \mathrm{Si}_{6} \mathrm{O}_{24}\left(\mathrm{SO}_{4}\right)+\mathrm{Cl}_{2} \\
\text { (sodalite) } \\
\text { (nosean) }
\end{array}
$$

The tests used to evaluate this series of reactions are presented in Table 11. Reaction 1 was investigated using nepheline with $\mathrm{NaCl}$, with a weight gain indicating a forward reaction. The test with sodalite without $\mathrm{NaCl}$, if accompanied by a weight loss, would indicate that the reverse of Reaction 1 was favored under the conditions tested. Albite was used both with and without $\mathrm{NaCl}$ and with combustion gas $\left(\mathrm{SO}_{2}\right)$ and without to study Reactions 2 and 4. To investigate the impact of $\mathrm{SiO}_{2}$ on Reaction 2, two tests were performed with $\mathrm{SiO}_{2}$ mixed with the sorbent. Tests with sodalite with a combustion gas and with and without $\mathrm{NaCl}$ were used to investigate Reactions 3 and 5.

Water was not included as a variable for this testing because of concerns of acid corrosion of the TGA equipment. While hydroxides are prevalent at higher operating temperatures typical of pc-fired systems, results of the modeling efforts reported in Section 2.2 indicate that the alkali sulfates and chlorides will be the primary gas phase species available for reaction. Some improvement in sorbent performance could be expected with water vapor due to the hydroxylation of inner layer reaction sites of the sorbents, and subsequent reaction of the hydroxylated sites with the vapor phase alkali. The inclusion of water vapor could also play a minor role in the above reactions through the formation of $\mathrm{HCl}$ and/or $\mathrm{H}_{2} \mathrm{SO}_{4}$, thereby changing the effective concentrations of $\mathrm{Na}_{2} \mathrm{SO}_{4}, \mathrm{NaCl}, \mathrm{SO}_{2}$, and $\mathrm{Cl}_{2}$. Results from the PFBR testing which will be discussed in Section 5 substantiate the importance of the sulfates rather than hydroxides.

Several other conventional sorbents were also screened using the TGA. These sorbents and the test conditions used are presented in Table 12. The more conventional sorbents of kaolinite and activated bauxite were tested to serve as a comparison to the sorbents involved in Reactions 1 through 5 and to allow 
comparison to work reported in the literature. A sample of zeolite that is used as a catalyst support surface was also tested to determine if its porous structure would serve as good sites for physical adsorption.

Table 11

Test Matrix for Evaluation of Sodalite Reactions Performed on the TGA

\begin{tabular}{lccccccc}
\hline & & \multicolumn{5}{c}{ Carrier Gas Used at Each Temperature } \\
\cline { 3 - 7 } Sorbent & $\mathrm{NaCl}$ & $700^{\circ} \mathrm{C}$ & $733^{\circ} \mathrm{C}$ & $766^{\circ} \mathrm{C}$ & $800^{\circ} \mathrm{C}$ & $800^{\circ} \mathrm{C}$ & $850^{\circ} \mathrm{C}$ \\
\hline Albite & Yes & - & - & - & - & - & $\mathrm{N}_{2}$ \\
Albite & No & - & - & - & - & - & $\mathrm{N}_{2}$ \\
Albite & Yes & $\mathrm{C}$ & $\mathrm{C}$ & $\mathrm{C}$ & $\mathrm{C}$ & $\mathrm{N}_{2}$ & - \\
Albite & $\mathrm{No}$ & $\mathrm{C}$ & $\mathrm{C}$ & $\mathrm{C}$ & $\mathrm{C}$ & $\mathrm{N}_{2}$ & - \\
Albite + & Yes & $\mathrm{C}$ & $\mathrm{C}$ & $\mathrm{C}$ & $\mathrm{C}$ & $\mathrm{N}_{2}$ & - \\
Quartz & & & & & & & \\
Albite + & Yes & $\mathrm{N}_{2}$ & $\mathrm{~N}_{2}$ & $\mathrm{~N}_{2}$ & $\mathrm{~N}_{2}$ & - & - \\
Quartz & & & & & & \\
Sodalite & Yes & $\mathrm{C}$ & $\mathrm{C}$ & $\mathrm{C}$ & $\mathrm{C}$ & $\mathrm{N}_{2}$ & - \\
Sodalite & No & $\mathrm{C}$ & $\mathrm{C}$ & $\mathrm{C}$ & $\mathrm{C}$ & $\mathrm{N}_{2}$ & - \\
Sodalite & Yes & $\mathrm{N}_{2}$ & $\mathrm{~N}_{2}$ & & $\mathrm{~N}_{2}$ & $\mathrm{C}$ & - \\
Nepheline & Yes & $\mathrm{C}$ & $\mathrm{C}$ & $\mathrm{C}$ & $\mathrm{C}$ & $\mathrm{N}_{2}$ & - \\
\hline
\end{tabular}

'Combustion gas.

Table 12

Test Matrix for Screening of Conventional Sorbents in the TGA

\begin{tabular}{lcccccc}
\hline & & \multicolumn{5}{c}{ Carrier Gas Used at Each Temperature } \\
\cline { 3 - 7 } Sorbent & $\mathrm{NaCl}$ & $700^{\circ} \mathrm{C}$ & $733^{\circ} \mathrm{C}$ & $767^{\circ} \mathrm{C}$ & $800^{\circ} \mathrm{C}$ & $800^{\circ} \mathrm{C}$ \\
\hline AlO $(\mathrm{OH})_{3}$ & Yes & $\mathrm{C}$ & $\mathrm{C}$ & $\mathrm{C}$ & $\mathrm{C}$ & $\mathrm{N}_{2}$ \\
Kaolinite & $\mathrm{Yes}$ & $\mathrm{C}$ & $\mathrm{C}$ & $\mathrm{C}$ & $\mathrm{C}$ & $\mathrm{N}_{2}$ \\
Bauxite & $\mathrm{Yes}$ & $\mathrm{N}_{2}$ & $\mathrm{~N}_{2}$ & $\mathrm{~N}_{2}$ & $\mathrm{~N}_{2}$ & $\mathrm{C}$ \\
Bauxite & $\mathrm{Yes}$ & - & - & - & - & $\mathrm{C}$ \\
Zeolite & $\mathrm{Yes}$ & $\mathrm{N}_{2}$ & $\mathrm{~N}_{2}$ & $\mathrm{~N}_{2}$ & $\mathrm{~N}_{2}$ & $\mathrm{C}$ \\
\hline
\end{tabular}




\subsection{Bench-Scale Testing}

The objective of this phase of testing was to perform dynamic tests under conditions that more closely simulate PFBC conditions to help define the effectiveness of selected sorbents under "real" conditions. The goal of these dynamic tests include an evaluation of 1) the impact of the sorbent on total gas-phase alkali concentration, 2) sintering or agglomeration in the bed, 3) deposition on heat-transfer surfaces, 4) bridging and blinding of hot-gas filter elements, and 5) the overall changes in the size distribution and quantity of the ash generated during the PFBC process. The equipment, the operational procedure, and the test matrix used to accomplish these goals are described in this section.

\subsubsection{Equipment Description}

The heart of the system used for this work is the PFBR. Flue gases generated in this system are collected in a hot-gas filter vessel. The flue gases are sampled for alkali using a specially designed alkalisampling probe. Figure 37 shows this equipment schematically. Each of these components is described.

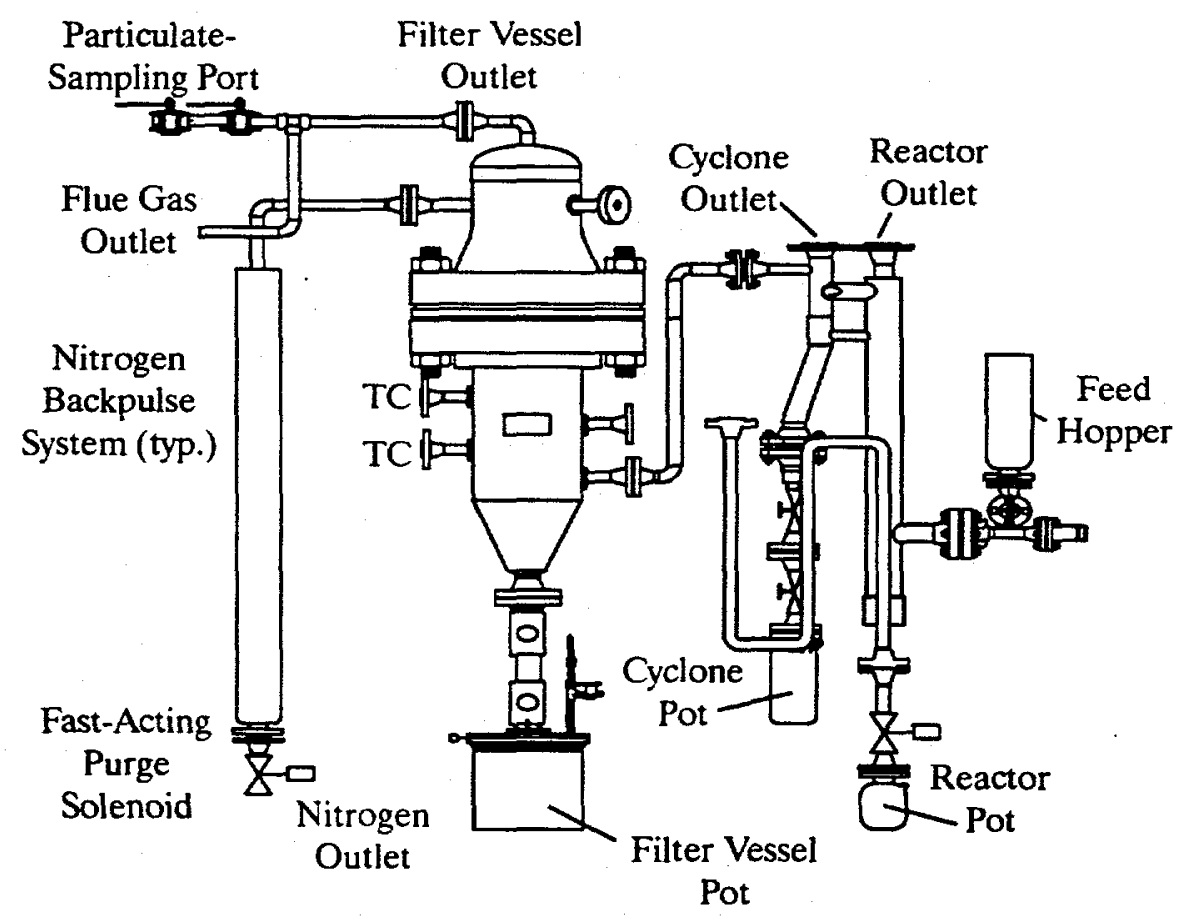

Figure 37. Schematic representation of the PFBR and hot-gas filter vessel test system 
The PFBR is used at the EERC to simulate the bed chemistry, ash interactions, and emissions from a PFB under closely controlled conditions. This reactor is used for sorbent characterization, gaseous emissions including trace elements, agglomeration, and hot-gas cleanup testing over a wide range of operational conditions. The $140-\mathrm{cm}(55$-in)-tall reactor is constructed of $7.6-\mathrm{cm}$ (3-in.) Schedule 80 pipe and is externally heated with three ceramic heaters. A hot cyclone collects the ash and bed material that is carried out of the reactor. Typical operating conditions for this reactor are shown in Table 13. The preheated fluidizing gas can be a mixture of air and nitrogen or just air; moreover, one additional gas such as carbon dioxide, carbon monoxide, sulfur dioxide, or a nitrogen oxide can be added to result in a flue gas similar to that generated in a full-scale $\mathrm{FBC}$. Preheated gas at temperatures of up to $593^{\circ} \mathrm{C}\left(1100^{\circ} \mathrm{F}\right)$ and pressures of up to 200 psig are supplied at the bottom of the reactor through a $2.5-\mathrm{cm}$ (1-in.) Schedule 40 pipe. The fluidizing gas is supplied at sufficiently high velocities to prevent the sized bed material from dropping out during operation. The use of both air and nitrogen as fluidizing gas allows excess air and gas velocity to be matched to any design condition.

Table 13

Typical PFBR Operating Conditions

\begin{tabular}{lc}
\hline Reactor Diameter & 2.875 -in. ID \\
Temperature & $1400^{\circ}-1700^{\circ} \mathrm{F}$ \\
Pressure & $0-150 \mathrm{psig}$ \\
Gas Flow Rate & $1-30 \mathrm{scfm}$ \\
Coal Feed Rates & $1-8 \mathrm{lb} / \mathrm{hr}$ \\
Velocities & $1-10 \mathrm{ft} / \mathrm{sec}$ \\
Cyclone Exit Temperature & Maximum $1600^{\circ} \mathrm{F}$ \\
Particulate Loading & $200-9000 \mathrm{ppm}$ \\
\hline
\end{tabular}

The fluidizing gas enters the $7.6-\mathrm{cm}$ (3-in.) main section of the reactor through a conical transition. This conical section was designed without a distributor plate to allow quick removal and quench of the bed material after completion of a test. Bed material can be sampled or collected using a lock hopper system located at the bottom of the reactor. Ports for alkali-sampling probes or gas-/solid-sampling probes are 
located at the top of the reactor and the top of the cyclone. An air-cooled deposition probe is located at the exit of the reactor. Alternatively, a sight port at the top of the reactor can be installed with a color videocamera for on-line observation of the bed during high-pressure operation. For this testing, the aircooled deposition probe was installed at the top of the main reactor, and the alkali-sampling probe at the top of the cyclone. Figure 38 is a schematic of the PFBR showing the feed port, hot cyclone, fluidizing gas inlet, the deposition probe at the top of the reactor, and the sampling port on the top of the cyclone.

Figure 39 is a photograph of the actual reactor vessel, cyclone, air preheater, reactor collection pot, and fuel feed hopper.

The use of external electric heaters around the reactor provides the capability to match the fuel feed rate to the amount of bed material in the reactor. The heaters can be used for maintaining the reactor and hot cyclone at temperatures of up to $1093^{\circ} \mathrm{C}\left(2000^{\circ} \mathrm{F}\right)$ for atmospheric operation and up to $925^{\circ} \mathrm{C}$ $\left(1700^{\circ} \mathrm{F}\right)$ for operation at $10.2 \mathrm{~atm}(150 \mathrm{psi})$.

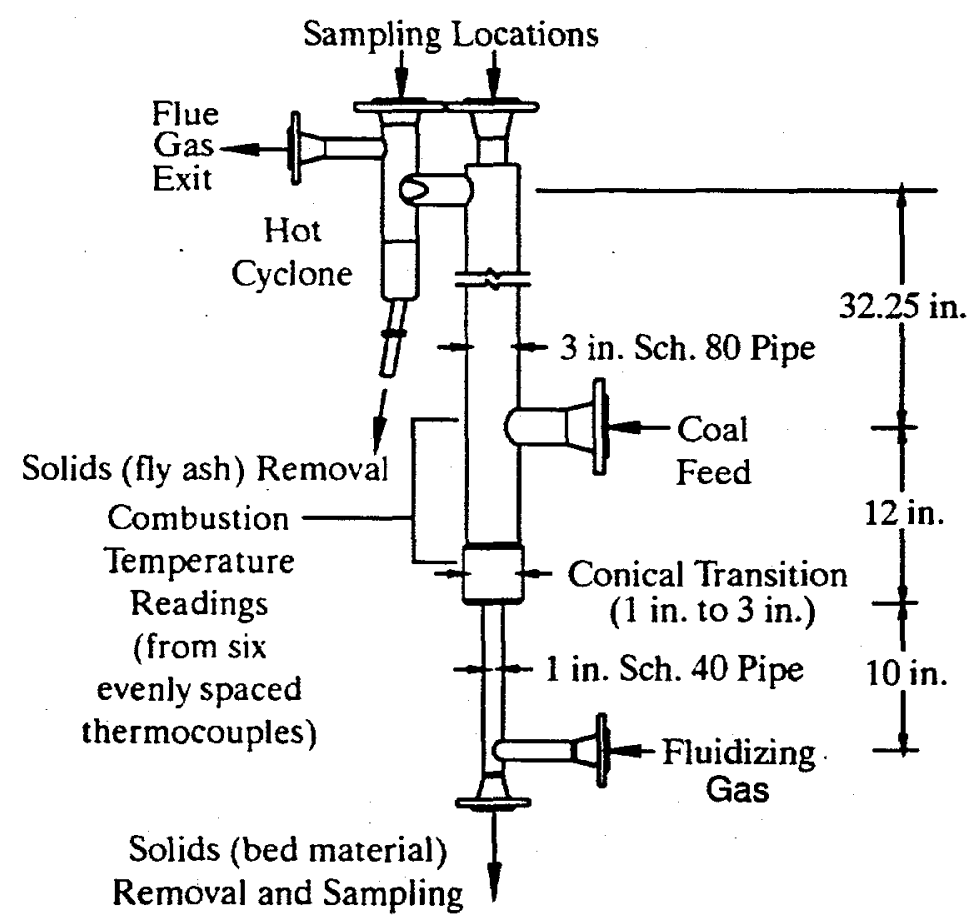

Figure 38. Schematic of PFBR pressure vessel 


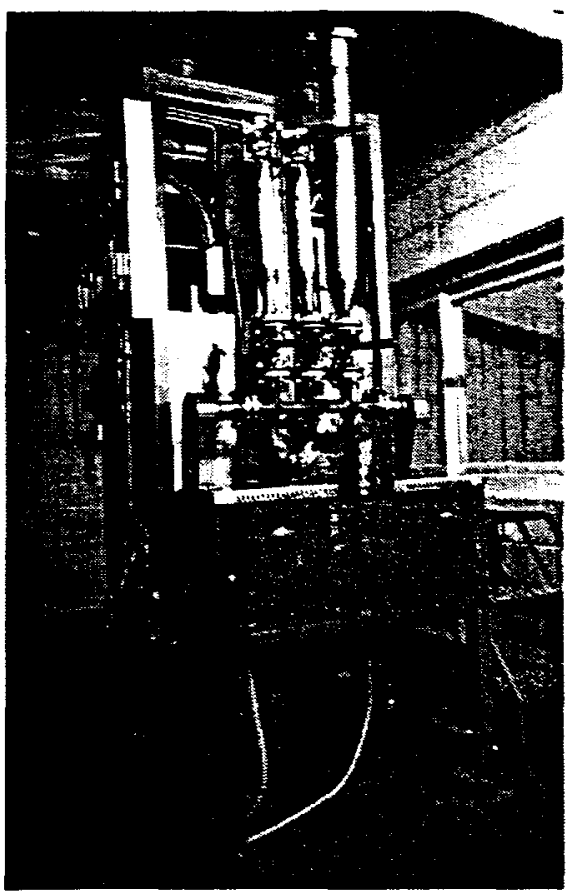

Figure 39. Photograph of PFBR pressure vessel

Dry coal and sorbent are premixed and metered into the reactor with a separate auger that feeds into a common water-cooled auger, which in turn carries the material into the reactor. A bed material hopper empties directly into the common auger, without flow control. Each hopper is maintained at a pressure slightly higher than that in the combustor during operation. The hoppers can be isolated from the pressurized system so that they can be refilled during a test. At the bottom of each hopper are sensors to alert the operator when the hoppers are empty and need to be refilled.

A data acquisition and control system is used to monitor and record all critical pressures, temperatures, flow rates, and emissions. These critical data include the gas flow rates, bed static pressure and differential pressures across the bed and cyclone. and eleven different internal reactor temperatures. These reactor temperatures are located at $0.25,1.75,3.5,5,7,9,11,15,23,31$, and 43.25 in. above the conical transition section. The air and nitrogen flow rates are controlled automatically to flow rate set points. The reactor pressure is automatically controlled to a pressure set point. Continuous emission sampling of the flue gas measured the levels of $\mathrm{O}_{2}, \mathrm{SO}_{2}, \mathrm{NO}_{\mathrm{x}}, \mathrm{N}_{2} \mathrm{O}, \mathrm{CO}, \mathrm{CO}_{2}$, and hydrocarbon. Solid 
samples can include bottom ash, fly ash, and particulate samples from the stack to determine particulate loading leaving the cyclone.

\subsubsection{Description of Hot-Gas Filter Vessel}

Figure 40 illustrates the hot-gas cleanup (HGCU) vessel for the testing of ceramic candle filters on the 7.6-cm (3-in.) PFBR. This vessel was designed to handle all of the gas flow from the PFBR at its nominal design conditions. The vessel is approximately $25-\mathrm{cm}(9.75-\mathrm{in}$.$) ID and 152-\mathrm{cm}(60-\mathrm{in}$.$) long$ (including cone, vessel, and cap) and is designed to handle a gas flow up to $30 \mathrm{scfm}$ at $843^{\circ} \mathrm{C}\left(1550^{\circ} \mathrm{F}\right)$ and $10.2 \mathrm{~atm}$ (150 psig). The tube sheet is interchangeable to handle different-sized filters. The filters can be sealed in the tube sheet with weighted metal donut rings or by metal clamps which counteract the upward force imparted across the candle filter by the filter's differential pressure. The vessel is sized such that it can handle three candle filters up to $45 \mathrm{~cm}$ (18 in.) long with a $6.0-\mathrm{cm}(2.375-\mathrm{in}$.) OD. This provides candle spacing of $9.8-\mathrm{cm}(3.85-$ in.) center line to center line and enables filter face velocities as low as $0.76 \mathrm{~m} / \mathrm{min}$ $(2.5 \mathrm{ft} / \mathrm{min})$ to be tested in the PFBR. Higher face velocities can be achieved by using shorter candles or higher gas flow rates. Operating conditions for the filter vessel are shown in Table 14.

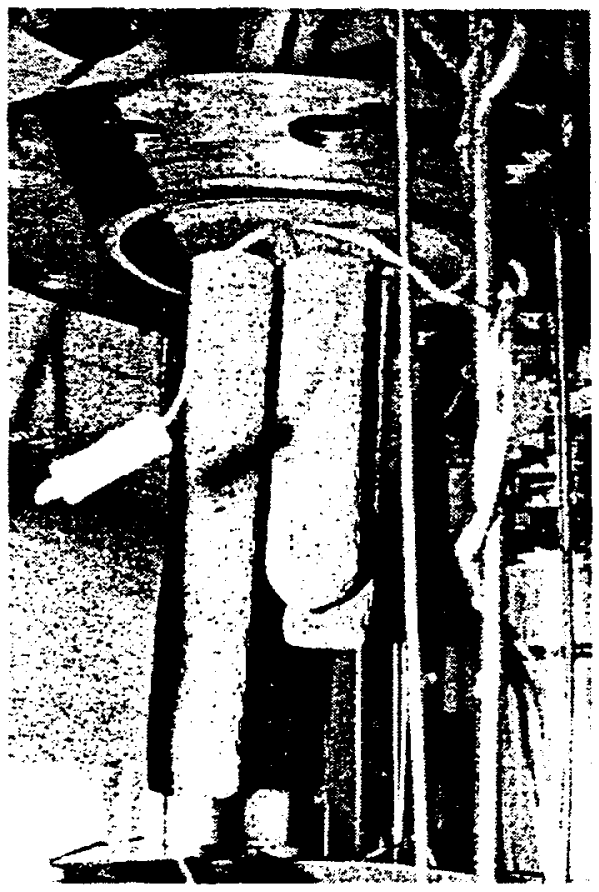

Figure 40. Photograph of the inside of the bench-scale hot-gas filter vessel on the PFBR 
Table 14

High-Temperature High-Pressure (HTHP) Filter Vessel Operating Capabilities

\begin{tabular}{ll}
\hline Vessel Diameter & 9.75 -in. ID \\
Temperature & up to $1550^{\circ} \mathrm{F}$ \\
Pressure & up to $150 \mathrm{psig}$ \\
Gas Flow Rate & up to $30 \mathrm{scfm}$ \\
Filter Sizes & 2.375 in. OD by 18 in. long \\
Number of Candles & Up to 3 \\
Filter Face Velocities & $2.5-12 \mathrm{ft} / \mathrm{min}$ \\
$\mathrm{N}_{2}$ Backpulse System & up to $1550^{\circ} \mathrm{F}$ inlet; both short, high-pressure and long, low-pressure \\
& pulses \\
\hline
\end{tabular}

Ports in the filter vessel allow temperature and pressure measurements to be obtained. These same ports can be utilized to insert a water-cooled borescope probe for visually inspecting the filter elements. The ash letdown station consists of two high-temperature valves to act as lock hoppers to isolate the ash hopper from the filter vessel.

The nitrogen backpulse system is designed to supply a minimum of three candle volumes per pulse for the longest candle filters and even higher for the shorter candle filters. The nitrogen is capable of being heated up to $815^{\circ} \mathrm{C}\left(1500^{\circ} \mathrm{F}\right)$ before it enters the filter vessel. The length and volume of nitrogen displaced into the vessel are controlled by the regulated pressure (up to $20 \mathrm{~atm}$ [ $300 \mathrm{psig}]$ ) of the cold nitrogen reservoir and the solenoid valves used to control the timing of the cold-gas pulse which displaces the hot nitrogen into the filter vessel. Because of a height limitation, a heated $2.5-\mathrm{cm}(1-\mathrm{in}$.) pipe is used to connect the 7.6-cm (3-in.) PFBR to the hot-gas filter vessel.

\subsubsection{EERC Alkali-Sampling Probe Equipment Description}

An alkali condensation sampling train was used to monitor the vapor-phase alkali concentrations in the PFBR tests. The condensation sampling train was chosen over the other techniques discussed in Section 2.6 because of its relatively low cost to build and operate and its relative simplicity to operate.

Disadvantages are the difficulty in collecting a representative sample, especially samples which might be collected under reducing conditions, and the delay in obtaining the analytical results. The alkali-sampling train typically extracts a representative sample from the cyclone outlet of the PFBR. 
The PFBR alkali-sampling probe consists of a 3.34-cm (1.3-in.) OD stainless steel pipe which has been fitted with a small ceramic filter provided by the CeraMem Corporation. The principle behind the sampling probe is to extract a hot-gas sample through a ceramic filter that is representative of the hot-gas filters currently being developed for advanced coal-fired power generation systems. After passing through the ceramic filter maintained at full system temperature, the gases and any vapor-phase alkali species which passed through the filter are cooled and allowed to condense on a high surface area "cold finger." The gas then passes through a final filter to collect any remaining aerosol particles and then through a series of water bubblers for the trapping of any additional alkali vapors and the removal of water vapor. This gas finally passes through pressure and flow measurement and control devices. Figure 41 is a diagram illustrating the alkali-sampling probe and heat exchanger with the bubbler train. The high surface area cold finger and the final filter are removed at the end of a test and washed with deionized water to dissolve the alkali species. The washings and the bubbler solutions are analyzed to determine the amount of alkali collected from the flue gas sampled. Measuring the volume of rinse solution and the concentration of alkali species in rinse solution and monitoring the total volume of gas sampled allow the vapor-phase alkali concentration to be calculated in the gas stream.

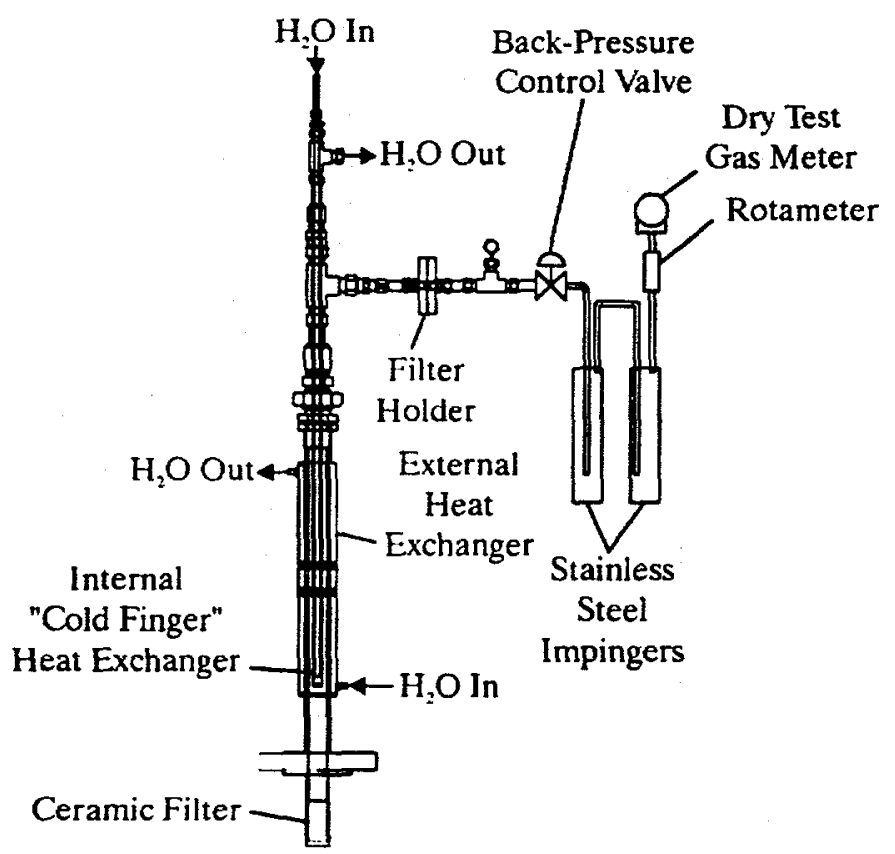

Figure 41. Schematic of EERC extractive alkali-sampling probe 


\subsubsection{PFBR Operations Protocol}

All tests performed on the PFBR followed the same operating procedures. The system was heated up to $840^{\circ} \mathrm{C}\left(1550^{\circ} \mathrm{F}\right)$ using the electrical heaters and was brought up to system pressure prior to the introduction of coal. The air and nitrogen flows to the system were balanced to a calculated ratio that would yield approximately $25 \%$ excess air once full coal feed was established. The total flow rate of these two gases was established to provide the desired gas velocity within the reactor. Once the system was at temperature and pressure, $1700 \mathrm{~g}$ of bed material was introduced into the reactor. This would lower the reactor temperature to about $480^{\circ} \mathrm{C}\left(900^{\circ} \mathrm{F}\right)$. Once all of the bed material was added, coal feed was initiated. The reactor temperature would climb back to the desired temperature over about a $10-\mathrm{min}$ time period. The flow rates of air and nitrogen were adjusted to provide $25 \%$ excess air and a superficial gas velocity of $0.91 \mathrm{~m} / \mathrm{sec}(3.0 \mathrm{ft} / \mathrm{sec})$. The reactor was allowed to stabilize at the selected conditions prior to starting the alkali sampling. This typically took about $30 \mathrm{~min}$. Alkali sampling was initiated by opening the valves to the sampling probe and establishing a flow rate of approximately $50 \mathrm{~L} / \mathrm{min}$ through the sampling probe. After $4 \mathrm{hr}$ of alkali sampling, the alkali probe was brought off-line by closing the valves. The remaining coal in the hoppers was allowed to run out, and the run was terminated. The total time on coal was typically $5 \mathrm{hr}$.

Once the coal supply was exhausted, the reactor temperature was allowed to cool to approximately $700^{\circ} \mathrm{C}\left(1300^{\circ} \mathrm{F}\right)$. The bed material was drained into the bottom hopper. The system was depressurized and the gas flows stopped. The filter vessel was pulsed once while the system was still hot. The system was allowed to cool overnight. The bed material, cyclone ash, and filter vessel hopper ash were retrieved, weighed, and put in sample containers for future analyses. The top of the reactor and the cyclone and the bottom of the filter vessel were removed, and any ash that was held up in the system was removed, weighed, and saved for future analysis. The deposition probe was removed and photographed. The alkali probe was removed, and washed into a 2-l flask for subsequent analysis of $\mathrm{Na}, \mathrm{Cl}$, and $\mathrm{SQ}$. The run data logged during the test were retrieved on diskette, with the data reduction performed off-line. 
Typical run conditions are shown in the following figures. Figure 42 shows the measured temperatures from one of the tests performed on the PFBR. The higher temperatures in the upper zones of the PFBR are indicative of fines burning in the freeboard. This is typical for FBCs which feed coal at a location high in the bed or over bed. The set point for this work was the average temperature in Zone 1. The reactor pressure held constant for all runs. The cyclone pressure drop remained constant all runs, indicating that the cyclone was not plugging during any of the tests. Some increase in bed pressure drop was noted, especially for those tests utilizing high sorbent add rates because of a buildup of solids in the bed.

Typical gas concentrations are shown in Figure 43. The concentration (partial pressure) of oxygen was held at a value comparable to a full-scale unit. The $\mathrm{CO}_{2}$ partial pressure, however, was lower. As explained in the equipment description, it is necessary to use a combination of nitrogen and air as the combustion gas for the PFBR. This helps balance the heat load to the combustor and allows the heat input per volume bed to approximate that of an operating PFBC. To maintain the correct excess air level without the addition of nitrogen, the coal feed rate would need to be unrealistically high as compared to

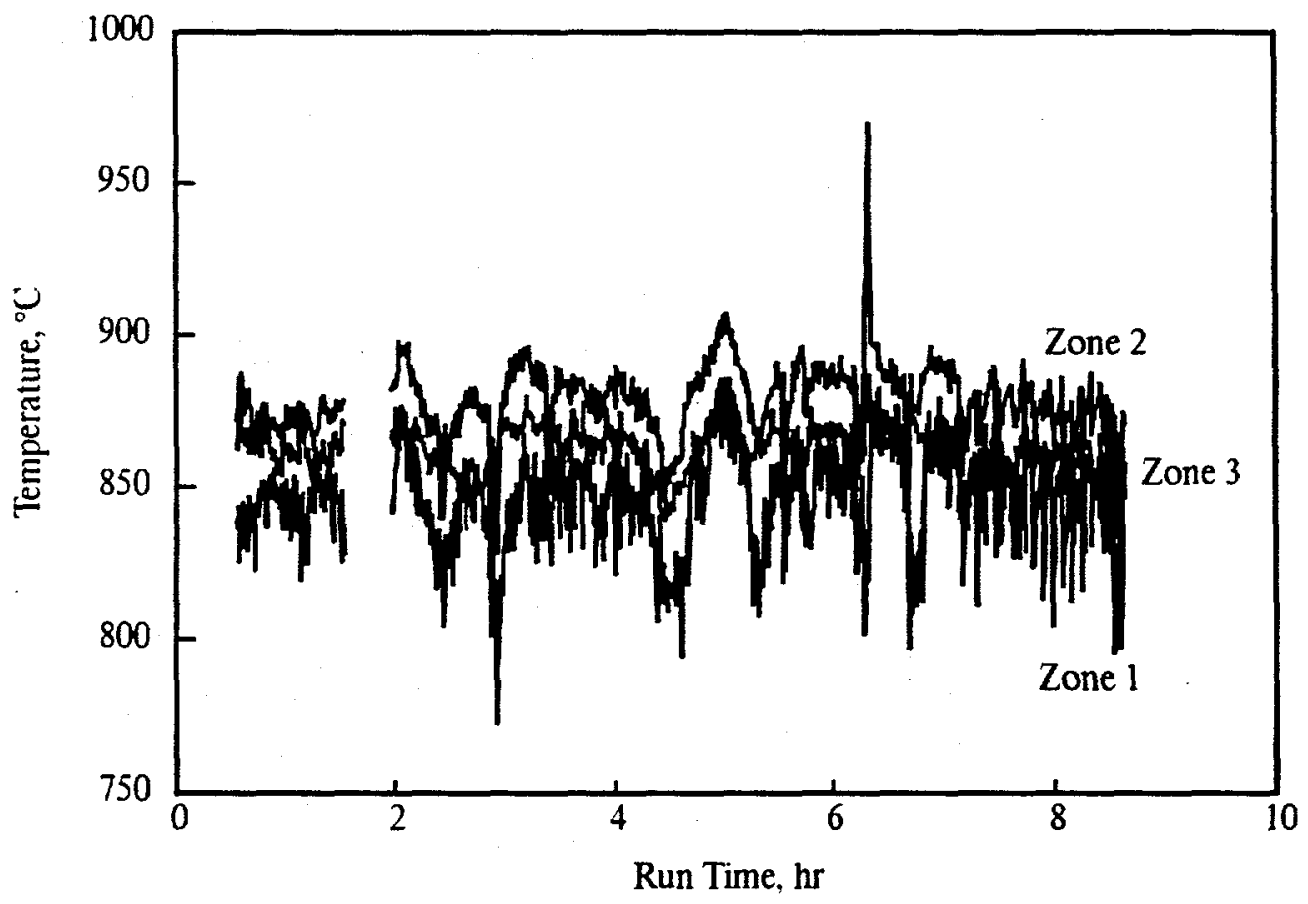

Figure 42. Characteristic measured temperatures for the PFBR 


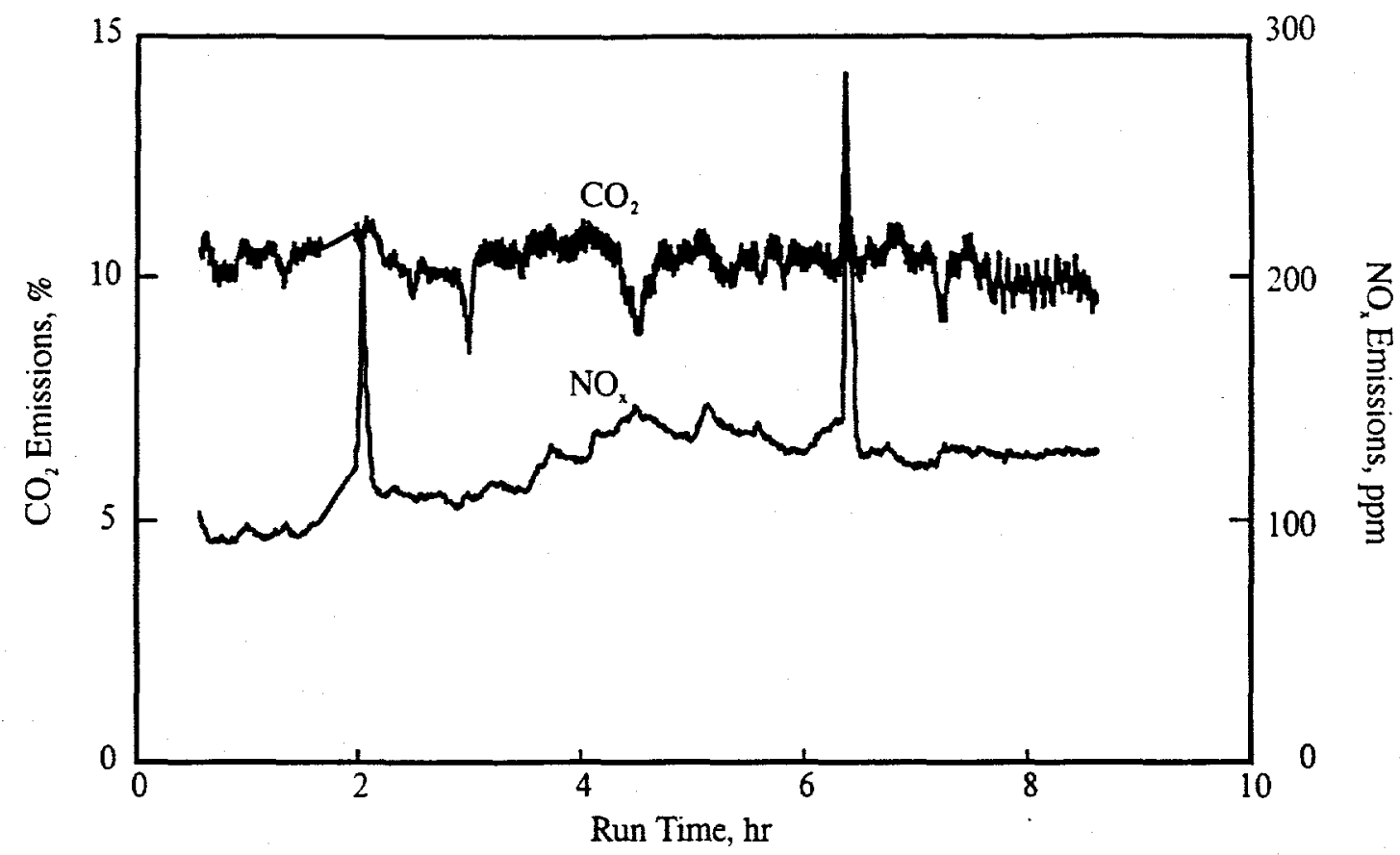

Figure 43. Characteristic gas compositions from the PFBR

commercial units and would make it difficult to maintain the proper temperature, excess air, and velocity balance within the reactor. One concern with this lower-than-normal partial pressure for $C Q$ is the potential for calcination of the carbonates to oxides in the PFBR, while in commercial units, the higher partial pressure would preclude any calcination. Figure 44 indicates that at the temperature and pressures utilized for these runs, the $\mathrm{CO}_{2}$ partial pressure may have been high enough to preclude calcination.

'The typical temperature profiles for the hot-gas filter vessel are shown in Figure 45. The filter vessel reaches temperature at a slower rate than the PFBR; however, this figure shows that the vessel was at steady state for most of the test. Pressures within the filter vessel are also shown (Figure 46). The effect of backpulsing on the filter pressure drop can be seen from this figure. Ideally, the pressure drop should return to its baseline value after pulsing. A rapid increase in pressure drop accompanied by an increase in the baseline pressure drop (clean value) is indicative of blinding and/or bridging in the filter vessel. 


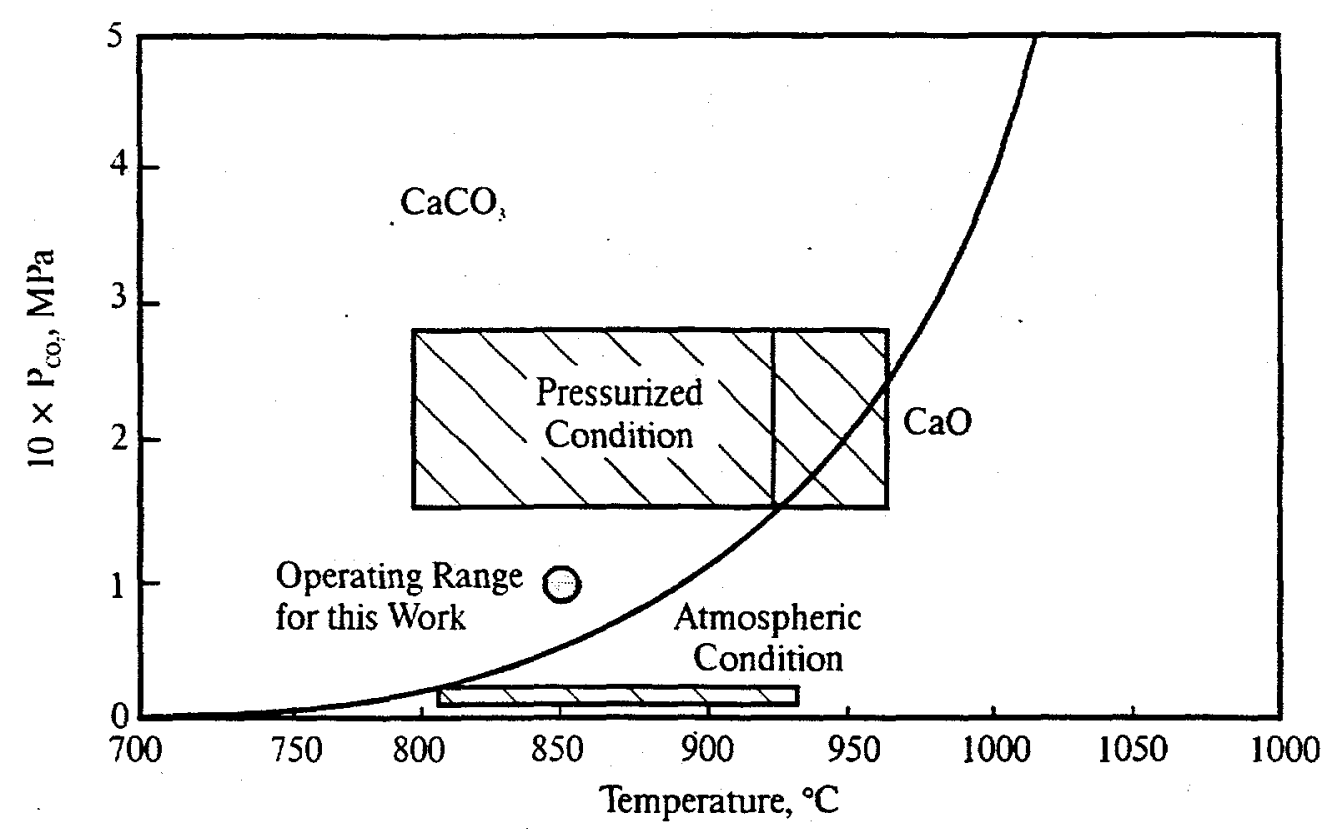

Figure 44. Pressure-temperature equilibrium of $\mathrm{CaCO}_{3}$ and $\mathrm{CaO}$

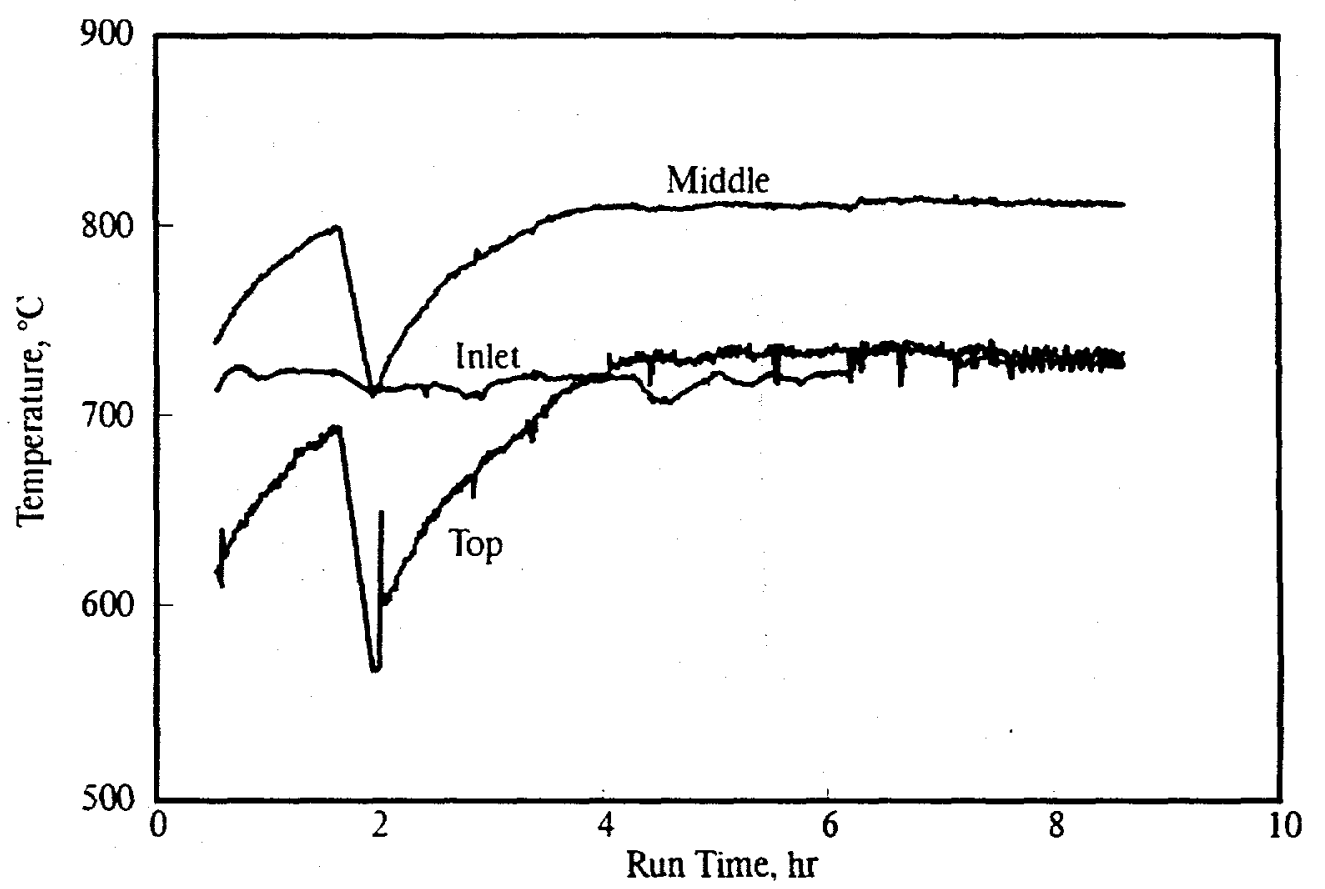

Figure 45. Characteristic temperature profile from the hot-gas filter vessel 


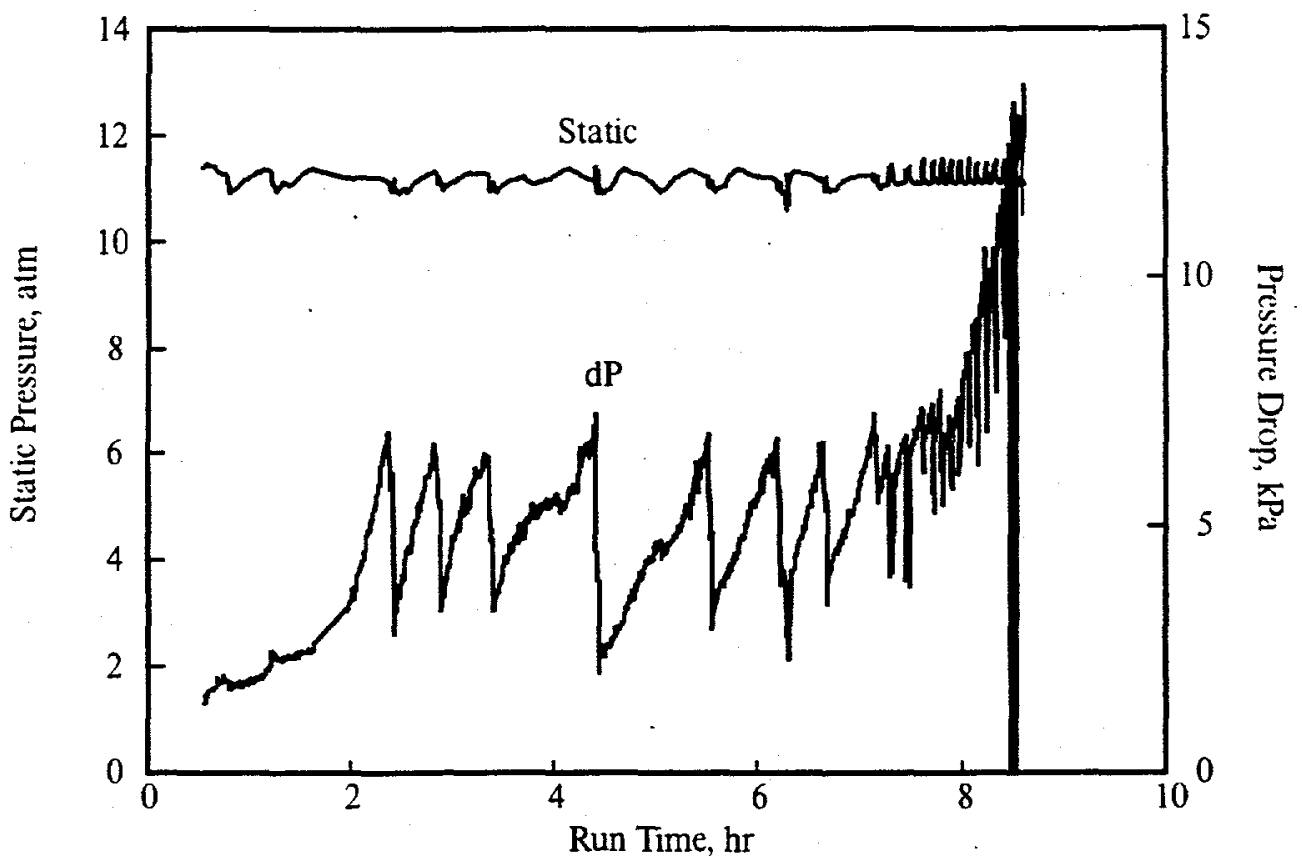

Figure 46. Characteristic pressure profile from the hot-gas filter vessel

\subsubsection{Test Matrix for PFBC Testing}

The matrix of tests used for this work is presented in Table 15. The first five tests were performed prior to the start of this work and were utilized as baseline tests. Test 1296 , the first test performed under this work, was to establish the effectiveness of albite as an alkali sorbent. The original test matrix included several additional tests utilizing. albite to determine operational effects such as sorbent add rate and size, sodium concentration in the feed, and system operating temperature. The poor performance of albite in the first test resulted in a change in the test matrix.

The coal choice for the next series of tests (1496-1896) was changed from Beulah, North Dakota, lignite to Belle Ayr, Wyoming, subbituminous. Compositions of these fuels are presented in Table 16. The reason for this change was that during Runs 1296 and 1396, the pressure drop in the filter vessel rose very quickly. Repeated pulsing could not drop the pressure drop to a safe operating range. Both Runs 1296 and 1396 had to be terminated prior to the scheduled $4 \mathrm{hr}$ of alkali sampling. Belle Ayr was chosen as a substitute coal because it had been extensively characterized during previous research and it had a relatively 
low inherent sodium content, thereby allowing the sodium content to be artificially established through the addition of sodium acetate.

Table 15

Test Matrix for Bench-Scale Testing Utilizing the PFBC

\begin{tabular}{lccccc}
\hline Test Number & Fuel & Sorbent & Sorbent Size & Sorbent/Na, wt/wt & Fuel Additive \\
\hline PR01A & Blacksville & Dolomite & $-1 / 8$ in. & - & None \\
B13-0894 & Beulah & Dolomite & $-1 / 8$ in. & - & None \\
B14-1294 & Beulah & None & - & - & None \\
B15-1294 & Beulah & Kaolinite & $-1 / 8$ in. & $30: 1$ & None \\
B17-1294 & Beulah & Kaolinite & -30 mesh & $30: 1$ & None \\
B1-1296 & Beulah & Albite & -30 mesh & $30: 1$ & None \\
B1-1396 & Beulah & None & - & - & None \\
BEL-1496 & Belle Ayr & None & - & - & None \\
BEL-1596 & Belle Ayr & None & - & - & NaAc, $S$ \\
BEL-1696 & Belle Ayr & Kaolinite & $-1 / 8$ in. & $10: 1$ & NaAc, S \\
BEL-1796 & Belle Ayr & Kaolinite & -30 mesh & $10: 1$ & NaAc, S \\
BEL-1896 & Belle Ayr & Bauxite & $-1 / 6$ in. & $10: 1$ & NaAc, S \\
B1-1996 & Beulah & Bauxite & $-1 / 8$ in. & $10: 1$ & None \\
B1-2096 & Beulah & Bauxite & $-1 / 8$ in. & $3: 1$ & None \\
B1-2196 & Beulah & Bauxite & $-1 / 8$ in. & $5: 1$ & None \\
\hline
\end{tabular}

' Sodium acetate and sulfur were added to the fuel.

The second change to the originally planned matrix was a switch from sodalite-forming sorbents such as albite to the more conventional sorbents of kaolinite and bauxite. This change was made since the albite was ineffective in capturing vapor-phase sodium and did not resolve the ash deposition and filterblinding issues. Kaolinite and bauxite were chosen since these two sorbents have been shown to be effective sorbents when utilized in either packed beds or entrained in the flue gas. It was suspected that they would be effective in the application being studied as a part of this research. 
Table 16

Properties of Fuels Used for Bench-Scale Testing on the PFBR

\begin{tabular}{|c|c|c|c|}
\hline $\begin{array}{l}\text { Mine Name: } \\
\text { Type: }\end{array}$ & $\begin{array}{l}\text { Blacksville } \\
\text { Bituminous }\end{array}$ & $\begin{array}{l}\text { Beulah } \\
\text { Lignite }\end{array}$ & $\begin{array}{c}\text { Belle Ayr } \\
\text { Subbituminous }\end{array}$ \\
\hline \multicolumn{4}{|l|}{ Proximate, $\mathrm{mf}, \mathrm{wt} \%$} \\
\hline Volatile Matter & 37.7 & 45.6 & 49.1 \\
\hline Fixed Carbon & 49.6 & 37 & 41.6 \\
\hline Ash & 12.7 & $17 . .4$ & 9.3 \\
\hline Moisture & 2.9 & 19.9 & 23.3 \\
\hline \multicolumn{4}{|l|}{ Ultimate, $\mathrm{mf}, \mathrm{wt} \%$} \\
\hline Carbon & 70.1 & 56.8 & 65.8 \\
\hline Hydrogen & 5 & 3.5 & 4.8 \\
\hline Nitrogen & 1.4 & 0.7 & 1 \\
\hline Sulfur & 2.8 & 3.1 & 0.4 \\
\hline Oxygen & 8 & 18.5 & 18.7 \\
\hline Ash & 12.7 & 17.4 & 9.3 \\
\hline Heating Value, Btu/lb & 12,388 & 9203 & 11,230 \\
\hline \multicolumn{4}{|c|}{ Ash Composition, $\%$ as oxides, $\mathrm{SO}_{3}$-free basis } \\
\hline $\mathrm{SiO}_{2}$ & 48.2 & 31.3 & 27.5 \\
\hline $\mathrm{Al}_{2} \mathrm{O}_{3}$ & 21.6 & 14.5 & 13 \\
\hline $\mathrm{Fe}_{2} \mathrm{O}_{3}$ & 23.8 & 24.4 & 3.9 \\
\hline $\mathrm{TiO}_{2}$ & 0.8 & 0.8 & 1.1 \\
\hline $\mathrm{P}_{2} \mathrm{O}_{5}$ & 0.2 & 0.4 & 0.7 \\
\hline $\mathrm{CaO}$ & 1.8 & 15.3 & 38 \\
\hline $\mathrm{MgO}$ & 1.8 & 8.8 & 3.2 \\
\hline $\mathrm{Na}_{2} \mathrm{O}$ & 0.3 & 4.3 & 1.2 \\
\hline $\mathrm{K}_{2} \mathrm{O}$ & 1.5 & 0.1 & 0.3 \\
\hline $\mathrm{SO}_{3}$ & 2.6 & 21.7 & 11.2 \\
\hline
\end{tabular}

Test 1496 was, therefore, performed to establish a baseline on the Belle Ayr coal. Test 1596 established a baseline for the Belle Ayr at a higher sodium content. For Tests 1596 through 1896, sodium acetate was added at a rate of $3.76 \mathrm{~g}$ per $\mathrm{kg}$ coal, resulting in a final sodium concentration of $0.164 \mathrm{wt} \%$. 
The intent was to add sodium to the Belle Ayr at a level to duplicate the percentage of $\mathrm{NaO}$ in the ash of the Beulah lignite. Sulfur was added to the Belle Ayr to a level comparable to the Beulah lignite. The sodium acetate and sulfur were premixed with the coal.

Tests 1696 and 1796 were designed to determine the impact of utilizing kaolinite as a sorbent and the impact of particle size. Test 1896 tested the effectiveness of bauxite. Results from these three tests showed bauxite to be a better sorbent than kaolinite and the coarse material favorable to the fine with regard to alkali capture and reducing deposition. Therefore, Tests 1996 through 2196 were designed using the coarse bauxite for the sorbent. The fuel was switched back to Beulah to 1) demonstrate that bauxite could mitigate the filter blinding, capture a high percentage of vapor-phase alkali, and control depositional problems encountered during tests 1296 and 1396 and 2) determine the add rate required for the bauxite to be effective. 


\section{CHAPTER 4}

\section{RESULTS OF TGA SCREENING TESTS}

The results of the work performed on the TGA will be presented in this chapter along with its interpretation. First, the data from the tests will be tabulated to provide an overall view of the work performed. Since one purpose of this work was.to investigate the reaction scheme for sodalite formation, results will first be applied to those reactions. Following this discussion, the data will be represented in various forms to show reaction mechanisms for the different sorbents tested and to present the reasoning used in selecting sorbents for testing in the bench-scale reactor.

\subsection{Rate Data from TGA Testing}

Seventeen different TGA tests were performed. A typical thermogram is shown in Figure 47. Thermograms from all seventeen tests are given in Appendix C. For each temperature, the rate of adsorption was calculated as follows:

$$
\left(w t \%_{t}-w t \%_{i}\right) /\left(t-t_{j}\right)
$$

where $w t \%$ is the weight $\%$ at the beginning of the test period, $w \zeta$ is the weight percent at the end of the test period, and $t_{i}$ and $t$ are the corresponding initial and ending times. The calculated values are adjusted to obtain units of $\mathrm{mg} / \mathrm{g} / \mathrm{hr}$. For example, for the $733^{\circ} \mathrm{C}$ condition, the rate of $18 \mathrm{mg} / \mathrm{g} / \mathrm{hr}$ is calculated as follows:

$$
(101.9 \%-101.0 \%) /(110 \mathrm{~min}-81 \mathrm{~min}) \times(1000 \mathrm{mg} / \mathrm{g}) \times(60 \mathrm{~min} / \mathrm{hr})
$$

Table 17 presents the results for each TGA condition. A rate of $2 \mathrm{mg} / \mathrm{g} / \mathrm{hr}$ represents a weight gain of only $0.1 \mathrm{wt} \%$. Although this represents only a small weight change over each test condition, weight changes of 


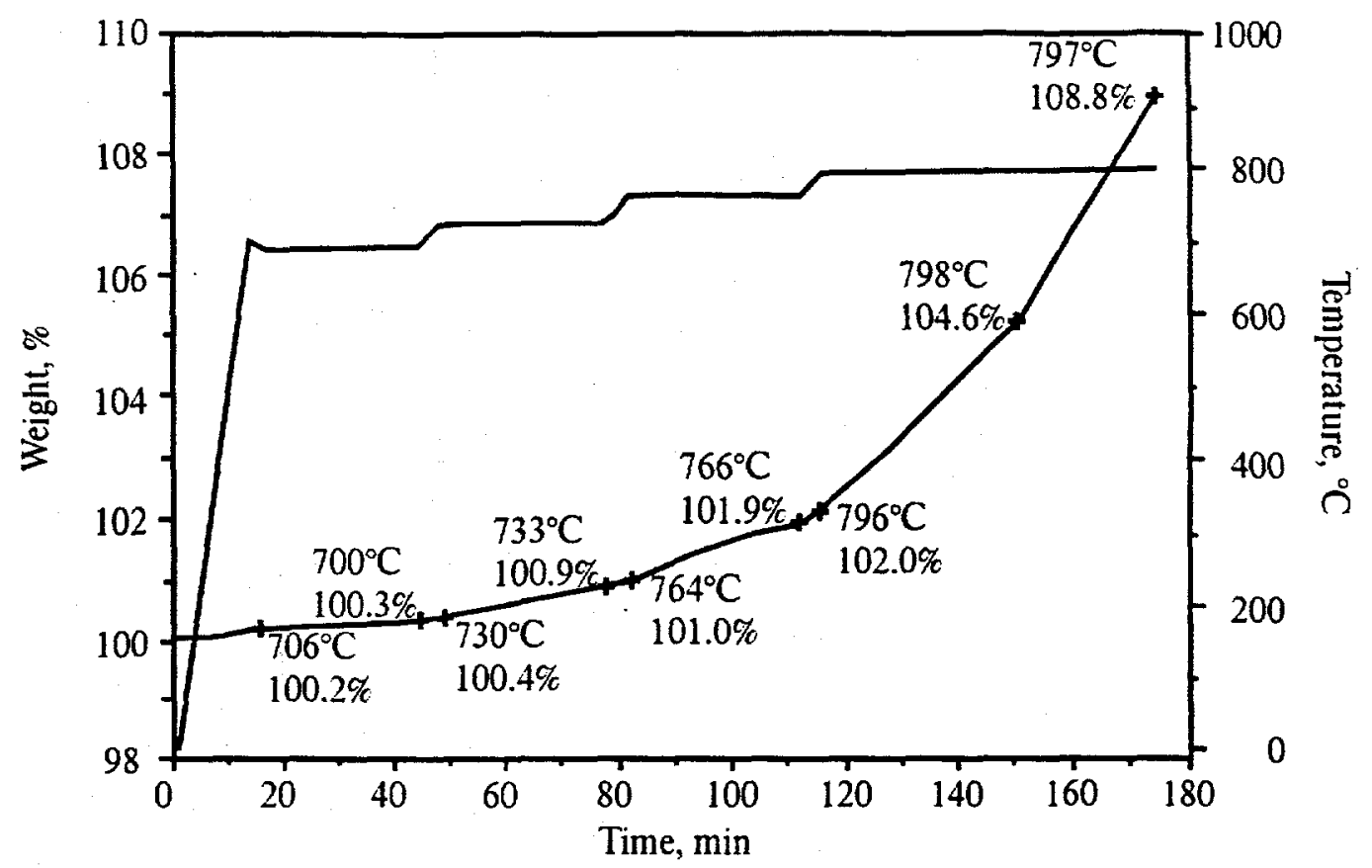

Figure 47. Thermogram of albite exposed to $\mathrm{NaCl}$ with a combustion carrier gas

this magnitude are within the sensitivity of the instrument. It is important to note that for Tests 3,5 , and 10 the $\mathrm{NaCl}$ melted at the last condition. For those tests, the rate change prior to the melting was taken and is recorded in Table 17.

\subsection{Sodalite Reactions}

As proposed in Section 1.6, a series of five reactions were viewed as important in the use of sodalites for capture of alkali, chlorine, and sulfur. This reaction scheme is again presented here to facilitate discussion of the relevant TGA tests.

$$
\begin{gathered}
\mathrm{NaCl}+3 \mathrm{NaAlSiO}_{4}-\mathrm{Na}_{4} \mathrm{Al}_{3} \mathrm{Si}_{3} \mathrm{O}_{12} \mathrm{Cl} \\
\text { (nepheline) } \\
\text { (sodalite) } \\
\mathrm{Na}_{4} \mathrm{Al}_{3} \mathrm{Si}_{3} \mathrm{O}_{12} \mathrm{Cl}+6 \mathrm{SiO}_{2}-\mathrm{NaCl}+3 \mathrm{NaAlSi}_{3} \mathrm{O}_{8} \\
(\text { sodalite) } \\
\mathrm{Na}_{4} \mathrm{Al}_{3} \mathrm{Si}_{3} \mathrm{O}_{12} \mathrm{Cl}+\mathrm{Na}_{2} \mathrm{SO}_{4}-2 \mathrm{NaCl}+\mathrm{Na}_{8} \mathrm{Al}_{6} \mathrm{Si}_{6} \mathrm{O}_{24}\left(\mathrm{SO}_{4}\right) \\
\text { (sodalite) }
\end{gathered}
$$




$$
\begin{array}{cc}
\mathrm{Na}_{8} \mathrm{Al}_{6} \mathrm{Si}_{6} \mathrm{O}_{24}\left(\mathrm{SO}_{4}\right)+12 \mathrm{SiO}_{2}=\mathrm{Na}_{2} \mathrm{SO}_{4}+6 \mathrm{NaAlSi}_{3} \mathrm{O}_{8} \\
\text { (nosean) } & \text { (albite) } \\
2 \mathrm{Na}_{4} \mathrm{Al}_{3} \mathrm{Si}_{3} \mathrm{O}_{12} \mathrm{Cl}+\mathrm{SO}_{2}+\mathrm{O}_{2}-\mathrm{Na}_{8} \mathrm{Al}_{6} \mathrm{Si}_{6} \mathrm{O}_{24}\left(\mathrm{SO}_{4}\right)+\mathrm{Cl}_{2} \\
\text { (sodalite) } & \text { (nosean) }
\end{array}
$$

\begin{tabular}{|c|c|c|c|c|c|c|c|c|c|}
\hline $\begin{array}{l}\text { Test } \\
\text { No. }\end{array}$ & Sorbent & $\mathrm{NaCl}$ & Initial Gas & $\begin{array}{l}29 \mathrm{ppm} \\
700^{\circ} \mathrm{C}\end{array}$ & $\begin{array}{l}68 \mathrm{ppm} \\
733^{\circ} \mathrm{C}\end{array}$ & $\begin{array}{c}158 \mathrm{ppm} \\
766^{\circ} \mathrm{C}\end{array}$ & $\begin{array}{c}336 \mathrm{ppm} \\
800^{\circ} \mathrm{C}\end{array}$ & $\begin{array}{c}336 \mathrm{ppm} \\
800^{\circ} \mathrm{C}\end{array}$ & $850^{\circ} \mathrm{C}^{\prime}$ \\
\hline 1 & Albite & Yes & Nitrogen & - & - & - & - & - & 9.3 \\
\hline 2 & Albite & No & Nitrogen & - & - & - & - & - & -1.6 \\
\hline 3 & Albite & Yes & Combustion & 2 & 20 & 18 & 72 & 72 & - \\
\hline 4 & Albite & No & Combustion & 2 & 1 & 1 & 1 & 0 & - \\
\hline 5 & $\begin{array}{c}\text { Albite + } \\
\text { Quartz }\end{array}$ & Yes & Combustion & 2 & 14 & 28 & 60 & 58 & - \\
\hline 6 & $\begin{array}{c}\text { Albite + } \\
\text { Quartz }\end{array}$ & Yes & Nitrogen & 0 & 2.4 & 2.3 & 2.3 & - & - \\
\hline 7 & Sodalite & Yes & Combustion & 11 & 7 & 18 & 35 & 20 & - \\
\hline 8 & Sodalite & No & Combustion & 8.1 & 4.1 & 2.7 & 1.2 & -2.4 & - \\
\hline 9 & Sodalite & Yes & Nitrogen & 0 & 3.2 & 3 & 3.8 & - & - \\
\hline 10 & Nepheline & Yes & Combustion & 5.4 & 9.4 & 16 & 18 & 16 & - \\
\hline 11 & $\mathrm{AlO}(\mathrm{OH})_{3}$ & Yes & Combustion & 32 & 19 & 28 & 24 & 15 & - \\
\hline 12 & Kaolinite & Yes & Combustion & 1 & 6 & 15 & 24 & 28 & - \\
\hline 13 & $\begin{array}{l}\text { Activated } \\
\text { Bauxite }\end{array}$ & Yes & Nitrogen & -6 & 0 & 0.7 & 1.8 & 36 & - \\
\hline 14 & $\begin{array}{c}\text { Activated } \\
\text { Bauxite }\end{array}$ & Yes & Combustion & - & - & - & - & 55 & - \\
\hline 15 & Zeolite & Yes & Nitrogen & -10 & -6 & -5 & -9 & 4.3 & - \\
\hline 16 & Sodalite & No & Nitrogen & 0 & 0 & 0 & 0 & - & - \\
\hline 17 & Albite & Yes & Combustion & 5.9 & 6.2 & 13 & 19 & - & - \\
\hline
\end{tabular}

Table 17

Rates of Adsorption Calculated from TGA Experiments

\footnotetext{
'Switch from combustion gas to nitrogen, or nitrogen to combustion gas for Tests 13,15 , and 16 .
} 
Several tests were performed with albite and sodalite, since they participate in several of the reactions listed above. Tests 8 and 10 was designed to determine whether nepheline would react with $\mathrm{NaCl}$ under the expected conditions in the PFBC to form sodalite under Reaction 1, or if the temperatures were such that sodalite would decompose and release the $\mathrm{NaCl}$ from its structure. Results from Test 10 indicate a weight gain over the concentration and temperature range tested, with that rate increasing with concentration/temperature, indicating that Reaction 1 was proceeding to the right. The results from this test showed a definite weight gain at the lower temperatures when sodalite was exposed to combustion gas with no $\mathrm{NaCl}$. This indicates that the sodalite was probably adsorbing $\mathrm{SO}_{2}$. It cannot be determined directly from these data if the sodalite would decompose in the presence of an inert gas and force Reaction 1 to the left at the temperatures of interest for this study. Test 16 was, therefore, performed using sodalite in nitrogen. The lack of weight gain or loss indicates that decomposition is not occurring over the range of temperatures from $700^{\circ}$ to $800^{\circ} \mathrm{C}$.

A rate decrease in Test 10 using nepheline, from 18 to $16 \mathrm{mg} / \mathrm{g} / \mathrm{hr}$, was measured as the gas was switched from a combustion gas to inert. This indicates that the $\mathrm{SO}_{2}$ and $\mathrm{Cl}_{2}$ may be competing for the same reaction sites. Reactions 3 and 5 show this reaction, with the sodalite that was formed from Reaction 1 reacting with the $\mathrm{SO}_{2}$ to form nosean and releasing $\mathrm{Cl}_{2}$. The weight gains observed during Test 8 give clues to this reaction. Since $\mathrm{SO}_{4}$ is heavier than the $\mathrm{Cl}_{2}$ that it replaces, a weight gain is expected if Reaction 5 (or 3 ) is to proceed to the right. A moderate weight gain was noted during Test 8 at the lower temperatures. This rate decreased from 8.1 to $1.4 \mathrm{mg} / \mathrm{g} / \mathrm{hr}$ at the temperature increased from $700^{\circ} \mathrm{C}$ to $800^{\circ} \mathrm{C}$. Furthermore, when the gas was changed from a combustion gas to an inert gas, the rate became negative. This indicates that the replacement of the chlorine with sulfate is preferred at the lower temperatures and that in the absence of gas phase $\mathrm{SO}_{2}$, desorption of the $\mathrm{SO}_{4}$ from the sodalite is likely to occur. Test 16 confirmed that the weight loss was not from decomposition of the sodalite.

While Test 8 examined Reactions 3 and 5 to determine whether sodalite would preferentially replace the chlorine with $\mathrm{SO}_{4}$, Test 7 examined these reactions with both $\mathrm{SO}_{2}$ and $\mathrm{NaCl}$ present in the gas phase to 
determine which direction the reaction would proceed over a range of $\mathrm{SO}_{2}$-to-chlorine partial pressures. These results show a weight gain for the sodalite, with this weight gain increasing with increasing $\mathrm{NaCl}$ content. It is important to remember that the concentration of $\mathrm{NaCl}$ is over one order of magnitude greater at $800^{\circ}$ than at $700^{\circ} \mathrm{C}$. This indicates that over the range of partial pressures of $\mathrm{SO}_{2}-\mathrm{to}-\mathrm{Cl}$ tested, Reactions 3 and 5 would be expected to proceed to the right and that the $\mathrm{SO}_{4}$ would replace $\mathrm{Cl}$. Since the adsorption rates were decreasing with temperature during Test 8 showing an inverse temperature dependence of $\mathrm{SO}_{2}$ sorption by sodalite, the results of Test 7 indicate that Reaction 3 , rather than Reaction 5 , is responsible for the change in weight. Therefore, the $\mathrm{Na}_{2} \mathrm{SO}_{4}$ obviously plays a very important role in this reaction scheme, much more so than just the $\mathrm{SO}_{2}$. This may be due to kinetic or diffusion limitations; however, a more probable explanation is the importance of gas condensation on the sorbent particle resulting in "wetting" of the solid. This changes the reaction from one of gas-solid to liquid-solid, with the rate of the liquid-solid reaction expected to be much higher than its gas-solid counterpart. There is evidence of these liquid-solid reactions from tests using the albite that will be presented later.

The thermoequilibrium modeling reported in Section 2.2 also confirms this conclusion. As can be seen by Figure 14 , as the amount of sodium or sulfur changes (indicated by a change in the $(\mathrm{K}+\mathrm{Na}) / \mathrm{S}$ ratio), the vapor-phase concentration of the $\mathrm{Na}_{2} \mathrm{SO}_{4}$ remains constant due to changes in the amount of $\mathrm{Na}_{2} \mathrm{SO}_{4}$ that condenses. The amount of condensation that occurs to maintain this equilibrium will increase as either the sodium or sulfur vapor content increases at a given condition.

Since both temperature and $\mathrm{NaCl}$ concentrations are changing simultaneously in these TGA tests, SOLGASMIX was used to indicate the change of liquid $\mathrm{Na}_{2} \mathrm{SO}_{4}$ over the range of conditions tested. For the simple system $\mathrm{C}, \mathrm{O}, \mathrm{S}, \mathrm{Na}$, and $\mathrm{Cl}$ SOLGASMIX shows the liquid $\mathrm{Na}_{2} \mathrm{SO}_{4}$ concentration to be $0.145 \times 10^{-4}$ at $700^{\circ} \mathrm{C}$ and $29 \mathrm{ppm} \mathrm{NaCl}$, and $1.68 \times 10^{-4}$ at $800^{\circ} \mathrm{C}$ and $336 \mathrm{ppm} \mathrm{NaCl}$. This shows that as the concentration of $\mathrm{NaCl}$ increases, the condensed $\mathrm{Na}_{2} \mathrm{SO}_{4}$ will increase, even though the temperature has increased. Test 17 verified the importance of $\mathrm{SO}_{2}$ concentration in the overall reaction scheme. Keeping everything else constant, reducing the gas-phase $\mathrm{SO}_{2}$ concentration by $4(2015$ to $500 \mathrm{ppm})$, the rate of 
adsorption decreased dramatically. It is speculated that this difference is caused by the reduction in condensable $\mathrm{Na}_{2} \mathrm{SO}_{4}$.

Tests 3 through 6 were designed to look specifically at Reactions 2 and 4 . Test 3 utilized albite as the sorbent with $\mathrm{NaCl}$ addition to examine Reactions 2 and 4 moving to the left. These are the favored reactions for alkali capture with this system with the alkali being either $\mathrm{NaCl}$ or $\mathrm{NaSO}_{4}$. High rates of adsorption showed that albite has promise as an alkali sorbent. It is known in solutions saturated in silica that Reactions 2 and 4 will proceed to the right. Stormer and Carmichael (1971) discuss the impact of silica saturation on sodalite formation in an albite system as shown in Figure 48. The calculated stability field of sodalite at $727^{\circ} \mathrm{C}\left(1340^{\circ} \mathrm{F}\right)$ and $1127^{\circ} \mathrm{C}\left(2060^{\circ} \mathrm{F}\right)$ is shown. Sodalite will be stable at silica and $\mathrm{NaCl}$ activities below both curves; the upper curve is for pure albite, the lower for an activity of 0.5 albite in coexisting feldspar. The lower boundary of the shaded area labeled "Quartz Bearing" is defined by the activity of silica glass in equilibrium with crystallizing quartz. Below this line, quartz will not be stable. The upper boundary of the shaded area labeled "Nepheline Bearing" is defined by the activity of silica in equilibrium with nepheline and albite. Above this line, nepheline will not be stable; below it an albite-rich feldspar will not be stable.

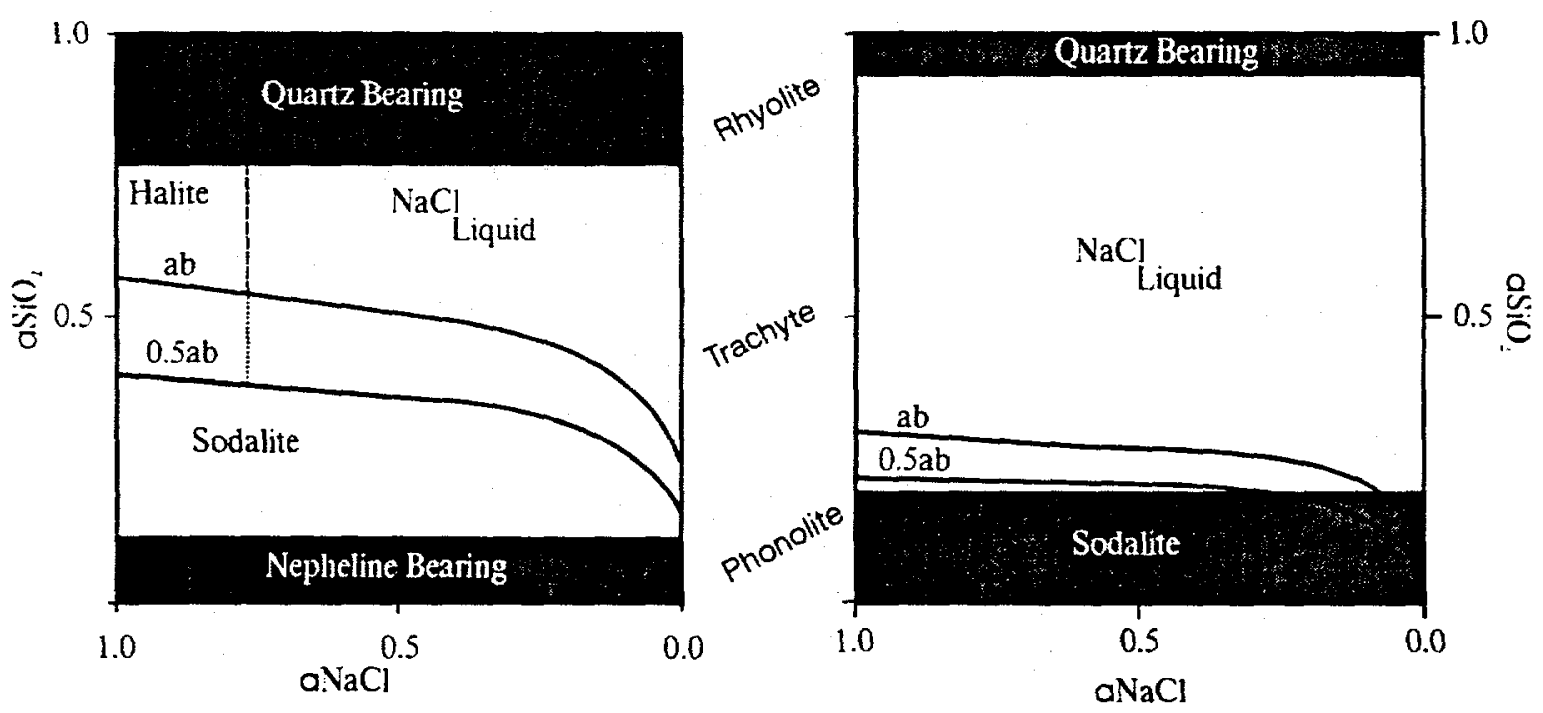

Figure 48. Stability field of sodalite at $727^{\circ}$ and $1127^{\circ} \mathrm{C}$ 
Because many coal ashes contain relatively large amounts of silica, it was important to determine the impact of the silica on alkali adsorption at the conditions found in the PFBC. Test 5 addressed this issue. The addition of the silica in a 50:50 weight ratio of silica to albite did not impact the rate of adsorption. It was interesting to note that when the carrier gas was switched to inert, the adsorption rate further increased. However, in Test 6 , where nitrogen was used as the carrier gas, no significant adsorption was seen at any temperature. Apparently, as discussed above, the $\mathrm{SO}_{2}$ or $\mathrm{Na}_{2} \mathrm{SO}_{4}$ is necessary to initially wet the sorbent and initiate the adsorption reactions. Once a wetted surface exists, then the albite and/or silica is able to adsorb the $\mathrm{NaCl}$ in addition to the $\mathrm{Na}_{2} \mathrm{SO}_{4}$. Test 4, performed with $\mathrm{SO}_{2}$ but without $\mathrm{NaCl}$, and Test 6 , performed with $\mathrm{NaCl}$ but no $\mathrm{SO}_{2}$, confirm that the $\mathrm{Na}_{2} \mathrm{SO}_{4}$ is the initiating (wetting) agent.

Evidence of this can be seen in Figures 49 and 50. After completion of Tests 3 and 5, the reacted sorbents were mixed and examined using the scanning electron microscope (SEM). These samples were combined to provide a sample large enough for SEM characterization. In Figure 49 , the large quartz particle can be seen to be wetted by sodium and sulfur. The elemental map shows this wetting as localized areas high in sodium and sulfur. Particle analysis indicates little penetration (reaction) of the sodium or

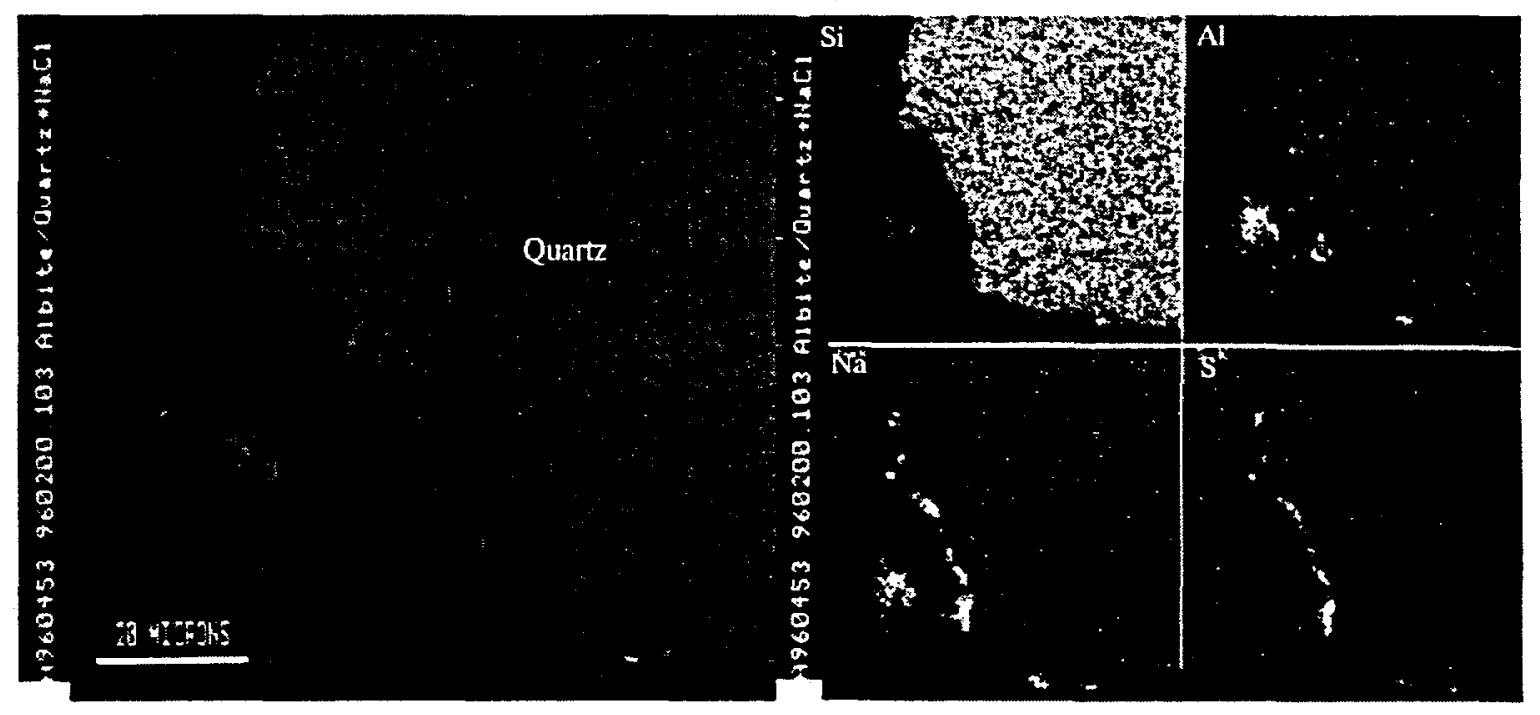

Figure 49. SEM photograph of albite and quartz sample from TGA using $\mathrm{NaCl}$ and combustion gas 


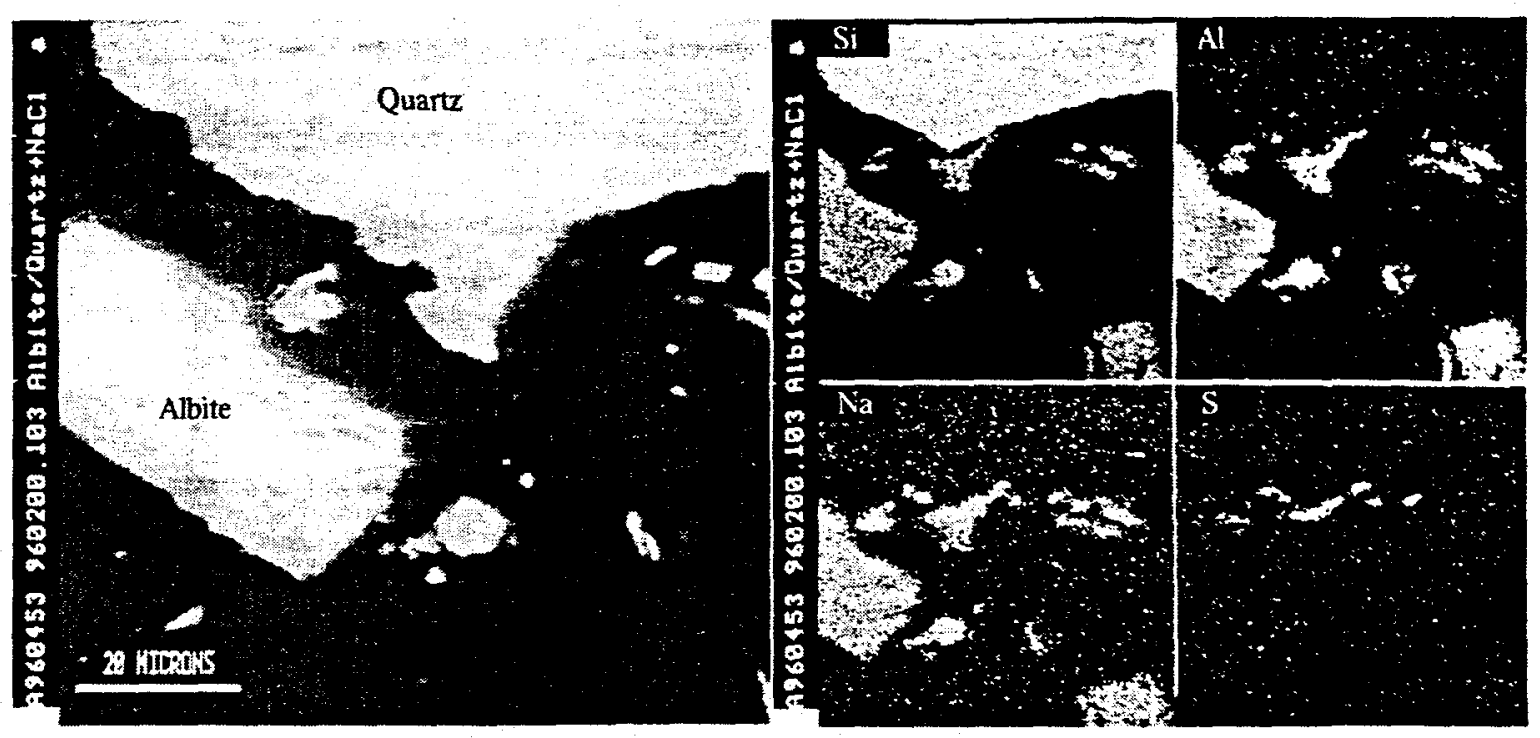

Figure 50. SEM photograph of albite and quartz sample from TGA using $\mathrm{NaCl}$ and combustion gas

sulfur into the quartz particle. Some reaction of sodium and sulfur with the small albite particle is seen.

The silica particle can be easily differentiated from the albite particle by comparing areas with silicon only (quartz) to those with silicon, aluminum. and sodium (albite).

Figure 50 shows a similar trend. Again, sodium and sulfur are seen to be wetting the surface of the quartz particle, with no evidence or reaction with the quartz. It should be noted that surface reactions are likely occurring but are not detectable under the SEM. An albite particle is seen in the vicinity of the quartz particle in the area of the sodium sulfate. It is uncertain if this albite particle plays a role in the wetting and subsequent reaction of the sodium sulfate with quartz.

Figure $5 \mathrm{I}$ further examines the mechanism of alkali capture with albite. An analysis of several points were performed, with the results shown in Table 18. Some variation in the albite is noted from Point 1 to Point 3. At Point 4 , a sharp increase in sodium and sulfur is noted, indicating a reaction with sodium sulfate. Points 5 and 6 show a similar trend. Point 6 marks the transition back to the unreacted albite identified as Point 7. It is interesting to note that at the interface between the albite of Point 7 and the 


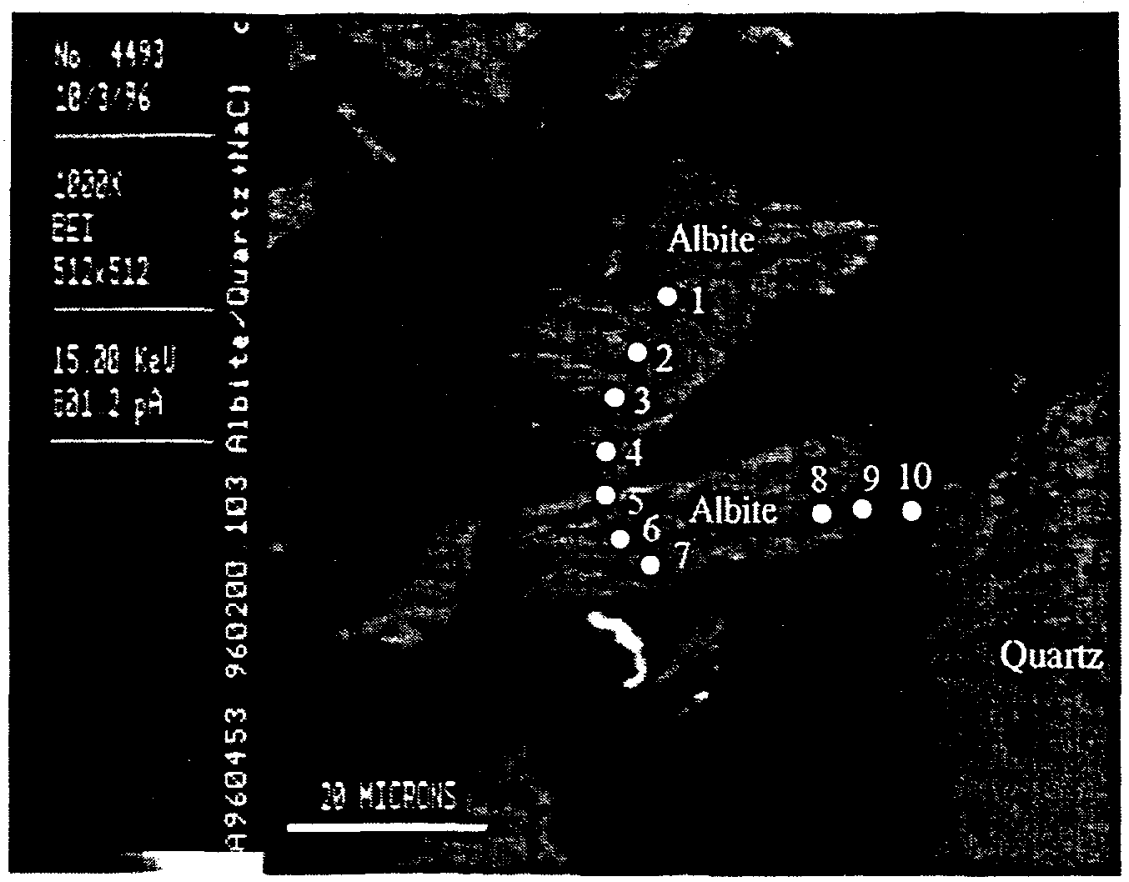

Figure 51. SEM point analysis of albite and silica exposed to $\mathrm{NaCl}$ in combustion gas in TGA

Table 18

Point Analysis of SEM of Albite and Quartz Particles from SEM Using $\mathrm{NaCl}$ and Combustion Gas

\begin{tabular}{|c|c|c|c|c|c|c|c|c|c|c|}
\hline Point & 1 & 2 & 3 & 4 & 5 & 6 & 7 & 8 & 9 & 10 \\
\hline \multicolumn{11}{|c|}{ Elemental Analysis, mole $\%$} \\
\hline $\mathrm{Na}$ & 7.3 & 7.7 & 7.5 & 15 & 12.6 & 9.6 & 7.4 & 8.3 & 8.4 & 0.4 \\
\hline Al & 8 & $8.3^{\circ}$ & 9.4 & 5 & 6.8 & 7.9 & 9.1 & 8.7 & 17.2 & 0 \\
\hline $\mathrm{Si}$ & 23.6 & 24.5 & 29.1 & 14.5 & 20.6 & 22.7 & 27.6 & 25.8 & 21.7 & 35.6 \\
\hline S & 0 & 0 & 0 & 8.5 & 5.7 & 1.6 & 0 & 0.9 & 1.8 & 0.2 \\
\hline $\mathrm{Cl}$ & 0.1 & 0 & 0 & 0 & 0.1 & 0 & 0 & 0.8 & 1.1 & 0.1 \\
\hline $\mathrm{O}$ & 60.9 & 59.5 & 54 & 56.9 & 54.2 & 58.1 & 55.8 & 49.8 & 49.8 & 63.7 \\
\hline \multicolumn{11}{|c|}{ Stoichiometry } \\
\hline $\mathrm{Na}$ & 1.9 & 2.1 & 2.2 & 4.2 & 3.7 & 2.7 & 2.1 & 2.4 & 2.7 & 0.1 \\
\hline Al & 2.1 & 2.2 & 2.8 & 1.4 & 2 & 2.2 & 2.6 & 2.5 & 5.5 & 0 \\
\hline Si & 6.2 & 6.6 & 8.6 & 4.1 & 6.1 & 6.2 & 7.9 & 7.4 & 7 & 9 \\
\hline$S$ & 0 & 0 & 0 & 2.4 & 1.7 & 0.5 & 0 & 0.2 & 0.6 & 0 \\
\hline $\mathrm{Cl}$ & 0 & 0 & 0 & 0 & 0 & 0 & 0 & 0.2 & 0.4 & 0 \\
\hline $\mathrm{O}$ & 16 & 16 & 16 & 16 & 16 & 16 & 16 & 16 & 16 & 16 \\
\hline
\end{tabular}


quartz of Point 10 both sulfur and chlorine are detected along with a comparable amount of sodium. It is speculated that the reaction was initiated by the sodium sulfate during the first part of the TGA test, while the chlorine may have been incorporated into the melt during the last part of the test, when high adsorption rates were seen using nitrogen as the carrier gas. This also provides evidence that both the sulfur and chlorine can coexist in the sorbent particle and that depending upon the ratio of $\mathrm{SO}_{2}-\mathrm{to}_{-}-\mathrm{Cl}_{2}$ partial pressure, simultaneous capture of alkali, chlorine, and sulfur may be possible.

Figure 52 is taken from Stormer and Carmichael (1971) and shows the relationship between chlorine and sulfur in the sodalite system. According to Reactions 3 and 5, an equilibrium exists between nosean (sulfur-bearing) and sodalite (chlorine-bearing). The weight gain in Test 8 indicates that Reaction 5 may be proceeding to the right. When exposed to both $\mathrm{SO}_{2}$ and $\mathrm{Cl}$ as in Test 7 , the reaction still proceeds to the right. Assuming an ideal gas, the $\log f_{\mathrm{SO} 2} / f_{\mathrm{Cl} 2}$ is approximated by $\log \mathrm{C}_{\mathrm{SO} 2} / \mathrm{C}_{\mathrm{C} 12}$ where $f$ and $\mathrm{C}$ are the fugacities and concentrations of $\mathrm{SO}_{2}$ and $\mathrm{Cl}_{2}$. At $700^{\circ} \mathrm{C}$, the $\log \mathrm{f}_{\mathrm{SO} 2} / \mathrm{f}_{\mathrm{Cl} 2}$ is approximately 2.5 ; assuming all of the $\mathrm{Cl}$ released by vaporizing the $\mathrm{NaCl}$ is present as $\mathrm{Cl}_{2}$. At $800^{\circ} \mathrm{C}$, this value is approximately 1.1 . The corresponding $f_{\mathrm{O} 2}$ is approximately $5 \times 10^{-2}$, again assuming ideal gas. This indicates that nosean is indeed

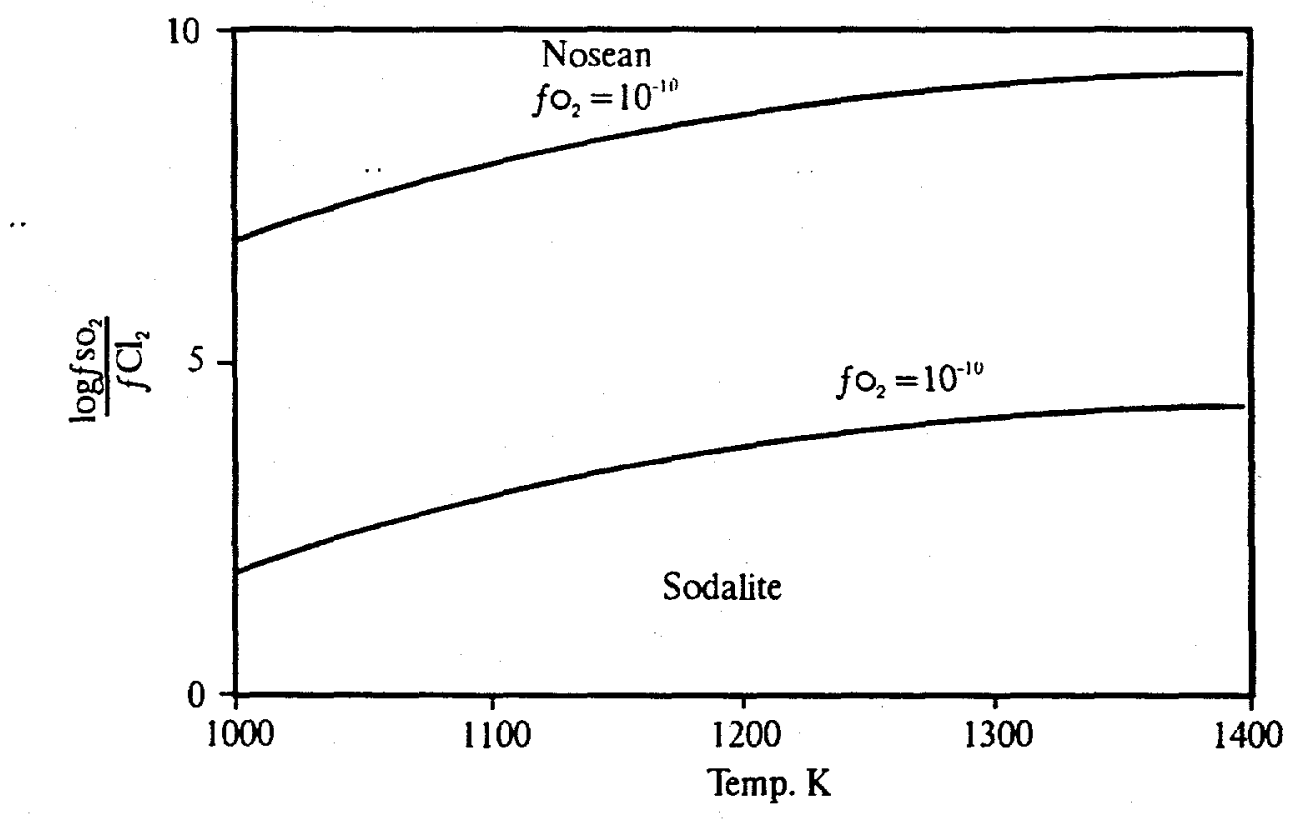

Figure 52. Equilibrium between nosean and sodalite at constant oxygen fugacity (Stormer and Carmichael, 1971) 
thermodynamically preferred for the low-temperature conditions. Extrapolating the $f_{0 z}$ to $5 \times 10^{-2}$ indicates that nosean may also be thermodynamically preferred at the higher-temperature case. Sodalite would be the preferred species for a higher chlorine concentration.

The results from this screening exercise indicate that over the range of temperature and sodium, chlorine, and $\mathrm{SO}_{2}$ concentrations tested that nosean is the preferred product. Using albite as the starting material, there may be a number of intermediate reactions occurring including sodalite formation, but these reactions, in the presence of $\mathrm{SO}_{2}$, will proceed to nosean formation. Sodalite could be formed at relatively low $\mathrm{SO}_{2}$ concentrations and high $\mathrm{Cl}$ concentrations. Low $\mathrm{SO}_{2}$ concentrations may be favored in the PFBC because of dolomite addition for control of sulfur emissions; however, for most coals, the chlorine content will also be low. Simultaneous alkali and chlorine capture, to any significant degree, are, therefore, not expected.

\subsection{Adsorption Rates and Mechanisms}

Section 4.2 focused primarily on the reaction scheme presented for the capture of alkali, sulfur, and chlorine using sodalites. This section looks at the eight different materials tested to compare the overall adsorption rates and mechanism of adsorption. The data taken for each test were reduced to generate rate vs. $\mathrm{NaCl}$ concentration and $\ln \mathrm{k}$ vs. $1 / \mathrm{T}$ curves where $\mathrm{k}$ is the rate/concentration and $\mathrm{T}$ is the temperature. An example of the type of curves generated is given as Figure 53. The following background discussion is added to justify the approach taken and the conclusions reached.

The rate expression for adsorption at equilibrium conditions, assuming both adsorption and desorption are occurring, can be written as the rate of adsorption of the gas species $\mathrm{A}$ onto the surface minus the rate at which $A$ is desorbed (Fogler, 1974), or:

$$
R_{a d s}=k_{a}\left(P_{a} C_{v}-C_{a s} / K_{a}\right)
$$

where $R_{a d s}$ is the rate of adsorption, $k_{a}$ is the rate constant, $P_{a}$ is the partial pressure of the adsorbent (alkali in this case), $C_{v}$ is the number of vacant sites of the absorber (sorbent), $C_{a s}$ is the number of active sites on the sorbent, and $K_{a}$ is the ratio of the rate constant for adsorption divided by the rate constant for desorption. The work on the TGA measured the initial rates of adsorption for the system and not the equilibrium. 


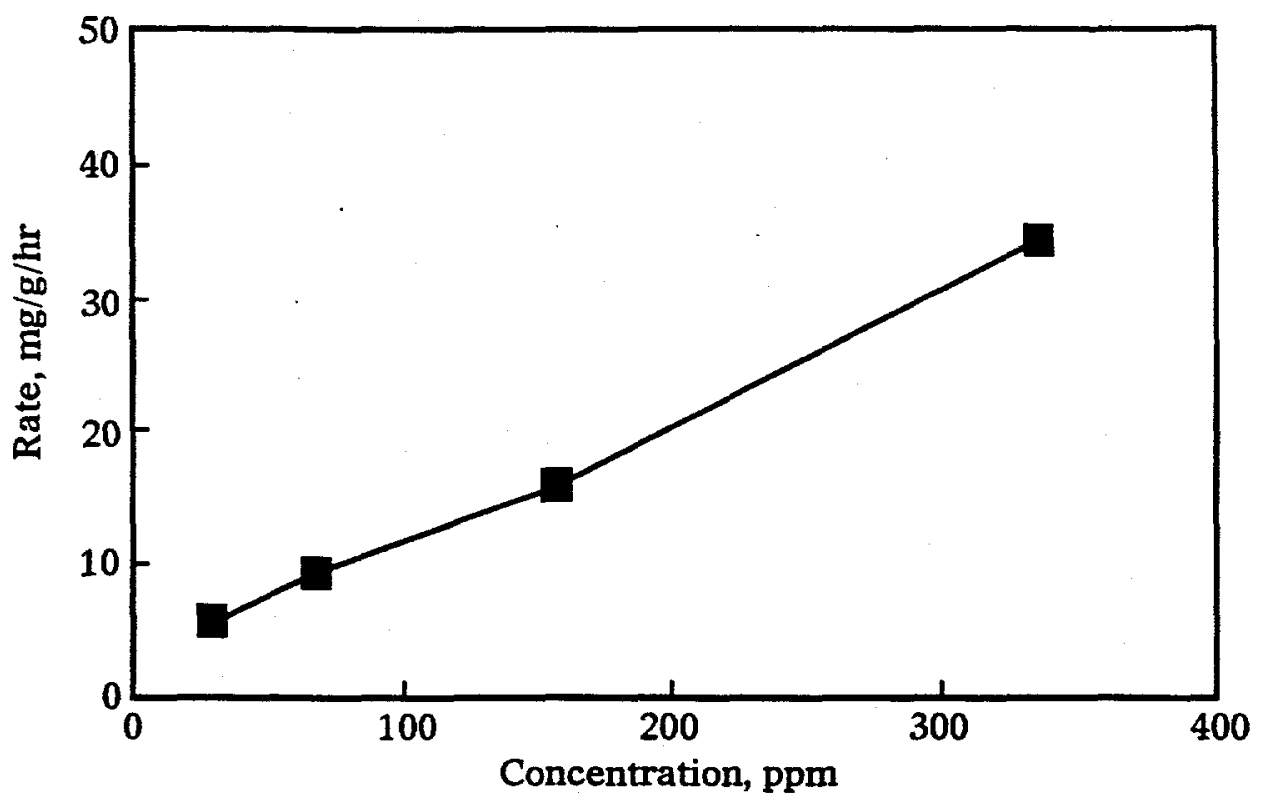

Rate of weight gain as a function of $\mathrm{NaCl}$ vapor-phase concentration

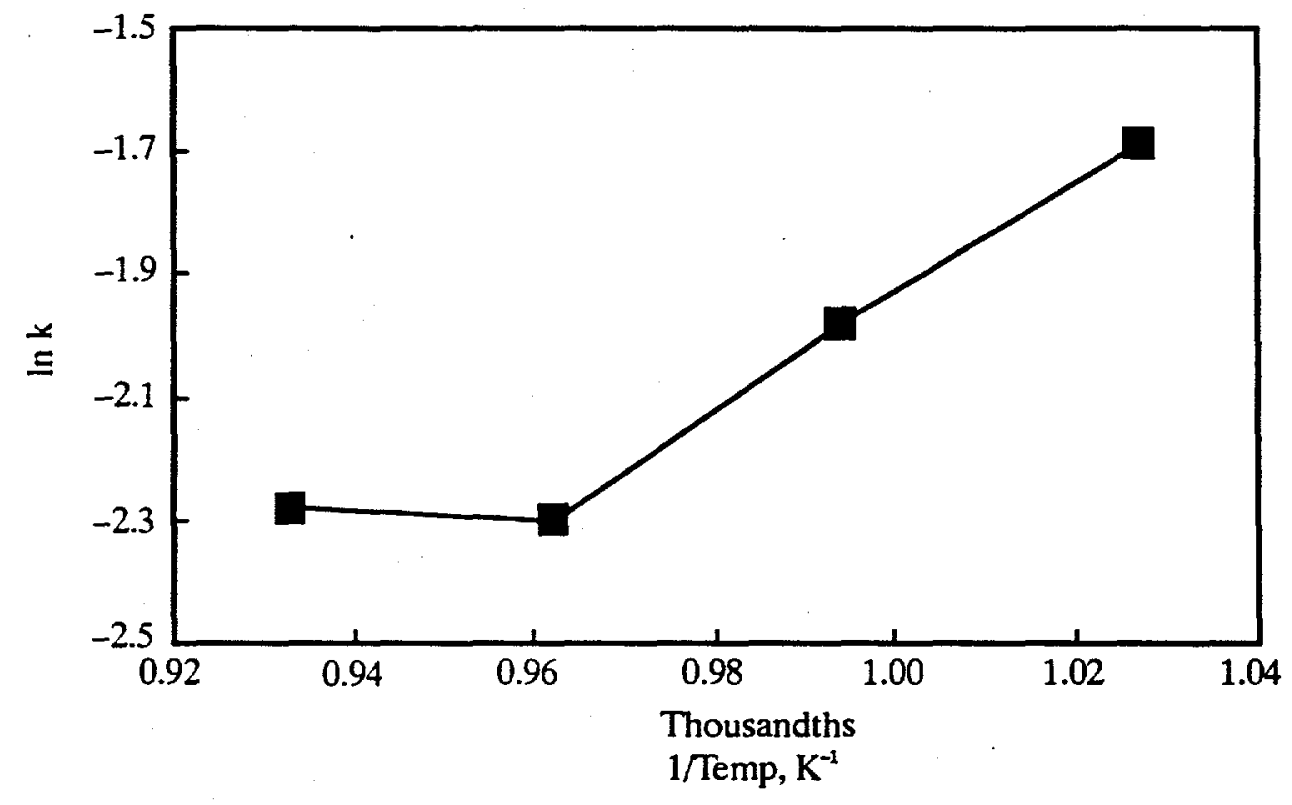

In $\mathrm{k}$ (rate/concentration) as a function of $1 /$ temperature

Figure 53. Graphical presentation of TGA data utilized for extracting kinetic information 
Therefore, there is little or no alkali to be desorbed, and term $C_{a s} / K_{a}$ can be ignored. One can also assume that until a significant amount of the alkali has been adsorbed, the number of vacant sites will remain relatively constant. One can also substitute $C_{a} P_{T}$ for $P_{a}$ where $C_{a}$ is the concentration of the alkali and $P_{T}$ is the total pressure. The rate expression can then be expressed simply as:

$$
R_{a d s i}=K C_{a}
$$

or:

$$
K=R_{a d s i} / C_{a}
$$

where $K=k_{a} P_{a} C_{v}$ and $R_{\text {ads }}$ is the initial rate of adsorption. $K$ may be a function of temperature. If so, the Arrhenius equation is assumed to be valid, and $\mathrm{K}$ can also be expressed as:

$$
K=A e(-E / R T)
$$

In the FBC, Uberoi and others (1990) have developed the rate expression specifically for fluid beds. In this case, the rate equation becomes:

$$
R_{a d s}=\left(1-\epsilon_{o}\right) K C_{o}\left(1-C_{s f} / C_{s}\right)
$$

where $\epsilon_{o}$ is the porosity of the bed and $C_{s f} / C_{s}$ is the ratio of used sites to total sites available on the sorbent. Initially, $C_{s f} / C_{s}$ is zero since no sites are taken. For a defined system, $\left(I-\epsilon_{0}\right)$ is a constant, so the initial rate of adsorption can be again written as

$$
R_{a d s s}=K C_{o}
$$

If $K$ varies with temperature, it can be expressed as the same Arrhenius expression used above.

The TGA data were plotted as rate vs. concentration and $\ln K$ vs. $1 / T$ where $K$ is rate/concentration. In addition, a linear regression was performed about $\ln \mathrm{K}$ and $1 / \mathrm{T}$, with the intercept of the regression being equal to $\ln A$ and the slope equal to $-E / R$ in accordance to Eq. 66. Results from this analysis are presented in Table 19. 
Table 19

Rate Data Collected During TGA Experiments

\begin{tabular}{|c|c|c|c|}
\hline & $\mathrm{NaCl}$ & Initial Gas & $\mathrm{E}, \mathrm{kcal} / \mathrm{mole}$ \\
\hline \multicolumn{4}{|c|}{$\begin{array}{l}\text { Positive Rate vs. Concentration } \\
\text { Negative in } \mathrm{k} \text { vs. } 1 / \mathrm{T}\end{array}$} \\
\hline Albite & Yes & Combustion & 20 \\
\hline Albite & Yes & Combustion (500 ppm) & 25 \\
\hline Albite + Quartz & Yes & Combustion & 17 \\
\hline Kaolinite & Yes & Combustion & 19 \\
\hline \multicolumn{4}{|c|}{$\begin{array}{l}\text { Positive Rate vs. Concentration } \\
\text { Positive Ln K vs } 1 / t\end{array}$} \\
\hline Sodalite & Yes & Combustion & -0.5 \\
\hline Nepheline & Yes & Combustion & -13 \\
\hline $\mathrm{AlO}(\mathrm{OH})_{3}$ & Yes & Combustion & -54 \\
\hline \multicolumn{4}{|c|}{ Flat Rate vs. Concentration } \\
\hline Albite & No & Combustion & $N A^{\prime}$ \\
\hline Albite + Quartz & Yes & Nitrogen & NA \\
\hline Sodalite & No & Combustion & NA \\
\hline Sodalite & Yes & Nitrogen & NA \\
\hline Activated Bauxite & Yes & Nitrogen & NA \\
\hline Zeolite & Yes & Nitrogen & NA \\
\hline
\end{tabular}

' Analogy not applicable to nonadsorbing cases.

The data are grouped into three categories. The first category showed a positive slope on the rate vs. concentration curve, indicating that these materials are potentially good sorbents. This group also has a negative slope of $\ln K$ vs. 1/T. The negative slope (positive $E / R$ ) for these materials is indicative of chemical reaction being the primary mechanism of adsorption. As an example, the characteristic plots for albite are shown in Figure 47. This is consistent with the observed reaction of the sodium sulfate with the 
albite and silica as discussed previously and work by previous researchers using kaolinite (Uberoi et al., 1990). For comparison, the activation energy for kaolinite as calculated from this work, $19 \mathrm{kcal} / \mathrm{mole}$ is in fair agreement with the value of $31 \mathrm{kcal} /$ mole calculated by Uberoi and others (1990).

The second category had a positive rate vs. concentration curve, again indicating that these materials have the propensity to adsorb the alkali, but have a positive slope for the $\ln \mathrm{K} v \mathrm{vs} 1 / \mathrm{T}$. The positive $\mathrm{E} / \mathrm{R}$ (negative activation energy) indicates that the mechanism for adsorption for these materials is physical. These curves are shown in Figure 53 for sodalite as an example. This result is somewhat surprising, since it was expected that the sodalite and nepheline would react chemically according to Eqs. 1 through 5 as discussed above. The open structure of the sodalite, as discussed in Section 2.4.1, does provide space within the crystalline structure necessary for physical adsorption. The structure of nepheline is not as open as the sodalite and would be expected to have more difficulty physically adsorbing material. The synthetic bauxite $\left(\mathrm{AlO}[\mathrm{OH}]_{3}\right)$ also has a porous structure.

The third category is for those materials with a flat rate vs. concentration curve. This would indicate that the rate of adsorption is independent of alkali concentration and, therefore, probably limited by diffusion of the gas into the sorbent particle. All of these materials showed very low adsorption rates, and their independence of alkali concentration most likely means that these materials are not effective sorbents. It is interesting to note that all of the materials in this category were tested under the conditions of either no $\mathrm{NaCl}$ addition or with nitrogen as the carrier gas. All materials tested with both $\mathrm{NaCl}$ and combustion gas $\left(\mathrm{SO}_{2}\right)$ showed a significant amount of adsorption. It is also noted that for the bauxite, switching from nitrogen to combustion gas at the end of the test resulted in a high rate of adsorption ( $36 \mathrm{mg} / \mathrm{g} / \mathrm{hr}$ ), while the rate in nitrogen was less than $2 \mathrm{mg} / \mathrm{g} / \mathrm{hr}$.

SEM photographs were taken of the bauxite after exposure to $\mathrm{NaCl}$ in a combustion gas and an elemental map generated (Figure 54). In addition, several point analyses were performed. The SEM map shows that the sodium and sulfur are dispersed fairly evenly throughout the bauxite particle. This indicates that the vapor-phase alkali and sulfur are diffusing into the bauxite and being physically adsorbed followed 


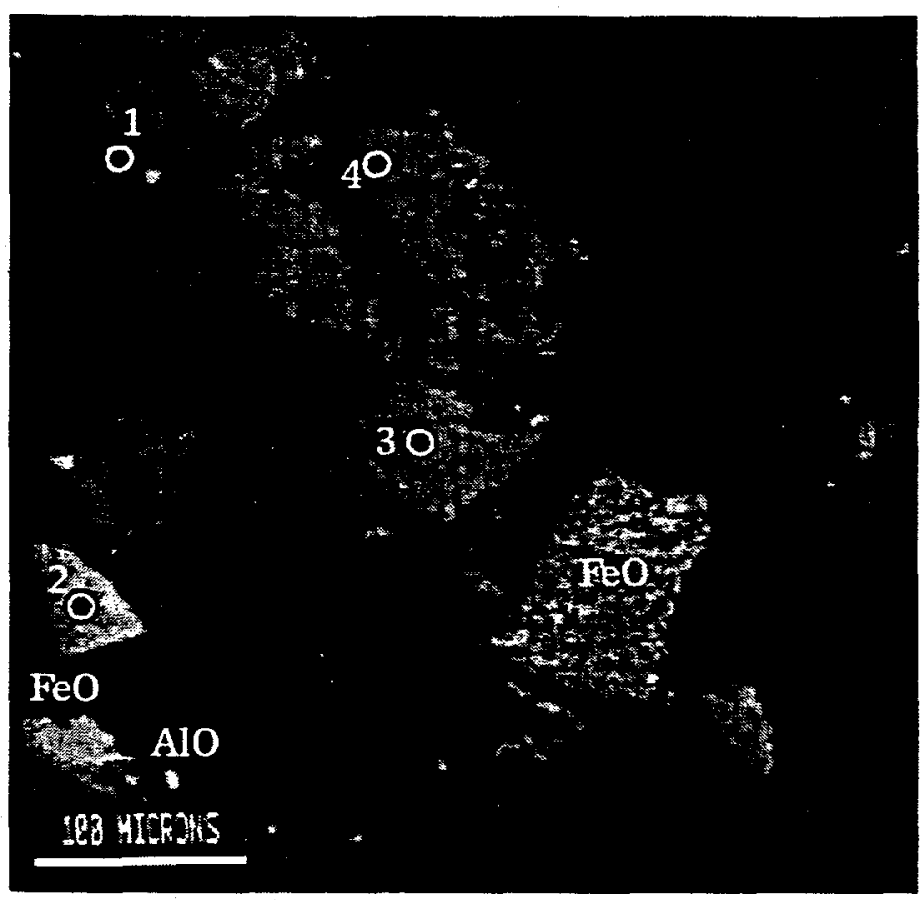

SEM photograph showing locations of particles on elemental map and of point analysis

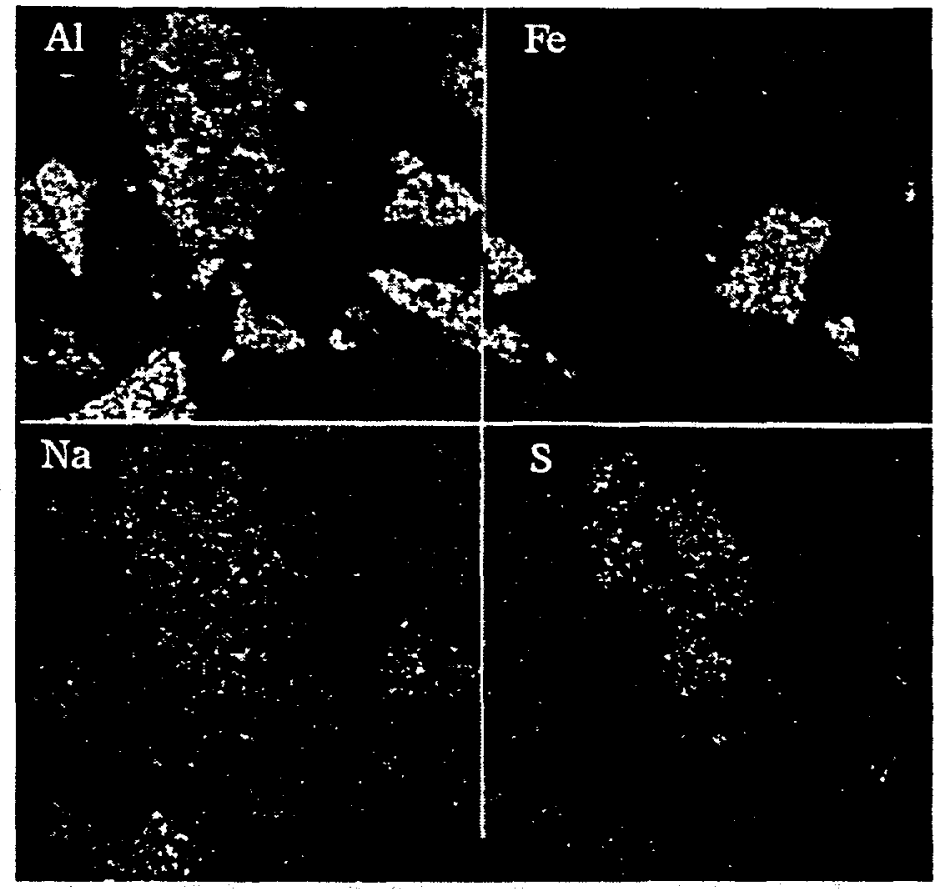

Elemental mapping

Figure 54. Morphology of bauxite after 6-hr exposure to combustion gas and $\mathrm{NaCl}$ in the TGA 
by a chemical reaction. There is no evidence of wetting of the surface with $\mathrm{NaSO}_{4}$ as was the case with the albite, representing a completely different adsorption mechanism. The SEM point analysis (Table 20) shows a portion of the bauxite with some adsorption occurring at Point 1 . Point 2 is an iron oxide particle from impurities in the bauxite. No adsorption is noted on the iron particle. Points 3 and 4 in the interior of the bauxite particles show sodium and sulfur even in the deep interior of the particle.

\subsection{Selection of Sorbents}

Albite was chosen as the most likely candidate for a commercial sorbent from the sodalite-based compounds because it is more available and less costly than the other minerals. Nepheline and sodalite are more rare than albite, more costly and, therefore, less applicable as a commercial sorbent. Albite is commercially mined for use in refractory manufacture. There is no reference of the use of albite in benchor pilot-scale systems of any kind to make a judgment on its expected performance based on previous research.

Table 20

Point Analyses of Bauxite after $6 \mathrm{hr}$ of Exposure to Combustion $\mathrm{Gas}$ and $\mathrm{NaCl}$ in the TGA

\begin{tabular}{lcccc}
\hline Point & 1 & 2 & 3 & 4 \\
\hline Elemental Analysis, mole \% & & & & \\
Sodium & 0.8 & 0.3 & 1.4 & 1.4 \\
Aluminum & 40.9 & 0.1 & 21.2 & 21.6 \\
Silicon & 0.2 & 0 & 4 & 3.58 \\
Sulfur & 0.7 & 0.3 & 3.85 & 3.1 \\
Chlorine & 0.2 & 0.1 & 0.1 & 0 \\
Iron & 0.7 & 37.5 & 3.2 & 0.3 \\
Oxygen & 56.5 & 61.6 & 66.3 & 67.1 \\
\hline Stoichiometry & & & & \\
Sodium & 0.2 & 0.1 & 0.3 & 0.3 \\
Aluminum & 11.6 & 0 & 5.1 & 5.2 \\
Silicon & 0.1 & 0 & 1 & 0.9 \\
Sulfur & 0.2 & 0.1 & 0.9 & 0.7 \\
Chlorine & 0.1 & 0 & 0 & 0 \\
Iron & 0.2 & 9.7 & 0.8 & 0.7 \\
Oxygen & 16 & 16 & 16 & 16 \\
\hline
\end{tabular}


Of the other sorbents tested, kaolinite and bauxite appeared to be the best candidates based on their rate of adsorption. The initial adsorption rate for kaolinite as measured by the TGA experiments using $\mathrm{NaCl}$ in a combustion gas was $24 \mathrm{mg} / \mathrm{g} / \mathrm{hr}$, while that for bauxite ranged from 36 to $55 \mathrm{mg} / \mathrm{g} / \mathrm{hr}$. The corresponding rate for albite is $72 \mathrm{mg} / \mathrm{g} / \mathrm{hr}$. Both bauxite and kaolinite are commercially available and have been tested in granular and packed-bed filters with success in removing up to $99 \%$ of the incoming vaporphase alkali.

The candidates selected for testing on the bench-scale PFBR, therefore, were albite, kaolinite, and bauxite. 


\section{CHAPTER 5}

\section{BENCH-SCALE TESTING OF ALKALI SORBENTS}

Results from the TGA testing indicated that several materials could make good sorbents for capturing alkali. The purpose of the bench-scale testing was to determine how effective these sorbents could be in capturing alkali in a dynamic system that more closely approximates the conditions in a

commercial PFBC. Factors used to evaluate the sorbent's effectiveness included the gas-phase alkali concentration, impacts on ash deposition and agglomeration, and changes in hot-gas filter performance. The 7.6-cm (3-in.) PFBR described in Section 3.3 was utilized for this work. This chapter discusses the results of the testing on the PFBR. A summary of the run conditions and general operating performance will be presented first, followed by results showing the distribution of ash and sorbent. These two sections will serve as background for discussing the phenomenon that is occurring with regard to vapor-phase alkali (Section 5.3), ash deposition (Section 5.4), and hot-gas filter performance (Section 5.5).

\subsection{Summary of Operating Data from PFBR Testing}

Eleven tests were performed on the PFBR as part of this research. These tests are designated as B11296 through B1-2296. The tests were performed with the hot-gas filter vessel on-line and with the ash deposition probe in place. Vapor-phase alkali sampling was performed for all of these tests. Five other tests were performed previously, but only vapor-phase alkali sampling was performed. Results from these five tests are included in the results of Section 5.3, Capture of Vapor-Phase Alkali, but are not included elsewhere.

The matrix of tests for the PFBR testing was discussed in Section 3.3 and is repeated in Table 21 for convenience. All tests were designed to operate at the same temperature, excess air, and velocity to eliminate operating conditions as variables, allowing the work to focus on differences in fuel and additives. 
Variables included in this test matrix include fuel type, sodium content, sorbent type, sorbent add rate, and sorbent size.

Table 21

Test Matrix for PFBR Testing

\begin{tabular}{lccccc}
\hline Test Number & Fuel & Sorbent & Sorbent Size & $\begin{array}{c}\text { Sorbent/Na, } \\
\text { wt/wt }\end{array}$ & Fuel Additive \\
\hline B1-1296 & Beulah & Albite & -30 mesh & $30: 1$ & None \\
B1-1396 & Beulah & None & - & - & None \\
BEL-1496 & Belle Ayr & None & - & - & None \\
BEL-1596 & Belle Ayr & None & - & - & NaAc, ${ }^{3}$ S \\
BEL-1696 & Belle Ayr & Kaolinite & $-1 / 8$ in. & $10: 1$ & NaAc, S \\
BEL-1796 & Belle Ayr & Kaolinite & -30 mesh & $10: 1$ & NaAc, S \\
BEL-1896 & Belle Ayr & Bauxite & $-1 / 8$ in. & $10: 1$ & NaAc, S \\
B1-1996 & Beulah & Bauxite & $-1 / 8$ in. & $10: 1$ & None \\
B1-2096 & Beulah & Bauxite & $-1 / 8$ in. & $3: 1$ & None \\
B1-2196 & Beulah & Bauxite & $-1 / 8$ in. & $5: 1$ & None \\
B1-2296 & Beulah & Bauxite & $-1 / 8$ in. & $5: 1$ & None \\
\hline
\end{tabular}

'Sodium acetate and sulfur added to the fuel.

${ }^{2}$ Repeat of Test B1-2196.

The two fuels utilized for the testing were Beulah Standard North Dakota lignite and Belle Ayr, Wyoming, subbituminous coal. The Beulah lignite is characterized by a relatively high sodium content in the ash and was, therefore, chosen as a good baseline coal for testing the effectiveness of the alkali sorbents. The ash content of this coal is approximately $11 \mathrm{wt} \%$ on an as-received basis. Most of the alkaline and alkaline earth elements of the ash are present as organically bound cations, while the iron is present as relatively small pyrite. The Belle Ayr is low in sodium and has a relatively high calcium content which is also primarily organically bound as is the case with the lignite. The Belle Ayr is also low in sulfur. This coal was chosen because its low sodium and sulfur allowed it to be spiked to allow control of the final levels of these elements without changing the rest of the makeup of the coal.

Prior to each test, the fuel feed was premixed to match the specified test conditions. All of the additives, including the sodium acetate to adjust the sodium content, the elemental sulfur to adjust the sulfur 
content, and the sorbents (albite, kaolinite, bauxite, and dolomite) to capture the alkali and sulfur were weighed and mixed with the coal. This mixture was then added to the coal hopper to be used for the testing. The addition of these materials altered the makeup of the ash material being fed into the combustor. Table 22 presents an analysis of the additives used in the PFBR testing. A new fuel composition was calculated for each run to take into account the added sodium and sulfur and to establish a baseline for comparing the results of the tests. Table 23 presents the calculated analysis of the fuels and ashes, including the sodium, sulfur, and the additives. Test B1-1396 was the baseline (no additives) for the Beulah lignite, and BEL-1496 was the baseline for the Belle Ayr subbituminous.

Table 22

Analysis of Additives Used During PFBR Testing

\begin{tabular}{lcccc}
\hline & Bauxite & Kaolinite & Albite & Dolomite \\
\hline $\mathrm{SiO}_{2}$ & $11.0 \%$ & $52.1 \%$ & $62.3 \%$ & $0.0 \%$ \\
$\mathrm{Al}_{2} \mathrm{O}_{3}$ & $84.2 \%$ & $44.9 \%$ & $26.3 \%$ & $0.0 \%$ \\
$\mathrm{Fe}_{2} \mathrm{O}_{3}$ & $4.8 \%$ & $0.8 \%$ & $0.0 \%$ & $0.0 \%$ \\
$\mathrm{NaO}_{2}$ & $0.0 \%$ & $0.0 \%$ & $11.4 \%$ & $0.0 \%$ \\
$\mathrm{CaO}$ & $0.0 \%$ & $0.0 \%$ & $0.0 \%$ & $36.6 \%$ \\
$\mathrm{MgO}$ & $0.0 \%$ & $0.0 \%$ & $0.0 \%$ & $15.2 \%$ \\
\hline
\end{tabular}

A summary of selected run conditions is presented in Tables 24 and 25. Appendix A includes the average and standard deviations for all measured points. For all of the tests, the reactor ran very smoothly as indicated by the curves for temperature, pressure, and emissions (Figures 42-46) similar to those presented in Section 5.3 and the low standard deviations for each measured point. Although each test was designed to run at exactly the same conditions, some discrepancies exist. Each test was planned for approximately $4.5 \mathrm{hr}$ at steady state to allow a $4-\mathrm{hr}$ alkali sample to be taken. Test B1-1296 utilizing the Beulah with albite as the alkali sorbent was stopped after $2.6 \mathrm{hr}$ because of blinding of the hot-gas filter. As will be shown in Section 5.3.3, the pressure drop rose at a rapid rate and could not be reduced by backpulsing the filter elements. Therefore, the run was terminated to protect the hot-gas filter vessel and 
Table 23

Analysis of the Fuels Used for PFBR Testing Including Added Sodium, Sulfur, and Sorbents

\begin{tabular}{|c|c|c|c|c|c|c|c|c|c|c|c|}
\hline & $\mathrm{BI}-1296$ & $\mathrm{~B} 1-1396$ & BEL-1496 & $3 E L-1596$ & BEL-1696 & BEL-1796 & EL-1896 & B1-1996 & B1-2096 & B1-2196 & B1-2296 \\
\hline \multicolumn{12}{|c|}{ Proximate Analysis, as received, wt $\%$} \\
\hline Moisture & 19.90 & 19.90 & 16.70 & 16.70 & 16.70 & 16.70 & 16.70 & 19.90 & 19.90 & 19.90 & 19.90 \\
\hline Volatile Matter & 37.29 & 37.29 & 37.87 & 37.87 & 37.87 & 37.87 & 37.87 & 37.29 & 37.29 & 37.29 & 37.29 \\
\hline Fixed Carbon & 31.86 & 31.86 & 40.56 & 40.56 & 40.56 & 40.56 & 40.56 & 31.86 & 31.86 & 31.86 & 31.86 \\
\hline Ash & 10.95 & 10.95 & 4.87 & 4.87 & 4.87 & 4.87 & 4.87 & 10.95 & 10.95 & 10.95 & 10.9 \\
\hline Higher Heating Value, Btu/lb & 7,693 & 7,693 & 9,750 & 9,802 & 9,802 & 9,802 & 9,802 & 7,693 & 7,693 & 7,693 & 7,693 \\
\hline \multicolumn{12}{|c|}{ Ultimate Analysis, as received, $w t \%$} \\
\hline Carbon & 48.21 & 48.21 & 57.50 & 55.97 & 55.97 & 55.97 & 55.97 & 48.21 & 48.21 & 48.21 & 48.21 \\
\hline Hydrogen & 3.12 & 3.12 & 4.32 & 4.21 & 4.21 & 4.21 & 4.21 & 3.12 & 3.12 & 3.12 & 3.12 \\
\hline Nitrogen & 0.74 & 0.74 & 0.70 & 0.68 & 0.68 & 0.68 & 0.68 & 0.74 & 0.74 & 0.74 & 0.74 \\
\hline Sulfur & 1.32 & 1.32 & 0.36 & 3.01 & 3.01 & 3.01 & 3.01 & 1.32 & 1.32 & 1.32 & 1.32 \\
\hline Oxygen & 15.76 & 15.76 & 15.56 & 15.14 & 15.14 & 15.14 & 15.14 & 15.76 & 15.76 & 15.76 & $15.76 \stackrel{N}{N}$ \\
\hline Ash & 10.95 & 10.95 & 4.87 & 4.74 & 4.74 & 4.74 & 4.74 & 10.95 & 10.95 & 10.95 & 10.95 \\
\hline Moisture & 19.90 & 19.90 & 16.70 & 16.25 & 16.25 & 16.25 & 16.25 & 19.90 & 19.90 & 19.90 & 19.90 \\
\hline \multicolumn{12}{|l|}{ Ash Composition, $\%$ as oxides } \\
\hline Calcium, $\mathrm{CaO}$ & 12.00 & 12.00 & 26.60 & 22.10 & 21.20 & 21.10 & 21.10 & 12.00 & 12.00 & 12.00 & 12.00 \\
\hline Magnesium, $\mathrm{MgO}$ & 6.90 & 6.90 & 7.00 & 5.80 & 5.60 & 5.60 & 5.60 & 6.90 & 6.90 & 6.90 & 6.90 \\
\hline Sodium, $\mathrm{Na}_{2} \mathrm{O}$ & 3.40 & 3.40 & 1.30 & 1.80 & 1.70 & 1.70 & 1.70 & 1.70 & 3.40 & 3.40 & 3.40 \\
\hline Silica, $\mathrm{SiO}_{2}$ & 24.50 & 24.50 & 27.80 & 23.10 & 24.30 & 22.60 & 22.60 & 24.50 & 24.50 & 24.50 & 24.50 \\
\hline Aluminum, $\mathrm{Al}_{2} \mathrm{O}_{3}$ & 11.40 & 11.40 & 13.10 & 10.90 & 12.30 & 13.90 & 13.90 & 11.40 & 11.40 & 11.40 & 11.40 \\
\hline Ferric, $\mathrm{Fe}_{2} \mathrm{O}_{3}$ & 19.10 & 19.10 & 5.50 & 4.60 & 4.40 & 4.60 & 4.60 & 19.10 & 19.10 & 19.10 & 19.10 \\
\hline Titanium, $\mathrm{TiO}_{2}$ & 0.60 & 0.60 & 1.30 & 1.10 & 1.10 & 1.10 & 1.10 & 0.60 & 0.60 & 0.60 & 0.60 \\
\hline Phosphorus, $\mathrm{P}_{2} \mathrm{O}_{3}$ & 0.30 & 0.30 & 1.00 & 0.80 & 0.80 & 0.80 & 0.80 & 0.30 & 0.30 & 0.30 & 0.30 \\
\hline Potassium, $\mathrm{K}_{2} \mathrm{O}$ & 0.10 & 0.10 & 0.30 & 0.30 & 0.20 & 0.20 & 0.20 & 0.10 & 0.10 & 0.10 & 0.10 \\
\hline Sulfur, $\mathrm{SO}_{3}$ & 21.70 & 21.70 & 16.00 & 29.60 & 28.40 & 28.40 & 28.40 & 21.70 & 21.70 & 21.70 & 21.70 \\
\hline
\end{tabular}


Table 24

Summary of Process Data from PFBR Testing of the Beulah Lignite

\begin{tabular}{|c|c|c|c|c|c|c|}
\hline Test No. & B1-1296 & B1-1396 & B1-1996 & B1-2096 & B1-2196 & $\mathrm{B} 1-2296$ \\
\hline Coal Feed Rate, $\mathrm{kg} / \mathrm{hr}$ & 2.59 & 2.59 & 2.54 & 2.41 & 2.71 & 2.54 \\
\hline Dolomite Feed Rate, $\mathrm{kg} / \mathrm{hr}$ & 0.00 & 0.00 & 0.29 & 0.15 & 0.17 & 0.16 \\
\hline Additive & Albite & None & Bauxite & Bauxite & Bauxite & Bauxite \\
\hline Additive Feed Rate, $\mathrm{kg} / \mathrm{hr}$ & 0.26 & 0 & 0.27 & 0.08 & 0.15 & 0.14 \\
\hline Cyclone Pressure Drop, $\mathrm{kPa}$ & 1.78 & 2.54 & 1.23 & 1.74 & 1.31 & 1.69 \\
\hline Reactor Pressure, $\mathrm{MPa}$ absolute & 1.13 & 1.20 & 1.13 & 1.13 & 1.14 & 1.14 \\
\hline \multicolumn{7}{|l|}{ Fluidizing Gas, lpm } \\
\hline Air & 348 & 328 & 354 & 339 & 362 & 346 \\
\hline Nitrogen & 295 & 326 & 297 & 296 & 288 & 289 \\
\hline Total & 644 & 655 & 652 & 636 & 650 & 636 \\
\hline \multicolumn{7}{|l|}{ Flue Gas } \\
\hline Oxygen, $\%$ & 4.85 & 4.56 & 4.795 & 4.62 & 4.88 & 4.94 \\
\hline Excess Air, \% & 25.0 & 23.4 & $24: 1$ & 23.8 & 26.0 & 25.1 \\
\hline FG SGV, $1 \mathrm{~m} / \mathrm{sec}$ & 0.94 & 0.87 & 0.97 & 0.93 & 0.96 & 0.94 \\
\hline \multicolumn{7}{|l|}{ Reactor Temperatures, ${ }^{\circ} \mathrm{C}$} \\
\hline Preheater Exit & 326 & 314 & 319 & 323 & 319 & 324 \\
\hline Plenum & 413 & 439 & 393 & 406 & 397 & 412 \\
\hline Zone 1 Average & 848 & 776 & 846 & 834 & 836 & 845 \\
\hline Zone 2 Average & 856 & 816 & 880 & 868 & 881 & 878 \\
\hline Zone 3 Average & 861 & 863 & 858 & 856 & 872 & 862 \\
\hline Reactor Average & 838 & 806 & 859 & 848 & 857 & 859 \\
\hline Cyclone Exit Temperature & 821 & 805 & 799 & 801 & 732 & 722 \\
\hline \multicolumn{7}{|l|}{ Filter Vessel Temperatures, ${ }^{\circ} \mathrm{C}$} \\
\hline Inlet & 821 & 805 & 799 & 800 & 732 & 722 \\
\hline Low & 826 & 791 & 797 & 805 & 800 & 798 \\
\hline Middle & 813 & 775 & 791 & 795 & 789 & 785 \\
\hline Top & 757 & 716 & 715 & 736 & $N A^{2}$ & 706 \\
\hline
\end{tabular}

${ }^{1}$ Flue gas superficial gas velocity.

${ }^{2}$ Not available. 
Table 25

Summary of Process Data from PFBR Testing of the Belle Ayr Coal

\begin{tabular}{|c|c|c|c|c|c|}
\hline Test No. & BEL-1496 & BEL-1596 & BEL-1696 & BEL-1796 & BEL-1896 \\
\hline Coal Feed Rate, kg/hr & 1.98 & 2.21 & 2.06 & 2.10 & 2.00 \\
\hline Dolomite Feed Rate, $\mathrm{kg} / \mathrm{hr}$ & 0.00 & 0.00 & 00.0 & 0.00 & 0.00 \\
\hline Additive & None & None & Kaolinite & Kaolinite & Bauxite \\
\hline Additive Feed Rate, $\mathrm{kg} / \mathrm{hr}$ & 0 & 0 & 0.08 & 0.08 & 0.08 \\
\hline Cyclone Pressure Drop, $\mathrm{kPa}$ & 1.79 & 1.52 & 1.71 & 1.98 & 1.62 \\
\hline Reactor Pressure, MPa absolute & 1.13 & 1.13 & 1.13 & 1.13 & 1.13 \\
\hline \multicolumn{6}{|l|}{ Fluidizing Gas, lpm } \\
\hline Air & 368 & 368 & 354 & 361 & 347 \\
\hline Nitrogen & 283 & 283 & 282 & 269 & 291 \\
\hline Total & 651 & 651 & 636 & 630 & 637 \\
\hline \multicolumn{6}{|l|}{ Flue Gas } \\
\hline Oxygen, \% & 4.86 & 4.70 & 4.80 & 4.02 & 4.75 \\
\hline Excess Air, \% & 25.5 & 23.9 & 25.2 & 25.9 & 24.6 \\
\hline FG SGV, m/sec & 0.96 & 0.97 & 0.95 & 0.94 & 0.93 \\
\hline \multicolumn{6}{|l|}{ Reactor Temperatures, ${ }^{\circ} \mathrm{C}$} \\
\hline Preheater Exit & 321 & 318 & 324 & 328 & 323 \\
\hline Plenum & 427 & 414 & 424 & 415 & 395 \\
\hline Zone 1 Average & 830 & 842 & 850 & 844 & 846 \\
\hline Zone 2 Average & 877 & 888 & 875 & 884 & 868 \\
\hline Zone 3 Average & 923 & 912 & 889 & 904 & 869 \\
\hline Reactor Average & 863 & 869 & 866 & 868 & 857 \\
\hline Cyclone Exit Temperature & 821 & 805 & 799 & 801 & 732 \\
\hline \multicolumn{6}{|l|}{ Filter Vessel Temperatures, ${ }^{\circ} \mathrm{C}$} \\
\hline Inlet & 846 & 854 & 837 & 831 & 807 \\
\hline Low & 830 & 832 & 811 & 821 & 815 \\
\hline Middle & 816 & 821 & 799 & 806 & 806 \\
\hline Top & 762 & 763 & 737 & 738 & 738 \\
\hline
\end{tabular}


tube sheet. Test B1-1396 was also stopped prematurely, after $0.8 \mathrm{hr}$, also due to uncontrollably high pressure drops across the ceramic filters in the hot-gas filter vessel. Test B1-2196 was stopped after only 1 hour due to computer problems. The data from this test are included, although their quality is somewhat suspect because of the short test duration and computer problems. Test B1-2296 was an 8-hr test.

The reactor pressure was held constant at the $1.13 \mathrm{MPa}(150 \mathrm{psig})$ for all tests. A rise in pressure in the PFBR is noted when the filter vessel is being backpulsed with high-pressure air 1.8 to $2.3 \mathrm{MPa}$ (240 to $300 \mathrm{psig}$ ). Therefore, for those tests where it was necessary to backpulse the filters, a higher average reactor pressure is noted. For Test 1396, the filter was backpulsed repeatedly, which accounts for its significantly higher reactor pressure. Excess air was consistently around $25 \%$ and the SGV at its set point of $0.91 \mathrm{~m} / \mathrm{s}(3 \mathrm{ft} / \mathrm{s})$.

The set point for the temperature was an average bed (Zone 1) temperature of $843^{\circ} \mathrm{C}\left(1550^{\circ} \mathrm{F}\right)$. Tests 1296 and 1396 were performed at lower temperatures $\left(818^{\circ} \mathrm{C}\left[1504^{\circ} \mathrm{F}\right]\right.$ and $776^{\circ} \mathrm{C}\left[1429^{\circ} \mathrm{F}\right]$, respectively) because of miscommunication with the PFBR operator. For these two tests, the control point used was the Zone 3 temperature rather than Zone 1. The remainder of the reactor temperatures are within $20^{\circ} \mathrm{C}$ of the set point. A second difference to note in temperatures is the higher Zone 3 temperature for the Belle Ayr tests versus those with the Beulah. This indicates that more of the Belle Ayr was burning in the freeboard region of the bed. This impacts the alkali and sulfur capture efficiencies since the fuel burning in the freeboard does not contact the in-bed sorbents.

Tables 26 and 27 summarize the emission data from these tests. Test 1396 showed high $\mathrm{CO}$ and low $\mathrm{CO}_{2}$ emissions. This is probably due to the shortness of the test. Carbon monoxide is typically high at the beginning of the testing as coal is first introduced. For a longer duration run, these high $\mathrm{CO}$ values for the short time period for conversion to coal would not have a noticeable effect on the run averages. The other emission to note is the apparent reduction in $\mathrm{NO}_{\mathbf{x}}$ with the addition of bauxite and kaolinite. Since $\mathrm{NO}_{\mathrm{x}}$ emissions are very sensitive to temperature, the $\mathrm{NQ}_{x}$ was plotted versus temperature in Figure 55 . The lowered emissions are clearly not temperature-dependent. Limestone has been demonstrated to have a catalytic effect on $\mathrm{NO}_{\mathrm{x}}$ emissions, and a similar phenomena may be occurring here. Albite did not appear to affect the $\mathrm{NO}_{x}$ emissions. 
Table 26

Emissions Data from PFBR Tests Performed Using Beulah Lignite

\begin{tabular}{|c|c|c|c|c|c|c|}
\hline & B1-1296 & B1-1396 & B1-1996 & B1-2096 & B1-2196 & B1-2296 \\
\hline $\mathrm{O}_{2}, \%$ & 4.85 & 4.56 & 4.80 & 4.62 & 4.88 & 4.94 \\
\hline Excess Air, \% & 25.48 & 23.13 & 25.30 & 23.96 & 25.80 & 26.25 \\
\hline CO Content, ppm & 11 & 290 & 11 & 16 & 25 & 5 \\
\hline CO Content, ${ }^{\prime} \mathrm{ppm}$ & 12 & 318 & 12 & 18 & 28 & 6 \\
\hline CO Emission, lb/MMBtu & 0.034 & 1.121 & 0.031 & 0.048 & 0.073 & 0.014 \\
\hline CO Content, corrected ppm & 23 & 633 & 22 & 33 & 50 & 10 \\
\hline $\mathrm{CO}_{2}$ Content, $\%$ & 4.7 & 3.8 & 5.3 & 4.9 & 5.0 & 5.1 \\
\hline $\mathrm{CO}_{2}$ Content, ${ }^{1} \%$ & 5.2 & 4.1 & 5.8 & 5.3 & 5.6 & 5.7 \\
\hline $\mathrm{CO}_{2}$ Content, corrected $\%$ & 9.7 & 8.2 & 10.7 & 10.0 & 10.1 & 10.4 \\
\hline $\mathrm{NO}_{\mathrm{x}}$ Content, ppm & 69 & 67 & 76 & 58 & 108 & 61 \\
\hline $\mathrm{NO}_{\mathrm{x}}$ Content, ${ }^{1} \mathrm{ppm}$ & 77 & 73 & 84 & 64 & 121 & 68 \\
\hline $\mathrm{NO}_{\mathrm{x}}$ Emission, lb/MMBtu & 0.353 & 0.426 & 0.347 & 0.286 & 0.516 & 0.289 \\
\hline $\mathrm{NO}_{x}$ Content, corrected ppm & 142 & 146 & 155 & 119 & 217 & 125 \\
\hline $\mathrm{SO}_{2}$ Content, ppm & 55 & 75 & 4 & 8 & 25 & 25 \\
\hline $\mathrm{SO}_{2}$ Content,' ppm & 61 & 82 & 4 & 9 & 28 & 28 \\
\hline $\mathrm{SO}_{2}$ Emission, lb/MMBtu & 0.392 & 0.663 & 0.025 & 0.055 & 0.166 & 0.165 \\
\hline $\mathrm{SO}_{2}$ Retention, ${ }^{2} \%$ & 85.7 & 75.8 & 99.1 & 98.0 & 93.9 & 94.0 \\
\hline $\mathrm{SO}_{2}$ Content, corrected ppm & 113 & 164 & 8 & 16 & 50 & 51 \\
\hline Avg. Comb. Temp., ${ }^{\circ} \mathrm{C}$ & 821 & 805 & 799 & 800 & 732 & 722 \\
\hline Moisture in FG, vol\% & 5.0 & 5.0 & 5.0 & 5.0 & 5.0 & 5.0 \\
\hline
\end{tabular}

' Corrected to $3 \% \mathrm{O}_{2}$.

2 Moisture-free fuel carbon and sulfur values used in the sulfur retention calculation. 
Table 27

Emissions Data from PFBR Tests Performed Using Belle Ayr Coal

\begin{tabular}{|c|c|c|c|c|c|}
\hline & BEL-1496 & BEL-1596 & BEL-1696 & BEL-1796 & BEL-1896 \\
\hline $\mathrm{O}_{2}, \%$ & 4.86 & 4.70 & 4.80 & 5.02 & 4.75 \\
\hline Excess Air, \% & 25.67 & 24.51 & 25.18 & 26.76 . & 24.82 \\
\hline CO Content, ppm & 0 & 0 & 8 & 31 & 18 \\
\hline CO Content, ${ }^{1}$ ppm & 0 & 0 & 9 & 35 & 20 \\
\hline CO Emission, lb/MMBtu & 0.000 & 0.000 & 0.022 & 0.082 & 0.050 \\
\hline CO Content, corrected ppm & 0 & 0 & 16 & 61 & 37 \\
\hline $\mathrm{CO}_{2}$ Content, $\%$ & 5.0 & 4.9 & 4.8 & 5.0 & 4.8 \\
\hline $\mathrm{CO}_{2}$ Content, ${ }^{1} \%$ & 5.6 & 5.4 & 5.3 & 5.7 & 5.3 \\
\hline $\mathrm{CO}_{2}$ Content, corrected $\%$ & 9.9 & 9.5 & 9.6 & 9.9 & 9.7 \\
\hline $\mathrm{NO}_{x}$ Content, ppm & 77 & 172 & 61 & 41 & 54 \\
\hline $\mathrm{NO}_{\mathrm{x}}$ Content, ${ }^{1} \mathrm{ppm}$ & 86 & 190 & 68 & 46 & 60 \\
\hline $\mathrm{NO}_{x}$ Emission, lb/MMBtu & 0.347 & 0.775 & 0.277 & 0.178 & 0.247 \\
\hline $\mathrm{NO}_{\mathrm{x}}$ Content, corrected ppm & 152 & 336 & 122 & 81 & 110 \\
\hline $\mathrm{SO}_{2}$ Content, ppm & 16 & 470 & 348 & 441 & 381 \\
\hline $\mathrm{SO}_{2}$ Content,' ppm & 18 & 519 & 387 & 497 & 422 \\
\hline $\mathrm{SO}_{2}$ Emission, lb/MMBtu & 0.100 & 2.949 & 2.201 & 2.672 & 2.430 \\
\hline $\mathrm{SO}_{2}$ Retention, ${ }^{2} \%$ & 86.3 & 51.8 & 64.0 & 56.4 & 60.3 \\
\hline $\mathrm{SO}_{2}$ Content, corrected ppm & 32 & 918 & 694 & 866 & 776 \\
\hline Avg. Comb. Temp., ${ }^{\circ} \mathrm{F}$ & 1585 & 1597 & 1590 & 1594 & 1575 \\
\hline Moisture in FG, vol\% & 5.0 & 5.0 & 5.0 & 5.0 & 5.0 \\
\hline
\end{tabular}

1 Corrected to $3 \% \mathrm{O}_{2}$.

${ }^{2}$ Moisture-free fuel carbon and sulfur values used in the sulfur retention calculation. 


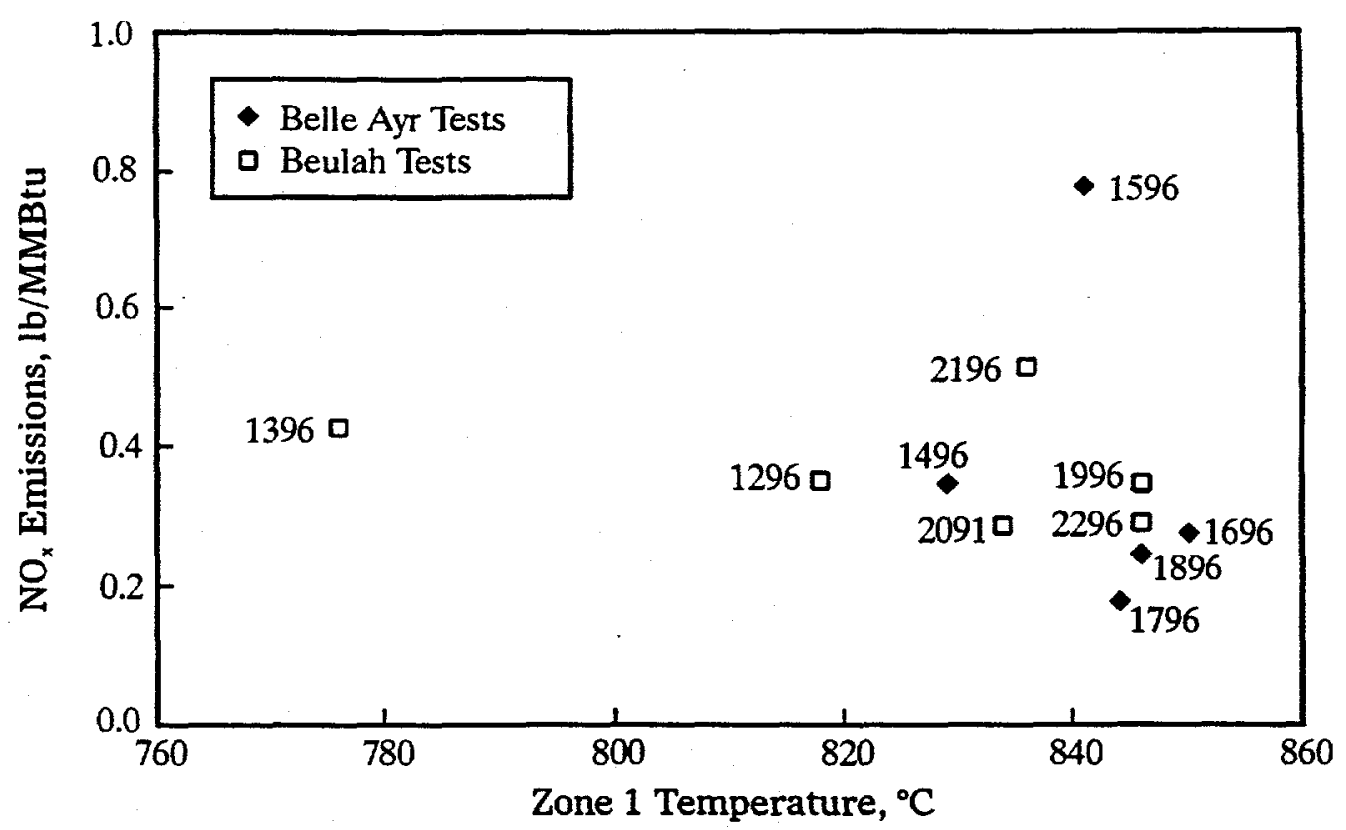

Figure 55. $\mathrm{NO}_{\mathrm{x}}$ emissions as a function of temperature for PFBR tests

\subsection{Distribution and Chemistry of the Ash Generated from Capture Tests}

At the conclusion of each test, ash in the bed, cyclone, and filter vessel drain pots were collected, weighed, and submitted for analysis. During maintenance, material that was deposited on the reactor or cyclone walls and the deposition probe was removed and weighed. The filters were pulsed cold at $50 \mathrm{psig}$, and this material was also collected and weighed. Material balances were performed for each of the tests with the results presented here. Knowing how each of the sorbents will affect the solids loadings going into the primary cyclone and the filter vessel is important in evaluating the overall impacts of the sorbent on performance.

Figure 56 presents graphically the material balances for each of the tests performed as the percentage of ash removed in the cyclone, filter vessel, and bed based on the total percent of ash and bed material fed into the system. A miscellaneous category accounts for ash that built up in the crossover from the reactor to the cyclone or the cyclone to the filter vessel. Closures were near $100 \%$ for most tests. If one first looks at the base case for the test for the Beulah coal, Test B1-1396, the following observations can be made. Only a 


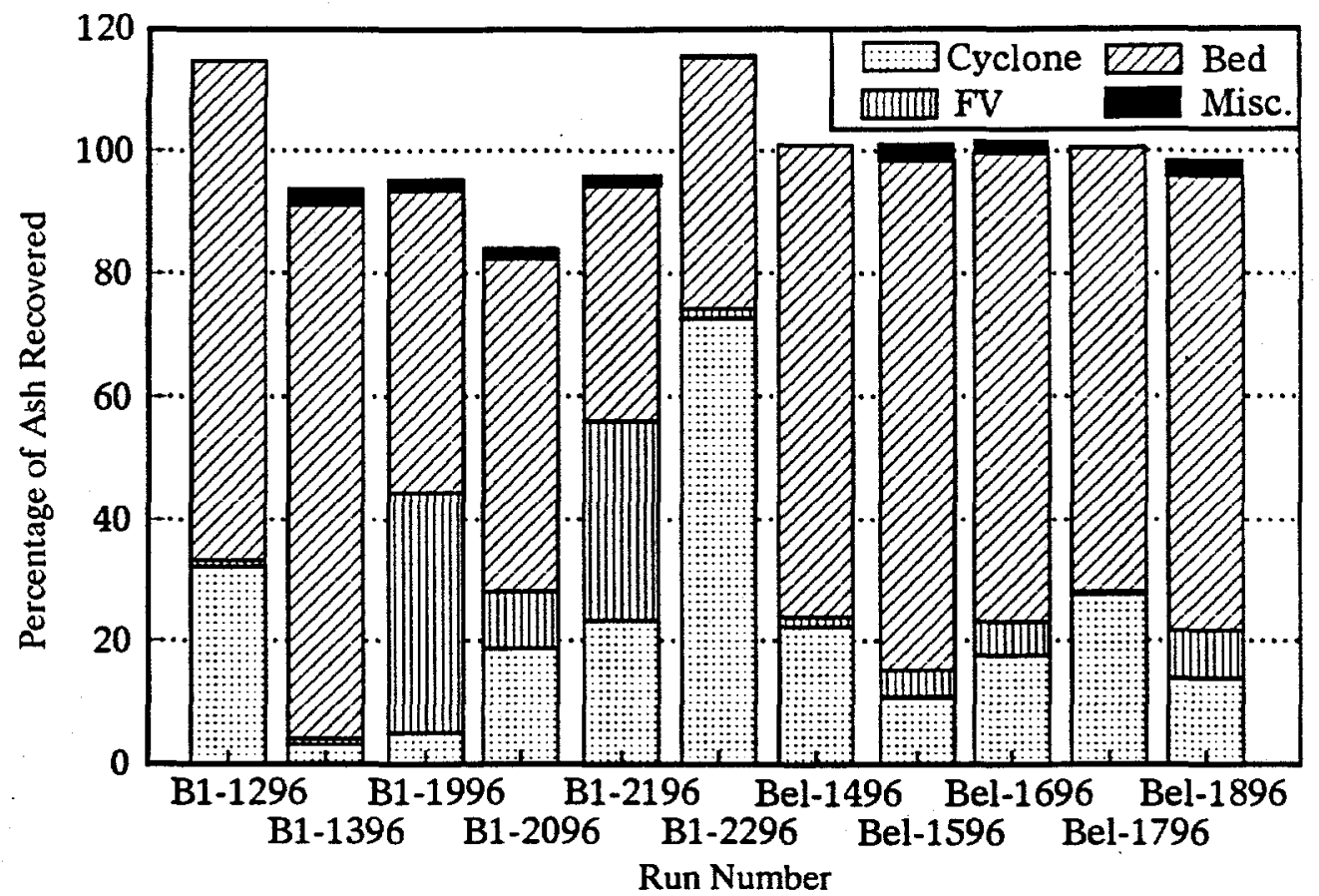

Figure 56. Material balance for PFBR testing expressed as percent of ash removed based on total solid material added

small percentage of the ash left the bed and entered into the cyclone and filter vessel. Also, a significant amount of material was found hung up in the reactor. Observation of the bed material at the conclusion of the test indicated the onset of agglomeration. Agglomeration is the build up of ash on the bed particles and has been shown to be caused by the organically bound sodium in the coal fluxing with calcium and forming sodium calcium sulfates (Mann et al., 1995). The generation of this sticky ash kept a large percentage of the ash in the bed, rather than releasing it from the bed as fly ash.

The test using albite as the sorbent (B1-1296) as compared to the baseline test $(B 1-1396)$ shows a significant increase in the percentage of cyclone ash generated. It is speculated that this increase is due to carryover of the albite into the cyclone. Table 28 presents an analysis of the material collected from the cyclone for each test. It is obvious from the high silica levels that some of the quartz bed material is breaking up and being carried out of the bed. The quartz bed material is more prevalent in the coarser cyclone ash ( $d_{50}$ approximately 100 microns) compared to the fine filter vessel ash ( $d_{00}$ approximately 30 microns). Figure 57 shows the size distribution for the major ash streams from Test 1296. 
Table 28

Elemental Analysis of Cyclone and Filter Vessel Ash from PFBR Testing on Sulfur-Free Basis, mole \%

\begin{tabular}{lcccccccccc}
\hline Run & 1296 & 1396 & 1496 & 1596 & 1696 & 1796 & 1896 & 1996 & 2096 & 2296 \\
$\mathrm{Coal}$ & $\mathrm{B} 1$ & $\mathrm{~B} 1$ & $\mathrm{BEL}$ & $\mathrm{BEL}$ & $\mathrm{BEL}$ & $\mathrm{BEL}$ & $\mathrm{BEL}$ & $\mathrm{B} 1$ & $\mathrm{~B} 1$ & $\mathrm{~B} 1$ \\
\hline \multicolumn{2}{l}{ Filter Vessel } & & & & & & & & & \\
$\mathrm{Si}$ & 30.9 & 31.7 & 34.8 & 42.7 & 40.3 & 39.5 & 39.6 & 25.8 & 28.6 & 25.4 \\
$\mathrm{Al}$ & 11.6 & 12.8 & 15.8 & 16.9 & 17.3 & 17.6 & 25.5 & 13.3 & 15.7 & 9.6 \\
$\mathrm{Fe}$ & 8.3 & 14.3 & 7 & 7.6 & 7.9 & 6.6 & 10.2 & 7 & 10.5 & 13.2 \\
$\mathrm{Ca}$ & 29.2 & 18.5 & 31.9 & 23.9 & 25.7 & 21.2 & 12.8 & 31.8 & 26.2 & 20.5 \\
$\mathrm{Mg}$ & 16.4 & 4 & 6.5 & 3.5 & 3.3 & 6.2 & 4.5 & 18.5 & 11.7 & 8.4 \\
$\mathrm{Na}$ & 1.3 & 17.1 & 1.7 & 2.9 & 2.9 & 6.2 & 4.9 & 2.6 & 6.2 & 20.9 \\
$\mathrm{~S}$ & 15.2 & 18 & 4 & 10.8 & 20.1 & 11.8 & 8.5 & 4.4 & 11.2 & 27.2 \\
$\mathrm{Cyclone}$ & $\mathrm{Ash}$ & & & & & & & & & \\
$\mathrm{Si}$ & 41.7 & 51.8 & 43.5 & 47.9 & 60.7 & 44.2 & 48.1 & 48.9 & 29.5 & 27.4 \\
$\mathrm{Al}$ & 14.5 & 12.1 & 14.5 & 14.9 & 14.2 & 21.4 & 20.6 & 11.8 & 14.7 & 14.8 \\
$\mathrm{Fe}$ & 121.4 & 12.2 & 6.7 & 6.7 & 5.4 & 6.7 & 9.9 & 8.9 & 9.9 & 13.3 \\
$\mathrm{Ca}$ & 16.9 & 14.8 & 26.4 & 22.4 & 12.7 & 18.6 & 15.6 & 18.8 & 27.4 & 26.7 \\
$\mathrm{Mg}$ & 5.8 & 4.2 & 5.6 & 4 & 3.8 & 4.3 & 2.7 & 8.3 & 14.5 & 13 \\
$\mathrm{Na}$ & 7.5 & 4.4 & 1 & 1.8 & 1.5 & 2.5 & 1.2 & 2.9 & 3.3 & 3.6 \\
$\mathrm{~S}$ & 6.3 & 7.6 & 2.9 & 8.9 & 3.5 & 4.5 & 4.6 & 5.6 & 6.7 & 8.5 \\
\hline
\end{tabular}

Continuing with the comparison of Tests 1296 and 1396, the higher aluminum and sodium contents for Test 1296 are indicative of enrichment of albite in the cyclone ash. The percentage of ash collected in the filter vessel appears to be similar for both cases. However, by comparing the rates of ash collected in the cyclone and filter vessel as is done in Figure 58 , it can be seen that fine fly ash was being generated at a higher rate for the base test than for the test with albite. The albite may be limiting the amount of fine $\mathrm{Na}_{2} \mathrm{SO}_{4}$ that either forms by reaction or by serving as a site for heterogeneous condensation. TGA tests (Section 4.2) showed condensation of $\mathrm{Na}_{2} \mathrm{SO}_{4}$ on the albite particle followed by chemical reaction. 


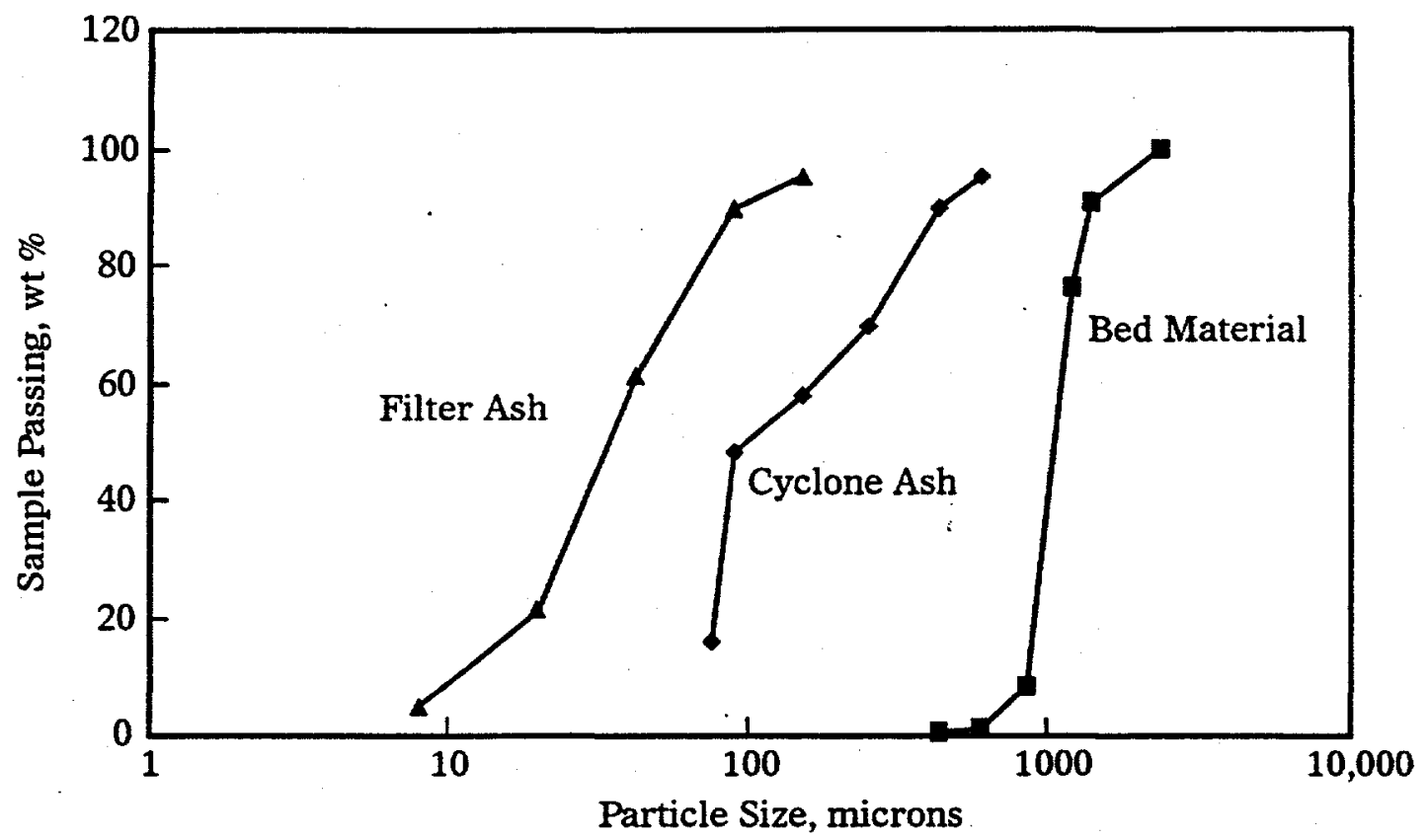

Figure 57. Distribution of size of bed material, cyclone, and filter ash for Test B1-1296

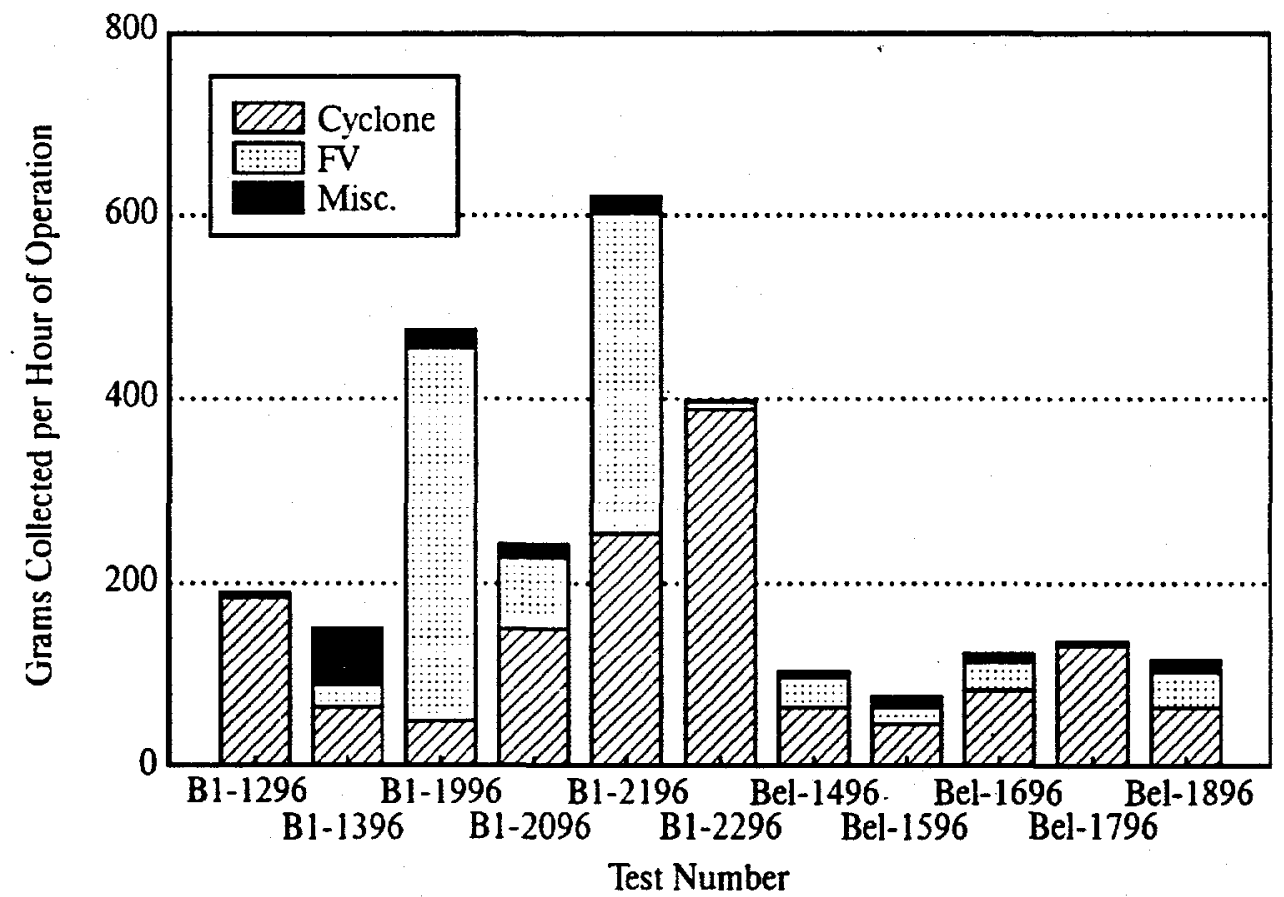

Figure 58. Mass flow of cyclone and filter vessel ash from PFBR tests 
The impact of using the bauxite additive for alkali capture on the distribution of ash from the Beulah tests is shown by the bars for B1-1996 (10:1 bauxite:sodium), B1-2096 (3:1 bauxite:sodium), and B1-2196 and B1-2296 (5:1 bauxite:sodium). The percentage of ash ending up in the filter vessel increases with increasing amounts of added bauxite as shown in Figure 56. The loading to the filter vessel, as shown in Figure 58, is about three times as high as the base case for the 3:1 add rate of bauxite and an order of magnitude higher for the 10:1 add rate. The potential impact of these changes on filter vessel performance will be discussed in more detail in Section 5.5. It should be noted that for Test B1-2296, the filters were not backpulsed after the test; therefore, the mass balance does not reflect the real amount of filter ash collected during the test. A difference is also noted in the amount of cyclone catch between Tests B1-2096 (3:1) and B1-2196 and 2296 (5:1). The increase in cyclone ash corresponds with the increases noted in the filter vessel ash, indicating that the bauxite was generating fines that were leaving the bed. The difference between these two tests and B1-1996 (10:1) is that two different samples of bauxite were used, with that used in B1-1996 being coarser than the second batch that was used for the last three tests. The coarser bauxite seemed to remain in the bed more than the fine bauxite. The fact that the fines generation, as indicated by the filter vessel collection, more closely followed the add rate indicates that these fines are probably generated by relatively small pieces of the bauxite being flaked off larger bauxite particles by the mechanical action of the bed, rather than the larger bauxite particles fragmenting into several smaller pieces. Analyses of the ash streams tend to confirm these trends. The cyclone ash catch from B1-1996 has lower aluminum than the base case of B1-1396, indicating that bauxite was not building up in the cyclone. This can be more easily seen from Table 29 which shows the deviation of the cyclone and filter vessel ashes from the original fuel mix used for the test. The numbers for each element presented in the table are calculated by dividing the percent in the cyclone or filter vessel ash by the percent in the fuel. Therefore, a number greater than one represents an enrichment of that element in the ash while a number less than one represents a depletion. Focusing on aluminum, a number greater than one would indicate that the ash contains a greater percentage of the sorbent than originally mixed in the fuel while a number less than one represents a disproportionately higher quantity of ash from the original coal. Tests B1-2096 and 2296 show an enrichment in aluminum presumably due to elutriation of the bauxite from the bed. In the filter vessel, 
both Tests B1-1996 and 2096 show an enrichment in aluminum (bauxite). Test 2196 may not show this enrichment since the filters were not pulsed after the test, with the finer bauxite remaining on the filters.

Table 29

Comparison of the Ash Chemistry of the Cyclone and Filter Vessel Ash to the Parent Fuel Mix ${ }^{1}$

\begin{tabular}{lllllllllll}
\hline Test & 1296 & 1396 & 1496 & 1596 & 1696 & 1796 & 1896 & 1996 & 2096 & 2296 \\
\hline \multicolumn{2}{l}{ Filter Vessel } & & & & & & & & & \\
$\mathrm{Si}$ & 0.92 & 1.26 & 1.43 & 1.89 & 1.51 & 1.63 & 1.86 & 1.37 & 1.32 & 0.97 \\
$\mathrm{Al}$ & 0.68 & 0.96 & 1.23 & 1.4 & 1.13 & 1.27 & 1.65 & 0.89 & 1.19 & 0.55 \\
$\mathrm{Fe}$ & 0.37 & 0.48 & 0.97 & 1.13 & 1.09 & 1 & 1.55 & 0.32 & 0.42 & 0.43 \\
$\mathrm{Ca}$ & 2.05 & 0.98 & 0.9 & 0.72 & 0.73 & 0.67 & 0.41 & 1.51 & 1.25 & 0.81 \\
$\mathrm{Mg}$ & 20.6 & 0.44 & 0.83 & 0.48 & 0.41 & 0.87 & 0.65 & 2.01 & 1.24 & 0.73 \\
$\mathrm{Na}$ & 0.15 & 3.04 & 0.94 & 1.04 & 0.96 & 2.29 & 1.88 & 0.64 & 1.31 & 3.62 \\
$\mathrm{~S}$ & 1.24 & 1.15 & 0.34 & 0.49 & 0.94 & 0.55 & 0.4 & 0.33 & 0.77 & 1.9 \\
$\mathrm{Cyclon}$ & & & & & & & & & & \\
$\mathrm{Si}$ & 1.37 & 2.31 & 1.81 & 2.16 & 2.75 & 1.98 & 2.35 & 2.57 & 1.42 & 1.31 \\
$\mathrm{Al}$ & 0.94 & 1.03 & 1.14 & 1.26 & 1.12 & 1.67 & 1.4 & 0.78 & 1.17 & 1.06 \\
$\mathrm{Fe}$ & 0.61 & 0.47 & 0.94 & 1.02 & 0.9 & 1.1 & 1.57 & 0.4 & 0.41 & 0.55 \\
$\mathrm{Ca}$ & 1.31 & 0.88 & 0.75 & 0.69 & 0.44 & 0.64 & 0.53 & 0.88 & 1.38 & 1.33 \\
$\mathrm{Mg}$ & 0.92 & 0.52 & 0.72 & 0.55 & 0.59 & 0.65 & 0.41 & 0.89 & 1.61 & 1.43 \\
$\mathrm{Na}$ & 0.99 & 0.89 & 0.59 & 0.64 & 0.58 & 1 & 0.46 & 0.69 & 0.74 & 0.79 \\
$\mathrm{~S}$ & 0.51 & 0.48 & 0.25 & 0.4 & 0.16 & 0.21 & 0.22 & 0.42 & 0.46 & 0.59 \\
\hline
\end{tabular}

' Numbers in table are the cyclone or filter ash concentrations divided by the fuel ash.

The results of the tests with the Belle Ayr coal show similar trends as the tests with the Beulah, with some differences due mainly to differing sodium levels between the two fuels. A comparison of B1-1396 and BEL-1496 in Figure 57, both fuels without any additives, show a higher rate of ash production for the Beulah coal as expected because of the higher ash content of the Beulah. While significant amounts of the Beulah ash remained in the bed or hung up in the reactor piping, very little of the Belle Ayr ash remained in the bed, and the piping was clean after the test. These differences are due to the low sodium in the Belle 
Ayr as compared to the Beulah. When the Belle Ayr was spiked with sodium for Test BEL-1596, more ash was retained in the bed, and some holdup in the reactor was noted, indicating that this additional sodium was promoting bed agglomeration and ash deposition.

With regard to the additives used for the Belle Ayr tests, increases in the amount of fly ash generated were noted when the additives were used similar to the Beulah case. The add rates for the Belle Ayr were less than for the Beulah cases; therefore, much smaller increases in mass flow rates were noted. For the two tests with coarse and fine kaolinite, Tests BEL-1696 and BEL-1796 in Figure 57, respectively, a change in the distribution between cyclone and filter ash was noted. For the coarse kaolinite, a lower percentage of the cyclone ash and a higher percentage of the filter vessel was noted as compared to the fine kaolinite test. The probable reason for this is similar to that noted for the coarse and fine bauxite from the tests with the Beulah coal. For the coarse kaolinite, the fines are generated from small pieces breaking off of the larger kaolinite particles, creating a very fine ash fraction. The fine kaolinite was small enough that much of it could elutriate from the reactor without any breakage. Therefore, the fly ash generated from the fine kaolinite feed is coarser than that generated from the coarse kaolinite feed. The chemical analysis of both the cyclone and filter vessel ash (Table 29) shows an enrichment in kaolinite as noted by the higher aluminum content for these tests. Test BEL-1896 utilized bauxite as the alkali sorbent. The quantity and distribution of the ash is similar to Test BEL-1696, which used kaolinite of the same size and add rate.

\subsection{Capture of Vapor-Phase Alkali}

One of the initial goals of this project was to determine if alkali could be reduced to accepted levels by using in-bed sorbents for protecting the gas turbine. There is some discrepancy as to what level of vapor-phase alkali is acceptable, but it typically ranges from 24 to $125 \mathrm{ppb}$, as discussed in Section 1.1. The alkali, chlorine, and sulfur vapor concentrations measured as a part of this work are presented in Table 30. In addition, six tests that had been previously performed and are included to expand the basis for discussion. Results from these additional tests are not presented in the other subsections of Section 5 because no material balances or analytical work were performed for the tests. 
Table 30

Measured Vapor Concentrations of Sodium and Chlorine from the PFBR Tests

\begin{tabular}{lcccccccc}
\hline Test & $\begin{array}{c}\text { Na in } \\
\text { Fuel, } \\
\text { ppm }\end{array}$ & Fuel & Sorbent & $\begin{array}{c}\text { Sorbent } \\
\text { Na }\end{array}$ & $\begin{array}{c}\text { Na in } \\
\text { Gas, } \\
\text { ppb }\end{array}$ & $\begin{array}{c}\text { Na } \\
\text { Capture, } \\
\%\end{array}$ & $\begin{array}{c}\text { Cl, } \\
\text { ppb }\end{array}$ & $\begin{array}{c}\text { Zone 1 } \\
\text { Temp. }\end{array}$ \\
\hline PR01A & 381 & Blacksville & Dolomite & - & 640 & - & 11000 & 862 \\
B13-0894 & 2745 & Beulah & Dolomite & - & 3000 & 17 & 2970 & 808 \\
B13-1294 & 2745 & Beulah & None & 0 & 3616 & - & 3000 & 798 \\
B14-1294 & 2745 & Beulah & Kaolin & $30: 1$ & 840 & 77 & 560 & 831 \\
B17-1294 & 2745 & Beulah & Kaolin & $.30: 1$ & 270 & 93 & 680 & 831 \\
B1-1296 & 2745 & Beulah & Albite & $18: 1$ & 4771 & - & 137 & 818 \\
BEL-1496 & 468 & Belle Ayr & None & 0 & 940 & - & 373 & 829 \\
BEL-1596 & 865 & Belle Ayr & None & 0 & 3327 & - & 2062 & 841 \\
BEL-1696 & 865 & Belle Ayr & Kaolin & $10: 1$ & 742 & 57 & 1468 & 850 \\
BEL-1796 & 865 & Belle Ayr & Bauxite & $10: 1$ & 673 & 62 & 2674 & 844 \\
BEL-1896 & 865 & Belle Ayr & Bauxite & $10: 1$ & 587 & 67 & 1706 & 846 \\
B1-1996 & 2745 & Beulah & Bauxite & $10: 1$ & 506 & 90 & 1462 & 846 \\
B1-2096 & 2745 & Beulah & Bauxite & $3: 1$ & 2185 & 54 & 1846 & 834 \\
B1-2296 & 2745 & Beulah & Bauxite & $5: 1$ & 1850 & 61 & 2260 & 846 \\
\hline
\end{tabular}

Tests B13-0894 and B14-1294 were performed under similar operating conditions and provide an indication of reproducibility. The slightly lower sodium concentration for B13-0894 may be due to some physical adsorption of the sodium on the dolomite. The test with albite as the sorbent, 1296, showed the highest vapor-phase sodium content. This indicates that the albite was ineffective at capturing sodium in the bed. The temperature for this test was higher than that for Test B13-1294, and the higher alkali concentration could also be a function of this higher temperature. 
Tests 1496 and 1596 were both performed with the Belle Ayr coal, with the difference being that the feed for 1596 was spiked with sodium acetate and sulfur. The impact of doubling the sodium concentration in the fuel essentially doubled the vapor-phase alkali concentration. The higher alkali content in the vapor phase also appeared to increase the vapor-phase chlorine concentration. This is reasonable based on the modeling results presented in Figure 13 which show an increased level of $\mathrm{NaCl}$ as the $(\mathrm{Na}+\mathrm{K}) / \mathrm{Cl}$ ratio increases.

The impact of the sorbent size on alkali capture was investigated for kaolinite during Tests B14-1294 and B17-1294 and for bauxite during Tests 1796 and 1896. As discussed in the previous subsection, the coarser material has more of a tendency to stay in the bed and will result in a longer residence time to react with the alkali. The finer sorbents have significantly more surface area than the coarser material. For both the kaolinite and bauxite, the alkali sorbents were more effective for the finer size, indicating the higher surface area of the fine material more than offset the shorter bed residence time.

Tests 1696 and 1796 provide a direct comparison of the effectiveness of kaolinite versus bauxite for capturing alkali. As can be seen by Table 30 , the bauxite showed a slight improvement in collection efficiency over the kaolinite ( $62 \%$ versus $57 \%$ ) This may be within the experimental error for these tests and indicates that if considering vapor-phase alkali capture alone, both would serve equally well.

The impact of add rate on the efficiency of alkali capture for bauxite was determined during Tests 1996, 2096, and 2296. As expected, the higher the sorbent add rate, the lower the vapor-phase alkali. These results also show that extremely high add rates of sorbents would be required to meet turbine specifications. However, as will be discussed in the next two subsections, other improvements in operating performance are noted at the lower add rates.

Chlorine and sulfur concentrations were also determined for each test. The chlorine values shown in Table 30 do not appear to exhibit any clear trends. The sulfur, not shown here, followed the expected trends of lower sulfur emissions for those tests using dolomite as a sorbent. The other sorbents (kaolinite, bauxite, and albite had no effect on $\mathrm{SO}_{2}$ emissions. The values of sulfur measured corresponded reasonably well with the $\mathrm{SO}_{2}$ emission data presented in Tables 26 and 27. 


\subsection{Ash Deposition}

It has been demonstrated in other work (Mann et al., 1995) that coals high in alkali have a tendency to form deposits on heat-transfer tubes and other surfaces within the fluid bed. Depending upon the amount of alkali in the fuel and the nature of the other constituents of the ash, these deposits may or may not be troublesome to the overall operation of the fluid bed. Therefore, as a part of these studies, the impact of reducing the vapor-phase alkali content on ash deposition was studied. One of the primary methods was the use of a deposition probe that was inserted into the top of the reactor. Figure 59 shows the location of this probe relative to the reactor exit and the upper flange. It is important to note that a portion of the probe resides in a stagnant zone at the top of the reactor and only the bottom portion is exposed to the flow of flue gases as they leave the reactor. This results in two distinct types of deposits on the probe. As can be seen in Figure 60 , the deposit on the bottom potion of the probe is what one would expect to see in the convective pass of an FBC. The deposit on the upper part of the probe is not representative of a real system and appears to be formed when larger particles are entrained into the freeboard. Burning coal particles in this upper stagnant region provide the temperature required to fuse these entrained ash/bed particles.
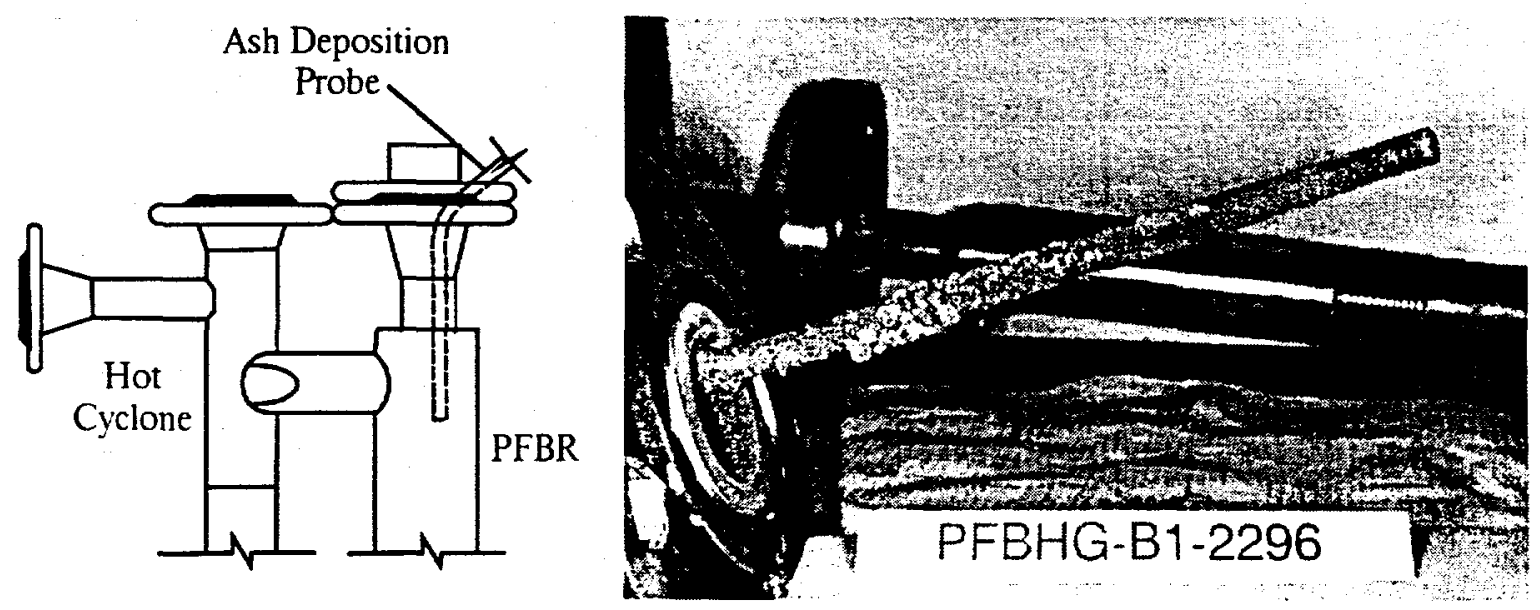

Figure 59. Schematic of the top of the PFBR showing the location of the ash deposition probe 

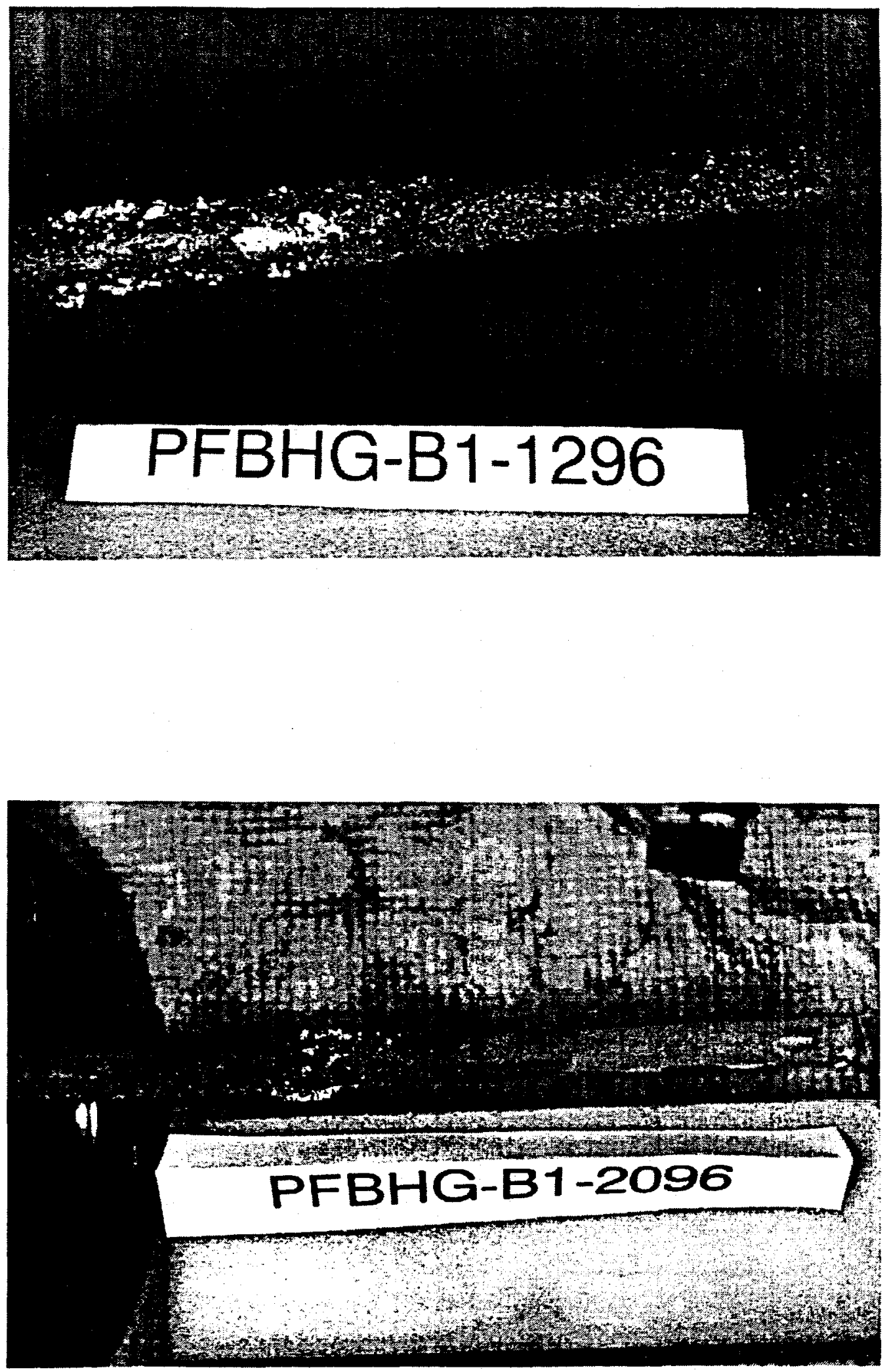

Figure 60. Photographs of ash deposition probe from the PFBR after alkali capture tests 
To allow a comparison between each test condition, photographs of the deposition probe were taken after every test. A qualitative assessment of the severity of deposition was made for each test based on visual inspection of the probes after the tests and through the use of the photographs. Results of this qualitative assessment are given in Table 31. For comparison, the deposition was rated from 1 to 10 , with 10 representing the level of deposition for the baseline Beulah test (B1-1396). The baseline test with the Belle Ayr (1496) represents the least amount of deposition and was assigned a value of 1 . The test with the albite as a sorbent showed no improvement in the nature of the ash deposited on the probe. Adding sodium and sulfur to the Belle Ayr coal increased its propensity for deposition as expected. When kaolinite was added as an alkali sorbent, the amount of material deposited seemed to increase. The nature of the deposit also changed from a sintered deposit for the baseline cases, with the kaolinite-based deposit appearing to be a less compact, cohesive powder and more loosely bonded to the probe surface. The use of the fine kaolinite as sorbent resulted in more deposition than did the case with the coarse kaolinite. For the tests with the Belle Ayr, the test with bauxite resulted in very little evidence of deposition. When used with the Beulah coal, the bauxite caused a significant improvement in deposition over the baseline case.

Table 31

Weights of Material Collected after Each Test Used to Qualify Deposition Rates

\begin{tabular}{lccccc}
\hline Run Number & Sorbent & Reactor, $g$ & Cyclone, $g$ & Probe, $g$ & $\begin{array}{c}\text { Probe Deposit } \\
\text { Ranking }\end{array}$ \\
\hline B1-1296 & Albite & 50 & 551 & NA & 10 \\
B1-1396 & None & 312 & 81 & NA & 10 \\
BEL-1496 & None & NA & NA & NA & 1 \\
BEL-1596 & None & 25 & 65 & 0.2 & 3 \\
BEL-1696 & Kaolinite & 18 & 53 & 1.2 & 3 \\
BEL-1796 & Kaolinite & 57 & 625 & 2.5 & 6 \\
BEL-1896 & Bauxite & 10 & 84 & 1.4 & 1 \\
B1-1996 & Bauxite & 14 & 74 & 0.2 & 2 \\
B1-2096 & Bauxite & 1 & 78 & 0.4 & 4 \\
B1-2196 & Bauxite & 26 & 22 & 1.9 & 3 \\
B1-2296 & Bauxite & 25 & 58 & 1.6 & 3 \\
\hline
\end{tabular}


Another indication of the propensity of the ash to deposit at various locations in the PFBC is the quantity of material that would be found sticking to the walls of the reactor and cyclone after the completion of a test. These values are recorded in Table 31. Significant quantities of material hung up in the reactor and/or cyclone for the baseline test with the Beulah coal as expected based on its relatively high sodium content. The test with albite also displayed an ash with a strong tendency to stick. Since the albite was ineffective in capturing the vapor-phase sodium, it is not surprising that similar deposition rates are seen for this case. The only other test with substantial hang up of material is the test using fine kaolinite and the Belle Ayr coal. This type of deposition would pose a problem for a commercial PFBC and would preclude using the fine kaolinite as a sorbent.

To provide an indication of the potential source of this deposition, an analysis was performed on the material hanging up in the reactor from three tests. The tests chosen, B1-1296, BEL-1696, and BEL-1896 represent the three sorbents tested: albite, kaolinite, and bauxite. The analyses in Table 32 show that for the case of the albite and the Beulah coal, the deposited material was enriched in sodium, calcium, and sulfur. These components are common in low-temperature deposition phenomena, with the sticky material being sodium calcium sulfate. Table 33 compares materials from the test using the $-1 / 8-i n$. kaolinite as sorbent. The analysis of the material collected from the top of the reactor after the test shows a buildup of silica from the bed and kaolinite-derived material. Sodium, calcium, and sulfur are depleted in this sample, indicating that this phase was not the cause of the deposition as was the case with the Beulah coal and albite. It is speculated that the fines generated from the kaolinite are acting as the material to stick to the surfaces of the reactor. The case with the bauxite, Test BEL-1896, was similar to that with kaolinite and showed an enrichment in silica, aluminum, and iron, indicating that the deposited material was primarily sorbent based (Table 34). In a real system, it is expected that the type of deposition from the kaolinite and bauxite would be easier to control through the use of soot blowers than the more tenacious deposits that are typical of sodium calcium sulfates. 
Table 32

Elemental Analysis of Material from Run B1-1296: Sulfur-Free Basis

\begin{tabular}{|c|c|c|c|c|c|c|}
\hline & $\begin{array}{l}\text { Fuel Mix } \\
\text { Ash }\end{array}$ & $\begin{array}{c}\text { Bed } \\
\text { Material }\end{array}$ & $\begin{array}{l}\text { Top of } \\
\text { Reactor }\end{array}$ & $\begin{array}{c}\text { Cyclone } \\
\text { Ash }\end{array}$ & $\begin{array}{c}\text { Filter } \\
\text { Vessel Ash }\end{array}$ & $\begin{array}{l}\text { Candle } \\
\text { Deposit }\end{array}$ \\
\hline \multicolumn{7}{|c|}{ Expressed as Mole Fraction } \\
\hline $\mathrm{Si}$ & 32.5 & 83.3 & 38.8 & 41.7 & 30.9 & 41 \\
\hline $\mathrm{Al}$ & 16.4 & 4.2 & 15.4 & 14.5 & 11.4 & 10.1 \\
\hline $\mathrm{Fe}$ & 21.6 & 3.8 & 12.9 & 12.4 & 7.3 & 5.8 \\
\hline $\mathrm{Ca}$ & 13.8 & 2.2 & 17.2 & 16.9 & 29.7 & 16.4 \\
\hline $\mathrm{Mg}$ & 6.7 & 3 & 5.2 & 5.8 & 17.2 & 5.2 \\
\hline $\mathrm{Na}$ & 8.1 & 3.1 & 9.6 & 7.5 & 1.3 & 18.7 \\
\hline$S$ & 12.3 & 2.9 & 7.5 & 6.3 & 9.9 & 15.9 \\
\hline \multicolumn{7}{|c|}{ Expressed as a Percent of Feed } \\
\hline $\mathrm{Si}$ & 1 & 2.56 & 1.19 & $\cdot 1.28$ & 0.95 & 1.26 \\
\hline Al & 1 & 0.26 & 0.93 & 0.88 & 0.7 & 0.62 \\
\hline $\mathrm{Fe}$ & 1 & 0.18 & 0.6 & 0.57 & 0.34 & 0.27 \\
\hline $\mathrm{Ca}$ & 1 & 0.16 & 1.25 & 1.22 & 2.16 & 1.19 \\
\hline $\mathrm{Mg}$ & 1 & 0.44 & 0.77 & 0.86 & 2.56 & 0.78 \\
\hline $\mathrm{Na}$ & 1 & 0.38 & 1.19 & 0.92 & 0.16 & 2.31 \\
\hline S & 1 & 0.24 & 0.61 & 0.51 & 0.8 & 1.29 \\
\hline
\end{tabular}

\subsection{Filter Performance}

The place where in-bed alkali sorbents may have the greatest impact on performance is in the hotgas filter vessel. As the filters remove the ash from the gas stream, ash builds up on the candles, and the pressure drop across the filter increases. The candles are periodically backpulsed with high-pressure gas to remove the material from the filters. Once the ash is removed from the filters by the backpulse, the 
Table 33

Elemental Analysis of Material from Run BEL-1696: Sulfur-Free Basis

\begin{tabular}{|c|c|c|c|c|c|c|}
\hline & $\begin{array}{c}\text { Fuel Mix } \\
\text { Ash }\end{array}$ & $\begin{array}{c}\text { Bed } \\
\text { Material }\end{array}$ & $\begin{array}{l}\text { Top of } \\
\text { Reactor }\end{array}$ & $\begin{array}{c}\text { Cyclone } \\
\text { Ash }\end{array}$ & $\begin{array}{c}\text { Filter } \\
\text { Vessel Ash }\end{array}$ & $\begin{array}{l}\text { Candle } \\
\text { Deposit }\end{array}$ \\
\hline \multicolumn{7}{|c|}{ Expressed as Mole Fraction } \\
\hline $\mathrm{Si}$ & 27.1 & 37.9 & 60.7 & 40.3 & 37.2 & 28.9 \\
\hline $\mathrm{Al}$ & 15.5 & 18 & 14.2 & 17.3 & 16.9 & 15.8 \\
\hline $\mathrm{Fe}$ & 7.4 & 8.3 & 5.4 & 7.9 & 7.7 & 9.4 \\
\hline $\mathrm{Ca}$ & 36.1 & 26.1 & 12.7 & 25.7 & 23 & 30.9 \\
\hline $\mathrm{Mg}$ & 8 & 4.1 & 3.8 & 3.3 & 4.1 & 4.3 \\
\hline $\mathrm{Na}$ & 3 & 2.1 & 1.5 & 2.9 & 8.4 & 7.3 \\
\hline $\mathrm{S}$ & 21.3 & 14.8 & 3.5 & 20.1 & 19.4 & 24.8 \\
\hline \multicolumn{7}{|c|}{ Expressed as a Percent of Feed } \\
\hline $\mathrm{Si}$ & 1 & 1.4 & 2.24 & 1.49 & 1.38 & 1.07 \\
\hline $\mathrm{Al}$ & 1 & 1.22 & 0.96 & 1.17 & 1.14 & 1.07 \\
\hline $\mathrm{Fe}$ & 1 & 1.13 & 0.73 & 1.07 & 1.04 & 1.28 \\
\hline $\mathrm{Ca}$ & 1 & 0.73 & 0.36 & 0.72 & 0.65 & 0.87 \\
\hline $\mathrm{Mg}$ & 1 & 0.91 & 0.46 & 0.41 & 0.51 & 0.53 \\
\hline $\mathrm{Na}$ & 1 & 0.69 & 0.48 & 0.94 & 2.77 & 2.4 \\
\hline$S$ & 1 & 0.69 & 0.16 & 0.94 & 0.91 & 1.16 \\
\hline
\end{tabular}

pressure drop will return to a baseline value and then build up again as it starts its next cleaning cycle. The ash that is pulsed off of the filters falls into an ash hopper where it is removed. Two primary concerns in hot-gas filtration are bridging and blinding. Bridging is the phenomenon where ash builds up on the candles to the point where an ash "bridge" forms between two or more candles. These bridges can eventually block flows and result in failure of the filtering system. Bridging is not usually accompanied by sharp and 
Table 34

Elemental Analysis of Material from Run BEL-1896: Sulfur-Free Basis

\begin{tabular}{|c|c|c|c|c|c|c|}
\hline & $\begin{array}{l}\text { Fuel Mix } \\
\text { Ash }\end{array}$ & $\begin{array}{c}\text { Bed } \\
\text { Material }\end{array}$ & $\begin{array}{l}\text { Top of } \\
\text { Reactor }\end{array}$ & $\begin{array}{c}\text { Cyclone } \\
\text { Ash }\end{array}$ & $\begin{array}{c}\text { Filter } \\
\text { Vessel Ash }\end{array}$ & $\begin{array}{l}\text { Candle } \\
\text { Deposit }\end{array}$ \\
\hline \multicolumn{7}{|c|}{ Expressed as Mole Fraction } \\
\hline $\mathrm{Si}$ & 25 & 39.4 & 48.1 & 39.6 & 24.9 & 31.3 \\
\hline Al & 17.9 & 19.3 & 20.6 & 25.5 & 14.6 & 21.2 \\
\hline $\mathrm{Fe}$ & 7.6 & 11.5 & 9.9 & 10.2 & 7.8 & 12.1 \\
\hline $\mathrm{Ca}$ & 36 & 20 & 15.6 & 12.8 & 42.6 & 22.3 \\
\hline $\mathrm{Mg}$ & 8 & 4.9 & 2.7 & 4.5 & 7.6 & 3 \\
\hline $\mathrm{Na}$ & 3 & 2.4 & 1.2 & 4.9 & 1.1 & 6.9 \\
\hline$S$ & 21.3 & 9.9 & 4.6 & 8.5 & 16.2 & 20.7 \\
\hline \multicolumn{7}{|c|}{ Expressed as a Percent of Feed } \\
\hline $\mathrm{Si}$ & 1 & 1.59 & 1.94 & 1.6 & 1.01 & 1.26 \\
\hline $\mathrm{Al}$ & 1 & 1.08 & 1.15 & 1.42 & 0.81 & 1.18 \\
\hline $\mathrm{Fe}$ & 1 & 1.51 & 1.29 & 1.33 & 1.02 & 1.59 \\
\hline $\mathrm{Ca}$ & 1 & 0.56 & 0.43 & 0.36 & 1.18 & 0.62 \\
\hline $\mathrm{Mg}$ & 1 & 0.61 & 0.034 & 0.56 & 0.95 & 0.38 \\
\hline $\mathrm{Na}$ & 1 & 0.8 & 0.38 & 1.61 & 0.35 & 2.27 \\
\hline$S$ & 1 & 0.46 & 0.22 & 0.4 & 0.76 & 0.97 \\
\hline
\end{tabular}

uncontrollable rises in pressure drop. Filter blinding, on the other hand, does result in high pressure drops across the filter. These pressure drops sometimes may be controlled by frequent backpulsing. In the case of severe blinding, the filter vessel must be shut down and brought off-line for cleaning. 
Both blinding and bridging were noted for the tests performed as a part of this project. Figure 61 presents the pressure drop curves for the tests performed with the Beulah lignite. A rise in pressure drop can be seen in these curves as an ash layer builds up on the filters. An instantaneous decrease in pressure drop (over a 3-min backpulse sequence) is seen as this ash layer is removed during backpulsing followed by an increase in pressure drop as the ash cake builds up again during the next cleaning cycle. Ideally, the pressure drop would rise to a predetermined value and would return to a constant baseline value after each cleaning cycle. The length of time between cleaning would also be consistent and of a relatively long duration.

With this as background, the data presented in Figure 61 can be interpreted. The baseline test with Beulah coal, 1396, had to be terminated after approximately $45 \mathrm{~min}$ because the pressure drop rose so fast and could not be reduced by backpulsing. The pressure drop for that test approached $200 \mathrm{in}$. of water before the reactor could be shut down. Pressure drops of this magnitude can potentially cause mechanical failure of the tube sheet supporting the system or to the filter themselves. Test 1296 using the Beulah

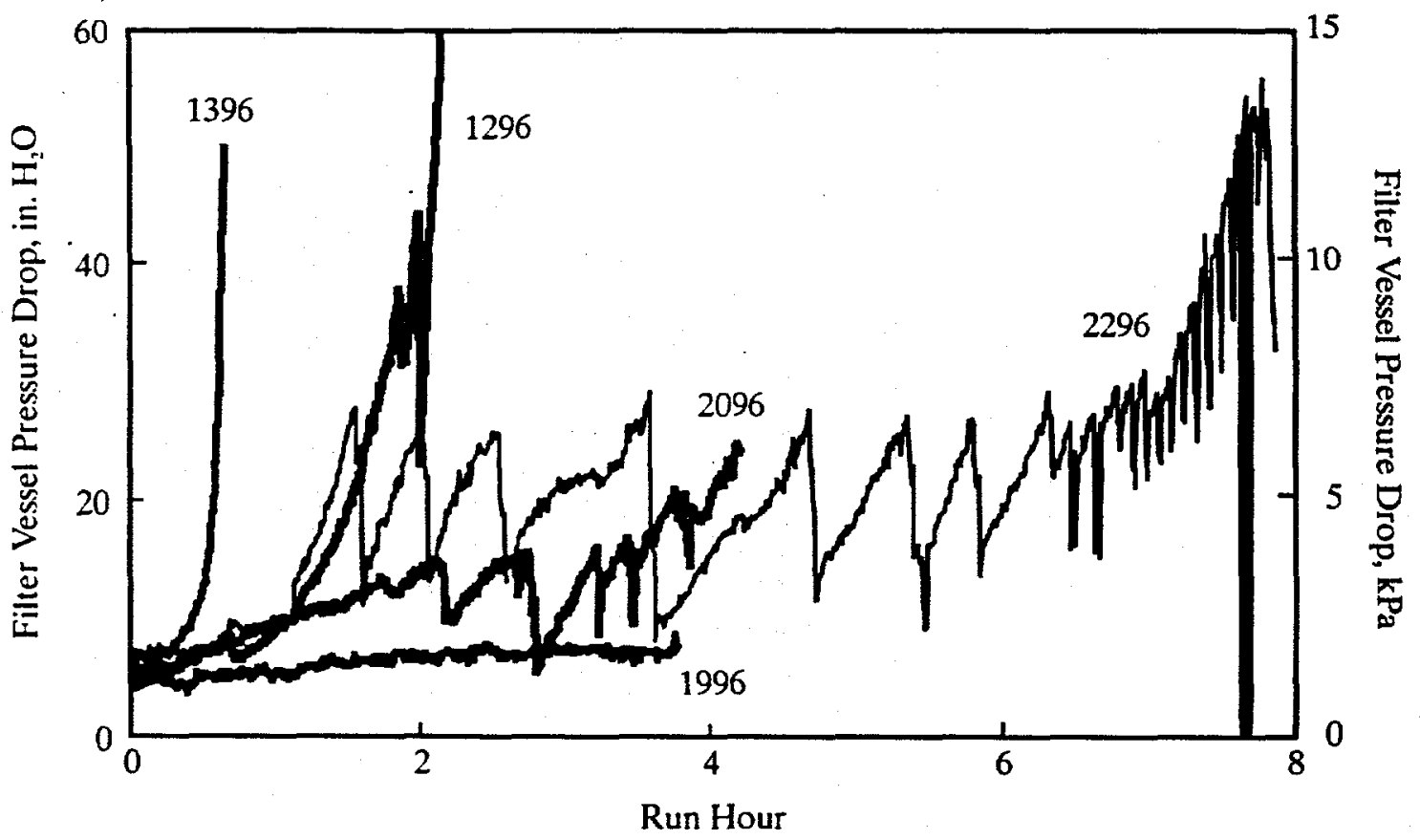

Figure 61. Filter pressure drop for PFBR tests using Beulah lignite 
lignite with albite had to be terminated after $2 \mathrm{hr}$. Again, the pressure drop rose very fast and could not be returned to a safe baseline value after several successive attempts to backpulse. Test 1996 at a 10:1 bauxite-to-sodium feed ratio showed complete control over the blinding problems noted in Tests 1296 and 1396. During this test, the pressure drop showed very little rise over the 4-hr test duration. The success of this test was the basis for performing Test 2096 at the $3: 1$ bauxite add rate. The pressure drop rose much faster for this test, but appeared to be controllable by backpulsing for the first several cleaning cycles. At the end of the test, the backpulsing was becoming less effective at reducing the pressure drop, and given more time, the filter may have become blinded. This test was terminated because the supply of feed material for the test was exhausted (each test was planned for $4 \mathrm{hr}$ ). Test 2296 utilized the bauxite at a 5:1 feed rate and was planned for $8 \mathrm{hr}$ in duration to provide longer-term trends. For the first $6 \mathrm{hr}$ of this test, the pressure drop appeared to be under control. However, starting at Run Hour 6, the backpulse time interval had to be shortened to several minutes, and it was not effective at returning the pressure drop to the baseline value. This test was terminated before the scheduled $8 \mathrm{hr}$ because of the blinding of the filters.

The results from the tests with the Belle Ayr are less dramatic. As can be seen in Figure 62, the addition of sodium and sulfur in 1596 resulted in a higher rate of increase in pressure drop as compared to 1496, which was the test with the as-received Belle Ayr. The pressure drops for Tests 1696 through 1896 show that both the kaolinite and bauxite were effective in reducing the pressure drop across the filters. This improved performance is directly attributable to the reduction in vapor-phase sodium. The difference in filter performance between the Belle Ayr and Beulah is also directly related to the sodium content of the flue gas. Figure 63 shows the condition of the filters after tests performed on Belle Ayr coal (part of a separate program and not the same filters used in this work) and from the tests with the Beulah coal. The Belle Ayr ash did not cause a noticeable buildup of material on the filters. However, the filters removed after Test 2296 with the Beulah coal and 5:1 bauxite addition show a substantial buildup on all three of the filters. 


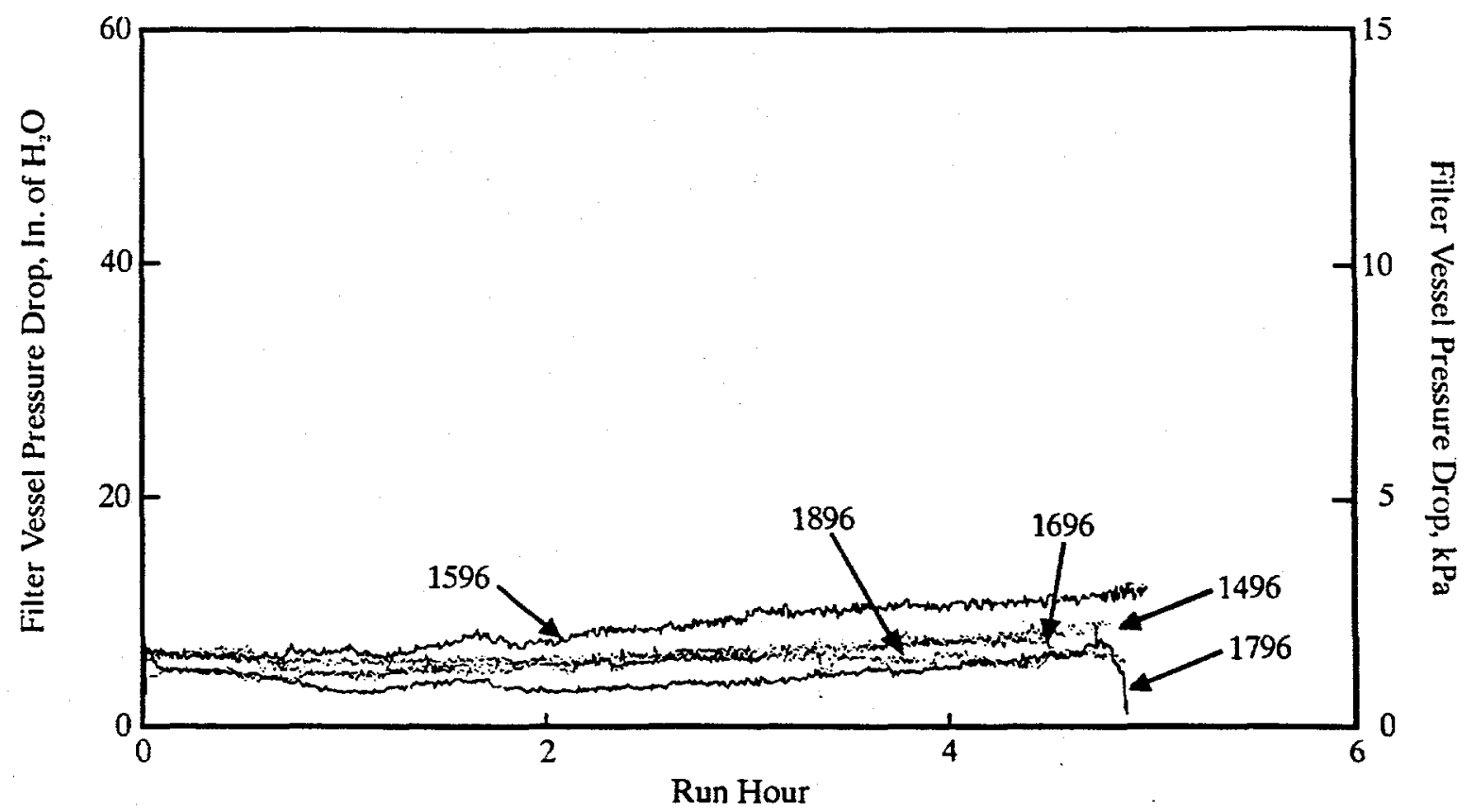

Figure 62. Filter vessel pressure drop for the Belle Ayr tests on the PFBR

Detailed analyses were performed on a number of samples to obtain a better grasp of the physical observations made. Figure 64 shows an SEM image of a cross section of deposit removed from a filter after the test with the albite. This test caused filter blinding and a forced shutdown after $2 \mathrm{hr}$ of operation. This photograph shows that the interface between the deposit and the filter was an almost continuous layer of fused material. It is easy to visualize how this type of deposit would blind a candle filter. This deposit was analyzed using the SEM with an elemental map, also shown in Figure 64. This map shows that the interface between the deposit and filter is sodium sulfate. This material appears to have formed from condensation of sodium sulfate on the surface of the candle filters. The filter cake that was built up on top of this sodium sulfate layer is a mix of fly ash with sodium and calcium sulfates coating some of the particles and producing necks that are holding the particles together. The SEM photo and map of Figure 65 show this. Discrete ash and albite particles can be seen and identified as discrete particles from the elemental maps of silicon and aluminum. The sulfate layers and necks can be seen in the photograph, with the composition of the coatings shown as sodium and/or calcium based from the elemental map. The map of sulfur (not shown) 


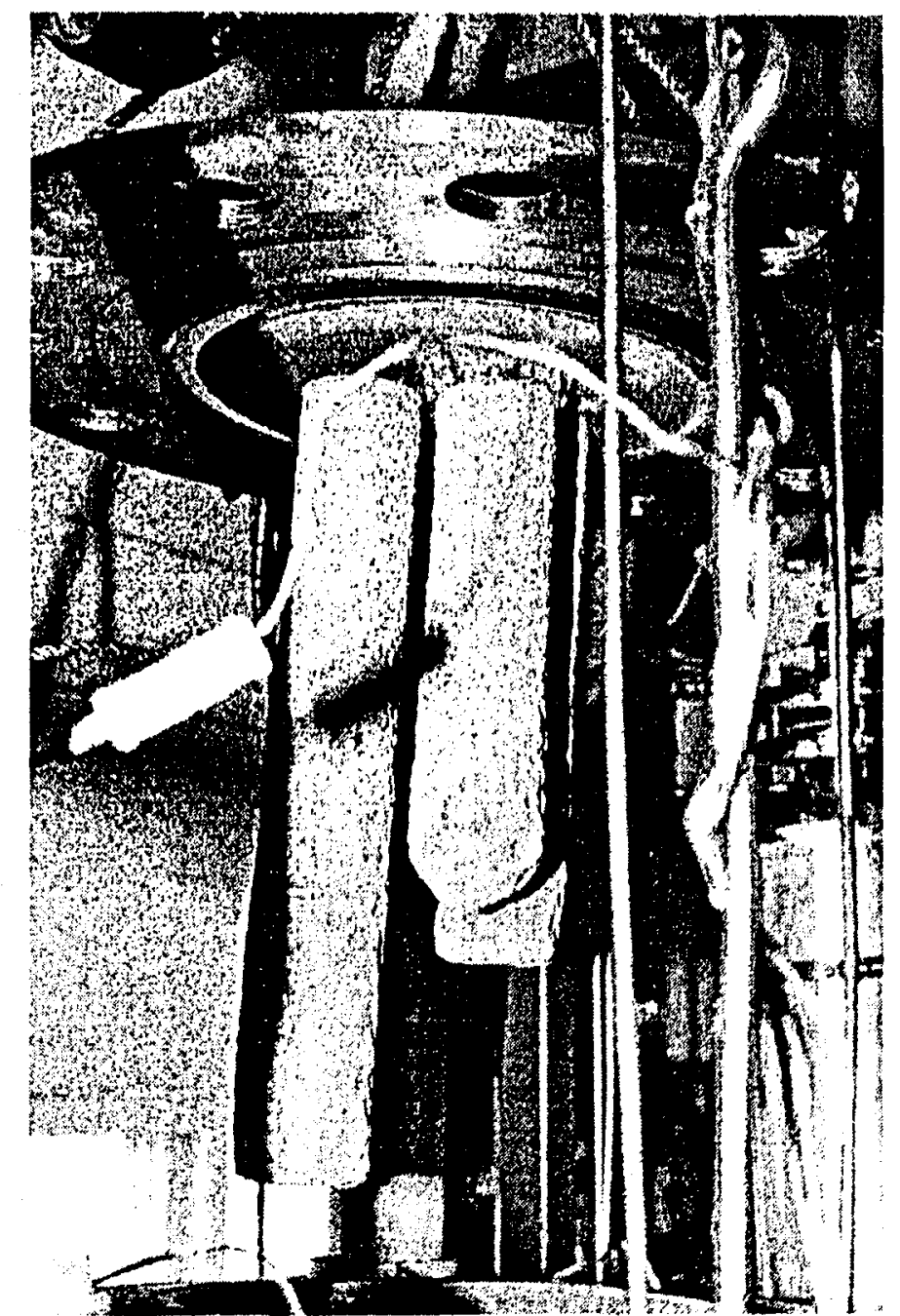

Filters after testing with Belle Ayr coal

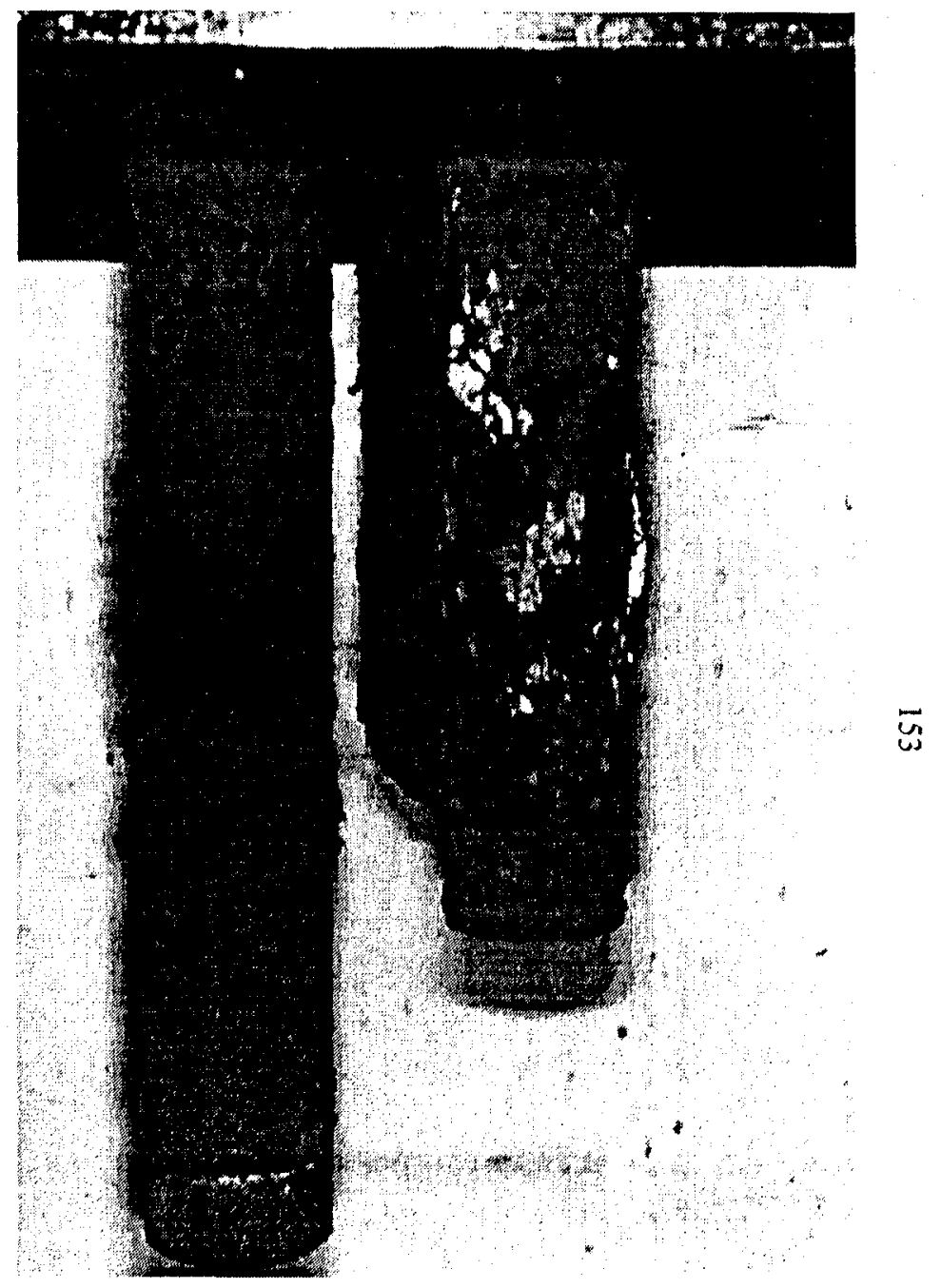

Filters after testing with Beulah.Lignite

Figure 63. Photograph of candles after PFBR testing. 

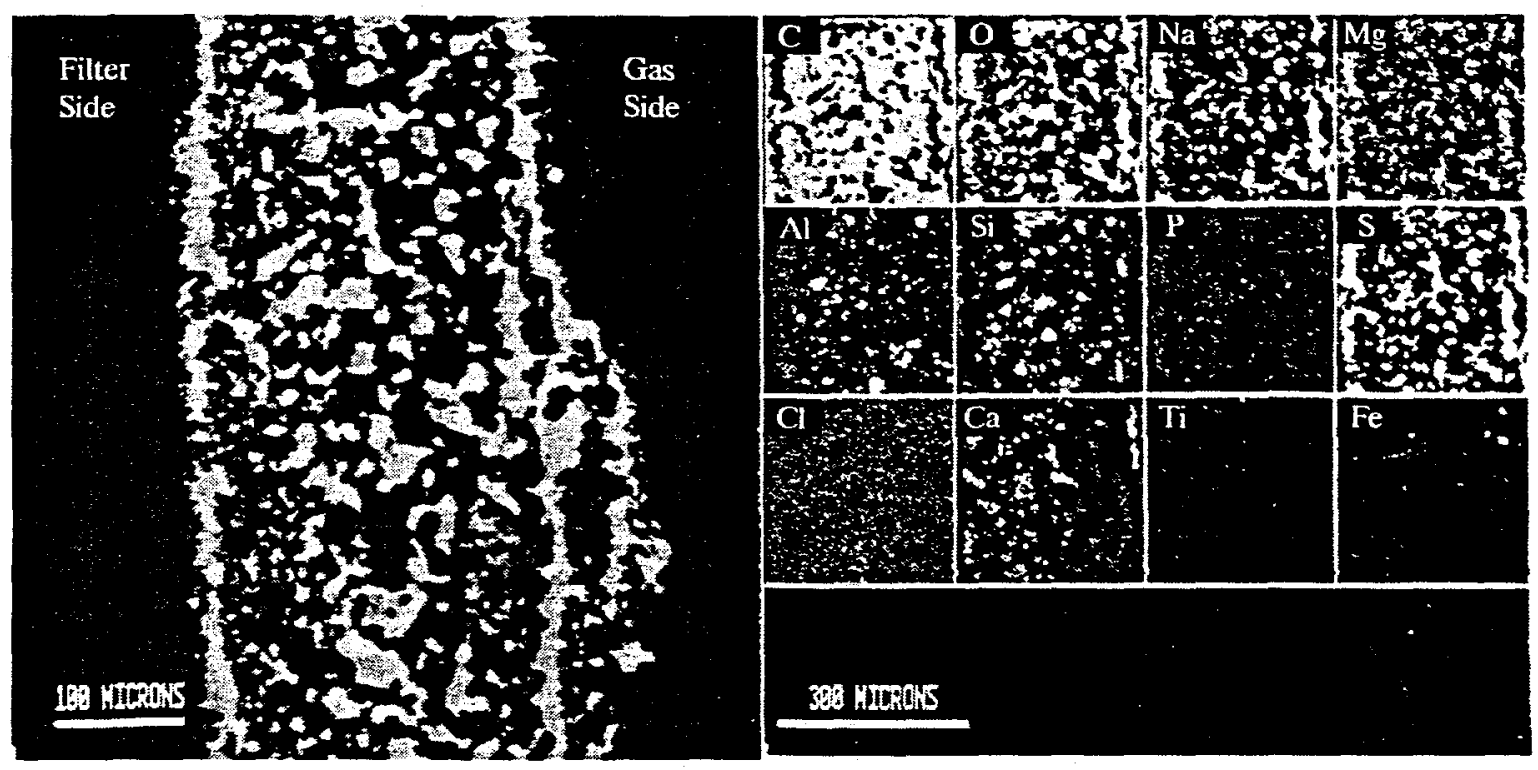

Figure 64. SEM photograph and elemental map of candle deposit from Test 1296

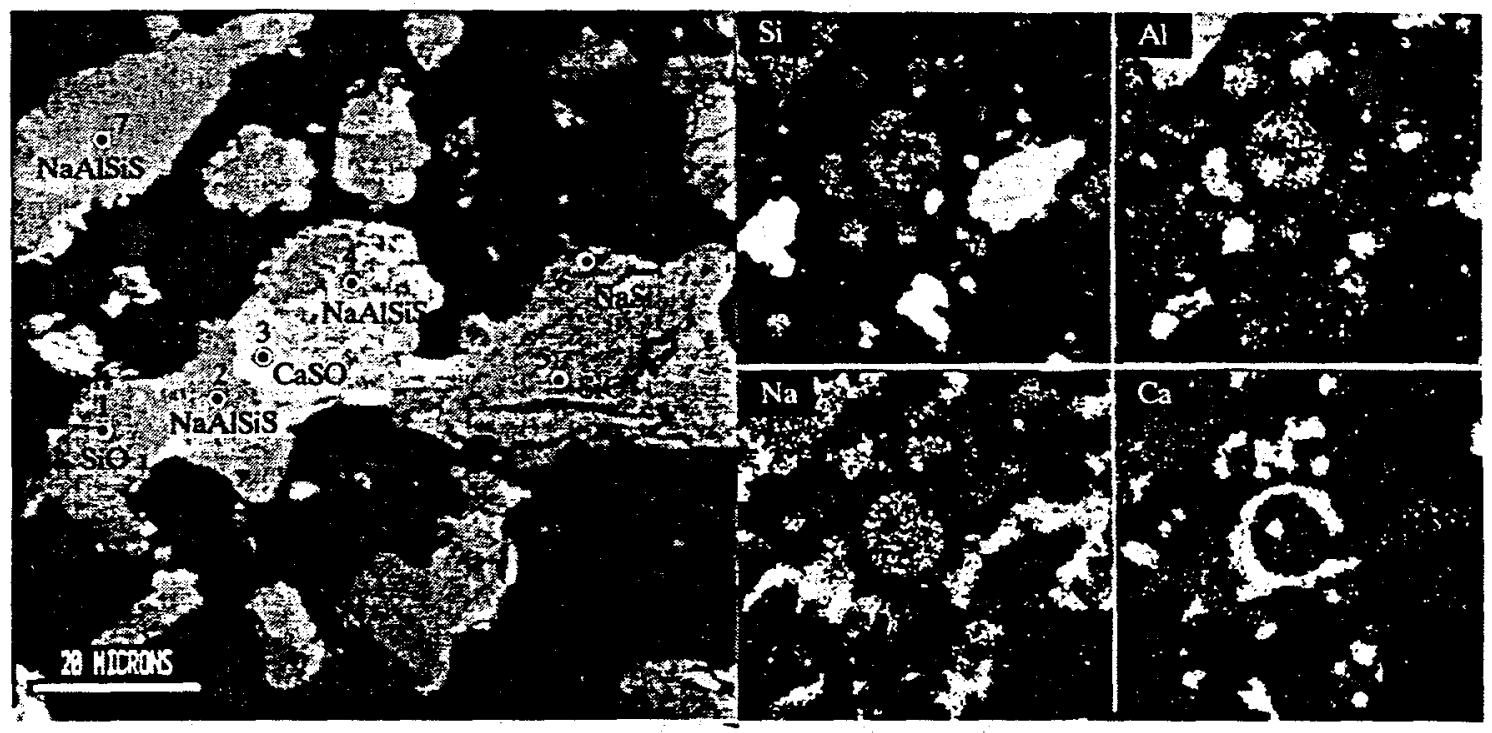

Figure 65. Close-up SEM photograph and elemental map of filter deposit from Test B1-1296 
corresponds to the sodium and calcium verifying that this is the material binding the ash particles together. Specific points within this mix were analyzed with the point analysis given in Table 35 . The quartz grains can be easily identified at Points 1 and 5. Points 2, 4, and 7 appear to be albite-derived. These particles have interacted with the sodium, calcium, and sulfur. Points 3 and 6 show the calcium and sodium calcium sulfates. A look at the stoichiometry suggests that this material is fully sulfated. It is speculated that they condensed as sulfates on the surface of the candle filters and on the ash particles that were building up the filter cake. This condensation was probably occurring continuously since the beginning of the test, and material had been condensed quickly enough to form a continuous layer on the filters and cause the blinding.

Table 35

Point Analysis of the Filter Deposit from Test B1-1296 and Shown in Figure 65

\begin{tabular}{|c|c|c|c|c|c|c|c|}
\hline & 1 & 2 & 3 & 4 & 5 & 6 & 7 \\
\hline \multicolumn{8}{|c|}{ Elemental Analysis, mole \% } \\
\hline $\mathrm{Na}$ & 0 & 8.8 & 0 & 8.3 & 0 & 20.1 & 4 \\
\hline $\mathrm{Al}$ & 0 & 11.4 & 5.7 & 10.1 & 0 & 3.9 & 13.8 \\
\hline$" \mathrm{Si}$ & 36.5 & 12.3 & 0 & 15.5 & 36.7 & 0.9 & 13.7 \\
\hline$S$ & 0 & 7.1 & 19.4 & 5.7 & 0 & 28.5 & 6.7 \\
\hline $\mathrm{Ca}$ & 0.1 & 2.1 & 18.8 & 1.3 & 0 & 5.2 & 0.9 \\
\hline $\mathrm{Fe}$ & 0.1 & 0.2 & 0 & 0.8 & 0 & 0.5 & 0 \\
\hline $\mathrm{O}$ & 63.3 & 58 & 56.1 & 58.3 & 63.3 & 40.9 & 61 \\
\hline
\end{tabular}

At the completion of Test BEL-1896, small flakes of filter were noted in the ash material collected from the filter vessel. Apparently, one of the filters installed was starting to lose its integrity, and it was shedding its outside layer. The inside of the filter maintained its integrity, as indicated by the filter's ability to maintain a pressure drop; no visible particulates in an outlet gas sample; and a clean, white filter interior noted at the end of this test campaign. The presence of these pieces of filter provided the opportunity to examine the ash-filter interface. Figure 66 is an SEM photograph of an unexposed section of the filter. An 


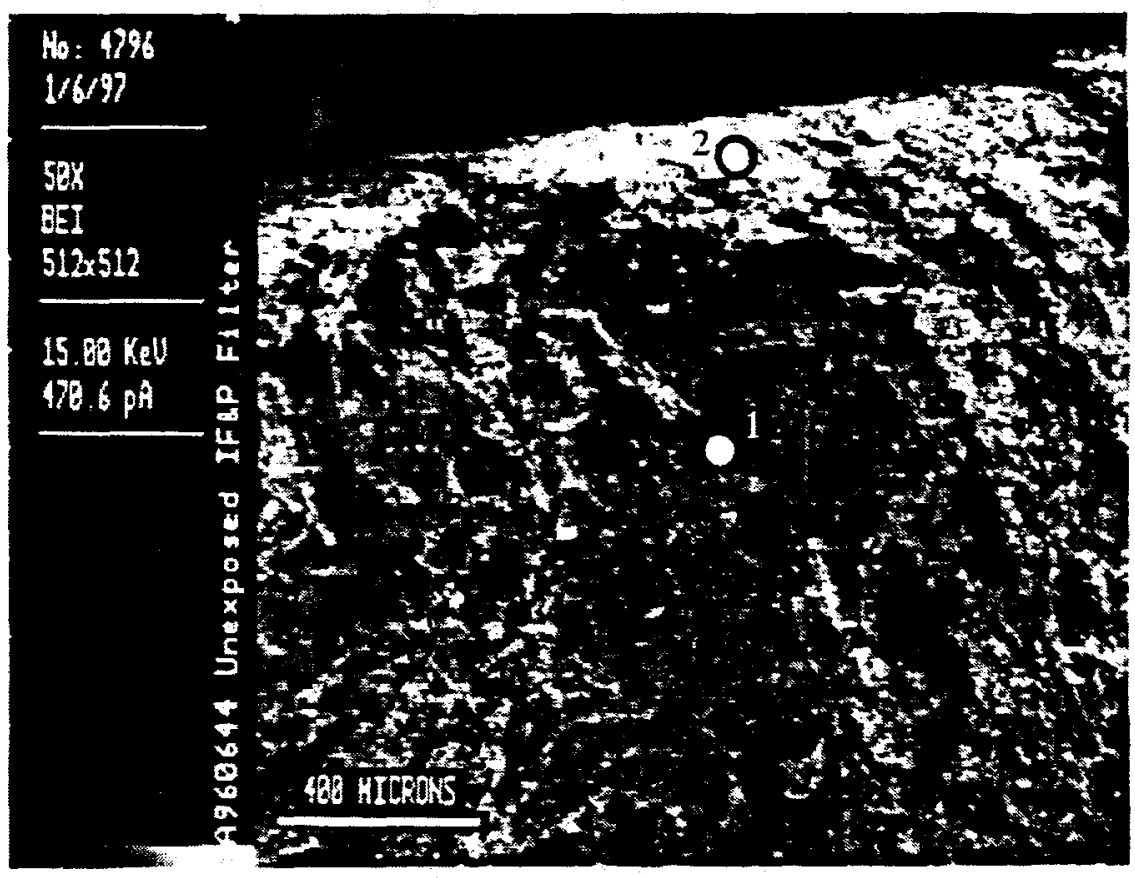

Figure 66. SEM photograph of an unexposed section of the filter that failed during the PFBR tests

analysis of the outer coating and the inner filter material is presented in Table 36 . Figure 67 presents SEM photographs of a piece of filter removed after Test 1896. The porous nature of the filter can be seen from these figures. The thin coating of ash is also seen. There was very low pressure drop buildup during this test. A point analysis (Table 36) taken at the edge of the filter yields some interesting results that help explain the failure of the filter. This particulate filter is made up of silica and alumina and is coated with ytrium to provide a protective coating. Point 5 is an analysis of a point within the actual filter, showing the relative composition of silica and aluminum. The other four points taken at the ash-filter interface show high concentrations of yttrium that was utilized for the coating. These analyses indicate that sulfur was attacking the yttrium coating and forming a yttrium sulfate. Calcium and sodium appear to associated with the yttrium coating also and may be partially responsible for the destruction of the protective layer of ytrium.

Figure 68 shows SEM photos of a piece of the same filter removed after Test B1-1996. This piece shows a much thicker ash layer. This is logical. since this fuel resulted in a much higher pressure drop than that observed in the previous test. Again, the porous nature of the filter is seen. The filter cake from this 
Table 36

Analysis of Selected Points from an Unexposed Filter and the Filter after Test 1896 and Shown in Figures 66 and 67

\begin{tabular}{cccccccc}
\hline & 1 & 2 & 3 & 4 & 5 & 6 & 7 \\
\hline \multicolumn{2}{l}{ Elemental } & Analysis, mole \% & & & & & \\
$\mathrm{Na}$ & 0.8 & 0 & 4.8 & 0.3 & 0.4 & 0 & 4.5 \\
$\mathrm{Al}$ & 24.7 & 1.4 & 0 & 0.3 & 19.7 & 0 & 0 \\
$\mathrm{Si}$ & 20.4 & 0 & 0 & 0 & 16.1 & 0 & 0 \\
$\mathrm{~S}$ & 0 & 0 & 18.4 & 14.8 & 1.1 & 15.8 & 18.6 \\
$\mathrm{Ca}$ & 0 & 0 & 2.5 & 0 & 0.1 & 0 & 0.1 \\
$\mathrm{Y}$ & 0 & 93.2 & 13.8 & 22.3 & 0 & 15.4 & 19.3 \\
$\mathrm{O}$ & 54.8 & 2.4 & 60.5 & 62.4 & 62.6 & 68.9 & 57.6 \\
\hline
\end{tabular}

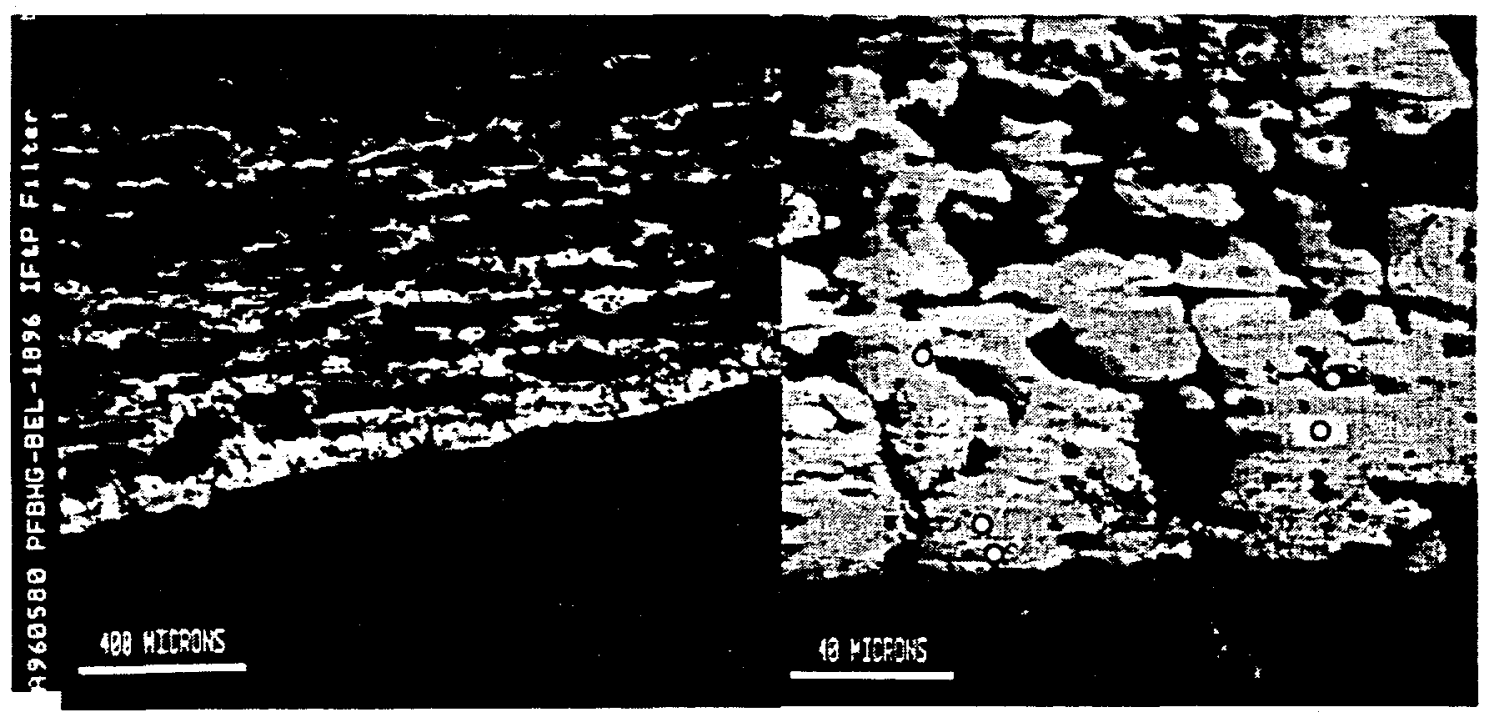

Figure 67. SEM photographs of a section of filter with ash layer taken after Test BEL-1896 


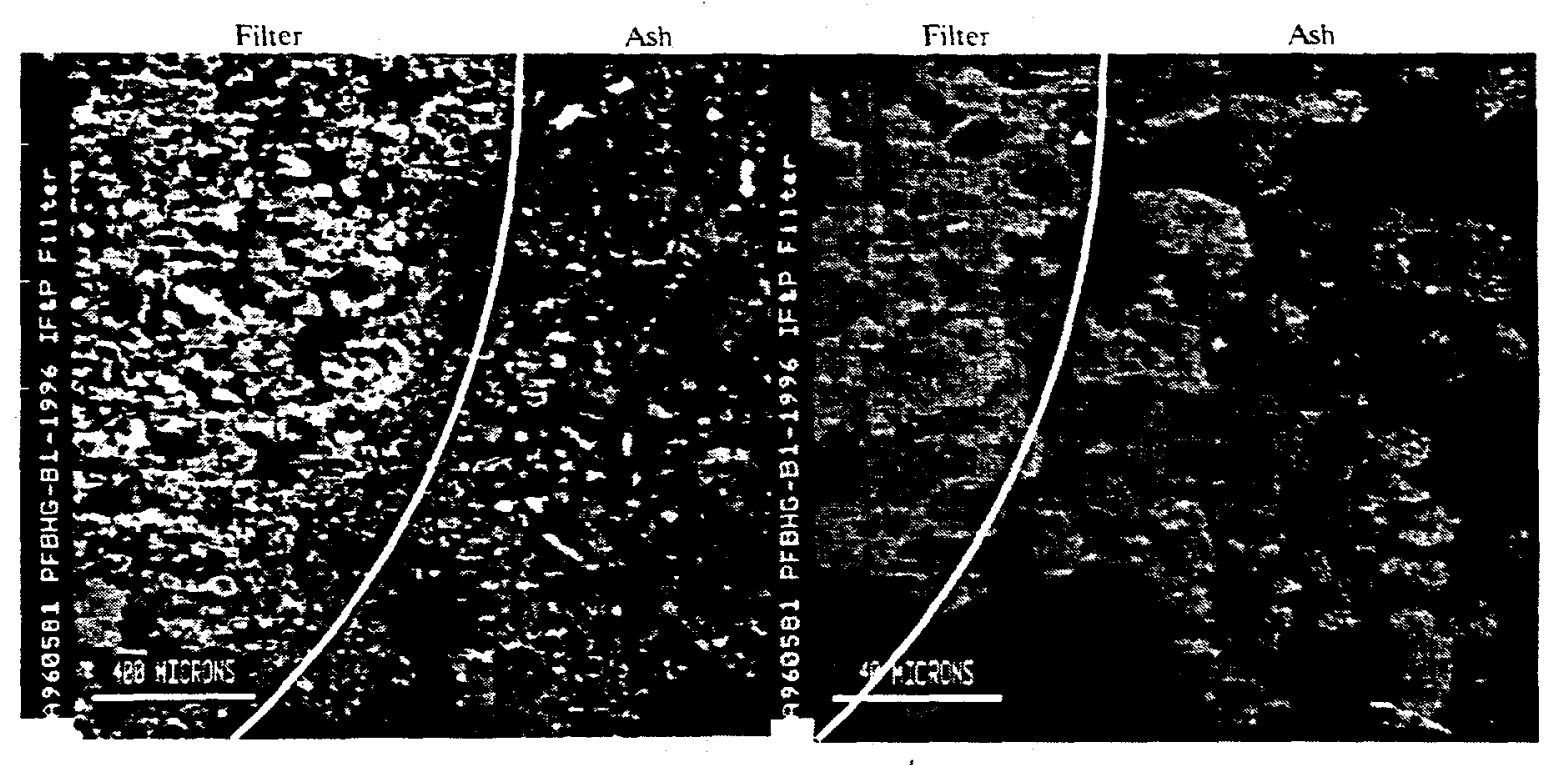

Figure 68. SEM photograph of a piece of filter removed after Test B1-1996

test also appears porous, and there is no evidence of the continuous layer of sodium sulfate noted for the baseline case with the Beulah coal. Elemental maps for a small section of this filter are given in Figure 69. The aluminum and silicon making up this filter are easily seen in these maps. What is interesting to note is the impregnation of sodium. calcium, iron, and sulfur into the interior of this filter. A continued buildup of this sulfated material within the interior of a filter would be expected to eventually cause the filter to fail because of blinding and excessively high pressure drops. The likely source of this material is condensation. A green substance was found in the alkali-sampling probe and the outlet piping of the filter vessel. This condensed material was analyzed and determined to consist mainly of iron and sulfur with some nickel and chromium. The iron, nickel, and chromium may come from the alloys making up the reactor. The only source of the sulfur is the coal. Therefore, in a commercial system, iron may not impregnate the filter as noted during this work. but the sodium. calcium. and sulfur definitely would be available to potentially cause failure of the filter.

Bridging was noted after Test B1-2096 using the Beulah coal and bauxite at an add rate of 3:1. Figure 70 is a photograph of the bridge formed during this run. This material was removed and analyzed with the elemental composition given in Table 37 . This material is high in sodium, calcium, and sulfur as 


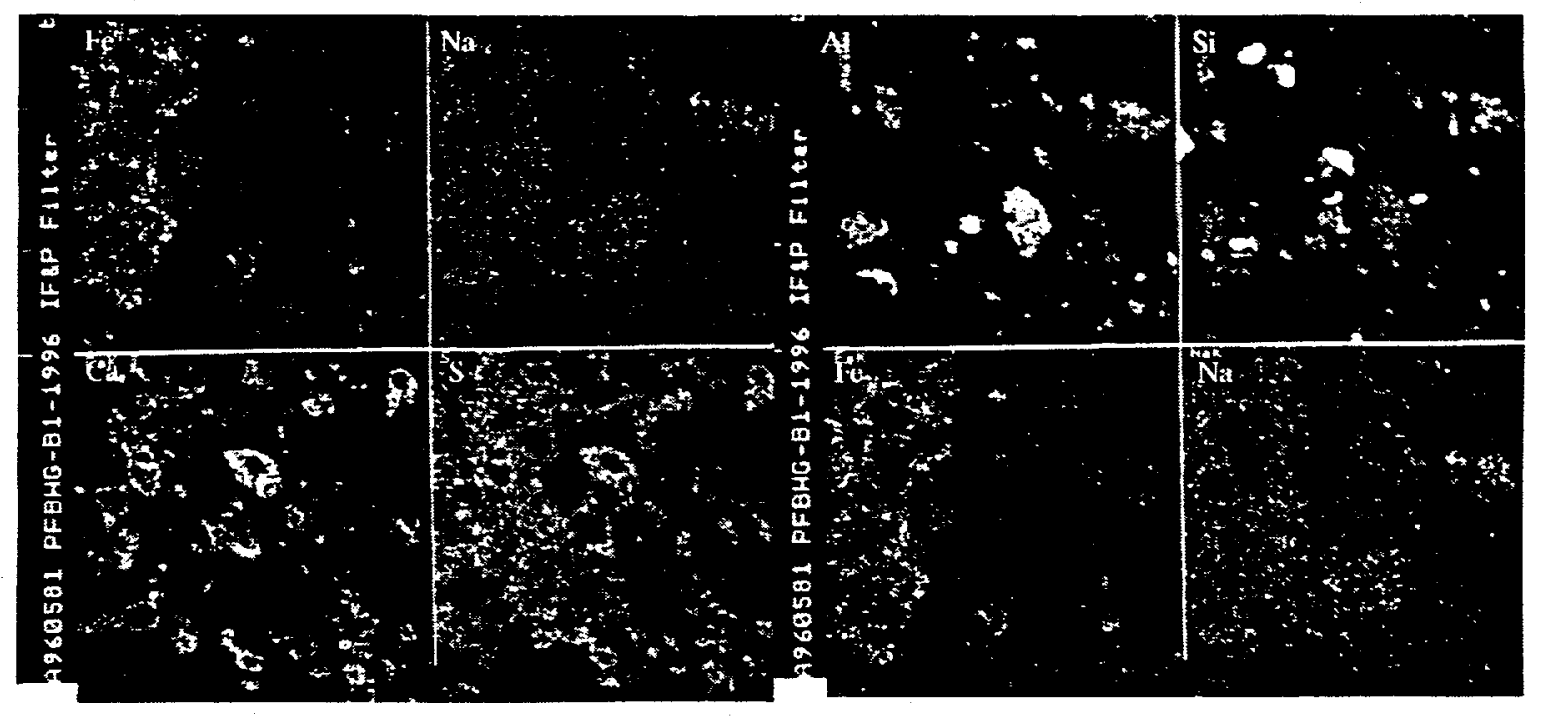

Figure 69. Elemental map of a piece of filter with deposit from Test B1-1996

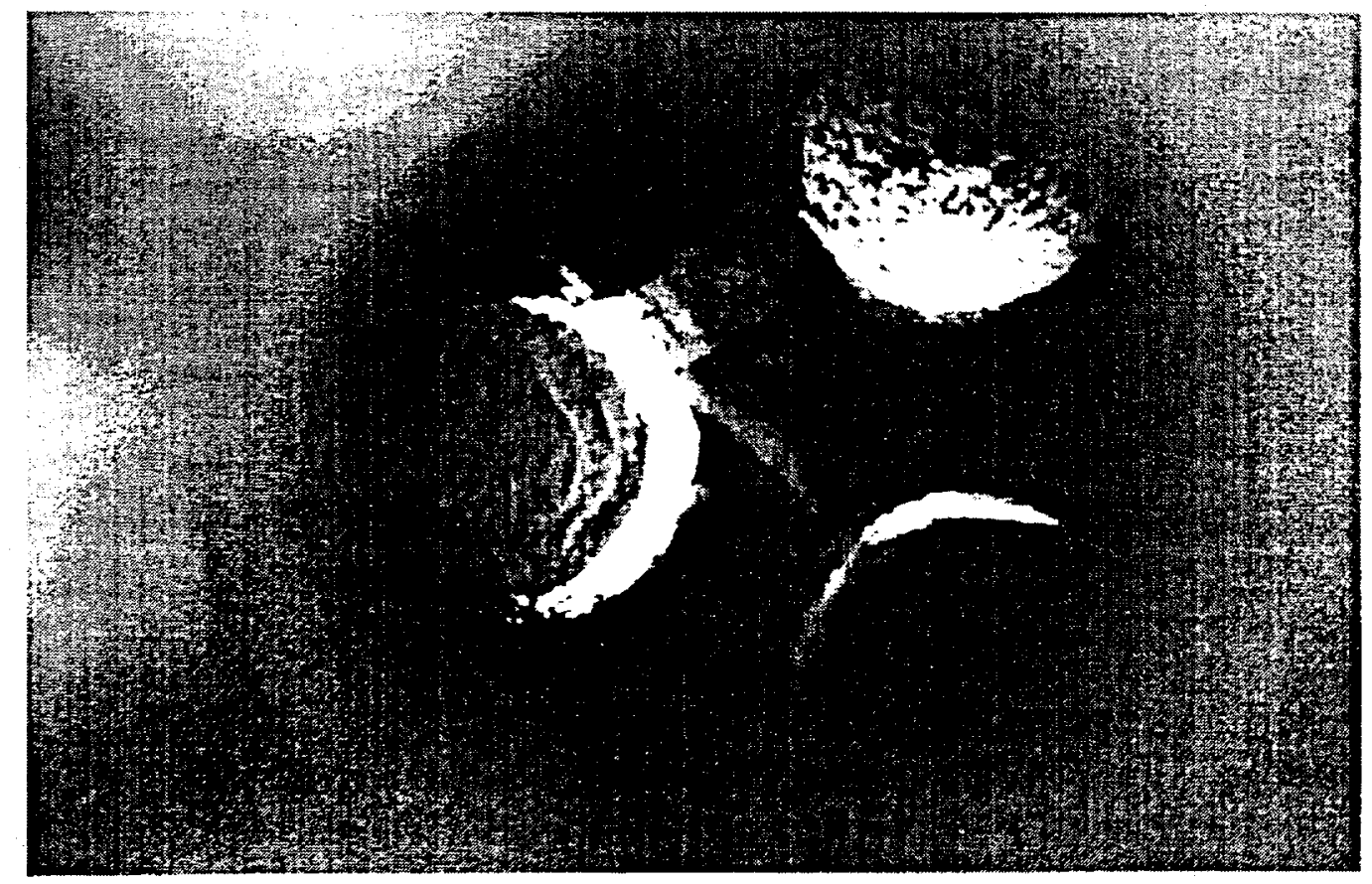

Figure 70. Photograph of an ash bridge formed in the filter vessel during Test B1-2096 
Table 37

Analysis of the Bridge and Other Ash Material from Test B1-2096

\begin{tabular}{ccccc}
\hline & Fuel Mix Ash & Cyclone Ash & Filter Vessel Ash & Filter Bridge \\
\hline Elemental Analysis, mole \%, sulfur-free basis & & & \\
$\mathrm{Si}$ & 22.6 & 29.5 & 28.6 & .26 .5 \\
$\mathrm{Al}$ & 13.7 & 14.7 & 15.7 & 11.6 \\
$\mathrm{Fe}$ & 26.2 & 9.9 & 10.5 & 11.3 \\
$\mathrm{Ca}$ & 21.8 & 27.4 & 26.2 & 25.6 \\
$\mathrm{Mg}$ & 9.8 & 14.5 & 11.7 & 9 \\
$\mathrm{Na}$ & 4.9 & 3.3 & 6.2 & 14.3 \\
$\mathrm{~S}$ & 14.5 & 6.7 & 11.2 & 22.4 \\
$\mathrm{Expressed}$ as Percent of Feed & & & \\
$\mathrm{Si}$ & 1 & 1.31 & 1.27 & 1.18 \\
$\mathrm{Al}$ & 1 & 1.07 & 1.14 & 0.85 \\
$\mathrm{Fe}$ & 1 & 0.38 & 0.4 & 0.43 \\
$\mathrm{Ca}$ & 1 & 1.26 & 1.21 & 1.18 \\
$\mathrm{Mg}$ & 1 & 1.47 & 1.19 & 0.92 \\
$\mathrm{Na}$ & 1 & 0.68 & 1.26 & 2.91 \\
$\mathrm{~S}$ & 1 & 0.46 & 0.77 & 1.54 \\
\hline
\end{tabular}

seen by the enrichment ratios of $3.74,1.45$, and 1.18 , respectively, from the feed material. Its composition is similar to the cyclone ash and filter vessel ash with the exception of the sodium and sulfur. The sodium concentration is almost 2.5 times higher than the ash removed from the filter vessel, and the sulfur is about twice that of the filter vessel ash. Deposits that have been removed from the candles during the cold backpulsing have also been analyzed (see Table 38) and show the same trend: high concentrations of sodium, calcium, and sulfur. This again points to the critical role that sodium plays in bridging and blinding mechanisms. Its role is probably a combination of condensation within the filter vessel due to its slightly lower temperature than the reactor and from fine sodium and calcium sulfate particles that formed as the 
result of homogeneous and heterogeneous condensation prior to reaching the filter vessel. These mechanisms of ash formation have been discussed in Section 2.1. Removal of the sodium from the gas using an alkali sorbent is, therefore, a crucial aspect for the operation of the hot-gas filter vessel using fueis with relatively high alkali contents.

Table 38

Elemental Analysis of Candle Deposits from Various PFBR Tests

\begin{tabular}{ccccc}
\hline & B1-1296 & BEL-1696 & BEL-1896 & B1-1996 \\
\hline Expressed as Mole Fraction, sulfur-free basis & & & \\
$\mathrm{Si}$ & 41 & 28.9 & 31.3 & 39.1 \\
$\mathrm{Al}$ & 10.1 & 15.8 & 21.2 & 12.5 \\
$\mathrm{Fe}$ & 5.8 & 9.4 & 12.1 & 9.5 \\
$\mathrm{Ca}$ & 16.4 & 30.9 & 22.3 & 22.6 \\
$\mathrm{Mg}$ & 5.2 & 4.3 & 3 & 11.3 \\
$\mathrm{Na}$ & 18.7 & 7.3 & 6.9 & 4.2 \\
$\mathrm{~S}$ & 15.9 & 24.8 & 20.7 & 9.1 \\
$\mathrm{Expressed}$ as a Percent of Feed & & & \\
$\mathrm{Si}$ & 1.26 & 1.07 & 1.26 & 0.82 \\
$\mathrm{Al}$ & 0.62 & 1.07 & 1.18 & 0.71 \\
$\mathrm{Fe}$ & 1.28 & 1.59 & 0.43 \\
$\mathrm{Ca}$ & 0.27 & 0.87 & 0.62 & 0.93 \\
$\mathrm{Mg}$ & 1.19 & 0.93 & 0.38 & 0.61 \\
$\mathrm{Na}$ & 0.78 & 2.4 & 2.27 & 4.59 \\
$\mathrm{~S}$ & 2.31 & 1.16 & 0.97 & 1.68 \\
\hline
\end{tabular}




\section{CHAPTER 6}

\section{CONCLUSIONS AND RECOMMENDATIONS}

The work performed as a part of this dissertation consisted of three main efforts: the literature survey, thermogravimetric testing, and bench-scale testing. Conclusions from each of these three efforts are presented. Following the conclusions, recommendations are presented based on the findings of this work.

\subsection{Conclusions from Literature Review}

- Electricity generating demands are expected to grow at a rate ranging from $1 \%$ to $2 \%$ per year in the United States, creating a need for over $200 \mathrm{GW}$ of new generating capacity over the next 20 years. PFBC is projected to capture up to $25 \%$ of the new market for advanced coal technologies, with much of its market penetration in the area of repowering. Therefore, PFBC is expected to be a major source of new power in the 21 st century.

- A number of issues must be resolved for PFBC to capture its projected share of the market. These issues include reducing capital costs and improving reliability and environmental performance. Technical issues related to hot-gas particulate removal, alkali and chlorine control, trace emissions, and the use of advanced cycles must also be resolved for PFBC to reach its full potential.

- The reactions of organically associated mineral matter are of importance in the operating regime of the PFBC. The alkalies, chlorine, and sulfur will vaporize and condense heterogeneously on the surfaces of other ash particles, condense homogeneously to form very fine aerosols, or remain in the vapor phase. These constituents can cause agglomeration and ash deposition, bridging and blinding of hot-gas filters, and corrosion and deposition of turbine blades and, therefore, must be controlled to allow proper operation of the PFBC. 
- Measured gas-phase alkali concentrations of 500 to $4000 \mathrm{ppm}$, depending upon coal type, are high relative to turbine blade specifications of $24 \mathrm{ppb}$. Therefore, turbine manufacturer specifications for vapor-phase alkali are exceeded even though less than $1 \%$ of the total sodium in the fuel is present as vapor. Gas-phase alkali will be higher for those fuels higher in chlorine. The sodium sulfate concentration in the gas phase remains relatively constant because of condensation.

- When sorbents are used in the bubbling fluid bed for adsorption of components from the gas phase, the outlet concentration of the controlled gas will vary inversely with the amount of the sorbent utilized. Therefore, very high sorbent feed rates will be required for high removals of alkali from the gas phase. The capture efficiency will vary directly with sorbent particle size for kinetically limited systems and with the square of particle size for diffusion-controlled systems, assuming there is no elutriation of fines from the bed.

- Aluminosilicates have the most potential for adsorbing alkali under PFBC conditions. Bauxite, kaolinite, and emathlite have been demonstrated to effectively remove alkali vapors when used in packed, moving, and fixed beds.

- Reactions leading to the formation of sodalites have the potential for combined alkali and chlorine removal.

- Alkali metals can be measured either on-line (producing instantaneous alkali values) or off-line (using batch-sampling techniques). The accuracy of on-line methods is still not reliable enough for use in PFBC. Therefore, batch-sampling procedures are recommended even though they only provide average values of alkali metal over a given period of time.

\subsection{Conclusions from TGA Screening Tests}

- The pTGA at the EERC could not be equipped to feed a continuous and controlled amount of sodium vapor into the pTGA without extensive modifications. Therefore, testing was performed at atmospheric pressure.

- The atmospheric TGA made a good tool for screening sorbents and determining reaction mechanisms. The TGA allows the impact of gas type, temperature, and alkali concentration to 
be evaluated and rate data extracted. Samples large enough for analysis by SEM can be generated in the TGA, with these analyses used to help understand the reaction mechanisms.

- Nosean, a sulfur-bearing zeolite, was the favored reaction product when using sorbents for combined alkali, chlorine, and sulfur under the conditions tested. Sodalite, the chlorine-bearing counterpart, would be favored at higher chlorine-to-sulfur ratios and/or higher oxygen partial pressures. Albite reacts with $\mathrm{NaCl}$ vapor in an $\mathrm{SO}_{2}$-bearing gas to capture sodium. The primary mechanism is condensation of $\mathrm{Na}_{2} \mathrm{SO}_{4}$ on the surface of the albite followed by chemical reaction. The rate of sodium adsorption decreases with decreasing $\mathrm{SO}_{2}$ concentration in the gas phase because of reductions in the amount of condensed sulfate.

- Albite, quartz, and kaolinite captured sodium by chemical reaction and were kinetically limited. Sodalite and bauxite use physical adsorption as the primary capture method and are diffusioncontrolled. After being physically adsorbed, some reaction occurs to permanently bind the alkali.

- The sorbents identified to have commercial potential from the TGA screening tests include albite, kaolinite, and bauxite.

\subsection{Conclusions from Bench-Scale Testing}

\subsubsection{General Observations from the Use of Alkali Sorbents}

- The PFBR at the EERC provides a good tool for determining the effectiveness of sorbents in controlling ash chemistry in the PFBC. The impacts of sorbents on bed agglomeration, ash deposition, ash distribution and chemistry, filter blinding and bridging, amount of vapor-phase alkali, and sulfur and nitrogen oxide emissions can be determined.

- The use of bauxite and kaolinite as in-bed sorbents resulted in a decrease in $\mathrm{NQ}_{x}$ over the base case without sorbent addition. This may be due to a catalytic effect of the sorbent on the $\mathrm{NO}_{\mathrm{x}}$ formation and destruction reactions, similar to those reported for dolomite.

\subsubsection{Impacts of Sorbents on Ash Distribution}

- Tests with the Beulah coal, which is indicative of fuels with high organically bound sodium, tended to form bed agglomerates, deposit on heat-transfer surfaces, and form loosely bonded 
deposits that hung up in the reactor piping. Reduction of the vapor-phase sodium content using bauxite as an in-bed sorbent eliminated these problems.

- All sorbents increased the mass loading of ash to both the cyclone and the filter vessel. The fine sorbents ( -30 mesh) caused a disproportional increase in cyclone ash, while the coarse sorbents $(-1 / 8$ in. $)$ caused a disproportional increase in filter vessel ash.

- The fine sorbents displayed a higher tendency to form loosely bonded deposits that hung up in the reactor.

\subsubsection{Impacts of Sorbents on Vapor-Phase Alkali Concentration}

- The vapor-phase alkali concentration is directly related to the quantity of organically bound alkali in the fuel. The vapor-phase sodium concentrations measured from the Beulah, Belle Ayr, and spiked Belle Ayr were approximately proportional to the initial sodium concentration in the starting fuel.

- Kaolinite and bauxite were effective and albite was not effective at reducing the vapor-phase alkali concentration. Kaolinite and bauxite captured similar amounts of sodium at comparable add rates, indicating both were equally effective at alkali capture.

- At a 10:1 sorbent-to-sodium add rate, kaolinite and bauxite reduced the vapor-phase sodium concentration to between 500 and $700 \mathrm{ppb}$. At a 30:1 add rate, the resulting sodium concentration was $270 \mathrm{ppb}$. Therefore, it is unlikely that the turbine specifications of 25 to 125 ppb total alkali can be reached using in-bed sorbents.

- In-bed sorbents have a much higher capture efficiency for higher initial alkali concentrations. For example, $90 \%$ reduction in sodium from $3600 \mathrm{ppb}$ was realized for tests with the Beulah lignite but only $67 \%$ reduction from $1700 \mathrm{ppb}$ using the Belle Ayr coal at the same sorbent add rate.

- The fine sorbents were more effective at reducing vapor-phase sodium concentrations than the coarser sorbents, indicating that the increases in surface area more than offset the shorter bed residence time experienced by the finer sorbents. 


\subsubsection{Impacts of Sorbents on Ash Deposition}

- For fuels high in organically bound sodium (Beulah lignite for example), sodium calcium sulfates form dense, tenacious deposits. When alkali sorbents are utilized to capture sodium, the amount of deposition is reduced, and the form changes to loosely bonded, lightly sintered deposits that could easily be removed by sootblowing.

- The use of albite as a sorbent resulted in no change in deposition characteristics. When kaolinite was used, some reduction in deposition was noted; however, considerable amounts of fines deposited in the reactor piping. Bauxite effectively eliminated deposition at add rates of 10:1 bauxite-to-sodium and greatly reduced the deposition at lower add rates. This indicates that certain sorbents themselves have a propensity for deposition regardless of the vapor-phase sodium concentration, since the kaolinite and bauxite were equally effective at reducing the vapor-phase sodium concentration.

- Bed agglomeration was apparent when utilizing the Beulah lignite. Bauxite effectively controlled agglomeration while albite did not. No evaluation for kaolinite was available from this work.

\subsubsection{Impacts of Sorbents on Filter Performance}

- The vapor-phase sodium concentration directly impacts bridging of the ceramic filter used for hot-gas particulate removal. Severe filter blinding was noted when the Beulah lignite was used that had a vapor-phase sodium concentration of $3600 \mathrm{ppb}$. When using the as-received and sodium-spiked Belle Ayr ( 900 and 1700 ppb vapor-phase sodium), no blinding occurred. Analyses indicate the blinding was caused by condensation and freezing of $\mathrm{NaSO}_{4}$ on the surface of the filter, forming a relatively impervious layer that cannot be removed by backpulsing.

- For the Beulah lignite with a baseline vapor-phase alkali concentration of $3600 \mathrm{ppb}$, the addition of bauxite at a 10:1 sorbent-to-sodium ratio effectively controlled pressure drop in the filter vessel. An add rate of 3:1 was not effective at controlling pressure drop, while a 5:1 add rate of bauxite was only marginally effective. 
- For the sodium-spiked Belle Ayr subbituminous with a baseline vapor-phase alkali concentration of $1700 \mathrm{ppb}$, the pressure drop in the filter vessel never exceeded $10 \mathrm{in.} \mathrm{H}_{2} \mathrm{O}$ for the entire duration of the tests using both the kaolinite and bauxite as sorbents at the 10:1 add rate. The pressure drop without the use of sorbents approached $15 \mathrm{in} . \mathrm{H}_{2} \mathrm{O}$, indicating that the sorbents were effective in reducing filter pressure drop.

- The size of the sorbent utilized had no apparent effect on filter pressure drop at similar add rates.

- Bridging was noted after the test with Beulah coal with bauxite at a 3:1 add rate, which showed only a moderate reduction in vapor-phase sodium concentration. Sodium calcium sulfate was the major component of the bridging material. High sorbent add rates may be effective at eliminating bridges by facilitating high vapor-phase sodium removal, thereby reducing the amount available for homogeneous and heterogeneous condensation to form sticky sulfates.

- During the test program, one of the ceramic filters experienced degradation in the form of spalling from the exterior of the filter. While the filter itself did not fail during the test program, it is speculated that, over time, this spalling would result in a filter failure. The sodium and sulfur appear to be attacking the protective yttrium coating on certain ceramic filters. Yttrium sulfate appears to be the reaction product. The more mobile phases, such as sodium, sulfur, and calcium, were found impregnated deep within the surface of the candle.

The overall conclusion from this work is that in-bed alkali sorbents can effectively reduce the vaporphase alkali concentration. This reduction is of a magnitude great enough to control ash deposition and agglomeration and filter blinding, but not to a level low enough to meet current turbine manufacturer recommendations for vapor-phase alkali. Bauxite was the best sorbent tested based on its ability to control all of the above-mentioned problems. Kaolinite is less effective because of its tendency to form ash bridges and soft deposits from its fine fraction. Finally, although sodalite and nosean can be formed and result in combined sodium and chlorine or sulfur capture, they do not form at a rate high enough to make them effective sorbents under PFBC conditions. 


\subsection{Recommendations}

Bauxite and kaolinite are both effective in reducing the vapor-phase sodium concentration. The increased loading to the cyclone and filter vessel indicates that they have a limited residence time in the bed. These tests also indicated that the high surface area of finer sorbents enhanced alkali removal.

Therefore, alkali capture could be improved by changing the form of the sorbent to keep the high surface area, but increase the size and physical strength to give the sorbent a longer in-bed residence time. This could be accomplished by pelletizing a fine sorbent into pellets of a size approaching the mean size of the bed material. It is recommended that pelletization techniques be examined to determine if they can be utilized for kaolinite and bauxite. If not, other aluminosilicate materials should be researched to find a selection that has a propensity to adsorb alkalies and can form good, strong pellets. Even if these alternative sorbents may not be as effective as bauxite and kaolinite in their raw form, if pelletizing can substantially increase their residence time in the bed, they could prove to be more effective overall.

If bauxite is chosen as a sorbent, consideration should be given to capturing the cyclone and filter ash and recycling the material back to the PFBC. This should improve the overall efficiency of both the bauxite and the dolomite. Pelletizing the sorbent material prior to reintroducing it to the combustor would help stabilize the recycled ash and increase its residence time. The presence of the dolomite in the ash may improve the pelletizing characteristics. This process has been demonstrated for the recycle of fly ash from the circulating FBC of petroleum coke and increased utilization of the limestone from approximately $35 \%$ to over $70 \%$.

For future testing on the PFBR to screen alkali sorbents, consideration should be given to sampling from the outlet of the filter vessel in addition to the top of the reactor. This would provide an indication of how much alkali, if any, is captured by the entrained ash and the ash that builds up on the filters. Results of other work have shown that $\mathrm{SO}_{2}$ is captured on the filters as the flue gas passes through the filter cake. These measurements would be a better indication of the final vapor-phase concentration that the turbine blades would see. Tests at various filter vessel temperatures could provide information to determine how much cooling of flue gas is required to lower the alkali content from the nominal 500 to $700 \mathrm{ppb}$ measured during this work to the 25 to $125 \mathrm{ppb}$ recommended by turbine manufacturers. 
Testing should continue to find effective in-bed sorbents for PFBC. If the PFBC is to realize high coal-to-electricity conversion efficiencies, inexpensive methods of capturing alkali are required. In-bed sorbents offer the capability to accomplish this goal. 
APPENDIX A

\section{GLOSSARY OF TERMS AND ACRONYMS}

Table 39 lists the common acronyms and abbreviations used in this text. Table 40 lists the notations used for equations. 
Table 39

Acronyms and Abbreviations

\begin{tabular}{|c|c|c|c|}
\hline$\overline{\mathrm{AA}}$ & & atomic absorption & \\
\hline AASB & & analytical alkali sorber bed & \\
\hline$a b$ & & albite & \\
\hline AFBC & & atmospheric fluidized-bed combustion & . \\
\hline ANL & & Argonne National Laboratory & \\
\hline APST & & alkali and particulate sampling train & \\
\hline atm & & atmosphere & \\
\hline B1 & & Beulah & \\
\hline BEL & & Belle Ayr & \\
\hline $\mathrm{C}$ & & combustion gas & \\
\hline $\mathrm{cm}$ & & centimeter & \\
\hline $\mathrm{COE}$ & & cost of electricity & \\
\hline CPC & & Combustion Power Company & \\
\hline DOE & & Department of Energy & \\
\hline DRI & & Data Research Institute & \\
\hline DTA & & differential thermal analysis & \\
\hline E & $-\ldots$ & activation energy & \\
\hline EEI & & Edison Electric Institute & \\
\hline EERC & & Energy \& Environmental Research Center & \\
\hline EIA & & Energy Information Administration & \\
\hline$f$ & & fugacity & \\
\hline FBC & & fluidized-bed combustion & \\
\hline FETC & & Federal Energy Technology Center & \\
\hline FG & & flue gas & \\
\hline FOAM & & fiber-optic alkali monitor & \\
\hline FRG & & Federal Republic of Germany & \\
\hline FSU & & Former Soviet Union & \\
\hline $\mathrm{ft}$ & & feet & \\
\hline FT-IR & & Fourier transform infrared & \\
\hline g & & gram & \\
\hline GBF & & granular bed filter & \\
\hline GC & & gas chromatography & \\
\hline GHSV & & gas hourly space velocity & \\
\hline GRI & & Gas Research Institute & \\
\hline GW & & gigawatt & \\
\hline HAP & & hazardous air pollutant & \\
\hline $\mathrm{HGCU}$ & & hot-gas cleanup & \\
\hline HHV & & higher heating value & \\
\hline $\mathrm{hr}$ & & hour & \\
\hline
\end{tabular}

Continued... 
Table 39 (continued)

\begin{tabular}{|c|c|}
\hline HRSG & heat recovery steam generator \\
\hline HTHP & high temperature, high pressure \\
\hline ID & inside diameter \\
\hline IEA & International Energy Agency \\
\hline IGCC & integrated gasification combined cycle \\
\hline in. & inch \\
\hline ISO & International Organization for Standardization \\
\hline $\mathrm{kg}$ & kilogram \\
\hline $\mathrm{kPa}$ & kilopascals \\
\hline $\mathrm{lb}$ & pound \\
\hline LHV & lower heating value \\
\hline LIBS & laser-induced breakdown spectroscopy \\
\hline LIFS & laser-induced fluorescence spectroscopy \\
\hline LIPF & laser-induced photo and fluorescence \\
\hline m & meter \\
\hline METC & Morgantown Energy Technology Center \\
\hline mg & milligram \\
\hline $\mathrm{mm}$ & millimeter \\
\hline MMBtu & million British thermal units \\
\hline MS & mass spectrometry \\
\hline MWe & megawatt electricity \\
\hline $\mathrm{NaAc}$ & sodium acetate \\
\hline ne & nepheline \\
\hline NERA & National Economic Research Association \\
\hline NERC & North American Electric Reliability Association \\
\hline NRC & Nuclear Regulatory Committee, National Research Council \\
\hline NYU & New York University \\
\hline OD & outside diameter \\
\hline OECD & Organization for Economic Cooperation and Development \\
\hline pc & pulverized coal \\
\hline PC & personal computer \\
\hline PFB & pressurized fluidized bed \\
\hline PFBC & pressurized fluidized-bed combustion(tor) \\
\hline PFBHG & pressurized fluid-bed reactor with hot gas cleanup \\
\hline PFBR & pressurized fluid-bed reactor \\
\hline ppbw & parts per billion by weight \\
\hline ppm & parts per million \\
\hline ppmv & parts per million by volume \\
\hline ppmw & parts per million by weight \\
\hline psig & pounds per square inch gauge \\
\hline pTGA & pressurized thermogravimetric analysis \\
\hline $\mathrm{qz}$ & quartz \\
\hline
\end{tabular}

Continued ... 
173

Table 39 (continued)

\begin{tabular}{ll}
\hline R & universal gas constant \\
R\&D & research and development \\
scfm & standard cubic feet per minute \\
Sch & Schedule \\
Sec & second \\
SEM & scanning electron microscopy \\
SGV & superficial gas velocity \\
SRI & Southern Research Institute \\
STP & standard temperature and pressure \\
TGA & thermogravimetric analysis \\
UV & ultraviolet \\
WEFA & Wharton Economic Forecasting Association \\
WRI & Western Research Institute \\
wt & weight \\
\hline
\end{tabular}

Continued ... 
Table 40

Notation Used for Equations

\begin{tabular}{|c|c|}
\hline $\bar{A}$ & gaseous reactant \\
\hline$A_{1}$ & cross-sectional area of the bed \\
\hline B & solid reactant \\
\hline $\mathrm{C}_{\mathrm{a}}$ & concentration of alkali in the gas phase \\
\hline $\mathrm{C}_{\mathrm{A}}{ }^{\circ}, \mathrm{C}_{\mathrm{Ai}}, \mathrm{C}_{\mathrm{AO}}, \mathrm{C}_{\mathrm{Aex}}$ & $\begin{array}{l}\text { concentration of vapor } A \text { in gas in equilibrium with solids, in the entering gas } \\
\text { stream, at the top of the bed, and at the exit of the FBC }\end{array}$ \\
\hline $\mathrm{C}_{25}, \mathrm{C}_{s}, \mathrm{C}_{\mathrm{s}}, \mathrm{C}_{\mathrm{v}}$ & number of active sites, total sites available, used sites, and vacant sites \\
\hline$d_{p}$ & particle diameter \\
\hline$D_{\mathrm{s}}$ & effective diffusivity of gas through the product blanket \\
\hline e & charge of electron \\
\hline $\mathbf{E}(\mathrm{t})$ & exit age distribution \\
\hline$F_{0}$ & feed rate of solids \\
\hline$k, k_{2}, k_{c}, k_{r}$ & $\begin{array}{l}\text { rate constants, for adsorption, for first-order surface reaction, for first-order } \\
\text { gas-solid reaction }\end{array}$ \\
\hline $\mathrm{K}$ & rate of adsorption (change in weight) divided by the alkali concentration \\
\hline $\mathrm{K}_{\mathrm{a}}$ & $\begin{array}{l}\text { ratio of the rate constant for adsorption divided by the rate constant for } \\
\text { desorption }\end{array}$ \\
\hline $\mathrm{K}_{\mathrm{bc}}, \mathrm{K}_{\mathrm{ce}}$, & $\begin{array}{l}\text { coefficient of gas interchange between bubble and cloud-wake region, and } \\
\text { between cloud-wake region and emulsion phase }\end{array}$ \\
\hline $\mathrm{K}_{\mathrm{t}}$ & rate constant for first-order catalytic reactions \\
\hline$L_{m}, L_{m f}, L_{f}$ & $\begin{array}{l}\text { height of fixed bed, bed at minimum fluidizing velocity, and bubbling } \\
\text { fluidized bed }\end{array}$ \\
\hline $\mathrm{M}_{\mathrm{T}}$ & Thiele-type modulus, defined in Eq. 31 \\
\hline$N_{A}, N_{B}$ & number of moles of $A$ and $B$, respectively \\
\hline$Q, Q_{i}, Q_{i}^{*}, Q_{0}$ & $\begin{array}{l}\text { moisture faction of particles, at initial conditions, at equilibrium conditions, } \\
\text { and at exit conditions }\end{array}$ \\
\hline $\mathrm{R}$ & radius of particle \\
\hline $\mathrm{R}_{12}$ & separation between ions \\
\hline$R_{\mathrm{ads}}$ & rate of adsorption \\
\hline $\mathbf{r}_{\mathrm{c}}$ & radius of unreacted core of reactant solid \\
\hline t bar & mean residence time of gas or solid in vessel \\
\hline$t$ & time \\
\hline $\mathrm{T}$ & temperature \\
\hline$u_{m e} u_{o}$ & $\begin{array}{l}\text { superficial gas velocity at minimum fluidizing conditions and at operating } \\
\text { conditions }\end{array}$ \\
\hline $\mathrm{V}_{\mathrm{s}}$ & volume of solids in a fluidized-bed reactor \\
\hline W & mass of solids \\
\hline$z_{i, 2}$ & valence of respective ions \\
\hline
\end{tabular}




\section{APPENDIX B}

\section{SUMMARY OF RUN DATA FROM THE PFBR}

Data from each of the tests on the bench-scale PFBR are presented in Tables 41 through 51. The tables, generated from the data reduction program for the PFBR, contain the tag number, which refers to the number assigned by the data acquisition system, a description of what each point is, the units, average, and standard deviation. All of the averages are presented with two numbers to the right of the decimal point. This is the convention used in the data reeducation program and does not necessarily reflect the number of significant figures for that point. 
Table 41

Run Summary from Test B1-1296

\begin{tabular}{|c|c|c|c|c|}
\hline \multicolumn{4}{|c|}{ PFBHG-B1-1296 } & \multirow{2}{*}{$\begin{array}{l}\text { Oct. } 16,1996 \\
\text { Std. Dev. }\end{array}$} \\
\hline Tag & Description & Units & Average & \\
\hline AIRFLOW & Air Flow Rate & scfm & 12.31 & 0.402 \\
\hline N FLOW A & Orifice N Flow & scfm & 10.44 & 0.273 \\
\hline FLOW IN & Total Flow In & scfm & 22.75 & 0.607 \\
\hline VELOCITY & Reactor SGV & $\mathrm{ft} / \mathrm{sec}$ & 2.84 & 0.111 \\
\hline FG SGV & FG SGV & $\mathrm{ft} / \mathrm{sec}$ & 2.93 & 0.113 \\
\hline EA & Excess Air & $\%$ & 25.08 & 3.420 \\
\hline $\mathrm{HC} 13111$ & $Z 1$ Heater Temp & ${ }^{\circ} \mathrm{F}$ & 1529.09 & 28.327 \\
\hline HT2PID & Z 1 Heater output & $\%$ & 50.78 & 29.818 \\
\hline $\mathrm{HCl} 13211$ & Z 2 Heater Temp & ${ }^{\circ} \mathrm{F}$ & 1563.19 & 27.791 \\
\hline HT3PID & Z 2 Heater output & $\%$ & 11.24 & 24.366 \\
\hline $\mathrm{HC} 13311$ & Z 3 Heater Temp & ${ }^{\circ} \mathrm{F}$ & 1525.57 & 18.941 \\
\hline HT4PID & Z 3 Heater output & $\%$ & 15.17 & 28.262 \\
\hline TC11010 & Inlet Gas temp & ${ }^{\circ} \mathrm{F}$ & 617.61 & 5.611 \\
\hline TC14001 & Reactor Inlet temp & ${ }^{\circ} \mathrm{F}$ & 776.49 & 29.041 \\
\hline TC14002 & RT@0.25" & ${ }^{\circ} \mathrm{F}$ & 1373.86 & 32.266 \\
\hline TC14003 & RT@1.75" & ${ }^{\circ} \mathrm{F}$ & 1486.26 & 55.310 \\
\hline TC14004 & RT@3.50" & ${ }^{\circ} \mathrm{F}$ & 1499.86 & 58.916 \\
\hline TC14005 & RT@ 5.00" & ${ }^{\circ} \mathrm{F}$ & 1504.79 & 58.986 \\
\hline TC14006 & RT@7.00" & ${ }^{\circ} \mathrm{F}$ & 1512.45 & 57.312 \\
\hline $\mathrm{TC} 14007$ & RT@ 9.00" & ${ }^{\circ} \mathrm{F}$ & 1519.92 & 56.023 \\
\hline TC14008 & RT@11.00" & ${ }^{\circ} \mathrm{F}$ & 1531.91 & 53.976 \\
\hline TC14009 & RT@15.00" & ${ }^{\circ} \mathrm{F}$ & 1567.42 & 49.282 \\
\hline TC14010 & RT@23.00" & ${ }^{\circ} \mathrm{F}$ & 1618.24 & 37.001 \\
\hline TC14011 & RT@31.00" & ${ }^{\circ} \mathrm{F}$ & 1662.03 & 25.118 \\
\hline $\mathrm{TCl} 4012$ & RT@43.25" & ${ }^{\circ} \mathrm{F}$ & 1500.59 & 93.920 \\
\hline TCl 4028 & Cyclone Exit & ${ }^{\circ} \mathrm{F}$ & 1509.28 & 8.241 \\
\hline TC15001 & HX FG Out & ${ }^{\circ} \mathrm{F}$ & 569.74 & 12.234 \\
\hline TC18010 & Stack Temp & ${ }^{\circ} \mathrm{F}$ & 411.16 & 11.317 \\
\hline ZONE 1 & Zone 1 Avg & ${ }^{\circ} \mathrm{F}$ & 1504.66 & 56.975 \\
\hline ZONE 2 & Zone $2 \mathrm{Avg}$ & ${ }^{\circ} \mathrm{F}$ & 1572.52 & 46.099 \\
\hline ZONE 3 & Zone $3 \mathrm{Avg}$ & ${ }^{\circ} \mathrm{F}$ & 1581.31 & 55.307 \\
\hline$T(A \vee G)$ & Avg Reactor temp & ${ }^{\circ} \mathrm{F}$ & 1540.35 & 49.556 \\
\hline $\mathrm{SO} 2-\mathrm{A}$ & $\mathrm{FG} \mathrm{SO}-\mathrm{A}$ & ppm & 0.00 & 0.000 \\
\hline $\mathrm{SO} 2-\mathrm{B}$ & $\mathrm{FG} \mathrm{SO}-\mathrm{B}$ & ppm & 54.52 & 70.233 \\
\hline $\mathrm{O} 2-\mathrm{A}$ & $\mathrm{FG} \mathrm{O}_{2}-\mathrm{A}$ & $\%$ & 4.78 & 0.516 \\
\hline O2-B & $\mathrm{FGO}_{2}-\mathrm{B}$ & $\%$ & 4.88 & 0.567 \\
\hline $\mathrm{CO} 2$ & $\mathrm{FG} \mathrm{CO}$ & $\%$ & 4.69 & 0.642 \\
\hline $\mathrm{CO}$ & $\mathrm{FG} \mathrm{CO}$ & ppm & 11.24 & 1.263 \\
\hline NOX & $F G \mathrm{NO}_{\mathrm{x}}$ & ppm & 68.78 & 5.174 \\
\hline
\end{tabular}

Continued ... 
Table 41 (continued)

\begin{tabular}{|c|c|c|c|c|}
\hline PFBHG-B1-1296 & & & & Oct. 16,1996 \\
\hline Tag & Description & Units & Average & Std. Dev. \\
\hline $\mathrm{N} 2 \mathrm{O}$ & $\mathrm{FG} \mathrm{N}_{2} \mathrm{O}$ & ppm & 23.20 & 3.600 \\
\hline $\mathrm{HC}$ & FG HC & ppm & 0.95 & 0.126 \\
\hline Calculated & S Ret & $\%$ & 89.52 & 11.215 \\
\hline S RET & Sulfur Retention & $\%$ & 94.79 & 5.579 \\
\hline $\mathrm{E}-\mathrm{SO} 2-\mathrm{A}$ & $\mathrm{FG} \mathrm{SO}-\mathrm{A}$ & $\mathrm{lb} / \mathrm{MMBtu}$ & 0.00 & 0.000 \\
\hline E-NOx & $\mathrm{FG} \mathrm{NO}_{\mathrm{x}}$ & $\mathrm{lb} / \mathrm{MMBtu}$ & 0.35 & 0.063 \\
\hline E-N2O & $\mathrm{FG} \mathrm{N}_{2} \mathrm{O}$ & lb/MMBtu & 0.12 & 0.030 \\
\hline $\mathrm{E}-\mathrm{CO}$ & FG CO & $\mathrm{lb} / \mathrm{MMBtu}$ & 0.04 & 0.006 \\
\hline Feedrate & Theor. Coal feed & $\mathrm{lb} / \mathrm{hr}$ & 4.77 & 0.641 \\
\hline TC16010 & HX 1 exit temp & ${ }^{\circ} \mathrm{F}$ & 132.13 & 10.071 \\
\hline TC16020 & HX 2 exit temp & ${ }^{\circ} \mathrm{F}$ & 0.00 & 0.000 \\
\hline TC16030 & HX 3 exit temp & ${ }^{\circ} \mathrm{F}$ & 241.02 & 5.637 \\
\hline TC12101 & Auger HX exit & ${ }^{\circ} \mathrm{F}$ & 84.54 & 5.834 \\
\hline TC17001 & Alk. Probe temp & ${ }^{\circ} \mathrm{F}$ & 172.87 & 111.780 \\
\hline TC17002 & Alk. Probe temp & ${ }^{\circ} \mathrm{F}$ & 313.44 & 105.985 \\
\hline TC17003 & Cyclone Pot temp & ${ }^{\circ} \mathrm{F}$ & 114.68 & 2.575 \\
\hline PT14020 & Reactor Static & atm & 11.18 & 0.141 \\
\hline PT 14020 & Reactor Static & psia & 164.26 & 2.068 \\
\hline PT14021 & Reactor dP & in $\mathrm{H}_{2} \mathrm{O}$ & 19.86 & 1.294 \\
\hline РT10999 & Barometric & psia & 14.45 & 0.011 \\
\hline PT 14022 & Cyclone dP & in $\mathrm{H}_{2} \mathrm{O}$ & 7.16 & 0.465 \\
\hline TC16040 & Reactor HX temp & ${ }^{\circ} \mathrm{F}$ & 0.00 & 0.000 \\
\hline R STATIC & Reactor Static & psig & 149.81 & 2.070 \\
\hline HG IN & HG IN & ${ }^{\circ} \mathrm{F}$ & 1509.24 & 8.372 \\
\hline HG TOP & HG TOP & ${ }^{\circ} \mathrm{F}$ & 1394.79 & 2.413 \\
\hline HG UpMid & HG UpMid & ${ }^{\circ} \mathrm{F}$ & 1494.77 & 4.456 \\
\hline HG LoMid & HG LoMid & ${ }^{\circ} \mathrm{F}$ & 1519.49 & 2.244 \\
\hline HG Out & HG Out & ${ }^{\circ} \mathrm{F}$ & 966.67 & 7.151 \\
\hline Htr Top & Htr Top & ${ }^{\circ} \mathrm{F}$ & 1031.38 & 3.492 \\
\hline $\mathrm{Htr} \mathrm{Btm} l$ & $\mathrm{Htr} \mathrm{Btml}$ & ${ }^{\circ} \mathrm{F}$ & 971.18 & 7.095 \\
\hline $\mathrm{Htr} \mathrm{Btm} 2$ & $\mathrm{Htt} \mathrm{Btm} 2$ & ${ }^{\circ} \mathrm{F}$ & 946.06 & 6.053 \\
\hline Fltrl Up & Fltrl Up & ${ }^{\circ} \mathrm{F}$ & 1188.52 & 7.937 \\
\hline Fltrl Lo & Fitrl Lo & ${ }^{\circ} \mathrm{F}$ & 1330.07 & 11.643 \\
\hline Fltr2 Up & Fltr2 Up & ${ }^{\circ} \mathrm{F}$ & 0.00 & 0.000 \\
\hline Fltr2 Lo & Fltr2 Lo & ${ }^{\circ} \mathrm{F}$ & 0.00 & 0.000 \\
\hline Fltr3 Up & Fltr3 Up & ${ }^{\circ} \mathrm{F}$ & 0.00 & 0.000 \\
\hline Fltr3 Lo & Fltr3 Lo & ${ }^{\circ} \mathrm{F}$ & 0.00 & 0.000 \\
\hline HG Presr & HG Presr & psig & 158.11 & 2.329 \\
\hline HG dP & HG dP & $\mathrm{kPa}$ & 5.29 & 5.965 \\
\hline $\mathrm{HG} \mathrm{dP}$ & HG dP & in $\mathrm{H}_{2} \mathrm{O}$ & 21.23 & 23.947 \\
\hline Ash Pot & Ash Pot & ${ }^{\circ} \mathrm{F}$ & 109.35 & 2.231 \\
\hline
\end{tabular}


Table 42

Run Summary from Test B1-1396

\begin{tabular}{|c|c|c|c|c|}
\hline$\overline{\text { PFBHG-B1-1396 }}$ & . & & & Oct. 21,1996 \\
\hline Tag & Description & Units & Average & Std. Dev. \\
\hline AIRFLOW & Air Flow Rate & scfm & 11.60 & 1.114 \\
\hline N FLOW A & Orifice N Flow & scfm & 11.53 & 0.951 \\
\hline FLOW IN & Total Flow In & $\operatorname{scfm}$ & 23.13 & 1.725 \\
\hline VELOCITY & Reactor SGV & $\mathrm{ft} / \mathrm{sec}$ & NA & \\
\hline FG SGV & FG SGV & $\mathrm{ft} / \mathrm{sec}$ & 2.97 & 0.268 \\
\hline EA & Excess Air & $\%$ & 23.45 & 4.774 \\
\hline $\mathrm{HC} 13111$ & Z 1 Heater Temp & ${ }^{\circ} \mathrm{F}$ & NA & \\
\hline HT2PID & Z 1 Heater output & $\%$ & NA & \\
\hline $\mathrm{HC} 13211$ & Z 2 Heater Temp & ${ }^{\circ} \mathrm{F}$ & NA & \\
\hline HT3PID & Z 2 Heater output & $\%$ & NA & \\
\hline $\mathrm{HC} 13311$ & Z 3 Heater Temp & ${ }^{\circ} \mathrm{F}$ & NA & \\
\hline HT4PID & Z 3 Heater output & $\%$ & NA & \\
\hline TC11010 & Inlet Gas temp & ${ }^{\circ} \mathrm{F}$ & 597.34 & 9.933 \\
\hline TCl4001 & Reactor Inlet temp & ${ }^{\circ} \mathrm{F}$ & 822.06 & 36.531 \\
\hline $\mathrm{TCl} 4002$ & RT@0.25" & ${ }^{\circ} \mathrm{F}$ & 1409.29 & 90.321 \\
\hline TC14003 & RT@1.75" & ${ }^{\circ} \mathrm{F}$ & 1393.39 & 128.408 \\
\hline TC14004 & RT@ 3.50" & ${ }^{\circ} \mathrm{F}$ & 1432.56 & 135.949 \\
\hline TC14005 & RT@ $5.00^{\prime \prime}$ & ${ }^{\circ} \mathrm{F}$ & 1436.77 & 135.130 \\
\hline TC14006 & RT@7.00" & ${ }^{\circ} \mathrm{F}$ & 1441.65 & 137.636 \\
\hline TC14007 & RT@ 9.00" & ${ }^{\circ} \mathrm{F}$ & 1441.53 & 138.655 \\
\hline TC14008 & RT@11.00" & ${ }^{\circ} \mathrm{F}$ & 1451.20 & 143.836 \\
\hline TCl4009 & RT@15.00" & ${ }^{\circ} \mathrm{F}$ & 1475.57 & 150.062 \\
\hline $\mathrm{TC} 14010$ & RT@23.00" & ${ }^{\circ} \mathrm{F}$ & 1574.60 & 119.725 \\
\hline TC14011 & RT@31.00" & ${ }^{\circ} \mathrm{F}$ & 1659.90 & 92.008 \\
\hline $\mathrm{TCl} 4012$ & RT@43.25" & ${ }^{\circ} \mathrm{F}$ & 1512.21 & 84.789 \\
\hline $\mathrm{TC} 14028$ & Cyclone Exit & ${ }^{\circ} \mathrm{F}$ & 1480.54 & 85.435 \\
\hline TC15001 & HX FG Out & ${ }^{\circ} \mathrm{F}$ & 488.53 & 32.463 \\
\hline TC18010 & Stack Temp & ${ }^{\circ} \mathrm{F}$ & 365.62 & 14.522 \\
\hline ZONE 1 & Zone I Avg & ${ }^{\circ} \mathrm{F}$ & 1429.18 & 134.634 \\
\hline ZONE 2 & Zone 2 Avg & ${ }^{\circ} \mathrm{F}$ & 1500.46 & 137.552 \\
\hline ZONE 3 & Zone 3 Avg & ${ }^{\circ} \mathrm{F}$ & 1586.06 & 87.141 \\
\hline $\mathrm{T}(\mathrm{AVG})$ & Avg Reactor temp & ${ }^{\circ} \mathrm{F}$ & 1481.94 & 125.377 \\
\hline $\mathrm{SO} 2-\mathrm{A}$ & $\mathrm{FG} \mathrm{SO}=\mathrm{A}$ & $\mathrm{ppm}$ & 6.00 & 3.565 \\
\hline SO2-B & $\mathrm{FG} \mathrm{SO}_{2}-\mathrm{B}$ & ppm & 75.22 & 22.733 \\
\hline O2-A & $\mathrm{FG} \mathrm{O}_{2}-\mathrm{A}$ & $\%$ & 4.55 & 0.702 \\
\hline O2-B & $\mathrm{FG} \mathrm{O}_{2}-\mathrm{B}$ & $\%$ & 4.58 & 0.613 \\
\hline $\mathrm{CO} 2$ & $\mathrm{FG} \mathrm{CO}$ & $\%$ & 3.75 & 0.837 \\
\hline $\mathrm{CO}$ & FG CO & ppm & 290.43 & 247.076 \\
\hline
\end{tabular}

Continued ... 
Table 42 (continued)

\begin{tabular}{|c|c|c|c|c|}
\hline PFBHG-B1-1396 & & & & Oct. 21,1996 \\
\hline Tag & Description & Units & Average & Std. Dev. \\
\hline NOX & FG NO & ppm & 67.17 & 6.347 \\
\hline $\mathrm{N} 2 \mathrm{O}$ & $\mathrm{FG} \mathrm{N} \mathrm{N}_{2} \mathrm{O}$ & ppm & 0.10 & 0.023 \\
\hline $\mathrm{HC}$ & FG HC & ppm & 2.11 & 0.426 \\
\hline Calculated & S Ret & $\%$ & 80.68 & 3.330 \\
\hline S RET & Sulfur Retention & $\%$ & 90.37 & 1.660 \\
\hline $\mathrm{E}-\mathrm{SO} 2-\mathrm{A}$ & $\mathrm{FG} \mathrm{SO}-\mathrm{A}$ & $\mathrm{lb} / \mathrm{MMBtu}$ & 0.06 & 0.044 \\
\hline E-NOx & FG NO & $\mathrm{lb} / \mathrm{MMBtu}$ & 0.44 & 0.085 \\
\hline $\mathrm{E}-\mathrm{N} 2 \mathrm{O}$ & $\mathrm{FG} \mathrm{N}_{2} \mathrm{O}$ & $\mathrm{lb} / \mathrm{MMBtu}$ & 0.00 & 0.000 \\
\hline $\mathrm{E}-\mathrm{CO}$ & FG CO & $\mathrm{lb} / \mathrm{MMBtu}$ & 1.45 & 2.012 \\
\hline Feedrate & Theor. Coal feed & $\mathrm{lb} / \mathrm{hr}$ & 3.96 & 0.951 \\
\hline $\mathrm{TC} 16010$ & HX 1 exit temp & ${ }^{\circ} \mathrm{F}$ & 106.73 & 5.492 \\
\hline $\mathrm{TC} 16020$ & HX 2 exit temp & ${ }^{\circ} \mathrm{F}$ & 0.00 & 0.000 \\
\hline $\mathrm{TCl} 6030$ & HX 3 exit temp & ${ }^{\circ} \mathrm{F}$ & 174.02 & 12.279 \\
\hline $\mathrm{TC} 12101$ & Auger $\mathrm{HX}$ exit & ${ }^{\circ} \mathrm{F}$ & 74.12 & 1.506 \\
\hline $\mathrm{TC17001}$ & Alk. Probe temp & ${ }^{\circ} \mathrm{F}$ & 0.00 & 0.000 \\
\hline TC17002 & Alk. Probe temp & ${ }^{\circ} \mathrm{F}$ & 139.77 & 3.517 \\
\hline TC17003 & Cyclone Pot temp & ${ }^{\circ} \mathrm{F}$ & 101.51 & 4.306 \\
\hline PT 14020 & Reactor Static & atm & 10.83 & 0.538 \\
\hline PT14020 & Reactor Static & psia & 159.18 & 7.905 \\
\hline PT14021 & Reactor $\mathrm{dP}$ & in $\mathrm{H}_{2} \mathrm{O}$ & 8.00 & 2.574 \\
\hline PT10999 & Barometric & psia & 14.46 & 0.009 \\
\hline PT14022 & Cyclone $\mathrm{dP}$ & in $\mathrm{H}_{2} \mathrm{O}$ & 10.20 & 1.508 \\
\hline TC16040 & Reactor HX temp & ${ }^{\circ} \mathrm{F}$ & 204.06 & 16.282 \\
\hline R STATIC & Reactor Static & psig & 144.72 & 7.906 \\
\hline HG IN & HG IN & ${ }^{\circ} \mathrm{F}$ & 1480.70 & 84.945 \\
\hline HG TOP & HG TOP & ${ }^{\circ} \mathrm{F}$ & 1320.96 & 28.708 \\
\hline HG UpMid & HG UpMid & ${ }^{\circ} \mathrm{F}$ & 1427.40 & 34.666 \\
\hline HG LoMid & HG LoMid & ${ }^{\circ} \mathrm{F}$ & 1455.42 & 34.581 \\
\hline HG Out & HG Out & ${ }^{\circ} \mathrm{F}$ & 1200.00 & 0.000 \\
\hline Htr Top & Htr Top & ${ }^{\circ} \mathrm{F}$ & NA & \\
\hline Htr Btm l & Htr Btml & ${ }^{\circ} \mathrm{F}$ & NA & \\
\hline $\mathrm{Htr} \mathrm{Btm} 2$ & $\mathrm{Htr} B t m 2$ & ${ }^{\circ} \mathrm{F}$ & NA & \\
\hline Fltrl Up & Fitrl Up & ${ }^{\circ} \mathrm{F}$ & NA & \\
\hline Fltrl Lo & Fltrl Lo & ${ }^{\circ} \mathrm{F}$ & NA & \\
\hline Fltr2 Up & Fltr2 Up & ${ }^{\circ} \mathrm{F}$ & NA & \\
\hline Fitr2 Lo & Fltr2 Lo & ${ }^{\circ} \mathrm{F}$ & NA & \\
\hline Fitr3 Up & Fltr3 Up & ${ }^{\circ} \mathrm{F}$ & NA & \\
\hline Fltr3 Lo & Fltr3 Lo & ${ }^{\circ} \mathrm{F}$ & NA & \\
\hline HG Presr & HG Presr & psig & 143.20 & 9.002 \\
\hline HG dP & HG dP & $\mathrm{kPa}$ & 3.41 & 2.981 \\
\hline HG dP & HG dP & in $\mathrm{H}_{2} \mathrm{O}$ & 13.71 & 11.967 \\
\hline Ash Pot & Ash Pot & ${ }^{\circ} \mathrm{F}$ & NA & \\
\hline
\end{tabular}


Table 43

Run Summary from Test BEL-1496

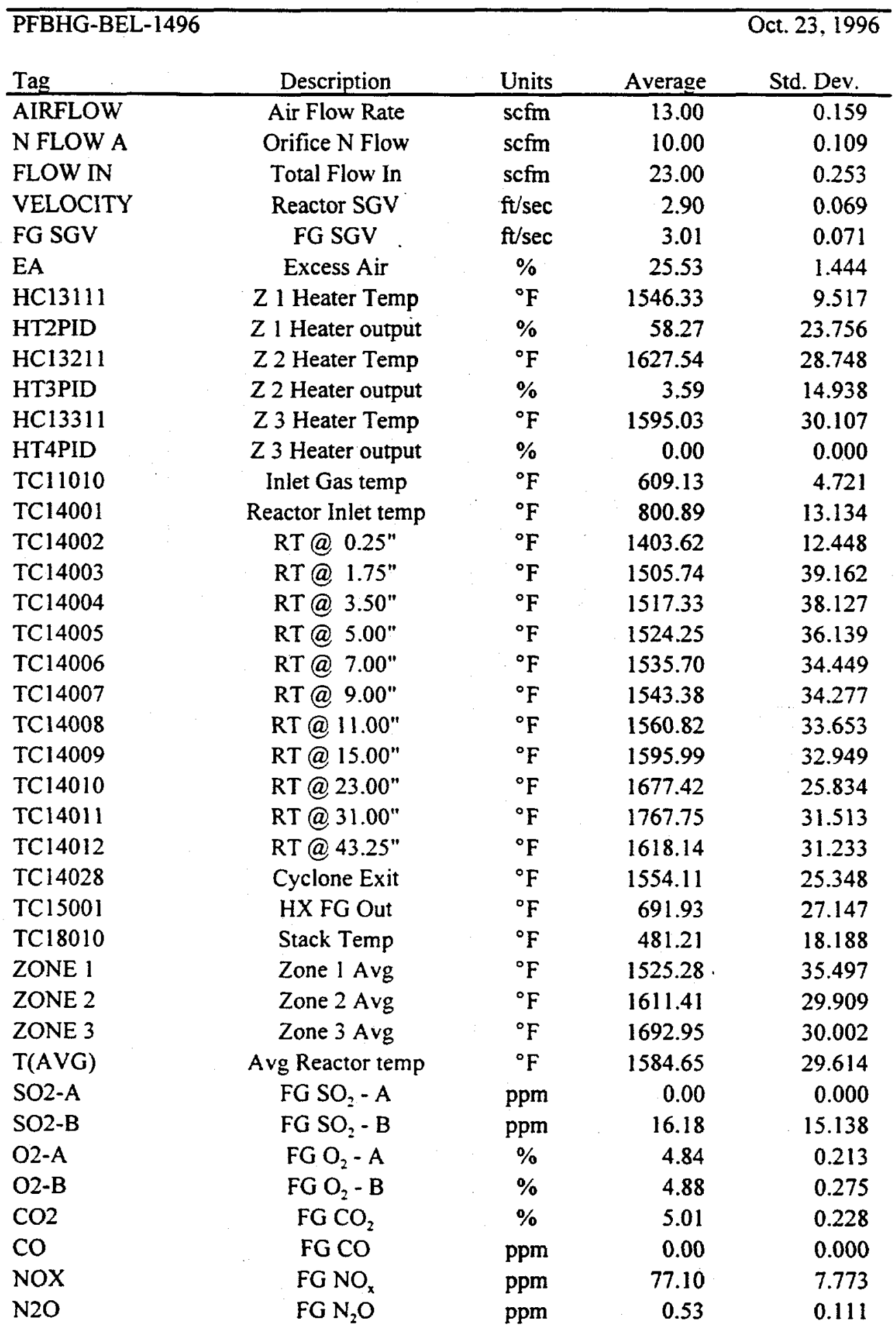

Continued ... . 
181

Table 43 (continued)

\begin{tabular}{|c|c|c|c|c|}
\hline PFBHG-BEL-1496 & & & & Oct. 23,1996 \\
\hline Tag & Description & Units & Average & Std. Dev. \\
\hline $\mathrm{HC}$ & FG HC & ppm & 17.28 & 1.963 \\
\hline Calculated & S Ret & $\%$ & 86.24 & 12.761 \\
\hline S RET & Sulfur Retention & $\%$ & 86.48 & 12.540 \\
\hline $\mathrm{E}-\mathrm{SO} 2-\mathrm{A}$ & $\mathrm{FG} \mathrm{SO}_{2}-\mathrm{A}$ & $\mathrm{lb} / \mathrm{MMBtu}$ & 0.07 & 0.630 \\
\hline E-NOx & $F G \mathrm{NO}_{\mathrm{x}}$ & $\mathrm{lb} / \mathrm{MMBtu}$ & 0.35 & 0.044 \\
\hline $\mathrm{E}-\mathrm{N} 2 \mathrm{O}$ & $\mathrm{FG} \mathrm{N} \mathrm{N}_{2} \mathrm{O}$ & $\mathrm{lb} / \mathrm{MMBtu}$ & 0.00 & 0.001 \\
\hline E-CO & FG CO & lb/MMBtu & 0.00 & 0.000 \\
\hline Feedrate & Theor. Coal feed & $\mathrm{lb} / \mathrm{hr}$ & 3.93 & 0.240 \\
\hline $\mathrm{TC} 16010$ & HX 1 exit temp & ${ }^{\circ} \mathrm{F}$ & 215.14 & 8.888 \\
\hline TC16020 & HX 2 exit temp & ${ }^{\circ} \mathrm{F}$ & 0.00 & 0.000 \\
\hline TC16030 & HX 3 exit temp & ${ }^{\circ} \mathrm{F}$ & 243.97 & 20.274 \\
\hline $\mathrm{TC} 12101$ & Auger HX exit & ${ }^{\circ} \mathrm{F}$ & 80.03 & 1.703 \\
\hline $\mathrm{TC} 17001$ & Alk. Probe temp & ${ }^{\circ} \mathrm{F}$ & 148.07 & 43.388 \\
\hline TC17002 & Alk. Probe temp & ${ }^{\circ} \mathrm{F}$ & 303.61 & 169.241 \\
\hline TC17003 & Cyclone Pot temp & ${ }^{\circ} \mathrm{F}$ & 97.80 & 5.765 \\
\hline PT14020 & Reactor Static & atm & 11.20 & 0.076 \\
\hline PT14020 & Reactor Static & psia & 164.54 & 1.118 \\
\hline PT14021 & Reactor dP & in $\mathrm{H}_{2} \mathrm{O}$ & 10.82 & 0.444 \\
\hline PT10999 & Barometric & psia & 14.41 & 0.026 \\
\hline PT14022 & Cyclone $\mathrm{dP}$ & in $\mathrm{H}_{2} \mathrm{O}$ & 7.19 & 0.235 \\
\hline TC16040 & Reactor $\mathrm{HX}$ temp & ${ }^{\circ} \mathrm{F}$ & 294.25 & 15.020 \\
\hline R STATIC & Reactor Static & psig & 150.13 & 1.118 \\
\hline $\mathrm{HG} \mathbb{I N}$ & HG IN & ${ }^{\circ} \mathrm{F}$ & 1553.98 & 25.324 \\
\hline HG TOP & HG TOP & ${ }^{\circ} \mathrm{F}$ & 1404.46 & 27.174 \\
\hline HG UpMid & HG UpMid & ${ }^{\circ} \mathrm{F}$ & 1500.75 & 29.926 \\
\hline HG LoMid & HG LoMid & ${ }^{\circ} \mathrm{F}$ & 1525.42 & 27.266 \\
\hline HG Out & HG Out & ${ }^{\circ} \mathrm{F}$ & 936.64 & 39.536 \\
\hline Htr Top & Htr Top & ${ }^{\circ} \mathrm{F}$ & 1004.26 & 7.971 \\
\hline $\mathrm{Htr} \mathrm{Btm} 1$ & $\mathrm{Htr} \mathrm{Btml}$ & ${ }^{\circ} \mathrm{F}$ & 795.78 & 15.027 \\
\hline $\mathrm{Htr} \mathrm{Btm} 2$ & Htr Btm2 & ${ }^{\circ} \mathrm{F}$ & 950.31 & 16.841 \\
\hline Fltrl Up & Fltrl Up & ${ }^{\circ} \mathrm{F}$ & 1147.08 & 59.297 \\
\hline Fitr1 Lo & Fltr I Lo & ${ }^{\circ} \mathrm{F}$ & 1313.16 & 31.857 \\
\hline Fltr2 Up & Fltr2 Up & ${ }^{\circ} \mathrm{F}$ & 0.00 & 0.000 \\
\hline Fltr2 Lo & Fltr 2 Lo & ${ }^{\circ} \mathrm{F}$ & 0.00 & 0.000 \\
\hline Fltr3 Up & Fltr3 Up & ${ }^{\circ} \mathrm{F}$ & 0.00 & 0.000 \\
\hline Fltr3 Lo & Fltr3 Lo & ${ }^{\circ} \mathrm{F}$ & 0.00 & 0.000 \\
\hline HG Presr & HG Presr & psig & 154.39 & 3.427 \\
\hline $\mathrm{HG} d \mathrm{P}$ & HG dP & $\mathrm{kPa}$ & 1.65 & 0.211 \\
\hline$H G d P$ & HG dP & in $\mathrm{H}_{2} \mathrm{O}$ & 6.61 & 0.846 \\
\hline Ash Pot & Ash Pot & ${ }^{\circ} \mathrm{F}$ & $88: 23$ & 4.648 \\
\hline
\end{tabular}


Table 44

Run Summary from Test BEL-1596

\begin{tabular}{|c|c|c|c|c|}
\hline \multicolumn{4}{|c|}{ PFBHG-BEL-1596 } & \multirow{2}{*}{$\begin{array}{l}\text { Oct. } 25,1996 \\
\text { Std. Dev. }\end{array}$} \\
\hline Tag & Description & Units & Average & \\
\hline AIRFLOW & Air Flow Rate & scfm & 13.00 & 0.143 \\
\hline N FLOW A & Orifice N Flow & scfm & 10.00 & 0.097 \\
\hline FLOW IN & Total Flow In & scfm & 23.00 & 0.231 \\
\hline VELOCITY & Reactor SGV & $\mathrm{ft} / \mathrm{sec}$ & 2.93 & 0.056 \\
\hline FG SGV & FG SGV & $\mathrm{ft} / \mathrm{sec}$ & 3.04 & 0.057 \\
\hline $\mathrm{EA}$ & Excess Air & $\%$ & 23.88 & 1.854 \\
\hline $\mathrm{HC} 13111$ & Z 1 Heater Temp & ${ }^{\circ} \mathrm{F}$ & 1546.06 & 30.534 \\
\hline HT2PID & Z 1 Heater output & $\%$ & 14.81 & 26.306 \\
\hline HC13211 & Z 2 Heater Temp & ${ }^{\circ} \mathrm{F}$ & 1615.54 & 14.931 \\
\hline HT3PID & Z 2 Heater output & $\%$ & 0.72 & 7.023 \\
\hline $\mathrm{HC} 13311$ & Z 3 Heater Temp & ${ }^{\circ} \mathrm{F}$ & 1588.52 & 20.258 \\
\hline HT4PID & Z 3 Heater output & $\%$ & 0.00 & 0.000 \\
\hline TC11010 & Inlet Gas temp & ${ }^{\circ} \mathrm{F}$ & 605.05 & 4.731 \\
\hline TC14001 & Reactor Inlet temp & ${ }^{\circ} \mathrm{F}$ & 777.46 & 22.258 \\
\hline TC14002 & $R T @ 0.25^{\prime \prime}$ & ${ }^{\circ} \mathrm{F}$ & 1394.36 & 34.083 \\
\hline TC14003 & RT@1.75" & ${ }^{\circ} \mathrm{F}$ & 1520.91 & 38.198 \\
\hline TC14004 & RT@3.50" & ${ }^{\circ} \mathrm{F}$ & 1537.44 & 30.673 \\
\hline TC14005 & RT@5.00" & ${ }^{\circ} \mathrm{F}$ & 1546.49 & 26.186 \\
\hline TC14006 & RT@7.00" & ${ }^{\circ} \mathrm{F}$ & 1561.22 & 23.816 \\
\hline TC14007 & RT@9.00" & ${ }^{\circ} \mathrm{F}$ & 1569.59 & 23.769 \\
\hline TCl 4008 & RT@11.00" & ${ }^{\circ} \mathrm{F}$ & 1588.09 & 23.545 \\
\hline TC14009 & RT@15.00" & ${ }^{\circ} \mathrm{F}$ & 1627.51 & 24.109 \\
\hline $\mathrm{TC} 14010$ & RT@23.00" & ${ }^{\circ} \mathrm{F}$ & 1676.31 & 18.373 \\
\hline $\mathrm{TC} 14011$ & RT@31.00" & ${ }^{\circ} \mathrm{F}$ & 1737.23 & 21.579 \\
\hline $\mathrm{TCl} 4012$ & RT@43.25" & ${ }^{\circ} \mathrm{F}$ & 1609.42 & 35.069 \\
\hline TC14028 & Cyclone Exit & ${ }^{\circ} \mathrm{F}$ & 1569.16 & 14.575 \\
\hline $\mathrm{TC} 15001$ & HX FG Out & ${ }^{\circ} \mathrm{F}$ & 724.85 & 16.844 \\
\hline TC 18010 & Stack Temp & ${ }^{\circ} \mathrm{F}$ & 511.51 & 14.857 \\
\hline ZONE 1 & Zone I Avg & ${ }^{\circ} \mathrm{F}$ & 1547.13 & 26.219 \\
\hline ZONE 2 & Zone 2 Avg & ${ }^{\circ} \mathrm{F}$ & 1630.64 & 20.966 \\
\hline ZONE 3 & Zone 3 Avg & ${ }^{\circ} \mathrm{F}$ & 1673.33 & 26.196 \\
\hline $\mathrm{T}(\mathrm{AVG})$ & Avg Reactor temp & ${ }^{\circ} \mathrm{F}$ & 1597.42 & 18.798 \\
\hline $\mathrm{SO} 2-\mathrm{A}$ & $\mathrm{FG} \mathrm{SO}_{2}-\mathrm{A}$ & ppm & 397.71 & 246.218 \\
\hline $\mathrm{SO} 2-\mathrm{B}$ & $\mathrm{FG} \mathrm{SO}_{2}-\mathrm{B}$ & ppm & 470.48 & 117.513 \\
\hline $\mathrm{O} 2-\mathrm{A}$ & $\mathrm{FG} \mathrm{O}_{2}-\mathrm{A}$ & $\%$ & 4.60 & 0.280 \\
\hline $\mathrm{O} 2-\mathrm{B}$ & $\mathrm{FG} \mathrm{O}_{2}-\mathrm{B}$ & $\%$ & 4.81 & 0.309 \\
\hline $\mathrm{CO} 2$ & $\mathrm{FG} \mathrm{CO}$ & $\%$ & 4.85 & 0.266 \\
\hline $\mathrm{CO}$ & FG CO & ppm & 0.02 & 0.173 \\
\hline
\end{tabular}

Continued... 
183

Table 44 (continued)

\begin{tabular}{|c|c|c|c|c|}
\hline \multicolumn{2}{|l|}{ PFBHG-BEL-1596 } & & & \multirow{2}{*}{$\begin{array}{l}\text { Oct. } 25,1996 \\
\text { Std. Dev. }\end{array}$} \\
\hline Tag & Description & Units & Average & \\
\hline NOX & $\mathrm{FG} \mathrm{NO}_{\mathrm{x}}$ & $\mathrm{ppm}$ & 172.48 & 72.095 \\
\hline $\mathrm{N} 2 \mathrm{O}$ & $\mathrm{FG} \mathrm{N} \mathrm{N}_{2} \mathrm{O}$ & ppm & 3.68 & 7.638 \\
\hline $\mathrm{HC}$ & FG HC & ppm & 1.02 & 0.062 \\
\hline Calculated & S Ret & $\%$ & 57.56 & 25.440 \\
\hline S RET & Sulfur Retention & $\%$ & 48.49 & 12.603 \\
\hline $\mathrm{E}-\mathrm{SO} 2-\mathrm{A}$ & $\mathrm{FG} \mathrm{SO}-\mathrm{A}$ & $\mathrm{lb} / \mathrm{MMBtu}$ & 2.53 & 1.519 \\
\hline E-NOx & $\mathrm{FG} \mathrm{NO}_{\mathrm{x}}$ & $\mathrm{lb} / \mathrm{MMBtu}$ & 0.81 & 0.366 \\
\hline E-N2O & $\mathrm{FG} \mathrm{N} \mathrm{N}_{2} \mathrm{O}$ & $\mathrm{lb} / \mathrm{MMBtu}$ & 0.02 & 0.035 \\
\hline $\mathrm{E}-\mathrm{CO}$ & FG CO & $\mathrm{lb} / \mathrm{MMBtu}$ & 0.00 & 0.001 \\
\hline Feedrate & Theor. Coal feed & $\mathrm{lb} / \mathrm{hr}$ & 3.80 & 0.202 \\
\hline $\mathrm{TCl} 16010$ & HX 1 exit temp & ${ }^{\circ} \mathrm{F}$ & 221.47 & 11.227 \\
\hline TC16020 & $H X 2$ exit temp & ${ }^{\circ} \mathrm{F}$ & 0.00 & 0.000 \\
\hline TC16030 & HX 3 exit temp & ${ }^{\circ} \mathrm{F}$ & 263.47 & 9.142 \\
\hline $\mathrm{TC} 12101$ & Auger HX exit & ${ }^{\circ} \mathrm{F}$ & 79.40 & 1.863 \\
\hline TC17001 & Alk. Probe temp & ${ }^{\circ} \mathrm{F}$ & 42.80 & 73.808 \\
\hline TC17002 & Alk. Probe temp & ${ }^{\circ} \mathrm{F}$ & 176.98 & 18.958 \\
\hline TC17003 & Cyclone Pot temp & ${ }^{\circ} \mathrm{F}$ & 96.87 & 1.694 \\
\hline PT 14020 & Reactor Static & atm & 11.19 & 0.110 \\
\hline PT14020 & Reactor Static & psia & 164.38 & 1.610 \\
\hline PT14021 & Reactor dP & in $\mathrm{H}_{2} \mathrm{O}$ & 1.53 & 2.617 \\
\hline PT10999 & Barometric & psia & 14.40 & 0.016 \\
\hline PT14022 & Cyclone $\mathrm{dP}$ & in $\mathrm{H}_{2} \mathrm{O}$ & 6.09 & 1.228 \\
\hline TC16040 & Reactor HX temp & ${ }^{\circ} \mathrm{F}$ & 310.61 & 7.385 \\
\hline R STATIC & Reactor Static & psig & 149.98 & 1.610 \\
\hline HG IN & HG IN & ${ }^{\circ} \mathrm{F}$ & 1569.09 & 14.629 \\
\hline HG TOP & HG TOP & ${ }^{\circ} \mathrm{F}$ & 1405.99 & 17.110 \\
\hline HG UpMid & HG UpMid & ${ }^{\circ} \mathrm{F}$ & 1509.31 & 12.156 \\
\hline HG LoMid & HG LoMid & ${ }^{\circ} \mathrm{F}$ & 1528.97 & 12.709 \\
\hline HG Out & HG Out & ${ }^{\circ} \mathrm{F}$ & 969.79 & 24.117 \\
\hline Htr Top & Htr Top & ${ }^{\circ} \mathrm{F}$ & 1022.37 & 8.590 \\
\hline $\mathrm{Htr} \mathrm{Btml}$ & Htr Btml & ${ }^{\circ} \mathrm{F}$ & 781.34 & 20.845 \\
\hline $\mathrm{Htr} \mathrm{Btm} 2$ & Htr Btm2 & ${ }^{\circ} \mathrm{F}$ & 938.40 & 12.589 \\
\hline Fltrl Up & Fltrl Up & ${ }^{\circ} \mathrm{F}$ & 1171.38 & 34.656 \\
\hline Fltrl Lo & Fltrl Lo & ${ }^{\circ} \mathrm{F}$ & 1322.79 & 15.414 \\
\hline Fltr2 Up & Fltr2 Up & ${ }^{\circ} \mathrm{F}$ & 0.00 & 0.000 \\
\hline Fltr2 Lo & Fltr2 Lo & ${ }^{\circ} \mathrm{F}$ & 0.00 & 0.000 \\
\hline Fltr3 Up & Fltr3 Up & ${ }^{\circ} \mathrm{F}$ & 0.00 & 0.000 \\
\hline Fltr3 Lo & Fltr3 Lo & ${ }^{\circ} \mathrm{F}$ & 0.00 & 0.000 \\
\hline HG Presr & HG Presr & psig & 152.88 & 2.354 \\
\hline HG dP & HG dP & $\mathrm{kPa}$ & 2.16 & 0.469 \\
\hline HG dP & $\mathrm{HG} d P$ & in $\mathrm{H}_{2} \mathrm{O}$ & 8.66 & 1.883 \\
\hline Ash Pot & Ash Pot & ${ }^{\circ} \mathrm{F}$ & 90.32 & 2.993 \\
\hline
\end{tabular}


Table 45

Run Summary from Test BEL-1696

\begin{tabular}{|c|c|c|c|c|}
\hline PFBHG-BEL-1696 & & & & Oct. 28,1996 \\
\hline Tag & Description & Units & Average & Std. Dev. \\
\hline AIRFLOW & Air Flow Rate & scfm & 12.52 & 0.237 \\
\hline N FLOW A & Orifice N Flow & scfm & 9.95 & 0.225 \\
\hline FLOW IN & Total Flow In & scfm & 22.47 & 0.290 \\
\hline VELOCITY & Reactor SGV & $\mathrm{ft} / \mathrm{sec}$ & 2.90 & 0.090 \\
\hline FG SGV & FG SGV & $\mathrm{ft} / \mathrm{sec}$ & 3.03 & 0.093 \\
\hline EA & Excess Air & $\%$ & 25.23 & 2.768 \\
\hline $\mathrm{HC} 13111$ & Z 1 Heater Temp & ${ }^{\circ} \mathrm{F}$ & 1559.17 & 8.227 \\
\hline HT2PID & Z 1 Heater output & $\%$ & 3.25 & 12.938 \\
\hline HC13211 & Z 2 Heater Temp & ${ }^{\circ} \mathrm{F}$ & 1584.17 & 15.381 \\
\hline HT3PID & Z 2 Heater output & $\%$ & 0.13 & 1.881 \\
\hline $\mathrm{HC} 13311$ & Z 3 Heater Temp & ${ }^{\circ} \mathrm{F}$ & 1550.12 & 14.748 \\
\hline HT4PID & Z 3 Heater output & $\%$ & 0.00 & 0.000 \\
\hline TCl1010 & Inlet Gas temp & ${ }^{\circ} \mathrm{F}$ & 615.75 & 6.241 \\
\hline TC14001 & Reactor Inlet temp & ${ }^{\circ} \mathrm{F}$ & 794.60 & 8.665 \\
\hline TC14002 & RT@ 0.25" & ${ }^{\circ} \mathrm{F}$ & 1407.74 & 8.108 \\
\hline TC14003 & RT@ 1.75" & ${ }^{\circ} \mathrm{F}$ & 1548.51 & 28.030 \\
\hline TC14004 & RT@ 3.50" & ${ }^{\circ} \mathrm{F}$ & 1561.12 & 27.202 \\
\hline TC14005 & RT@ $5.00^{\prime \prime}$ & ${ }^{\circ} \mathrm{F}$ & 1564.11 & 26.529 \\
\hline TC14006 & RT@ $9.00^{\prime \prime}$ & ${ }^{\circ} \mathrm{F}$ & 1568.22 & 25.139 \\
\hline TC14007 & RT@ 9.00" & ${ }^{\circ} \mathrm{F}$ & 1570.38 & 24.424 \\
\hline TC14008 & RT@11.00" & ${ }^{\circ} \mathrm{F}$ & 1580.27 & 24.163 \\
\hline TC14009 & RT@15.00" & ${ }^{\circ} \mathrm{F}$ & 1602.05 & 24.567 \\
\hline TC14010 & RT@23.00" & ${ }^{\circ} \mathrm{F}$ & 1643.27 & 20.126 \\
\hline TC14011 & RT@31.00" & ${ }^{\circ} \mathrm{F}$ & 1701.66 & 22.443 \\
\hline TC14012 & RT@43.25" & ${ }^{\circ} \mathrm{F}$ & 1562.28 & 31.001 \\
\hline TC14028 & Cyclone Exit & ${ }^{\circ} \mathrm{F}$ & 1537.71 & 20.103 \\
\hline TC15001 & HX FG Out & ${ }^{\circ} \mathrm{F}$ & 674.76 & 44.482 \\
\hline TC18010 & Stack Temp & ${ }^{\circ} \mathrm{F}$ & 473.85 & 31.506 \\
\hline ZONE 1 & Zone 1 Avg & ${ }^{\circ} \mathrm{F}$ & 1562.47 & 25.606 \\
\hline ZONE 2 & Zone 2 Avg & ${ }^{\circ} \mathrm{F}$ & 1608.53 & 22.022 \\
\hline ZONE 3 & Zone 3 Avg & ${ }^{\circ} \mathrm{F}$ & 1631.97 & 24.706 \\
\hline $\mathrm{T}(\mathrm{AVG})$ & Avg Reactor temp & ${ }^{\circ} \mathrm{F}$ & 1590.19 & 22.050 \\
\hline $\mathrm{SO} 2-\mathrm{A}$ & $\mathrm{FG} \mathrm{SO}_{2}-\mathrm{A}$ & $\mathrm{ppm}$ & 382.20 & 152.139 \\
\hline SO2-B & $\mathrm{FG} \mathrm{SO}_{2}-\mathrm{B}$ & ppm & 348.16 & 197.361 \\
\hline O2-A & $\mathrm{FG} \mathrm{O}_{2}-\mathrm{A}$ & $\%$ & 4.80 & 0.435 \\
\hline $\mathrm{O} 2-\mathrm{B}$ & $\mathrm{FGO}_{2}-\mathrm{B}$ & $\%$ & 7.59 & 6.499 \\
\hline $\mathrm{CO} 2$ & $\mathrm{FG} \mathrm{CO} 2$ & $\%$ & 4.81 & 0.434 \\
\hline $\mathrm{CO}$ & FG CO & ppm & 8.14 & 24.947 \\
\hline
\end{tabular}

Continued... 
Table 45 (continued)

\begin{tabular}{|c|c|c|c|c|}
\hline \multicolumn{4}{|c|}{ PFBHG-BEL-1696 } & \multirow{2}{*}{$\begin{array}{l}\text { Oct. } 28,1996 \\
\text { Std. Dev. }\end{array}$} \\
\hline Tag & Description & Units & Average & \\
\hline NOX & $\mathrm{FG} \mathrm{NO}_{\mathrm{x}}$ & ppm & 60.75 & 9.626 \\
\hline $\mathrm{N} 2 \mathrm{O}$ & $\mathrm{FG} \mathrm{N} \mathrm{N}_{2} \mathrm{O}$ & ppm & 0.10 & 0.020 \\
\hline $\mathrm{HC}$ & FG HC & ppm & 13.99 & 17.028 \\
\hline Calculated & S Ret & $\%$ & 58.35 & 14.926 \\
\hline S RET & Sulfur Retention & $\%$ & 19.83 & 33.702 \\
\hline $\mathrm{E}-\mathrm{SO} 2-\mathrm{A}$ & $\mathrm{FG} \mathrm{SO}_{2}-\mathrm{A}$ & $\mathrm{lb} / \mathrm{MMBtu}$ & 2.49 & 0.891 \\
\hline E-NOx & $\mathrm{FG} \mathrm{NO}{ }_{x}$ & lb/MMBtu & 0.29 & 0.049 \\
\hline $\mathrm{E}-\mathrm{N} 2 \mathrm{O}$ & $\mathrm{FG} \mathrm{N} \mathrm{N}_{2} \mathrm{O}$ & $\mathrm{lb} / \mathrm{MMBtu}$ & 0.00 & 0.000 \\
\hline $\mathrm{E}-\mathrm{CO}$ & FG CO & $\mathrm{lb} / \mathrm{MMBtu}$ & 0.02 & 0.071 \\
\hline Feedrate & Theor. Coal feed & $\mathrm{lb} / \mathrm{hr}$ & 3.72 & 0.340 \\
\hline TC16010 & HX 1 exit temp & ${ }^{\circ} \mathrm{F}$ & 213.51 & 20.158 \\
\hline TC16020 & HX 2 exit temp & ${ }^{\circ} \mathrm{F}$ & 0.00 & 0.000 \\
\hline $\mathrm{TC} 16030$ & HX 3 exit temp & ${ }^{\circ} \mathrm{F}$ & 241.14 & 18.407 \\
\hline TC12101 & Auger $\mathrm{HX}$ exit & ${ }^{\circ} \mathrm{F}$ & 77.94 & 1.153 \\
\hline TC17001 & Alk. Probe temp & ${ }^{\circ} \mathrm{F}$ & 64.08 & 123.450 \\
\hline TC17002 & Alk. Probe temp & ${ }^{\circ} \mathrm{F}$ & 246.43 & 64.815 \\
\hline TC17003 & Cyclone Pot temp & ${ }^{\circ} \mathrm{F}$ & 111.56 & 4.909 \\
\hline PT14020 & Reactor Static & atm & 11.13 & 0.242 \\
\hline PT14020 & Reactor Static & psia & 163.64 & 3.557 \\
\hline PT14021 & Reactor dP & in $\mathrm{H}_{2} \mathrm{O}$ & 10.60 & 0.531 \\
\hline PT10999 & Barometric & psia & 14.54 & 0.030 \\
\hline PT14022 & Cyclone dP & in $\mathrm{H}_{2} \mathrm{O}$ & 6.87 & 1.014 \\
\hline TC16040 & Reactor HX temp & ${ }^{\circ} \mathrm{F}$ & 284.90 & 25.196 \\
\hline R STATIC & Reactor Static & psig & 149.10 & 3.562 \\
\hline HG IN & HG IN & ${ }^{\circ} \mathrm{F}$ & 1537.76 & 20.076 \\
\hline HG TOP & HG TOP & ${ }^{\circ} \mathrm{F}$ & 1359.48 & 50.022 \\
\hline HG UpMid & HG UpMid & ${ }^{\circ} \mathrm{F}$ & 1470.67 & 38.394 \\
\hline HG LoMid & HG LoMid & ${ }^{\circ} \mathrm{F}$ & 1491.65 & 34.678 \\
\hline HG Out & HG Out & ${ }^{\circ} \mathrm{F}$ & 909.64 & 63.184 \\
\hline Htr Top & Htr Top & ${ }^{\circ} \mathrm{F}$ & 988.73 & 43.039 \\
\hline $\mathrm{Htr}$ Btml & Htr Btm 1 & ${ }^{\circ} \mathrm{F}$ & 780.57 & 26.597 \\
\hline $\mathrm{Htr} \mathrm{Btm} 2$ & Htr Btm2 & ${ }^{\circ} \mathrm{F}$ & 942.24 & 22.264 \\
\hline Fltrl Up & Fltrl Up & ${ }^{\circ} \mathrm{F}$ & 1103.51 & 90.671 \\
\hline Fltrl Lo & Fltrl Lo & ${ }^{\circ} \mathrm{F}$ & 1287.02 & 42.501 \\
\hline Fltr2 Up & Fltr2 Up & ${ }^{\circ} \mathrm{F}$ & 0.00 & 0.000 \\
\hline Fltr2 Lo & Fltr2 Lo & ${ }^{\circ} \mathrm{F}$ & 0.00 & 0.000 \\
\hline Fltr3 Up & Fltr3 Up & ${ }^{\circ} \mathrm{F}$ & 0.00 & 0.000 \\
\hline Fltr3 Lo & Fltr3 Lo & ${ }^{\circ} \mathrm{F}$ & 0.00 & 0.000 \\
\hline HG Presr & HG Presr & psig & 151.96 & 7.001 \\
\hline $\mathrm{HG} \mathrm{dP}$ & HG dP & $\mathrm{kPa}$ & 1.50 & 0.244 \\
\hline HG dP & HG dP & in $\mathrm{H}_{2} \mathrm{O}$ & 6.01 & 0.978 \\
\hline Ash Pot & Ash Pot & ${ }^{\circ} \mathrm{F}$ & 94.53 & 11.204 \\
\hline
\end{tabular}


Table 46

Run Summary from Test BEL-1796

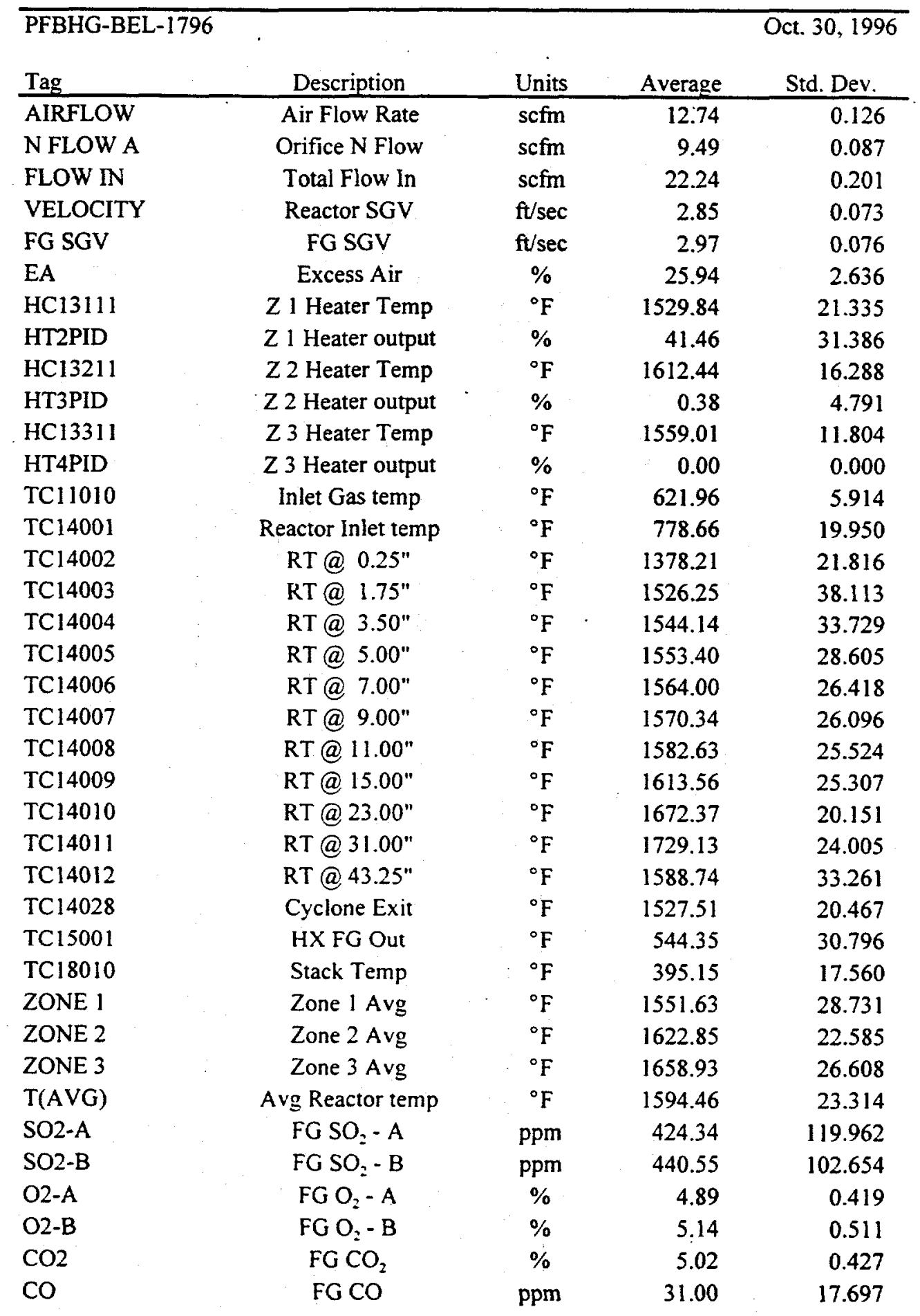

Continued ... 
Table 46 (continued)

\begin{tabular}{|c|c|c|c|c|}
\hline PFBHG-BEL-1796 & & & & Oct. 30,1996 \\
\hline Tag & Description & Units & Average & Std. Dev. \\
\hline NOX & FG NO & $\mathrm{ppm}$ & 40.71 & 5.802 \\
\hline $\mathrm{N} 2 \mathrm{O}$ & $\mathrm{FG} \mathrm{N} \mathrm{N}_{2} \mathrm{O}$ & ppm & 16.99 & 2.660 \\
\hline $\mathrm{HC}$ & FG HC & ppm & 1.31 & 0.577 \\
\hline Calculated & S Ret & $\%$ & 55.87 & 9.432 \\
\hline S RET & Sulfur Retention & $\%$ & 0.00 & 0.000 \\
\hline E-SO2-A & $\mathrm{FG} \mathrm{SO}_{2}-\mathrm{A}$ & $\mathrm{lb} / \mathrm{MMBtu}$ & 2.63 & 0.562 \\
\hline E-NOx & $\mathrm{FG} \mathrm{NO}_{\mathrm{x}}$ & $\mathrm{lb} / \mathrm{MMBtu}$ & 0.19 & 0.034 \\
\hline $\mathrm{E}-\mathrm{N} 2 \mathrm{O}$ & $\mathrm{FG} \mathrm{N}_{2} \mathrm{O}$ & $\mathrm{lb} / \mathrm{MMBtu}$ & 0.07 & 0.014 \\
\hline $\mathrm{E}-\mathrm{CO}$ & FG CO & $\mathrm{lb} / \mathrm{MMBtu}$ & 0.08 & 0.033 \\
\hline Feedrate & Theor. Coal feed & $\mathrm{lb} / \mathrm{hr}$ & 3.84 & 0.336 \\
\hline TC16010 & $\mathrm{HX} 1$ exit temp & ${ }^{\circ} \mathrm{F}$ & 106.86 & 4.437 \\
\hline TC16020 & HX 2 exit temp & ${ }^{\circ} \mathrm{F}$ & 0.00 & 0.000 \\
\hline TC16030 & HX 3 exit temp & ${ }^{\circ} \mathrm{F}$ & 229.10 & 13.057 \\
\hline $\mathrm{TC} 12101$ & Auger $\mathrm{HX}$ exit & ${ }^{\circ} \mathrm{F}$ & 74.61 & 1.625 \\
\hline $\mathrm{TC} 17001$ & Alk. Probe temp & ${ }^{\circ} \mathrm{F}$ & 35.40 & 67.848 \\
\hline TC17002 & Alk. Probe temp & ${ }^{\circ} \mathrm{F}$ & 236.14 & 42.482 \\
\hline TC17003 & Cyclone Pot temp & ${ }^{\circ} \mathrm{F}$ & 108.07 & 3.765 \\
\hline PT14020 & Reactor Static & atm & 11.17 & 0.181 \\
\hline PT14020 & Reactor Static & psia & 164.13 & 2.667 \\
\hline PT14021 & Reactor $\mathrm{dP}$ & in $\mathrm{H}_{2} \mathrm{O}$ & 11.04 & 0.467 \\
\hline PT10999 & Barometric & psia & 14.47 & 0.020 \\
\hline PT14022 & Cyclone dP & in $\mathrm{H}_{2} \mathrm{O}$ & 7.93 & 0.560 \\
\hline TC16040 & Reactor $\mathrm{HX}$ temp & ${ }^{\circ} \mathrm{F}$ & 231.54 & 15.683 \\
\hline R STATIC & Reactor Static & psig & 149.66 & 2.669 \\
\hline HG IN & HG IN & ${ }^{\circ} \mathrm{F}$ & 1527.55 & 20.350 \\
\hline HG TOP & HG TOP & ${ }^{\circ} \mathrm{F}$ & 1360.53 & 39.420 \\
\hline HG UpMid & HG UpMid & ${ }^{\circ} \mathrm{F}$ & 1482.41 & 34.952 \\
\hline HG LoMid & HG LoMid & ${ }^{\circ} \mathrm{F}$ & 1509.22 & 31.217 \\
\hline HG Out & HG Out & ${ }^{\circ} \mathrm{F}$ & 931.26 & 55.647 \\
\hline Htr Top & Htr Top & ${ }^{\circ} \mathrm{F}$ & 1001.98 & 28.480 \\
\hline $\mathrm{Htr} \mathrm{Btml}$ & $\mathrm{Htr} \mathrm{Btml}$ & ${ }^{\circ} \mathrm{F}$ & 731.64 & 46.340 \\
\hline $\mathrm{Htr} \mathrm{Btm} 2$ & $\mathrm{Htr}$ Btm2 & ${ }^{\circ} \mathrm{F}$ & 951.63 & 17.346 \\
\hline Fltrl Up & Fltrl Up & ${ }^{\circ} \mathrm{F}$ & 1127.88 & 83.522 \\
\hline Fltrl Lo & Fltrl Lo & ${ }^{\circ} \mathrm{F}$ & 1308.03 & 41.165 \\
\hline Fltr2 Up & Fitr2 Up & ${ }^{\circ} \mathrm{F}$ & 0.00 & 0.000 \\
\hline Fltr2 Lo & Fltr2 Lo & ${ }^{\circ} \mathrm{F}$ & 0.00 & 0.000 \\
\hline Fltr3 Up & Fltr3 Up & ${ }^{\circ} \mathrm{F}$ & 0.00 & 0.000 \\
\hline Fltr3 Lo & Fltr3 Lo & ${ }^{\circ} \mathrm{F}$ & 0.00 & 0.000 \\
\hline HG Presr & HG Presr & psig & 155.92 & 5.260 \\
\hline HG dP & $H G d P$ & $\mathrm{kPa}$ & 1.09 & 0.252 \\
\hline HG dP & HG dP & in $\mathrm{H}_{2} \mathrm{O}$ & 4.39 & 1.011 \\
\hline Ash Pot & Ash Pot & ${ }^{\circ} \mathrm{F}$ & 95.54 & 8.006 \\
\hline
\end{tabular}


Table 47

Run Summary from Test BEL-1896

\begin{tabular}{|c|c|c|c|c|}
\hline \multicolumn{4}{|c|}{ PFBHG-BEL-1896 } & \multirow{2}{*}{$\begin{array}{l}\text { Nov. } 1,1996 \\
\text { Std. Dev. }\end{array}$} \\
\hline Tag & Description & Units & Average & \\
\hline AIRFLOW & Air Flow Rate & scfm & 12.24 & 0.227 \\
\hline N FLOW A & Orifice N Flow & scfm & 10.26 & 0.202 \\
\hline FLOW IN & Total Flow In & scfm & 22.51 & 0.252 \\
\hline VELOCITY & Reactor SGV & $\mathrm{ft} / \mathrm{sec}$ & 2.88 & 0.047 \\
\hline FG SGV & FG SGV & $\mathrm{ft} / \mathrm{sec}$ & 3.00 & 0.048 \\
\hline $\mathrm{EA}$ & Excess Air & $\%$ & 24.56 & 2.567 \\
\hline $\mathrm{HC} 13111$ & Z 1 Heater Temp & ${ }^{\circ} \mathrm{F}$ & 1490.30 & 27.900 \\
\hline HT2PID & Z 1 Heater output & $\%$ & 34.33 & 30.580 \\
\hline $\mathrm{HC} 13211$ & Z 2 Heater Temp & ${ }^{\circ} \mathrm{F}$ & 1563.29 & 13.092 \\
\hline HT3PID & Z 2 Heater output & $\%$ & 0.75 & 6.943 \\
\hline $\mathrm{HC} 13311$ & Z 3 Heater Temp & ${ }^{\circ} \mathrm{F}$ & 1512.23 & 12.385 \\
\hline HT4PID & Z 3 Heater output & $\%$ & 1.71 & 8.888 \\
\hline TC11010 & Inlet Gas temp & ${ }^{\circ} \mathrm{F}$ & 613.17 & 4.733 \\
\hline $\mathrm{TCl} 4001$ & Reactor Inlet temp & ${ }^{\circ} \mathrm{F}$ & 743.19 & 20.463 \\
\hline TC14002 & RT@ 0.25" & ${ }^{\circ} \mathrm{F}$ & 1332.10 & 31.011 \\
\hline TC14003 & RT@1.75" & ${ }^{\circ} \mathrm{F}$ & 1539.44 & 20.175 \\
\hline TC14004 & RT@3.50" & ${ }^{\circ} \mathrm{F}$ & 1553.22 & 19.725 \\
\hline TC14005 & RT@ $9.00^{\prime \prime}$ & ${ }^{\circ} \mathrm{F}$ & 1556.10 & 19.118 \\
\hline TC14006 & RT@7.00" & ${ }^{\circ} \mathrm{F}$ & 1560.79 & 17.312 \\
\hline TC14007 & RT@9.00" & ${ }^{\circ} \mathrm{F}$ & 1566.44 & 16.879 \\
\hline TC14008 & RT@11.00" & ${ }^{\circ} \mathrm{F}$ & 1573.72 & 17.096 \\
\hline TC14009 & RT@15.00" & ${ }^{\circ} \mathrm{F}$ & 1591.55 & 18.840 \\
\hline TC14010 & RT@23.00" & ${ }^{\circ} \mathrm{F}$ & 1620.03 & 17.765 \\
\hline TC14011 & RT@31.00" & ${ }^{\circ} \mathrm{F}$ & 1658.23 & 21.859 \\
\hline $\mathrm{TCl} 14012$ & RT@43.25" & ${ }^{\circ} \mathrm{F}$ & 1534.73 & 28.241 \\
\hline TC14028 & Cyclone Exit & ${ }^{\circ} \mathrm{F}$ & 1484.60 & 27.186 \\
\hline TC15001 & HX FG Out & ${ }^{\circ} \mathrm{F}$ & 577.62 & 17.587 \\
\hline TC18010 & Stack Temp & ${ }^{\circ} \mathrm{F}$ & 416.12 & 13.591 \\
\hline ZONE 1 & Zone 1 Avg & ${ }^{\circ} \mathrm{F}$ & 1555.20 & 17.490 \\
\hline ZONE 2 & Zone 2 Avg & ${ }^{\circ} \mathrm{F}$ & 1595.10 & 17.215 \\
\hline ZONE 3 & Zone 3 Avg & ${ }^{\circ} \mathrm{F}$ & 1596.48 & 23.772 \\
\hline$T(A \vee G)$ & Avg Reactor temp & ${ }^{\circ} \mathrm{F}$ & 1575.43 & 15.144 \\
\hline $\mathrm{SO} 2-\mathrm{A}$ & $\mathrm{FG} \mathrm{SO}-\mathrm{A}$ & ppm & 299.16 & 164.734 \\
\hline $\mathrm{SO} 2-\mathrm{B}$ & $\mathrm{FG} \mathrm{SO}_{2}-\mathrm{B}$ & ppm & 381.33 & 138.649 \\
\hline $\mathrm{O} 2-\mathrm{A}$ & $\mathrm{FG} \mathrm{O}_{2}-\mathrm{A}$ & $\%$ & 4.70 & 0.384 \\
\hline $\mathrm{O} 2-\mathrm{B}$ & $\mathrm{FG} \mathrm{O}_{2}-\mathrm{B}$ & $\%$ & 4.80 & 0.386 \\
\hline $\mathrm{CO} 2$ & $\mathrm{FG} \mathrm{CO}$ & $\%$ & 4.77 & 0.331 \\
\hline $\mathrm{CO}$ & FG CO & ppm & 17.90 & 7.884 \\
\hline
\end{tabular}

Continued... 
Table 47 (continued)

\begin{tabular}{|c|c|c|c|c|}
\hline PFBHG-BEL-1896 & & & & Nov. 1,1996 \\
\hline Tag & Description & Units & Average & Std. Dev. \\
\hline NOX & $\overline{F G N O}$ & $\mathrm{ppm}$ & 53.50 & 6.191 \\
\hline $\mathrm{N} 2 \mathrm{O}$ & $\mathrm{FGN}_{2} \mathrm{O}$ & ppm & 16.54 & 1.107 \\
\hline $\mathrm{HC}$ & FG HC & ppm & 0.89 & 0.050 \\
\hline Calculated & S Ret & $\%$ & 67.69 & 16.520 \\
\hline S RET & Sulfur Retention & $\%$ & 49.98 & 22.067 \\
\hline $\mathrm{E}-\mathrm{SO} 2-\mathrm{A}$ & $\mathrm{FG} \mathrm{SO}_{2}-\mathrm{A}$ & $\mathrm{lb} / \mathrm{MMBtu}$ & 1.93 & 0.986 \\
\hline E-NOx & $F G \mathrm{NO}_{x}$ & $\mathrm{lb} / \mathrm{MMBtu}$ & 0.26 & 0.036 \\
\hline $\mathrm{E}-\mathrm{N} 2 \mathrm{O}$ & $\mathrm{FG} \mathrm{N} \mathrm{N}_{2} \mathrm{O}$ & $\mathrm{lb} / \mathrm{MMBtu}$ & 0.08 & 0.008 \\
\hline $\mathrm{E}-\mathrm{CO}$ & FG CO & $\mathrm{lb} / \mathrm{MMBtu}$ & 0.05 & 0.022 \\
\hline Feedrate & Theor. Coal feed & $\mathrm{lb} / \mathrm{hr}$ & 3.69 & 0.259 \\
\hline TCl6010 & HX 1 exit temp & ${ }^{\circ} \mathrm{F}$ & 106.91 & 3.014 \\
\hline $\mathrm{TC} 16020$ & HX 2 exit temp & ${ }^{\circ} \mathrm{F}$ & 0.00 & 0.000 \\
\hline TCl6030 & HX 3 exit temp & ${ }^{\circ} \mathrm{F}$ & 233.41 & 6.998 \\
\hline $\mathrm{TC} 12101$ & Auger HX exit & ${ }^{\circ} \mathrm{F}$ & 76.62 & 0.690 \\
\hline $\mathrm{TCl} 7001$ & Alk. Probe temp & ${ }^{\circ} \mathrm{F}$ & 0.00 & 0.000 \\
\hline TC17002 & Alk. Probe temp & ${ }^{\circ} \mathrm{F}$ & 244.59 & 40.218 \\
\hline $\mathrm{TC} 17003$ & Cyclone Pot temp & ${ }^{\circ} \mathrm{F}$ & 108.18 & 3.670 \\
\hline PT14020 & Reactor Static & atm & 11.20 & 0.082 \\
\hline PT 14020 & Reactor Static & psia & 164.60 & 1.199 \\
\hline PT14021 & Reactor dP & in $\mathrm{H}_{2} \mathrm{O}$ & 10.91 & 4.034 \\
\hline PT10999 & Barometric & psia & 14.58 & 0.017 \\
\hline PT14022 & Cyclone $\mathrm{dP}$ & in $\mathrm{H}_{2} \mathrm{O}$ & 6.49 & 1.117 \\
\hline TCl6040 & Reactor HX temp & ${ }^{\circ} \mathrm{F}$ & 240.38 & 8.832 \\
\hline R STATIC & Reactor Static & psig & 150.03 & 1.200 \\
\hline HG IN & HG IN & ${ }^{\circ} \mathrm{F}$ & 1484.63 & 27.191 \\
\hline HG TOP & HG TOP & ${ }^{\circ} \mathrm{F}$ & 1360.69 & 17.684 \\
\hline HG UpMid & HG UpMid & ${ }^{\circ} \mathrm{F}$ & 1482.02 & 17.156 \\
\hline HG LoMid & HG LoMid & ${ }^{\circ} \mathrm{F}$ & 1498.71 & 14.630 \\
\hline HG Out & HG Out & ${ }^{\circ} \mathrm{F}$ & 948.14 & 32.228 \\
\hline Htr Top & Htr Top & ${ }^{\circ} \mathrm{F}$ & 1006.86 & 9.549 \\
\hline Htr Btml & $\mathrm{Htr} \mathrm{Btml}$ & ${ }^{\circ} \mathrm{F}$ & 763.74 & 22.412 \\
\hline $\mathrm{Htr} \mathrm{Btm} 2$ & $\mathrm{Htr} \mathrm{Btm} 2$ & ${ }^{\circ} \mathrm{F}$ & 938.45 & 12.716 \\
\hline FItrl Up & Fltrl Up & ${ }^{\circ} \mathrm{F}$ & 1154.27 & 47.650 \\
\hline Fltrl Lo & Fitr 1 Lo & ${ }^{\circ} \mathrm{F}$ & 1303.37 & 20.861 \\
\hline Fltr2 Up & Fltr2 Up & ${ }^{\circ} \mathrm{F}$ & 0.00 & 0.000 \\
\hline Fltr2 Lo & Fltr 2 Lo & ${ }^{\circ} \mathrm{F}$ & 0.00 & 0.000 \\
\hline Fltr3 Up & Fltr3 Up & ${ }^{\circ} \mathrm{F}$ & 0.00 & 0.000 \\
\hline FItr3 Lo & Fltr3 Lo & ${ }^{\circ} \mathrm{F}$ & 0.00 & 0.000 \\
\hline HG Presr & HG Presr & psig & 154.74 & 3.113 \\
\hline $\mathrm{HG} \mathrm{dP}$ & $\mathrm{HG} \mathrm{dP}$ & $\mathrm{kPa}$ & 1.38 & 0.157 \\
\hline$H G \mathrm{dP}$ & HG dP & in $\mathrm{H}_{2} \mathrm{O}$ & 5.55 & 0.632 \\
\hline Ash Pot & Ash Pot & ${ }^{\circ} \mathrm{F}$ & 96.06 & 8.385 \\
\hline
\end{tabular}


Table 48

Run Summary from Test B1-1996

\begin{tabular}{|c|c|c|c|c|}
\hline \multirow{2}{*}{$\begin{array}{l}\text { PFBHG-B1-1996 } \\
\text { Tag }\end{array}$} & \multirow[b]{2}{*}{ Description } & \multirow[b]{2}{*}{ Units } & & \multirow{2}{*}{$\begin{array}{c}\text { Nov. 5, } 1996 \\
\text { Std. Dev. }\end{array}$} \\
\hline & & & Average & \\
\hline AIRFLOW & Air Flow Rate & scfm & 12.53 & 0.212 \\
\hline N FLOW A & Orifice N Flow & scfm & 10.52 & 0.162 \\
\hline FLOW IN & Total Flow In & scfm & 23.05 & 0.359 \\
\hline VELOCITY & Reactor SGV & $\mathrm{ft} / \mathrm{sec}$ & 2.95 & 0.058 \\
\hline FG SGV & FG SGV & $\mathrm{ft} / \mathrm{sec}$ & 3.08 & 0.056 \\
\hline EA & Excess Air & $\%$ & 24.13 & 2.300 \\
\hline $\mathrm{HC} 13111$ & Z 1 Heater Temp & ${ }^{\circ} \mathrm{F}$ & 1523.77 & 30.202 \\
\hline HT2PID & Z 1 Heater output & $\%$ & 36.53 & 32.056 \\
\hline $\mathrm{HC} 13211$ & Z 2 Heater Temp & ${ }^{\circ} \mathrm{F}$ & 1582.36 & 17.123 \\
\hline HT3PID & Z 2 Heater output & $\%$ & 0.00 & 0.000 \\
\hline $\mathrm{HC} 13311$ & Z 3 Heater Temp & ${ }^{\circ} \mathrm{F}$ & 1501.50 & 9.945 \\
\hline HT4PID & Z 3 Heater output & $\%$ & 4.21 & 12.382 \\
\hline $\mathrm{TC} 11010$ & Inlet Gas temp & ${ }^{\circ} \mathrm{F}$ & 605.85 & 7.368 \\
\hline TC14001 & Reactor Inlet temp & ${ }^{\circ} \mathrm{F}$ & 739.17 & 24.038 \\
\hline TC14002 & RT@0.25" & ${ }^{\circ} \mathrm{F}$ & 1356.82 & 32.233 \\
\hline TC14003 & RT@1.75" & ${ }^{\circ} \mathrm{F}$ & 1525.76 & 27.148 \\
\hline TC14004 & RT@3.50" & ${ }^{\circ} \mathrm{F}$ & 1552.92 & 25.469 \\
\hline $\mathrm{TC} 14005$ & RT@ $9.00 "$ & ${ }^{\circ} \mathrm{F}$ & 1557.24 & 23.709 \\
\hline TC14006 & RT@7.00" & ${ }^{\circ} \mathrm{F}$ & 1566.65 & 22.133 \\
\hline TC14007 & RT@9.00" & ${ }^{\circ} \mathrm{F}$ & 1572.96 & 22.242 \\
\hline TC14008 & RT@11.00" & ${ }^{\circ} \mathrm{F}$ & 1587.58 & 20.597 \\
\hline TC14009 & RT@15.00" & ${ }^{\circ} \mathrm{F}$ & 1618.68 & 19.872 \\
\hline TC14010 & RT@23.00" & ${ }^{\circ} \mathrm{F}$ & 1643.57 & 20.152 \\
\hline TC14011 & RT@31.00" & ${ }^{\circ} \mathrm{F}$ & 1641.58 & 18.636 \\
\hline TC 14012 & RT@43.25" & ${ }^{\circ} \mathrm{F}$ & 1510.54 & 13.777 \\
\hline TC14028 & Cyclone Exit & ${ }^{\circ} \mathrm{F}$ & 1470.07 & 10.152 \\
\hline $\mathrm{TC} 15001$ & HX FG Out & ${ }^{\circ} \mathrm{F}$ & 549.85 & 11.658 \\
\hline $\mathrm{TC} 18010$ & Stack Temp & ${ }^{\circ} \mathrm{F}$ & 403.42 & 8.513 \\
\hline ZONE 1 & Zone I Avg & ${ }^{\circ} \mathrm{F}$ & 1555.11 & 22.402 \\
\hline ZONE 2 & Zone 2 Avg & ${ }^{\circ} \mathrm{F}$ & 1616.61 & 19.549 \\
\hline ZONE 3 & Zone 3 Avg & ${ }^{\circ} \mathrm{F}$ & 1576.06 & 14.495 \\
\hline$T(A \vee G)$ & Avg Reactor temp & ${ }^{\circ} \mathrm{F}$ & 1577.75 & 18.051 \\
\hline SO2-A & $\mathrm{FG} \mathrm{SO}_{2}-\mathrm{A}$ & ppm & 2.03 & 9.332 \\
\hline SO2-B & $\mathrm{FG} \mathrm{SO}=\mathrm{B}$ & ppm & 3.63 & 8.924 \\
\hline $\mathrm{O} 2-\mathrm{A}$ & $\mathrm{FG} \mathrm{O}_{2}-\mathrm{A}$ & $\%$ & 4.62 & 0.350 \\
\hline $\mathrm{O} 2-\mathrm{B}$ & $\mathrm{FG} \mathrm{O}_{2}^{-}-\mathrm{B}$ & $\%$ & 4.97 & 0.453 \\
\hline $\mathrm{CO} 2$ & $\mathrm{FG} \mathrm{CO}_{2}$ & $\%$ & 5.25 & 0.442 \\
\hline $\mathrm{CO}$ & FG CO & ppm & 11.02 & 4.207 \\
\hline
\end{tabular}

Continued... 
191

Table 48 (continued)

\begin{tabular}{|c|c|c|c|c|}
\hline \multicolumn{4}{|l|}{ PFBHG-B1-1996 } & \multirow{2}{*}{$\begin{array}{c}\text { Nov. } 5,1996 \\
\text { Std. Dev. }\end{array}$} \\
\hline Tag & Description & Units & Average & \\
\hline NOX & FG NO & ppm & 75.87 & 18.944 \\
\hline $\mathrm{N} 2 \mathrm{O}$ & $\mathrm{FG} \mathrm{N}_{2} \mathrm{O}$ & ppm & 0.10 & 0.019 \\
\hline $\mathrm{HC}$ & FG HC & ppm & 1.40 & 0.272 \\
\hline Calculated & S Ret & $\%$ & 99.61 & 1.870 \\
\hline S RET & Sulfur Retention & $\%$ & 99.67 & 0.835 \\
\hline $\mathrm{E}-\mathrm{SO} 2-\mathrm{A}$ & $\mathrm{FG} \mathrm{SO}-\mathrm{A}$ & $\mathrm{lb} / \mathrm{MMBtu}$ & 0.01 & 0.063 \\
\hline E-NOx & FG NO & $\mathrm{lb} / \mathrm{MMBtu}$ & 0.34 & 0.095 \\
\hline $\mathrm{E}-\mathrm{N} 2 \mathrm{O}$ & $\mathrm{FG} \mathrm{N} \mathrm{N}_{2} \mathrm{O}$ & lb/MMBtu & 0.00 & 0.000 \\
\hline $\mathrm{E}-\mathrm{CO}$ & FG CO & $\mathrm{lb} / \mathrm{MMBtu}$ & 0.03 & 0.012 \\
\hline Feedrate & Theor. Coal feed & $\mathrm{lb} / \mathrm{hr}$ & 5.47 & 0.446 \\
\hline TC16010 & HX 1 exit temp & ${ }^{\circ} \mathrm{F}$ & 106.58 & 2.811 \\
\hline TC16020 & HX 2 exit temp & ${ }^{\circ} \mathrm{F}$ & 0.00 & 0.000 \\
\hline TC16030 & HX 3 exit temp & ${ }^{\circ} \mathrm{F}$ & 226.37 & 7.240 \\
\hline TC12101 & Auger HX exit & ${ }^{\circ} \mathrm{F}$ & 73.44 & 0.703 \\
\hline TC17001 & Alk. Probe temp & ${ }^{\circ} \mathrm{F}$ & 0.08 & 0.880 \\
\hline TC17002 & Alk. Probe temp & ${ }^{\circ} \mathrm{F}$ & 261.17 & 29.982 \\
\hline TC17003 & Cyclonę Pot temp & ${ }^{\circ} \mathrm{F}$ & 106.79 & 1.968 \\
\hline PT 14020 & Reactor Static & atm & 11.18 & 0.089 \\
\hline PT14020 & Reactor Static & psia & 164.35 & 1.308 \\
\hline PT] 4021 & Reactor dP & in $\mathrm{H}_{2} \mathrm{O}$ & 16.56 & 8.964 \\
\hline PT10999 & Barometric & psia & 14.51 & 0.014 \\
\hline PT14022 & Cyclone dP & in $\mathrm{H}_{2} \mathrm{O}$ & 4.95 & 0.329 \\
\hline TC 16040 & Reactor HX temp & ${ }^{\circ} \mathrm{F}$ & 233.42 & 7.814 \\
\hline R STATIC & Reactor Static & psig & 149.84 & 1.309 \\
\hline HG IN & HG IN & ${ }^{\circ} \mathrm{F}$ & 1470.08 & 10.154 \\
\hline HG TOP & HG TOP & ${ }^{\circ} \mathrm{F}$ & 1318.88 & 27.101 \\
\hline HG UpMid & HG UpMid & ${ }^{\circ} \mathrm{F}$ & 1455.51 & 7.632 \\
\hline HG LoMid & HG LoMid & ${ }^{\circ} \mathrm{F}$ & 1466.61 & 4.752 \\
\hline HG Out & HG Out & ${ }^{\circ} \mathrm{F}$ & 928.50 & 26.889 \\
\hline Htr Top & Htr Top & ${ }^{\circ} \mathrm{F}$ & 1004.91 & 13.055 \\
\hline $\mathrm{Htr} \mathrm{Btml}$ & Htr Btml & ${ }^{\circ} \mathrm{F}$ & 762.97 & 19.482 \\
\hline $\mathrm{Htr} \mathrm{Btm} 2$ & $\mathrm{Htr} \mathrm{Btm} 2$ & ${ }^{\circ} \mathrm{F}$ & 950.02 & 11.237 \\
\hline Fltrl Up & Fitrl Up & ${ }^{\circ} \mathrm{F}$ & 1115.76 & 43.434 \\
\hline Fltrl Lo & Fltrl Lo & ${ }^{\circ} \mathrm{F}$ & 1255.86 & 13.884 \\
\hline Fltr2 Up & Fltr2 Up & ${ }^{\circ} \mathrm{F}$ & 0.00 & 0.000 \\
\hline Fltr2 Lo & Fltr2 Lo & ${ }^{\circ} \mathrm{F}$ & 0.00 & 0.000 \\
\hline Fltr3 Up & Fltr3 Up & ${ }^{\circ} \mathrm{F}$ & 0.00 & 0.000 \\
\hline Fltr3 Lo & Fltr3 Lo & ${ }^{\circ} \mathrm{F}$ & 0.00 & 0.000 \\
\hline HG Presr & HG Presr & psig & 156.37 & 2.925 \\
\hline $\mathrm{HG} \mathrm{dP}$ & $\mathrm{HG} d P$ & $\mathrm{kPa}$ & 1.59 & 0.237 \\
\hline HG dP & HG dP & in $\mathrm{H}_{2} \mathrm{O}$ & 6.38 & 0.953 \\
\hline Ash Pot & Ash Pot & ${ }^{\circ} \mathrm{F}$ & 124.81 & 21.792 \\
\hline
\end{tabular}


Table 49

Run Summary from Test B1-2096

\begin{tabular}{|c|c|c|c|c|}
\hline$\overline{\text { PFBHG-B1-2 }}$ & & & & Nov. 7,1996 \\
\hline Tag & Description & Units & Average & Std. Dev. \\
\hline AIRFLOW & Air Flow Rate & scfm & 11.99 & 0.254 \\
\hline N FLOW A & Orifice N Flow & scfm & 10.48 & 0.232 \\
\hline FLOW IN & Total Flow In & scfm & 22.47 & 0.479 \\
\hline VELOCITY & Reactor SGV & $\mathrm{ft} / \mathrm{sec}$ & 2.85 & 0.111 \\
\hline FG SGV & FG SGV & $\mathrm{ft} / \mathrm{sec}$ & 2.99 & 0.115 \\
\hline $\mathrm{EA}$ & Excess Air & $\%$ & 23.89 & 1.858 \\
\hline HC13111 & Z 1 Heater Temp & ${ }^{\circ} \mathrm{F}$ & 1507.11 & 77.315 \\
\hline HT2PID & Z 1 Heater output & $\%$ & 49.03 & 29.486 \\
\hline HC13211 & Z 2 Heater Temp & ${ }^{\circ} \mathrm{F}$ & 1561.86 & 24.183 \\
\hline HT3PID & Z 2 Heater output & $\%$ & 7.08 & 20.863 \\
\hline $\mathrm{HC} 13311$ & Z 3 Heater Temp & ${ }^{\circ} \mathrm{F}$ & 1495.79 & 12.887 \\
\hline HT4PID & Z 3 Heater output & $\%$ & 7.03 & 18.581 \\
\hline TC11010 & Inlet Gas temp & ${ }^{\circ} \mathrm{F}$ & 614.46 & 5.913 \\
\hline TC14001 & Reactor Inlet temp & ${ }^{\circ} \mathrm{F}$ & 763.24 & 39.033 \\
\hline TC14002 & RT@0.25" & ${ }^{\circ} \mathrm{F}$ & 1355.70 & 74.167 \\
\hline TC14003 & RT@1.75" & ${ }^{\circ} \mathrm{F}$ & 1513.61 & 62.320 \\
\hline TC14004 & RT@ 3.50" & ${ }^{\circ} \mathrm{F}$ & 1527.41 & 56.107 \\
\hline TC14005 & RT@5.00" & ${ }^{\circ} \mathrm{F}$ & 1532.00 & 54.994 \\
\hline TCl4006 & RT@7.00" & ${ }^{\circ} \mathrm{F}$ & 1540.26 & 50.614 \\
\hline TC14007 & RT@9.00" & ${ }^{\circ} \mathrm{F}$ & 1548.51 & 47.501 \\
\hline TCl4008 & RT@11.00" & ${ }^{\circ} \mathrm{F}$ & 1562.24 & 43.657 \\
\hline TC14009 & RT@15.00" & ${ }^{\circ} \mathrm{F}$ & 1596.64 & 37.893 \\
\hline TC14010 & RT@23.00" & ${ }^{\circ} \mathrm{F}$ & 1623.67 & 30.776 \\
\hline TC14011 & RT@31.00" & ${ }^{\circ} \mathrm{F}$ & 1633.50 & 18.139 \\
\hline TC14012 & RT@43.25" & ${ }^{\circ} \mathrm{F}$ & 1513.21 & 18.808 \\
\hline TC14028 & Cyclone Exit & ${ }^{\circ} \mathrm{F}$ & 1472.67 & 5.438 \\
\hline TC15001 & HX FG Out & ${ }^{\circ} \mathrm{F}$ & 521.99 & 26.976 \\
\hline TC18010 & Stack Temp & ${ }^{\circ} \mathrm{F}$ & 385.62 & 17.229 \\
\hline ZONE 1 & Zone 1 Avg & ${ }^{\circ} \mathrm{F}$ & 1532.36 & 53.606 \\
\hline ZONE 2 & Zone 2 Avg & ${ }^{\circ} \mathrm{F}$ & 1594.18 & 36.764 \\
\hline ZONE 3 & Zone 3 Avg & ${ }^{\circ} \mathrm{F}$ & 1573.35 & 15.277 \\
\hline$T(A \vee G)$ & Avg Reactor temp & ${ }^{\circ} \mathrm{F}$ & 1559.10 & 38.995 \\
\hline $\mathrm{SO} 2-\mathrm{A}$ & $\mathrm{FG} \mathrm{SO}_{2}-\mathrm{A}$ & ppm & 0.01 & 0.163 \\
\hline $\mathrm{SO} 2-\mathrm{B}$ & $\mathrm{FG} \mathrm{SO}-\mathrm{B}$ & ppm & 8.23 & 3.700 \\
\hline O2-A & $\mathrm{FGO}_{2}-\mathrm{A}$ & $\%$ & 4.61 & 0.294 \\
\hline $\mathrm{O} 2-\mathrm{B}$ & $\mathrm{FG} \mathrm{O}_{2}-\mathrm{B}$ & $\%$ & 4.65 & 0.347 \\
\hline $\mathrm{CO} 2$ & $\mathrm{FG} \mathrm{CO}$ & $\%$ & 4.86 & 0.341 \\
\hline $\mathrm{CO}$ & FG CO & $\mathrm{ppm}$ & 15.70 & 1.657 \\
\hline
\end{tabular}

Continued ... 
Table 49 (continued)

\begin{tabular}{|c|c|c|c|c|}
\hline PFBHG-B1-2096 & & & & Nov. 7, 1996 \\
\hline Tag & Description & Units & Average & Std. Dev. \\
\hline NOX & $F G N O_{x}$ & ppm & 58.47 & 8.476 \\
\hline $\mathrm{N} 2 \mathrm{O}$ & $\mathrm{FG} \mathrm{N}_{2} \mathrm{O}$ & ppm & 0.10 & 0.019 \\
\hline $\mathrm{HC}$ & FG HC & ppm & 0.00 & 0.000 \\
\hline Calculated & S Ret & $\%$ & 98.35 & 0.737 \\
\hline S RET & Sulfur Retention & $\%$ & 99.18 & 0.367 \\
\hline $\mathrm{E}-\mathrm{SO} 2-\mathrm{A}$ & $\mathrm{FG} \mathrm{SO}_{2}-\mathrm{A}$ & $\mathrm{lb} / \mathrm{MMBtu}$ & 0.00 & 0.001 \\
\hline E-NOx & FG NO & $\mathrm{lb} / \mathrm{MMBtu}$ & 0.29 & 0.042 \\
\hline $\mathrm{E}-\mathrm{N} 2 \mathrm{O}$ & $\mathrm{FG} \mathrm{N}_{2} \mathrm{O}$ & $\mathrm{lb} / \mathrm{MMBtu}$ & 0.00 & 0.000 \\
\hline $\mathrm{E}-\mathrm{CO}$ & FG CO & $\mathrm{lb} / \mathrm{MMBtu}$ & 0.05 & 0.005 \\
\hline Feedrate & Theor. Coal feed & $\mathrm{lb} / \mathrm{hr}$ & 4.97 & 0.358 \\
\hline TC16010 & HX 1 exit temp & ${ }^{\circ} \mathrm{F}$ & 102.07 & 2.008 \\
\hline TC16020 & $\mathrm{HX} 2$ exit temp & ${ }^{\circ} \mathrm{F}$ & 0.00 & 0.000 \\
\hline TC16030 & HX 3 exit temp & ${ }^{\circ} \mathrm{F}$ & 218.78 & 11.536 \\
\hline TC12101 & Auger $\mathrm{HX}$ exit & ${ }^{\circ} \mathrm{F}$ & 72.79 & 2.023 \\
\hline TC17001 & Alk. Probe temp & ${ }^{\circ} \mathrm{F}$ & 909.80 & 1069.379 \\
\hline TC17002 & Alk. Probe temp & ${ }^{\circ} \mathrm{F}$ & 263.36 & 32.310 \\
\hline TC17003 & Cyclone Pot temp & ${ }^{\circ} \mathrm{F}$ & 107.96 & 3.662 \\
\hline PT14020 & Reactor Static & atm & 11.18 & 0.100 \\
\hline PT 14020 & Reactor Static & psia & 164.30 & 1.468 \\
\hline PT14021 & Reactor $\mathrm{dP}$ & in $\mathrm{H}_{2} \mathrm{O}$ & 20.85 & 2.366 \\
\hline PT10999 & Barometric & psia & 14.41 & 0.016 \\
\hline PT14022 & Cyclone dP & in $\mathrm{H}_{2} \mathrm{O}$ & 6.99 & 0.864 \\
\hline TC16040 & Reactor HX temp & ${ }^{\circ} \mathrm{F}$ & 222.64 & 15.737 \\
\hline R STATIC & Reactor Static & psig & 149.90 & 1.469 \\
\hline HG IN & HG IN & ${ }^{\circ} \mathrm{F}$ & 1472.57 & 5.492 \\
\hline HG TOP & HG TOP & ${ }^{\circ} \mathrm{F}$ & 1357.66 & 34.928 \\
\hline HG UpMid & HG UpMid & ${ }^{\circ} \mathrm{F}$ & 1463.57 & 27.714 \\
\hline HG LoMid & HG LoMid & ${ }^{\circ} \mathrm{F}$ & 1480.34 & 24.680 \\
\hline HG Out & HG Out & ${ }^{\circ} \mathrm{F}$ & 905.85 & 47.622 \\
\hline Htr Top & Htr Top & ${ }^{\circ} \mathrm{F}$ & 991.62 & 40.291 \\
\hline Htr Btml & Htr Btml & ${ }^{\circ} \mathrm{F}$ & 838.97 & 17.120 \\
\hline Htr Btm2 & Htr Btm2 & ${ }^{\circ} \mathrm{F}$ & 940.95 & 19.107 \\
\hline Fltrl Up & Fltrl Up & ${ }^{\circ} \mathrm{F}$ & 1088.93 & 70.792 \\
\hline Fitrl Lo & Fltrl Lo & ${ }^{\circ} \mathrm{F}$ & 1253.22 & 41.849 \\
\hline Fltr2 Up & Fltr2 Up & ${ }^{\circ} \mathrm{F}$ & 0.00 & 0.000 \\
\hline Fltr2 Lo & Fltr2 Lo & ${ }^{\circ} \mathrm{F}$ & 0.00 & 0.000 \\
\hline Fltr3 Up & Fltr3 Up & ${ }^{\circ} \mathrm{F}$ & 0.00 & 0.000 \\
\hline Fltr3 Lo & Fltr3 Lo & ${ }^{\circ} \mathrm{F}$ & 0.00 & 0.000 \\
\hline HG Presr & HG Presr & psig & 154.01 & 4.011 \\
\hline$H G d P$ & HG dP & $\mathrm{kPa}$ & 2.98 & 1.007 \\
\hline $\mathrm{HG} \mathrm{dP}$ & HG dP & in $\mathrm{H}_{2} \mathrm{O}$ & 11.95 & 4.043 \\
\hline Ash Pot & Ash Pot & ${ }^{\circ} \mathrm{F}$ & 93.92 & 11.157 \\
\hline
\end{tabular}


Table 50

Run Summary from Test B1-2196

\begin{tabular}{|c|c|c|c|c|}
\hline$\overline{\text { PFBH-B1-2196 }}$ & & & & Nov. 27,1996 \\
\hline Tag & Description & Units & Average & Std. Dev. \\
\hline AIRFLOW & Air Flow Rate & $\operatorname{scfm}$ & 12.80 & 0.246 \\
\hline N FLOW A & Orifice N Flow & $\operatorname{scfm}$ & 10.18 & 0.206 \\
\hline FLOW IN & Total Flow In & scfm & 22.98 & 0.395 \\
\hline VELOCITY & Reactor SGV & $\mathrm{ft} / \mathrm{sec}$ & 2.91 & 0.109 \\
\hline FG SGV & FG SGV & $\mathrm{ft} / \mathrm{sec}$ & 3.04 & 0.113 \\
\hline $\mathrm{EA}$ & Excess Air & $\%$ & 26.07 & 3.633 \\
\hline $\mathrm{HC} 13111$ & Z 1 Heater Temp. & ${ }^{\circ} \mathrm{F}$ & 1518.29 & 39.796 \\
\hline HT2PID & Z 1 Heater output & $\%$ & 43.13 & 34.418 \\
\hline $\mathrm{HC} 13211$ & Z 2 Heater Temp & ${ }^{\circ} \mathrm{F}$ & 1604.38 & 25.872 \\
\hline HT3PID & Z 2 Heater output & $\%$ & 0.63 & 6.374 \\
\hline $\mathrm{HC} 13311$ & Z 3 Heater Temp & ${ }^{\circ} \mathrm{F}$ & 1506.45 & 27.532 \\
\hline HT4PID & Z 3 Heater output & $\%$ & 4.27 & 15.190 \\
\hline TC11010 & Inlet Gas temp & ${ }^{\circ} \mathrm{F}$ & 605.54 & 10.162 \\
\hline TC14001 & Reactor Inlet temp & ${ }^{\circ} \mathrm{F}$ & 747.12 & 30.888 \\
\hline $\mathrm{TCl} 4002$ & RT@0.25" & ${ }^{\circ} \mathrm{F}$ & 1343.93 & 42.699 \\
\hline TCl4003 & RT@1.75" & ${ }^{\circ} \mathrm{F}$ & 1513.50 & 56.817 \\
\hline $\mathrm{TC} 14004$ & RT@3.50" & ${ }^{\circ} \mathrm{F}$ & 1535.23 & 57.557 \\
\hline TC14005 & RT@5.00" & ${ }^{\circ} \mathrm{F}$ & 1536.64 & 59.343 \\
\hline TC14006 & RT@7.00" & ${ }^{\circ} \mathrm{F}$ & 1543.62 & 59.744 \\
\hline TC14007 & RT@ 9.00" & ${ }^{\circ} \mathrm{F}$ & 1552.32 & 59.332 \\
\hline TC14008 & RT@11.00" & ${ }^{\circ} \mathrm{F}$ & 1567.84 & 55.177 \\
\hline TC14009 & RT@15.00" & ${ }^{\circ} \mathrm{F}$ & 1623.65 & 38.887 \\
\hline TC14010 & RT@23.00" & ${ }^{\circ} \mathrm{F}$ & 1666.64 & 35.964 \\
\hline $\mathrm{TC} 14011$ & RT@31.00" & ${ }^{\circ} \mathrm{F}$ & 1670.81 & 32.930 \\
\hline $\mathrm{TC} 14012$ & RT@43.25" & ${ }^{\circ} \mathrm{F}$ & 1530.75 & 41.667 \\
\hline TC14028 & Cyclone Exit & ${ }^{\circ} \mathrm{F}$ & 1348.70 & 14.774 \\
\hline $\mathrm{TC} 15001$ & HX FG Out & ${ }^{\circ} \mathrm{F}$ & 672.97 & 51.605 \\
\hline TC18010 & Stack Temp & ${ }^{\circ} \mathrm{F}$ & 469.26 & 38.943 \\
\hline ZONE 1 & Zone $1 \mathrm{Avg}$ & ${ }^{\circ} \mathrm{F}$ & 1536.26 & 57.802 \\
\hline ZONE 2 & Zone 2 Avg & ${ }^{\circ} \mathrm{F}$ & 1619.38 & 28.923 \\
\hline ZONE 3 & Zone 3 Avg & ${ }^{\circ} \mathrm{F}$ & 1600.78 & 35.541 \\
\hline $\mathrm{T}(\mathrm{AVG})$ & Avg Reactor temp & ${ }^{\circ} \mathrm{F}$ & 1574.10 & 38.575 \\
\hline $\mathrm{SO} 2-\mathrm{A}$ & $\mathrm{FG} \mathrm{SO}_{2}-\mathrm{A}$ & ppm & 15.59 & 36.633 \\
\hline $\mathrm{SO} 2-\mathrm{B}$ & $\mathrm{FG} \mathrm{SO}=-\mathrm{B}$ & ppm & 25.33 & 141.800 \\
\hline $\mathrm{O} 2-\mathrm{A}$ & $\mathrm{FGO}_{2}-\mathrm{A}$ & $\%$ & 4.90 & 0.485 \\
\hline $\mathrm{O} 2-\mathrm{B}$ & $\mathrm{FG} \mathrm{O}_{2}-\mathrm{B}$ & $\%$ & 4.87 & 0.477 \\
\hline $\mathrm{CO} 2$ & $\mathrm{FG} \mathrm{CO}$ & $\%$ & 5.02 & 0.622 \\
\hline $\mathrm{CO}$ & FG CO & ppm & 25.17 & 175.529 \\
\hline
\end{tabular}

Continued... 
Table 50 (continued)

\begin{tabular}{|c|c|c|c|c|}
\hline PFBH-B1-2196 & & & & Nov. 27,1996 \\
\hline Tag & Description & Units & Average & Std. Dev. \\
\hline NOX & FG NO & ppm & 107.99 & 22.844 \\
\hline $\mathrm{N} 2 \mathrm{O}$ & $\mathrm{FG} \mathrm{N} \mathrm{N}_{2} \mathrm{O}$ & ppm & 0.10 & 0.016 \\
\hline $\mathrm{HC}$ & FG HC & ppm & 6.52 & 15.232 \\
\hline Calculated & S Ret & $\%$ & 95.00 & 23.768 \\
\hline S RET & Sulfur Retention & $\%$ & 97.55 & 14.025 \\
\hline $\mathrm{E}-\mathrm{SO} 2-\mathrm{A}$ & $\mathrm{FG} \mathrm{SO}_{2}-\mathrm{A}$ & $\mathrm{lb} / \mathrm{MMBtu}$ & 0.16 & 0.742 \\
\hline E-NOx & $\mathrm{FGNO}$ & $\mathrm{lb} / \mathrm{MMBtu}$ & 0.52 & 0.141 \\
\hline $\mathrm{E}-\mathrm{N} 2 \mathrm{O}$ & $\mathrm{FG} \mathrm{N} \mathrm{N}_{2} \mathrm{O}$ & $\mathrm{lb} / \mathrm{MMBtu}$ & 0.00 & 0.000 \\
\hline $\mathrm{E}-\mathrm{CO}$ & FG CO & $\mathrm{lb} / \mathrm{MMBtu}$ & 0.17 & 1.240 \\
\hline Feedrate & Theor. Coal feed & $\mathrm{lb} / \mathrm{hr}$ & 5.23 & 0.645 \\
\hline $\mathrm{TC} 16010$ & HX 1 exit temp & ${ }^{\circ} \mathrm{F}$ & 227.28 & 44.813 \\
\hline TC16020 & HX 2 exit temp & ${ }^{\circ} \mathrm{F}$ & 0.00 & 0.000 \\
\hline TC16030 & HX 3 exit temp & ${ }^{\circ} \mathrm{F}$ & 245.87 & 25.388 \\
\hline TC12101 & Auger HX exit & ${ }^{\circ} \mathrm{F}$ & 71.36 & 1.346 \\
\hline TC17001 & Alk. Probe temp & ${ }^{\circ} \mathrm{F}$ & 0.00 & 0.000 \\
\hline TC17002 & Alk. Probe temp & ${ }^{\circ} \mathrm{F}$ & 235.30 & 22.433 \\
\hline TC17003 & Cyclone Pot temp & ${ }^{\circ} \mathrm{F}$ & 113.22 & 15.695 \\
\hline PT14020 & Reactor Static & atm & 11.22 & 0.110 \\
\hline PT14020 & Reactor Static & psia & 164.90 & 1.622 \\
\hline PT14021 & Reactor dP & in $\mathrm{H}_{2} \mathrm{O}$ & 15.70 & 3.849 \\
\hline PT10999 & Barometric & psia & 14.69 & 0.022 \\
\hline PT14022 & Cyclone dP & in $\mathrm{H}_{2} \mathrm{O}$ & 5.26 & 1.928 \\
\hline TC16040 & Reactor HX temp & ${ }^{\circ} \mathrm{F}$ & 284.53 & 34.971 \\
\hline R STATIC & Reactor Static & psig & 150.21 & 1.626 \\
\hline HG IN & HG IN & ${ }^{\circ} \mathrm{F}$ & 1348.78 & 14.741 \\
\hline HG TOP & HG TOP & ${ }^{\circ} \mathrm{F}$ & 133.61 & 6.892 \\
\hline HG UpMid & HG UpMid & ${ }^{\circ} \mathrm{F}$ & 1452.84 & 37.797 \\
\hline HG LoMid & HG LoMid & ${ }^{\circ} \mathrm{F}$ & 1471.39 & 33.226 \\
\hline HG Out & HG Out & ${ }^{\circ} \mathrm{F}$ & 895.72 & 62.223 \\
\hline Htr Top & Htr Top & ${ }^{\circ} \mathrm{F}$ & 977.40 & 45.386 \\
\hline Htr Btml & $\mathrm{Htr} \mathrm{Btml}$ & ${ }^{\circ} \mathrm{F}$ & 856.57 & 34.117 \\
\hline Htr Btm2 & $\mathrm{Htr} \mathrm{Btm} 2$ & ${ }^{\circ} \mathrm{F}$ & 968.09 & 26.554 \\
\hline Fltrl Up & Fltrl Up & ${ }^{\circ} \mathrm{F}$ & 1065.55 & 82.267 \\
\hline Fltrl Lo & Fltr l Lo & ${ }^{\circ} \mathrm{F}$ & 1256.80 & 42.813 \\
\hline FItr2 Up & Fitr2 Up & ${ }^{\circ} \mathrm{F}$ & 0.00 & 0.000 \\
\hline Fltr2 Lo & Fltr2 Lo & ${ }^{\circ} \mathrm{F}$ & 0.00 & 0.000 \\
\hline Fltr3 Up & Fltr3 Up & ${ }^{\circ} \mathrm{F}$ & 0.00 & 0.000 \\
\hline Fltr3 Lo & Fltr3 Lo & ${ }^{\circ} \mathrm{F}$ & 0.00 & 0.000 \\
\hline HG Presr & HG Presr & psig & 153.39 & 2.970 \\
\hline HG dP & HG dP & $\mathrm{kPa}$ & 3.18 & 1.592 \\
\hline $\mathrm{HG} \mathrm{dP}$ & $\mathrm{HG} \mathrm{dP}$ & in $\mathrm{H}_{2} \mathrm{O}$ & 12.76 & 6.393 \\
\hline Ash Pot & Ash Pot & ${ }^{\circ} \mathrm{F}$ & 116.98 & 34.511 \\
\hline
\end{tabular}


Table 51

Run Summary from Test B1-2296

\begin{tabular}{|c|c|c|c|c|}
\hline \multicolumn{4}{|c|}{ PFBHG-B1-2296 } & \multirow{2}{*}{$\begin{array}{c}\text { Dec. } 4,5,1996 \\
\text { Std. Dev. }\end{array}$} \\
\hline Tag & Description & Units & Average & \\
\hline AIRFLOW & Air Flow Rate & $\operatorname{scfm}$ & 12.25 & 0.389 \\
\hline N FLOW A & Orifice N Flow & scfm & 10.22 & 0.337 \\
\hline FLOW IN & Total Flow In & sefm & 22.48 & 0.715 \\
\hline VELOCITY & Reactor SGV & $\mathrm{ft} / \mathrm{sec}$ & 2.88 & 0.122 \\
\hline FG SGV & FG SGV & $\mathrm{ft} / \mathrm{sec}$ & 3.02 & 0.124 \\
\hline EA & Excess Air & $\%$ & 25.15 & 1.469 \\
\hline $\mathrm{HC} 13111$ & Z I Heater Temp & ${ }^{\circ} \mathrm{F}$ & 1528.35 & 31.540 \\
\hline HT2PID & Z 1 Heater output & $\%$ & 33.48 & 32.390 \\
\hline $\mathrm{HCl} 13211$ & Z 2 Heater Temp & ${ }^{\circ} \mathrm{F}$ & 1582.19 & 14.226 \\
\hline HT3PID & Z 2 Heater output & $\%$ & 0.51 & 5.526 \\
\hline $\mathrm{HC} 13311$ & Z 3 Heater Temp & ${ }^{\circ} \mathrm{F}$ & 1501.02 & 12.695 \\
\hline HT4PID & Z 3 Heater output & $\%$ & 2.18 & 10.799 \\
\hline TC11010 & Inlet Gas temp & ${ }^{\circ} \mathrm{F}$ & 615.13 & 7.029 \\
\hline TC14001 & Reactor Inlet temp & ${ }^{\circ} \mathrm{F}$ & 773.39 & 29.255 \\
\hline $\mathrm{TC} 14002$ & RT@0.25" & ${ }^{\circ} \mathrm{F}$ & 1355.07 & 30.682 \\
\hline $\mathrm{TC} 14003$ & RT@1.75" & ${ }^{\circ} \mathrm{F}$ & 1534.01 & 39.322 \\
\hline $\mathrm{TC} 14004$ & RT@ 3.50" & ${ }^{\circ} \mathrm{F}$ & 1551.62 & 33.000 \\
\hline TC14005 & RT@5.00" & ${ }^{\circ} \mathrm{F}$ & 1555.58 & 31.809 \\
\hline TC14006 & RT@7.00" & ${ }^{\circ} \mathrm{F}$ & 1563.07 & 28.149 \\
\hline TC 14007 & RT@9.00" & ${ }^{\circ} \mathrm{F}$ & 1568.74 & 25.429 \\
\hline TC 14008 & RT@11.00" & ${ }^{\circ} \mathrm{F}$ & 1582.89 & 23.064 \\
\hline TC14009 & RT@15.00" & ${ }^{\circ} \mathrm{F}$ & 1616.40 & 23.583 \\
\hline TC14010 & RT@23.00" & ${ }^{\circ} \mathrm{F}$ & 1640.11 & 20.156 \\
\hline TC14011 & RT@31.00" & ${ }^{\circ} \mathrm{F}$ & 1647.78 & 16.692 \\
\hline TC14012 & RT@43.25" & ${ }^{\circ} \mathrm{F}$ & 1520.66 & 18.825 \\
\hline TC14028 & Cyclone Exit & ${ }^{\circ} \mathrm{F}$ & 1331.58 & 12.498 \\
\hline TC15001 & HX FG Out & ${ }^{\circ} \mathrm{F}$ & 535.39 & 46.588 \\
\hline TC18010 & Stack Temp & ${ }^{\circ} \mathrm{F}$ & 396.37 & 30.188 \\
\hline ZONE 1 & Zone I Avg & ${ }^{\circ} \mathrm{F}$ & 1554.61 & 30.007 \\
\hline ZONE 2 & Zone 2 Avg & ${ }^{\circ} \mathrm{F}$ & 1613.13 & 21.278 \\
\hline ZONE 3 & Zone 3 Avg & ${ }^{\circ} \mathrm{F}$ & 1584.22 & 15.817 \\
\hline$T(A \vee G)$ & Avg Reactor temp & ${ }^{\circ} \mathrm{F}$ & 1578.09 & 21.133 \\
\hline SO2-A & $\mathrm{FG} \mathrm{SO}-\mathrm{A}$ & ppm & 1.16 & 12.789 \\
\hline SO2-B & $\mathrm{FG} \mathrm{SO}-\mathrm{B}$ & ppm & 25.01 & 20.986 \\
\hline $\mathrm{O} 2-\mathrm{A}$ & $\mathrm{FG} \mathrm{O}_{2}-\mathrm{A}$ & $\%$ & 4.78 & 0.223 \\
\hline $\mathrm{O} 2-\mathrm{B}$ & $\mathrm{FG} \mathrm{O}_{2}-\mathrm{B}$ & $\%$ & 5.10 & 0.273 \\
\hline $\mathrm{CO} 2$ & $\mathrm{FG} \mathrm{CO} 2$ & $\%$ & 5.07 & 0.274 \\
\hline $\mathrm{CO}$ & FG CO & ppm & 4.59 & 2.367 \\
\hline NOX & FG NO & ppm & 60.86 & 9.956 \\
\hline $\mathrm{N} 2 \mathrm{O}$ & $\mathrm{FG} \mathrm{N}_{2} \mathrm{O}$ & ppm & 0.11 & 0.021 \\
\hline
\end{tabular}

Continued ... 
Table 51 (continued)

\begin{tabular}{|c|c|c|c|c|}
\hline \multicolumn{4}{|c|}{ PFBHG-B1-2296 } & \multirow{2}{*}{$\begin{array}{c}\text { Dec. } 4,5,1996 \\
\text { Std. Dev. }\end{array}$} \\
\hline Tag & Description & Units & Average & \\
\hline $\mathrm{HC}$ & FG HC & ppm & 1.05 & 0.392 \\
\hline Calculated & S Ret & $\%$ & 99.81 & 2.053 \\
\hline S RET & Sulfur Retention & $\%$ & 97.64 & 1.759 \\
\hline $\mathrm{E}-\mathrm{SO} 2-\mathrm{A}$ & $\mathrm{FG} \mathrm{SO}-\mathrm{A}$ & $\mathrm{lb} / \mathrm{MMBtu}$ & 0.01 & 0.069 \\
\hline E-NOx & $F G \mathrm{NO}_{\mathrm{x}}$ & $\mathrm{lb} / \mathrm{MMBtu}$ & 0.28 & 0.043 \\
\hline $\mathrm{E}-\mathrm{N} 2 \mathrm{O}$ & $\mathrm{FG} \mathrm{N}_{2} \mathrm{O}$ & lb/MMBtu & 0.00 & 0.000 \\
\hline $\mathrm{E}-\mathrm{CO}$ & FG CO & lb/MMBtu & 0.01 & 0.007 \\
\hline Feedrate & Theor. Coal feed & $\mathrm{lb} / \mathrm{hr}$ & 5.19 & 0.325 \\
\hline TC16010 & HX l exit temp & ${ }^{\circ} \mathrm{F}$ & 108.57 & 7.266 \\
\hline TC16020 & HX 2 exit temp & ${ }^{\circ} \mathrm{F}$ & 0.00 & 0.000 \\
\hline TC16030 & HX 3 exit temp & ${ }^{\circ} \mathrm{F}$ & 218.82 & 22.093 \\
\hline TC12101 & Auger HX exit & ${ }^{\circ} \mathrm{F}$ & 71.62 & 1.151 \\
\hline TC17001 & Alk. Probe temp & ${ }^{\circ} \mathrm{F}$ & 150.17 & 150.149 \\
\hline TC17002 & Alk. Probe temp & ${ }^{\circ} \mathrm{F}$ & 220.00 & 59.997 \\
\hline TC17003 & Cyclone Pot temp & ${ }^{\circ} \mathrm{F}$ & 120.71 & 10.565 \\
\hline PT 14020 & Reactor Static & atm & 11.19 & 0.135 \\
\hline PT14020 & Reactor Static & psia & 164.42 & 1.988 \\
\hline PT14021 & Reactor dP & in $\mathrm{H}_{2} \mathrm{O}$ & 21.76 & 1.795 \\
\hline PT10999 & Barometric & psia & 14.35 & 0.095 \\
\hline PT14022 & Cyclone $\mathrm{dP}$ & in $\mathrm{H}_{2} \mathrm{O}$. & 6.78 & 0.732 \\
\hline TC16040 & Reactor HX temp & ${ }^{\circ} \mathrm{F}$ & 228.36 & 24.083 \\
\hline R STATIC & Reactor Static & psig & 150.07 & 1.984 \\
\hline HG IN & HG IN & ${ }^{\circ} \mathrm{F}$ & 1331.64 & 12.483 \\
\hline HG TOP & HG TOP & ${ }^{\circ} \mathrm{F}$ & 1302.67 & 68.353 \\
\hline HG UpMid & HG UpMid & ${ }^{\circ} \mathrm{F}$ & 1445.06 & 45.718 \\
\hline HG LoMid & HG LoMid & ${ }^{\circ} \mathrm{F}$ & 1467.80 & 40.399 \\
\hline HG Out & HG Out & ${ }^{\circ} \mathrm{F}$ & 916.93 & 71.266 \\
\hline Htr Top & Htr Top & ${ }^{\circ} \mathrm{F}$ & 992.65 & 51.199 \\
\hline Htr Btml & $\mathrm{Htr} \mathrm{Btml}$ & ${ }^{\circ} \mathrm{F}$ & 988.01 & 23.019 \\
\hline $\mathrm{Htr} \mathrm{Btm} 2$ & $\mathrm{Htr} \mathrm{Btm} 2$ & ${ }^{\circ} \mathrm{F}$ & 959.70 & 23.186 \\
\hline Fltrl Up & FIttl Up & ${ }^{\circ} \mathrm{F}$ & 1103.77 & 96.947 \\
\hline Fltrl Lo & Fltrl Lo & ${ }^{\circ} \mathrm{F}$ & 1262.39 & 62.565 \\
\hline Fltr2 Up & Flt 2 Up & ${ }^{\circ} \mathrm{F}$ & 0.00 & 0.000 \\
\hline Fltr2 Lo & Fltr2 Lo & ${ }^{\circ} \mathrm{F}$ & 0.00 & 0.000 \\
\hline Fltr3 Up & Flm3 Up & ${ }^{\circ} \mathrm{F}$ & 0.00 & 0.000 \\
\hline Fltr3 Lo & Fltr3 Lo & ${ }^{\circ} \mathrm{F}$ & 0.00 & 0.000 \\
\hline HG Presr & HG Presr & psig & 157.50 & 5.034 \\
\hline $\mathrm{HG} \mathrm{dP}$ & $H G d P$ & $\mathrm{kPa}$ & 5.02 & 2.167 \\
\hline HG dP & $H G \mathrm{dP}$ & in $\mathrm{H}_{2} \mathrm{O}$ & 20.15 & 8.700 \\
\hline Ash Pot & Ash Pot & ${ }^{\circ} \mathrm{F}$ & 100.31 & 9.869 \\
\hline
\end{tabular}




\section{APPENDIX C \\ THERMOGRAMS FROM SORBENT-SCREENING TESTS}

Thermograms from the TGA testing used to investigate the sodalite reactions and to screen the conventional sorbents are presented in this appendix. Table 52 shows the test conditions for each test. The thermograms are presented as Figures 71 through 87. 
Table 52

Matrix for TGA Testing

\begin{tabular}{|c|c|c|c|c|c|c|c|c|}
\hline \multirow[b]{2}{*}{ Test } & \multirow[b]{2}{*}{ Sorbent } & \multirow[b]{2}{*}{$\mathrm{NaCl}$} & \multicolumn{6}{|c|}{ Carrier Gas Used at Each Temperature } \\
\hline & & & $700^{\circ} \mathrm{C}$ & $733^{\circ} \mathrm{C}$ & $766^{\circ} \mathrm{C}$ & $800^{\circ} \mathrm{C}$ & $800^{\circ} \mathrm{C}$ & $850^{\circ} \mathrm{C}$ \\
\hline 1 & Albite & Yes & - & - & - & - & - & $\mathrm{N}_{2}$ \\
\hline 2 & Albite & No & - & - & - & - & - & $\mathrm{N}_{2}$ \\
\hline 3 & Albite & Yes & $\mathrm{C}^{1}$ & $\mathrm{C}$ & $\mathrm{C}$ & C & $\mathrm{N}_{2}$ & - \\
\hline 4 & Albite & No & C & C & C & C & $\mathbf{N}_{2}$ & - \\
\hline 5 & $\begin{array}{l}\text { Albite + } \\
\text { quartz }\end{array}$ & Yes & $\mathrm{C}$ & $\mathrm{C}$ & $\mathrm{C}$ & C & $\mathrm{N}_{2}$ & - \\
\hline 6 & $\begin{array}{c}\text { Albite + } \\
\text { quartz }\end{array}$ & Yes & $\mathrm{N}_{2}$ & $\mathrm{~N}_{2}$ & $\mathrm{~N}_{2}$ & $\mathrm{~N}_{2}$ & - & - \\
\hline 7 & Sodalite & Yes & $C$ & C & $C$ & C & $\mathrm{N}_{2}$ & - \\
\hline 8 & Sodalite & No & C & $\mathrm{C}$ & C & C & $\mathrm{N}_{2}$ & - \\
\hline 9 & Sodalite & Yes & $\mathrm{N}_{2}$ & $\mathrm{~N}_{2}$ & & $\mathrm{~N}_{2}$ & C & - \\
\hline 10 & Nepheline & Yes & $\mathrm{C}$ & C & C & $\mathrm{C}$ & $\mathrm{N}_{2}$ & - \\
\hline 11 & $\mathrm{AlO}(\mathrm{OH})_{3}$ & Yes & $\mathrm{C}$ & $\mathrm{C}$ & $\mathrm{C}$ & $\mathrm{C}$ & $\mathrm{N}_{2}$ & - \\
\hline 12 & Kaolinite & Yes & C & C & C & C & $\mathrm{N}_{2}$ & - \\
\hline 13 & Bauxite & Yes & $\mathrm{N}_{2}$ & $\mathrm{~N}_{2}$ & $\mathrm{~N}_{2}$ & $\mathrm{~N}_{2}$ & $\mathrm{C}$ & - \\
\hline 14 & Bauxite & Yes & - & - & - & - & $C$ & - \\
\hline 15 & Zeolite & Yes & $\mathrm{N}_{2}$ & $\mathrm{~N}_{2}$ & $\mathrm{~N}_{2}$ & $\mathrm{~N}_{2}$ & $\mathrm{C}$ & - \\
\hline 16 & Sodalite & No & $\mathrm{N}_{2}$ & $\mathrm{~N}_{2}$ & $\mathrm{~N}_{2}$ & $\mathrm{~N}_{2}$ & $\mathrm{C}$ & - \\
\hline 17 & Albite & Yes & $\mathrm{C}$ & $\mathrm{C}$ & $\mathrm{C}$ & $\mathrm{C}$ & $\mathrm{N}_{2}$ & \\
\hline
\end{tabular}

' Combustion gas 


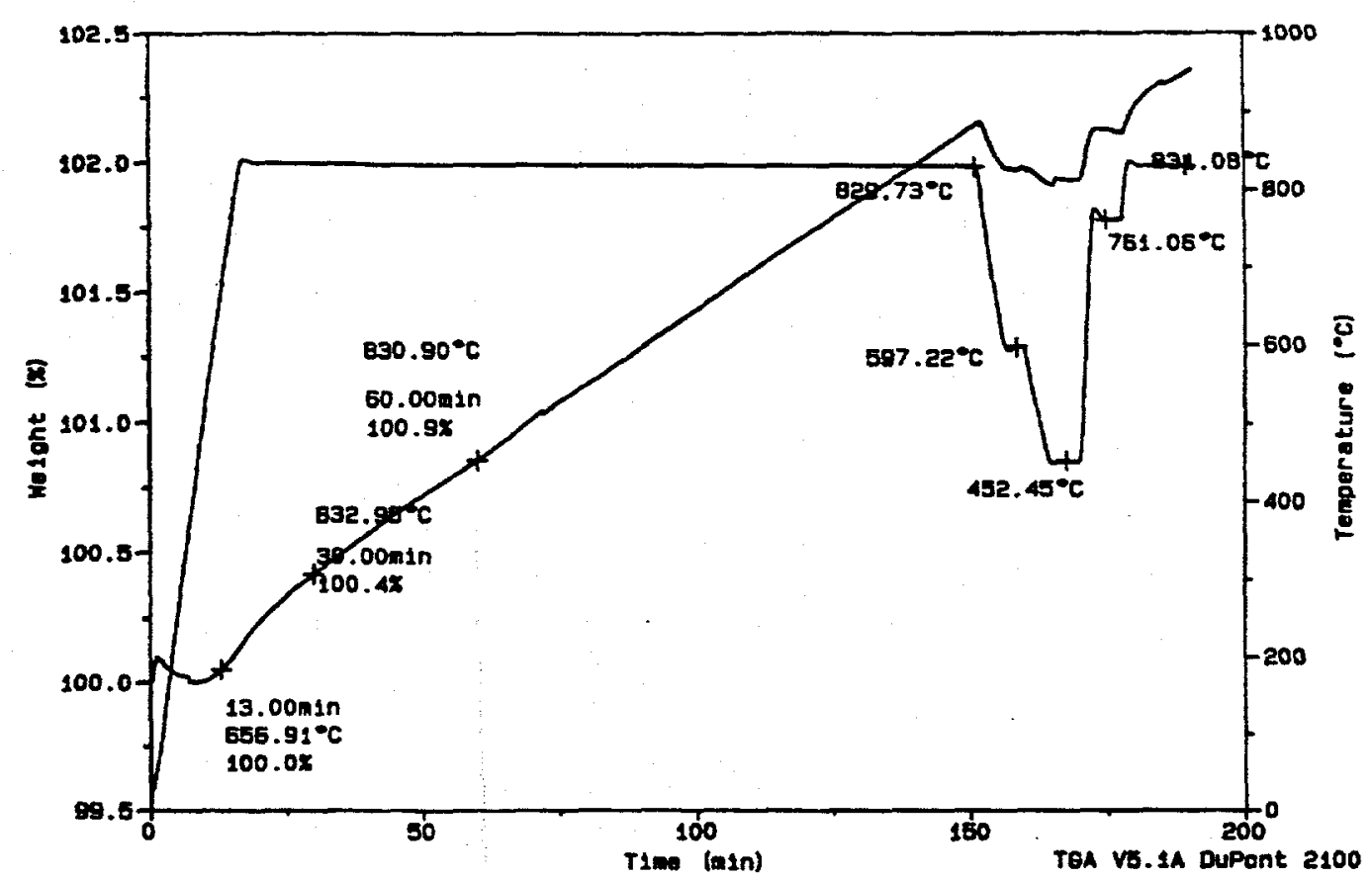

Figure 71. Thermogram from Test 1 , albite with $\mathrm{NaCl}$ and nitrogen as the initial gas

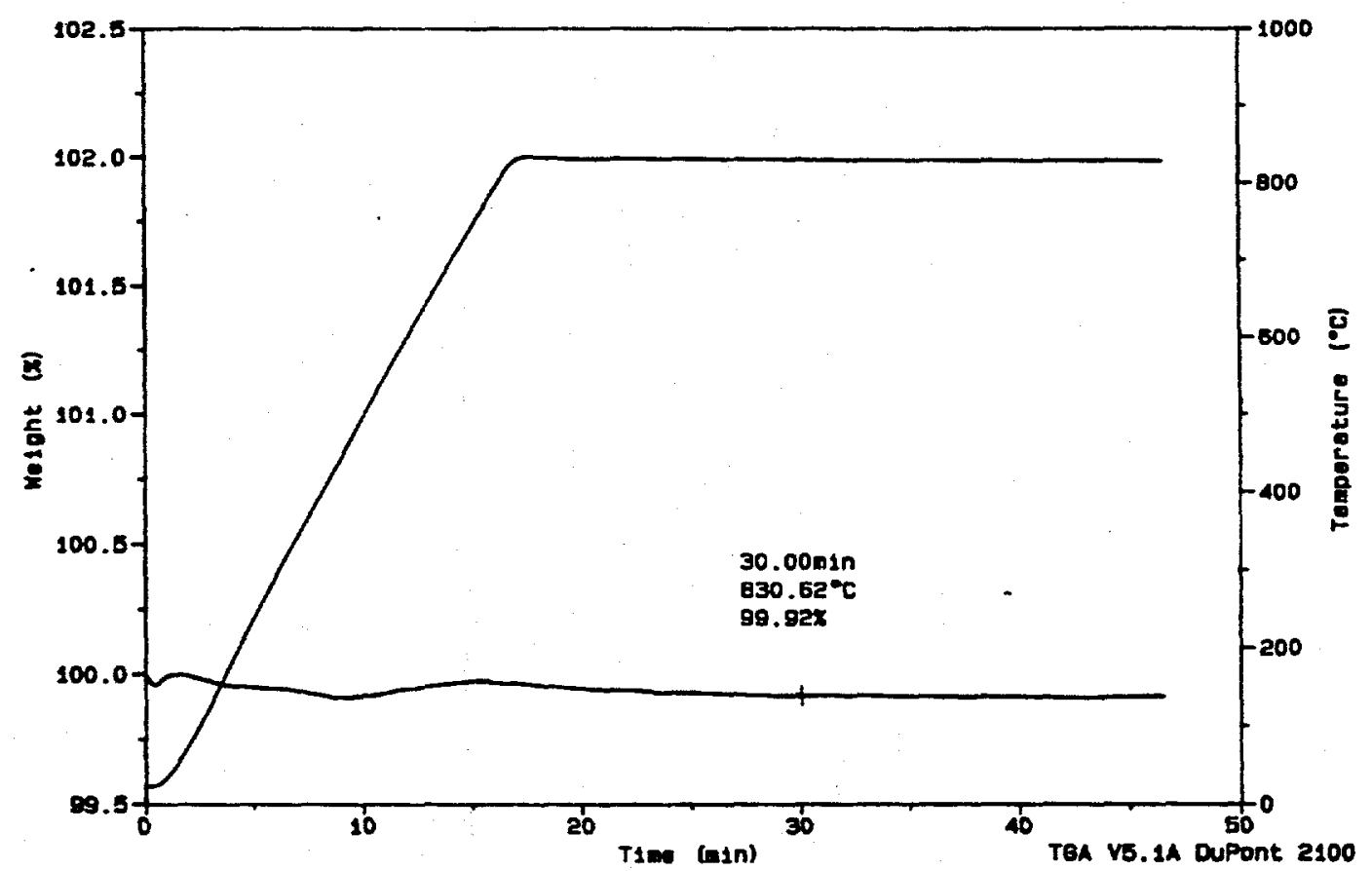

Figure 72. Thermogram from Test 2 , albite without $\mathrm{NaCl}$ and nitrogen as the initial gas 


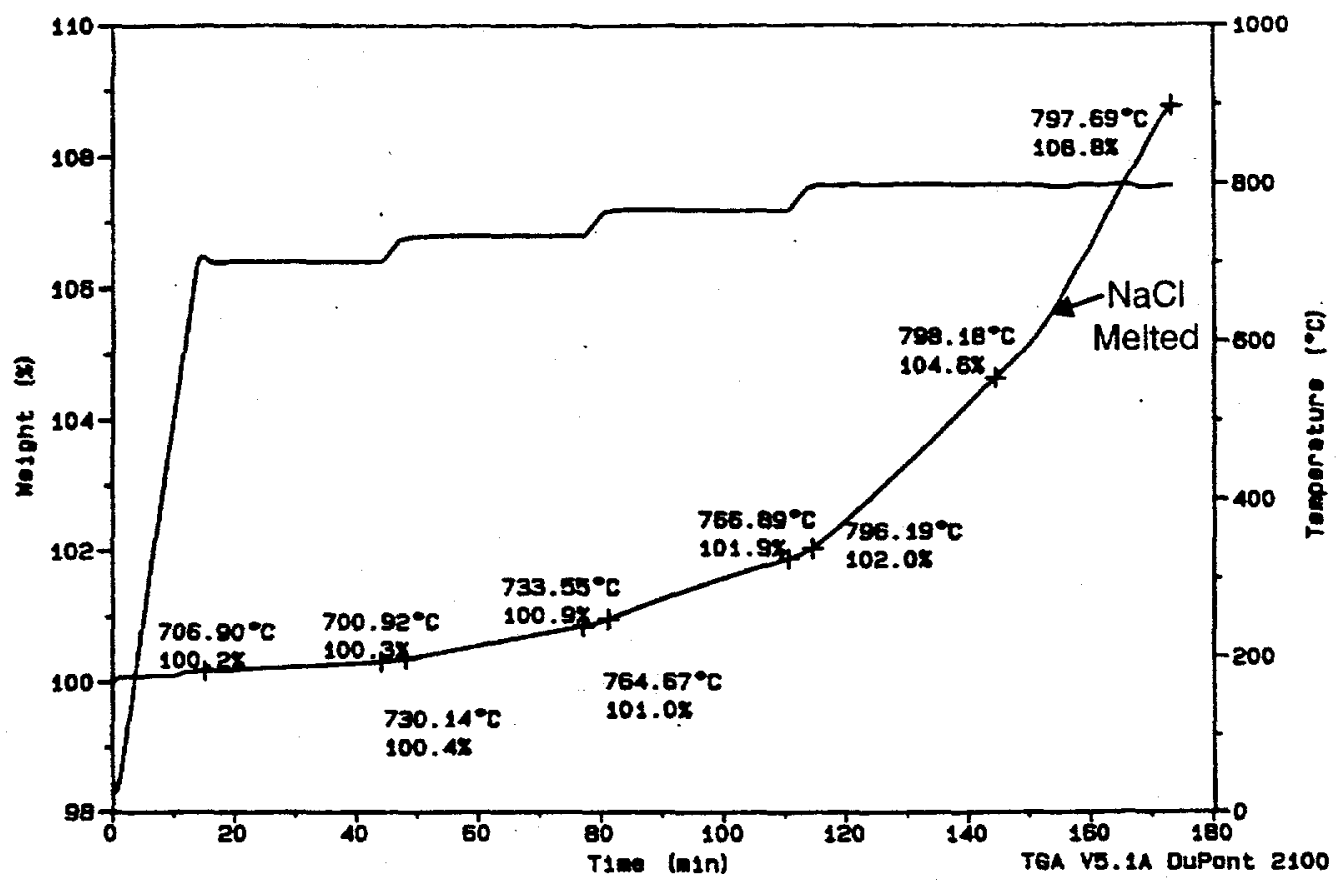

Figure 73. Thermogram from Test 3 , albite with $\mathrm{NaCl}$ and combustion gas as the initial gas

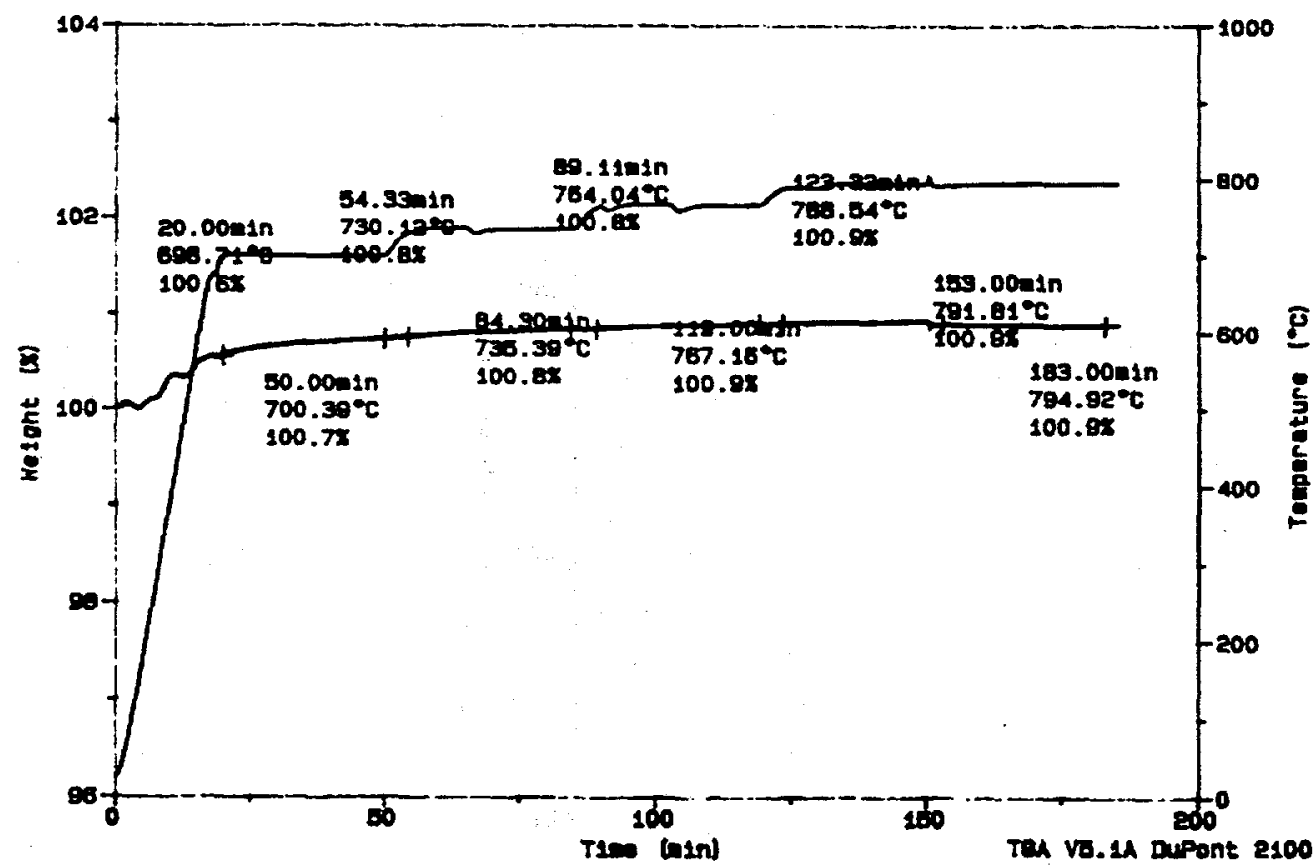

Figure 74. Thermogram from Test 4 , albite without $\mathrm{NaCl}$ and combustion gas as the initial gas 


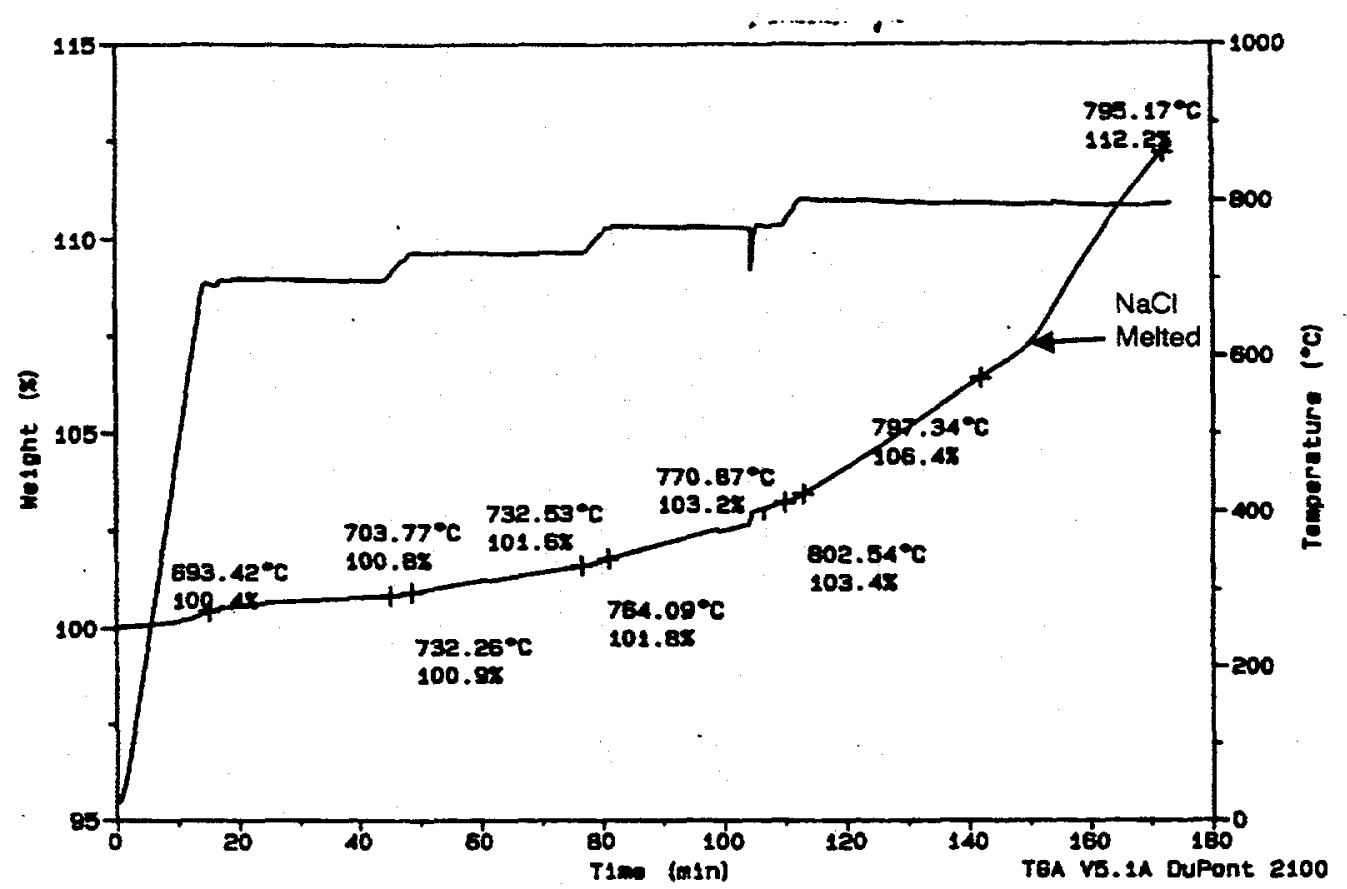

Figure 75. Thermogram from Test 5 , albite and quartz with $\mathrm{NaCl}$ and combustion gas as the initial gas

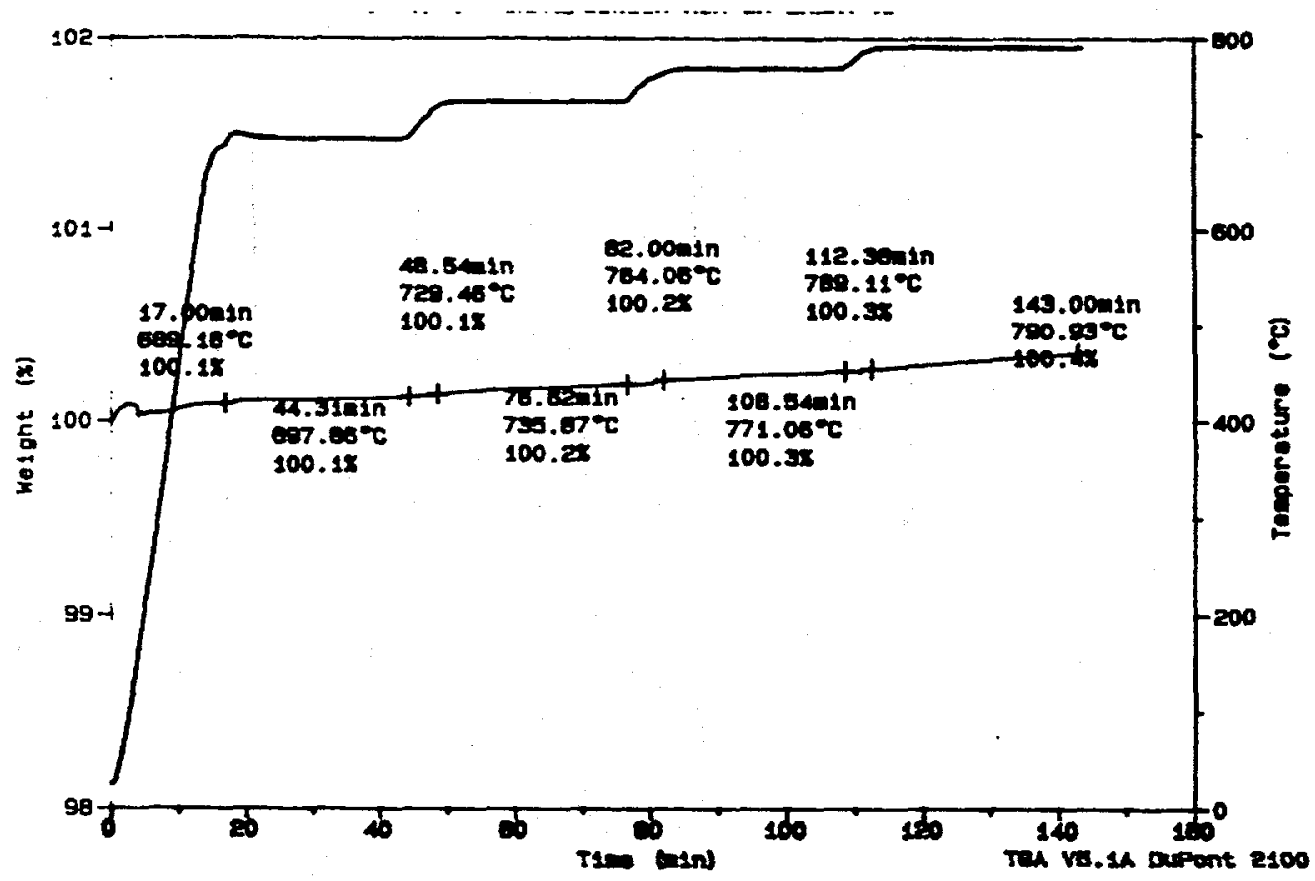

Figure 76. Thermogram from Test 6 , albite and quartz with $\mathrm{NaCl}$ and nitrogen as the initial gas 


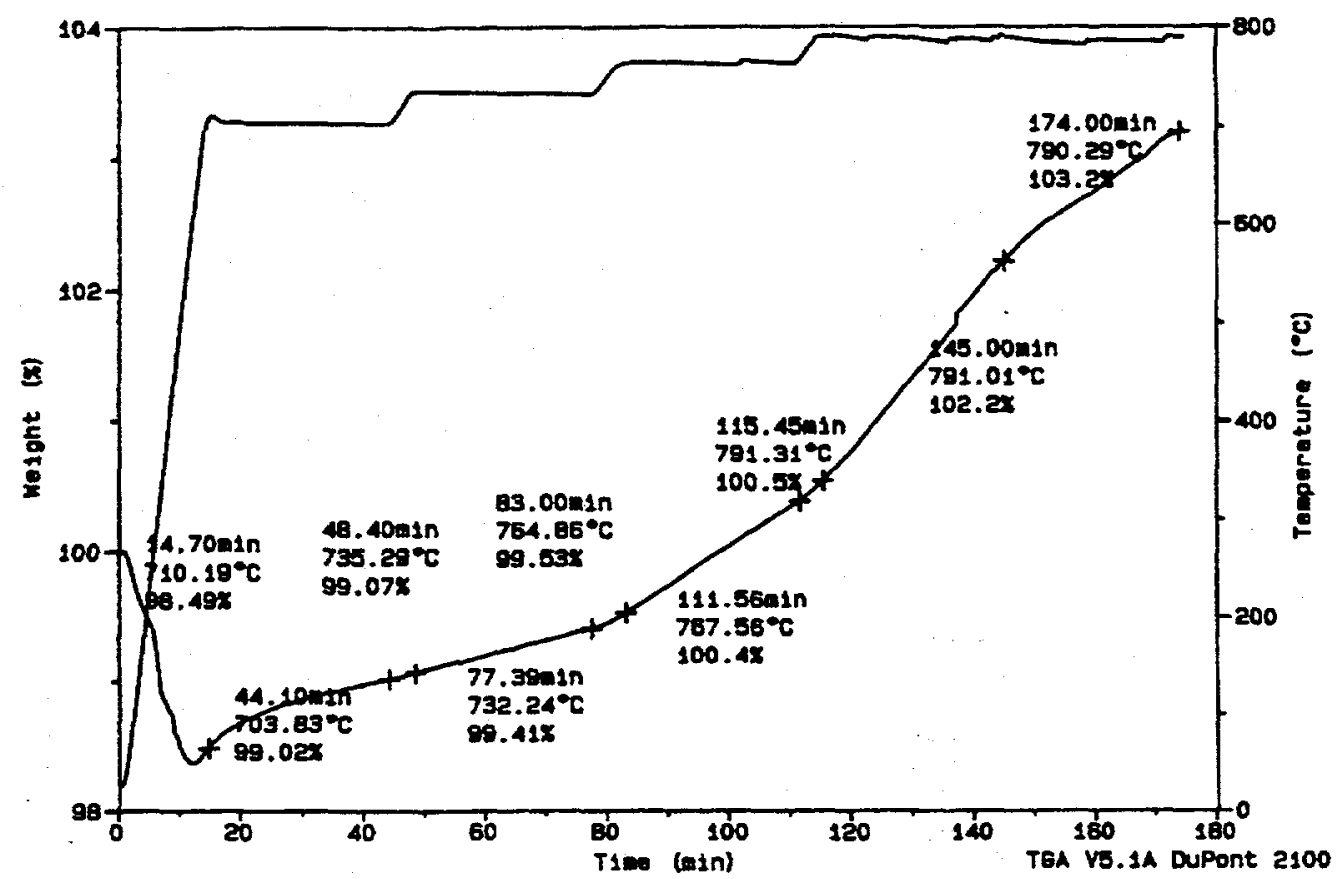

Figure 77. Thermogram from Test 7 , sodalite with $\mathrm{NaCl}$ and combustion gas as the initial gas

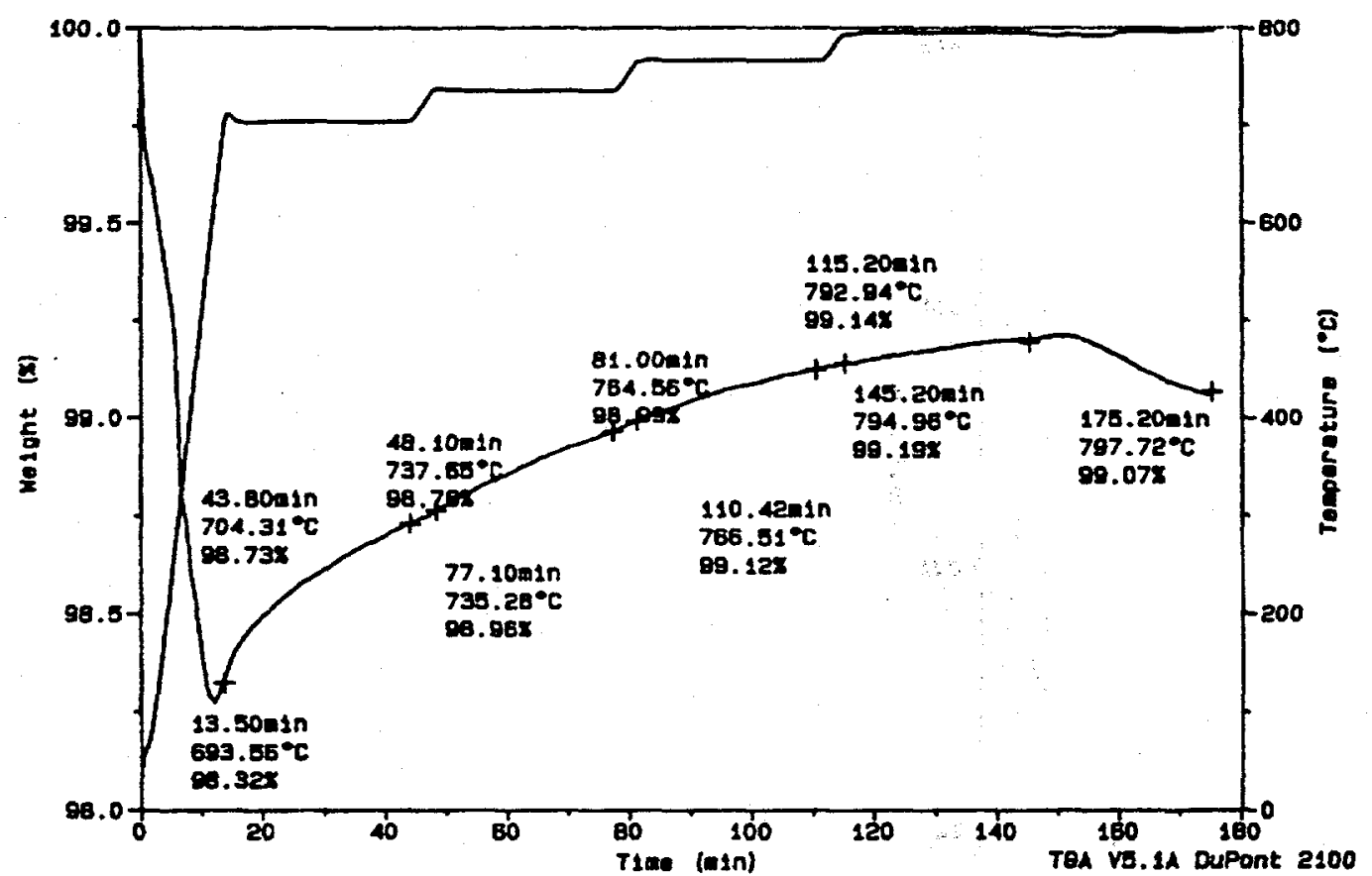

Figure 78. Thermogram from Test 8 , sodalite without $\mathrm{NaCl}$ and combustion gas as the initial gas 


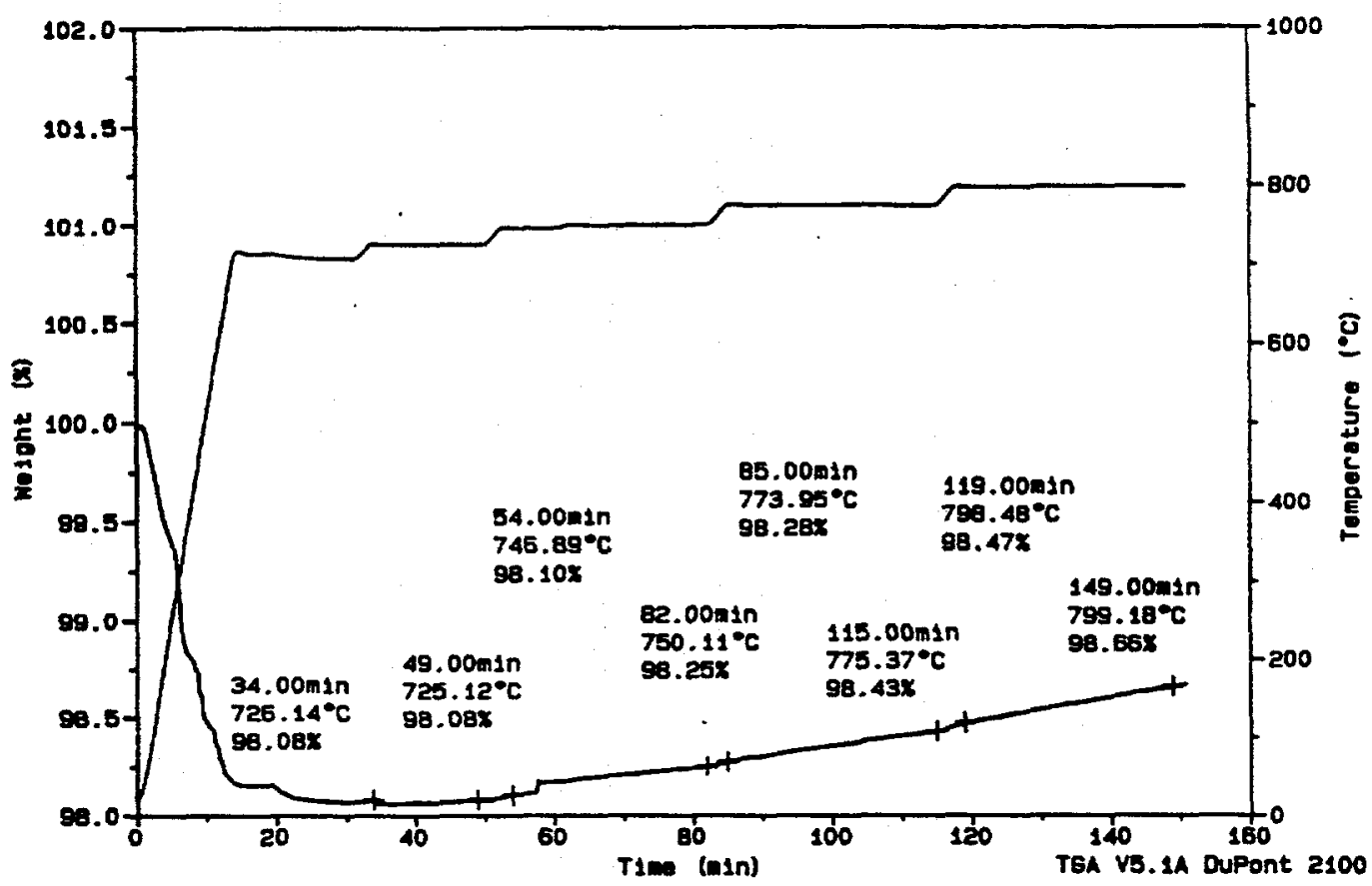

Figure 79. Thermogram from Test 9 , sodalite with $\mathrm{NaCl}$ and nitrogen as the initial gas

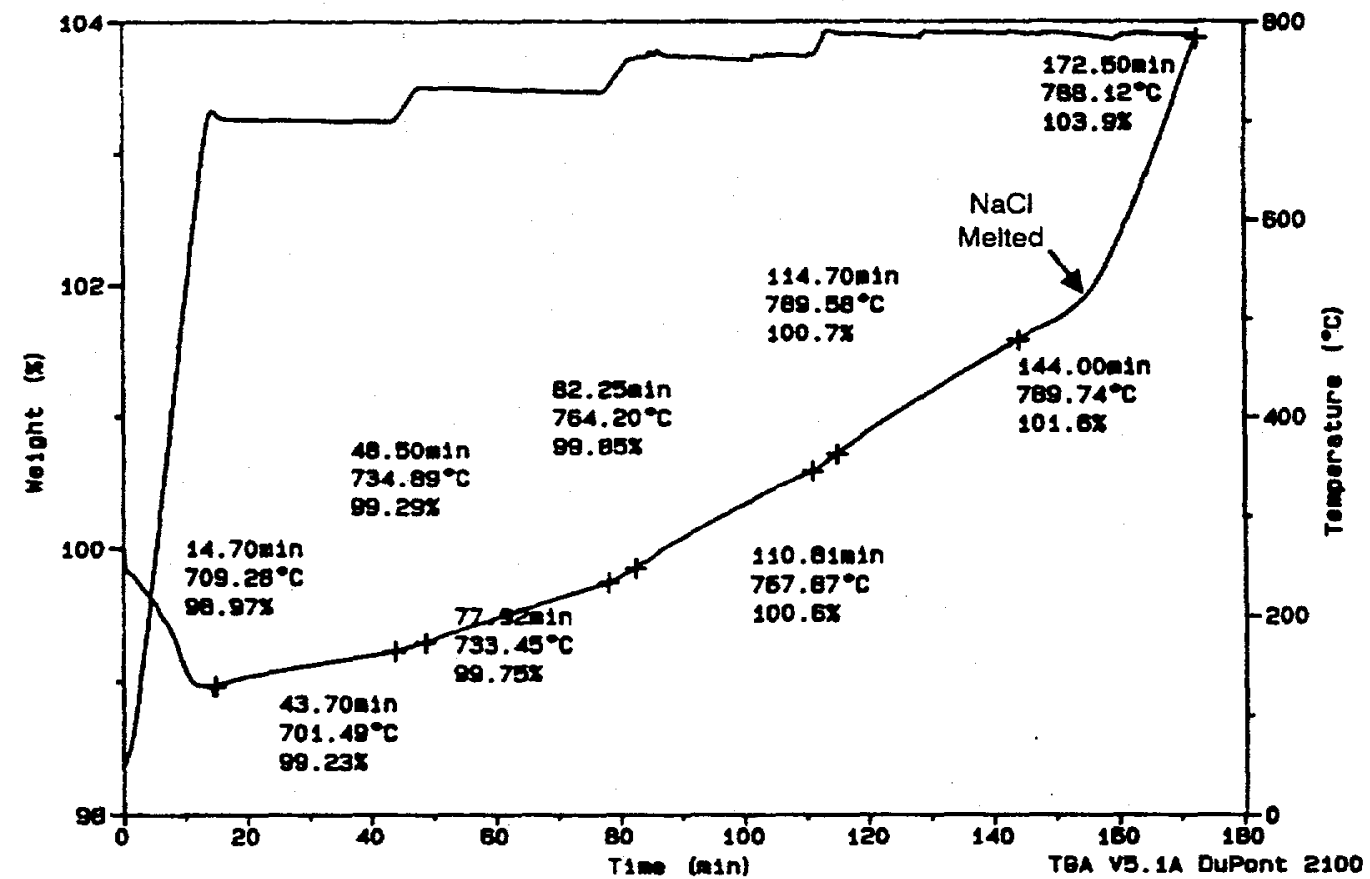

Figure 80. Thermogram from Test 10 , nepheline with $\mathrm{NaCl}$ and combustion gas as the initial gas 


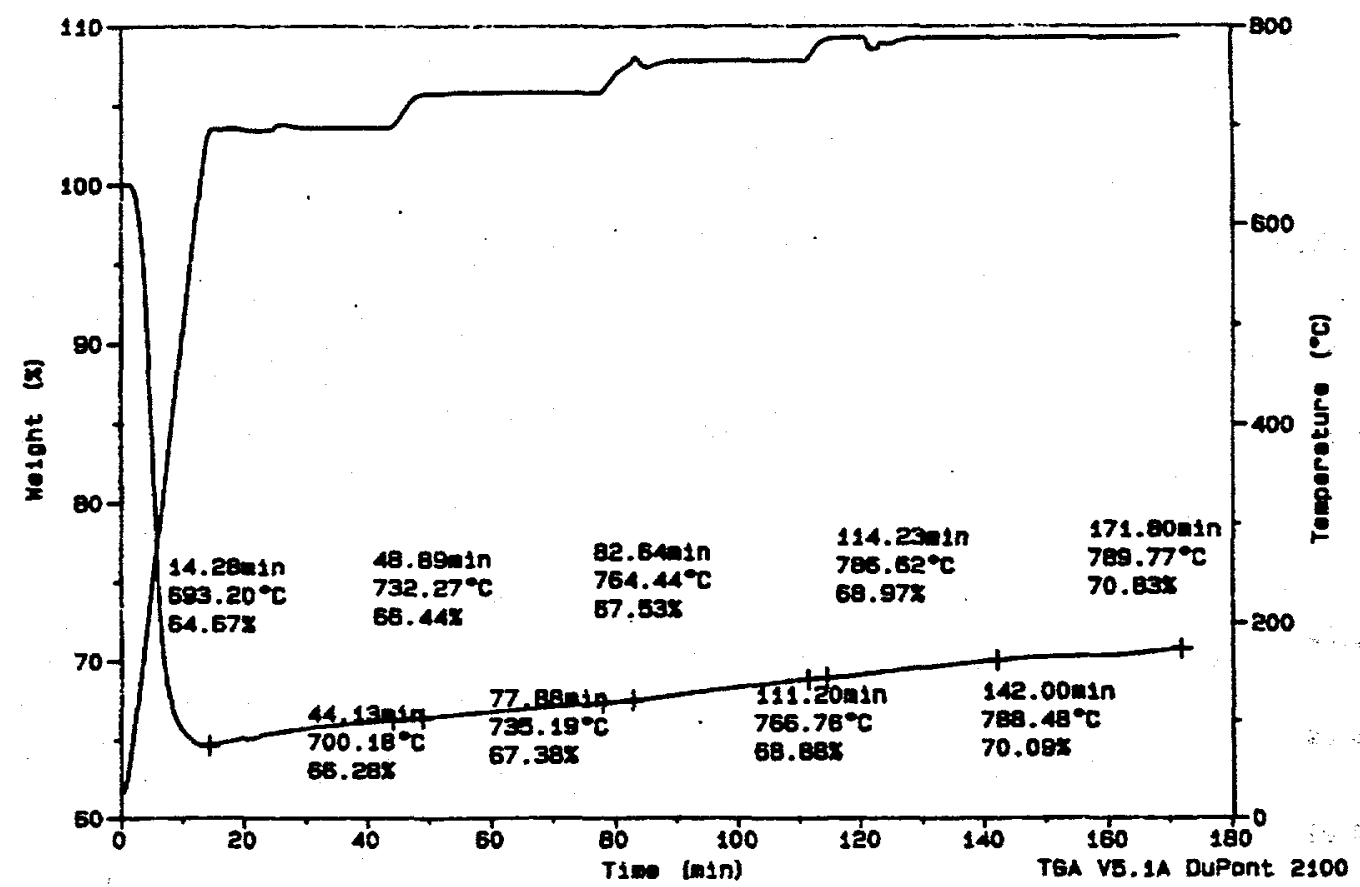

Figure 81. Thermogram from Test $11, \mathrm{AlO}(\mathrm{OH})_{3}$ with $\mathrm{NaCl}$ and combustion gas as the initial gas

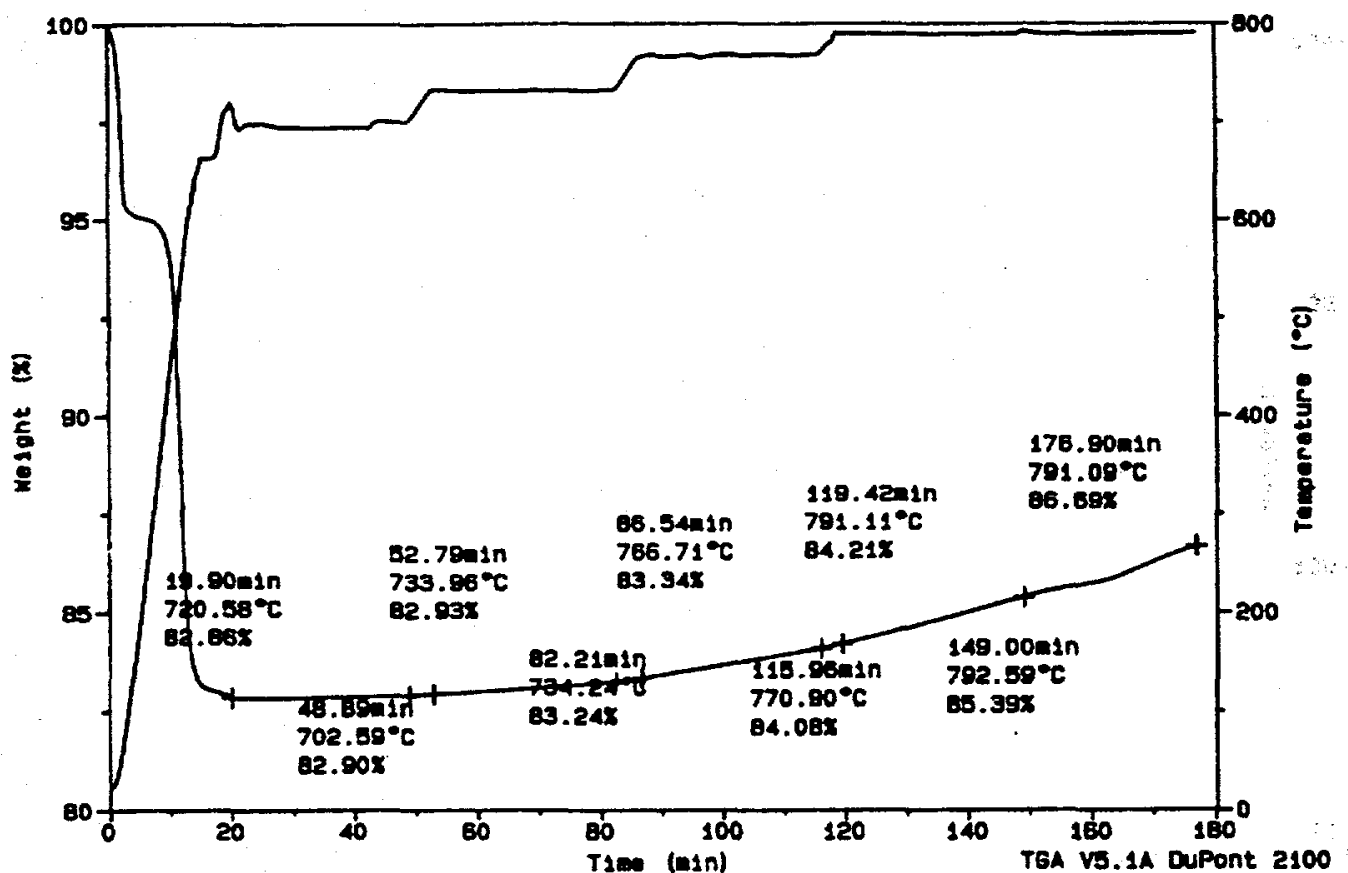

Figure 82. Thermogram from Test 12 , kaolinite with $\mathrm{NaCl}$ and combustion gas as the initial gas 


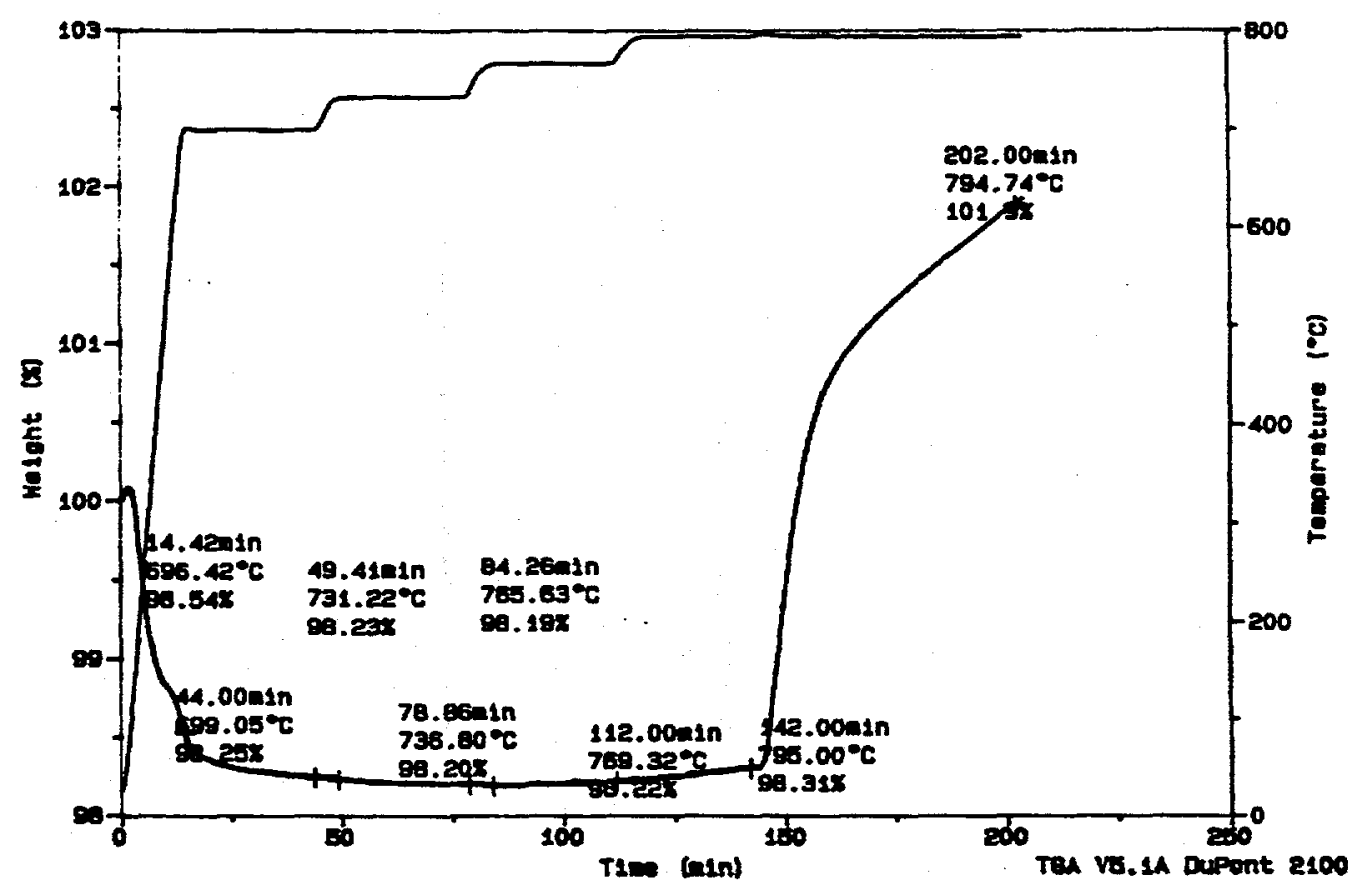

Figure 83. Thermogram from Test 13 , activated bauxite with $\mathrm{NaCl}$ and nitrogen as the initial gas

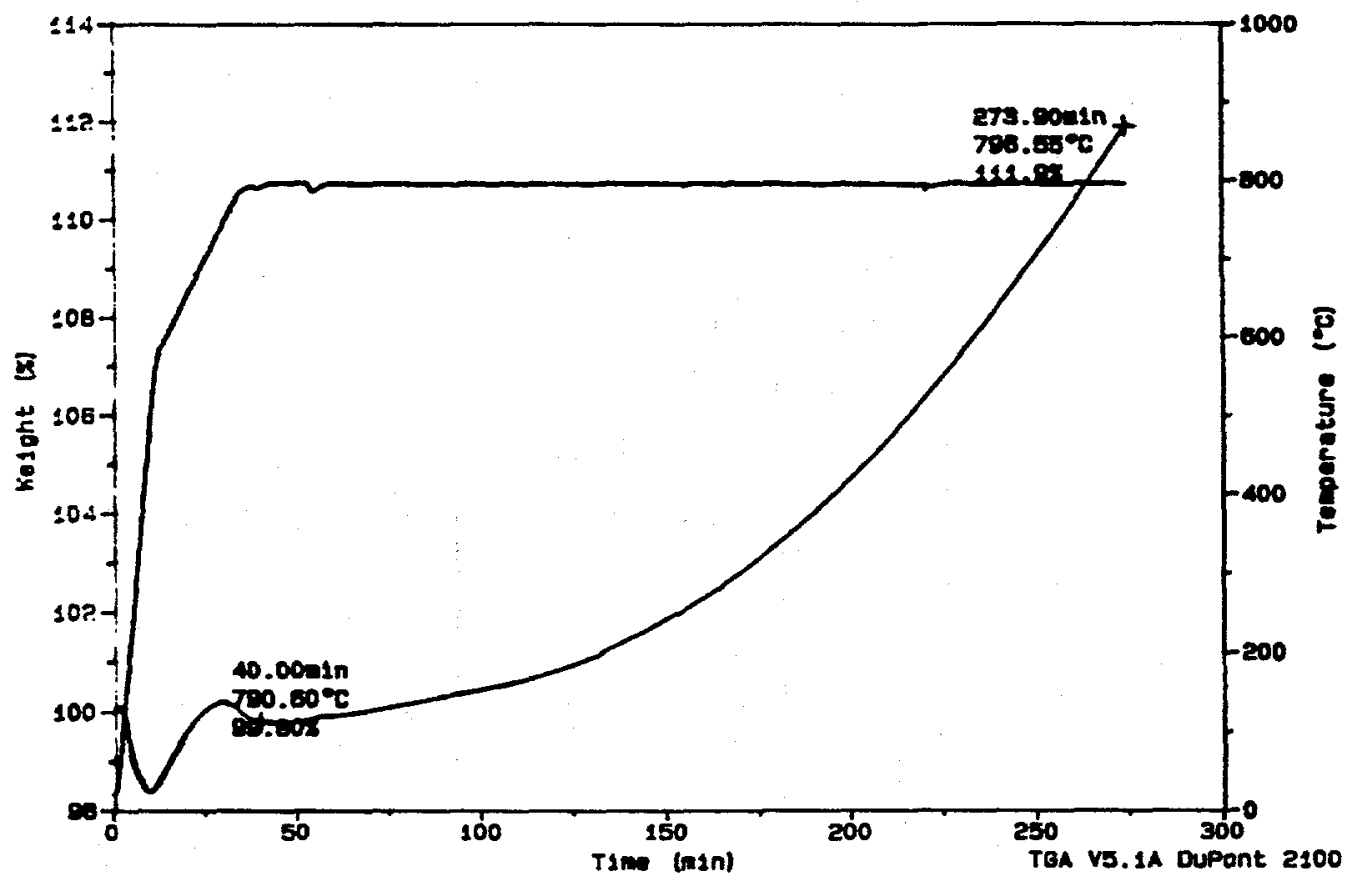

Figure 84. Thermogram from Test 14 , activated bauxite with $\mathrm{NaCl}$ and combustion gas as the initial gas 


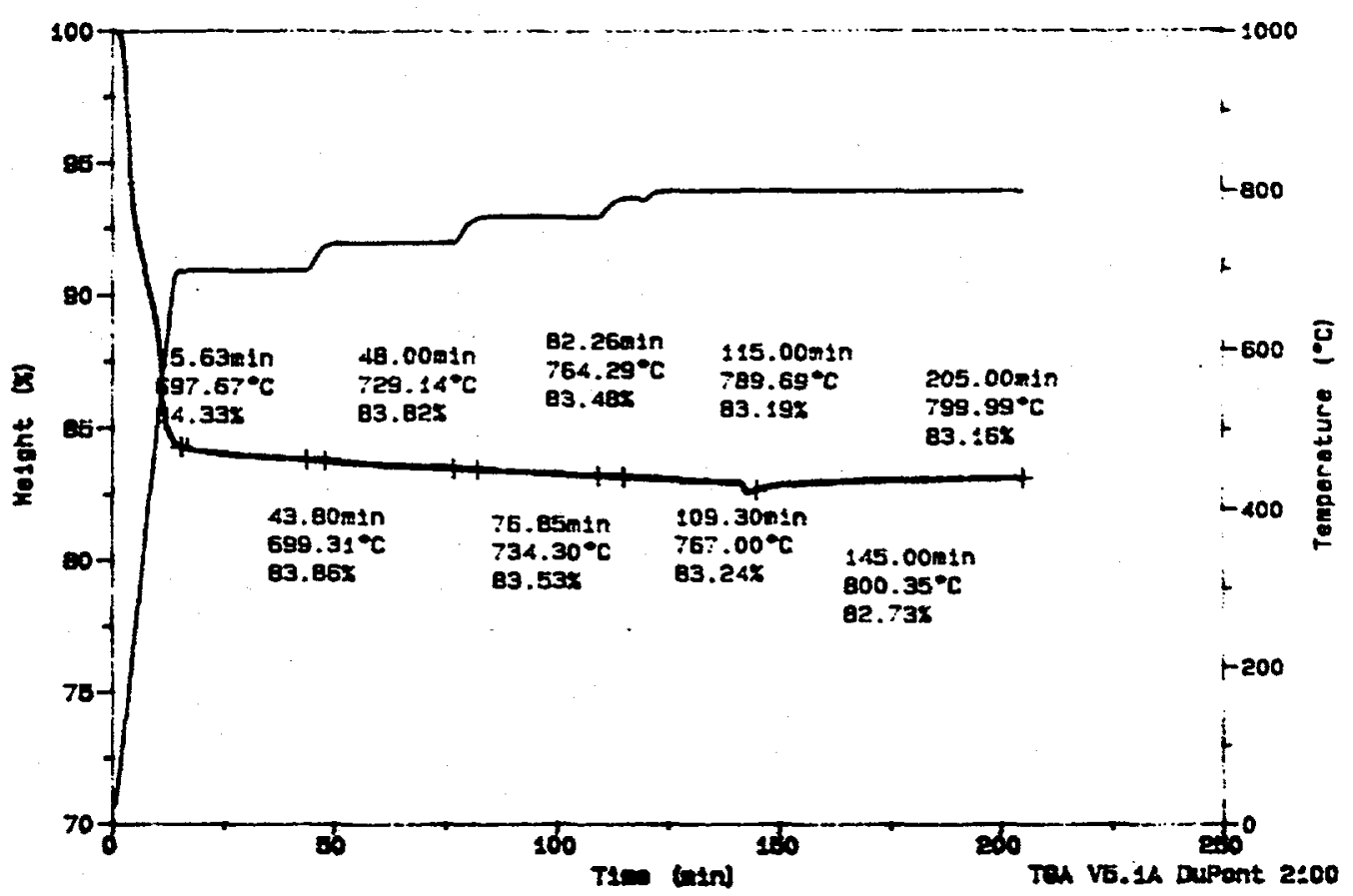

Figure 85. Thermogram from Test 15 , zeolite with $\mathrm{NaCl}$ and nitrogen as the initial gas

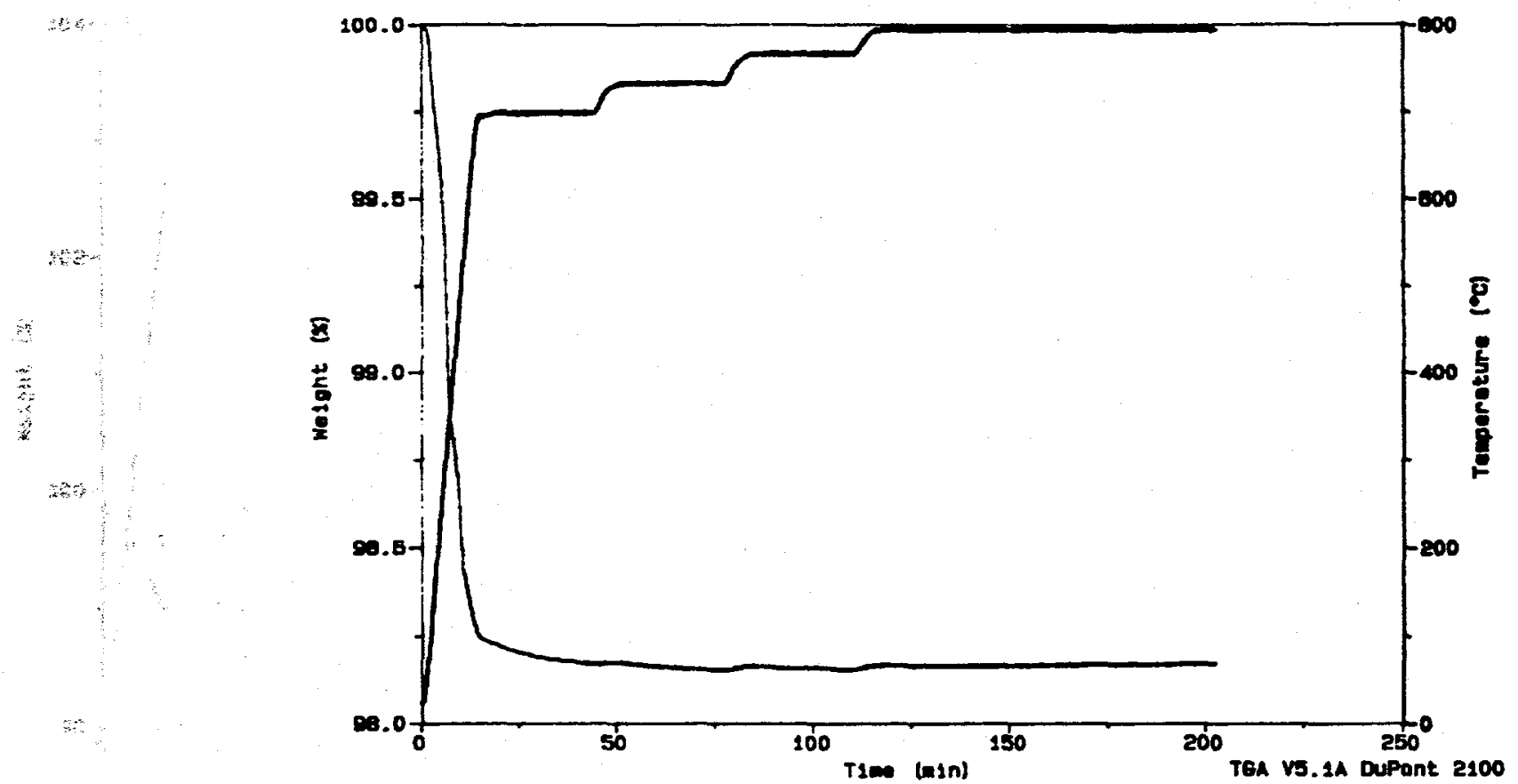

Figure 86. Thermogram from Test 16 , sodalite without $\mathrm{NaCl}$ and nitrogen as the initial gas 


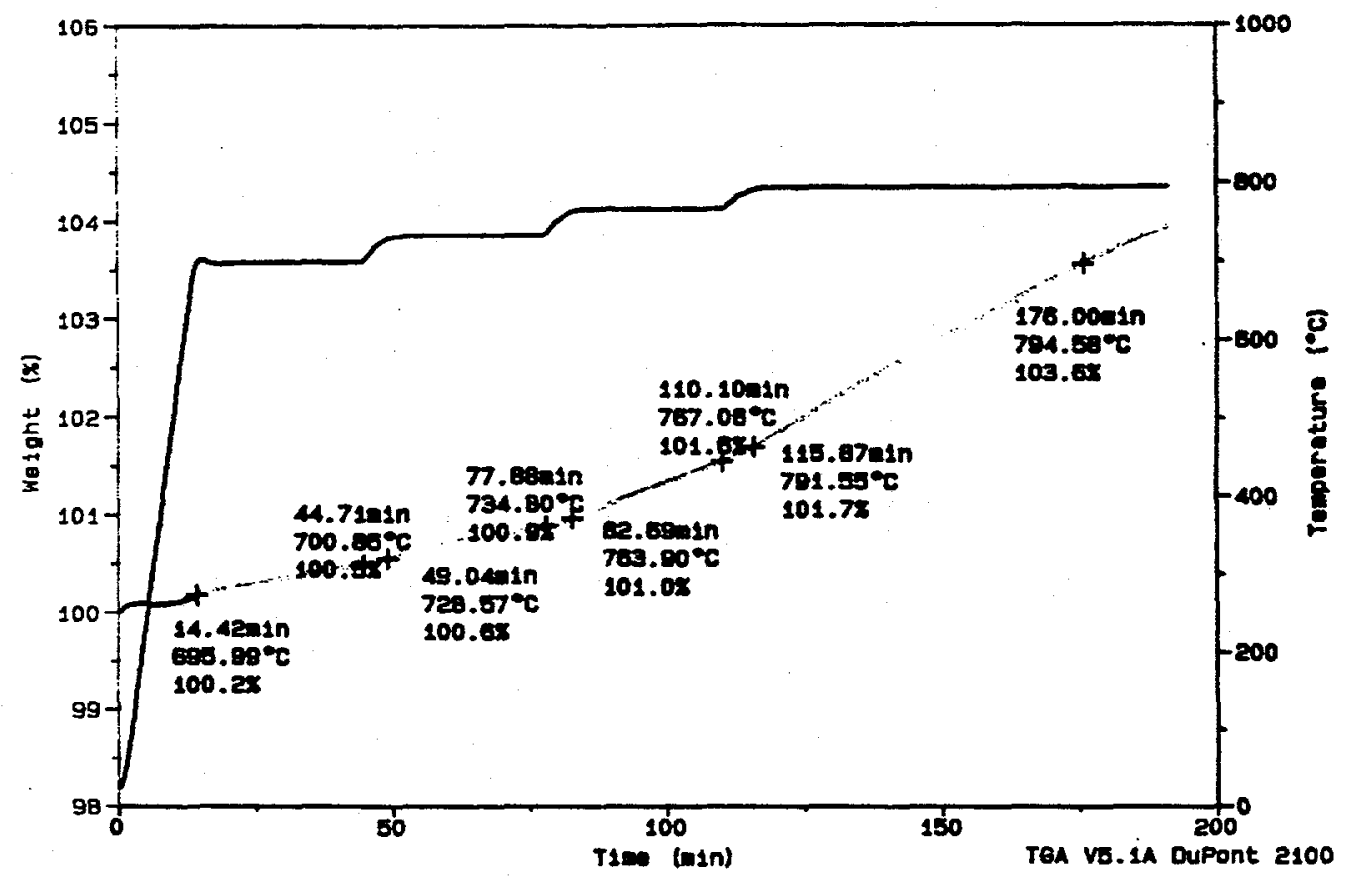

Figure 87. Thermogram from Test 17 , albite with $\mathrm{NaCl}$ and combustion gas as the initial gas 


\section{REFERENCES}

Abbasian, J.; Rehmal, A. "H $\mathrm{H}_{2} \mathrm{~S}$ Removal from Fuel Gas During Coal Gasification," In Proceedings of the 199th ACS National Meeting; Boston, MA, April 22-27, 1990; Vol. 35, No. 1, pp 196-206.

Abdulally, I. "Foster Wheeler Energy International," Personal communication, May 21, 1996.

Alliance to Save Energy. "An Alternative Energy Future," American Gas Association and Solar Energy Industries Association: Washington, DC, 1992.

Bachovchin, D.M; Alvin, MA. "A Study of High-Temperature Removal of Alkali in a Pressurized Gasification System," In Proceedings of the Gas Stream Cleanup Papers from DOE-METC-Sponsored Contractors' Review Meetings in 1987; DOE/METC-87/6082, Oct. 1987.

Bachovchin, D.M.; Alvin, M.A.; DeZubay, E.A.; Mulik, P.R. "A Study of High-Temperature Removal of Alkali in a Pressurized Gasification System," final report DOE/FETC/20050-2226; Oct. 1986.

Brdar, R.D. "Advanced Coal-Fired Power Systems," Presented at the 1996 Hot-Gas Cleanup Contractors Review Meeting, Morgantown, WV, July 16, 1996.

Benson, S.A.; Abrahamson, H.A.; Zygarlicke, C.J.; Mills, M.E. "Combustion Inorganic Transformations," final technical report for April 1988-June 1989; Contract No. DE-FC21-86MC10637, 1989.

Benson, S.A.; Holm, P.A. "Comparison of Inorganic Constituents in Three Low-Rank Coals," Industrial and Engineering Chemistry Product Research and Development 1985, 24, 145-149.

Benson, S.A.; Hurley, J.P. "Distribution of Inorganics," quarterly report for Contract DOE/FE/60181$1531 ; 1983$.

Benson, S.A.; Hurley, J.P.; Steadman, E.N. "Distribution of Inorganics," quarterly report for Contract DOE/FE/60181-1574, 1984a.

Benson, S.A.; Hurley, J.P.; Steadman, E.N. "Distribution of Inorganics," quarterly report for Contract DOE/FE/60181-1642, 1984b.

Bergerson, C.G.; Risbud, S.H. Introduction to Phase Equilibria in Ceramics; The American Ceramic Society, Inc.: Columbus, Ohio, 1984.

Boteler; D.C.; Boley, C.C. "Partial Devolatilization of Coal in Two Entrained-Bed Carbonizers," v.s. Bureau of Mines, RI-7843, 1973.

Boley, C.C.; Fegley, M.M. "Design and Operation of Two Refractory-Lined, Internally Heated, EntrainedBed Carbonizers," GFERC/RI-77/1, p 38, 1977. 
Calvert, S. et al. "The A.P.T. Dry Plate Scrubber for Alkali Vapor Control," In Proceedings of the 2nd Annual Contractors' Meeting on Contaminant Control; Morgantown, WV, Feb. 3-5, 1981.

Cramer, H. VGB Kraftwerks Technik 1986, 66, 750-753.

Coal and Synfuels Technology 1993, 14 (47), 47.

Cuenca, M.A.; Anthony, E.J., Eds. Pressurized Fluidized Bed Combustion; Blackie Academic \& Professional: London, 1995.

Dellefield, R.J.; Reed, M.E. "U.S. Department of Energy Perspective on PFBC," U.S. Department of Energy Morgantown Energy Technology Center report; 1992.

Energy Information Administration, U.S. Department of Energy. Annual Energy Outlook; DOE/EIA0383(94), Washington, DC, 1994.

Energy Information Administration, U.S. Department of Energy. International Energy Annual 1993; DOE/EIA-0219(93), Washington, DC, May 1995.

Energy Information Administration, U.S. Department of Energy. Supplement to the Annual Energy Outlook 1994; DOE/EIA-0554(94), Washington, DC, 1994.

Energy Information Administration, U.S. Department of Energy. World Energy Project Systems; Washington, DC, 1996.

Energy Information Administration, U.S. Department of Energy. 1992 Annual Energy Outlook; DOE/EIA0383 (92), Washington, DC, 1992.

Erickson, G. Chemica Scripta 1978, 8, 100-103.

Erickson, T.A.; Ludlow, D.K.; Benson, S.A. "Interaction of Sodium, Sulfur, and Silica during Coal Combustion," Energy \& Fuels 1991, 5 (4), 539-547.

Erickson, T.A.; Ludlow, D.K.; Benson, S.A. "Fly Ash Development from Sodium, Sulphur, and Silica During Coal Combustion," Fuel 1992, 71, 15-18.

Fantom, I.R. "Measurements and Control of Alkali Metal Vapors in Coal-Derived Fuel Gas," In Proceedings of the 2nd Int. Symp. on Gas Cleaning at High Temperatures; Blackie Academic and Professional, pp 541-555, 1993.

Fogler, H.S. The Elements of Chemical Kinetics and Reactor Calculations; Prentice-Hall Inc., Englewood Cliffs, NJ, 1974.

Gas Research Institute. Baseline Projection of U.S. Energy Supply and Demand; Chicago, 1994.

Gilberti, D.F. et al. "Hot Gas Cleanup Using Porous Ceramic Cross-Flow Filters," In Proceedings of the 3rd Annual Contractors' Meeting on Contaminant Control; Morgantown, WV, Feb. 17-19, 1982.

Golan, L.P. et al. "Demonstration of the Feasibility of a Magnetic Stabilized Bed for the Removal of Particulates and Alkali," in Proceeding of the 3rd Annual Contractors' Meeting on Contaminant Control; Morgantown, WV, Feb. 17-19, 1982.

Goldback, G.; Haas, J. “Combustion Power Company, Inc.," Personal communication, June 17, 1991. 
Greene, F.T.; O'Donnell, J.E. "Investigation of the Mechanisms of Ash Deposit Formation from Low-Rank Coal Combustion," report for Contract DOE/FC/10287-2416; 1987.

Guha, M.; McCall, G. "Predicting the Market Penetration of the Next Generation of Coal-Fired Technologies," Power-Gen 1990.

Helbe, J.J.; Srinivasacher, S.; Boni, A.A.; Charon, O; Modestino, A. "Measurement and Modeling of Vapor-Phase Sodium Chloride Formed During Pulverized Coal Combustion," CST90-05-23, 1990.

Hurley, J.P. "A Pilot-Scale Study of the Formation of Ash During Pulverized Low-Rank Coal Combustion," Ph.D. Thesis, The Pennsylvania State University, 1990.

Hurley, J.P.; Steadman, E.N.; Kleesattel, D.R. "Distribution of Inorganics," final report for Contract DOE/FE/60181; 1986.

31th IEA FBC Meeting, Nov. 2-4, 1995, Aix-en-Provence, France.

International Energy Agency. Annual Report 1992-1993; Organization for Economic Cooperation and Development: Paris, 1993.

Ishida, M.; Wen, C.Y., AIChE J. 1968, 14, 311.

Jackson, P.J. Ash Deposits and Corrosion Due to Impurities in Combustion Gases; Bryers, R.W., Ed.; Hemisphere Publishing: Washington, DC, 1978; pp 147-161.

Jannson, S.; Pillai, K.; Malm, H. "PFBC-The Leading Clean Coal Technology for the Future," New Electricity 21 Conference, May 1992.

Jansson, S.A. "Status of PFBC," In Proceedings of the Institute of Energy's 5th International Fluid Combustion Conference: FBC Technology and the Environmental Challenge; London, December 1991; Adam Hilger: Bristol, UK, 1991, pp 19-30.

Karner, F.R.; Hurley, J.P.; Beckwith, DC; Kleesattel, D.R.; Roaldson, R.R.; Steadman, E.N.; Zygarlicke, C.J. "Distribution of Inorganics," quarterly report for Contract DOE/FE/60181-1845, 1984.

Kimura, S.J. Chem. Eng. Japan 1981, 14, 190.

Kimura, S.; Tone, S., Otake, T. J. Chem. Eng. Japan 1982, 15, 73.

Kingery, W.D.; Bowen, H.K.; Uhlmann. D.R. Introduction to Ceramics; John Wiley \& Sons, Inc.; New York, 1976.

Krishnan, G.N.; Wood, B.J.; Korens, N.; Anderson, G.L. "High-Temperature Coal Gas Chloride Cleanup for Molten Carbonate Fuel Cell Applications," In Proceedings of 6th Annual Contractors' Review Meeting on Contaminant Control in Coal-Derived Gas Streams; DOE/METC-86/6042, (DE86001088), July 1986, pp 48-57.

Kunii, D.; Levenspiel, O. Fluidization Engineering; Butterworth-Heinemann; Stoneham, MA, 1991.

Laatikaninen, J.; Nieminen, M.; Hippinen, I. "Release of Sodium and Potassium in PFB Combustion of Peat and Coal," In Proceedings of the 1993 International Fluidized-Bed Combustion Conference; 1993, pp 1369-1374. 
Lee, S.H.D.; Carls, E.L. "Bench-Scale Tests of Alkali Vapor Removal from PFBC Exhaust Using a Fixed Bed of Activated Bauxite Sorbent," Presented at the 1988 METC Heat Engines Contractors Review Meeting, Morgantown, WV, 1988.

Lee, S.H.D.; Carls, E.L. "Measurement of Alkali Metal Vapors and Their Removal from a Pressurized Fluidized-Bed Combustor Process Stream," Annual Report ANL/FE-88-4, Oct. 1986-Sept. 1987, 37 p.

Lee, S.H.D.; Johnson, I. "Removal of Gaseous Alkali Metal Compounds from Hot Flue Gas by Particulate Sorbents,"Transactions of the ASME: Journal of Engineering for Power 1980, 102, 397-402.

Lee, S.H.D.; Myles, K.M. “Alkali Measurement in PFBC and Its Control by a Granular Bed of Activated Bauxite," In Proceedings of the 10th International Fluidized Bed Conference; May 1989, pp 793-801.

Lee, S.H.D.; Myles, K.M. "Alkali Metal Vapor Removal from a Pressurized Fluidized-Bed Combustor Process Stream," annual report for the period October 1985 - September 1986; ANL/FE-88-3, DE88013966, March 1988.

Lee, S.H.D.; Swift, W.M. "A Fixed Granular-Bed Sorber for Measurement and Control of Alkali Vapors in PFBC," In Proceedings of the 1991 International Fluidized Bed Combustion Conference; 1991, pp 1095-1103.

Lee, S.H.D.; Teats, F.G.;Swift, W.M.; Banerjee, D.D. "Alkali-Vapor Emission from PFBC of Illinois Coals," Short Communication, Combust. Sci. and Tech. 1992, 86, 327-336.

Lee, S.H.D.; Teats, F.G.; Swift, W.M.; Banerjee, D.D. "Measurement of Alkali-Vapor Emission from Pressurized Fluidized-Bed Combustion of Illinois Coals," In Proceedings of the 1993 International Fluidized Bed Combustion Conference; 1993, pp 1359-1368.

Levenspiel, O. Chemical Reaction Engineering, 2nd ed.; Wiley, New York, 1972.

Lippert, T.E.; Alvin, M.A.; Bachovchin, D.M.; Haldipur, G.B.; Newby, R.A.; Smeltzer, E.E. "Development and Commercialization of Hot-Gas Filtration Systems," Presented at the 11 th International Conference on Fluidized-Bed Combustion, Montreal, Canada, 1991.

Longwall, J.P.; Rubin, E.S.; Wilșon, J. "Coal: Energy for the Future," Prog. Energy Combust. Sci. 1995, $21,269-360$.

Makovich, L.; Smalley, G. Electric World 1993, 207 (11), 17-24.

Mann, M.D. "Investigation of Tidd PFBC Agglomeration Chemical Characterization," EERC Publication No. 94-EERC-01-1, 1994.

Mann, M.D.; Swanson, M.L.; Yagla, S. "Characterization of Alkali and Sulfur Sorbents for Pressurized Fluidized-Bed Combustion," In Proceedings of the 13th International Fluidized Bed Conference; Orlando, FL, May 1995.

Manzoori, A.R. "Role of the Inoganic Matter in Agglomeration and Defluidization During the Circulating Fluid Bed Combustion of Low-Rank Coals," Ph.D. thesis, The University of Adelaide, 1990.

McLaughlin, J. "The Removal of Volatile Alkali Salt Vapours from Hot Coal-Derived Gases," Ph.D. thesis, Guildford, UK, Department of Chemical and Process Engineering, University of Surrey, Nov. 1990, 214p. 
Miller, R.N.; Given, P.H. "A Geochemical Study of the Inorganic Constituents of Some Low-Rank Coals," report for Contract DOE/FE-2494-TR-1; 1979.

Minchener, A.J.; Clark, R.C.; Dawes, S.G. “The British Coal Topping Cycle Development Programme," In Proceedings of the 11 th International Conference on Fluidized-Bed Combustion; ASME 1991, pp 115-118.

Mojtahedi, W.; Backman, R. "Release of Alkali Metals in Pressurized Fluidized-Bed Combustion and Gasification of Peat," Technical Research Center of Finland, Publication 53, 1989.

Mojtahedi, W.; Nieminen, M.; Hulkkonen, S.; Jahkola, A. "Partitioning of Trace Elements in Pressurized Fluidized-Bed Combustion," Fuel Processing and Technology 1990, 26, 83-97.

Morgan, M.E. "Inorganic Constituents in American Lignites," Master's Thesis, The Pennsylvania State University, 1980.

Mulik, P.R. "High-Temperature Removal of Alkali Vapors in Hot Gas Cleaning Systems," In Proceedings of the 3rd Annual Contractors' Review Meeting on Contaminant Control; Morgantown, WV, Feb. 1982.

Mulik, P.A.; Alvin, M.A.; Bachovchin, D.M. "Simultaneous High-Temperature Removal of Alkali and Particulates in a Pressurized Gasification System," DOE-MC-1632-8, 1983.

National Research Council. "Policy Implications of Greenhouse Warming," Committee on Science, Engineering, and Public Policy National Academy of Science Press: Washington, DC, 1992.

NCB Coal Utilization Research Laboratory. "20 Atmosphere Rig PFBC Test Results: Tests 10 and 12 Investigations into the Use of Limestone as a Sorbent," DOE/MC/14129-1463 (DE83015869); Aug. 1983.

Neville, M.; Quann, R.J.; Haynes, B.S.; Sarofim, A.F. "Vaporization and Condensation of Mineral Matter During Pulverized Coal Combustion," In Proceedings of the 18th Symposium (International) on Combustion; The Combustion Institute, 1981, pp 1267-1274.

O'Gorman, J.V.; Walker, P.L. "Thermal Behavior of Mineral Fractions Separated from Selected American Coals," Fuel 1973, 52, 71-79.

Oldenberg, R.C. "Optical Detection of Corrosive Compounds," In Proceedings of the Advanced Research and Technology Development Direct Utilization, Instrumentation, and Diagnostics Contractors' Review Meeting; DOE/FETC-89/6108 (DE90000424), Oct. 1989; Vol. 1, pp 87-99.

Park, J.Y.; Levenspiel, O. Chem. Eng. Sci. 1975, 30, 1207

Pintsch. S.; Gudenau, H.W. "Alkaline Hot Gas Cleaning in Combined Cycle Processes, Part 1: State of the Art as in Literature," VGB Kraftwerkstechnik 1991a, l, 40-45.

Pintsch, S.: Gudenau, H.W. "Alkaline Hot Gas Cleaning in Gas Turbine and Steam Turbine Processes, Part 2: Thermodynamic Calculations," VGB Kraftwerkstechnik 1991b, 3, 199-205.

Pitrolo, A.A.; Bechtel, T.F. "Simplied IGCC: Coal's 'Adam Smith' Response to a Changing World," In Proceedings of the 7th Annual EPRI Contractors' Conference on Coal Gasification; EPRI AP-6006-SR, 1988.

Punjak, W.A.; Uberoi, M.; Shadman, F. "High-Temperature Adsorption of Alkali Vapors on Solid Sorbents," AIChE Journal 1989, 35 (7). 